

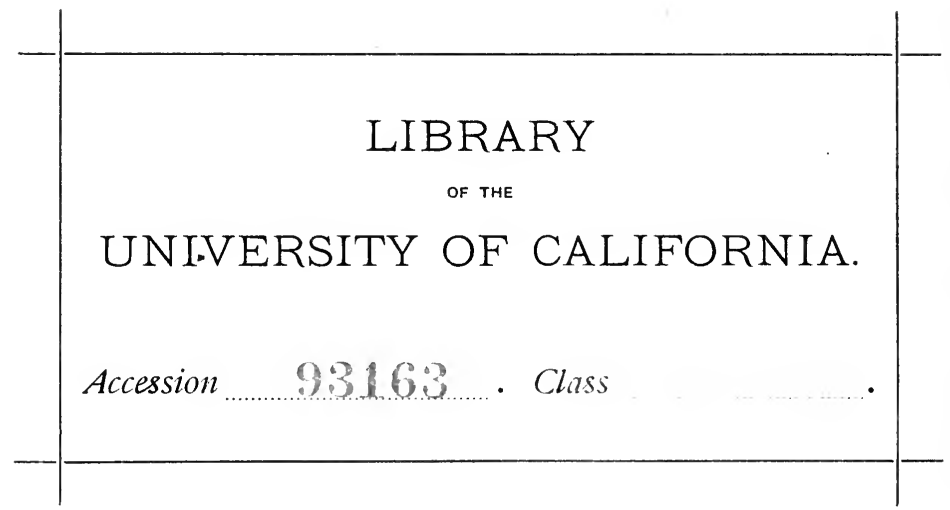



Digitized by the Internet Archive in 2007 with funding from Microsoft Corporation

http://www.archive.org/details/philosophyofreli00caldrich 
THE PHILOSOPHY OF RELIGION IN ENGLAND AND AMERICA 



\title{
THE
}

\section{PHILOSOPHY OF RELIGION}

\author{
IN ENGLAND AND AMERICA
}

BY

\section{ALFRED CALDECOTT, D.D.}

PROFESSOR OF LOGIC AND MENTAL PHILOSOPHY IN KING'S COLLEGE, LONDON FORMERLY FELLOW AND DEAN OF ST. JOHN'S COLLEGE, CAMBRIDGE

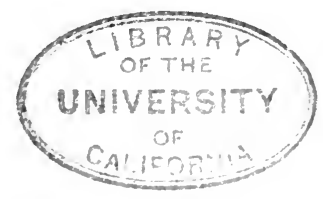

METHUEN \& CO.

36 ESSEX STREET W.C.

LONDON 
$\mathbb{E}<51$

C 33 


\section{PREFACE}

The literature of the Philosophy of Religion is composed of expositions differing from each other in various ways, and yet each professing that it has secured the true solution of the problem undertaken. In some cases it is plain that the profession is grounded upon a conviction that a victory over rival explanations has been won; in others, it appears rather as a comfortable assumption, in happy ignorance of what else is to be said. Before further effort is made, a conspectus of what has been done all over the field seems desirable. This is really only one case of the need for historical study which is felt in every department of philosophy and theology as the nineteenth century passes into the twentieth. The century now behind us has teemed with new ideas and fresh methods, and in some quarters it is closing in a mood of depression through our failure to secure a commanding and dominant result for philosophy of religion after so much mental activity has been applied to it. A survey of the past and a comparison of the methods which compete for our acceptance in the present may be the remedy needed by the tendency to agnosticism on the one hand, and the apparently chaotic advocacy of incompatible systems on the other. Such a conspectus it is the aim of this volume to supply.

It is not intended, however, to go beyond the limits of the literature of Britain and America, and the survey will begin with the period following upon the Reformation. This will give quite as much material as a single volume could usefully deal with, and the present writer makes no claim to be competent to deal with more. Of course it is true that British thought has moved in vital connection with thought on the Continent, sometimes in close attachment, at other times in 
some independence. Reference to Continental theology and philosophy cannot be avoided, but it will be made only in connection with such leaders as have plainly introduced real changes into the currents of our own thought.

The exposition of a Theism does not properly include the work of the sciences or of philosophy, and it need not therefore assume the portentous dimensions of very many of the treatises formally devoted to it. As matter of fact, many of the most significant statements occupy but a few chapters, or even but a few pages, in the introductory portions of Systematic Theologies or the concluding portions of Philosophical Systems. But too many writers have deemed it necessary to include much philosophical, and even much scientific exposition, instead of assuming that that had been done and giving the results which they had elaborated or which they had accepted from others. I have therefore avoided entering upon any account of such extraneous work, a course which in large measure accounts for what may appear to be strange in the proportions of space allotted to the various writers, that allotment having been made quite apart from regard to the dimensions of their treatment.

Another cause of the bulkiness of many works on the subject is that much space is occupied with polemics; it has not sufficed for the writers to make good their own positions, there were opponents to be dislodged. This is quite legitimate, of course, and much light can often be thrown upon a writer's position by observing how he regarded the counter-positions. But in this introductory study I have confined myself almost exclusively to those portions of the writings cited in which a positive doctrine is enunciated.

In the subject-matter itself I have not been able to include any treatment of Theodicy. It is most true that a Theism will be judged by many minds very largely by reference to its capacity for dealing with the problem of Evil and Unhappiness. Nevertheless, there are questions which precede this in order of thought; just as the question of ideal Good precedes the question 
of Evil in Ethics, and the question of ideal Truth that of imperfect truth and error in Logic, so in theology the questions of necessity, infinity, personality, goodness, precede the questions arising from the defects from these which are manifest in the world as we know it. Every particle of Evil left irreducible will cause a weakening of the Theism which leaves it unreduced; it is the appearance of waste and confusion in nature, the mystery of pain, and, above all, the presence of moral evil, which give pause to many who are otherwise impelled to religious convictions. But yet the main body of thinking men accept the method of dealing first with the normal and the ideal, and then proceeding to allow for deflections and oppositions. Within the compass of this volume it is only the primary part of Theology which can be dealt with, the doctrine of the Divine Being as to Existence and Attributes, with Theodicy held in reserve.

A classification is offered on lines described in the Introduction. It would probably conduce to easier estimation of the value of the classification if some, at least, of the illustrative examples in Part II. are read before a judgment is formed. I am under no illusion as to the value of a classification when dealing with so complex a matter as a serious Theism must be; the value is dependent upon the purpose in view, which is no mere grouping for grouping' sake, but the formation of classes which will exhibit the leading principles which men have selected.

The treatment of not a few of the theologians and philosophers named will naturally give rise to some protests, either that they should not be placed definitely under this or that Type, or that they have been wrongly placed, on the ground that they have expressed themselves differently in other writings. So far as this appeal goes, the answer lies in the fact that History has to make its own needs its first law, even though this involves some injustice to the 'men' or 'persons' who have made the history. Doubtless the personalities of Cæsar and Cromwell were not wholly engrossed in the ambitions of statesmanship; Hume had some positive beliefs and Samuel Clarke 
some doubts. But History is not Biography, and in the history of philosophy or theology a great man's name becomes attached to the cardinal principles of his doctrine. When, therefore, a man has put his strength into a Theism on certain lines, it is with that main doctrine that a history of Theism will concern itself; other opinions which he may have held may be taken into consideration if the biography of the man becomes the matter in hand.

The literature of Theism comes from two sources: there are the writings of the great men in theology and philosophy in so far as they applied themselves to Natural Theology, perhaps in a few pages only, but enunciating their view as either the foundation or the coping-stone of an important system, as in the cases of Pearson, Locke, and Newman. And then there are the men whose reputation has been gained from their having applied themselves to this very question, being comparatively or entirely undistinguished as philosophers or theologians in any other field: such men as Samuel Clarke, John Caird, Mansel.

Some objection will be made that space has been wasted upon the tenets and methods of men who have sunk into obscurity, if not into oblivion. It might possibly have been more beneficial to occupy the limited space with ampler treatment of a few great men. But all do not feel alike as to this: a visit to a picture-gallery may be devoted to a close scrutiny of the few masterpieces, but there is also profit for the historian of Art in including the work of the minor artists, the rank and file: the smaller men may very well give better material for a just appreciation of the general trend of artistic sentiment and workmanship. And in matters of opinion this is quite as likely to be the case. The method is, at any rate, an alternative one to that which would study only the greater thinkers.

But there is another reason for the appearance of some of the writings selected for separate treatment. Religious belief is a concern of practice and sentiment as well as of thinking, and the subject-matter itself would be in danger of being only partially brought into view if we disregarded the variety of 
human nature on its religious side. The wide-ranging treatment by academical minds needs checking by reference to the judgments and sentiments of men who have lived in close contact with the religious life of their day. I have therefore made a point of looking for expressions of the views of leaders in the different denominations of British Christianity, to see the kinds of argument and opinion which have commended themselves to men who wielded influence over definite portions of the religious community, Anglican, Presbyterian, Methodist, Congregationalist, Unitarian, and Romanist. These communities have all had leaders who formulated the grounds of religious belief in ways that have actually proved acceptable to religious minds, and I have given special attention to the books which have been received as more or less official by the different bodies of Christian people.

After the Table of Contents will be found a brief list of ambiguous terms of frequent occurrence, intended to show in each case which of two alternative uses I have adopted and have endeavoured to abide by.

I have to thank Miss E. E. C. Jones, of Girton College, Cambridge, for suggestions covering the philosophical matter of the whole volume; Mr. W. E. Cooper, of Keble College, Oxford, Mr. Lias, of Emmanuel College, and Mr. J. E. M'Taggart, of Trinity College, Cambridge, for suggestions on certain portions. And I am indebted to Mr. F. D. Brookes, of Christ's College, Cambridge, Mr. G. E. Newsom, of King's College, London, and Mr. Briggs Carlill, for valuable assistance in the revisal of the proofs.

Frating Rectory, Colchester, 9th November 1900. 



\section{CONTENTS}

\section{PART I.-INTRODUCTION}

\section{THE TYPES DESCRIBED}

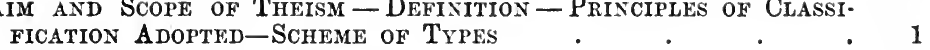

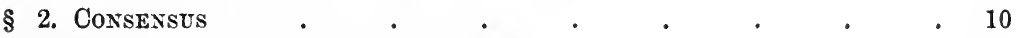

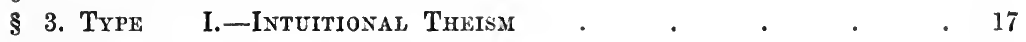

$\S$ 4. Type II.-Demonstrative Theism (À posteriori) $\quad$ a 20

$\S 5$. The Ontological Argument . . . . $\quad$. 27

\$ 6. Type III.-Transcendental Idealism (Speculative) • . 29

§ 7. Type IV.--Ethical Theism (Rationalist) . • . . . 46

§ 8. Type V.-Combined Speculative and Ethical Rationalism • 58

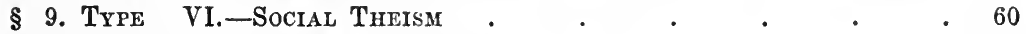

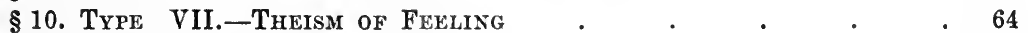

§ 11. TyPE VIII.-TheisM OF WILL . . . . . . . . 72

§ 12. TYPE IX.-PersonalisM . $\quad . \quad$. $\quad . \quad$. $\quad . \quad 80$

§ 13. TyPE X.-IntuitivisM, oR MrsticisM . . . . . 86

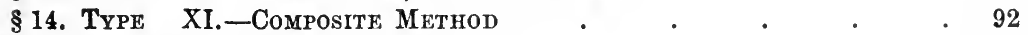

§ 15. TYPE XII.-SoMe QUASI-TheisMs . . . . . . . $\quad$. 94

§ 16. TYPE XIII.-RESORT to ReVELAtioN . $\quad . \quad$. $\quad$. $\quad$. 94

\section{PART II.-HISTORICAL}

THE TYPES ILLUSTRATED

CHAPTER I

Intuitional Theism

§1. INTRODUCTORY

\$2. Herbert of Cherbuli .

§3. Theodore Parker

§4. MoRell .

§5. HARRIS, S. T.

§6. MURPHY, J. J.

§ 7. KNIGHT, W.

CHAPTER II

Demonstrative Theism

§1. INTRODUCTORY . • . • • • • . . 105

§ 2. Romanist Theologians; Boedder; Clarke, R. F. • • . 107 
PAOE

\$ 3. LOCKE . . . . . . . . . . . . 111

§. Seventeesth And Eighteenth Centunies . . . . . 114

§ 5. MOZLEY . . . . . . . . . 120

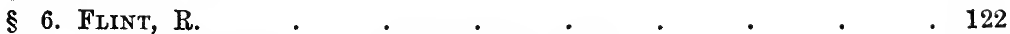

§ 7. Hodge, A.; Randles, M.; Clarke, W. N. . . . . 126

Teleological, Mainly

$\S$ 8. Paley; Priestlet ; Brovgham ; Badfe Poweli, . . 129

§ 9. Chalmers . . . . . . . . . . 133

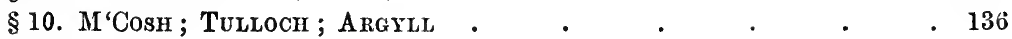

ONTOLOGICAL.

§ 11. Clarke; Gillespie
Appendix $\Lambda$ : Ladd, G. T.

CHAPTER III

Transcendental Theism

\$ 1. CAIRD, JoHN . . . . . . . . . 146

§ 2. CAIRD, E. . . . . . . . . . . . .

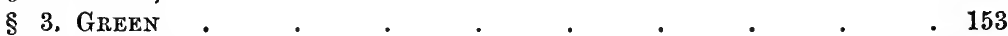

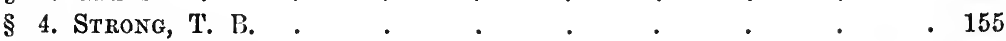

\$ 5. StiRLING, J. H. . . . . . . . . . . . . 158

§ 6. Momerie, A. W. $\quad$. $\quad . \quad$.

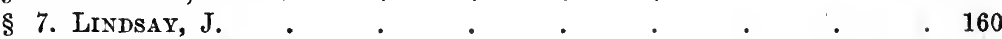

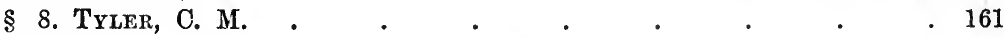

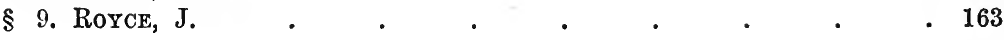

Quasi-Transcendentalism

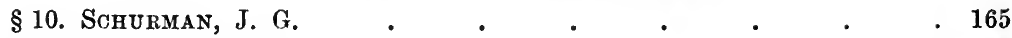

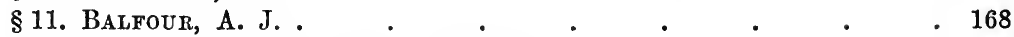

§ 12. SaUnders, T. B.; LeckY, W. E. H. . . . . . $\quad$ - 175

CHAPTER IV

Ethical Theism (Rational)

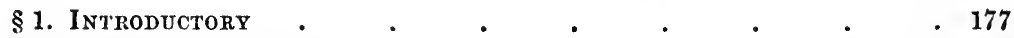

§ 2. Temple, ARchBishop $\quad . \quad$.

§3. FRASER, A. C. . . . . . . . 183

§4. SETH, A. . . . . . . 186

§5. Æsthetic, General . . . . . . . . 187

\$6. RUSkIN . . . . . . . . . . . . 190

\$7. (SEELEY) . $\quad$. $\quad$.

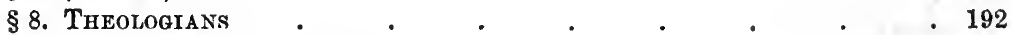

APPENDIX B: Howison, G. H. 


\section{CHAPTER V}

Combined Speculative and Ethical Theism

§1. Hooker .

§ 2. BERKELEY

§3. ButLER

§4. BoLINGBRoKe

§ 5. Steere; Thompson, R. A. ; Cooke

$\S 6$. WARD, W. G.

§7. Fiske, J., ANd Le Conte, J. .

\section{CHAPTER VI}

Social Theism

\$ 1. Philosophers . . . . . . . . . . . 225

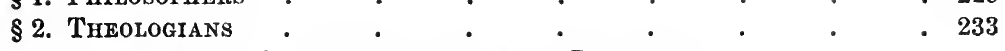

Appendix C: Anthropology and Psychology.

CHAPTER VII

Theism of Feeling

VARIOUS WRITERS

CHAPTER VIII

TheisM of WILL

§1. Psychologists

§. Theologians

\section{CHAPTER IX}

\section{Personal Theism}

\section{§1. NEWMAN .}

§ 2. HoRT

§ 3. Аввотт, E. A

§4. MasON, A. J.

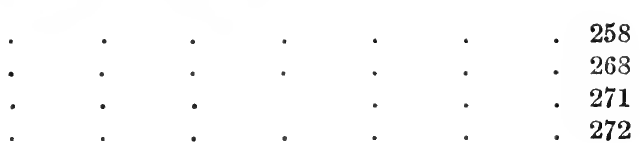

\section{CHAPTER $\mathrm{X}$}

InturtivisM, oR Mysticism

§1. The Cambridge Platonists

§2. Eighteenth Century; Law, $\mathrm{W}$.

§3. Coleridge and Wordsworth

§4. The Trinity Collegr Group .

§5. MAURICE .

§6. Carltue and Emerson .

87. Newman, Francis 
§ 8. Liddon; Maitland, B.; Ellicott, Bishop ; Swete, H. B.; Murphy,

J. J.; Pope, W. B.; Fisher, G. P.; De Vere, A.; Lilly, W. S. 305

§ 9. Westcott, Bishop . . . . . . . . . 314

§ 10. Moore; Illingworth ; Romanes . . . . . . . 322

§ 11. Upton, C. B. . . . . . . . . . . . . . $\quad$. 335

\section{CHAPTER XI}

Composite Types

§ 1. Barry, Bishop; Lias, J. J.; Travers Smith, R. • • . 338

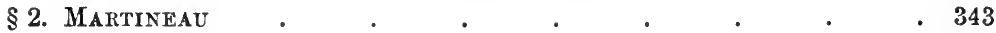

§3. CONDER . . . . . . . . . . . . . . 353

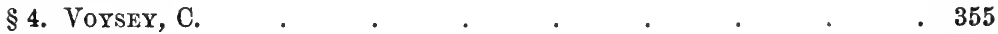

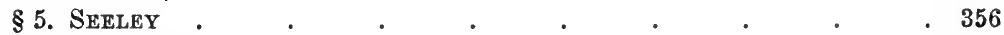

§6. Davidson, W. L. . . . . . . . . . 361

Appendix C: Baldwin, J. M.

\section{CHAPTER XII}

\section{QUASI-THEISMS}

§ 1. HoBBES .

§ 2. The Deists

§ 3. HUME

§ 4. MILL, J. S.

§ 5. Religion of Humanity (George Elio') . . . . . 381

§6. Schiller, F. C. S. . . . . . . . . 384

§7. Spencer, H. . . . . . . . . . . . 387

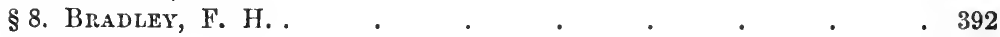

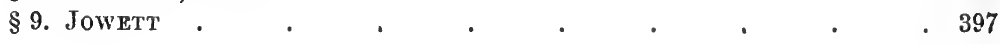

CHAPTER XIII

REVELATION ONLY

§1. INTRODUCTORY . . . . . . . . . 400

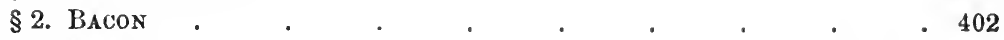

§3. Mansel . . . . . . . . . . . 405

§ 4. Dale; Bruce; Wace, H. ; Holland, H. S.; Gwatkin. H. M. $\quad 410$

§5. General . . . . . . . . . . . . 414

RETROSPECTIVE . . . . . . . 416

\section{APPENDICES-}

APPENDix A: LADD, G. T. . . . . . . . 423

Appendix B: Howison, G. H. . . . . $\quad$. 426

Appendix C: Anthropology and Pyschologr ; Baldwin, J. M. 427 


\section{NOTE}

IN the case of certain oft-recurring terms which are ambiguous in signification, it is desirable to indicate the sense in which they are used in this volume. The following list is not intended to offer strict definitions but just sufficient discrimination to show the alternative uses. It is the second of the two meanings which will be used in all cases where choice between the alternatives is necessary:-

Philosophy . . . Explanation in terms of pure or speculative thought, rational, theoretical.

Any explanation which is seriously offered as ultimate.

RELigion . . . Man's attitude to the most elevated object he knows.

Man's attitude to a Being (or beings) distinguished from self and the world.

Philosophy of Religion. The making Religious belief intelligible, the proving it by Reason.

The reference of Religious belief to its primary factors or grounds, whether in Reason or outside it.

Natural Theology . . The study of the religious significance of Nature ; in some cases, of External nature only.

The study of religion in so far as it is the issue of ordinary processes of our nature, apart from Revelation.

Theism . . . Equivalent to Natural Theology in the second sense, but understood to conclude against the need, or the possibility, of Revelation.

Equivalent to Natural Theology, but without any pre-judgment as to the possibility of Revelation.

Speculative . . . Referring to trials or surmises as to what may be true beyond what is known.

Equivalent to Intellectual, Rational, Theoretical.

Empirical. . . A certain method of intellectual construction of knowledge by manipulation of particular experiences.

Any appeal to particular experiences as ultimate sources of belief. 
process by which it has been attained. Keen intelligences and lofty spiritual characters have been concerned in elaborating and elucidating it, or devoted to promulgating and enforcing it. The literature of the world, the systems of philosophy, the theories of nature, the codes of law, the aims of life, and views of human destiny, would all be impoverished if it were withdrawn. It is not always presented in fulness, by any means. In some expositions there may be little more than the assertion of what may be called the Existence of a Deity. But bare existence is unthinkable without some character, and, as a matter of fact, every conception includes some element or elements which can act vitally on meditations, aspirations, and practical activities.

Whether the delineation refers to a valid Belief with a supposition that a Reality is its Object, or to what is only a mental conception, is the problem of Natural Theology; if only a part of it is valid, then what part. Those who hold a Theism seek to exhibit it controversially against negations or conflicting beliefs; or against occasional competition of doubts in their own minds arising from apparently inconsistent beliefs or from the absence of connection between this and others; or, quite positively, in order to set it in its place amongst their other beliefs, which by its very nature it should draw together and then take up its true position as their consummation. Christian Theology supposes that the belief is held by the members of the Church of Christ: but this does not decide whether the belief is to be obtained by natural methods, or whether it is wrapt up with the Gospel of the Incarnation, and is unattainable by ordinary channels. The vast majority of Christians hold that it is at least supported from outside Revelation; many hold that it can be satisfactorily established by the light of Nature: all of these offer a welcome to the double source of its authority. But others may be unable to satisfy themselves with anything that Natural Theology has to offer, and await the bestowal of farther illumination before they can take as granted to mankind the knowledge of such harmony between natural and revealed truth. And to many Christians the interest in the problem is vicarious; not endowed with capacities for extensive exercise of natural thought, or not vouchsafed freedom from occupations of exacting character in other directions, it does not vitally concern them. Others, again, are so absolutely satisfied with the assurances of 
their own Christian experience that they have no need for articulating these with the sciences and philosophies from which they stand aloof. But they understand that others attach independent weight to natural religion, perhaps even preeminent value: and for their sakes they find an interest in investigating what Reason has to say.

Then from the other end, there are those whose minds begin with natural knowledge: they advance from stage to stage, and, practically without exception, recognise the supreme importance of determining the character of the belief in which all beliefs must culminate at last if they are to culminate at all. The ordering of all that the world has to show and that inner experience has to tell, brings them finally to the question of Theism.

It is the intention of this introduction to the history of Theism in Great Britain to include both those who work up to Theism from nature and reason, and those who come down from Dogmatic Theology to natural knowledge to see what it has to say as to the belief they already have in possession. Natural Theology is deeply indebted to both. Whether we resort to the opening chapters of a treatise on the Christian Creed - the doctrine of God - or to the closing chapters of a work on Philosophy, it is with the same problem that we have to deal: in the light of Nature, what grounds appear for belief in the Divine Being? or, when all nature, physical and mental, is explored, what final Belief emerges?

For various reasons the term 'Natural Theology' is under a cloud, and we find 'Philosophy of Religion' in vogue at present. This latter term has a special value in directing us to observe a distinction between Philosophy of Religion and Science of Religion. The Science of Religion takes in hand the positive religions of the world, and includes not only forms of conception of the Deity, but rites and worship, institutions and codes, and draws out, more scientiarum, the leading examples, traces their growth, associates them, and, moved by an ideal of unity, even aims at drawing them together in related system. The Philosophy of Religion investigates its foundations in the principles of belief as applied to the data produced by science and philosophy. The term Theism is also at our service, and it has the advantages belonging to a single word.

Theism, or Philosophy of Religion, is in its ideal single and comprehensive: it acts upon the presumption that there is an 
attained philosophy and that there are completed sciences, both of thought and life: it seeks the true belief which is required to crown the great result of these. And, as I take it, the name may be claimed for every attempt to justify the belief in a Divine Being, whatever the method of justification, whatever the criterion of reality, adopted. Inasmuch, however, as the subordinate ideal of philosophy, and even the ideals of the sciences, are not in fact attained, Philosophy of Religion also has to be content with presenting a plural appearance: it offers a number of competing views, in correspondence with the various fundamental principles which constitute the philosophies deemed worthy of consideration. Even where there is a sense of agreement as to what is to be explained, the way of establishing it varies with the philosophy adopted; or, per contra, the various philosophies take different ways of defining their theological issues, their consummating principles, with the result that variety appears in the conception itself. There are then many Philosophies of Religion as we stand to-day: as many as there are serious endeavours to refer Religion to its ultimates. If the term is used in singleness it is so used by each Philosophy claiming to be supreme.

\section{CLASSIFICATION}

The first broad distinction is between Rationalism and Empiricism.

Rationalism holds that Thought has power to construct; that it has a right to carry us, in a sense, beyond experience, or else, to reshape experience into forms which its original occurrence did not yield; a right to be trusted when it invites us to allow that its own contribution to knowledge possesses as much right to our assent as can be claimed by the presentations of our senses. Reason, it is maintained, works by certain categories or ideas. Men as thinkers are architects, applying ideas of Reason to the presentations of immediate experience as material. Rationalist Theists hold that this architectural activity carries us beyond our experience, which is finite and contingent in its character, and impels us to complete the edifice by means of belief in an infinite and necessary Being or Principle. The belief in God is therefore the result of the constructive activity of Reason. That this is more than a 
mental construction, that there is a Reality corresponding to this necessity of Thought, is assumed. Indeed, the fundamental principle of Rationalism is the assumption that Thought is valid, and the belief in the reality of a Supreme Being or Principle is the highest and most significant application of the assumption. There are various theories of the way in which Reason works, and various opinions as to the categories employed, and consequently there is variety in the form of the result. But the common principle is that the constructive power of Reason applied to the facts of experience gives the means by which man can attain to belief in God.

Empiricism claims that deeper than the constructions of our thinking lie the basal assertions of experience. In application to Theism an Empirical Theist holds that there are experiences which assert the presence of a Divine Being, and this objectively as something of which we have experience. He holds that experience is competent to make the direct assertion that there is a Divine Being. The assertion may be made by experience as a whole, or by some one or other of its factors; e.g. it may be a kind of knowing (intuition), or an assurance of Feeling, or the issue of an act of Faith in which Will predominates.

Within Empiricism note must be taken of the difference which arises from our taking the individual or the community as the true subject of religious belief. The Religions of the world are, as a matter of fact, racial or national beliefs, the number of individuals who have endeavoured to make sure their own personal position on every point of the religion to which in the main they adhere being comparatively small. Accordingly, some Empiricists rest content with the declaration of the Common Sense of mankind, and commend it to the individual as giving a broader ground for belief than his own personal experience could possibly supply. Other Empiricists repudiate tradition or social authority, and insist that it is personal conviction alone which can lead to a religious belief worthy of the name. Among non-Rational systems, therefore, we shall find Theisms which are Individualistic and Theisms which are Social in their character.

In the inquiry it is assumed that Empiricisms are entitled to the use of the term 'Philosophy,' and therefore to offer their Philosophy of Religion, or Theism. Each of them aims at giving an ultimate account of things: as to religious belief, an 
ultimate account of that. It is very usual for Rationalists to denounce them as intruders, as irregular and imperfectly developed combatants in the field of intelligent inquiry. But the student of history is unable to acquiesce in this somewhat haughty treatment, as he finds the records crowded with the names of upholders of Empiricism in some form or other, many of them men of serious mind and conspicuous earnestness. This is so in Great Britain more especially; in philosophy generally, and in philosophy of religion in particular.

Within the territory of Rationalism there enters an important distinction, giving rise to a subdivision: the distinction between Rationalism as pure Thought and Rationalism as giving the idea or conception of the Good (and the Beautiful): the Pure Reason and the Practical Reason of Kant; Intellectual or Speculative Reason and Moral Reason; or, according to aims, the mind contemplating Truth, and the mind in pursuit of the Good, the Beautiful, the Perfect.

It is quite true that the finality both of our main distinction, that between Rationalism and Empiricism, and of the subordinate distinction between Speculative and Moral Rationalism, is denied in some quarters. But whatever may be the case when we engage in an attempt to fix our own philosophical position, from the point of view of historical study these lines stand out, marked clearly by great men. We are not now about to confine our inquiry to the productions of the sublimated intellects which can see that Reason and Sensibility are in essence identical, and that there is a graduated series of experiences, beginning with much sensibility and little thinking, and ending in the rarefied atmosphere of little sensibility but wide-ranging thought. Our concern is with the vast majority of men who have regarded these as opposite poles of mental Experience, and have shaped their philosophies according to the pole which they regarded as the one where they felt they must stand when determining knowledge and belief. Nor are we about to deal only with those who affirm that they have penetrated into the recesses where the Truth is seen to be always Good, and the Good to be wholly and solely what is true. We shall have to deal with many who are impressed by the fact of conflict, who seem obliged to recognise, however sadly, some things as true which are not good and some things as good which cannot yet be adequately known to be true, and on whom 
therefore is imposed the necessity of choice between these as final criteria of what a man ought to believe. And we shall find others who accept them both, but as separate and independent criteria. As guiding lines for an historical inquiry these time-honoured distinctions are indispensable, whatever may be their ultimate value when a final Philosophy appears.

By way of preliminary illustration let us take some prominent examples of English Theism, and note how they differ :-

Locke said: I exist; there must be a Cause for me; that Cause is God.

Mozley said: The world (including myself) exists; there must be a Cause for it (and me); that Cause is God.

Butler said: There is in me a sense of Moral Obligation; Obligation implies a Law, and a Lawgiver; that Lawgiver is God.

Newman said: With the mass of faculties and capacities and experiences which constitute my personal nature I believe there is a God.

John Caird said: My self-conscious spirit and the world over against it are in irreconcilable opposition, so far as thought is concerned, unless I believe there is a Supreme Spirit, God.

Bishop Westcott says, at the outset, simply: I feel that there is a God.

Now the difference between Locke and Mozley and the difference between these and Butler are differences as to datum or basis; all three agree in relying upon the constructive power of thought, which all regard as acting in the same way, by inference a posteriori. But the difference between these on the. one hand and Newman on the other is not the above difference : Newman casts a wider net for his data, including the whole of his experience in the utmost variety and concreteness, and then he makes no inference, but simply asserts his assent. Bishop Westcott agrees with Newman in not making inferential construction, he is assertive simply; but his assertion is that of an undefined and apparently unique faculty, not that of a joint operation of ordinary faculties, as Newman's was. Caird, on the other hand, agrees with the first three that there is inferential construction, but his datum is different from theirs, and his intellectual method is different too. These examples may suffice to illustrate some of the directions in which advocacy of Theism may proceed. 


\section{SCHEME OH CLASSIFICATION}

\section{RATIONALISM :}

Intellectual or Speculative, Ethical being subordinate or disallowed.

Intuitional: direct intuition or perception of a Divine Being.

Demonstrative or Inferential: that there is a Divine Being.

A posteriori (cosmological, teleological).

$\grave{A}$ priori (ontological).

Transcendental.

Ethical : that there is a Being Perfect in Goodness and Beauty, or a Being whose Will is our Law.

Inferential from Moral Law, or Moral distinctions :

$\dot{A}$ posteriori.

Transcendental.

Combination of Speculative and Ethical Rationalism.

EMPIRICISM: Traditional and National and Racial Experiences: Social Theism.

Assertions of the Experience of the Individual believer:-

FeEuING: which demands Reality for the ideas which evoke it.

WILL: which asserts the free right to choose to believe.

Will aNd Feeling combined: the assertion of the right to choose what will satisfy profound and ineradicable Feeling.

Personal: the whole complex of our nature as individual persons.

Special Faculty : a unique endowment for Knowledge of the Divine Being: Intuitivism or Mysticism.

COMPOSITE: where factors from both Rationalism and Empiricism are accepted and combined.

CHRISTIAN REVELATION: failure of Natural Theology; resort to Revelation alone. 
A survey of the writings of philosophers and theologians in Great Britain gives us insufficient material for filling a chapter with what has been said by Ontologists, so I have not taken that as a type of British Theism requiring separate treatment; and the same remark applies to what may be called Theism of Beauty in the Esthetic sense, which I have included under Ethical Theism.

On the other hand, there are some influential writers who advocate a portion of Theistic doctrine more or less explicitly, but in so manifestly partial a manner that it is somewhat straining terminology to apply the term 'Theism' to their results: some of these are exhibited in a separate section under the title Quasi-Theisms.

The Types as actually treated are therefore as follows:-

I. Intuitional Theism.

II. Demonstrative Theism (à posteriori).

III. Transcendental Theism.

IV. Ethical Theism.

V. Combined Speculative and Ethical Theism.

VI. Social Theism.

VII. Theism of Feeling.

VIII. Theism of Will and Feeling.

IX. Personal Theism.

$\mathrm{X}$. Intuitive Theism (Mysticism).

XI. Composite Theism, from both Rational and Empirical sources.

XII. Some Quasi-Theisms.

XIII. Resort to Christian Revelation alone.

It is a legitimate question to ask of every Theology, how much it includes in its Definition of the Divine Being. There is, indeed, artificiality in endeavouring to speak of Existence in complete contradistinction to Nature, as if any 'existence' could be known to us in the complete absence of attributes. There must be some Nature before us, if we are to begin to think at all. Then comes the question how much of the Nature is to be regarded as of the Essence, failing any part of which we should disallow the Name. It is quite possible to elaborate a doctrine of Fundamental attributes and then proceed to deduce from them further attributes depending upon them. Some such 
procedure is indispensable if we are to take into account such a Definition as that given by Newman, which contains twenty-two predicates. ${ }^{1}$

The Definition I have set before me contains six points. ${ }^{2}$ Whether all of these are ultimate or not, they appear to me to be the points imperatively required by Christian Theology, or rather, I should say, the points in which Christian Theology is vitally interested and for which it is asking when Natural Theology is before it. This, then, is the clue which I have had in my hand when following the windings of Natural Theology in Britain. A reader who objects to it and would rather take a different one must be asked to make the necessary allowances. $^{3}$

\section{$\S 2$. Consensus}

The wide prevalence of religious belief is a feature which has not failed to command attention ever since Natural Theology was commenced. Had it made sporadic or occasional appearances in history its reception must have been very different. But the interpretation of this fact and its employment in Theism may take several divergent courses. It may be claimed as a confirmation of his result by every one who has arrived at Theism independently; or it may be regarded as itself a fact requiring explanation, offering a new datum among those which form his basis. In both these ways it is the individual who is

${ }^{1}$ Grammar of Assent, c. v. $\S 1$.

2 See p. 1 .

${ }^{3}$ It may be convenient to the reader to have before him some of the Definitions offered in various quarters.

Some Philosophers :-

DESCARTES: A substance infinite [eternal, immutable], independent, allknowing, all-powerful, by whom I myself and every other thing which exists, if any such there be, were created (Meditations, III.).

LOCKE : God is an eternal, most powerful, and most knowing Being; from this idea duly considered will easily be deduced all those other attributes which we ought to ascribe to this eternal Being (Essay, Iv. $x$ ).

Huse: Genuine Theism represents us as the worknianship of a Being perfectly good, wise, and powerful (Dialogues, xIr.).

KANT: A supreme Being who is the free and intelligent author of all things. This (conception) alone has interest for humanity (Critique, Dialectic c. iii. $\S 7)$.

HEGEL : It is a right and proper requirement that God should be defined as Absolute Spirit (Logic, Wallace's Tr. \$ 50).

CAIRD, Dr. E. : The only Deity we can believe in, nay, we might say, the only Deity we can disbelieve in or seriously deny, is a universal God, a spiritual principle manifested in all nature and history (Evolution of Religion, 
working out Theism for himself to whom the consensus gentium offers support or provides a new fact. But there is another way, different from both of these: it may be possible for the individual to renounce regarding himself as the supreme judicial authority in favour of the general opinion of his tribe or nation or of mankind at large. This is an employment of Consensus not as confirmatory but as a substitute; it is not now a subordinate consideration, but the principal method of belief. The difference, great as it is, has been much disregarded, as we shall find. I am taking this method to be entitled to recognition as a separate Type which, for want of better title, I am calling Social Theism, or Sociological Theism.

In this place some observations will be made upon Consensus as Confirmatory.

By Empirical Theists its assistance is usually welcomed cordially. For they are aware that philosophy of religious belief should account for the factor of necessity in the conception, and they are aware that an assertion of an individual's experience is by no means tantamount to a necessary truth. They therefore seek to arrive at necessity by means of universality: if a belief is universal it has a prima facie appearance of being necessary; and the fact of a prevalence so wide as to be practically universal is gladly incorporated into their systems for the purpose of con-

Lect. IIr.). Again : An infinite or Divine Being, who is the Source of all Existence and of all Knowledge (Lect. Iv.).

Some Theologians :-

Pearson: A Being or Nature of infinite perfection: a Being of itself, and independent from any other, upon which all things depend, governing all things (Creed, Art. I.).

EllicotT, Bishop: A personal God, the Creator and moral Governor of the world (Being of God, Address II.).

Flivt, Dr.: One Infinite Personal Being, almighty, all-wise, and all-holy .. . the Creator and Upholder of the world and the Father of our spirits (Theism, pp. 18, 5).

Martineau : A Divine Mind and Will ruling the Universe and holding Moral relations with Mankind (Study of Religion, Bk. I. c. i.).

Moore, AUBrey : The eternally existent One, the Being on Whom we depend, and in Whom we live, the source of all reality and the goal to which creation moves, the Object alike of religion and philosophy, the eternal Energy of the natural world, and the immanent Reason of the Universe ... the eternally Righteous One . . and Infinite Love (Lux Mundi, Essay II.).

Westcotr, Bishop: The absolutely One and Eternal . . . the wise Designer ... One who may be loved and who Himself loves . . Holy and Just (Grospel of Life, c. i.). 
ferring upon them this aspect of universality and necessity. There are Empiricists who despise this aid: for just as there have been hermits on the practical side of religious life, so there have been souls wholly absorbed in personal contemplation or adoration, and we find monadistic religious beliefs; every man in direct and solitary communion with the Almighty. The Intuitivists or Mystics are the chief representatives of this mood; but it will be remembered that Newman too once wrote that the only supreme realities to a man were God and his own Soul. But, as said above, the majority of Empiricists gladly incorporate Consensus for the sake of the appearance of 'universality' which it gives. Those who are building on Feeling, or on Ethical considerations into which Feeling enters largely, welcome the support given when the desires they appeal to are acknowledged to be common.

In a similar position stand the Intuitionalists. They, as a rule, welcome the confirmatory character, sometimes going so far as to mistake it for a complete establishment of the universal or natural or normal character of the belief, as thorough as can be claimed for the proofs of Reason itself: 'Natural Light,' 'Common Instinct,' 'Voice of Nature' are claimed as appropriate terms.

The Inferential Schools are in a different position. They have in Reason adequate provision for universality and necessity. A man who reasons is participating in a process which is concerned with Universals open to all rational beings. So that the inferential schools look round upon the testimony of mankind with a subordinate interest only : it is not of the first importance to them that a believer in Reason should find others agreeing with him; the others may be following some perversity or distortion, whereas he is, supposedly, in face of demonstrated truth, and the others will have to come round to him, some day. But inasmuch as it is acknowledged that the exercise of pure Reason is encumbered with obstructions from alien quarters of the mind, when a number of minds come to the same conclusion there arises a probability that these alien factors have been cleared away. And so, the resort to Consensus discharges for these schools a subsidiary office, that of showing that nonrational factors had been properly disallowed, and that the rational process had been permitted free course when the Theistic conclusion was reached. A second use is that, as even rationalists 
must rest their inferences on data, they are as glad of the support of Consensus in assuring them that there is agreement as to the data, as the Empirical Schools themselves.

Secondly, there is its aspect as a fact, as a datum, a portion of the experience of mankind which the Individual should take into account as part of what he has to find explanation for. Here is a widespread fact: a good explanation of it would be that the belief corresponds to reality; it is but a weak one to maintain that the belief arises, wholly objectless, in the minds of man after man all over the world and through the centuries, and that all the prayers and piety connected with it are unsubstantial exhalations that melt away when they have been expressed. Between these extremes others can be interposed, as by Bayle, for example, who summed up the causes of the belief as Ignorance of Second Causes, Fear, and Fraud; and Comte thought much the same. A very different estimate of what is required to account for it is that of Mr. Spencer, who makes the widespread character of the belief the great datum of religion, which philosophy takes into account and sets about supplying with a corresponding object.

It is specially necessary to distinguish this employment of Consensus as a datum for reasoning, from its employment as a confirmation of reasoning, because in too many cases they are confused. The method just described contributes a new argument of what may be called an 'absolute' value, of which not sufficient advantage is taken by many who use Consensus only in the corroborative sense.

Appeals to Consensus as Fact may vary:-

(1) As to its Extent. There are differences of opinion as to the prevalence, taking mankind at large. The existence of atheistic individuals has been denied, as has the existence of atheistic tribes or races. If 'atheism' is softened into 'agnosticism' the former denial is certainly untenable; the recognition of the existence of agnosticism in vigorous and amiable minds has rendered the resort to Consensus less easy for the Individualistic Schools. But when the standpoint of nations is taken, the evidence of history remains substantially what it was; the exceptions still take the appearance of aberrations or defects when confronted with the mass of religious belief and observance. For classical antiquity Cicero and Plutarch are 
competent and sufficiently unprejudiced witnesses; and there are masses of evidence collected by Cudworth and Stillingfleet and Hamilton. With the enlarged knowledge of mankind placed at our disposal by the labours of Anthropologists of recent times, the weight of authority is settling down on the side of universal prevalence. Of the counter opinion Dr. Jevons says: "This point we have no intention of discussing, because, as every anthropologist knows, it has now gone to the limbo of dead controversies. Writers approaching the subject from such different points of view as Professor Tylor, Max Müller, Ratzel, de Quatrefages, Tiele, Waitz, Gerland, Peschel, all agree that there are no races, however rude, which are destitute of all ideas of religion." 1

But the extent or sphere of reference may be altered by appealing not to the masses of mankind but to the select; to the leaders of thought and life. Here the consensus is quite as striking. Even in the line of great intellects it is impressive; but when greatness in other ways is regarded, greatness in poetry and art, in public affairs and in practical influence on human progress, it is stronger still.

The testimony for general prevalence given by historians and moralists is not to be ignored, for these with practical unanimity assert that religious beliefs and interests, either through their promulgators or through the dissensions among religious people, have been the most influential determinants of the vicissitudes which the history of nations records.

In this reference what Aristotle says is worth bearing in mind, namely, that in matters of vital concern men are much more nearly of equal value as judges than a philosopher might be inclined at first to allow. Another reflection is that it is legitimate to appeal to latency, capacity for belief, as, e.g., Bishop Wilkins did, and as Mr. Rutgers Marshall does in his acute treatment of the Religious Instinct, ${ }^{2}$ where he insists, not that the actual operation of the Religious instinct is universal, but that if 'appropriate stimulus' is forthcoming the power of responding is universal.

The old designation $e$ consensu gentium recalls to our minds the social character of religion. This aspect is dealt with as an independent method, as already intimated; but it is quite

${ }^{1}$ Jevons, F. B., Introduction to the History of Religion (1896), p. 7.

${ }^{2}$ In Mind, 1897 ; Instinct and Reason, 1898. 
within the compass of the employment of consensus, either as confirmatory of other methods, or as a separate fact to be explained, to point out that the extent of prevalence finds most conspicuous evidence in the public life of mankind. From the dawn of History provision for worship in some way recognising the Unseen has been an indispensable part of the institutions, rites, offices, and edifices set up by the nations of the earth; and codes of law would be unintelligible or expressed without sanctions in innumerable cases if reference to the Unseen were removed from them; whilst language itself has abounded in provision for ideas applicable either primarily or ultimately in a religious sense.

(2) As to Content. We have to ask, for every Theism, how its particular definition receives support from Consensus. Here there will at once appear a serious reduction in the claims which any one of them may put forward. In looking at the record every Theist will find in it more than he needs and more than he likes; and, per contra, he will also find less. Defective ideas abound, to a degree equalled in the other direction by the excesses of superstition. So that there is plausibility in the endeavour to confine the support of the appeal to only so much of Theism as an abstraction from all concreteness yields: the vague undefined Something supramundane to which it is impossible to give a name without at once forfeiting some part of the support appealed to.

But the loss is not so serious as appears: another method is open than that of jejune abstraction in search of a skeleton. The whole historical development in all its ramifications and variations may be studied and a permeating principle or principles be discovered. The lower, the imperfect, the tentative may be absorbed, not cast out: taken up, not thrown away as false; and the truth be the issue of a complex process in which the ideas of later stages incorporate those of earlier by using them in their essence and aim. If there is progress in human history, then the later stages will show us men and nations more worthy of credit than those of the earlier stages. Few believe in a decline except in the one lapse from a primitive elevation comprised in a long current view of the doctrine of the Fall, by which religious ideas are regarded as fragments preserved in a ruin. The general tendency to accept progress- 
whether as the first movement upward or as recovery, Natural Theology cannot say-not in a straight line and in every detail, but in total and in complexity, leads to choice between the course taken by Comte and that taken by Hegel with regard to Consensus: Comte taking it that men of the later stages of civilisation were abandoning Religion: Hegel, that the later stages of humanity were exhibiting an ever-advancing progress in the quality of their Religious belief. Theists themselves have sometimes referred so fondly to early ages of the world and primitive 'revelations' that they have rendered their position difficult in face of the belief in Progress, which cannot acquiesce in the superior value of early testimony: but they have not been consistent with themselves, for they have been equally accustomed to point to the decay of Fetichism, Polytheism, and Idolatry, in face of the advance of civilisation, as a sign of the falsity involved in those primitive religions. It is therefore incumbent on those who accept the progress of mankind as a fact to set themselves right in this way. There is no need to abandon the argument, as Mozley did, ${ }^{1}$ peremptorily. It only needs that they take trouble to show that Theism is the belief towards which the others were working; that it holds a place in relation to them parallel with that held by astronomy to astrology ; that it stands in the van. We do not search the Chaldean astrologies for testimony to facts of Solar Physics which they had no instruments for coming into contact with; nor need Theists undertake the task of showing that Eleusinian mysteries or Druidic rites had secret systems in which the Theistic ideas of a Leibnitz or a Berkeley were esoterically concealed. What the Theist is concerned to show, when relying on the Consensus argument, is the solidarity of the whole thought and aspiration of the human race, exhibited in progress towards purer and ampler doctrine and worship. The appeal to mankind is not abandoned, but rejuvenated and elevated, Comte notwithstanding.

What we have to do in reference to Consensus in our inquiry is to indicate (1) where Social Theism is taken as the principal method; (2) where it is used as confirmatory of other methods; or (3) where it is used absolutely, in its character as a fact amongst those which it is the business of philosophy to explain. 


\section{EXPOSITION OF THE TYPES}

The course of thought in Britain after the Reformation retained the primacy of the Intellectual factor in Belief. Belief was regarded as having most immediate connection with knowledge; what a man could not know he could not believe: Reality presented itself prominently in the form of Truth. The Being of God was a legitimate subject for speculative inquiry, and it was all-important for man to ascertain whether or not his existence could be proved. The philosophers of the time were full of fresh vigour and, with the marked exception of Bacon, they claimed the supervision of Religious belief, a claim which was soon carried far into Christian Revelation, and the reasonableness of Christianity was an indispensability to the educated man, if he was to remain a believer. Hence we commence with the various forms of Rational or Intellectual Theism.

\section{§3. Type I.-Intuitionalism}

First comes the primitive and often quite naive statement that religious belief comes by Intuition. It is not by scrutiny of the meaning of phenomena that man knows God. But when he is engaged in looking at phenomena he has a power of vision, of intuition, which discloses Realities behind and distinct from the things which appear; his own personal identity, the external world as a single entity, and the Deity. Behind finites is seen the Infinite, behind all 'times' is Eternity, behind the powers of nature and of will is an Infinite Will, behind the forms of goodness and beauty is Perfection: and, finally, all these are seen as attributes of a single Being, God. These are ideas which Locke described-not speaking for himself, however-as the knowledge in which "the mind is at no pains of proving or exarnining, but perceives the truth as the eye doth the light, only by being directed towards it." 1 Hamilton said ${ }^{2}$ Intuition is "an immediate apprehension of a thing in itself, in contrast to a representative, vicarious, or mediate apprehension of it, in and through something else." "Perceptions which are singular, -(i.e. of single objects), -incomplex, and immediate are intuitions in the good old logical meaning of the word." 3 The Divine

\footnotetext{
' Essay, Iv. 2. $\quad 2$ Reid, note A. $\quad{ }^{3}$ Semple, Kant's Ethics, p. 34.
} 
Being, it is claimed, is known by direct and immediate regard by the simple outlooking of the mind. The phenomena which are presented are not in more immediate relation to the mind than is the ultra-phenomenal Being of whom they are manifestations. As finite things and finite persons however complex in their structures have in their constitutions 'elements' which must be regarded as plainly given to the beholding mind: so with the Infinite and Perfect Being. After-meditation may fill in the knowledge, but there is an original and integral nucleus given to the mind as it looks out. Thought must begin somewhere, and these Intuitions give the beginnings. The Intuition of God is the principal of them all.

The fact of the presentation of this reality, its immediacy in the sense of its being wholly impossible to derive it from or through anything lower than itself, its singleness in totally differing from anything made up or compounded, and its universality for all who open their eyes and look out, these are relied on as marks of the necessity which should characterise a deliverance of the Intellect in its Intuitional function. The external world is known in this way; so is one's self. Resembling one another in being underived and immediate, these beliefs are related simply by their adjacency in the mind; though some few Intuitionalists are not afraid of boldly adventuring on forming them into a graduated scheme. Such a belief is plainly one that carries with it certitude. Why then is it not universal and resistless? The answer is given by referring to psychology: the natural mind may have its vision obscured as the bodily eye has; or the belief may be latent. Intuitionalists hold that a sane mind in mature vigour looking with sincerity will not, cannot, fail to see simply Nature, Self and God; and they claim that the common sense of mankind is on their side.

But all who occupy this standpoint are not of one mind as to the extent to which they rely upon Intuition for perception of the Divine Being. For some it covers the whole of the Divine Nature: his existence is not more clearly perceived than his Infinity, and so on. They do not see how Infinity could. by any mediate way be known: knowledge of any other order would be limited and imperfect, and so would not be knowledge of Divine Attributes. But others will limit the scope of immediate knowledge to certain attributes; and others will be content 
with acceptance of the immediacy of the single article of the existence of a Supreme Being in whom analysis will disclose some Attributes, and whom experience will teach us to invest with more. In the filling-up choice may be made of various methods, and Theisms which are erected on this base may afterwards be of various forms. It is only after some circumspection that I have decided in any case to allow Intuitionality to be the classifying determinant: only when the cardinal article of Existence is clearly and uncompromisingly asserted to be so secured. The method is resorted to chiefly by some of those who have been dissatisfied with the attempts to demonstrate Theism. They have turned attention to Reasoning, and have endorsed its inability to give convincing proof by ascribing this to the inherent incompetency of Reasoning to discharge such an office at all. By the application of its forms and categories Reasoning was endeavouring to get over to the Infinite, and it has necessarily failed, they think, for its powers are not adequate for that enterprise: whatever Reasoning touches at once becomes finite and conditioned. They assert that the Infinite, the Necessary, can be discerned only by direct and immediate union of the mind with that which transcends the categories which give order to finite experience.

It is obvious that this method will find it difficult to get beyond Individualism in religious belief : my assertion that these Intuitions are in my possession stands as my own assertion, a ground of experience common to myself and others is not available. Hence resort to Consensus will be made in order to adduce testimony that we men do, as individuals, one and all (or many) possess these intuitions.

There will be a tendency to polytheism, however refined. For unless we have some means of determining what Intuitions constitute the stock which every enlightened mind possesses, there is bound to be variety; many pretenders will present themselves, many 'superstitions' find a home. And it is difficult to see by what means pretenders are to be unmasked.

And, further, the separateness of the object of Intuition from the remainder of experience leaves the Divine Being out of connection with the world, indeterminate so far as that is concerned, and without anything to show how $\mathrm{He}$ can be brought into relation with it, or how it can be brought into relation with Him. 


\section{§ 4. Type II.-Demonstrative Theism (à posteriori)}

The second method is the one which for a long time enjoyed the title of Rationalism, namely, inference by $\dot{a}$ posteriori Demonstration.

This proceeds to prove one thing from another, to pass from data by means of certain principles to conclusions. The process is $\dot{a}$ posteriori in the Aristotelian sense, moving from things or events to the things or events or principles upon which they depend: backward in logical order from consequences to causes. In Theism its datum is the world of finites; from this the mind moves to the belief in the Infinite, and carries with it the conviction of Reality. The principle is that of Causation, in two aspects, from effect to cause and from order to purpose: both yielding lines of argument now hoary with antiquity and refined to the utmost precision by long usage. From the world of phenomena both physical and mental, to substantialities beyond phenomena; from the material world and the thinking self, or in some cases from one of these alone, the inference is drawn that there is an Infinite supra-phenomenal Being. The process backward-or upward, if time be neglected and order of dependence substituted-is performed by reason, and assent accompanies it, as reason has a right to demand that it should do. The assent to the conclusion is of no less force than the assent to the reality of the data combined with the acknowledgment of the reliability of reason. The reality of self and of a world of similar spirits, and of the external world with all the facts disclosed by the sciences, are the data: reasoning upon them issues in an assent to the conclusion, the existence of a Supreme Causal Being. The history of European Theism shows an absorbing attachment to this method along both its lines, and takes the form of the two famous Proofs, the Cosmological and the Teleological.

The Cosmological argument consists in the application by reason of certain general ideas to the world as given in experience, in all the complexity disclosed by the sciences. The world exists; we exist: but it does not satisfy Reason to stay there; a ground of existence is sought. There are, however, a considerable number of different ways of stating the proof, because there are different ways of regarding what it is in existence 
which requires a ground beyond itself. The following forms are found:-

1. From the world as a mass of causes and effects to a Cause which is never Effect but only Cause: sometimes expressed as a series of causes and effects taking place in time, for which a First Cause is required.

2. From the world as changes to something Permanent.

3. From the world as things dependent on something not themselves to something Self-dependent.

4. From the world as contingencies to a Necessary Being.

5. From the world as a mass of finites to an Infinite.

6. From the world as in time to something Eternal.

7. From the world as relativities to something Absolute.

8. From the world as phenomenal to a Noumenal Being.

9. From the world as potential to something actual. ${ }^{1}$

It is not a matter of indifference which form is chosen. What is chosen here leads to men being inevitably pledged to certain forms of conclusion when consequences come to be drawn out. Especially the selection of First Cause in preference to the others has led to a narrowing down to order in time, and straight on to what is known as Deism, which places a Divine Being at the beginning of the series, at the commencement of the world: this involved two embarrassments, the necessity of showing that the world, the course of things, has had a beginning; and the reduction of Divine operation to creation, supplemented by interventions whenever a true novelty appeared among phenomena, i.e. a restriction to Transcendency. All the others differ from this in resting upon a ground which involves Immanency, a permanent and present relation: e.g. the dependent requires a Self-dependent now and not only at its origination; and they are not committed to the difficulty of showing that the world had a beginning.

As every complete Theism has to endeavour to combine Transcendency and Immanency, those who confine themselves to only one form of the Argument will have a special task.

But to every form it is objected that the argument involves a great leap, from finite to Infinite, from contingent to Necessary.

${ }^{1}$ For example, Aristotle uses 1, 2, and 9 ; Aquinas 1 and 4 ; Locke 1; Leibnitz 4; Clarke 1, 4, 5; Kant calls 1 and 4 the 'Cosmological Ideas'; J. Caird mentions $1,4,5,7$, himself putting it in the main as 3 ; Martineau 1, 2, 3 ; Green 7 ; Stirling $3 ;$ Mr. Illingworth 1 and 7 . 
This spring of the mind must be clearly shown. It is clear that the argument is by no means $\dot{a}$ posteriori in the sense that its whole substance is found in the data; the data are limited, yet the conclusion is infinite. What is claimed is that there is a right in Reason to require assent to general ideas: causation, necessity, infinity, substantiality, or some equivalent. And it is in reference to these ideas that the battle has to be waged. Those who hold to the possession by Reason of constructive power, compelling assent, will take their stand on that; for them the argument is cogent, and the result a Demonstration.

Since Kant the main objection has gone deeper still. Reason may indeed assert a necessary Cause, but after all it is only itself that it satisfies. That the necessity carries with it actuality is denied; actuality being thus supposed to be something different from what Reason can give. This difference is precisely what Rationalism rejects, of course.

From its having been first formulated for European thought by Aristotle-though only partially, as Cause of Motion, with some filling up from other effects - this demonstration is often referred to as Aristotelian.

The Teleological argument, from Design, or Final Causes, is still older in order of formulation, and indeed in a naïve form may fairly be claimed to be co-eval with human thinking.

It proceeds from three characters of the data given by experience-(1) The constitution of individual 'things': whilst a large number are mechanically composed in ways that offer no further signs of order beyond the general operation of the laws of physics, mechanics, and chemistry, there is a vast multitude of organised bodies, each of which in itself gives evidence of order. (2) There are instances of things which seem to have a purpose to fulfil over and above their individual intrinsic being; effects to produce on other things, from which in some cases a reciprocal action proceeds to themselves, e.g. the relation of the plant kingdom to the animal: there is at least an appearance of this correlation having been in the view of whatever may be supposed to be the power or powers which have operated to produce them. And (3) the single order observed among 'things' which is disclosed to the observing mind in various degrees and in many ways; with everincreasing accuracy and widening scope Science has disclosed the 
evidences of order. By means of such generalities as gravitation, conservation of energy in the physical world, the law of habit, and the relation of will to feeling in the mental world, for example, we have the material world and the mental world reduced in some aspects to order within themselves; there is difference of opinion as to the relations between matter and mind, some holding unity to be attained, others perforce contented with a duality: but at most the world is regarded as dual, and by many as a single order.

The data or evidences for this argument lie at every man's door, obvious and popular, and yet yielding ever richer examples of order as the sciences penetrate into the inner economies or extend their sweep over wider ranges of fact. There are gaps and lacunae - out beyond the stellar systems there may be a law of gravitation different in its numerical measure, or even no law at all; nor is the law of conservation of energy of a character which justifies its extension over all possible physical worlds. In the inner lives of men's souls there are vagaries, flashes of genius and profundities of stupidity, tempests of passion and abysses of stolidity, which have not been reduced to orderly explanation; and beyond humanity there may be spiritual beings of a wholly different generic nature. But, as Romanes said," "so far as human observation can extend, there is unquestionable evidence of some one integrating principle," while "whenever we tap organic nature it seems to flow with purpose."

From such a cosmos, as effect, the inference is that there must be operating as cause a controlling intelligence, at least adequate in extent of power and in range of intelligence to produce this limited mass of effects, with the farther possibility of its being able to fill eternity and infinite space with similar ' designed' existences.

We shall find two modes of stating the inferential Character of the Argument-(1) As an Analogy: The world is compared with a watch or some other work of human art known to be produced by an intelligent and purposive maker. If the points which in the watch are the results of this designing activity appear in the world, we have an analogy: as the watch to its maker, so the world to $x$, or rather perhaps, as the watch to the world, so the human maker to an $x$ maker. Or (2) 
As a direct inference, from such and such marks in the effect to such and such character of the cause, without any need to compare with a watch or anything else. The inference by which we infer from marks of symmetrical shaping on a flint that it had a designer, is precisely the same as that by which we argue to a Designer of the world: the inference is perfectly plain and direct in each case.

The heat of controversy has led some minds, e.g. Dr. Flint, to despise the analogical form of the inference in favour of the direct form. But in so doing they are cutting themselves off from much of the popular support which has been a strong commendation of the argument to the student who is affected by reference to actual history: this support has been given to it chiefly in its character as a telling analogy. Both forms may well stand. The strength of the Analogy form lies in the direct reference to ourselves and the way in which we know that we act and the marks which appear in the things we effect. In this way we have our own intelligent activity as a vera causa: our inference therefore is not to a merely hypothetical cause; we may boldly say that purposive intelligence is certainly at work, although whether or not to call it Divine raises a farther question.

Of the three bases in the inference-order, intrinsic organisation, and extrinsic adaptation-one or other has prevailed at different times; the resort has shifted from one support to the other as the comparative volumes of evidence have altered. There is only need here to mention that the course of science since its entry upon modern fields of biology both classificatory and microscopic led to increased admiration for both extrinsic adaptation and intrinsic organisation, that concurrently there was an advance of mechanical theory and a persistent endeavour to extend it to cover biology, and, indeed, the whole field of nature, mind included, and therefore a growing opposition to teleology; and that the appearance in this century of the doctrine of natural evolution came as a strengthening of the opposition to teleology. The volume of evidence seemed to be reduced; extrinsic adaptation was wholly dismissed, and intrinsic organisation challenged, and it seemed that only order in general was left. But the general tendency soon appeared to be content with the abandonment of adaptation-Schopenhauer 'hoped' that it was being tried 'only by Englishmen' even in his day, 
half a century ago-retaining the demand for teleological explanation for organisms. And in compensation there came such an access of new scope to the first basis, that of the designed character of order in general, that any loss from giving up adaptation, and even for allowing much encroachment of mechanism in biology, was more than made up. Connections between individuals and between orders of beings were disclosed, more abundant and more delicate than had ever been dreamt of before; and of the course of the world it became more and more reasonable to hold that "each preceding stage is a prophecy of the following, each succeeding one a memorial of the past, and, throughout the immeasurable series, every single member of it is a witness to all the rest." 1 In fact the general testimony of Evolution-science in favour of progress provides evidence far far beyond that which was at the disposal of præ-evolutional science. For if there is progress, the operation of Intelligence, internal or external, seems manifest.

The objection that the Teleological inference cannot carry us to an Infinite Cause is without point against any Theists save a very few; only a scanty body of writers has maintained that it does so, or has desired to extract from the inference more than the conclusion that there is an Intelligent Cause, while most are content with confining it to the attachment of Intelligence to a Cause established on different grounds.

The objection that it supposes a 'material' to be supplied for ordering and adaptation applies to those who regard Matter as inert material; but the advance of Science has carried order and adaptation right down to the very heart of 'matter,' which is itself regarded as amenable to teleological interpretation, even though that is not yet attained. The recourse to the Analogy with human art does certainly expose the Argument to this objection, and the advisability of having farther recourse to the direct inference is evident.

Theists differ as to whether or not it is advisable to include in this Argument reference to a concrete ultimate end or ends in the world we know. It suffices some teleologists to take the inter-connection of ends as sufficient without endeavouring to designate any ultimate end. Before this century there was confident assertion of the anthropocentric character of the

${ }^{1}$ Gladstone, Later Gleanings, p. 137. 
universe, parallel with the geo-centric character of the physical portion of it. Then came abandonment of these centres one after the other. But the course of reflexion is leading us back again to the explanation of the physical world as in subordination to the spiritual, and this most forcibly on the part of Evolutionists themselves.

In some quarters the contest between Mechanism and Teleology has been settled by allowing to each a comprehensive range, while insisting that they both operate side by side. If the mechanical theory is true universally, it is far from being true exclusively; the range of teleology is just as universal. It is not a case of conflict: the endeavour to insert teleology within the sphere of mechanism in order to wrest portions of nature from the latter is futile: everything proceeds mechanically: but the counter-position must also be taken, everything proceeds teleologically also. There is no teleology that works without mechanism; but also, there is no mechanism uncontrolled by purpose. This double play was, in fact, the view of Plato and Aristotle: as against Descartes and Spinoza, it was reasserted by Leibnitz; Kant endorses it, and Lotze sets it forth in one of the most beautiful chapters of his Microcosmus. And now we are in presence of a distinct revival of this dualism, with a growing tendency to seat teleology in the place of honour if the question of rank is raised.

It is necessary to note that Teleology has been used too much in reference to only a portion of phenomena, the physical sphere. We shall find in England that some vigorous work was done in the mental sphere as well, and also in setting out the relation of one sphere to the other.

The Teleological argument is very rarely used in independence. The usual course is to attach it to the Cosomological. The existence of the Divine Cause having been secured, teleology gives knowledge of his character, namely, Purposive Intelligence, Personality. That the teleological constitution of a limited range of things could not lead us direct to an Infinite Creator is obvious on the face of it: the subordinate character of the argument as ancillary to the Cosmological is almost universally acknowledged. At the same time it is recognised also that in suggestive force it is the Teleological which is really the more potent. It appears earlier in history. Anaxagoras, Socrates, and Plato had set it out in vivacious language before 
Aristotle formulated the Cosmological. They use the argument from adaptations and from organisms, but there is also the argument from general order at the bottom of their thought, and they anticipate the necessity of setting out mechanism and teleology as efficient and final causes in a double order. Kant, as is well known, rises to vehemence of expression in his statement of its force on the mind. From the Greek source of European thinking we find this double aspect of Causality - cosmological and teleological - soon installed in Theism, current under the designation of Demonstrative reason. While in Britain, at the close of the nineteenth century, the Grand Lodge of Freemasonry warned all lodges against recognising a certain French lodge, on the express ground that this lodge had excluded from its proceedings the statement of 'belief in the Great Architect of the Universe,' an essential landmark of the English Order: the fabric of the average English mind will have to change before this form of Theism ceases to appeal to it.

In Britain we shall find among Teleologists men who set this argument in the forefront, on its own merits; but usually they apply themselves to it because it interested them most, and they express their allegiance to Cosmology as satisfactorily settled apart from their labours. In a very few cases cosmology is denied, and teleology left to stand as the sole Intellectual method.

\section{§5. ONTOLOGICAL (à priori)}

Following the clue of historical association with the Demonstrative arguments, our first $\grave{a}$ priori argument will be the socalled Ontological Proof of Anselm and Descartes. We shall not find that it has enlisted many adherents in Great Britain, but it has secured an amount of attention which requires our taking it into consideration.

It is an endeavour to formulate an argument from the idea of God to his existence; from possession of an idea to assent or belief in an objective reality corresponding to it.

Amongst the various forms of statement are found-Existence is included in the idea of a Being than which a greater cannot be conceived (Anselm and Leibnitz); in the idea of a most Perfect Substance (ditto); in the idea of a most Perfect Being (Descartes); in the idea of a self-caused Substance (Spinoza); in the idea of an Ens Realissimum (Descartes, Wolff). How, 
it is asked, could a limited or an imperfect or a dependent or a caused or a contingent mind-whichever form we takeoriginate such an idea? Or, again, if existence is not included in the idea, then the idea of perfection fails in completeness and perfection: which is a contradiction.

The stock objections that a perfectly round island is not necessarily in existence simply because we have an idea of it; that the thought of a hundred guineas in my purse does not prove them to be there, have served even great thinkers as sufficient weapons with which to attack this argument. But Anselm and Descartes were, surely, thinkers of greater penetration and subtlety than to allow themselves to rely upon what is open to any such attacks of the market-place. In our idea of an island perfect circularity of contour is a purely accidental quality, unimportant and casual; so is the precise locality or exact ownership of a hundred guineas. But Anselm and Descartes are not speaking of casual or optional ideas; they consider that the idea of a Perfect Being is a necessary idea, and clear as daylight, so to speak; one which is an innate possession of the thinking mind: clear and precise and self-evident. There must be some explanation of it; and the simplest explanation is that it is evoked by the operation of an Object, of a Reality. To suppose that Anselm and Descartes and Leibnitz could not distinguish between the kind of objectivity attaching to an endeavour to sketch a Perfect Commonwealth, and the kind of objectivity attaching to the idea or thought they were dealing with, is to have little respect for their intelligence and the place they have won in the intellectual world. The necessity of the idea is the pivot of the whole position to them. And this necessity they allege to be of a wholly $\dot{a}$ priori character and to provide a sufficient ultimate ground for Theism, even if there were no other.

It has been said that we shall not find any English Theists definitely taking their stand on this argument. Their attitude to it has varied. Some have exhibited a disinclination to attach any weight to it at all. Of these some have expressed themselves hesitatingly and with distant respectfulness. Clarke, for example, calls it 'obscure' and 'defective,' and indeed perhaps only nominal, although he acknowledges that it is 'not easy to dispute.' Others have dismissed it with abrupt discourtesy. Reid's opinion is well known, and we shall find others not dissimilar. On the whole, 
they anticipate the decision of the Roman Inquisition, which in 1861 decided that Ontologism could not 'safely be taught,' non tuto tradi. But some have adopted it as an additional argument, as a new strand in a composite cord; having independent force but to be combined with the others; and claim is made that increase of strength is gained by means of the addition. Others have accepted it as a necessary part of their complete scheme: they adopt it as the formulation of that $\dot{a}$ priori factor which manifestly shows itself in any clear exposition of the Cosmological argument. Then on this as the $\dot{a}$ priori base they construct their scheme by means of the Cosmological and other proofs from experience.

The attitudes above referred to are those of Theists of the Demonstrative School. Those who on other grounds belong to an $\dot{a}$ priori school regard this Ontological argument as leading up to the adoption of a complete a priori method, of which it is an early formulation. The Argument has held the ground, they say, during the eclipse of true $\dot{a}$ priori thought, and having served its purpose it is now of only historical interest. Still, the dispensing with the Ontological argument and that formulation of how thought and reality are related which it was designed by its greatest expounders to provide, can hardly fail to leave an appearance of headlessness to the scheme of Proofs.

\section{§6. Type III.-Transcendental Idealism (Speculative)}

From Kant's resetting of philosophy and restatement of the $\grave{a}$ priori and $\grave{a}$ posteriori methods, and their relative functions in leading to Belief, dates the appearance of a new $\dot{a}$ priori method, known by the designation Transcendentalism.

The procedure of the $\dot{a}$ posteriori Demonstrative School, the assertive or dogmatic character of the Intuitionalists, and the tentative formula of the Ontological proof, each and all seemed to Kant inadequate as against the growing force of Empirical. and Sceptical objections. He therefore devoted himself to a severe scrutiny of the whole situation, and by his 'critical' theory of knowledge he sank mines under them which were considered to have exploded those fair fabrics of centuries of thought.

For the methods of reasoning hitherto employed he substituted what is known as Transcendental method. Of this 
method he was only the originator, however; he himself was unable to attach to it more than a limited office in the formation of Religious Belief, and it is not as Kant stated it, but as it was developed by a series of successors, pre-eminently by Hegel, that Transcendentalism as a really constructive method now stands before the world. The kernel of the full doctrine is that Necessary thought is constructive of intelligent experience, and that the 'idea' or 'object' which it presents is entitled to our full belief as Real. That we have some intelligent experience, and that it is veridical, is taken for granted; it is the fact to be explained : whatever idea, or thought, or belief can be shown to be necessarily involved or implied therein as its prius is a true thought; as veridical as the datum itself, to say the least. The mark of necessity is allimportant. The necessary character means necessary for the bringing into shape and order the manifold data of experience: after subordinate categories have been applied to the data of perception there is a function for Ideas, namely, to arrange a higher order still, and, it is hoped, a final one. If it can be shown that such an order is induced, the Ideas stand vindicated and must be believed in. The three Ideas are the Soul or Self which perceives, understands, thinks, and is conscious of itself; the World, which is perceived; and God, in whom the opposition between subject and object is unified. Here then we have a new mode of Theism. The Idea of God is necessary for the explanation of the Ideas of Self and the World-in themselves and in relation to each other-and all three in combination are necessary for the explanation of experience in general.

But it is at once obvious that there is an appearance in this of our moving only in the realm of 'thought' and 'experience'; a feeling that we do not touch 'objectivity' in the sense of a something independent of and outside, so to speak, our own mental life. Well, this kind of objectivity was precisely what Kant may be taken to have repudiated: it is not possible that there should be a presentment by Reason of something which is not Rational; it is a contradiction in terms to require such a thing. Kant did, indeed, himself reserve a blank $x$ as a source of reality, but some of his followers considered that in this he was retaining an incoherent relic of the older thought; while opponents, it may be said, took it as 
an acknowledgment on his part that he had very nearly cast objectivity out and grasped at this to save himself. His followers accordingly dispensed with this relic and took the path of insisting that Necessary thought is itself always and inherently strictly correlative with objective reality. In short, that what Reason thinks is Real. There is no distinction between being 'necessarily thought' and being 'thought of as real,' or, in other words, being real. This is fundamental. Take away this correlativeness and higher Reason is futile, ordered knowledge is a dream, universal truth is unattainable, empirical positivism or even scepticism must ascend the throne hitherto claimed by philosophy. In the name of constructive Thought therefore Transcendentalism claims the adhesion of human intelligence.

In relation to lower ranges of knowledge the higher Reason stands thus. Experience unquestionably shows fields of positive knowledge of two kinds, first, that which is within the range of my own consciousness, my own personal history, and, with this, the inferred history of my fellow-men; and second, the accumulation of knowledge of the physical world given us by the physical sciences : in short, the whole content of the sciences, psychological and physical, in varying degrees of concreteness and abstractness, of verified fact and probable hypothesis. Within both fields it is futile, vain, and self-contradictory to endeavour to find either self or world or God. The 'Objects' corresponding to these ideas belong to a higher order. Self is the necessary basis of soul-existence; the World, of outer objects; and God, of both these. But any attempt to depict these three Ideas in terms of sense-knowledge, even as ordered by the Understanding, must plainly be to deprive them of their special character as Ideas of Reason. Or it is to make them what is banned as Transcendent; to attempt to carry sense and understanding into the upper realm; to assume that we have what Kant always seemed to be lamenting the absence of in our nature, an Intuitive Understanding.

Is, then, reality to be denied to this higher order? On what ground? What is there in the lower order which entitles it to monopolise that claim? The answer is, There must be a complete turning round from the empirical standpoint: reality must be ascribed to the upper order: and that primarily, for the very reason that this is the order of which we must necessarily think. In the lower world all is finite, contingent, 
conditioned. Surely it is delusive to claim reality for this in comparison with a realm of principles which are Infinite, Necessary, and Unconditioned?

It is also to be noticed that while Transcendentalism brings the individual mind into full play, it is not individualistic: what is necessarily thought by me is necessarily thought by every other mind: we are each of us participating in a universal Reason when we are thinking; hence the necessity and the universality. But whether I think all this immediately and originally, or acquire it through the medium of fellow-minds, is a different matter.

It has perhaps been venturesome to endeavour in a few paragraphs to indicate this new philosophical position: probably every sentence written is open to objection. The statement of it by Transcendentalists has required iteration and reiteration in original works, in essays, in histories, and in commentaries. But the endeavour has to be made; or of what avail is the new method if after a century of elaboration it must remain incapable of formulation in a few working principles?

Its application to Theism I take in this way. The thought of God is a necessary thought; it enters into the structure of experience, of reasoning, of knowledge; it gives form to that structure, it exhibits it as a consistent and coherent whole. Without it, experience falls asunder into shapeless and disconnected masses, so to speak: our mental picture is a chaos, like the disconnected patches of colours on a painter's palette. The ordering of the lives of finite spiritual beings like ourselvesnay, the very lives themselves, each of which is inexplicable so long as it is regarded in isolation-depends upon the reality of the ordering principle, which is therefore, as an object of belief, inevitable and necessary; and this ordering principle is God. To say that God exists is absolutely true; but it is a bare and barren way of stating the truth. He does more; He acts, He lives. His actions and His life are seen in the world which expresses Him, and in the Spiritual world which not only expresses Him, but is conscious of doing so. This is often called Idealism; but if the charge is brought that this would mean that the Divine Being is only a creation of Thought as opposed to something which might be more real, the charge rests on a delusion : namely, the supposition that something more real could be found 
than the object of necessary thought. If the term means that Ideas of Reason show us reality, and that thus God is rationally believed in as the supreme Reality, the term is accepted.

Transcendental Idealism therefore claims that it exhibits a Theistic world; and that its world-view is rational and satisfying, while any other is incoherent and either leaves the soul desolate in an alien and opposing universe, or in a multitude or manifold of things which is no universe at all. Theism sets firmly together the thinking spirit and the finite objects of its thought, and by reason of this combining invests them with a higher kind of reality than they had before. And we have to choose between this and either a Subjective Idealism by which the Self stands as a solitary reality; or, a Materialism in which reality of the Spirit is suppressed or subordinated; or, an unrelated Dualism; or else, some form of Pantheism; or, finally, acquiescence in there being nothing at all worthy of the name of reality. The Theistic reality of the Transcendentalist, on the other hand, vindicates the subordinate reality both of our own spiritual being and of the world by necessary reference of both to the Supreme Reality in which they live and move and have their being.

How does Transcendentalism stand in relation to the older à priori schools? How does it differ from such laying down of an Intuition of God or from such proof by Demonstration as Kant is supposed to have rendered obsolete for all who work through his 'Critical' polemic?

In the first place, in this new à priori method we no longer suppose that we can attain to belief in a transcendent Being known per se as beyond and above and outside experience; instead of this, we see Him through the experience which His presence renders intelligible, and in that alone. It teaches us to avoid trying to look upon God as a possible member of His created world. But did the older schools ever do so naĩve a thing as this? Not expressly, and in terms; but they imply it, and their adversaries find it always plausible to attack them as doing so. The Intuitionalist talks of seeing God directly, as if $\mathrm{He}$ were one object among others: the Cosmologist works his way to Him backward or upward from the finite world, over against which stands the Infinite. But the Transcendentalist sets God as necessarily existing in relation to His world, not away from it, not known per se, not worked up to and then regarded as known or perceived in Himself with the world and self left behind; 
but ever as the Supreme in correlation with that which depends on Him.

So that Transcendentalism takes the place of the Intuitional and Ontological methods in the $\dot{a}$ prior $i$ sphere: taking their place by providing the $\dot{a}$ priori basis. Then the other arguments follow. In the world of events things and persons, as exhibited by experience, the application of the conception of Causality comes in as a mode of moulding the manifold into ordered experience, under the direction of the architectonic Idea. And thus the Cosmological 'proof' is not separate and independent, leading up to the Divine Being, but recognition of the display of His activity in the world. It thus takes up the $\dot{a}$ priori element which is always involved in a statement of the Cosmological inference, and sets it in position ready for application to the realm of phenomena. It is not regressive but progressive. Similarly the Teleological proof may be regarded as an inductive verification, as the exhibition, after inspection of phenomena, of the actual way in which the Supreme Reality working by Intelligent Purpose, is pleased to produce and develop a finite created universe: or progressively, starting from the purpose of God, we have a key to the knowledge of an ordered world. Not otherwise do the Moral and Esthetic arguments show how He awakens in our spirits the sense of Goodness and of Beauty, and leads us to take delight in rendering them into conduct and character or to rejoice in the appreciation of them as characteristics of nature and of life.

Kant was the pioneer of this method, or rather its inaugurator; but, as has been indicated, by him its scope was inadequately apprehended, and he still clung to a remnant of the older mode of $\dot{a}$ priori thought. But his own strenuous toil prepared the way, and others came in the freshness of youth to enjoy its results and move forward. Kant did not allow that in the idea of God we had any other kind of reality than that of an Idea, i.e. so far as the speculative Intellect was concerned. $\mathrm{He}$ himself regarded this limitation with equanimity because he regarded perception of Right as a separate function of Reason, by means of which Theistic belief is validly and conclusively attained.

But in various ways the method of Transcendentalism soon stimulated into profuse vitality the thought of Germany, both philosophical and theological. The great name of Hegel stands 
pre-eminent in Germany, of course, where his influence has been felt in many quarters, although few now accept the detail of his work. In England it has been especially through his formulation of this method and his encyclopædic application of it that adherents have been won. At least this is so as regards Transcendentalism on the speculative side. On the Ethical others have had their share of influence.

This leads me to say that by Transcendentalism pure and simple is often meant the resort to it for the Intellectual or Speculative establishment of Theism. Kant is not called a Transcendentalist for Theism, because speculatively he could not see how to get beyond his scepticism; only in Ethics could he build Theism by his new method. But I shall apply the term to Ethics also, and shall treat Ethical Theism by Transcendental method as a leading type.

But Hegel held that the method availed to justify speculative belief in the reality of the Divine Being. Inasmuch, however, as the method of Hegel was not found to be compulsorily cogent, so to speak, as explaining the relation of Thought to Reality, division among Hegelians set in, according as Thought or Actuality received most stress; there was a Right wing giving primacy to Thought, and a Left wing giving primacy to actual History of experience. In Theism these differences take the form either of reading phenomena in the light of $\dot{a}$ priori Theological ideas, or else of rising from the study of actual experience and insisting that the ideas found there constitute Theology. In one direction man's thought about God leads to knowledge of the world: Theology is History; in the other, man's study of the world is necessarily at the same time the study of God: History is Theology. In face of this division our British Hegelians had to reconsider his method for themselves, and to incorporate factors and elements from their own resources.

Two points require noting here on the bearing of Transcendentalism on Theology.

(1) This view does not claim that our knowledge of God is full at the beginning of our study. We begin with the belief in a Spiritual principle or Absolute Spirit: invested with the vastness of necessity and infinity, with immanence and transcend. ence and goodness. To the Intellect this is full of promise; to the imagination it is exceedingly indistinct. But we proceed 
on one or another of the above lines,-development of Thought or study of Fact,-and every grain of 'experience' becomes material for further knowledge of Him. Fulness in this respect is for ever impossible by the very reason that our powers of knowing are finite, and the history of the world is a history of finitudes. But in the ever-increasing volume of human experience there is a progressive enrichment of Theological knowledge. This progress is the privilege of the human spirit in so far as it is guided by the Perfect Idea of God.

(2) This view has special affinity also with Christian Theism because it is itself in essence a Theory of knowledge in which the finite sphere is regarded as a Revelation. According to both, the world takes the form of a system of 'signs,' of 'words,' of 'messages,' interpretable by the spirit of man. The Transcendentalist reads the universe as a Symbolism. To English readers it is only necessary to refer to Carlyle and Emerson to indicate what is meant by this. In studying the universe and ourselves, we are rethinking the thoughts of the supreme Mind; in directing our life to the pursuit of Good, we are making our life the manifestation of the Divine Will.

The term Transcendentalism is not the only one used to designate this school. John Caird calls it 'Speculative Idealism'; as Green expounds it, the term 'Spiritual Idealism' is appropriate; Hegel called it 'Absolute Idealism,' as does a recent defender, Professor John Watson, of Canada; it might also be called Rational Idealism.

\section{Reflections on Transcendentalism}

The recency of the appearance of this type of Theism in Britain and America, the high favour it has already acquired in influential academic circles where Theism begins with philosophy rather than with Theology, and the consequent effects in others where Theology is the prior interest, render advisable some attention of a more detailed kind than was necessary for types of longer prevalence and in closer contact with the ordinary theology of Great Britain.

The school unquestionably exhibits great intellectual powers devoted to the expression of wide-sweeping and yet profoundly penetrative theory. And it is one in which philosophy is connected by inner and necessary connection with Theology. The 
doctrine of the Divine Being is in itself the initial and the final doctrine of the system. Here is no rising to the idea of God as an afterthought, from a system of science and philosophy already complete without it; philosophy is theological.

The six points are all here ex professo: Necessity in the strongest way, Immanence, Transcendence, Goodness and Beauty in perfection, Personality or Spirituality, and Infinity. To discuss whether they are established or not would bring the whole philosophy into court. This adjudication is not my business, but some observations may be made from the standpoint of our comparative method.

In the first place, Idealists must not be surprised if theologians are cautious in coming over to them. The informed theologian cannot but be aware that no general verdict of experts in philosophy has been won by the speculative Idealists, even in Germany itself. They are aware that Kant's own opening of the school was followed promptly by a marvellously rich application of thought on one or other of the lines indicated by his method. But the history of post-Kantian philosophy shows a network of out-branching lines. On Hegel's track alone we find a right and a left centre, with a right and a left wing, each occupied by men of mark. Now of all these our English and Scottish Hegelianism is but another ramification, and prima facie it can hardly expect an unquestioning welcome. And then within our islands, the theological student learns that the Cairds stand almost alone in their strong intellectualism, that Green and Mr. Bradley deviate again, and that other quondam Hegelians are losing confidence and going straight back to the Ethical Idealism of Kant, thence to begin much of the nineteenth century work over again. Apart therefore from inherent capacity to judge, the man who is asking for guidance stands perplexed, and feels that in spite of the confident tone and high claims of the Transcendentalists he hears too little volume of voice on their side to feel a call upon himself to abandon better-trodden ways of Theism.

Of the objections urged, the most pressing is that both the datum and the result are too remote from experience. By the Cairds we are called from ordinary life into our inner consciousness and in that to self-consciousness. Arrived at this remote point, we have then to go back a stage farther and find the self-consciousness in which ours is to be explained. At two 
removes therefore from what can be recognised as concrete experience we find the Supreme. From this double remoteness return has to be made to life, and the endeavour to secure this is much less effective and less articulate than the advance had proved. So that there is a feeling that necessary as the reference to a Unity of Self-consciousness beyond our finite selfconsciousness may be, we seem landed on an étage by an upward impulse, and there we stay. To turn round and synthetically reconstruct experience is an arduous task, and grave critics assert frankly that the return to experience is not, to their mind, accomplished by the Transcendentalists. Especially two 'mysteries' of experience, our Moral responsibility and the fact of changes in Time, are held to be inexplicable on this transcendental principle; if so, its Theism is inadequate, for unless it can show that God is implied in this world it leaves the idea of Him outside the actualities of experience. Another objection is that the Theism is too expressly intellectual. John Caird may reply that his work is on philosophy of Religion : yes, but he calls it 'Religion,' and not 'Theology' pure and simple, and therefore other factors should have been brought to the front, whereas they are placed in subordination to the thought of the Absolute Spirit. His Sermons and Gifford Lectures show decisively that as a preacher he took a full view of Religion; but should any of the elements which he there insists uponand with manly eloquence-have been omitted in a 'philosophy' of it? What he says as a preacher is so full that it might have been taken from the Cambridge Platonists: which is right, he or they, when in writing a philosophy he omits so much which they retain and hold fast to all along? And Dr. E. Caird's book is entitled Evolution not of Theology, but of Religion, and free resort is made to the phrase religious consciousness; yet the development actually sketched is concentrated on ideas, the intellectual factor. Green turned more closely to experience, partly deserting his metaphysics in favour of resort to full ethical life; so much so that he considered himself entitled to play the critic as to John Caird's method. Mr. Bradley works still closer to experience; and it may be that by his means the transition to a less intellectual form may be deemed to have been furthered, if not accomplished.

So far for Intellect as challenged from outside. But within the Intellectual arena another class of objection arises. For 
the ordinary English mind has run for so many centuries on the quasi-Aristotelian lines of the Schoolmen, or those of Empirical Induction or Intuition, that Transcendental Theism can hardly expect naturalisation for a long time to come. With Causation and Design we are familiar; our scientific men and our historians use these conceptions; and we pass easily to their use for Theism. God as Being and Substance sound familiar; but God as Principle sounds strange to us, and as Assumption and Postulate the idea comes with distinctly chilling influence. If we are told that 'existence of God' is a cold phrase, too, we find that on many minds it has much more 'grip': it goes with their logic, and they retain a readiness to expect that truth should lend itself to 'proof.' When they hear that the problem of Theism is 'beyond proof,' since it raises the question of the 'Proof of all proofs,' they acknowledge the success of the rhetoric, but are not convinced that it contains a meaning of any value for themselves. If the term Spirit is made fundamental they are more at ease; but disappointment recurs when it is refined to spiritual principle; and when they find Mr. Bradley grudging and resisting when asked to say what concrete element he can at all agree to admit into his idea of Spirit, they are bewildered. Even a strong intellect like Dr. Flint's cannot distinguish the Transcendental Absolute from pure Being; indeed from Nothing. And so, both the old Rationalism and the old Empiricism still enjoy the allegiance of not a few in these islands, as the bibliography of Demonstrative Theism since 1870 proves.

And another protest comes from Kantians: for them the Transcendentalists go too far towards hypostatising an idea or conception: if not in the old illegitimate way which they join in condemning, yet with the old illegitimate result. The self of self-consciousness is turned into an object of Knowledge: which it can never be, according to Kant. The term 'principle' is but a disguise because they wish to avoid the ban placed upon the old 'Substance,' but its effect is the same when it designates illegitimate objectification of self and of not-self, and of the principle of unity in knowledge. It is all 'true,' say the Kantians; but it is not Reality: it is only Transcendentally true in order to explain how knowledge is possible: no objectifying is legitimate. It would be hard on the Speculativists to say that they do not see all this; they make strenuous efforts to avoid it, but 
the objection is made from the Kantian standpoint, that they do not succeed; that the history of the soul and of the world lies in a region from which they have sailed away.

From Ethical idealism comes its own protest that the sphere of moral life is quitted for a remoteness in which moral consciousness finds itself reduced to a pale shadow. And when the promised return is attempted it proves impracticable. The movement is not made. Solvitur ambulando, says Dr. Fraser, and he avers that he waits in vain for the mind to march. Where does the Will come in, where everything is Divine manifestation? Where is human personality? Where and what is Goodness? And Ethical idealists invite us to return to Kant's abandonment of Speculative for Ethical Theism, where good work has been done which does not need speculative idealism, nor depend upon it.

From Feeling and Imagination comes still another protest. These have suffered much from the old Rationalism, but after the Evangelical and the Romantic revivals they thought they had vindicated their place among the essentials of Theistic belief. They had even succeeded to some extent in winning from the Demonstrative school admission to partnership, and were enjoying a restoration, attached with agreeable ease to Causation and Design. To God as Creator and Ruler, to supreme Spirit and Divine Person, 'Feeling could be attached, and Imagination could construct an embodied religion by the aid of the analogies of human life, individual, family and social. But the exchange for Principle and Postulate seemed to dissolve all this, and Feeling and Imagination were again abandoned. The offer of recognition as factors in 'Religion' after expulsion from Theology has come too late: and even the allowance of superior practical importance cannot be accepted from the hands of men who have said such strong things on the dominant right of Truth to suzerainty of the soul seeking after God.

The quarrel is sharpest between Speculative Idealism and the other Intellectual systems. It might be brought to consort with the Theology of Feeling, or Personality, or Ethics. Hegel allowed all these to be stages of advance towards philosophy of religion. But with Demonstrative Rationalism and Empiricism the fight is to the death, for the dispute is for the same territory.

The older Rational Theology will press for decisive answers to 
two questions: (1) Immanence is manifest, but is Transcendence secured? It may be, but the tendency to limit knowledge of the Infinite to its manifestations naturally gives rise to the impression that no further positive thought of God Himself must be attempted. This may be quite legitimate, and its opposite a mere ignis fatuus. I am not expressing an opinion. But Englishmen will not be ready to acquiesce when they are told that they must not think of God as having His own existence, His own character, His own majesty and glory, over and above all that can be seen or known. We know that some, e.g. Fichte, have found it natural to pass into identification of humanity with deity. I do not think that any of the Englishmen whose work I have sketched in this section are open to this charge, especially when to their systematic exposition we add their occasional utterances; but I find the objection made, as if a real difficulty had been felt.

(2) And on the other side it would seem from numerous criticisms that Pantheism, as identification of the Deity with his world, easily presents itself as the broad effect of this type of Theism. If the Deity is at the beginning and at the end, and all through the stages, where is human personality? Is our independence really preserved, or are we only appearances? Is our Freedom a phantom? The difficulty of seeing how to get away from Pantheism is too commonly felt to be ignored. That Pantheism is contrary to the intention of this method is plain, and abundance of vigorous statements can be brought to show that it is contrary. But to many English readers it is not clearly manifest that a true personal Theism, which retains reality for the worshipper as well as for the Divine Being, is attained, however bravely attempted.

Per contra, there is much that is attractive for Christian Theologians in the work of the Speculative Idealists. I have indicated how profound and thoroughgoing is their identification of Theology with Philosophy, how broadly and penetratively Theistic their view of thought, and of the universe which Thought discloses.

Hence, their world-view is profoundly Revelational. We are to regard the universe as a 'revelation' of God, and ourselves as endowed with an 'inspiration' which enables us to interpret it. And Christian Theology will insist that it cannot be easy for such a Theism to lay down a canon which will exclude the possibility of the appearance in the universe of 
new phenomena utterly unlike those already manifested to us; new events which require for explanation a fresh resort to the activity of the Infinite; persons charged with fresh missions from the Divine Spirit. Pre-eminently the Incarnation itself, with all that prepared for it, and the new Kingdom of God which has issued from it-only partially realised, yet with indefinite promise of progress - can by it be brought into relation with our worldview and exhibited as our central point of light and life.

Again, its doctrine of Reason is so lofty in comparison with that of the older Rationalism, and so lifted above that of Empiricism, that it is akin to what has been somewhat inarticulately set up as the doctrine of 'Faith' as above 'Sight,' as the evidence of things not seen indeed, but thought or held ideally by Reason. For this very reason the method is to be used with caution by Christian Theology. Under this philosophy history is apt to be sublimated into the history of ideas: the character of 'accidentalness' is carried very far into the constitution of persons and things, in order that only spiritual essence may be retained. A glance over Green's two theological lectures, the 'Witness of God' and 'Faith,' in which the Person of Christ is taken out of the region of history, will indicate what I mean. The method may possibly be the very best schoolmaster to bring Thought into Christian Belief, but with not a few it has taken the course of replacing it: not by opposition, but by the elimination as accidental of much hitherto regarded as of the structural constitution, and by the absorption of the rest into itself. The Christian religion as claiming to stand on an historical basis may find itself justified and illumined by Idealism, but if the procedure is to be a remoulding of history by the substitution of a process of ideas, Christian experience will protest and incline rather to forego the advantage of elevated and consistent thought if the result is to leave outside it elements, events, movements, persons, which are in the heart of the Christian community and in the life which makes men conscious of sonship of God through the Incarnation of the Divine Son.

\section{Some Forms of Quasi-Transcendentalism}

We shall find among English doctrines of Theism in the latter part of the nineteenth century some cases of partial adoption of the Transcendental method. 
(a) There are men who accept the Transcendental mode of establishing Theism by reference to proof from its illuminative efficiency, its success as an interpretative power. But they do not go with Transcendentalists in their way of building upon the original necessity of the Spiritual principle, from its being seen to be either speculatively or morally necessary when the conditions or implications of self-consciousness and our knowledge of an objective world or of moral consciousness are explored. They would be glad of such a necessity, no doubt, but they do not find it given.

This mode I call Quasi-Transcendentalism. In this school are found some whose minds have been occupied rather with the sciences than with philosophy, who adopt the logic of the Inductive Sciences, as expounded by Whewell and Jevons-not Mill. Their method runs on those familiar lines somewhat thus: facts as classified and arranged by the sciences; hypotheses to account for the facts; deduction to consequences; verification amongst the facts and amongst other facts not previously in view. In this way we have the idea of the Divine Being set forth as arising after the manner of a hypothesis, to be verified by its interpretative power. It is through this verification that the method presents some kinship with that of Transcendentalism. But it stands far away from it by reason of the absence of any recognition of the character of necessity in the original idea; how the hypothesis arises is not explained. As a mode of Theism this will be attacked from all quarters.

In philosophy the question has been pressed upon Kant and upon Kantians, how they get at the 'Categories' which they spend so much time in justifying. How do we know there are not others equally worthy of attention? It is all very well to talk of Postulates, but if they are capriciously chosen I can never feel sure that there may not be others as good. And I cannot press my own postulate on pain of Fallacy of consequent: if $A$ is, $B$ should be found to be: $B$ is found to be, $\therefore A$ is, will not stand, for other antecedents may be as good as mine. A hypothesis which is not a necessary presumption is a very unsatisfying thing: it is a competitor among other hypotheses; there may be hundreds or thousands of them, all entitled to be tested by verification. Professor James is complacently satisfied with this: "It matters not to an empiricist," he says, "from what quarter a hypothesis may come to hin: he may have 
acquired it by fair means or by foul ; passion may have whispered or accident suggested it, but if the total drift of thinking continues to confirm it, that is what he means by its being true." 1 But it is through a dim perception of this accidental and casual character that popular imagination stands aghast at a method which so easily lends itself to the scoffer, as in the famous saying of Laplace, as commonly understood. The regarding the thought of God as a hypothesis is sufficiently shocking to many minds to prevent this mode from having any wide acceptance.

The contrast between this and true Transcendentalism can be seen by a perusal of Professor Royce's chapter, 'The World of Postulates,' in his Religious Aspect of Philosophy. ${ }^{2}$ Dr. Royce admits it for science, but rejects it if it offers itself as competent for philosophy.

(b) There is a mode of Theism which employs construction of the Transcendental kind in application to the whole area of our personal life. Its maxim may be described as Satisfaction of the needs of life in all their scope and variety: whatever is required in order to give a ground for all the factors of our manifold life may be believed in, nay, must be believed in. The inference is after the transcendental manner. "The transcendental regress is a process in which by reflexion we become conscious of the principles involved in our intelligible experience," says Dr. Edward Caird. ${ }^{3}$ Broadening this out we can say, "The transcendental regress is a process in which by reflexion we become convinced of the reality of objects indispensable to the satisfaction of the whole complex of our experience."

A form of it is the 'argument from desire,' but that is a very partial statement of it: we must bring our whole nature into view. If an atheistic view of the world cools the ardour of our tenderest and most elevated feeling, if it leaves in vacuo our noblest aspirations and aims, if it leaves in disorder our thoughts of nature and of humanity, while a Theistic view sustains feeling, gives a goal for conduct, and introduces harmony into our sciences and our philosophy, then the Theistic view is entitled to our assent.

Such an argument must be employed with great care and circumspection, of course. We cannot derive a belief that the Emperor of China is a singularly wise and beneficent personage from the opinion that the benefit of such a man being ruler
${ }^{1}$ Essnys, p. 17.
${ }^{2}$ See postea, r. 163.
${ }^{3}$ Kant, vol. i. p. 484. 
of a third of the human race would be incalculable. We must cut out some accidentals here. We may think that the continuance in the government of China of any Emperor, whether wise or foolish, is better for China than the substitution of a foreign Viceroy and council or a native mandarinate or a national democracy, and that the 'needs' of China are best satisfied by centuries of the present dynasty. Then the satisfying of these needs is a proof of the presence of some qualities of goodness in the dynastic system, though none are discernible by inspection or analysis of the system itself.

If therefore we are considering human life as a whole and find that men, taken over a large area and in varied circumstances, can do more and bear more, can live higher and more noble lives when animated by belief in a supernatural Goodness and an All-seeing Judge ruling the universe, this is a kind of proof that such a being exists. To state it as the 'argument from consequences' is to put it somewhat meagrely perhaps, and in that form it lies open to much real objection. Still, it is in use in the Sciences, and our question is, Is it legitimate as an inference from experiences of all kinds to a something transcending experience? In the sphere of knowledge we find it claimed as legitimate by Transcendental Idealism, although the term 'consequences' is inadequate to express what is meant; and also in the sphere of Ethics. May it not be applied to our personal experience as a whole, in the form that satisfaction of imperious, persisting, and honourable needs of life is a good guide to belief, to truth?

That the concrete forms of the object of religious belief have been so arrived at is precisely what the Science of religions tells us : is it illegitimate to hold that the broad question of the existence of the object and the purification of the idea of it may be similarly established by the co-operation of rational, sentimental, and ethical demands? If the light of God is illuminative for Reason, offers support for Ethical maxims, and satisfies deepest Feeling, is not the light shown to be a true one?

This mode may be adopted by a man who does not accept Transcendentalism when applied either speculatively or ethically in a rigorous demonstration after the manner of Hegel or of Kant; he may be unable to accept it as a method of Theism when so limited, while he can resort to it in application to 
experience as a whole. Perhaps if pressed he could be driven from any right to use it over the whole of life if he has repudiated it in the separate factors; but at anyrate there are examples of some minds which do resist it in those special applications but accept it when applied to the complex needs of our personal life, with its demand for satisfactions and happiness as well as for intellectual consistency and for ethical sufficiency of the strictly rational kind. A leading example of their type will be found in the Theism of Mr. Balfour. He doubts Transcendentalism on the speculative side, while he maintains that for the scientific, the ethical, and the rsthetic aspects of life the interpretation given by Theism is superior to that given by Naturalism, and therefore he is a Theist.

\section{§ 7. Type IV.-Ethical Theism (Rationalist)}

The basis here is the sense of the reality of the deliverances of the Moral judgment; of the obligation to do right, to be virtuous, to love goodness and to pursue it. This is taken as a fact of human experience, explored and set in position by Ethics of various schools. The only requirement is that the basis be there: the reality of moral obligation and moral goodness.

In Ethics the main conceptions of the deliverance of the Moral Consciousness are two: Moral Duty, as imposing obligation ; and Moral Goodness as inviting acceptance : the conception of Law to be obeyed, and the conception of End to be achieved. As Duty, it carries with it a circle of dependent ideas; such moral conceptions as responsibility, crime, guilt, punishment, retribution; obedience, service, loyalty; with a part of the range of human legislation and social institutions extending beyond the deliverance of the individual conscience. As Goodness, it expresses the purposiveness of our nature; our being born to pursue ends, end upon end, with some final end which consummates all: in working towards this end, or rather as really living in pursuit of it, we truly live our normal and natural life. Under either conception, or under both, our Will is called into play: our active nature is appealed to. The conception of ourselves as agents acting out freely our own characters, putting ourselves forth, making our potentialities actual, is dominated by a consciousness that there is a guidance over us or with us. Duty regards it as something which is over against 
us, which addresses us with imperativeness and expects the submission of our will, our obedience; and acts upon our feeling by means of a profound sentiment of rest and happiness accompanying or following every act of obedience, or a penetrating pain of remorse when disloyalty has prevailed. Goodness carries Feeling with it: it penetrates the consciousness by a disclosure of the inner nature and purport of the end enjoined. In both cases there is present, essentially, in consciousness, the sense of limitation, imperfection, partial failure on our part: the whole of the Duty is never done, the Obedience is never exhaustive; or the complete End in its perfection of excellence is never attained. Ever the ideal is before us, surpassing the accomplishment, higher and fuller than the actuality: what ought to be ever exceeds what is. Now it is this ideality which is the spring of the true Moral argument to Theism.

Failure to perceive this has led to its statement in attenuated forms, and the consequent relegation of it to a subordinate position, and to some curiously meagre views of its capabilities even on the part of writers quite disposed to seek its aid. "Unless a man already believes in a God on other grounds," writes an able Romanist theologian of our day,, "I should be very sorry to have to convert him by means of the argument from conscience." The fact is, he is stating the moral argument apart from ideality: either as an inductive inference from signs of benevolence in the world, or as an inference from the existence in ourselves of feelings which accompany the deliverance of Moral judgments. These bases, although sufficient to furnish an argument for the writer himself, do not suffice, in Dr. Clarke's own opinion, for a universally convincing argument. Again, Dr. Flint ${ }^{2}$ does not fix himself on ideality; and consequently he says, "The Moral argument cannot be stated in any valid form which does not imply the legitimacy of the argument from efficiency and order" - Causality and Design: and he assigns to it only a contributory function. This, indeed, has been the procedure of the à posteriori school all along: to allot primacy of convincing force to the Causality arguments, reinforcing them with the Moral, in varying degrees of effectiveness of statement. It is the mark of our next Type to state the Moral argument independently, and assign to it at least equal impressiveness.

${ }^{1}$ R. F. Clarke, S.J., Existence of God, p. 43.

${ }^{2}$ Theism, Lect. vII. 
We must distinguish between the ways of employing the resort to Ethical consciousness : there is a choice of two Methods of Rational construction: the Demonstrative and the Transcendental. The writers indicated above use the older Demonstrative Method; they place their reliance for construction upon à posteriori Reasoning. And though the inferences from law to lawgiver, from goodness to its source, are simple enough, they are really only forms of Causality inference after all; in them the Moral argument is only called upon to fulfil a limited task, that of enriching and elevating the Causality argument by reason of the emriched and elevated nature of the data to which it is applied. The Causality argument pure and simple is from existence of any and every kind: it becomes enriched when special attention is drawn to facts which have moral character. Employed in this way the inference is very simple. The very expression Moral Law leads immediately to the thought of a Lawgiver. "Without a notion of a lawgiver," as Locke says, "it is impossible to have a notion of a law, and an obligation to observe it." And when the Law is presented as of absolute obligation and Duty as inexorable, as is done by Intuitional Moralists, there is no possibility of adequately explaining it by reference to a limited lawgiver. The admission of the conception of Law as necessary for the description of Moral fact, with the consequent reference to a seat of authority, gives a datum for an inferential Demonstration leading direct to Theism. And a parallel argument can be constructed from Goodness to a source in absolute and perfect Goodness. In this way Reason is at work by means of the category of Causality or Dependence, and the Moral 'argument' is presented in an inferential form.

But Reason is no longer confined to this older form; the new strength of Transcendentalism is available for application to the moral consciousness. That it was so applied by Kant is the most patent fact in the history of recent philosophy, after the decision that in the realm of Pure Reason only regulative ideas were at our disposal, by any possibility. But there were, and are, two very divergent opinions as to the import of Kant's procedure. It appeared to some that Moral consciousness, the domain of Practical Reason, was a place of refuge into which the defeated philosopher retired reluctantly and with regret. But to others it was regarded as no retreat; the Moral Sphere was precisely the sphere where Kant fixed the Angelpuintit of his 
philosophy, not only in all confidence, but with complete satisfaction. The unbiassed reader of his Critique of Practical Reason and of his Metaphysic of Ethics will hardly gather that he is in the company of a defeated general trying another method of assault: there is rather, I think, the tone of one who has dislodged a pretender, and is now engaged in making good the claims of the right of the sovereign. He denounces abuses on the Speculative side as having made 'Theology a magic-lantern of chimæras,' but of Moral Theology he says, the idea of a Supreme Being as a practical Idea is one "the possibility of which no human intelligence will ever fathom, but the truth of which no sophistry will ever wrest from the conviction even of the commonest man." 1

It comes to this, as between Transcendental Speculation of Type III. and Transcendental Ethical Theism; the former seeks the starting-point, the fact to be explained, in self-consciousness as knowing; the latter seeks it in self-determination towards an ideal of goodness; the former plants itself in the sphere of consciousness, of knowledge; the latter in the sphere of conduct consciously directed to an end deemed to be good, the Moral consciousness.

It must not be supposed that those who adopt Ethical Theism have no concern with the rest of experience. Although the moral life is their anchoring-ground, yet Ethical Idealists have their say as to the non-moral and the physical ranges of phenomena, in relation to Theism. They insist that these must be spiritualised, and that the operation is in process. They welcome such a treatment of Nature in relation to mind as is lucidly worked out by Mr. Illingworth, ${ }^{2}$ with copious historical references from Egyptology and Sanskrit literature, through the Greeks and Romans and the Christian Fathers, the Renaissance and Reformation, to Rousseau and Goethe, Shelley, Byron, and Wordsworth; and such a spiritualisation as is one of the prominent concerns of Dr. Ward in his Gifford Lectures. ${ }^{3}$

So far as concerns our own lower or non-moral nature, we were long ago taught that the 'natural' comes before the 'spiritual' in the order of time in our own history. The rise

${ }^{1}$ Critique of Practical Reason, Bk. II. c. ii. Abbott's Translation.

2 Divine Immanence, cc. i. and ii.

${ }^{3}$ Naturalism and Agnosticism, 1899. 
of spirituality and its victory in conflict with the natural, is what is explicitly regarded as the 'Moral Life' by Hegel as by Aristotle. And we are religious in so far as we thus rise above the conflict and enter more and more into the life of spirituality: to do this we must have help, aै $\nu \omega \theta \epsilon \nu$, from above. That there is such help to be had is the very anchor which Religious faith provides, and the Divine existence is the anchoring-ground. Thus in Moral faith is found the principle of Theism. To go elsewhere and look to Intellect for the principle is the mark of Transcendentalism proper, as we have seen, which stands upon consciousness in general, and takes up moral consciousness as special. But Ethical Idealism rests securely on the Moral Consciousness as ultimate.

It is easier for the Ethical School to make themselves at home with other parts of human nature than it is for the Speculative School. As to Will, it is incorporated fundamentally, for into the Moral Consciousness Will enters as well as Reason. But with regard to Feeling or Sentience there is no manifest ground for accepting any superiority of the Ethical form of Rationalism over the Speculative form. Feeling cannot be brought in by linking it with Will, under pain of crossing the river and entering the sphere of Empiricism; no one Feeling is, per se, more Rational than any other. And the way in which Feeling is attached is really the same for both Schools. The Ethical Rationalist refers to a special Feeling which is aroused in us by the dignity of the Moral Law; Reverence, as Kant called it: and by its means Moral Reason can exercise influence in the Sentient region of life. But the Speculative Rationalist makes a precisely similar claim upon Feeling: he points to a similar Reverence for Reason, respect for the dignity of Truth, and in his opinion it is this which is the most valuable sentiment of our nature, and with it he too goes forth to insist on sovereignty in the Sentient region. To both, Reverence is the natural handmaid which Feeling supplies: and both are equally removed from any charge of basing their Theism on a wish to believe.

The form of Ethical Theism which incorporates influence upon Feeling as a part of the object, so to speak, by speaking not of judgments of mere speculation or fact, but of judgments of value, is by that very incorporation carried outside the pale of the constructive truth which Rationalism supposes itself to 
be dealing with. Accordingly I have treated it as coming under one or other of the Empirical Schools (see Types VII. and VIII.).

How does Ethical Rationalism stand with regard to providing us with the full Theism of our Definition? Is there any failure obvious on the surface, in any of the points marked down?

As to Objectivity and Necessity, Ethical Rationalism stands on the same footing as Speculative Rationalism: the reality of moral law, of moral good, is taken to give as real a startingpoint as existence in general or consciousness in general was taken to give by the two kinds of Speculative Rationalism described. If Speculative Rationalism is idealist, so is Ethical Rationalism, too: if Idealism is as good as Realism for one, so it is for the other. God as cause of the world is in no way more real than God as author of moral right and good: the Idea of God as ground of conscious spirit, no more real than the Idea of God as ground of realisability of the good in the life of spirit.

Again, as to Transcendence and Immanence, no difference appears: to the Ethical Theist God is just as much above and beyond and at the same time immanent in the good, as the Speculative Theist had found him in existence or in consciousness in general.

With regard to Infinity or Absoluteness there is an apparent advantage, for it is easier to allow Absoluteness to the Good than to any other idea whatever. At least it may be said that more minds have expressed themselves as in possession of the idea of absolute rightness than of any other kind of absoluteness: the assertion that in moral distinctions we have something of eternal and universal validity has been made more freely and more unreservedly than is the case with any other field of human experience.

As to Goodness this is in the very essence of this method; and Personality is more comprehensively implicated in the activity which is involved in Practical Reason than it is in the comparatively spectatorial and impersonal operations of purely Speculative Reason.

No special objections, then, appear to lie against this form of Rationalism; it is liable to the same as those made against Rationalism in general: in going forth to meet its rivals it 
appears to be encumbered with no arrière-pensée that within Rationalism it occupies an inferior position; but rather the reverse.

This distinction of sphere or basis is the most penetrating differentia among Rationalists: judged by its effects more penetrating than even the distinction between $\grave{A}$ posteriori and Transcendental employment of Reason. To separate between Truth and Goodness, between Speculative conclusions and Practical, and to prefer the former, puts a man rather with Parmenides than with Plato, with Aquinas than with Abelard, with Descartes and Spinoza than with Kant and Fichte; in Britain with Locke and Clarke rather than with Butler and Berkeley.

\section{§ 7. Type IV. (continued)-Asthetic (Beauty)}

The fact that life is enriched with much enjoyment through adıniration of the Beautiful is an unquestionable fact: what is its significance, whether it has any legitimate part as incentive to religious Belief is in question. By the Beautiful is meant what is admired, in every form of it: as well the lovely and the exquisite, the tender and the pathetic, as the massive, the grand, the majestic, the sublime.

Much has been missed in the survey of this field because a comprehensive range has not been insisted upon. Too many discussions on the Beautiful engage themselves exclusively with what is admired in external nature; much more than this must be brought into view. The glories of a tropical sunset, the rolling of the waves as seen from the deck after a storm, give impressions never to be effaced; but there are delights of a more subtle kind than these; the refined enjoyment of the survey of mathematical properties, geometrical or algebraical; the love of music and of painting; and beyond these, human life: the charm of infancy, the grace of cheerful old age; the whole range of the Comedy and the Tragedy of life; the histories of the rise and fall of Nations. When therefore the question as to what Esthetic is worth is before us, all this range should be kept in mind.

As a datum for Theism the Beautiful could be used either by Empirical or Transcendental or Demonstrative Methods, 
just as Goodness may be ; and any man's method is likely to be the same for one as for the other. But before looking at Method it will be necessary in this case to give attention to the Datum: for the significance and character of this are so much in dispute that few Theists have made any use of it whatever.

There are two objections which would cut away the ground from a treatment of Beauty as capable of supplying an independent source of belief.

First. Its distinctive reality is denied, its efficacy is assigned wholly to Utility: that is to say, reference to beauty as something separate from subserviency to ordinary needs or purposes is disallowed. Some purposes to be served within the range of their own nature account for all the forms and endowments of objects: in the physical world, for instance, the mechanical play of the forces which constitute them: in human life, the ordinary movements and enjoyments. The enjoyment derived from their contemplation is only a complex of agreeable feeling arising from the perception of utilities. In the inorganic world where utilities cannot always be traced, the mechanical explanation is still offered as sufficient: things take the forms they do, and we find ourselves surrounded by them and grow up to take delight, or the reverse, in their presence. In the organic world the utility which is primarily intrinsic can often be exactly traced in relation to life, health, development. In human life we have appreciation of what we find useful to ourselves and in ourselves, and by sympathy we are moved similarly when we imagine similar beneficial states in others.

As against this view the counter-assertion is, that utility for other purposes cannot be proved, nor association with such utilities, in countless cases where admiration is aroused. Some of the fairest objects being as 'useless' as can be conceived, their high value for us who perceive them is witness to a something in them independent of utility: if their beauty is not a specific quality we are under some inexplicable illusion in being affected by them in the way we are. This inexplicability runs into every region of the Beautiful, inorganic, organic, and personal: Nature and History teem with objects and situations which are rich with interest of a kind in which no traceable connection with other interests appears. Since Augustine thought it necessary in a treatise (not extant) to distinguish, 
De Apto et Pulcro; and since Hutcheson gave close attention to this aspect of life, a distinction has been made between Absolute or Free Beauty, and Dependent or Relative: and a line of defenders of Absolute Beauty has not failed, though often overborne.

Second. The other objection acknowledges the specific character of the Beautiful, but only as a state of mind, only in the experience of the percipient: no qualities in the objects explain it: it is mental, sensitive for the most part, and its explanation is to be given by psychology, in the alternations of feeling, the play of activities furthered or restrained, the satisfaction of the senses, intellectual consistencies and harmonies, sympathetically extended over human affairs, and carried down to the animate and even the inanimate world.

The counter-assertion here insists that the full statement is that it is qualities of the objects which give rise to the rsthetic emotions in the percipients. It is obvious that Beauty requires a beholder, and an appreciative one: but that the beholder's mind creates the beauties of Nature or of the drama of History is held to be as incredible as that the beauties of a painting of Giotto are put there by the connoisseur, or those of a poem of Spenser by the admiring reader.

To provide a basis for Theism of a Rationalist kind, it is these counter-positions which must be taken up. Beauty must be something more than the Utility which has been already dealt with in the Good: more than Subjective Enjoyment; which is to be taken into account in the Theology of Feeling. It is those who hold that there is such a quality as Absolute Beauty, and who hold that it resides in the Objective which is presented to the subject, who regard it as an independent datum. They need not make it a wholly separate basis: it may be taken in close association with Goodness, and used for enlargement of what is broadly termed the 'Ethical' argument, to which it adds a special character.

That Beauty is both objective and subjective is the traditional view from Mediæval scholasticism, though but little attention was given to it. As the manifested glory of God it was distinguished as external objective, in the objects; and external formal, in the minds of the beholders. The double character 
is well expressed by Reid: ${ }^{1}$ "All the objects we call beautiful agree in two things, which seem to concur in our sense of beauty. First, when they are perceived, or even imagined, they produce a certain agreeable emotion or feeling in the mind; and, secondly, this agreeable emotion is accompanied with an opinion or belief of their having some perfection or excellence belonging to them."

The method may be Demonstrative: from the presence of Beauty in the world to a Cause adequate to account for it, a Being from whom it proceeds, infinitely Beautiful in Himself. This inference may be made in order to assign a Source to the beauty we perceive. Knowing that we do not produce it, and that yet it is a quality of the objects in which it is perceived, we infer a Being who has effected this beneficent harmony between us and the object-world. And when we think of the vast ranges of objects capable of awakening æsthetic enjoyment, which yet are unperceived and unenjoyed so far as the presence of human beholders is concerned, to whom shall we ascribe that unenjoyed Beauty? Is it only latent, waiting for man to pass by, within the glories of scenes of unexplored Nature, massive or molecular, or the moral beauties of obscure and secluded lives of human souls? Is not a Beholder suggested? One who sleeps not, but for whose pleasure all things are and were created? Pondering on the unregarded beauty of a lizard and its complacent happiness, and passing on to the spectacle of a group of children at play, a Cambridge man of our day writes : ${ }^{2}$ "This joy of the children spread in all directions like scattered light, and was caught up and passed on again by beholders-and if there did not chance to be any such upon the earth, still, it seemed to me that there might be Angels gazing down with eager eyes from on high-until, in the course of its reflections gladdening many on its way, it should be brought to its final focus in the glory of God." God, then, as the Creator of Beauty, and its Beholder, is what Eisthetic Theism sets before us.

I do not see that it makes any difference whether the inference is made by Demonstrative or by Transcendental procedure: the one is stated as an inference from the Beautiful in the effect to Perfect Beauty as the Cause: the other finds Beauty floating as it were and in unintelligible latency, unless

1 Intellectual Powers, Essay vir.

"Lathan, H., A Service of Angels, p. 5. 
we think of it as before the Mind of One who made it, and now rejoices in it.

There is no necessary inadequacy in this Theism except that Goodness is narrowed down if Beauty be claimed as the sole cause of religious belief. The suggestion of Infinity is as clear as that which comes from Goodness; for Beauty, too, is ideal. No soul can be filled with such admiration as finite objects can excite, this yearning for perfection is never satisfied: what is granted to us is an earnest of something higher, a symbol of what may be hereafter. And the influence on the Will is similar, too: in the hope of attaining more refined Beauty, moral and spiritual above all, we are called upon to decide to throw ourselves into such life as points that way: to resolve to believe anything rather than abandon the glow and the glory of our hopes. The Transcendency and the Immanency of the Divine Being are both involved: Immanency indeed is specially vivid, as the general attitude of poets proves. Personality is clear in the sense that we feel our own personality involved in the appreciation of the truly Beautiful, especially in spiritual character. And Universality is there for those who make clear to themselves that it is 'Absolute Beauty' which is before them, a Beauty not subjective, but waiting only for the appreciative mind. Endowments of men may differ, but the proverb de gustibus is not seriously maintained by those who have reflected on the Fine Arts: as to our highest 'tastes' there is no scope for disputation: a man is a boor who cannot be inspired by the noblest works even of human genius. If there is any man to whom the heavens declare no glory, and in whom the moral law inspires no reverence, his 'spirit' is not yet born. And the Theistic interpretation is for those who hold it no less universal in its claim.

Asthetics has a long and serious charge to bring against Philosophy. It has been excluded for ages from its range. The variations of Sensibility have pressed too heavily on the thoughts of men, and the universal character of the higher range of æsthetic ideals has been missed. And so Philosophy has left this field to Poets, those in whom sensibility to Beauty is especially refined and the passion for it intense and consuming. And Theism has been involved in the same course: and a 'dryness,' an abstractedness from much that men valued has been the consequence. Theists have allowed that the 
æsthetic emotions constitute an important part of a man's religious life, but they have neglected or refused to take them into account when inquiring into the validity of religious belief. But poetical minds have estimated them at a different value. If Kant could not allow constructive force to the Æsthetical Judgment, Goethe could go so far as to place the Beautiful above the Good: and this century has shown us Coleridge and Wordsworth, Tennyson and Browning and Ruskin proclaiming that Beauty is a true symbol of Divinity.

If modern Philosophy has been severe against Æsthetic, some explanations of its attitude are not far to seek; but it is matter of more surprise that Christian Theologians should have followed so complacently in its train. There must have been a sad mechanicalism in the minds of those who have always enjoyed the assistance of the Psalms of Israel in their liturgies and yet have missed the privilege of being influenced by the contemplation of the glory of the Lord; as any reader of Dean Church's ${ }^{1}$ impassioned characterisation of the Psalter must feel. But so it has been, in Britain at anyrate. Amidst the great varieties of Theism which it is the purpose of this volume to indicate, there is not one of any importance which makes Esthetic the sole ground, and in the great majority it is either slightly glanced at and rejected, or absolutely ignored. It is quite likely that this has been the cause of many minds going direct to Revelation, where this need of the Soul would find satisfaction $;^{2}$ the Theisms find their punishment in being neglected in their turn. It is now being admitted with increasing cordiality of welcome: it has a place allotted, most usually in associa-

${ }^{1}$ Lectures in 1874 ; published with Gifts of Civilisation, 1898.

2 Dr. Dale in his Christian Doctrine (p. 10) gives the following narrative, which I cite as illustrating the statement in the text: "Some years ago a man, who was at that time a member of this congregation, told me the story of the beginning of his own religious life; I wish that I could tell it with the vividness and force with which he told it himself; but I cannot. He said in substance: 'I was living in a small town in one of the southern counties of England, and one Sunday afternoon I went out into the country for a stroll. It was summer, and after walking for a few miles I lay down on the side of a hill. I saw, stretching to the distant horizon, meadows and orchards and cornfields; the cloudless skies were gloriously blue, and the sun was flooding earth and heaven with splendour. The wonderful beauty filled me with excitement and delight. And then suddenly, through all that I saw, there came the very glory of God. I knew that He was there. His presence, His power, and His goodness took possession of me and held me for hours." So an English mind-it would seem-is capable of 'excitement' by beauty, and elevation to a degree which found its satisfaction only in Religious belief. 
tion with Moral Theism, sometimes with independent status. To indicate some of these admissions is almost all that can be done to give Aisthetic Theism any place in British Theology.

\section{§ 8. Type V.-Combined Speculative and Ethical RATIONALISM}

We have seen that there are those whose Theism is mainly and primarily a work of the speculative faculty: the question has been asked directly and simply, Does Reason declare that this is the Truth? i.e. Truth as speculatively proved. And others there are who can only give the affirmative answer when it is Practical Reason that is brought into operation, after Kant's method. But there are some who accept both of these methods, and their position is so distinctive as to constitute them a Type, according to my judgment.

They may hold that the two operations of Reason are on an equal footing, that speculatively or ethically Theism is proved with equal cogency. Or they may give a slight preference for one over the other: but not so much so as to depress either to a distinctly lower level or grade of validity. It is for those in whom there is a broad appearance of equality that this class is marked out.

Before we pass from Rationalist schools there is a way of resetting our problem which may be usefully applied.

The question may be asked, What conceptions gained in our study of human nature and of the world may legitimately be carried up to the Divine Being, the Perfect One ( $\tau$ é $\lambda \epsilon \iota$ s)?

The Eleatic criticism of intellectual conceptions said, none of these at all: and Kant, with modern Agnostics, agrees: speculative conceptions cannot be employed to construct an object which shall realise them in perfection; they all run into antinomies when the attempt is made. Kant, however, took the opposite view as to moral conceptions, ideal Goodness is essentially perfect. Aristotle, per contra, held that it was intellectual conceptions which could be applied, but moral, not. Modern Agnostics combine both exclusions. Of Dogmatic Rationalists some stand up for intellectual conceptions, others for moral, and others for both, as our classification has shown. By Transcendental Idealists who have profited by the criticism 
of the above Dogmatism it is claimed that a true method is now found by transformation of the doctrine of Personality, of Spirit. The essence of Spirit is self-conscious intelligence working freely for good, and the Perfect Being can be this and must be. The moral attributes disallowed by Aristotle were empirical only, arising through conflict between higher and lower, and these, of course, could not be sublimated to Perfection; while the intellectual attributes of the Eleatics and even of Kant were abstractions, and not the principles of real spiritual life, and therefore they also were inapplicable.

Another point. In what way are we to proceed in our application of principles to the determination of the Nature of the Divine Being?

It may be easy to show that difficulties and contradictions await the attempt to make a simple and direct application to the Infinite of what we have found true of the Finite, as Mansel and Mr. Spencer, for example, do, after the Eleatic manner. But, as said above, they had before them only abstractions and empirical matter; to anyone with a doctrine of the Spirit such as Idealists give us, their attempt is quite irrelevant. The Idealists find that, on their doctrine, the imperfect and finite life of a spiritual being absolutely requires the conception of a Perfect and Infinite Spirit for its explanation: in order of logic it is not that attributes are taken up from Finite Spirit and raised to application to Infinite Spirit, but that in the doctrine of Infinite Spirit, self-conscious, self-determinant, perfectly good, lies the ground of Finite Spirit, the source of its intelligibility.

By those who proceeded in the older form of Rationalism, $\grave{a}$ posteriori, there was developed a Canon or rule guiding them in the application, and guarding against such anthropomorphism as Empiricists are pleased to charge them with. The subject was carefully treated by Aquinas ${ }^{1}$ the gist of his position being (1) that predicates which connote no imperfection, such as justice, wisdom, can be properly predicated of the Divine Being, those which connote imperfection, such as space-occupancy, courage, not; (2) that such as are properly applied to Him are applied to Him in perfection, analogically therefore in comparison with the way in which they are used for His creatures; for instance, goodness, power, wisdom; and (3) that even predicates

${ }^{1}$ Sum. Theol. i., question 13. 
which cannot be properly applied, yet may be used metaphorically, such as anger, repentance, sorrow. The omission of careful treatment of the method of application in the writings of many Englishmen who belong to the Demonstrative school has laid them fairly open to the charge of anthropomorphism.

\section{§ 9. Type VI.-Social Theism}

In speaking of Consensus (p. 10), it was pointed out that Consensus, the common opinion or judgment of mankind, may itself be regarded as the true principal source of religious belief. Religion may be held to be not an individualistic matter at all in its primary and substantial meaning, but a matter concerning the type of mankind collectively. The collectivity may be taken either in a single vast whole, through the ages, over the whole field of the history of the race; or in natural groups, tribes, nations, civilisations. The Subject of religion is, on this view, mankind collectively, and the content is correspondingly the accumulation of centuries of human life, complex, varied. The individual mind must not expect to appropriate more than a fragment of what is in the religious consciousness of the 'peoples, nations, and languages' of history. The individual must plainly cease to regard himself as the centre of interest of the world-history, even to himself; he ought also at the same time to renounce regarding himself as the seat of authority in matters of belief, even of his own. As Nature is not what $I$ 'make' it, but what mankind does; as Morality is not my plans and aims; as Art is not the expression of $m y$ tastes, so neither is the object of Religion the correlative of $m y$ piety and meditation. If my smattering of the sciences were all that was known of nature, may each man say to himself; if my rectitude is all that is upright and righteous, my taste the measure of all that is beautiful, and my capacity for devotion the measure of all that is holy, how poor an object is within my reach!

Hence comes the appeal to substitute for myself the Race, or at least the Nation. We are bidden to approach the question of Theism with ourselves and our modest interests quite in the background: we are to inquire as citizens, as units of a people, as members of the human family. As worshippers we approach the altar raised by our fathers and maintained by successive generations of piety, as men of action we seek the Guide and 
Rules for our native land or for mankind at large. Thus identifying 'self' with the larger Subject we take the common belief as authoritative for ourselves. Such a Theism is empirical of course ; but it is parallel with the Theism of Personalism, only substituting the Race for the individual personality. This I have called Social or Sociological Theism.

The importance of setting this out as a Type has been impressed upon me as my study has proceeded. Its summary rejection cannot be justified, on the wide import of the term Philosophy of Religion adopted in this essay. It may claim to be the ultimate account of man's religious belief. That it is at least a proximate account of it is plain: it assigns a cause for it in the individual mind which is so manifestly in actual operation that no elaboration of this is called for. The religious belief of the vast majority of men is so arrived at, and, as a matter of fact, is so justified: men worship the God of their fathers : the temples and the religious rites of the world are expressions of religions socially generated and socially maintained.

The Subject of religious belief is, after this method, the tribe or the nation; or the race, as with the gods of Hellas; or the caste as with Brahmanism; or it may be a mass expanding beyond these boundaries and comprehensive of many, as with Islam. But it is open to the human mind to ignore all limitations and to seek for the common faith of the human Family. This century has seen great progress made in the history of Religions, and the development of a Comparative Science of Religion which seeks to trace connections and to indicate, if possible, a doctrine which shall co-ordinate and consummate them all. And it is a tenable position that a man should say to himself: "When I have found the consummating thoughts of the religions of mankind, in these I will believe: they shall be my faith; and I will work for a Religion of the Future in which all men, gradually led to abandon temporary and local elements, will join in what thus gathers up the common aspirations and thoughts of the race. In this faith I could both live and die." Such would be a religion of Humanity in which Humanity is the Subject which believes and worships: a truer view than that perverted one which goes on to make humanity the object of religion also.

A thousand modern voices will at once call out that this involves the suppression of Individual Freedom, which in matters 
of religion, above all, is an outrage to be abhorred. But it is not difficult to reduce the force of this charge so far as it is raised by Empiricists of every type. It would only need to ask, "Would you have every man take up only so much mathematical truth as he has himself awakened to perceive? Or declare that the Sun actually is precisely as he with his optical apparatus, such as it is, sees it? Should every man be his own astronomer, his own medical adviser?" But it is urged that though this must be allowed for the External world, yet that for conduct and life, freedom must at all costs be vindicated. Then is every man to shape his own social behaviour as he pleases? or to live by his own private moral code? If this is not required, or permitted, why then should a man say that his belief in a Supreme Being is to be confined to what he can himself see? in a Supreme Goodness to so much as he can himself appreciate? When Mill spoke contemptuously of 'second-hand evidence' did he realise even for a passing moment the break-up of the solidarity of human belief which would ensue? or was he unconsciously as rationalistic as anyone, and in the secret of his soul aware that there was absolute truth and every man was certain to find it if he sought? When Newman spoke of God and the solitary soul as the only supreme concerns of each man, did he for a moment realise that he was setting up a revolution against all the religions of the world? When Martineau demanded that response on the part of the individual should be the absolute measure of what it was right for the individual to believe, was he really satisfied that he meant every narrow mind, every thinfeatured soul, to give up the belief that there were visions and ideals beyond its own attainment yet already in the possession of more favoured men and women?

This Theism may ask that in religion the individual should be content with a place parallel to that which he can occupy as an observer of Nature or as a citizen of a commonwealth, namely, that he may have a little private territory of his own, but that his real concern and his true life will consist in his identifying himself with as large a sphere as possible of the territory of truth and goodness in the possession of mankind. In the appropriation of this the self will find not suppression, but enlargement and life. The Reformer will be the favoured individual who can press forward the boundary of the whole territory; his own special territory being added to it because 
he has been able to absorb the best that his progenitors have achieved and to go beyond it.

In Theology the claim of private judgment has been pressed to the point of demanding renunciation of all intermediation in the way of attaining to Truth. But the Social Theist might reply in this manner: "To me as matter of plain fact it is certain that I should not of myself have seen the moral and spiritual truths uncovered for me in Plato's Dialogues, in Burke's speeches, in Wordsworth's poetry, in Lotze's philosophy. And I cannot see that it is different in the field of religious truth. I do not, as matter of simple fact, feel alone with the Almighty; I know there are those who have been intermediaries between Him and me, who have shown me divine aspects of which I was not aware, and inspired me with feelings never experienced before they spoke to me." And if it is said, "Yes, but you have now secured these for yourself, and it is on that ground that they are your beliefs"; the reply could come: "But I insist on believing also in the existence of fair regions of truth and goodness awaiting my appropriation: seen by others, not yet by me."

We shall not discover any prominent British philosophers or writers who have taken up Social Theism as their method. Even strong supporters of 'high' Church views for Christian Faith have not extended the authority of the Community over Natural -Theology. The Romanists, as we shall see, insist on official recognition for à posteriori Rationalism: and of Anglican and Presbyterian Churchmen some follow that lead, and others take up other types as indicated in their place.

It only remains, therefore, to add some observations on the attitudes to Social Theism which may be adopted, by men building on other foundations.

Few Rationalists take any notice of it: they confine their use of Consensus to the secondary employment of it as suggestive but presently to be left behind as not giving us 'Proof,' or as confirmatory of Proof in assuring us that personal error has not vitiated our reasoning. Some few of them add the use of it as a fact of human history presented to the individual reasoner as a separate datum for Theistic inference.

It is true that post-Kantian Rationalism comes in differently from the pre-Kantian. A fundamental aim of Kant was to bring together individual experience and universal experience: 
this he endeavoured to accomplish by his combination of the Sensibility of the individual giving matter, with the Reason giving form in knowledge. Reason gave the universal element, every thinking man in this respect thought as homo rationalis, and his experience was, so far, universal in its validity. The main point was therefore secured. But Kant was entangled too much with the older Rationalism and its separateness from Sensibility to achieve more. It was left to Hegel especially to proceed to treat of experience as given in the life and thought of mankind, the bistory of human civilisation; for Religion, as for Morals and for Art. In his hands the sphere of Religion exhibited the mind of the individual expressing itself in articulation with the common mind or spirit of humanity. But he did not regard this as being really the highest sphere; that was reserved for philosophy where, so far as I understand him, the distinction between the individual mind and the universal is transcended. It is on these lines that the Scottish Hegelians John Caird and Dr. Edward Caird distinguish between the Philosophy of Religion and Religion itself.

\section{$\S$ 10. TyPe VII.-Theism of Feeling}

In the life of the soul we are sensitive as well as rational and active. In all our experience we are involved in pleasure or pain, in happiness or misery. We pass from the feeling attending the organic bodily changes to the refinements of the higher senses which culminate in Music and the Fine Arts, and onward to emotions of the personal life, affections, fear, abhorrence, hatred, pity, admiration, love, the moral sentiment. In this emotional atmosphere arises an interest in life, individual and personal, enlarged by imaginative sympathy with the emotional life of other souls, giving to them and receiving from them. And it is held by most that there is a passing out beyond egoistic and even beyond sympathetic interests to purely disinterested emotion, wherein personal enjoyment is surpassed in a love free from thought of self.

It will be strange indeed if this aspect of life is to be excluded from all share in the formation of belief generally, and in particular if it is excluded from the formation of religious belief. Yet this strange thing has been done, and the greatest repugnance has been shown to the admission of Feeling to any 
participation. The alternatives laid before us are-To admit Feeling as a legitimate factor of religious belief, or to reject it; if admitted, to rank it either as dominant over other factors, or on equal terms, or as subordinate. We find in the history of Theism examples of each of these courses. The elevation of Feeling to independent and controlling authority is so rare in Britain, however, that it can hardly be called a type of English Theism: the considerations now to be given have not in view these isolated cases so much as the general mass of those who allow the admission of Feeling in some degree or form.

From Feeling the impetus to Religion comes in two ways: a negative and a positive.

(1) The negative: From our experience of unsatisfied desires which reach out beyond the range of all that is given to us by the finite, and of all that we can do for ourselves; from the insatiableness of our longing, the inexhaustibility of our capacity for emotion, we insist that the search for satisfaction should be never-ending. And yet so long as we remain confined to self at the centre and to humanity as giving the horizon, end and limit are imposed; and therefore desire is unsatisfied, and the emotional life is not abidingly full. What is to be said of this Extra-feeling? We may take the course of the Buddhist and strain to suppress it as a flaw of our nature; or we may check and moderate it, to bring it down to the level of contentment as near as may be; or accept its validity as a natural endowment entitled to free course, and rightly requiring from Reason that an object be provided for it, and from Will that we be brought into union therewith; or we may ask these to stand aside and allow Imagination scope: but somehow, in some way, some object must be found for ineradicable Feeling.

Then (2) positive: When there is presented to us the idea of God, Feeling is aroused: feeling deep and penetrative and such as is not quickened by any finite source: by many held to be the overpassing Feeling of all our emotional experience. A man may have been for a long time immersed in mundane interests, his emotional nature may have developed only so far as those would carry it; and yet when some day he has a vision of what the Infinite Perfection the high and holy Majesty of a Divine Being must mean, a new Feeling is stirred in his innermost soul ; in this he trusts, and by it he believes. 
To insist on the legitimacy of this Trust in order either to fill up what is wanting in unsatisfied and unquenchable longing for something beyond the finite and imperfect, or to give substantiality and objectivity to the Idea of God at the bidding of the profound emotion which it stirs in us, is to have a Theology of Feeling. 'Since we love, we know enough,' is its formula as given by Browning.

So far, generally. But different forms of Feeling commend themselves to different observers as giving rise to religious belief. In the early stages of life the feeling may be the crude one of Fear; and it may really be only egoistic in its regard: a feeling towards an imaginary supersensible object or objects as a source of benefit or injury; and here come in the propitiatory devices so deeply ingrained in early religions, to procure pity and the withdrawal of threatening evils. This becomes more complex as life varies: there comes a sense of helplessness in face of ill-health, bereavement, and wickedness, of the futility of so many aims and the transitoriness of all, and then the thought of relief, of a rock and stronghold, a Friend, a Counsellor, a Redeemer, a Forgiver, stirs into life a Feeling which in order of natural growth cannot be far from the root of religious belief. It is not from idle men and women in trivial moods that the reference to the consolations of Religion has arisen. But Religion passes into a level above that of expectation of benefit for self or others when it includes admiration for what is above ourselves and our congeners, an Almighty Power sending a sense of strength into our expanding souls. A sense of Dependence is attained, but it is a welcome dependence, and a tone of reverential solemnity pervades the restful feeling of security. And so we have the grave, serious Fear of the Lord. Then when the excellence of moral and spiritual perfection is discerned, the emotion of love is kindled and the supreme revelation of the character of the Divine Being is made, so far as feeling is concerned. Now there arises a sense of union with Almightiness: the sense of conflict and unrest is appeased, we dare assert ourselves against all that opposes or obstructs-and $d_{0}$ and $b e$ as our Ideal urges us. Fear, Dependence, Love: this ascent is offered as a natural history of fundamental Religious Feeling. But others may be offered: this is taken as an instance of what is meant.

The adoption of an Evolutional view of human history 
operates in support of the contention that religious Feeling is a legitimate source of religious belief. What has no useful function cannot persist, says Natural selection. Religious Feeling in some form or other is a marked feature of human life. That an illusive, or, to put it plainly, a delusive Feeling, should have so long persisted is incredible. The unmeaning cannot be the 'fittest' to survive. What is purely fancy-born could not have maintained itself so long against hard fact and truth. A common way to turn the situation is to insist that mundane fact and truth can itself sustain Feeling at the very highest: that, for example, 'Humanity' is an object capable of doing this, of giving an enthusiasm of the kind required for religion; another, that the ideal world is the only real one, and the griefs and woes of the world only fleeting shadows. Failing such substitutes as these, the vindication of Religious belief as the necessary outcome of the Feeling above indicated is more 'natural' than ever now that Nature is more definitely seen to reject remorselessly that which has no 'useful' function to serve.

It need not be supposed that Religious Feeling comes only by means of direct resort to the Supreme Object, the Infinite and Perfect. It may be so with some minds, but with many it is led up to and fed by contemplation of the world. As Höffding says: " "The religious feeling is a cosmic vital feeling; as in the organic (bodily) vital feeling we have the fundamental mood which is excited in us by the course of the organic functions (of the body), so the religious feeling expresses the determination of our life of feeling by the course of natural evolution." The religious feeling proper is more than this, but by this it is nourished and amplified; and in its own proper form is the consummation of our feeling as generated by the contemplation and sense of cosmic life.

Is the claim for authority, whether sole or partial, for Feeling in itself plausible? Many British writers seem wholly unable to grant this in the smallest degree. To them it is wild, absurd.

But do these writers suppose that the claim means that the mind is being considered as having no objects at all before it? as being empty of all but feeling? a blind passivity? Such a psychological impossibility may well be set aside as 'absurd.' But this is not what is meant. What is claimed is that Feeling has a natural and a most important function when we

\footnotetext{
${ }^{1}$ Psychology, c. vi. $\S 8$.
} 
are forming our world-view. Just as our outward vision presents us with a phantasmagoria out of which we select the parts which delight, and turn from those which distress us; so in the field of mental vision it is under the selective guidance of feeling that we form our picture. Feeling itself operates in control of the power of seeing: through its influence we concentrate attention on the objects of desire, their dimensions enlarge, they become known with increasing delicacy of distinction, so much so as to be, in effect, new objects, as compared with what would have been presented had we remained uninterested or inactive spectators of a passing show. But it is urged, this is perilous surely? it is fiction, interference with fact. Not so: fiction is the enlargement or alteration of objects released from conditions of actualisation: but under feeling it is the objects which alter themselves: certain parts of the objective field have a chance given them, they come up from the background to the front, they are allowed to enter into combinations, and in consequence other objects are inhibited and fall back: feeling ' manufactures' nothing, but its selective action effects changes as legitimately as does that of the captain of a cricket eleven who allots his men their places in the field. without himself 'manufacturing' one of them into being other than he is.

The Theology of Feeling rests on the assumption that this selective operation of Feeling is natural and is justifiable, and that a mere passive reception of objects in a purely disinterested way is not justifiable, even if it were possible; which, to us men, as a matter of fact, it is not. The gratification of our Feeling for the Infinite is a natural right, and one upon which we are entitled to insist in face of what is at the outset a passively received world-picture. This feeling, high and profound-even if not, as prima facie it is, the highest and profoundest-so delicate and yet so strong, asserts itself as natural and normal in the formation of belief. That it should claim, absolutely, the chief place is, as was said, very rarely asked in Britain : its total rejection or neglect has been common enough; but it has of late been revindicated as a constituent factor, and the signs are that this course will continue to increase in favour.

Can high ground be claimed for a Theology of Feeling ? Is it not obviously restricted in two ways, namely, that it gives 
no access to real objectivity, and none to universality? It is urged that if we construct under the selective guidance of feeling we do not really go out of our own subjective life: we are moving only within the circle of egoistic feeling. In answer to this, reference is made to all that psychology has to tell us about Disinterested feeling, and it issues in the assertion that purified and perfect Love is itself the most anti-egoistic influence under which the mind can live. Intellectual indifference is but intermediary between egoism and this. By Love-taking this for the supreme disinterested feeling-the self is transcended and replaced, and the Divine Object takes its place, not by means of the assent of reason, but through the absorbing passion of adoration in which self is lost. From this love of God there easily flows out a sentiment which illumines the varied and too often the soiled and naturally repulsive face of humanity with a radiance not disclosed to the natural eye: and love to our neighbour becomes a dependent and welcome consequence. So far from Love locking us up within ourselves it is the very spring and force by which Self is caught up and absorbed in an object above itself, until Self re-emerges as no longer the object of primary but only of dependent and secondary regard, and along with it come our fellow-men, our neighbour as ourself, and ourself as our neighbour, both in emotional dependence upon the love of God.

Then, for universality. Feeling, it is alleged, might lead us to religious belief, but every man would have his own deity; and for the race there would be a pantheon in which each would worship his own, while gazing with more or less respectful sympathy upon the deities of his friends, and with repulsion upon those of uncongenial or hostile members of the human race. Undoubtedly this is easy: the history of religion is full of it. And this very fact is itself a testimony from history that it is Feeling which has predominated as a religious influence, and does so still. But when we turn to ask whether the influence of Feeling stops there, and is therefore to be resisted and shaken off and surpassed if a Theism for the race is to be possible, it is not difficult to show that it cannot stop there, except by an arrest which is pathological, not natural. For the individual mind, surely, it is a necessity that its highest Feeling should be free from resistances and obstructions; such freedom is necessary if the soul is to be dominated, if the passion 
is to be absorbing. Such Feeling could not be experienced unless there is unity in the object adored; not an abstract unity of singleness, but a unity which dominates and harmonises the multiplicity of experience. Only when assured of such a unity could we have the perfect peace of God which is essential to our perfect love. Each soul, then, which has attained Divine peace has its own absorbing object of highest and unsurpassable love: speaking emotionally there is-at the bighest levelbut one kind of religious Feeling in the human race, one kind of devotion, of adoration. ${ }^{1}$

The individual soul, then, reaching out by sympathy towards the Feeling of other souls, cannot but ascribe to them the same Feeling which is the life of its own life, and will shrink from and be repelled by anything in their objects of worship which indicates that their Feeling is different from this, and will be restless until it can bring others to the same Feeling as its own. If this is so, then religious Feeling in each of us will be an overmastering incentive to a belief that the Divinity who is the object of our adoration ought to be the Divinity of every soul of man. Whether this be proving a Universal to Reason or not, Feeling sets up its own claim that it establishes a Universal satisfying to itself. And it will ascribe the diversities in the objects of human worship to secondary, derivative, concrete constituents, within which is the same ultimate Presence, the same for every soul.

Feeling finds Reason hard-natured and preoccupied with its own integrity, whether as servant, partner, or master, and therefore calls in the aid of Will, yokes it with such quasirational processes as prove amenable, and proceeds by 'Faith.' As a stimulus to Imagination, it produces an array of fictionary images, the glowing cosmogonies and mythologies which constitute the main bulk of the matter of religion spread out before the human mind. Yet these may be so controlled as to replace Reason rather than oppose it, by taking up spheres which Reason

I The modern Master of the School of Fceling, Schleiermacher, endeavours to get to universality by regarding the individual socially. It is to a man's Fecling as a member of the Christian Community that appeal is made for the Development of his religion; he is associated with others, their Feeling is communicated to him, and a common religious consciousness is formed. But that Schleierinacher successfully grafted this social sentiment upon the original Feeling of Dependence is denied in many quarters, e.g. by Pfleiderer (Development of Theology, p. 105), who praises him for the Individualism of his Theology. 
is not competent, at a given time, to occupy. As time and education proceed, the opposing elements are reduced and cast out, and to Imagination are committed the regions beyond, across the confines of ascertained fact and compacted inference. But as the realm of Reason enlarges, it more and more presents a world-view and a soul-view which are able to sustain the deeper moods of Feeling. But in all stages it may be held that this very capacity to support and sustain religious Feeling is the criterion to which we have a right to resort; that in so far as stability for Feeling is secured by Reason or Imagination and the mind can rest, there is attainment of a true Religious belief. Doubt means that gaps and fissures are introduced by Reason, that we recognise that it is Imagination and not Reason which has painted the picture, and unrest and distress set in. But these may and must be cured; Feeling cannot be starved, or left in permanent unrest; and if Reason cannot do it, Will shall come in, and Imagination and Faith be invested with authority.

In relation to other types the Theology of Feeling has to face opposition sometimes of a kind which would exclude it wholly from any place of legitimate influence, e.g., when Ethical Theists denounce it as purely passive, or Rationalists as blind and egoistic obscurantism leaving men benighted and solitary; in answer to which the advocates of Feeling can assert themselves as indicated above. But are there not terms of alliance which can be found between it and the others? May not Reason be asked to strengthen its position by attaching to itself, in ultimate resort as against all other forms of Feeling, that specific emotion which Reason itself excites in us, respect for Reason, for fact, for truth: the sentiment of Rationality. And Ethics-except for the sternness of Stoicism-may welcome Feeling. Even the rigid sense of Duty and Obligation need not push away the sentiment of loyalty to Conscience. Much less should Moral Idealism neglect the passion which Goodness may kindle. Personalism does of course accept Feeling, including it in the complex which never must be analysed away by the inquirer into real assents. Intuitivism has always been attached to Feeling, and so closely that we have here some difficulty in accomplishing a disentanglement; indeed it is not common to find any distinction marked at all. Under the term Mysticism both Theology of Feeling and Intuitivism are covered in learned treatises as well as in popular usage; the question whether 
the procedure makes reference to Theistic Feeling as ordinary, though unusual in intensity, or to a unique movement of the soul, sui generis, not to be described exhaustively as Feeling at all, is not raised by any except those who have interest in accurate discrimination. Take, for example, the common application of the term Mystic to Schleiermacher; yet such competent German theologians as Strauss and Dr. Pfleiderer ${ }^{1}$ regard him as taking religious feeling to be only quantitatively different from other feeling, religious Faith to be 'a condition of devout feeling.' If we compare Butler ${ }^{2}$ who declares that our love of God is a natural feeling with Mystics who assiduously locate fundamental religious consciousness 'below and within' all our ordinary consciousness, in a source 'out of sight,' in a 'secret birthplace,' the difference is clear. It is the Rationalist who is responsible for ignoring the difference: to him anything that goes behind reason is going into 'secret' places, into Mysticism.

\section{$\S 11$. TyPe VIII.-TheISM OF THE WILL}

The formula of this type is I decide to believe: in all seriousness and in full of sense of responsibility I choose the positive answer to the question An Deus sit? and adopt it as my belief; I am prepared to give it authority over what intellect may have to say, to hold it against the clash of opinion and reasoning, if need be. This may be an original attitude of ours, the one in which we have lived all along: or it may be one upon which we fall back after attempts to secure guidance in the fields of intellect. It may be due to a marked preponderance of Will in our personal character which has all along operated in other matters as well as in religion; we may be already in the habit of making vigorous and firm decisions and abiding by them, and when circumstances call upon us to choose between holding religion to be a guide and clue to truth or only a creature of fancy or abstraction, we promptly take our choice, and decide to hold it to be real. Or it may be that after long balancing and perplexity we have found the state of suspense intolerable, the sinews of our frame becoming flaccid and the heart going out of our life, and we decide to take the side of positive adhesion: the apparent disregard for Reason is Reason's own fault: she should have been peremptory herself. There may even be cases,

${ }^{1}$ Development of Theology, 1. c. iii.

s Sermons, xiii. and xiv. 
however, where there is a clear consent to the displacement of Reason, and it may be in opposition to all that she can say that we flatly decline to follow; we feel being led or being drawn by her, but we rise and assert ourself and resolve to believe in spite of all.

It has been found a difficulty in the practical sphere of religion to make clear how Will can help belief. The appeals made by religious evangelists to inquirers, 'Only believe, and you are saved,' are met in many a mind by an irresistible feeling of incompetency, such as would be expressed by the terms, ' How can I create a belief? If it would come, I would welcome it; but how can I call it into being?' The pages of religious autobiographies teem with records of this difficulty. But modern psychology comes to our aid: the difficulty is fictitious after all, at least in part. It is like the old one as to how motion could begin. The reply is that in the physical world we are in face of motion, and have only to inquire how to direct and control it; and in the mental world and the moral world there is a continuous process of willing and believing, and what we are called upon to do is to effect a change in this process, or, more accurately, to guide a change that is always going on: to turn our Will into this direction rather than into that. In application to Theism it could be expressed somewhat in this way: "Up to the present I have been preferring unbelief or a misty semi-belief, in things Divine; I may either permit this current to continue or I may alter the idea by allowing certain aspects of experience to enter into the focus of my interest; absorbing my attention, they will inhibit other matters; lively feelings will be evoked, and powers of intellectual perception awakened that were not latent in me before."

The theological doctrine of Grace operates in Christian hearts in accordance with this analysis. The Will of the individual is in a position to obstruct the influence of Grace by keeping all our attention fixed on things incompatible with things divine, or it may be allowed to work with the influence of Grace. In neither case is there creation or destruction of Will, it is all a question of direction and control of an activity which never ceases save in sleep. We are always believing or disbelieving something or other, and we are invited to turn our minds to the divine aspect of things and believe or disbelieve them; according to the preferential action of our own minds, we are bidden to 
exercise Will. It is a distortion of what theology meant, to speak of this as if a man were attempting to create a divinity by his own Will; what he is doing is, to carry out his own part, as a Free agent accepting the Divinity which deigns to appeal to him.

It is of course obvious that Will could similarly be exercised on the side of Atheism or Agnosticism. That is a fact to be considered: but what we have here to note is that it can be exercised on the side of Theism, that there is a plausible method of Theism based upon decisions or resolutions of Will, choosing it in preference to scepticism or disbelief.

The operation of Will might be blind: Will pure and simple, a colourless, dry energy; a resolve akin in that respect to the blind Will to go on living even in pain and perturbation. This is the kind of Will supposed to operate in low stages of life with the mere conservation of life as its aim, without any influence derived from any of the more refined sides of life. But the possibility of such Will has been denied, and it is more usual to associate Will with Feeling even in its most primitive manifestations. Much more is it so regarded in the higher region where aimless action is a mere passing variety in comparison with action in accordance with satisfaction of Feeling and judgments as to worth and value in the objects at which the action aims. And so the reference is not to sheer naked Will, so to speak, so much as to Will exercising preferences, according to desires and aversions set up in Feeling. The intimacy of the union of Will and Feeling is so close that until Kant's influence brought in the Tripartite division, a dual division of the field of mental life sufficed, the Active and the Intellectual. And even now Professor Paulsen advises us to return to the dual plan.

Much that might here be said of Will taken with Feeling has been said in the preceding chapter on Feeling taken as if operative alone. The justification for separating them into two types rests upon the difference of opinion as to which feature should be predominant in the linked pair.

The vindication of Will as the source of religious belief has been made from two different quarters. It appears among theologians who recall attention to the place of 'Faith' in the formation of belief, and among philosophers who have been led to regard the practical side of experience as entitled to chief attention. 
Of the philosophers some have remained Rationalist, but have followed Kant in taking Practical Reason to be superior to Pure Reason so far as concerns Theistic inference, and this gives what I have called Type IV., Ethical Theism, under which we have to give account of the resort to the Active side of our nature in some form of alliance with Reason.

But there is also an Empirical method by which Will is resorted to, and this is so distinct from all others as to constitute a separate Type. It is the way of asserting the right of Will to make a choice, either arbitrarily or with a view to the satisfaction of Desire, but apart from any claim of illumination by Reason. The marked feature of recent study of mental phenomena is the great prominence into which the Will-psychology has been forced, in comparison with Intellect-psychology: a change which has not been wholly unaffected by the growth of attention to Biology during the century.

In Great Britain, besides our line of Sensation-psychologists we had early in the century Thomas Brown, and later Dr. Bain, great psychologists, both working hard at the Will; in Germany the brilliant talent of Schopenhauer has been followed, in this respect, by the great scientific ability of Wundt, Höffding, and Münsterberg: Professor Sully has kept it to the front in his expository works; and three psychologists who have added great credit to English reputation in the last quarter of the centuryDr. Ward of Cambridge, Dr. Stout of Cambridge and Oxford, and Dr. James of Harvard-are unmistakably for Will-psychology. In their various ways they regard mental life as consisting primarily of processes of will directed to the satisfaction of feeling; and making use of intellect as instrumental. In this way they describe much of every individual's experience as due to himself, inasmuch as he has neglected to attend to vast ranges of objects which have only just appeared in the confines of his field of view, but, killed by neglect, have perished. These have not been taken into experience therefore; which has been made up of those objects which received a welcome and were attended to by personal preference. Thus every man's 'world' is much more of his own creation than intellect-psychology had led us to suppose; much more the product of his own personal choice. It is, in short, personal choice which is the core and pith of the life of the human soul.

It is not difficult to see that this psychology will have 
influence when we come to consider our beliefs: implying that we have largely chosen many of these, perhaps most, certainly the most vital and influential of them. Far from being mere bricklayers taking such bricks as are supplied to us and placing them according to lines marked out for us, we have been architects exercising much choice among material, and ourselves contributing the lines of construction of the building which is the 'world' of our belief. If our taste has been for marble and a Palladian façade we have our building accordingly, if for red-brick and Tudor style, according to that. And this has come about because we have had these preferences and we have exercised our Will in accordance with them.

There is no manifest ground for withdrawing religious belief from the class of beliefs in general. On the contrary, the more deeply religion concerns us the more imperative it is for us, according to this psychology, to recognise the predominance of Will-choice in the formation of religious belief and in its justification. The religions of the world are the expressions of the preferences of the peoples of the world in the region of life the profoundest and the most comprehensive of all: in the gods of the nation we mark the character of the nation with the greatest confidence.

This is plain in lower regions, in the spontaneously produced religions of mankind. But in the opinion of this psychology a man is not called upon to forego reliance upon his Will even when he has been admitted to the school of speculative philosophy. For he should not expect from speculation more than the assistance which an official of the first rank may render to the ruling power: it is only such assistance that he should accept; illumination he may welcome, dictation he must reject.

In this way there has issued from psychology a vindication of Will in the region of belief, which is precisely on a par with that insistance upon it which has been maintained by the great mass of Christian theologians who have never bowed the knee to Rationalism, but have always held aloft the superior claim of Faith. It has been mentioned already that a great number of Christian theologians have accepted Rationalism for Theism, who have at the same time made resort to Faith when dealing with Christian doctrine. It would only be necessary for some of these to refer to Faith for explanation of belief in the First Person of the Holy Trinity as they do for the gospel of the 
Incarnation, the plan of Redemption, and the work of the Holy Spirit, for them to come under this Type. Inasmuch, however, as this has not been done in Great Britain, we shall have no names of British theologians to inscribe under it. But a reference to the treatment of Faith in the work of almost every theologian of eminence would show a constant under-current of dissatisfaction with the endeavour to stake all on Reason, and if ever they should lose confidence in Rationalist Theism this is a Type or Method for which they would find first-rate support in the best German and British and American psychology of the close of the nineteenth century.

A theology based on Will is obviously one which must expect to find religious belief take a large variety of forms, its express claim being that belief depends largely upon personal choice. Hence it would seem to be open as much as the Theism of Feeling to the reproach that it is likely to lead to polytheism rather than to monotheism, and that it has not any inherent right to oppose atheism except by the mere force of assertion against negation, of preference against rejection.

Its peril is the peril of Individualism : a possibility that religion may be reduced to a relation between the individual soul and God. A monadic view of the spiritual world seems before us; and there is no slight tendency to revive Monadism under the leadership of Lotze. "As many worlds as minds," boldly writes Dr. Ward. Each spirit knows the Divine Spirit independently: we are isolated in our individualities; no spiritual kingdom, no church. It is the standing advantage and attraction of Rationalism that it regards Reason as a common possession of rational beings and what it tells as having a universal character. The establishment of a similar universality has to be sought with persistent effort by the Theism of Will. The social ethics and the social religion so prominent in Hegelians may not have been established successfully on Hegel's principles, but the building on Reason rather than Will makes it nearer to attainment, in appearance at least.

The resort to Consensus will therefore be of great importance for it, and in some sense this will be the only way of arriving at a general vindication of belief at all. Consensus may also be of service in its third sense as itself being a fact to be taken account of; for to almost every mind it will furnish a new 
ground of preference; the prevalence of the belief will ensure it a welcome by endowing it with a new value as an attachment between man and man, adding the warmth of concord with the community to the austere joy of purely personal resolve.

To those who regard social life as itself essential for the display and development of moral nature which would otherwise remain embryonic, it is of more direct concern. And it is very largely on this latter ground that Utilitarians of the eighteenth century and Hegelians of the nineteenth have won adherents. They seemed to incorporate social life more fully than Individualists could possibly do, and to have it in the essence of their system more than those who were obliged to make an inexplicable leap in order to bring in the region of social activity and public life, and the history of nations. The moral order is the field of action; in it takes place the realisation of self so far as that is attained; this is a difficult position to secure afterwards if we have in our primary region been involved solely in any Individualist form of Ethics. To the Individualist the question is, Does moral history confirm what my Conscience suggests? does it support me in my self-assertion, or is it ever a hostile 'world' in face of which I must rely upon the Divine Spirit working directly within me? Must I return into solitude in order to know God? Must I leave the 'course of the world' as an enigma with which, after all, I am not vitally concerned? Must I with regard to everything outside myself make my act of moral Faith for myself, even if the traces of Providential order are not discovered?

That this type of Theism is not cut off from the gains of other types has been indicated above. Intelligence as servant of the Will may render most welcome aid. A man of this type may read the various arguments of the Rational types and accept such as his Reason approves; only he holds himself in reserve: he is to be the master, and all that the servant can do may be dispensed with or opposed: in his own house he is supreme administrator of the rites of hospitality.

Those who regard Will as operating always in connection with Feeling and with judgments of worth, will find themselves giving so much attention to the determination of worth or value - the reference to Will being so fundamental as not to need constant mention-that they would not inaptly be termed Ethical Theists. The Ethical nature of objects will be the 
ground of preference and the determinant of belief. The Will will be Der Wille zum Guten. But they will differ from our Ethical Theists of Type IV. in making no inference about it: they simply claim a right to believe when the Will chooses the good and beautiful among objects and adopts them. And this will be true of every kind of Ethics: whether it is the most pleasant, the most beneficial, or simply the right or the good and beautiful; whatever possesses the true Ethical stamp, according to the method employed, that is the preferable for the Will, and the Will will adopt it and act upon it.

By what possibility can such predicates as Infinity, Necessity, Personality be adjudicated upon by this Theistic method? In one of these two ways: (1) Reason may be accepted as a servant, and it may be that Reason has established these predicates. Or else (2) preferential Will may be applied to them directly: as between Infinity and acquiescence in Finitude as final, a man may prefer Infinity as of more worth; and similarly he may feel such a satisfaction in the trust in a Necessary Being that he may decide to indulge in it: a satisfaction in the Personality of the Supreme Being which he will not consent to be without: and so of Immanence and Transcendence.

By this school the Moral argument is stated in its true idealistic form. When we find that, strain as we may, our Will never achieves all the Good we aim at, and yet that we refuse absolutely to disbelieve in the worth of that unattained ideal, the only course open to us is to insist on its reality apart from its attainment by ourselves: we assert that reality vehemently: we bring our will into our belief, and stand thereon against the frowning aspect of appearances. Towards Nature, physical and mental, we stand up as sovereign, insisting on our right to bend her to our purposes: we then reflect, and find that in this very assertion of freedom we are strong with the power of a goodness not of ourselves. No such cool procedure as rational inference from 'facts' probes the depth of our meaning: Will, carrying Feeling with it, plants itself in the heart of our acceptance of the reality which is not known, and transmutes it into belief in a Divine Ideal. We thus remit to a secondary position the securing of intellectual consistency: if other parts of experience will not cohere with moral conviction, it is not this latter which we can consent to withdraw.

As yet there is but scant material, in Britain at least, for 
this section of Theism, taken as a separate Type. Its character, however, is too marked for it to be amalgamated with any other, and it is certain that the prevalence of Will-psychology, and the general inclination to Faith in theology, will cause this field to be more and more abundantly occupied in the near future.

\section{§ 12. Type IX.-Personalism}

Reason, Feeling, Will; so modern analysis gives the fundamentals of the life of the soul of man. In the Types of Belief delineated so far we have seen them used as furnishing separate bases or methods for Theism. But there is another type, of which the characteristic is that it refuses to make this separation at all, and insists on treating belief as an outcome of the soul acting as a whole. Its advocates hold that this is true of belief in general, so far as they have been called upon to investigate it; but, at any rate, it is emphatically asserted of Religious belief. Nothing is gained, they say, by the separative treatment of vitalities which in fact never do and never can act except together. If we want to discover the genesis of a belief which is fundamental we must explore our whole inner nature. Nothing but division and strife have been the result of the false method of treating such a belief as that in the Divine Being by referring to Will, Feeling, or Reason in the separate ways above described. A Theism which is to command the allegiance of mankind must show that man's living personality is at its basis and engaged in its evolution. If this joint action is granted for the foundation, then there may well be separate treatment afterwards - within a certain area-of each factor. But this must always be regarded as a temporary abstraction, and our eye must never lose the view of the other factors, lest we stray. And it is not allowed that the true belief is a resultant or composite of these three, supposed to have operated in separation and then brought their results together to form a compound. Even if such a composition were exhaustive, it would lack the unity of life. All along and at every stage each has been contributory: a complex result has issued from a complexity of process in which the fundamental unity of personality has always been finding expression.

In this respect the nature of Religious belief is not in itself different from that of belief in finite objects of the higher orders; 
in all that are personal in character, especially. No friendship, for example, worthy of the name is ever based on less than the whole personality. It is general tone or character rather than identity of intellectual conviction or similarity of tastes which is the root of friendship, for example, or of zeal for the public welfare. It is not different if the object in question is supersensible. Against the claim that Reason is the sole faculty of supersensible apprehension, Personalism opposes its assertion that here also Feeling and Will come into action: that the Infinite object is in part apprehended by love, and in part by the demands of our Ethical ideals, as well as by the demand for intellectual satisfaction.

So far for the distinction of Personalism from the methods which work by any single faculty or capacity of our nature. In taking it as a Type in the Empirical division, we are not including those who accept constructive power for Reason, either speculative or practical, and proceed to combine with it the deliverances of other factors of our nature: such Theism as that of the school of Coleridge and Hare, for example. These are placed in Types X. or XI. They may claim the term Personal, inasmuch as they, too, refer to the whole of our nature. But this mode is different from theirs in being wholly Empirical: whether or not it is judicious to assign the term Personalism to it is a question of nomenclature, raising obvious objections. But some name was required, and the term 'personal' as used in such phrases as 'personal equation'; 'this is my personal conviction'; 'a man's religious opinions are his personal concern,' and the like, seemed to be the most appropriate. It is the ordinary usage of the term, not the philosophical, of course, that is meant. The leading example of this Type of Theism in England will be Newman, as he defines his position in his Grammar of Assent.

It is distinguished also from that resort to a faculty behind all the others, unique, primitive, ultimate, which is the method of Intuitivism or Mysticism. Personalism is content with the ordinary faculties; it regards religious belief as the outcome of ordinary natural processes, carrying us right up to apprehension of the Infinite.

The Personal type of belief is unquestionably that of multitudes of people over whose habits of mind neither rational argument nor any other partial operation or process has a pre- 
eminent influence. They are not accustomed to yield themselves unreservedly to the sway of their feelings, nor are they in the habit of trusting themselves to their reason or the ventures of their will: they live in all their faculties of life, and they believe accordingly. They speak of God in personal terms, the Eternal Father, the Lord, the King of kings.

To many, however, the recourse to full personal life has been adopted after trial of separate types; especially, in our day, after trial of rational argumentation. But a great number have not made the trial for themselves; they have a general impression that other methods have not satisfied experts, and, notably, the very fact of division and discord among those who have given attention to the processes of religious belief has warned off those who have had no special opportunity for embarking upon investigation for themselves. They fall back therefore upon the total of experience, and welcome the appearance of writings on Theism which vindicate this procedure.

In theological literature this school includes a considerable portion of those who are fond of using the term spiritual in connection with religion, in common with the Intuitivists especially, but with Transcendentalists and Ethical Theists also. The choice of the term 'spirit' rather than of 'heart' indicates a sense that the Theology of Feeling has captured this latter term, which is therefore relinquished. It is passive in its reference, whereas recent psychology has justified those who insist on activity as operating in the production of belief; Personalists, of course, include reference to activity of Reason as well as assertion of Will, and Will is regarded as essentially directed to Ethical ends. "Faith," says Dr. Swete," "is in the last analysis the act of the will and not of the intellect ... in its essence a moral act." The Personalist accepts the inclusion of will and moral activity, though he admits intellect and feeling to equality of rank; to him belief is at once an active principle guiding life, a deposit of ideas, and a source of joy. And all this seems to him best covered by the term 'spiritual' when he is thinking of religious belief, faith in the Perfection and Infinity of God. At the same time it should be pointed out that the appeal to the Heart so familiar in religious writings is quite what Personalism means. The limitation of 'Heart' to Feeling is modern: it is against the usage of Scripture, and also of Classical literature; where by

1 Faith, Lect. II., 1895. 
the Heart is meant the centre of the soul's whole life in every capacity.

The strong point of this method is the breadth of its basis: it plants religious belief on the whole of our life, it draws water from every spring. The humblest intelligences and the least emotional natures are not excluded. It sows its seed beside all waters.

The difficulties of Personalism, therefore, are not the specific difficulties which attach to the separate factors: those are acknowledged by it, and it seeks a refuge from them. Each support taken separately has only whatever degree of strength and validity the particular Personalist assigns to it. Only, he enjoys the benefit of the amount of assent which all the supports, as he estimates them, can sustain. And he regards them as so acting together that to him they are as a single pillar for belief. He has pity for the man who has placed the burden all on one, and on its failure has lapsed into scepticism. Intellectual insufficiencies? Well, life in its concrete fulness has never been intellectually exhausted or explained, and yet it stands as fact for belief, and offers a basis for other belief therefore. Vagaries of Feeling? yes, if taken alone, but valuable if entwined with intellectual processes and ethical judgments, corrected and brought to order. Varieties and failures in effort towards Ethical ideals? Yet Feeling continues to sanction renewed effort, and Reason has at least suggestions whereby the failures may be explained and the future course better marked out.

The nature of the Divine Being is strongly marked as Personal: no element can be omitted. Abstract Principle, First Cause, Ideal Good, all these partialities fail. A Personal Deity, a Living God, is the object of belief and worship. Not the least potent among the influences inviting men to Personalism as the Method of Theism is its opposition to the movement to Pantheism which has been induced by the Theism of Feeling no less than by that of pure Rationalism.

The weakness is correlative with the strength. Personalism does not dip to the bottom of any well. It does not furnish answers to the ultimate questionings of intellect; perhaps no Method does, but some at least think they do; Personalism has no such persuasion. And similarly for other separate lines. Therefore Necessity and Universality seern beyond its range, with Infinity and Perfection. They may be held: they may be 
a part of personal belief: but the assertion of this does not validate them, they remain matters of assertion, and there is no prima facie ground for setting up the deliverance of the 'person' who holds them over the denial of another person who does not.

It is difficult to estimate the variety of result to which the appeal to character as a whole seems certain to lead. If man's resort is to the tangled mass of his own individual personality how shall he formulate a belief of universal validity? Even within himself his experience has varied: through waves of doubt, assurance, hesitation, decision, his life may have passed: each of these represented his personality at the time; at which time was there any clear right to insist that that and no other mood was the one which should prevail, even for himself, when reflecting over his whole life? And then varieties of character, divergences of national character, of race temperament-in all these is there to any plausible extent a source of universal belief?

For the Personal school a necessity arises for making clear the view taken of the relation of the individualistic and the social factors in human character. There may be ample recognition of the doctrine that man is essentially social, that he belongs by nature to his tribe, nation, race: that within the nation there are classes, castes, professions, and that the habits, thoughts, and tastes of these enter into his personal life. And it may be allowed that this is all 'natural,' 'essential,' not adventitious, accidental; that in reference to belief, therefore, of all kinds it must be taken into account; and that in religious belief no ground appears for treating it differently. Inasmuch, indeed, as religion presents itself to us in the form of creeds which have required centuries to weave and rites which have required thousands of years for elaboration and development, the prima facie case is, that for religious belief it is very specially incumbent on us to recognise the social factor most emphatically. Hence it is that we shall find now a revival of appeal to 'Authority,' to education, tradition, as rightly influencing belief; the contribution of the individual in his own consciously independent activity is relatively small: for the majority hardly perceptible, for even the few not really large. But if a man is so impressed with this that he sets 'Authority' as the primary source and tribunal he passes over into Social Theism (Type VI.). The Individualist is he who accepts it but insists on regarding it only as contributory to his personal judgment; as coming, after all, to a man from 
outside himself. It is useless to him unless he takes it in, and appropriates it. But this the Individualist claims that he may do, and then though he has received it, it has become his; for ' he' is largely it.

The course of nineteenth century thought in bringing back to men's minds the conception of the social constitution of human nature is too well known to need insistance upon it here. ${ }^{1}$ Resistance to its primacy marks a man as an Individualist, but the tide in favour of it runs so strong that already it is the Individualist who has to put himself on the defensive: at least this is so in higher walks of culture, although it is extremely doubtful whether it is so with the majority of the educated people of Britain and America, with whom Individualism is very potent in political life, but still more so in religious thought. Dogmasi.e. thoughts-evolved by generations, and the creeds and catechisms which embody them, are regarded as fetters on freedom never to be mentioned without aversion in the great journals of the day. Mr. Balfour's brilliant volume, for example, was welcomed in many quarters on account of its appeal to a wider range of life than the region of Rational proof, but its vehement revindication of 'Authority' evoked in these same quarters not less indignation than surprise. Under the suspicion that this might assist the recrudescence of Mediævalism, 'Authority' was denounced as external, in the name of entire freedom from dependence upon others, even upon the human race in general.

The Consensus argument in its confirmatory character acquires, therefore, peculiar importance for this school. If faith is determined by. each individual according to his own experiences, a broad induction over the history of the race is indispensable unless universality is to be abandoned. If, however, a Personalist is found, as many are found, secretly relying upon some peremptory intellectual or moral deliverances really universal in character, these must be brought to light, and he is passed from the school of pure Personalism to some other, accordingly.

Lastly, there is a difficulty for the Personalist in bringing within the range of theology the impersonalities of the world, its non-spiritnal side; a difficulty often overcome by the simple expedient of denying the existence of any such world, or, at anyrate, of asserting that it is too remote to be a concern for religion. And there is apt to be a retreat within the sphere of 
inner life, with the realm of external nature and vast ranges of ordinary life marked down as 'secular,' as the 'world,' and left outside the illumination of theological belief.

\section{$\S$ 13. Type X.-InturtivisM; OR MYsticism}

This designation I give to the method of founding religious belief upon a special faculty or capacity of our nature. By this we are supposed to reach beyond what is sensuous and intelligible, and even beyond the range of moral sense. It prefers to speak of God as discerned by the 'soul' or 'spirit,' rather than by mind or heart, as 'apprehended' rather than 'known'; and our relation to Him is indicated by such broad terms as ' union,' 'communion,' converse,' rather than knowledge or sentiment. Analysis of religious faith is vain, and reference to lower faculties misleading: Divine things belong to a realm of their own: Religious belief is experiential indeed, but this is in the sense that there is 'experience' over and above all that is gained in commerce with the world and from reflection on ourselves: similarly, it is natural, in the sense that there is in our 'nature' a capacity for direct access to a supersensible world, in which we can see God. $\mathrm{He}$ is presented to our soul as no abstraction, but as concrete; not as composite, but as simple; not inferentially known, but directly; not a Being only, but a Spirit. It is in this access to $\mathrm{His}$ presence that the true life of the soul is found: it rests upon the assumption of affinity between the soul and God; man is made in His image.

The Intuitivist can point with some confidence to the current in which the Science of Religions is flowing. After generations, during which belief in the Supernatural has been regarded as derivative from Animism, Nature-worship, and the like, the direction is being reversed and these are being regarded as derivatives from it; as the manifestations of a spirit of religiousness working underneath, like a ground-swell, and throwing up these forms on the surface. It is considered that religious belief has, in fact, been a continuum for so long as historical data are at our disposal, and that thus the primary faith which the Intuitivist finds in his own experience is precisely what the general history of mankind discloses.

In relation to ordinary experience Intuitivism is either Exclusive or Comprehensive. 
Exclusive Intuitivism (simple Mysticism).-(1) With some, religious life means a unique order of experiences into which the soul is permitted to rise from out of the ordinary life: carrying nothing up and bringing nothing down. There is the life of the body, the life of the mind as affected by the body, the purely mental and moral life, and then this higher range, spiritual life, in which the soul is absorbed in converse with the Ideal, the Perfect, the Infinite. This is the é $_{\sigma} \sigma \tau a \sigma \iota s$ of the extreme Mystics: we emerge from the life of Nature and stand out into the life of pure spirit. It is not professed that this is either easy or common: very far from it; Plotinus considered himself to have attained it but four times. The process of escape makes such demand upon the ordinary nature that the accounts given by Mystics of their experiences strike a modern Mystic, Mr. W. S. Lilly, as 'appalling.' And it ends in a life which is silent, and even without thought; the lower soul is in abeyance; the Divine Being has neither Attribute nor Name.

Comprehensive Intuitivism. ${ }^{-}$-(2) But there is a less ambitious and less exacting Intuitivism which may be called Comprehensive with regard to ordinary experience. It declares for the upper realm of the supersensible, but it insists on articulating the lower realm with it; the life of sense and reason is to be elevated and hallowed by the higher life of spirit. By this form of Intuitivism the knowledge of God is placed as the consummation of knowledge of phenomena, though it is not attained by Demonstrative proof; and it is placed at the beginning, though not by means of Transcendental proof: but in both cases it is known by direct communion. The light from above plays upon the region of ordinary experience; the power from above animates it ; the goodness gives a standard for its guidance. The facts of life become instinct with new meaning, $\sigma \eta \mu \epsilon \hat{\imath} a$, out of which the soul fabricates a world-view and sets before itself a destiny. The greater Christian Mystics are of this type; the Beatific vision is a promise to humanity, the fulfilment of which can be looked for only when the purified soul in a glorified body is called into the heavenly places. Meanwhile immense may be the progress,

1 The time has come when a stand must be made against allowing the term 'Mystic' to be appropriated by the Extremists. The word is of a useful structural form, and it is not all its historical associations that are of a derogatory kind. It may well be employed to designate either of the forms distinguished in the text, I venture to think. 
even in our present state, for the upward striving soul in which the life of nature is gradually sublimated into the life of grace; but in this advance, as the theological virtues of Faith, Hope, and Charity need the co-operation of the natural virtues prudence, fortitude, temperance, and justice, so the various talents and gifts of nature, the joys and delights of ordinary life, and its practical duties, are brought into order by the spirit of religious devotion. The saintly spirit is displayed in varied characters and varied lives: the hermit is but one variety, and that a comparatively unimportant one, in the great line of Christian saints. The rule of canonisation given by Benedict xIv. requires proof that the servant of God has practised those virtues which occasion demanded, in an evident and heroic degree, according to his condition in life, rank and circumstances. And M. Joly ${ }^{1}$ points out that the Church has canonised " not only monks, side by side with dukes, duchesses, kings, queens, emperors and empresses, but also merchants, schoolmasters, gardeners, workmen, shepherds and shepherdesses, lawyers, doctors, publicans, a retired public executioner, jailers, treasurers, magistrates, beggars, domestic servants, artisans, shoemakers, carpenters, blacksmiths, and fishermen." And in Britain do we not see that the being penetrated by religious devotion of this mystical order was the mainspring of the exercise of great and powerful natural gifts in thousands of men and women who have devoted themselves to religious and humane labours of the most beneficently practical character? Many are instances of 'mystics' of the Christian Church who saw God through the Gospel of Jesus Christ; but in other religions also mysticism has shown itself in similar alliance with natural activity. It is therefore only some mysticism, and that not the best, which insists upon annihilation of the natural man, and makes a claim of exclusiveness for the higher life of the soul.

We find very few 'Exclusive Mystics' in Britain, so far as Natural Religion is concerned; the Theologians of importance who build on Intuitivism do so in order to secure foundations for their Theism; they then interpret the Natural order in the light of the primary Faith, and find all gathered up again in consummation-partial but progressive consummation-in the developed knowledge of God into which all knowledge flows. ${ }^{2}$

${ }^{1}$ Psychology of the Saints, p. 25.

${ }^{2}$ It is necessary here to refer again (cf. p. 82) to the mistake made by Christian writers who use the term Heart as indicating that Feeling is what is signified. 
This type is liable to confusion with three of the others. With Intuitionalism, which also speaks of direct knowledge of God: but Intuitionalism is put forward as a form of knowledge in the proper sense; it is akin to perception and reasoning; it chooses perception, immediate apprehension of the object, as the kind of knowing which it considers to operate here. When we speak of Intuitionalists we think of the Scottish school, men who had little affinity with anything mystical. They wanted to explain how God is known, and they were not satisfied with any result of processes of reasoning; and so they chose direct apprehension, intuition.

It is also confused with the Theism of Feeling: so closely that the term Mysticism is frequently applied by Rationalists to the Asthetic method. The Intellectualist is seldom concerned to discriminate between two schools which seem equally to oppose him ; and it is the same with the Ethical Theist. Both Intuitivist and Asthetic have set aside Intellect and Ethics when choosing their foundation : and in their ' common blindness' the Rationalist finds little to distinguish. M. Cousin, for example, does not make the distinction, but occupies half his chapter on Mysticism with a criticism of Feeling; Schleiermacher is as often as not called a Mystic, though he founded his Theology most definitely on a certain Feeling; and Vaughan says, "Rationalism overrates reason, formalism action, and mysticism feeling." 1 Another reason for the confusion arises from the fact that when Intuitivism seeks for its own language and symbols, it turns most frequently to the deepest of the feelings, that of Love; and expresses the religious attitude of the soul as Love of God.

Further, it is confused with Personalism: they both reject Reason and Feeling and Moral sense as separate factors. But this is for different reasons: the Personal school combines them,

This is not the Scriptural use, which is much wider. It can be found at times to signify Feeling, certainly ; but it is also used as seat of Will, and even of Thought. And there are many places in which it is rather the combination after the manner of Personalism that is in view ; and still others where the reference is to a region beyond all these, after the Intuitivist manner. The fact is that the 'Heart' is a symbol of the central life of the soul and the manifestations thence proceeding, for the Scriptural writers as well as for the Classical writers generally. And when modern writers appeal to the 'heart' all that they should mean, if they wish to carry Scriptural authority with them, is the central and general rather than the special operations of soul-life. For full display of authorities for this, see the very interesting chap. xii. 'Heart and Head,' of Delitzsch's Biblical Psychology.

${ }^{1}$ Hours with the Mystics, Bk. I. c. 2. 
the Intuitive replaces them by a new capacity. Personalism is entirely opposed to extreme Intuitivism. On the other hand, the ordinary complex experiences on which Personalism takes its stand may very well be adopted by the comprehensive Intuitivist to bring him the ordinary knowledge which he is to illuminate with the extraordinary insight which he claims to possess. ${ }^{1}$

It is not an uncommon charge against Intuitivism that it is a counsel of despair. Men would not adopt it if they could help it, it is said, but they come to it after experience of the failure of all ordinary methods of belief. This is true perhaps of a few Mystics such as Pascal; but it is a poor diagnosis of the fervour and exaltation of the faith of the Mystic of the extreme type, and it is scarcely less misguided in the case of the enthusiasm of the much more extensive school of British Intuitivists who replace ecstasy by comprehension of the ranges of ordinary life.

The positive force of this method comes from the conviction that the Supernatural is so different from the Natural that it is futile to attempt to search for a consciousness of it among mere manipulations of the information given by the ordinary faculties. The true religious spirit is a Divine spark; no expansion of Nature, no elevation of natural capacities of the soul can take us into the presence of Eternal Perfection.

Intuitivism has to face some very obvious objections:

(1) The need of showing that we acquire our religious belief by a truly simple and primary faculty which yields to no analysis and shows no complexity. Now a conviction of the individual soul may be unanalysable by any introspective effort, but strenuous attempt will be made to show in other ways that it is really

${ }^{1} \mathrm{~A}$ difficulty arises in many cases in saying to which type a writer belongs, because however much an Intuitivist may strain to assert the separateness of the faculty, he cannot talk in 'unknown tongues'; he can only use images from the lower ranges of life; he will speak of seeing God, of having an idea of him, and so run near to Intuicionalism : of having a feeling that God is, and so running near the Esthetic school; of spiritually apprehending him, and so running near Personalism ; or he may try to avoid all these in the general term 'God-consciousness,' and yet we shall find that the moment he proceeds into more particularity he falls into one school in the other. In the case of the less profound writers a slight change in phraseology would suffice to alter their place in such a classification as I am attempting; and in not a few cases the assignment has been made with much misgiving. But in lucid minds deeper affinities are not wanting as guides where the phraseology fails. 
complex and has a history. Similarly as to directness and immediacy: attempt will be made to show that only in and through ordinary experiences is supersensuous experience given. The Rationalistic Theist, both Demonstrative and Transcendental, will resist being associated with Mysticism unless there is given him a clear exposition of the insufficiency of all his proofs. Agreeing that a Spiritual Being is known, he will not acquiesce in the claim for direct communication as the only way to this knowledge, and will shrink from it in some fear that it is resorting to faith instead of confidently standing on the powers of reason. The Rationalist is content to reach the region of Divine things by ascent as by a ladder, and disclaims the need of an endowment of Angels' wings. And other forms of Natural Theism will agree in calling Intuitivism supernatural, and in making against it a charge that it is sceptical as to our natural faculties, because it is in ignorance of what they can be trusted to accomplish without any need of resort to a unique faculty. The appearance of Mysticism will be put down to ignorance of what the natural faculties can do; or else to lassitude, to despair, or to presuming ambition.

(2) Even if primary and direct, it is only a fact of individual experience: how then can it be declared that there is universality? How shall we justify our insistance that everyone either has or ought to have this experience? Is this a Monadology of spirits, each in direct contact with the Infinite, but with universality of Faith quite beyond proof? In the inner life which this supernatural faculty enables us to enjoy, each can make his profession of faith for himself alone: the experience is within the confines of his own consciousness. The use of the term 'contemplation' points to an endeavour to escape from this Egoism: in contemplating there is a suggestion that there is an object open to everyone's regard: but this is really to resort to an Intellectual term and drop to Intuitionalism.

(3) It runs into the danger of finding the finite individuality gone. The absorption at which many Oriental forms confessedly aim affects all Mysticism, with its slender hold on what is granted to the individual as his own ' nature.' He is like a faintly flickering planet drawn nearer and nearer to the solar fires. The finite is in direct contact with the Infinite; all that it has and is, it 
receives: all that it knows is shown to it. In short, the old question stands before us again, Can man see God and live? It is not without reason that ordinary men have asked even prophets to veil their faces before they spoke when they had messages of Divine communication to deliver. And in thinking out towards God, modest souls may ask that He show Himself from behind phenomena and through ordinary avenues of intelligence rather than burn the soul with a direct vision which will imply a supernatural power of perception, in the exercise of which we ourselves are not ourselves. The Mystic must be able to assure us that it is still ourselves whose faith is the organ of apprehension.

It is in view of the second and third of these dangers that the Mysticism of the Church claims that it differs from philosophical Mysticism in having an historical body of doctrine, rites, and duties, in which ordinary human life provides a medium appropriate to the present status of the believer, as well as in anticipating for him a glory that shall be hereafter.

\section{$\S$ 14. Type XI.-Composite Method}

There are some minds especially characterised by amplitude and variety. They are awake all round; able to respond to appeals from all sides; with a window on every side of the house, sensitive to rays of every colour. If reason speaks they are influenced, if feeling stirs they are moved, if need for active effort comes they are ready. In such characters there is resentment against any attempt to confine the great questions of religious belief to the area dominated by any particular factor of mental life.

This is a similar character to that of the Personalists of Type IX. (Newman), so far as width is concerned. But our history requires the formation of a group containing those who accept Rationalism in some form or other and who use Empirical methods as well. In Type IX. I have meant to place those who are Empiricist only, unable to see their way to Rationalism in any of its forms. In this Type I place men who take factors from both sides of what I have adopted as the main line of cleavage. In doing this they will claim to be sympathetic and to enjoy the advantages of a cumulation of forces. But this amounts to a definite opposition to the claims of those who have taken separate methods in exclusive independence. The 
Rationalist has said that nothing unproved by Reason, speculative or moral, is to count in a philosophy of religion; the Empiricist refuses to allow such high responsibility to Reason with its inadmissible claims. The Composite method, therefore, will be despised by both as attempting to combine the incompatible.

This method limits the range of territory which it allows to any separate factor, whilst at the same time it confirms its title to the area allowed. A man may say, for example, "The argument from Causation is a very good one. I allow it, I insist upon it; there is a First Cause. But this intellectual assent is not a measure of my religious belief: into that my feelings and sentiments enter also, and I attach great importance to their influence; and farther, with the thought of a Divine Being ever in my mind and in the ardour of sentiment inspired thereby, my whole self as an active being exerts itself energetically and vigorously in the realm of things, action, and conduct. It is in the combined play of all my nature that I find myself when I say, 'I believe in God.' " And similarly, for other factors. "L'esprit (intelligence) a son ordre, qui est par principes et démonstrations; le cœur en a un autre," says Pascal (Pensées, Part I. Art. x.) ; and later, "Ceux qui sont accoutumés à juger par le sentiment ne comprennent rien aux choses de raisonnement . . . ; et les autres, au contraire, qui sont accoutumés à raisonner par principes, ne comprennent rien aux choses de sentiment." The synthetical minds which are Theistic after the method of this Type are those which move in both esprit and sentiment, and rejoice in the combination.

This combined activity, I think, is easy for Englishmen in general, and religious belief is so formed and so vindicated very largely on the part of many educated people; I have had therefore no small compunction in the cases of several prominent writers when confining them to one or other of the other types, and it is very likely that $I$ have done injustice to not a few in so doing. There are some cases perfectly clear; they distinctly repudiate any other method than the one adopted. But in other cases we have only a general impression that there is a strong preference for one method, with an acknowledgment that there is force in others. Under this Type, however, will come only those who have consciously faced the question as between combination and selection, and have expressly declared for the former. 


\section{$\S 15$. TyPe XII.-Some QUaSI-Theisms}

A review would be lacking in completeness of interest which omitted to notice as a Type with varieties some men who reach a doctrine akin to Theism, but in so attenuated a form as to render the term Theism itself inapplicable in the sense in which Englishmen are accustomed to employ it. It will be our lot to point out weaknesses in the methods of those who are called Theists, and to express grave doubts at times as to whether such and such a writer establishes his proofs. But this is not to put them in the same position as that of a man who deliberately acquiesces in a reduced conception. It is not that he fails to prove fulness, but that he substitutes his partiality for the fuller conception of other men, and would have the world be content with this lesser conception.

I do not propose to enter into a full scheme of all possible positions according to possible defections from fulness of Theistic doctrine. A few varieties which have actually presented themselves in a way which has attracted attention must suffice. They illustrate the following defects:-

Acquiescence in lack of proof of Immanence, complete satisfaction with Transcendence;

Lack of Infinity or Absoluteness, acquiescence in finite range, and yet endeavour to appropriate the terminology and to claim the feelings of 'religion' ;

Acceptance of Infinity, but lack of further content;

Indeterminateness accepted or approached;

Acquiescence in subjectivity of religious belief.

\section{\$ 16. Trpe XIII.-Resort to Revelation}

"Dim as the borrowed beams of moon and stars

To lonely, weary, wandering travellers

Is Reason to the soul."

Our last Type includes those for whom the light of Nature is too dim a guide in things divine to be entitled to employment in human life. It may be that this is the result of a comparison with the light of the positive Religions which as matter of fact have given birth to religious belief among the masses of mankind: belief vigorous and effective, covering the earth with temples, and penetrating the lives of men with religious rites and insti- 
tutions. In comparison with this path to belief, what inducement is there to embark upon a journey by the light of Natural inquiry? Omitting reference to the other positive Religions of the world, it is a plain fact that in Great Britain the Churches and the Bible have been the sources of belief in God, Natural Religion a concern of the higher education of culture only. And this is so not only for the masses but for the bulk of the leaders who have ministered to them as teachers, ministers, and priests. Large references to the Creatorship of God, the government of the world by His Moral Law, the peace of mind given by the sense of His Infinite Perfection are expected from time to time in the sermon and in the religious address, but these features of religion are to be insisted upon, not to be proved. If we consider the importance in the religious history of England of the Anglican and the Puritan movements of the seventeenth century, the Evangelical revival of the eighteenth, and the Oxford movement of the nineteenth; when we think of Andrewes, Leighton, Ken and Baxter; of Wesley and Simeon, of Keble and Pusey, and even Newman, how much had the light of Nature outside the Bible to do with these? There is, indeed, much 'human nature' in the experiences of Bunyan as recorded in Grace Abounding, and as appealed to in Law's Serious Call and in Frederick Robertson's Sermons, but the difficulties and crises are called up by the incitement of Bible ideas, and the solutions are found in the same circle of influences. To the great mass of religious people, then, the range of ideas and of feeling covered by the term Natural Theology is indefinite in character and faint in influence when compared with the range covered by Christian belief.

But our inquiry is as to Theists - those to whom it is a matter of concern to know what the light of Nature can show. And we conclude with noting as a type those who after examination have concluded against it, and declared that the choice is between Revelation and darkness. As the Hindu religion includes sceptical 'systems,' so we have amongst assured Christians men who are sceptics or agnostics in Natural Theology.

There may be as many motives to this course as there are types of Theism: for in connection with each type there may be men who have tried it and seemed to find it to fail, and know of no other resort. A man who has been accustomed to worship under the influence of Feeling may find the springs of natural 
Feeling run dry, and with that drought find scepticism set in. And similarly for each type: a man who has had a vigorous Personal Faith while the tide of life was running strong may find his Faith shrink with the shrinkage of vitality; or again, a man may be of such a temperament that he must be influenced mainly by Reason, and yet come to find that the effort of Reason does not yield him a belief in things unseen. Every one of the schemes may lead those who have tried it, and found it fail, and know of no other, to acquiesce in Christian Agnosticism. Or lastly, there may be those who have adopted a philosophy which has prevented them from ever trying to form a Theism, judging beforehand that the search was futile; while yet they accept the revelations of Religion, as established by history and welcomed by their own moral and spiritual nature.

We shall not have occasion to bring up many examples of this Type. The number of those who have no ground of religious belief outside their Christian Faith is not small, but it is only a few who are correctly designated Christian Agnostics, namely, those who can give such an account of their agnosticism as would bring them within the compass of an inquiry into Natural Theology. 


\section{P A R T I I}

\section{CHAPTER I}

\section{Type I.-Intuitional Theism}

\section{$\S 1$. Introductory}

THE historical position of the Intuitionalist school is that it insists upon knowledge, upon intelligence, upon truth as the main aspect of Belief, while it acquiesces in the failure of reasoning. In the eighteenth century it could not accept the $\dot{a}$ posteriori Demonstrative method, while the Transcendental had not yet arisen; so that all that remained to do, if it was to stand by Intelligence at all, was to assert: to maintain the simplicity of categorical affirmation, and declare that the Divine Being was known by immediate perception like the external world, or else by self-evident intuition like mathematical axioms.

This position is not one which has been occupied by many eminent names in philosophy, but there are many theologians who have taken it up, finding that it stands obviously at the threshold of the philosophical schools. It has, indeed, been largely through the encouragement of historical theology that Intuitionalism has appeared at all: the theological demand was urgent, and yet as no philosophical systems were forthcoming which could meet the demand for a universally acceptable doctrine, a doctrine had to be produced, though it were only by assertion and not by philosophical explanation at all. The central conception with which Theism deals was then asserted by Philosophy to represent a reality known by direct intuition, by direct gaze, by knowledge unmediated and underived, and therefore beyond range of 'explanation.'

I do not place under this Type those who were Intuitionalists in Ethics and from that basis inferred the existence of the Perfect 
Being: they come under Ethical Theism. This type comprises those who speak of direct intuition of the Infinite and Perfect Being.

\section{$\S 2$}

Herbert (Edward, Lord), of Cherbury: De Veritate, 1624

At the head of this line in England comes Lord Herbert of Cherbury, the brother of George Herbert of Bemerton. $\mathrm{He}$ is usually recognised as the precursor of those opponents of Revelation known as the English Deists: and he himself makes a vindication of Natural Religion his chief concern. His treatise on Truth (Tractatus de Veritate, 1624) was well known in the seventeenth century, and was in Locke's mind when he was dealing with Innate ideas. Herbert thought that there are notions or ideas as to which all men practically agree, and he lays down six marks by which the admission of any idea to such rank could be guided: priority, independence, universality, certainty, utility, and self-evidence. Amongst these ideas he places as the five communes notitiae of Natural religion-(1) there is a God; (2) He ought to be worshipped; (3) virtue and piety are the chief elements of worship; (4) repentance is indispensable for men as they are; (5) there is a future life with rewards and punishments: a wide range of beliefs for Intuition to endeavour to cover. But our interest in Herbert is not permanent, it arises because he gave the century a broad statement of a 'case' for both Empiricists and Demonstrationists to examine.

In the eighteenth century there was a revival of Intuitionalism by some Scottish writers: the school of Common Sense as a sphere of First Principles known directly and accepted by intelligent people generally. Reid, the founder of the School in Philosophy, did not himself, however, include knowledge of the existence of the Deity among these First Principles, but regarded it as an inference arrived at by their means (see Chap. II.), but Oswald ${ }^{1}$ and Beattie ${ }^{2}$ included Religious Knowledge within their sphere of Intuitions. These two writers, however, confused true Intuitionalism with the appeal to Consensus: see Hamilton's Reid, Note A, p. 752.

In the nineteenth century Intuitionalism has appeared from time to time both in Britain and America.

\footnotetext{
1 Oswald, Appeal to 'Common Sense' on behalf of Religion.

${ }^{2}$ Beattie, Essay on Truth.
} 


\section{$\S 3$}

Theodore Pakker: Theism, 1842 ; Discourse on Matters pertaining to Religion (Works, ed. 1865)

The famous New England preacher exhibits the most confident Intuitionalism I can find since Lord Herbert; a confidence which in both cases led to the regarding Revelation as unnecessary.

Parker claims that man possesses an Idea of the Infinite God, 'Infinite or Perfect in all possible relations.' His statement follows one of those used by Descartes. We have the Idea, existence of the object is implied by the veracity of our faculties; as much so as in the case of Mathematical truth. He says it may be called either an 'Intuition of Reason' or a 'Revelation from God.' It is a 'judgment à priori' ; transcending all experience. By analysis we then bring out that the Perfect Being is Omniscient, Omnipresent, Active; He is Spirit, Love, Righteousness: (although in another place the list of predicates is different from this).

At the same time he allows that in the 'genesis' of the Idea the sense of Dependence operates-and he refers to Schleiermacher-and he calls this specially the 'religious' element in the Belief.

The Belief is confirmed $\grave{a}$ posteriori: by Causation, Design, the sense of Right and Wrong, and ideas of Beauty. But he expressly says that these act only in confirmation; they could not produce the belief.

A marked characteristic is his comprehensive confidence in his deductive applications, e.g. the application to Providential ordering of the world, which he declares to be manifest in Motive, Method, Purpose, and Means, in spite of Misery in animal as well as in human life, and of Sin, which are explained in much the ordinary way. Inductive observation he confesses does not show completeness in this respect; but he sweeps over all by means of his deductions, with a rhetoric which can only be called audacious.

Parker protests against the cogency of any particular methods of filling in the 'Idea of God.' They are anthropomorphic, and they necessarily vary. He acknowledges indeed that the Idea above indicated is cold,- 'we call it abstract': but in the name of Reason all disguises must be torn away. He sometimes refers 
to Hegel, but there is no sign of appreciation of the method by which all that is learned in experience is gathered up into the Idea. He starts from the Abstract Idea, and after surveying experience comes back to it again much as it was.

In his two Sermons against Atheism, speculative and practical, there comes out either ignorance or carelessness. As against practical Atheism he assumes that its Ethics must be egoistic Hedonism, and that not of a calm Epicurean but of a passionfollowing kind. As against Speculative Atheism he supposes its advocates to acquiesce in believing that Chance characterises both the material and the spiritual world. The confidence of one who was an orator rather than a thinker marks all that he says, and accounts at once for the extent of his influence in his lifetime, and its cessation when his personality was removed.

\section{$\S 4$}

Morell, J. D. : Philosophy of Religion, 1849

Morell was an interpreter of German theology and philosophy of some repute in the middle of the nineteenth century. He published a volume on the Speculative Philosophy of the century, but says that Theology was his chief concern. $\mathrm{He}$ may be called in many respects a disciple of Schleiermacher, but he differs from him in looking not to Feeling but to Intelligence as the source of the fundamentals of religious belief; with Rothe he is in closer affinity.

His main care is to assert primary authority for Intuitionalism as compared with Inference in Thought: he is for the 'intuitional consciousness' against the 'logical,' as in the following emphatic statement:- "Intuitional certitude . . . involves no hypothesis; it has no reference to anything previously asserted: but simply affirms positively and categorically an objective existence. It is nothing whatever involving any comparison between an internal phenomenon and an external existence; truth in the intuitional sense is being-being manifesting itself to the human mind-being gazed upon immediately by the eye of the soul." To many this is incomprehensible, he says: "This idea may be termed the pons asinorum of metaphysics." Of the resort to logical inference he says that it only leads to negative ideas, and is useful only for formulation. He considers that it is the reasoning process which is varying and 
individualistic, while the spontaneously arising intuitions are generic and universalistic. For his position he claims nearly all the great names in philosophy, not allowing even Aristotle or Locke to be really against it.

The variations and the deficiencies in religious beliefs he explains by reference to obstructions, and it is for use against those that he finds criteria of truth needful, these being Distinctness, Uniformity, and Universality.

A curious point in Morell is that he acknowledges that Will is the centre of consciousness, but makes no farther reference to it, on the ground that it is 'always there,' and has no specific function: he therefore admits only a dual classification of the phenomena of consciousness, the intellectual and the emotional. The Emotional side of our nature operates in religious belief by compelling us to seek satisfaction, and when Intuitions are given us to lay hold on them and thus make them entirely our own.

We have therefore a Theism which is given us by Intuitional apprehensions, but these are not of a unique or extraordinary kind, and therefore he is no Mystic. They are the highest and most certain assurances of our consciousness as intelligent beings. The Theism cannot be claimed as a native English product, but it is of interest as an English interpretation of a fine type of German theology.

\section{$\S 5$}

Harris, S. T., of Yale : Philosophical Basis of Theism, 1887

This volume contains some excellent argumentation and criticism, but it is a work which few will be able to read through: it is too encyclopædic in its range, every point as it comes up is laboured de novo. In Theism it claims the primary position for Intuitions of the intellectual kind; they are designated ultimate realities (or ideas) of (or known through) Reason. The three ultimates of life, Truth, Beauty, and Goodness, Dr. Harris revises and restates as Truth, Right, Perfection, Goodness, and he adds a fifth, the Absolute or Unconditioned. Of all these we have Intuitional knowledge.

Then he dips down into a study of Man, and after a careful examination of materialistic objections sets forth man's Personality: to this is applied the Intuition of the Absolute and we have a Personal Absolute. 
This having been established, Dr. Harris proceeds to a proof or verification of a transcendental kind. The existence of such a Being is a necessary presupposition: it is required (1) to make Reason trustworthy; (2) to make knowledge 'common'; and (3) to enable thought to be brought into 'system.'

The strange feature of Dr. Harris's procedure is the curious attitude taken up in reference to what is so plainly of the utmost importance to him, namely, how the Absolute, known intuitionally, can be shown to be legitimately invested with the Personality derived from the study of human nature. $\mathrm{He}$ says that this attachment does not come within the scope of his book, the philosophy of Theism, but is ' relegated to Natural 'Theology.'

Feeling and Will are secondary factors of Belief; they come in as 'tests.'

The result is therefore an assertion of Intuitionalism for our belief in God as for that of self and of the world, God being taken as the Absolute: and a Personal character, vindicated for man, is to be connected with this primary conception by the procedure of a 'Natural Theology' which is not included in Philosophy of Theism, but was deferred to a work which appeared in 1899, The Self-Revelation of God.

\section{$\S 6$}

Murphy, J. J. : Scientific Bases of Faith, 1873 ; Natural Selection and Spiritual Freedom, 1893

Mr. Murphy, a layman of the Church of Ireland, is very insistant on the recognition of several grades of existence, e.g. mathematical quantities; life; consciousness. And the advance is real; the lower does not contain the germs of the higher, it is a basis strictly. But vice versa the knowledge gained of the higher illuminates the lower by exhibiting it as a stage necessary in the graduated scheme.

Surveying the universe, he accepts the Cosmological argument, but does not consider that it gives rigorous proof : it affords a presumption to be verified. The Teleological he uses in subordination to it. As might be expected from a student of science, he is clear in his treatment of Teleology. He disclaims the Analogy form of it, and insists that there is as direct an inference for Divine purposiveness as for human. He adopts 
Order as well as Adaptation. One of the principal marks of his treatment is the insistance on the formation of high types of human characters as an end which cannot be gainsaid, and he resorts to this when in view of the problem of evil. The Moral argument is cogent, the 'greatest in effect,' but still he does not take it to give rigorous proof.

He therefore takes his final stand upon Intuitionalism. There is a certitude in our knowledge of logical axioms; space; time; causation; the veracity of memory; the fact of law in Nature: and in its certitude Theistic belief is like these. $\mathrm{He}$ defends himself against Kantian reduction to subjectivity of thought, saying, "these were facts of Nature before they became forms of thought, and are forms of thought because they were facts of Nature," i.e. he is a Natural Realist in Philosophy and carries it into Theism. Intuitional as he is for fundamentals, he does not find need for a special faculty for Divine knowledge.

On the basis of these Intuitions he proceeds, comprehensively, to fill up knowledge of God from all that the Cosmological, Teleological, and Moral arguments can yield.

\section{$\S 7$}

Knight, W.: Aspects of Theism, 1893

This book is largely a judicious review of other báses than that taken by the author. The à priori schools, he says, do not avoid a petitio principii, and their issue is Absolute Idealism, which for Theism comes near to pure Pantheism; the Cosmological argument-which he prefers in the form of Contingency -does not work independently of the à priori; what strength it has it borrows from that; the Teleological-he enunciates two of the three forms and endorses Hume's objection from the uniqueness of the universe-is at best subsidiary; as a 'principal' argument its failure is 'signal.'

Intuitionalism is his own position: Intuition as equivalent to Intellectual and Moral second sight. Four tests are given: (1) persistence in the individual mind, (2) persistence in history, (3) harmony, (4) utility. It is a less inviting list on the whole than Herbert's, except for the harmony.

For the Intuition of God he claims an objectivity which he does not allow to intuitions of Space and Time; but surely all the above tests are very abundantly satisfied by Space and Time? 
Then into the lower field of experience this Intuition enters as the Infinite. Into the physical world it finds itself welcomed by modern conceptions of a single Force, and of Free Will, and so the Infinite takes up both these and is connected with the universe of Matter and of Mind. He defends the taking up of Personality against those who cannot connect it with the Infinite. In the Moral sphere it comes as Freedom and Authority, in the Asthetic as Beauty and Love. In the filling-up he pleads for comprehensiveness, for the symbolical and allegorical use of all our experience. The support of Consensus is most valued as the testimony of experts, not as the verdict of the Common Sense of mankind which his Scottish leaders delighted at once to vindicate and to claim as on their side.

A notable feature of Professor Knight's Theism is his strong reliance on the rsthetic side of experience as Enjoyment of the beautiful, as might be expected from one who has spent so much time with the poetry of Wordsworth. Intelligence is at the root of belief, but imagination and emotion must be brought in.

The whole is exceedingly well balanced; and the style is that of good general literature. Perhaps as a first introduction to the subject the volume is as likely to be stimulating to the general reader as any recent volume which could be named. ${ }^{1}$

${ }^{1}$ Professor Knight is placed under this Type rather than with the Intuitivists because of the predominantly intellectual character of the Intuition which he places at the foundation. His affinities seem to be with the Scottish Intuitionists rather than with Mystics. But the difference between him and some of those standing in the Intuitivist type is very slight, and I confess to great hesitancy as to whether he should not have been placed along with them. 


\section{CHAPTER II}

\section{Type II.-Demonstrative Rationalism}

\section{$\S 1$. Introductory}

THE famous fresco in the cloister of St. Maria Novella at Florence with a fine audacity shows Thomas of Aquino occupying the central seat among the mighty teachers of the world; even Moses and Solomon are on humbler seats. Within the Schools controversy had ever been keen; but when the world required some working result from Theology a choice was necessary among conflicting schemes, and it was from the mind of Aquinas that the scheme of Theism came which was selected by the Roman See for special commendation throughout Christendom.

There are reasons not far to seek why this was so. Two of these deserve a moment's attention as introductory to the study of writings of this Type. First, Aquinas was in some degree an eclectic, and therefore comprehensive, at least superficially. Not only had his mind some Platonic phases, derived from Augustine, no doubt, which the world would hardly have consented to miss in the man who should be chosen as supreme teacher; but he was definitely impressed by the Neo-Platonic writings of Dionysius. The Idealist element was not of first necessity to him, however: the kind of mind to which it appealed was one likely to be fully satisfied only with Revelation as source of Belief, but Aquinas wanted a Rational framework constructed out of more concrete material as well. And this requirement was endorsed by official authority, after some resistance: Theology was declared to have a Rational character; but of course care was taken to delimit its application in respect of some Christian doctrines, notably that of the Holy Trinity. Secondly: the scheme of Aquinas with its intellectual cast was adapted to the need of an age from which the glow of high spiritual speculation and activity was departing. The period 
which saw the early Crusades and designed the noblest of the Cathedrals, and gave birth to the Franciscan, the Dominican, and (practically) the Cistercian Orders, had been in affinity with Platonism so far as that was known. But as the intensity of spiritual force was exchanged after Plato for the intellectual force of Aristotle, so, later, the moral energy of William of Champeau and Abelard was exchanged for the massive thought of Aquinas. When the succeeding age had to choose between the idea of God as Perfect Goodness and the idea of Him as Infinite Truth, it chose the latter. Philosophy, it thought, seeks above all things Truth. And so the definition of the Divine Being which was to be to the front included such conceptions as self-existence, intelligence, unity, simplicity, infinity: goodness, holiness, and other 'spiritual' qualities were there, but they were secondary in logical order and in real prominence. This is in accordance with the course of change often noted in the comparative history of religions.

Perhaps a third reason may be hazarded. Is it too much to say that the is posteriori method in philosophy, as understood by Aquinas, ${ }^{1}$ is the easiest for human nature to grasp and to use? With the data of sense-knowledge as accessible material, and certain fairly obvious principles, such as Causation, for working this up into ' knowledge,' a philosophy was provided which could be taught by hundreds of teachers of no extraordinary gifts, and learnt by thousands of students of ordinary talent. No genius was required: for those who would give attention and not be over-critical it would almost run of itself.

For these reasons-or others-the scheme and mood of Aquinas formed the standard Natural Theology of the age intervening between the great period of the Schools and the revival of Letters: it became the great conservative Tradition.

When the revival came and after a century of ecclesiastical and religious strife the modern period of philosophy began, we find that the Tradition had strength to secure for itself persistence amid the new forms in which speculation took shape. We remark three of these forms: (1) the reform of Bacon in the method of acquiring knowledge, the logic of Induction: in

\footnotetext{
1 'This method does not really exhaust Aquinas' philosophy, any more than it does Aristotle's. The great Italian has affinities which we should now call Idealist. but it was with him as with Aristotle, there was a presentation of philosophy ad populum as it were, for everyday use; and it is this which has prevailed.
} 
reference to Theism, it could not even, at the outset, be supposed that we could by induction reach the Infinite side of Truth, so knowledge of the Deity was relegated to Revelation; (2) the reform of Descartes, by which the intellectual principles of Aristotle were retained, refined by the advance of Mathematics, but by which there was reopened a way to a spiritual Theism through attention to the source of knowledge in thought or consciousness; and (3) the via media of Locke, in whose eclectical system certain principles-but ill accounted for -were retained along with the recourse to inductive method, and with a confidence which carried philosophy far over the boundaries traditionally marked between Reason and Revelation.

\section{§2. Romanist Theologians}

The Roman See has definitively adopted the Demonstrative Theism of Aquinas. It has not left it an open matter, but requires that this be the teaching in its colleges and the normal method of answering the questions of those in whose minds the problem of Theism has been raised. At the Vatican Council of $1870,{ }^{1}$ after defining what is to be understood by Deus omnium rerum Creator, ${ }^{2}$ it proceeds-before defining Revelation-with this declaration as to Natural Theology: Sancta Mater Ecclesia tenet et docet Deum rerum omnium principium et finem naturali humanae rationis lumine e rebus creatis certo cognosci posse; invisibilia enim ipsius a creatura mundi per ea quae facta sunt conspiciuntur (Rom. i. 20). Later in the chapter on Reason and Faith, Etsi fides sit supra rationem nulla vera dissensio esse potest; cum idem Deus qui mysteria revelat et fidem infundit animo humano rationis lumen indiderit. But Faith works with the assistance of natural reason, Neque solum fides et ratio inter se dissidere nunquam possunt. Then specifically it sets out as to be condemned, ${ }^{3}$ Si quis dixerit, Deum unum et verum, Creatorem et Dominum nostrum, per ea quae facta sunt, naturali rationis humanae lumine certo cognosci non posse; A.S.

Cardinal Manning ${ }^{4}$ said on this: "The Vatican Council declared that the existence of God may be known with certitude by the reason of man through the works that $\mathrm{He}$ has created." This, he says, is the infallible light of the natural order. The

\footnotetext{
${ }^{1}$ Constitutio Prima, caput I. $\quad{ }^{2}$ Caput Ir. $\quad{ }^{3}$ De Revelatione, Canon i.

- Pref. to Wilhelm and Scannell's Manual of Catholic Theology.
} 
definition, he proceeds, was needed by the rationalism, scepticism, and naturalism pervading literature, public opinion, and political action, and the Council considered that it was thus dealing with the first predominant error of the time, the question of the authority of the Holy See being only the second.

This is a declaration for the $\grave{a}$ posteriori method: the argument from creation to the Creator, from effects to a. Cause. The nerve of the inference is Causality, as it was used by Aquinas in both its senses, Efficient and Final. His five Viae lead us to a First Cause of movement; a First Cause of the series of beings, supposed by him to be limited; a Necessary Cause; a Cause which shall contain in itself sufficiency for all the perfections and realities known in the effects, itself therefore Perfect and most Real; and a designing and directing Cause. The answer, then, to the question De Deo, an sit? is certain, certo cognosci. What it gives us as the essence of Deity is Selfexistence; to this Reason applies itself and arrives at unity, which is partly supported by induction from the effects, but chiefly by analysis of self-existence; simplicity; and, resting on these, infinity. Other attributes follow from these by consideration of the Deity in relation to $H$ is creation, according to certain 'canons,' carefully laid down.

Two recent English books recognised by official authorities may be taken as examples.

\section{Boedper, B. (S.J.): Natural Theology, 1891}

This is one of the Manuals of Catholic Philosophy in the Stonyhurst Series, approved by Episcopal authority.

As against other Methods Dr. Boedder names à priori and immediate intuition, and repudiates them: he denies that the early Fathers of the Church, such as Justin, Clement, Tertullian, Augustine, can be claimed for the latter, and refers to Kleutgen's Philosophie Scholastique for a full account of their views. $\mathrm{He}$ gives a specific 'refutation of Ontologism' himself.

$\mathrm{He}$ sets out first and foremost the Cosmological Proof, from dependency, and from the need to account for the origin of the world; then the Teleological Proof from the order observed in the world; and supports the conclusion by reference to Consensus. It is curious to English readers that he miscalls the Consensus, denominating it the 'Moral' argument. The argument from Conscience he allows as only an indirect guide, by drawing out 
the consequences of Agnosticism in pernicious conduct both individual and social. And yet he argues as if he had established the usual Moral argument when he comes to refute the Pantheism of Spinoza, Fichte, and (according to him) Hegel. But his main bases for Personality are Intelligence and Freedom. Beauty and Feeling are not employed at all.

Thus we get as the Essence of Deity, Self-existence: and we proceed to Unity, Simplicity, and Perfection, on the lines of Aquinas indicated above. Turning then to Deity in relation to creation, we arrive at Immutability, Eternity, Immensity, the Divine Will, the Divine Intellect: all these attributes being applied as against charges of anthropomorphism according to the three Canons of Aquinas, whose doctrine in this respect is emphatically asserted to be the doctrine of all Catholic philosophy.

Clarke, R. F. (S.J.) : Dialogue on The Existence of God, 1887

This Dialogue is published by the Catholic Truth Society, and its method is quite orthodox. ${ }^{1}$ Though short, it could only have been written by one to whom the whole subject is very familiar. It is conducted as between two friends, one of whom has 'submitted' to the Catholic Church and become a priest, and the other has drifted into being an Agnostic pure and simple.

The Intuitional method is set aside as invalid, in strong terms. In exposition precedence is given to the Design argument, but this is only for rhetorical convenience: it is the argument from both order and adaptation, and it is cautiously expressed. Leibnitz's inference to perfection is repudiated; not perfect wisdom, but 'high intelligence and great power' are claimed, and it is 'arranging' the world not 'creating' it for which this argument avails. Then the argument from Causation, especially from Dependence, but also by way of First Cause: this does its work 'irrefragably.' An independent self-existing Being, this is the essence ; infinity and power to produce all the perfections of the universe follow. The Infinity claimed is real infinity, not mere absence of limitations; it is of a different order from the finite, and there is no possibility of its being limited by what it creates, as some writers urge. Personality is distinguished from individuality: limitation belongs to created personality, not to personality as such. 1900).

1 Dr. Clarke has died while this volume is going through the Press (September 
By the Moral argument Dr. Clarke, unlike Dr. Boedder, means the argument from Conscience. But he regards it as subsidiary to the Intellectual. "Unless a man believes in God on other grounds, I should be very sorry to have to convert him by means of the argument from conscience." ${ }^{1}$ Again, "Next I look within," that is, after Causality and Design have been stated.' It is confirmatory only, 'clothing' the Selfexisting Being with attributes.

The Argument from Feeling is mentioned early in the Dialogue: it is not acclaimed as 'altogether a friend': but in substance it is defended as legitimate, although it is not worked into the Scheme.

The appeal to Consensus is guarded: its verdict is general not universal in extent, and the appeal is made not so much to men of intellect as to men of virtue: a curious choice for one who has placed intellectual proof where Dr. Clarke has done.

When he raises the question as to the order of the arguments he is unwilling to insist on any necessary order: but states his own as dependence first, causation (as origination); perfections; beauty in the world; conscience; necessity and eternity; consensus.

Intellectual though the Theism is, Dr. Clarke follows a psychology which assigns no absolute power to reason as productive of belief. He considers the proof from Causation to be 'sufficient' though not 'resistless,' 'convincing' but not 'compelling'; while the Moral proof is even lower, it is 'conclusive' but not 'convincing.' There are objections, and other interests and desires may lead us to lay hold on these; and, besides, our Will may set itself against acceptance, which of course opens the door to Theism of quite another type.

With regard to the Roman official theology, however, it is necessary to observe that the requirement of adhesion to the Demonstrative a posterior $i$ scheme does not exhaust the situation. No Romanist is at liberty to oppose it; and Newman's freedom in expressing himself on the 'axiom of Causation' was 'deeply deplored' even by Ward, ${ }^{3}$ who himself incorporated much else, and it is protested against by Romanists generally. But thinkers are at liberty to hold that conviction is the result of other factors besides 'conclusive reasoning,' as we see in Dr. Clarke;
${ }^{1}$ P. 43.
${ }^{2}$ P. 53.
${ }^{3}$ Theism, ii. 263. 
and they may even rate this Demonstration lower than other methods. Confining ourselves to English Romanists of note, it would appear that the Demonstrative argument is or should be matter of agreement; but that there may be variety of opinion as to its exact force over the whole mind and the place which should be assigned to it in relation to others, e.g. to the Moral argument, and even to the Intuitivist unless all Mystical writers are to be deemed out of the pale of orthodoxy (cf. W. G. Ward, p. 218 ; Mr. De Vere, p. 311; Newman, p. 258). A sign of restlessness under the yoke of attachment to the Traditional Scheme is found in a vigorous 'Plea for the Modern Method,' 1 by Mr. Cuthbert (O.S.F.C.); who claims that it is no betrayal of the past to advocate a more modern position: that Catholic Theology should be "a vast historical garden in which we shall find the growths of every age." He holds that the Scholastics aimed at 'ideal congruity' with inadequate reference to experience; that modern method dips down to experience, in the Sciences and in the Kantian philosophy. And he specially refers to Newman as a gift of Providence to English-speaking Catholics at once modern in his method and Catholic in his faith, as doing in our day what Anselm did in his, ' harmonising once more tradition and intellect': and he hopes for a new 'School of Bec.'

\section{$\S 3$ \\ Locke: Essay, 1690}

For modern English Theism of this Type, outside the Roman circle, let us first take the statement of Locke.

He expresses distrust of the Ontological argument, of course ; he will not examine it, because it is " an ill way of establishing this truth and silencing Atheists to lay the whole stress of so important a point as this upon that sole foundation ": which indeed he had implicitly discredited in Book I. in his polemic against Innate ideas, that of the Divine Being included. But in Book iv. he affirms that the knowledge of the existence of God is "the most obvious truth that reason discovers"; it is " a regular deduction from some parts of intuitive knowledge," namely, "the clear perception of our own being ": i.e. our being a something that actually and beyond question exists. The deductive reasoning comes from "an intuitive certainty" that "bare nothing

1 Tablet, 24th June 1899. 
cannot produce real being." And the conclusion is that from eternity there has been Something. Now on the principles of Books I. and Ir. Locke is entitled to use neither the fulcrum nor the lever which he here employs. A strict reading of the 'new way of ideas' left no place for 'intuitive knowledge' of self; nor for any 'intuitive certainty' of the principle of Causation, as Hume was to show.

However, Locke proceeds. Whatever 'power' and whatever 'knowledge' is found in ourselves Locke takes to be ground for attributing Most Powerfulness and Most Wisdom to the Eternal Being already reached; and this Most Powerful and Most Knowing Being who has existed from all eternity and has caused us, "whether any will please to call God, or not, it matters not." 1

From this idea 'duly considered' can easily be deduced all those attributes which we 'ought to ascribe' to this Eternal Being. Arrived at this, Locke considers that he has knowledge superior in certainty to anything that "our senses have not immediately discovered" to us; nay, he "presumes he may say" not even second to that. The existence of an external world and that of other persons like ourselves, although known adequately for our purposes, are not so certainly known as the existence of God.

This is plainly a high doctrine of the cognisability of the Divine Being. And that Locke really held it in this high sense is beyond question. He speaks with the utmost decisiveness. "For the visible works of extraordinary wisdom and power appear so plainly in all the works of the creation, that a rational creature, who will but seriously reflect on them, cannot miss the discovery of a Deity; and the influence that the discovery of such a being must necessarily have in the minds of all that have but heard of it is so great, and carries such a weight of thought and communication with it, that it seems stranger to me, that a whole nation of men should be anywhere found so brutish as to want the notion of a God, than that they should be without any notion of numbers or fire." 2 And again, it is "the most obvious truth that reason discovers," and "its evidence is equal to mathematical certainty." 3

But the lacunae in the argument are very manifest. From the affirmation of a cause for myself as existing here and now, Locke passes to a cause existing everywhere and for ever. $\mathrm{He}$ relies in his major premise upon Causality and in his minor upon
${ }^{1}$ Essay, IV. c. 10.
2. c. 4 .
${ }^{3}$ v. $x$. 
what is equivalent to Substantiality in meanings which his psychological theory of knowledge had left him no basis for maintaining. $\mathrm{He}$ is more consistent, however, in his loyalty to his own reduction of Infinity to Indefiniteness ; and he fills in his conception of the Divine Being, not with Infinitudes and Perfections, but with Superlatives only. But even here his honest inconsistency creeps in again, for he makes an exception in favour of Eternity.

It has been seen that Locke included at once the attribute of knowing: investigation of the effect plainly shows that the Cause must account for cogitation, and therefore be itself cogitative: this allied with Power comes as near to Personality as Locke gets.

For the Ethical argument Locke had no inclination: for his own mind was drawing away from à priori Ethics. Sometimes there is a leaning to the position that Moral truths may possibly be deducible from metaphysical principles; but if we keep him to his own procedure in Books I. and II. we have no option but to enrol him among the pioneers of Utilitarian Hedonism. That this was the main tenor of the Essay was at once recognised; Shaftesbury immediately placed his finger on what to others than Hedonists appeared to be Locke's abandonment of rationality in Moral distinctions. From this tentative Hedonism no support for Theism could come, worth stating alongside such demonstrative certainty as Locke had reached on the intellectual side. In fact it was his view that proof of Morality depended upon proof of Theism, rather than the other way.

As to the Consensus argument, although he protests against it as being regarded as universal (and so a proof of Intuitions or Innate Ideas), he allows it: but it is of trivial importance to him, as it could add no force to such rigorous certitude as he had already made secure.

This dualism in Locke-the traditional Demonstrative proof in spite of his new Empirical theory-must be borne in mind when we remember his leading position in English, and indeed in European, thought during the eighteenth century. It is beyond question that he is the great founder for Europe of the Empirical philosophy : and yet his Essay was at the same time the text-book in the Universities where that philosophy was dreaded and resisted. On lists of studies and lectures he is named as if he were a 'subject' in himself, like Euclid: e.g. "Classics, and Locke or Moral Philosophy"; "Natural Philosophy, Moral 
Philosophy, and Locke." At Oxford, indeed, his work never held the first position, Aristotle not being displaced; but at Cambridge, amongst professional men in London, at the Universities of Scotland and of Ireland, and on the Continent wherever Voltaire's influence could penetrate, Locke's leadership was undoubted. This was due to his being acclaimed by the rising Empiricists on the one hand, who pointed to his earlier Books; and by orthodox Theology on the other, which acclaimed his vigorous confidence in the Demonstrative method as above indicated. Competent thinkers-Stillingfleet, for examplesaw from the first how inconsistent he was, and it was against their protest that the Essay gained its place as a University text-book at a time when Theology was a regular part of the University curricula for laymen as well as for the future clergy.

\section{$\S 4$. Seventeenth and Eighteenth Centuries}

The general prevalence of the Demonstrative method in English Theology can be seen in the procedure of leading theologians. For example, Bishop Pearson's ${ }^{1}$ treatment reads like an echo of scholastic doctrine: he enunciates the dual elements of knowledge, the senses and the understanding: the mind is ' a fair, smooth table' before Sensations come upon it; but understanding comes and works up these Sensations by what Pearson calls ' rational collection.' Hence with him the idea of the Divine Being is not connatural but arrived at by operation of thought: and he then proceeds to use the First Cause argument without any explanation as to the source of its validity. He supports his conclusion by appeal to Common Consent, and also by reference to the argument from Conscience as disclosing a Divine Judge, but in a weak way, and confused with Causality. Unity and other attributes follow by à priori deduction. Pearson's view of belief is intellectual: it regards verities, truths. ${ }^{2}$

Bishop Wilkins' Principles and Duties of Natural Religion, 1678, is mainly on Demonstrative lines: it appeared before Locke's Essay, and has some interesting differences from the rigid proof which Locke was to make popular. Wilkins gives great attention to the logic of Belief : he has a scale of graduated knowledge; sense-knowledge (of internal as well as external events), then mathematical; then moral; then testimony; lastly,

1 The Creed, Art. I., 1659.

2 Art. I. § 2. 
probability or opinion. His own conclusion as to Theism is that it is 'indubitably certain' but not 'infallibly' so: and he thinks that practical considerations would rightly decide for it, even if the probabilities on the intellectual side were precisely equal. His scheme is (1) Consensus, into which he goes fully, and claims that it is latent where it is not explicit; (2) First Cause, for origin of the wolld; but he does not accept complete cogency because he has not made up his mind that an indefinite regress is unthinkable; (3) Design, the 'excellent contrivances' in natural things including mental as well as physical nature; (4) Moral; inductively from the 'works of Providence in the government of the world,' both ordinary and extraordinary; he uses this apart from the witness of conscience. Then he goes on to establish Attributes, each proved by Reason, and endorsed by testimony. On the Moral argument it is notable that he only says ' he might add' an argument from Natural Conscience as God's deputy: showing that it was not before Butler that this form was accepted as of first-rate importance. Bishop Wilkins had an original turn, and is at present best remembered for his ponderings over a Universal Language, but his theological treatise is less known than it deserves to be; it was in good repute in its day. The 1704 edition is the fifth, and Tillotson introduces it with a preface. By its range beyond the narrow line of Locke it might have done good service as against philosophical Deism. But it dropped out of notice as the eighteenth century advanced.

Bentley ${ }^{1}$ rejects innateness for demonstrability. His course is to state his Cosmology from the sphere of mental existences, and his Teleology from external Nature. He includes the argument from Beauty, as "a meliority beyond what was necessary to be." In Teleology the 'Leviathan' of Hobbes takes its place alongside the Eneid of Virgil as examples of what could not have been formed by chance aggregation of letters of the alphabet. The great classical scholar considered that the human body is formed like a language, 'good sense and true syntax and harmonious measures, in its constitution': and facing the already rising difficulty as to the smallness of man and the vastness of the physical universe, he emphatically declares that one soul is of more value than the sun and planets and stars, and is not unworthy of all the pains taken in making even a universe.

1 Folly of Atheism, 1692. 
In Bishop Stillingfleet's Origines Sacrae, 1697, the second volume is on the 'Foundations of Religion,' where the plan of five Books is sketched, but only some chapters of Book I. are finished. There is a copious collection of historical lore, especially directed to establish the Consensus argument. Stillingfleet claims the support of Classical thought for Theism, because it was held by the majority of the great writers of Greece and Rome, and this after criticism and scepticism had arisen and not merely as first suggestion or unscrutinised tradition. His treatment of Causality is very lengthy, especially of Final Cause, which he defends against Descartes and Spinoza. He himself is for a Cause which not only originated but still preserves the world, as against the Deism which was growing. Stillingfleet perceived that in the Ontological argument Descartes was forging an instrument to be used as an alternative to Cosmology. $\mathrm{He}$ criticises the argument severely, but defends Descartes as genuine in his intention when he put it forward. As regards Locke, though their line of Theism is in its chief feature the same he cannot accept as a defender of Theism the man who has made himself champion of the 'new way of ideas' (Empiricism): if Locke could not apply this to Theism he ought to have seen how weak it was. Hence the well-known controversy between the two. Stillingfleet was not in the front rank of thinkers: but his acuteness and his great stores of learning give weight to his adhesion to the Demonstrative method in days when many new 'ways' were being tried.

Bishop Burnet ${ }^{1}$ begins with Consensus, which he thinks goes a long way: he then takes up Design, and then First Cause: but he has evidently not thoroughly cleared his mind, as he mixes up with the last some considerations belonging to Design : and there is confusion also in his treatment of the Attributes. Bishop Beveridge ${ }^{2}$ takes Existence as postulated, and begins his exposition with the proof of Unity; and it is from the First Cause conception that he deduces it: and he then proceeds similarly for Omnipotence and other Attributes. Waterland ${ }^{3}$ stands simply upon the demonstration from our own existence: "We know and feel our own existence, and from thence can demonstrate the existence of God. I say demonstrate; for our knowledge of God is demonstrative only, not intuitive."

1 On the Articles, 1699.

3 On the Articles, 1710.

${ }^{3}$ Dissertation, 1734. 
In America Jonathan Edwards ${ }^{1}$ accepts explicitly the origin of Knowledge from Sensation, but supposes that there might be intuitive Knowledge of an Infinite and Eternal Being if our minds were 'strong' and 'comprehensive' enough-under these figures covering from himself a more intellectual theory while dimly perceiving its possibility. He then lays down the argument from secondary causes to an Eternal Cause; then to necessary existence, by argumentation; and the rest of the doctrine-the Perfections-comes by deductive development. Edwards most explicitly stakes all the scheme on the First Cause argument: in default of this, "all our evidence of the being of God is cut off at one blow."

Abraham Tucker's Light of Nature Pursued (1768-1774) was a work of considerable reputation in its day, and found its way into many a household. It was highly praised by Paley. Part I. is on Human Nature, II. on Theology, and III. on Nature and the Gospel Blended. In I. he works out Personality or Spirituality of Mind against the Materialists and Hylozoists. In II. he relies on First Cause, and includes Intelligence and Choice as what is carried up: the doing this is the mark of Theism versus Atheism, he considers. Consensus confirms. Then some attributes can be deduced, as unity, omnipresence, eternity. But he does not value arguments to Existence direct from Space, Time, Finitude: they do not convince, and cannot do so, owing to the imperfection of our faculties. $\mathrm{He}$ goes some way into Empiricism, and was a forerunner of Bentham in Morals. $\mathrm{He}$ does not like Immanence, and will not interpret Omnipresence and Omnipotence to imply it. In consequence he does not escape a flavour of Deism, and it is on that line that he defends the doctrine of Providence.

Bishop Randolph, ${ }^{2}$ when professor at Oxford, gave a course of lectures on Theology which includes ' Philosophical Religion.' He puts Design first, referring to it both for unity and for the relation of parts: and includes Beauty with order and uniformity; but he is not looking beyond physical nature. Then Consensus, and then 'Prime Cause,' of mind as well as of external nature. He has some compunction in placing Prime Cause after Design, because it is really more 'scientifical': but at least it is not so 'obvious.' The attributes are then deduced. Wisdom and goodness are established both deductively and

1 Frecolom of the Will, 1754.

2 Lcetures on Theology, 1784. 
inductively. Stillingfleet is evidently on his desk, and Wilkins; and he refers to Cudworth and Clarke, of the latter remarking that he is conclusive but not 'clear and plain.'

Timothy Dwight, ${ }^{1}$ President of Yale, whose system of Theology had great vogue in collegiate education in America, arranges his scheme, First Cause, Design, Deduction of Attributes : in fact, expressly taking his stand on Locke.

Reid, whose name is so often associated with the Intuitionalism or Common Sense of the Scottish School, was not an Intuitionalist in Theism. He did not include Knowledge of the Divine Being among the Intuitions of the Mind, but he regarded it as a result of applying an Intuitional or Common Sense principle to the data of experience. In his Essay the principle was Causality and Design (Essay, vi. cvi.), and he is classed by Stewart with Butler (Life, p. 32), as also relying on the Moral Argument; and he also used Common Sense as Consensus in the ordinary confirmatory way. In his Essay, vi. c. iv., on the Intellectual Powers, he distinguishes between Necessary and Contingent truths, and thinks the only 'necessary truth regarding existence' is that of 'the Supreme Being': and then goes on to make this declaration: "But although the existence of the Deity be necessary, I apprehend we can only deduce it from contingent truths. The only arguments for the existence of a Deity which I am able to comprehend are grounded upon the knowledge of my own existence, and the existence of other finite beings. But these are contingent truths."

Dugald Stewart, Professor of Philosophy at Edinburgh, was not a minister of any Church himself, but in his classes he moulded the philosophical thought of many of the Presbyterian ministers and laity of his time, and there was even a considerable resort to Edinburgh from England expressly for his lectures: He was not one of the Scottish Intuitionalists, or rather he did not carry his Intuitionalism into Theism; he was at one time Professor of Mathematics, and his mind turned for satisfaction to the old Demonstrative method in Theism. His lectures on Moral Philosophy (1793) are little more than notes of what he said, for he covered a great deal of ground, including Theology in Philosophy: in order to give a basis for duty to God, 'an examination of the principles of Natural Religion' was required. As to the $\dot{a}$ priori method of Clarke he follows Reid, 
and turns at once to the $\dot{a}$ posteriori as simple and obvious. Intuitive truth about God he expressly disallows.

For the Demonstrative method he claims that its premises belong to "the first principles which form an essential part of the human constitution," namely, Causality and Teleology: the process of reasoning from them "consists only of a single step." $\mathrm{He}$ insists strongly on 'incessant agency' as well as 'first establishment,' and allows 'occasional' acting by subordinate agents or instruments. His notes are most copious for Teleology. The Moral Argument he uses in a purely inductive manner : from the evidences of Benevolent Design and of a Moral Governor which are around us. Infinity he regards as only absence of bounds, and he finds that increase of knowledge keeps ever pushing the boundaries farther away.

Stewart taught that the above principles of Natural Religion ' hang together,' and, farther, are connected with knowledge of all other kinds. He claims that the great scientific discoveries have been made not by sceptics, who are usually 'paradoxical and sophistical,' but by men 'friendly to the principles of Natural Religion.'

These authors may suffice to show the extent to which the Demonstrative method prevailed in Theological circles in all branches of Christianity. Taking it in connection with the attitude towards the Ontological Method, which varied between hostility and what Paley would call 'otiose assent,' we are not surprised to find that the form of Theism known as Deism was prominent in England: the idea of the Divine Being became narrowed by the nature of the Proof to that of an Original Cause which had set all the second causes in operation: that this was the ultimate bearing of the argument was widely felt, and led to a considerable alienation of the religious community from Rational Theology.

For the nineteenth century, without attempting any general characterisation of the influence of German thought upon English Rational Theology it may be sufficient here to say that it had the effect of causing very much of a stampede from the Demonstrative camp; this camp was never wholly deserted, but no new work of any significance or distinction came from it during the first sixty years of the century. But after a time 
there came reconsideration and a renewal of vigorous and confident exposition on this time-honoured line: it was reshaped and enlarged by the incorporation of the results gained by the new light, and by the extension and enrichment of knowledge through the sciences. From among those who have restated and more or less reconstructed the Demonstrative scheme I take some representative names.

\section{$\S 5$}

Mozlex : Essays, 1878; University Sermons, 1876; Bampton Lectures, 1865

There are points in Mozley both of method and temperament which recall to mind a thinker who preceded him by nearly two hundred years, Samuel Clarke, to a degree which makes it doubtful whether Clarke should not be dealt with immediately before him. But, as will be seen, there is reason against placing Clarke in the Demonstrative School at all, while Mozley, in spite of those affinities, is within it.

Mozley's main pillar is Causality; but he relies also upon an $\dot{a}$ priori conception of Infinity as itself entitled to assent. Infinity is an idea which 'arises out of our own minds': and it corresponds to a reality: but how an idea arising out of our own mind is known to correspond with reality - which seems to be regarded as something not so arising-he does not show: he assumes it; he is a Realist. In illustrating his notion of Infinity he refers to Space; but when he comes to use it in reference to Causality it is Infinity of Time; and one cannot refrain from wondering whether if he had referred more closely to Infinity of Time at the outset, he would have had equal confidence in asserting that there is a 'reality' corresponding to our notion of Infinity. He acknowledges that Infinity is at times so difficult to grasp as to lead to scepticism, but with others it is a stay of Belief, and he instances Pascal as revelling in it in the latter sense.

In Causation, he insists on the element of necessity. This, he points out, is supplied by the intellect: observation shows us only antecedence. Explanations of this necessary element may differ among those who accept it: Mozley takes it as primary, axiomatic. In cases where voluntary action is concerned the Cause becomes personal, is designated an Agent. A true cause is, he considers, an uncaused cause; any other is secondary: " the very idea of ciuse implics a stop, and wherever we stop is 
the cause"; an infinite regress deals only with movement towards a cause, it does not touch the requirement to stop. $\mathrm{He}$ accepts this visible world as a sufficiently good startingpoint from which the application of Causality may be made, and the issue in God as Cause is demonstrative, i.e. he opposes to Kantian criticism the view that from the contingent reality of the world Intellect passes by Causality to transcendent truth.

With the Causal argument Mozley's proof of the existence of the Divine Being both begins and ends. This accomplished, he turns again to the world to seek for indications of Attributes.

The necessity for an adequate conception yields belief in Intelligence and Goodness: i.e. Personality. And from the presence of ideality in ourselves, we infer Perfection in Him.

Teleology now joins in : a subject to which Mozley devoted a scrutiny which was close and penetrating, but, unfortunately, incomplete. He insists that the Argument from Design is not invented or coined: adaptation, system, are part of what is observed; they 'adhere to the facts.' And, further, he will not accept the way of stating the argument merely as an inference by Analogy : it is direct and valid in itself: even if man had made nothing we should legitimately infer that some Purposive Agent made the world we see. But as he acknowledges that in the vast realm of the Plant-world he sees no 'End' except in relation to Animal life, nor in that except in relation to Man, we have a sufficiently empirical teleology. He recognises irregularities and anomalies, but claims that there is sufficient order in nature to refuse elimination and to give a backbone to teleology. As he does not himself require teleology as an argument for the existence of the Deity, this limited use of it affects only our inference as to His character, of course. On the objection that if God be Infinite no adaptive design could be necessary he has a fine passage. With regard to Darwinism he is not unwilling to accept it and work it in as a substitute for previons presentations of the plan, provided that it be remembered that it does not displace 'plan' itself. Mozley's great defect is the absence of allowance for intrinsic ends, subordinate to the general plan; all ends except those of Man are represented by him as extrinsic, not only physical but also vegetable and animal: nature is regarded as mechanical apart from spirit. And yet it is expressly because teleology can interpret Nature 
that he uses it to establish the Personality of the Supreme Cause.

But if Mozley's teleology is defective, a large credit must be given him for his restoring to high place the Argument from Beauty: a restoration all the more notable from his position in the very School which had most neglected it, and does so still. Beauty cannot be referred to the nature of the thing which has it, it is extrinsic to it, implying a mind which regards it and is impressed by it: it therefore carries contemplation away from the thing to its Creator: it is a potent factor in the Teleological argument, for him.

Taken as a whole, Mozley's contribution to Theism is disappointing. He writes with an appearance of rigour and a tone of assurance which again recall Clarke. But he makes serious mistakes: e.g. Kant's position is quite misrepresented when he assimilates him to Clarke on Causality, and omits to record Kant's insistance that the application of Causality would only lead to antinomies.

In spite, too, of his apparent definiteness he is not quite easy about the absolute cogency of 'Demonstrative reasoning' for Theism. The confidence of Locke that no truth was more certainly demonstrated is not shared by one who attributes a still higher force to Mathematics. So that we are not surprised, after all, when we find that the conclusion is so stupendous that Reason is not wholly adequate to it, and some resort must be made to Faith. The fact is, Mozley himself was strongly affected by a consideration for which the Demonstrative School has never succeeded in making articulate provision, having indeed but seldom appreciated the call to do so, namely, that the Theism which Theology is concerned to justify must include Infinity. His contributions were, however, fragmentary. Had he devoted himself to the construction of a regular Theism he had gifts which might have enabled him to produce the representative nineteenth century scheme of this type.

\section{$\S 6$}

FLINT, R.: Theism, Baird Lectures, 1876

A course of lectures delivered by Dr. Flint has come into wide vogue which aims at being a general exposition rather than an original investigation like Mozley's, although original 
thinking is not absent and the whole has been passed through the mind of the writer and is no mere compilation. But as a general exposition it has some obvious defects; it is far from comprehensive; it is not well balanced; and at some crucial points it is hesitating. Still, it is of interest as a late nineteenth century contribution to the Traditional scheme.

Dr. Flint takes up formally the composite source of Theological belief. Indeed here he improves upon Dr. Barry : better than the metaphor of the manifold cord of Dr. Barry is the 'organic unity' of Dr. Flint, each part separate and yet each contributing to the common result.

Yet the predominant note of Dr. Flint is the necessity for intellectual conviction. He rises to a rigour of demand for this which it would not be easy to match in recent years. If Feeling and Will are used without the Intellectual factor we are in sad case: "Unless there be such an object and unless it can be known "- this is the point_- "all the feeling and willing involved in religion must be delusive"; and he sides wholly with Reason in its protest that independent operations of feeling and willing "must be of a kind which reason and duty command us to resist and suppress." 1 This is a strong line as against the followers of Schleiermacher for example, and against those who insist on the Will-element as rightly leading us far beyond where Reason can take us. But Dr. Flint is uncompromising, "if God cannot be known, religion is merely a delusion or mental disease-its history is merely the history of a delusion or disease, and any science of it possible is merely a part of mental pathology." 2 A penalty has to be paid for this preliminary exaggeration, however, as we shall find later on.

Dr. Flint had promised to appeal to the whole nature of man in 'organic unity' - but as matter of fact we find the Asthetic basis omitted, and the Moral so treated as to leave a marked Intellectual colour over his whole scheme; which therefore reduces itself to the traditional Cosmology plus Teleology, and the Moral argument. In his exposition of Cosmology he meets the charge of abstractness brought against it by insisting on attention to the demonstration that the physical world has unmistakable marks of being an event, an effect, and by holding that the resort to an uncaused cause is necessitated by this aspect of the world and is not a supererogatory production of

$$
1 \text { P. } 4 .
$$


abstraction-forming minds. He then turns to the mental world, and in the fact of personal Will he finds exemplified a kind of originating cause, and from this rises to the conception of a Personal First Cause as the only conception which men who themselves possess personal will are ever likely to be satisfied with placing at the head of all things. But the usual defect of this method appears here; it cannot be said that Dr. Flint does really accomplish more than conduct us to a First Cause in the old Deistic way.

Dr. Flint's treatment of Teleology agrees almost completely with Mozley's. He rejects the analogy form of the argument and fixes himself in the facts of order and adjustment and adaptations as his data. He will not allow purpose or design to be in the data; the argument is not from design but to it, he says. But from the ordered character of the world to an intelligence with purposes there is a direct inference, the only one which is rational. To knowledge of ultimate ends he makes no claim; such instances as we can find are too scanty to make it other than hazardous to set out a scheme; but he has a clear account of the assistance given by the advances of natural science in enlarging the orderly character of the universe. Dr. Flint's treatment will be regarded as an abandonment of the Teleological Argument by those who think that the absence of ends is not compensated for by insistance on order, and that his condemnation of analogy takes away what mankind in general mean.

The Moral argument he states inferentially. Morality gives a concrete field yielded by observation, and supplying a hasis for direct inference. He thinks it can be stated so as to suit any Ethical theory, but his own view, the Intuitional, of course lends itself most easily to his treatment. Moral Law, Duty, Responsibility, Crime, Guilt : these are concrete disclosures to human reason: then arises the question, Whose law is it? Where is the authority? Then laying down Butler's position that morality is a normal attribute of human life, and that the normal tendency of human affiir's is to moral good, he defends Theism against objections arising from the fact that the tendency is often obstructed, or even is not evident at all.

The Arguments from Beauty and Feeling are not worked into the scheme.

Is there anything about is priori argument? A whole 
lecture is given to it, but the late appearance of this-it is the ninth-raises suspicions as to what it will contain. And this suspicion is justified. Dr. Flint cannot regard $\dot{a}$ prior $i$ reasoning in Theism as 'of vital interest,' although he feels unable to ignore it, and indeed sets some value upon it as 'disciplinary' of our thought. He thinks that infinity, eternity, and perfection are ideas: but the way of attaching them to the conception of the Divine Being yielded by Demonstrative argumentation is not clear to him. A curious sentence occurs which deserves attention: "It may be that the a priori arguments are faulty as logical evolutions of the truth of the Divine existence from ultimate and necessary conceptions, and yet that they concur in manifesting that if God be not, the human mind is of its very nature self-contradictory; that God can only be disbelieved in at the cost of reducing the whole world of thought to a chaos." 1 That any one could come so directly in face of the Transcendental position and describe it so clearly and yet come to no decision upon it is strange: "whether this be the case or not," he says; he will not face it, and decide. To reject a great method as illegitimate or unsound is one thing, but to look at it and commend it, and yet to relegate it to educative and disciplinary utility only, is to show absence of philosophic acumen, or else lack of resolute determination to treat the problem as it requires.

But before the lectures close we see the action of Nemesis for the exaggeration of Intellectual claims with which they began. The voice which was so loud at the outset wanes into feebler accents at the conclusion. There is an acquiescence in the possibility that the reasoning power of ordinary minds must not be taken to be adequate to establish Personal Theism as a matter of course, after all. Pantheism, Polytheism, even Atheism have not only been possible results of reasoning, but he goes even farther and says "they have always proved stronger, more popular, more influential "-on ordinary minds. And so he vindicates the need for Revelation. This is indeed a decline of confidence, and had it been expressed at the opening of the book the early chapters must have lost much of their crisp decisiveness of assertion. True, in his first lecture he has acknowledged that few have been Theists by rational conviction, the opinion that any man left to think it out for himself on a desert island

${ }^{1}$ P. 268. 
would acquire the belief is expressly rejected. But this seems forgotten when such claims for Reason as were quoted above come to be made in the course of the exposition of the Rational arguments. The weakness of the book as a statement of the whole case for Theism was sadly brought out when Romanes turned to it, and after reading it wrote his Candid, Examination, and fell into Atheism. Yet it has strong points, notably in its Teleology and its Moral theology.

Vartous Theologinas

Dr. Hodge of Princeton, U.S.A., in his Outlines of Theology (new ed., 1879) follows haltingly on Dr. Flint's lines. He starts with Consensus, and proceeds with Dr. Flint's scheme. In Teleology he claims both general order and special adaptations. In the Moral argument he compounds a curious mixture out of the appeal to consciousness, the induction from the moral history of mankind, the sense of dependence, and the sense of beauty. Before closing with a reference to Ontology, he has an argument which he calls the 'Supernatural.' It is obvious that Dr. Hodge had by no means obtained clearness of mind on this part of Theology, and it is with no surprise that we find that the whole scheme has but a meagre hold upon himself: "Reason never has availed," he says, "to lead men to certainty in the case of any historical community"; ${ }^{1}$ it has "always led men to scepticism and caprice." As our next writer remarks, Dr. Hodge "confuses proof and discovery"; the bent of his mind is dogmatic and his manner of expression correspondingly abrupt, though not without rough forcibleness, and the work is only referred to here as it is a text-book in some vogue in American Theological Colleges.

Dr. Randles is a professor in an English Wesleyan Methodist College, and was President of the Conference in $1897 .^{2} \mathrm{He}$ stands upon the $\dot{a}$ posteriori arguments; but he employs them in some complexity, gathering up the inferences from both morality and personality along with the central argument to First Cause. Teleology is then resorted to for farther definition; the Intuitive basis is disallowed, but Consensus is respected as

${ }^{1}$ P. 50.

${ }^{2}$ First Principles of Faith, 1884. 
rendering Atheism prima facie incredible. Acknowledging that different minds are influenced by different lines of argument, he avows his own preference for Causality as the only Intuition on which he can confidently rely: but this is to him ultimate and self-evident. like so many others of the school, he will not sweep aside ì priori argumentation, but like them he confines himself to that distant respect for it which leaves it unemployed. There is a breezy tone about this book, especially in the places where Dr. Flint was strong: and the hesitations, too, come in at similar points. But at the close Dr. Randles is more consistent: he thinks that Reason is not sufficient without Revelation, with the single exception of the Causality argument: on that he stands as on a rock. The other arguments are profitable only: they lead to presumptions, upon which Revelation descends in order to make them into convictions.

Dr. W. N. Clarke, ${ }^{1}$ the author of a valuable Outline of Christian Theology, devoted a course of lectures at Harvard in 1899 to the exposition of part of what is included in Theism. His argument is Demonstrative Rationalism.

He first argues to Mind in the universe from the presence of causes, efficient and final, and afterwards to Personality from the presence in the universe of intelligent and affectionate causative beings: we infer therefore a Thinker whose Will is the cause and support of the universe which $\mathrm{He}$ has created and maintains under the 'motive' of love, in analogy with human personalities, but, of course, in Him carried to perfection.

This he supports by the method of negation : "test the contrary," he says; go as far as you can without it, let the world be mindless and it is unintelligible, and then where is Science? let the world be heartless, then men who certainly have hearts are left at the summit of things excellent, they are the best kinds of existence known. These results he considers absurd, and the untenability of the negative hypotheses is proved.

Dr. Clarke's method does not go beyond establishing a Personality: he is content to define the Supreme as Personal, Good, Creator, working by Love as Motive. Infinity is of secondary importance; Absoluteness is a question for Philosophy; Self-existence is, he thinks, implied in being the Creator. It is not therefore a thoroughgoing Theism, but is an exposition

${ }^{1}$ Can I believe in God the Father? 1899. 
of what he considers to be required for the first Article of the Christian Creed: within its limited scope it is a lucid and vigorous exposition.

\section{Teleological Tineism}

The growth of Empirical philosophy after the impetus given by Locke had a dissolving effect upon the influence of the Demonstrative method. A distrust of the Causality argument, as containing something of an $\grave{a}$ priori character, grew apace, and there was a tendency to complete scepticism such as Hume's,-if his was complete,-or else to stand upon the lower but more congenial ground of pure Induction. For this purpose the Teleological argument was the great instrument: it seemed to be purely Inductive in character, and therefore lay under no ban.

It was obviously applicable both to external nature and to the sphere of mind and morals. The vivid character of some of the illustrations in the physical sphere and the great expository power of Paley have drawn an undue share of attention to what may be called Physical Teleology, although it is by no means all that was meant by most of those who have placed this argument in the front. We will take this line first, however, as the one that first rises up in most English minds of our day when the term Natural Theology appears.

Among English teleologists it is usual to give a first place to Ray, the great Naturalist. His Wisdom of God in the Creation was famous in the seventeenth century, and was full of instances of purposive adaptation, and of the detailed perfection of organisms, regarded by him as indicative of immediate operation of Creative intelligence. These greatly impressed popular attention, and Milton's view of Creation was, in the main, that of Ray. Even Newton could speak of the world as disclosing 'a Cause well skilled in mechanical ingenuity.' '

Isaac Barrow seemed unable to carry any influence from his Mathematical studies over into the religion of Theology but was quite Inductive there, arguments requiring 'metaphysical subtlety' not being so 'forcible,' in his opinion. Accordingly, neither in the summary known as his Exposition of the Creed (written in 1677) nor in his long-drawn Sermons on the Creed

\footnotetext{
${ }^{1}$ See Lettler in Pari ir. of Bentley's Works.
} 
do we find anything but four kinds of Inductive argument, namely, Teleology, Consensus, 'Supernatural effects' (including apparitions, fulfilled predictions, remarkable cures), and evidences of Providence in individual experience and in History. Nor is there any broad investigation of the competence of these arguments. In Teleology it should be noticed, however, that he is quite comprehensive, including all three kinds of order-(1) in individual existences, (2) as between these individuals, and (3) order in general, ' universal consort,' and he brings in human nature as well as the physical world. But he was too diffuse to be permanently effective, and we can learn to be thankful for the conciseness of eighteenth century expounders of similar methods when we are wading over the expansive fields of an exposition by Barrow.

The Boyle lecturer of 1713, William Derham, took as his theme 'Physico-Theology: a Demonstration of the Being and Attributes of God from His works of Creation'; followed in 1814 by his 'Astro-Theology.' These contain a conspectus of the sciences as then known, deftly probed for instances of adaptation and contrivance and of mutual connections in external nature. The books were very popular, and ran through many editions.

\section{$\S 8$}

Paley : Natural Theology, 1803

But the foremost work on this line of argument is that of William Paley. It is quite true that this treatise is issued as only part of a scheme: that Paley was not concerned to cover the whole ground even as it appeared to him. His commendation of Tucker's Light of Nature indicates what he regarded as a complete scheme. But his reasoning is so much concentrated on this lower position, and his exposition there is so admirable, that his reputation must bear with his being hailed as the foremost upholder of this kind of proof : a strictly à posteriori demonstration that the Maker and Supporter of the world is an Active Intelligent Personality who is Good. Although Paley uses arguments which separate his position from rigid sensationalism, especially in regarding Mind as a centre in which perceptions unite and from which actions flow, he is strictly empirical in his establishment of Infinity, Eternity, and even Self-existence: he is satisfied with superlatives or else, he says, we simply avoid 
putting limits, and he does not distinguish between these; all that he wants is attributes adequate to the magnitude, extent, and multiplicity of the operations observed. Hence it is the Design argument upon which he mostly relies, and he manipulates his material with consummate skill. He stands or falls by the Analogy form of the argument, both at the outset and in the chapter on Personality; it is from what we see and know of man's way of producing or manufacturing that we draw our inference.

Within his Teleology Paley employs the Moral Argument and also the Argument from Beauty. The Moral argument is only inductive, for he accepted Utilitarianism; the Esthetic is an additional support from the presence in Nature of evident pleasures beyond what are necessary for useful purpose: hence arises our confidence in Ruling Benevolence. An interesting example of Paley's empirical habit of mind is his closing his argument with a concentration of attention upon one first-rate instance; for his purpose he was so far at the pole opposite to that occupied by the mind which demands width of view that he says "amongst a multitude of proofs it is one that does the business": and he stands by what is proved from Anatomy. The modern mind rejoicing either in one sweeping proof with all the universe as basis, or like Bishops Ellicott and Barry and Dr. Flint resting on ascensively graded arguments or cumulation or organic constructions, finds it difficult to comprehend the mind which would rather fix upon one clear definite set of facts, however narrow.

At the same time Paley evidently takes up the work of his predecessors, such as Derham, and all the sciences of his day. No reason is apparent for our thinking him unwilling to include more, had more been effectively put before him to use. Martineau ${ }^{1}$ and Dr. Flint ${ }^{2}$ think it quite likely that he would have widened the argument had he lived in our day, and Dr. Schurman ${ }^{3}$ goes so far as to say that "by a wonderful forecast of genius Paley virtually accepted the modern theory of Evolution." This may be too strong a statement, but I agree that we have no reason for supposing that Paley would have resisted Evolution had the facts of the case as seen in our day been before him.

Taking Paley for what he was, it is a mistake to regard him as uninterested in Theology because he was not an originator; or as 
cold, because his argument was simple and his basis narrow. $\mathrm{He}$ rises to great impressiveness of conviction as he comes in sight of the end of his closely laboured argument: "The marks of Design are too strong to be gotten over, Design must have a designer. That designer must be a person. That person is God. It is an immense conclusion, there is a God."

Joseph Priestley built his Theism on the Design argument, although he does not state it without some confusion with the Cosmological. The argument is by analogy, with the works of man, and of animals (e.g. honeycomb). Originative causation he does not need, the world may very well be eternal; hence the view often taken that Priestley was a Materialist. What he finds is that in the universe there are evidences of intelligent purposive Causality, acting efficiently, doing work, moulding and shaping the course of events. The argument is ill stated: he does not look at events in a simple way but describes them from the outset as purposed effects: his conclusion is involved in his premises in the way of petitio principii, without any semblance of true inference.

As to Infinity he thinks Indefiniteness is all that we require, but that we can really demonstrate Infinity. From the cause of all activities we can infer to the cause of all possibilities, which is all the infinity he can conceive.

In Morals he uses inductive argument only as confirmatory: quite unexpectedly to those who know his position as a Hedonist he speaks of an Infinite Goodness as established à priori: and the Moral Government of the world he deduces from this, looking into the Hedonistic order only for verification. But he is conscious of incongruity and advises a correspondent to omit the study of his Letters on Infinity. Priestley thought that Theism led to Christianity, but he meant a completely rationalised Christianity.

The Design argument was the sole method of Theism for Thomas Brown (Lectures, 1820), one of the keenest and subtlest of the Empirical School. He was in some respects J. S. Mill's most direct master in Philosophy, and in Brown's advocacy of Theology as consisting simply of the proof from Design we see an anticipation of Mill's position fifty years later.

Lord Brougham in 1839 published an edition of Paley with Dissertations of his own: he had previously printed a Discourse 
on Natural Theology (4th edition, 1835). His express aim was to claim for Natural Theology that its true method was Induction. With reference to the Physical Sciences he considers that Paley and some recent writers, notably Cuvier, and Sir C. Bell-who contributed some fresh illustrations for Brougham to use-had done their work well, and that the inference to a Divine Being from the adaptations in Nature was as true an Induction as that to lost animals from their remains as discovered: which is perhaps as bizarre a statement of what an Empiricist could expect from Theology as any scoffing Transcendentalist could desire to find. But Brougham himself thought that he could do service best by taking up the psychological side of Nature as equally a field for Induction : from the uses and achievements of reasoning, memory, habit, and feelings making a parallel inference to that from physical anatomy. Then he marked out the ethical side of Nature, but he somewhat diverted his irregular mind from the path here, and gave most of his space not to the inference to the Deity but to the question of a Future Life. It is curious, too, that Brougham missed bringing his reading in Jurisprudence to bear: as, although not a profound lawyer, he knew something of law, and he was sufficiently versed in the moral, legal, and political reforms of his generation to have enabled him to give an interesting chapter on the Jural side of the moral argument. It is different with Metaphysics: he takes Reid and Stewart to be its leading representatives, and what he himself says about Infinity is mere waste of space. With an irregular and uneven mind at best, his work is only referred to as showing the kind of Natural Theology which actually commended itself not only to Theologians but to public men and to the philanthropists of the Diffusion of Knowledge Society at the commencement of the reign of Queen Victoria.

At this very time there appeared an Essay by a scientific man which put forward Teleology of a different kind from the Paleyan. Professor Baden Powell published in 1838 an Essay in which induction by Teleology is resorted to, but solely on the ground of general Order in the Universe. It was not meant that this was the whole of Theology: on the Moral side Baden Powell stood with Coleridge; but the Essay dealt only with the Physical Universe, and the leading point of it is as stated, its abandonment of the inference from adaptation in favour of that from general order. 
Cosmology as leading to First Cause is rejected: we are not in search of beginnings and ends; and to place a cause at the beginning is to make it really one of the series, and so only a 'second cause,' after all, he says. He wants a permanently acting Cause : and he considers that if we can show that order is a mark of Physical Nature, we may legitimately infer by analogy with Psychological causation, where we know causes. That this order is caused by a creating and directing Mind just as an arch is caused by an architect, is a plain piece of argument. He sets out a theory of Physical Causation which excludes efficient causation in that sphere: he admits only sequence: and this denial of Physical Efficiency is precisely his reason for insisting on the reference to 'Moral' Causation. An Inductive logic which casts out efficient causation from Nature, yet still finds Order there to be accounted for, should, he thinks, be welcomed by Theology. He is content with a modest result: and admits that the world does not show infinite benevolence: but that difficulty he remits to Moral Theology, although he did not work it out, at least in published writings. The gist of Baden Powell's procedure was to bring Physical Nature within range, by the fact of Order; and yet by denial of its self-efficiency to require resort to Moral Theology. In this way he thought that all Nature was brought into the field and contributed to Theism: but that the contribution of Physical Nature came through the Moral sphere. And he claimed that Inductive Method was ample to accomplish this aim, and that the Sciences when inductively worked contributed to Religious Belief, in their way, and so far as they went.

\section{$\S 9$}

Chalmers, Thomas : Bridgewater Treatise, 1834; Natural Theology, in vol. i. of Works ; Institutes, in vol. vii.

It was on the supposition that the work of Teleology in Nature had been well done that Dr. Chalmers turned his attention to its elucidation in the field of Mind. He opened the famous series of Bridgewater Treatises with his Discourse on The Adaptation of External Nature to the Moral and Intellectual Constitution of Man. In this he penetrated more deeply than the title indicates into enquiry as to adaptations within the Mind of its various constituents inter $\varepsilon$. Chalmers acknowledges his indebtedness to 
Butler for his view of man's mental and moral constitution, taking especially three points-(1) Conscience, (2) the inherent painfulness of vice, and (3) the law of habit. He then shows that External nature is excellently adapted to the calling out of these features. But he goes beyond Butler in passing more clearly to man's social nature: and here with great copiousness he exhibits a series of adaptations. Then he passes to intellectual nature, taking especially the laws of Association and the Expectation of Uniformity in Nature, and shows that these are most effective for their purpose. Finally, he examines the relation of the Moral and Intellectual faculties inter se. ${ }^{1}$

All this is a purely Inductive proceeding: it is occupied wholly with constituting the basis for an argument by showing that adaptations are in existence. Chalmers does not claim that the basis is sufficient to give more than "a considerable degree of probability," however: and Natural Theology in face of sin and guilt only indicates 'dangers' without showing 'deliverance': and stands in face of difficulties which it cannot dispose of.

Later, in his systematic exposition of Theology we find the same general position maintained. He severs himself expressly from $\grave{a}$ priori proofs, naming Clarke's expressly: and also from the Scottish Intuitionalists, blaming them for 'their tendency to excessive multiplication of the laws of our mental constitution,' and he thinks that Reid and Stewart felt the same objection to many of their associates.

In vindicating Teleology he introduces the Cartesian distinction between laws of Matter and the 'Collocation' of forces, in order to make room for Final Causes in Physics as against the Mechanical Theory. This distinction satisfied not a few,it was partially accepted by Herschel,-and often appears in Theological works still. But the advance of the philosophy of physics has now swept collocations and configurations all within the 'machine,' according to recent claims.' His references to Geology and Biology were of a kind which did good service in their day. Chalmers (in spite of his own Bridgewater Treatise) does not find Teleology so clearly exhibited in Mind as in

${ }^{1}$ It is a sign of how much this method was in vogue at the time that the Hulsean Leetures at Cambridge in 1837 (Parkinson) were on quite similar lines, with no special feature or force of their own, however.

${ }^{2}$ Cf. Dr. Ward, Naturalism and Agnosticism, i. 47. 
External nature. Mind has less variety. Still, he restates his examples of adaptation of the faculties one to another. But when he comes to Moral nature, he abandons Teleology and takes up the usual Demonstrative argument from the supremacy of Conscience to the existence of a Ruler and Judge. He sums up by saying that he is inclined to regard Teleology of the Physical Universe as the best evidence for the existence of God; and Teleology of Mind for His character.

Chalmers' mind is of unusual interest. Theology is not an affair of philosophers only, and Chalmers was the leading practical mind in Scotland for a generation. He had no time for the study of German Idealism; the Traditional Theism was out of accord with the Sciences as he read them and with the Scientific men with whom he came into contact: Induction offered itself as a Method, in the form of Teleology applied to contrivance and adaptation. We have seen how weak was his confidence in the result when he came to look at it after his case was stated. As a practical man it did not really concern him very much; he nearly escapes into Ethical Theism more than once; and Revelation was at hand to supply sufficient basis if Natural Theology should wholly fail. He might have followed Bacon and separated Nature from Grace altogether, and at times this is very nearly what he does. But he had a constant yearning for support from Reason. When he asks himself why should he not go to the Intuitionalism of his Scottish predecessors, he shrinks back: he is not "sure but there may be an immediate and irresistible sense" of God, but he fears surrendering himself to Mysticism if he trusts the suggestion. He acknowledges that to those who adopt Baconian logic there is some loss in the abjuring of the 'beauty' of the wider methods, e.g. of Descartes and Newton. He cannot accept Leibnitz on the origin of Evil, but he finds much to 'charm' in it. And after severely criticising Clarke he breaks out into eloquence on the enlargement of mind which comes when we endeavour to think broadly of eternity and infinity.

His just fame as a leader of Scotland not only in the ecclesiastical sphere but in the broad walks of national life leads us to express the feeling that an early acquaintance with German philosophy would have fitted Chalmers to be a leader in a loftier Natural Theology than his own confession shows him to have attained. 
M'CosH, J.: Method of Moral Government, 1850 ; Intuitions of the Mind, 2nd ed. 1865; First and Fundamental Truths, 1889

M'Cosh, himself a disciple of Chalmers, proceeded on the same line of Moral Teleology. He is an advocate of Inductive Method: expressly disallowing Intuitionalism, because the idea of God is 'cumulative,' our 'religious convictions have a genesis'; as to Intuitivism, we have 'no new intuitions' for religion, the 'God-consciousness' of post-Kantians is unreal: and he exchanges Demonstration by Causality for Induction by Teleology.

M'Cosh wrote very copiously. He surveys the world teleologically, not occupying much space with the physical Nature which he thinks Paley had well treated of, but dealing with considerable emphasis with the providential order in human history, and the moral nature of man-on lines of Intuitional Ethics. He claims that he is making an advance upon Chalmers in leaving the Adaptation form of Design for that of general order as necessarily implying Government.

Infinity he finds in the world and with it 'clothes' the Being shown by Teleology. He does not make up his mind clearly as to how he knows Infinity; he will not allow positive knowledge of it, and yet he blames Hamilton for stating it as only negative. In the second work cited he begins to have some tenderness for an Ontological argument as assisting in this process of 'clothing' the limited conception yielded by Inductive teleology; and in the third he had fairly landed himself in a mass of assertory Intuitions upon which to draw for 'Theism.

The strength of books like M'Cosh's lies in their appeal to the moral perceptions of mankind; to him as to so many men anything beyond this seemed to lead to 'dreaminess,' ' mere cloudland.'

With reference to $\mathrm{M}^{\prime} \mathrm{Cosh}$ it is to be remarked that he represents a considerable number of Theologians whose language as to the conclusions of Natural Theology is strong because they cannot refrain from drawing into its sphere some part of Revealed Theology. M'Cosh confesses to being one of those who have "often mourned over attempts to set the works against the Word of God ... to depreciate Nature with the view of exalting Revelation." And he proceeds to include in Nature 
' $\sin$ ' as well as 'vice,' without seeing that in introducing the thought of 'Sin' he has introduced that of God in the ordinary use of the word (which is his own), and therefore cannot infer to the existence of God from the world he has already constructed theistically. I think that the higher confidence in the tone of $\mathrm{M}^{\circ} \mathrm{Cosh}$ as compared with that of Chalmers-for Natural Theology on Inductive lines - is due to $\mathrm{M}^{\prime} \mathrm{Cosh}$ having extended his line within Theological territory, while Chalmers more clearly asked whether the Moral world gives evidence which of itself should lead us to belief in Government and therefore in God.

Tulloch, J.: Theism, 1855 ; Rational Theology in England, 1872 ;

Sermons before the Queen, 1866-76

I can find no fitter place in which to set Tulloch than this, if we take all the above writings into view. Before I read the Sermons I regarded him as a follower of Chalmers on the line of Moral Teleology, and I will first indicate what his position in his Burnett Essay was.

He will not have the Causality argument pure and simple, but he accepts the Teleological argument as stated in the following Syllogism :-

\footnotetext{
' Order proves Mind,

The Works of Nature show Order,

$\therefore$ The Works of Nature prove Mind.'
}

In this he plainly is wrapping the Teleological and the Cosmological together to some extent: from this combination he considers the conclusion a rational necessity. However that be, it is Final Cause which is intended: affected by the writings of Mill and Comte he considers that Paley and Chalmers were premature, and that Final Causation required reconsideration and revindication: which he here attempts. It is, he thinks, the 'vital point at issue'; here 'the whole contest of Theism centres.' Such words seem to rank him as one who stands or falls by Teleology.

But apart from the fact that he is not clear in keeping separate Final and Efficient Causation, his Teleology is supported by another position, that of demonstration of a Moral Governor from Intuitions of Conscience. And by still another when he takes Infinity as itself an Intuition. And there are passages which have strong touches of Personalism in them, 
when he protests against any separate consideration of motives to religious belief.

But if we take Tulloch the preacher we find ourselves in the Intuitivist School. He claims for religion a personal and emotional relationship to God: "the true analogy of religion is that of simple affection and trust." So far this is only ordinary Personalism: but he allows himself to speak of a special 'religious sphere,' a sphere where 'the welfare of the soul' is unconcerned with thoughts which he relegates to philosophy and theology. He depresses theology : it does not deal with vitalities. The spiritual region is 'to thousands the deepest reality', and this is the region to which Christianity makes its appeal.

In placing Tulloch with Chalmers and $\mathrm{M}^{\prime} \mathrm{Cosh}$ therefore, I must add that I have been guided by what he actually says when Theological work has to be done; because in that region he is for Moral Teleology. That he did not set any high store on Rational Theology at all, but referred to a region where the reality and vitality of religious belief are to be found lying behind Reason altogether is true, but it is not what he says in his Essay on Theism.

\section{Argyll, Eighth Duke of : Philosophy of Belief, 1896}

In the Duke of Argyll we have another Scotch advocate of the Teleological line of Theology, maintaining it to the close of the century. His volume completes a Trilogy, the Reign of Law, the Unity of Nature, and the Philosophy of religious Belief. A large portion of the book is occupied with Hebrew and Christian Theology. The Natural Theology can be summed up as a vigorous restatement of the Teleological construction of the universe both physical and human.

$\mathrm{He}$ identifies the ordering Cause with Will-personality in a few lines, but refers to the Reign of $\operatorname{Law}^{1}$ for fuller exposition. $\mathrm{He}$ does not regard it as an argument but as a self-evident truth, and calls the section in which it is given ' Intuitive Theology.' Of argument he has no great opinion. He examines Locke's brief scheme, and repudiates it as needless. As to metaphysical systems, 'the Absolute and Unconditioned' are terms without intelligible meaning. And, besides, the systems have all failed: Kant stamped failure on all his predecessors: nor have his successors been kinder to himself. 
The Duke does not set out the ethical element in human nature as part of his basis : no account of the ethical history of mankind appears in the 'Nature' which exhibits design, except a general statement as to our faculties and powers in the vein of Chalmers' Bridgewater Treatise, some references in Christian Theology, and the chapter on Christian Ethics. The fact to be regarded as the foundation on which to build even when we proceed to study the relations between ourselves and the Maker of the world is mainly the teleological constitution of External Nature. This suffices to bring religious belief out of the 'region of mere fancy.' At least this is the impression caused by the absence of definite treatment of the ethical side of natural life and its relegation to Hebrew and Christian Theology after the bare fact has been laid down.

In the Preface we are told candidly that the writer had no academic training in Theology or Philosophy. This is evident, and it leaves the book, so far as Natural Theology is concerned, simply a contribution to the Teleological argument drawn from the study of External Nature.

It would not be fair to some of the writers included under this Type to regard them as standing solely on the Teleological argument. Not a few writers who have contributed most to its exposition did so because they felt at home with it, or because they thought it most needed attention: but they accepted other parts of the Demonstrative system. When Brougham published his Discourse he brought upon himself a vigorous and racy pamphlet by the Regius Professor of Divinity at Cambridge, Dr. Turton, afterwards Bishop of Ely, to the effect that Natural Theology was not waiting for the ex-Lord Chancellor to bid it enlarge its borders beyond the Argument from Design. Turton pointed out that Ray, Derham, and Paley knew quite well what they were doing when they gave their strength to Teleology : and he cites a long list of eighteenth century writers who took a similar course. This view I cordially endorse. But there are some writers, as is seen above, who really did make Teleology, Physical or Moral, or both, the staple of their Theology. So much so that a French observer, de Rémusat, wrote, "La teléologie a été longtemps en Angleterre la base de la théologie." 1

\section{The Ontological Argument}

Cazenove ${ }^{2}$ says that no Schoolman of note followed Anselm; that Abelard and Bernard took no notice of his argument;

${ }^{1}$ Religion Naturelle en France et en Angleterre.

${ }^{2}$ IIstoric Aspects of the à priori Argument, 1886. 
that Aquinas indeed mentioned it, but he modified it, and expressed distrust of what it amounted to; and that only one other Schoolman, and he an obscure one, deals with it. Dr. Boedder cites no modern Roman Theology upon it in the chapter of his Natural Theology in which he repudiates it.

And yet there was in some quarters a sense that it was required in order to provide a complete scheme. The Cosmological and Teleological Proofs could not be stated with clearness without showing that somehow and from somewhere an Infinite had come in. Leibnitz saw this, and he too retained the Proof with some modification. His follower Wolff definitely appropriated it, and marked out the Three Proofs Scheme which Kant found in vogue. Criticising this scheme as they did, Kant and Hegel both thought that the Ontological argument was an essential part of it, but as they took the course of recasting Rational process altogether, they cannot be said to have adopted this argument themselves.

There are some who stand by the Three Proofs Scheme, in spite of the Kantian attack; for example, Dorner, who insists strongly on the necessity for keeping the Ontological argument, and indeed for placing it at the head of the scheme.

In Britain Dr. Hutchison Stirling, though much of a Hegelian, has an affection for the Three Proofs Scheme, and says that a thorough exposition of it still constitutes true Natural Theology. Mr. T. B. Strong takes much the same line, ${ }^{1}$ as also Dr. James Lindsay (cf. Part II. c. iii.). Their procedure is in effect that indicated in Part I. c. ii., that the setting this out as an 'argument' is a mistake, but that what it aims at-the providing of a statement of the validity of Thought-should precede the exposition of the Cosmological and Teleological Proofs.

This appears to be the best place for noticing the Theism of an Englishman of note, who regarded himself as propounding an a priori scheme at the beginning of the eighteenth century, Samuel Clarke.

${ }^{1}$ Mr. Strong is preparing a history of the Three Proofs for the series in which this volume appears. 


\section{$\S 11$}

Clarkf, Samuel: A Demonstration of the Being and Attributes of God, Boyle Lecture, 1704

There is difference of opinion as to the nature of Clarke's procedure. To some he appears to be mainly working by the Cosmological argument and therefore to belong to what is recognised as the it posteriori school. ${ }^{1}$ But he was certainly regarded throughout the eighteenth century as the advocate of a priori method: the most notable whom England had to show. And later, even Dr. Fraser, ${ }^{2}$ so careful in general, has given us indications of indecision here: he speaks of him in one place as 'elaborating' Locke: ${ }^{3}$ in another, as having given a 'oncefamous demonstration of intellectual necessity,' where he is speaking of Ontologists.

Able man as Clarke was, and evident as is the appearance of logical form in his way of expressing himself, to us of later days at least there is in him a singular mixture of assertion and ratiocination: and he does not himself seem to see which he is using. If his 'demonstrations' are sorted out it is quite easy to think that he is employing the Causality argument with some elaboration, as Dr. Fraser says. But a second sorting of them may result, as it has done with myself, in ranking him with those who meant to be à priori 'ontological.'

$\mathrm{He}$ does not start from a concrete experience: he will show that knowledge of God is strictly demonstrable from the most uncontestable principles of reason. His concern is with Being as Reason must think of it: his problem is metaphysical. His maxim is the Law of Contradiction; whatever is stated about Being must not be a Contradictory statement. Of Being certain predicates are true: unity, self-existence, self-causation, necessity. Of Finite things either separately or in aggregate these predicates are not true: if we attempt to attach them we fall into contradiction, e.g. to say that the contingent is necessary. We know therefore of a Being before we turn to the world of finites. Of course the first member of this argument is only a series of assertions: but Clarke takes them to be assertions of a selfevident character, parallel with the assertions of primary

${ }^{1}$ Cf. Hamilton, Reid, Note A, p. 762.

${ }^{2}$ Philosophy of Theism, i. 57.

3b. ii. 107. 
mathematical truths. This self-existent, self-caused, necessary Being, who is not the 'world,' is God.

But à priori determination does not stop here. Clarke holds that neither Time nor Space are 'things': they are conditions of existence, and they are infinite. Such conditions as these can in their infinity apply only to the necessary Being above asserted. God therefore is Infinite and Eternal. Omnipotence also can be proved. Further, Goodness is with Clarke necessary, absolute: in its proper meaning it can only belong to Him, not to relative and dependent creatures. The only great predicates for which he resorts to the world and proceeds $\grave{a}$ posteriori are Intelligence and Will (Freedom). Observation is then made use of to confirm these à priori results; and common consent confirms the interpretation of the individual thinker.

This is all very different from the Cosmological method as employed by the Demonstrative School. They begin from effect, or contingency, or some datum, and applying Causation they work backward; whereas Clarke considers that Thought is in face of Being with self-existence and other qualities or modes, as directly as it is in face of Mathematical verities. Whether or not he is right in thinking it possible to begin at this end, he at least stands, so far, where Descartes, with his quasi-inferential Argument from the Idea, and Spinoza, with his Substance, did. In confirmation of this view we find that he impressed Voltaire to a degree deprecated by a modern Frenchman, Jules Simon, who thought that he had all the dry apparatus of Spinoza, without his genius. But more, Clarke unconsciously felt that this was his position himself. $\mathrm{He}$ regarded Spinoza with stronger animosity than he did Hobbes because Spinoza came nearer to himself. In Spinoza he saw his own metaphysical vein of thought carrying a man into Pantheism-Atheism, he called it-opposing the Personality of the Deity and the possibility of Revelation. And so Clarke declares that it is not the à priori argument which will settle the main question between Atheists and Theists, but the question of Intelligence and Liberty. Now we saw that these did not form part of the $\grave{a}$ priori demonstration of Clarke at all, but were arrived at $\grave{a}$ posteriori, ab eminentia. With his position here may be compared Butler's assertion of Liberty in its relation to the 'opinion of Necessity,' which Butler ${ }^{1}$ also regards as "the very basis upon which infidelity grounds

1 Analogy, Chapter on Necessity. 
itself." Clarke thought that it would be to little purpose that Hobbes and his Eternal Matter should be overset if it was only to end in leaving us with the Impersonal Necessary Being of Spinoza. Of the two he expressly says that he thought the Atheism of Spinoza was the 'worst.' We are not left in much wonder, then, that Clarke's à priori demonstration was rather read than adopted, since so far as it went it left him with Spinoza. And his own careful inclusion of personality and liberty in the doctrine of God was not the part of his work which most caught the eye and became associated with his name.

Two points are of some special interest in Clarke. He has very frequently been supposed to have invented for himself an argument for Theism from the infinity of Time and Space. What is it that he actually does? We are aware of infinity in these, he says: they are not objects, they are objective, modes of some object; attributes of some substance. ${ }^{1}$ Surely that substance is at hand in the Necessary Being already put before us? So that Clarke is not proving from infinity of Time and Space that there is a Deity : His existence he considers himself to have established already: from Time and Space he gets the farther attribute of Infinity. It is somewhat strange that he should have been so misconceived as to be very widely represented as having invented a new Proof of 'Existence.' Through the eighteenth century that was the opinion, and it is passed on by Dugald Stewart, for instance, and although Bishop Turton endeavoured to scotch its course it continues still in vogue. John Caird denounces it in terms of unwonted violence, as a piece of 'meaningless jargon'; an unnecessary outburst if Clarke's aim has been misconceived.

In Ethics Clarke made what Professor Sidgwick calls 'an impressive attempt' to use à priori method. He considered that moral principles depended upon the 'necessary and eternal' natures of things, which gave 'fitnesses' or ' unfitnesses,' as directly apprehended as mathematical qualities. And therefore moral principles could be determined à priori: our duties could be determinable by abstract reason. Whatever the value of this position,- - and Dr. Martineau ${ }^{2}$ highly commends Clarke as standing up for 'Dianoetic' Ethics and giving 'powerful aid' to the

1 This is Newton's view. Clarke and he were friends. Newton's statement of it was not until 1713 ; Clarke's in 1704.

${ }^{2}$ Ethical Theory, vol. ii. 473. 
vindication of Duty as ' no more arbitrary than truth,' though he went too far in 'merging moral relations in intellectual,'-and however true it is that Clarke was driven into difficulty by his acceptance of 'psychological egoism' as true of actual men, his Ethics assisted him in giving $\dot{a}$ priori character to his Theism.

No English book on Theism has met with such a variety of reception as Clarke's. Hailed as a vigorous and confident champion of what offered itself as a rational proof of such a Deity as Christian Revelation assumed, he accordingly received much official recognition, alongside Locke: but gradually the affinity with Spinozism was discerned, I believe, and he ceased to have anything like equal rank in lists of studies, though few Professors omitted to note in their lectures the appearance of this black swan as interesting, and to claim some credit for English Natural Theology for having produced a work outside the accepted schools. Stewart, for example, while rejecting its logical validity, dwells on the 'enlargement of mind' which was derivable from the study of such high thoughts. Chalmers, ${ }^{1}$ along with the expression of his own opinion that it is ' an excogitation in which he himself has no faith,' breaks out into an eloquent passage in the same vein as Stewart's. But in some quarters in Britain it has drawn upon itself the strongest of philosophical vituperation. Thomas Brown called it 'mere verbal logic': John Caird ${ }^{2}$ says that it is a 'production' of 'an essentially fictitious character' which cannot be 'disguised' by ' an air of subtlety and pretence of demonstrative reasoning.'

It had a more appreciative reception in France, and is still regarded there as one of the chief works of English Theology.

But no one can read it now without seeing that Clarke was a strong man, and stood out from his contemporaries in seeing that there was a metaphysical position to be occupied; though, as it turned out, he had not the equipment for taking effectual possession of it.

Gillespie, W. H. : The Neccssary Existence of God, 1833

What Clarke was supposed to have done with Time and Space was actually offered as a Theism in the first part of the nineteenth century, in a curious treatise by a Scotchman,-a private student neither academical nor clerical, Gillespie of Torbanehill.

${ }^{1}$ Natural Theology, c. iii.

2 Essays, Butler, 
Impressed by the inefficiency of $\grave{a}$ posteriori method, and maintaining that an endless succession was in no way unlikely, he proceeds to give an à priori argument. He attacks Clarke, evidently not taking him in the usual sense, because he goes on to state that precise sense for himself. The eternity of Time and the infinity of Space are known, he says: these are not substances, so there must be substance behind them: then, there cannot be two substances, but one. Next, turning to the world and finding in it intelligence, this is ascribed to the unitary, eternal, and infinite Substance: and similarly, for power and freedom and true happiness. The argument is succinctly expressed in some twenty-nine pages (with 360 pages of controversy, elucidation, and notes): it runs off like a chain from a windlass: and if you agree with him at the start you may have to go with him all along. He added a volume on the Moral Attributes, to be similarly attributed to this Unitary and Infinite Being.

This work is noticed as an interesting example of private speculation: it has intellectual strength, as was acknowledged by Hamilton, de Rémusat, Tulloch, and Dr. Randles, and it is suffused with a grim Carlylean humour.

A similar demonstration is given by Dr. H. H. Moore, ${ }^{1}$ of St. Petersburg, U.S.A., but only at the outset of his volume, not again referred to when he proceeds to enlarge upon the Moral side of Theism.

See Appendix A for Professor Ladd, Theory of Reality.

1 The Anatomy of Theism, 1890.

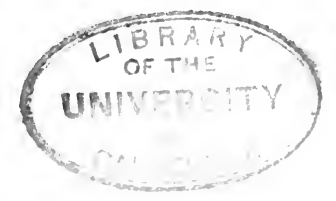




\section{CHAPTER III}

\section{Type III.-Transcendental Theism}

\section{$\S 1$ \\ CAIRd, John : Philosophy of Religion, 1880}

The late Principal Caird's lectures on the Philosophy of Religion, published in 1880, form a volume which is a singularly fine example of a philosophical treatise. Had there been just a little less use of technical terms they might have carried the subject over into general literature. As it is, they bring a broad literary style into theology.

Much space is necessarily occupied with criticism of counterpositions; the exposition of the centre of the philosophy is in Chapter viII., The Speculative Idea of Religion.

After a condemnation of abstract generalisation, as leading away from reality, we find the following starting-point:-

"Thought is capable of another and deeper movement. It can rise to a universality which is not foreign to, but the very inward nature of things in themselves; not the universal of an abstraction from the particular and different, but the unity which is immanent in them and finds in them its own necessary expression; not an arbitrary invention of the observing and classifying mind unifying in its own imagination things which are yet essentially different, but an idea which expresses the inner dialectic, the movement or process towards unity, which exists in and constitutes the being of the objects themselves. This deeper and truer universality is that which may be designated ideal or organic universality." ${ }^{2}$ This universal "is not last, but first. We do not reach it by first thinking the particulars, but, conversely, we get the true notion of the particulars only through the universal." 2 "Here then we have a kind of universality which is altogether different from the barren and formal uni-

1 1st Edition, p. 229.

${ }^{2}$ P. 230. 
versality of generalisation." 1 We are to note, then, that the Idea which we have here set before us is (1) transcendental yet immanent in the particulars, and (2) necessarily known, not a mere hypothesis. These are pivots in the transcendentalist position, as I endeavoured to show in the Introduction.

Applying this principle to religious ideas, we are " enabled to apprehend these ideas in their essential nature, their reciprocal relation, and their harmony and unity as a whole. . . . Nature, the finite mind, and God or the infinite Mind, are not discordant or irreconcilable ideas, but ideas which belong to one organic whole or system of knowledge" ... "religion is that practical solution of the difference between God and man, between the Infinite Spirit and the finite, which it is the problem of philosophy to explain." 2 Again, "a true solution can be reached only by apprehending the Divine and the Human, the Infinite and the Finite, as movements or members of an organic whole, in which both exist, at once in their distinction and their unity." 3 "Man has relations to other finite beings, but also to that which transcends the finite;" 4 and he emphasises the organic character of this relation: and the Infinite is no mere negative of the Finite, but 'its presupposition and end.' 5

This Universality or Absolute or Infinite has then to be examined, and it is plain that its nature is that of Spirit. An Infinite Spirit and a Finite Spirit would be able to be so related, i.e. not as negating one another, but each necessary to the other, and realising itself in and through the other. ${ }^{6}$ This is what religion means by the Infinite. It is this idea of it which "is simply the idea of God as Absolute Spirit." 7 It is of extreme importance now to observe that by Spirit Caird undoubtedly means Mind: 'Thought or self-conscious Mind,' ${ }^{8}$ he says, gives the only category under which such an Infinite can be conceived by us. "All other categories are still categories of the finite " $:{ }^{9}$ e.g. Substance, Cause or Creator, all has some necessary reference to something external, 'some unresolved element of finitude,' or else they reduce the finite, both Nature and human spirit, to 'mere evanescent accidents of His being.' “It is only when we think of God as Absolute Spirit or Self-consciousness that we attain to an idea of His nature which, while it gives to the finite the reality of

1 1st Edition, p. 232.

2 P. 233.

3 P. 241.

${ }^{4}$ P. 242.

${ }^{5}$ P. 243.

6 P. 245.

${ }^{7}$ P. 254.

${ }^{8}$ P. 254.

${ }^{9}$ P. 255. 
an object ever distinguishable from, never lost in the subject, yet refuses it any independence or individuality which cannot be brought back to a higher unity. In the light of this idea we see that the world and man have a being and reality of their own, even that highest reality which consists in being that whereby God reveals or manifests but Himself; we see also that their being is no limit to God's infinitude." 1

Here is the bed-rock of Caird's philosophy of Religion: the Speculative foundation in self-conscious Spirit.

This secured, his Moral Idealism follows; "for in the idea of a spiritual, as distinguished from a merely natural being, is involved the notion not only of self-consciousness, but of selfdetermination," 2 i.e. of Will, exercised self-assertively. Then follows an exposition of how Moral Idealism regards the ideal of goodness as coming into play in connection with our rational desires, which are to be brought into its service. Moral life is exhibited not as individualist but as social. "Morality, or the moral life, may be described as the renunciation of the private or exclusive self and the identification of our life with an everwidening sphere of Spiritual life beyond us." 3 This commences with the family, and extends to "the community, the state, the common brotherhood of humanity." "Apart from them I have no real self, or only the false self of a fragment taking itself for a whole." The inner character of Morality is essential- "then only do I truly perform my duties when they are no longer a law imposed on my will, but a law with which $I$ feel and know myself to be identified"; "it is when the moral life of society flows into me that my nature reaches a fuller development; and then only are my social duties adequately fulfilled when they cease to have the aspect of an outward law, and pass, in love and self-devotion, into the spontaneity of a second nature ": ${ }^{4}$ in the Sermons this is eloquently emphasised.

The theological bearing of Moral Idealism arises in the need of an Infinite Spirit to support the ideal of finite Spirits: an Infinite Spirit itself self-determining and Real: differing from the finite in its infinite or absolute character. In the moral life the solution of the opposition between "the natural and spiritual, the actual and ideal, the individual and universal nature of man " 5 is only partial. This arises from the unrealisability of the Ideal in its infinity, and our having to be content with approxima-
${ }^{3} 1$ st Edition, p. 256.
2 P. 259.
${ }^{3}$ P. $276 . \quad{ }^{4}$ P. $2 \pi \%$.
${ }^{5}$ P. 291. 
tions: "social morality, even at the best; love and self-sacrifice, even if they reached the point of the absolute extinction of any private self-will, are the identification of our individuality, not with an infinite, but only with an indefinitely progressive life." 1 The solution is to be sought in the present realising of the Ideal beyond ourselves in God. Now it is the very essence of Religion that in it "the infinite has ceased to be merely a far-off vision of spiritual attainment, an ideal of indefinite future perfection, and has become a present reality." 2 Our religious life means that we have found in God that the ideal is real, that the finite is 'suffused with the presence and life of the Infinite.' 3

But if Caird says all this, is he not Intuitivist? And if so, what does the explicit opposition to Intuitivism in Lecture II. signify? The answer to this question makes clearer the cardinal point of his position. He agrees with the Intuitivists that in religion we have the stupendous privilege of rising out of the finite, and of finding the ideal become real. Intuitivists rest here, in perfect satisfaction; here is both their religion and their philosophy. But Caird thinks that there is a power of probing deeper still; that power is Reason or Thought, which in face of this experience asks, with all respect, But is it true? Is there such an Infinite and Ideal Being? The answer of the Intuitivist is not final $:^{4}$ it is Thought only which can give the final answer. ${ }^{5}$ Religious experience goes with Feeling, Imagination, Morality, into what is to be explained, and explanation means allowance or rejection by Reason. For himself he finds an affirmative answer; and all is well.

In the depth then of self-consciousness, and, at just one stage less of profundity, in self-determination towards an ideal life, Caird's Transcendentalism finds the rocks on which it erects the edifice of belief in God. It claims that it comprehends both the infinite and the finite elements which we find in religion. In progressive knowledge, and progressive life, within the consciousness and life of the Infinite, the problem is solved.

In the subsidiary chapters of the book Caird shows what he thinks of the other types. Especially interesting are the rejections (1) of Feeling on the ground that we must find an element of knowledge for foundation; (2) of knowledge of the

1 1st Edition, p. 292.

${ }^{4}$ Pp. 57, 58.
2 P. 294.

${ }^{5}$ Pp. 61, 62, 175, 188 ,
3 P. 294. 
Intuitive kind as not being what it professes to be, immediate, and as being of that empirical character which it professes to transcend; (3) of knowledge of the Demonstrative order, the Proofs, as only furnishing 'steps by which we rise to knowledge,' but not carrying us all the way. The Ontological argument, which by its insistance on seeking reality in thought is in close kinship with Transcendentalism, is dismissed as confined to the mind of the individual thinker, his Consciousness of himself as individual, whereas Transcendentalism substitutes "a thought or self-consciousness which is beyond all individual selves, which is the unity of all individual selves and their objects, of all thinkers and all objects of thought." ${ }^{1}$ As indicated (p. 29), the Ontological argument held the ground by its partial reference to thought until a true and comprehensive reference should be forthcoming. It could not go beyond a subjective notion; while transcendentalism furnishes ' a necessary existence and reality.'

Every return to these Lectures increases admiration for them as a masterly exposition of a type of Theism which in other hands has proved difficult for trained thinkers and beyond comprehension for the majority of general readers, as is painfully evident in the perpetual issue of perplexed criticisms and irrelevant refutations. To determine how much of the prolific work of German idealism is here condensed and how much is due to the author himself would yield no substantial gain for our knowledge of this school. The book is no transcript; its masculine style and confident tone stamp it with the character of work which issues direct from the thinker's mind, from whatever source the dominant conceptions were acquired. It shows that the principles of Transcendentalism are human, and can be separated from German clothing. Let any reader take the two constructive chapters on the Speculative Idea and the Moral life, and he must feel that Idealism is one of the modes of Theism which the British mind as well as the German can conceive, expound, and invest with attractive and impressive character.

$\S 2$

CaIRd, Edward: Evolution of Religion, 1892 ; Essays, 1892 ; The Critical Philosophy of Kant, 1st ed., 1877 ; 2nd ed., 1889

It might be that the amplest view of Dr. Edward Caird's method would be obtained by collecting what he says in his 1 1st Edition, p. 158. 
voluminous Commentary on Kant, though it would be difficult in places to decide whether what is said is in elucidation of Kant or is the commentator's own opinion. But we shall do better perhaps to refer to the views enunciated directly in his Gifford Lectures on the Evolution of Religion. In these lectures, as he holds that evolution shows movement towards some true form of religious belief, it falls to him to state what that form is, to give a Theism of his own: although in an historical work he shows it more in result than in formation.

His sixth lecture is on the Idea of God as the beginning and end of knowledge. To him as to his brother there is necessity for a universal principle as 'the most real of all things,' the 'source of all other reality': it is the most universal of ideas, but so far is it from being abstract that it is the 'fullest of meaning' and is 'continually fertile of new meanings': 'it excludes nothing, but includes and explains everything.' Here again, it is the principle of unity in all consciousness which is the essence of the idea of God. It is hidden in the germ at the beginning of knowledge, it shows itself in 'all the conflict and reconciliation of self and not-self,' it expands, and in returning upon itself becomes more truly itself. "The idea of God in its purest germinal form-the form which is at the very root of all the other forms of it-is the idea of the unity presupposed in all the differences of the finite, especially the difference of self and not-self, of inner and outer experience." To trace the evolution from this 'germinal' form is the purpose of the course of lectures.

In development from this beginning it is obvious that the stress might be laid either on the subjective side of this difference or on the other side; accordingly Dr. Caird examines religions to see on which side their stress is laid: he finds it to be on the outer world in the Greek religion, on the inner in Buddhism, Stoicism, and the religion of Israel: while the mission of Christianity is to combine both, i.e. Christianity when rationalised, when expressed in its philosophical and moral significances.

Dr. Caird's own Transcendentalism enables him to throw light on the import and value of Kant's onslaught on the Proofs. Its force depends upon Kant's dualism as between the 'logical' and the 'empirical' ${ }^{1}$ it is the 'con-natural wound of Kant's system' that he did not see that his distinction between perception

${ }^{1}$ Kant, ii. p. 120. 
and thought was only relative: his polemic avails therefore only against his immediate predecessors and their assertion of identity between thought and reality. Kant's endeavour to storm their position by reviving once more the assertion that existence was precisely what was not thought ${ }^{1}$ was an absolute 'inversion' of the true result which his work has enabled his successors to achieve: Transcendentalism steps in to enjoy what he thus cut himself away from. So that in the unity of experience which the Transcendentalist asserts is found that very idea of God as a 'perceptive understanding' 2 which is the core of the speculative position.

The Moral Theism recognised by Kant is freed by Dr. Caird from its individualism, and the Divine Spirit becomes immanent as well as transcendent, while the ideal Community of spirits is no more merely ideal but is a reality.

Dr. Caird's treatment of Beauty is specially important and interesting. The Imagination most beneficently serves to brighten and guide the childhood of man and of the race until a time for 'earnestness' comes. "The age when poetry is truth .. . must yield to the age when it is discerned, as by Plato, to be only a 'noble untruth,' a truth of idea which is untruth of fact." ${ }^{3}$ Disillusionment must come, and the only remedy is the rising to a true conception of the relations of 'the objective and the subjective consciousness.' Dr. Caird will not allow the resort to poetic imagination for the purpose of filling in whatever religion may fail to secure from reason. He protests against the 'value-judgment' theory: and sets it forth as if it were luring us into the acceptance of the theoretically false under the guise of the practically true. And he insists that the true office of Imagination is to work conjointly with Reason, clothing the Universals with concrete forms but always so that it be remembered that "No great art could ever live if it ceased to regard itself as one with truth and goodness." 4

There is everywhere the impression that Sensibility, Feeling as such, is of little account for a philosophy of religion. In the treatment of Beauty, that Sensibility has a claim of its own is what is repudiated: Sensibility must follow the lead of Reason and Morality; happiness must wait upon earnest truth and noble conduct. On the other hand, very notable is the assurance

${ }^{1}$ Kant, ii. p. 122.

${ }^{3}$ Evolution, vol. i. Lect. xi.
2 P. 129.

${ }^{4} \mathrm{Ib}$. 
with which this great teacher of philosophy stands forth in an age of perplexity and announces as the result of his long-continued meditations that a rational being who sees what rational means is of necessity a religious being. No Mystic could be more confident, and indeed Dr. Caird regards Mysticism as in fault only in being too eager ; it outstrips thought ' and discounts its future gains.' But with his Spiritual Idealism he has reached out so far that on the essential point there is no future gain remaining to be won : conviction, rational conviction, is secured.

I have felt a special difficulty in even attempting to indicate Dr. Caird's position. When a Theologian presents his results (1) interwoven not only with his own philosophy but also with that of another in an intricate network of exposition and criticism, and (2) shown in operation in an historical construction, we have not before us the scheme of a 'Theism.' If Dr. Caird should care to give us a methodical treatise such as Dr. Martineau's, English theology would be greatly his debtor.

\section{$\S 3$}

Green, T. H. : Introduction to Hume, 1874 ; Proleyomena to Ethics, 1883

In these Introductions we find Green's philosophical position: and as the issue is belief in a Supreme Principle we have the source of a Theism, which, however, is not worked out beyond the fundamentals.

From the spiritual principle which, he holds, must be supposed to be expressed in Nature, and to be involved in our own knowledge, there arises an apparent dualism between ourselves as knowing and the principle of nature as known. Knowledge implies a spiritual principle: so does Nature. This is resolved in an eternal self-conscious principle manifesting itself in both. What is perceived emanates from a like consciousness, an intelligence, a spiritual principle. After illustrating from what is involved in our reading a book with the presumption that we are in search of a 'meaning' and have a capacity for extracting it, he says: "May we not take it to be in a similar way that the system of related facts, which forms the objective world, reproduces itself, partially and gradually, in the soul of the individual who in part knows it? . . . the attainment of knowledge is only explicable as a reproduction of itself in the human soul, by the consciousness for which the cosmos of 
related facts exists in a reproduction of itself, in which it uses the sentient life of the soul as its organ." 1

On the active side it is in the freedom of man as intelligence that we have our idea of a free Cause; and in the ideal of Goodness we cannot rest without a personal embodiment, progressive and eternal.

God is this Spiritual Principle: the presupposition of Knowledge, of Freedom, and of Moral Goodness, and of Nature. His reality carries with it the reality of all these: remove it and they vanish into appearances, possibly illusions. Upon the Ethical consciousness Green's interest was concentrated, taking it both in the Moral and the Political sphere. His work upon Locke and Hume was done to vindicate his metaphysics against empiricism, and he could then turn to Ethics. He wanted to know what was the philosophy of life, the best life for man : but the German genealogy of his idealism made him uneasy until he could show to the English mind how it stood towards the characteristic work of the great English and Scottish schools of empiricism. In Ethics he considered that there is a serious gap in Butler in the absence of a theory of Will as freedom in distinctness from natural action, and the consequent 'dichotomy' of the moral activity as if man were a 'ready-made compound' of conscience, self-love, and benevolence; the relations of the factors being treated by Butler in a vacillating way. By indicating where Butler himself had a glimpse as through a loophole into higher regions, in his Sermon on the Love of God, Green sets his own position in line with the ethical thought endeared to the English mind; and considers the reduction of philosophy to ' a sort of movement of the absolute thought' to be 'the one essential aberration of Hegel.' '

His treatment of 'religion' as the sphere where the Imagination with Feeling comes in and gives the ideas expression in finite forms is the same as that of the Cairds, but Green brings religion into the heart of his conception of spirit. Altogether Green keeps in contact with more of the concrete of experience than the Cairds. His spiritual principle presents itself very directly to us as evoked by the necessity of explaining ourselves and the world as our ordinary living experience. Taking his own statement in $\S 14$ and reading it with $\S 73$, as Mr. Farebrother suggests, 3 this

\footnotetext{
${ }^{1}$ Proleg. p. 76.

${ }^{2}$ Essay on Popular Philosophy, in Works, ed. 1885.

${ }^{3}$ The Philosophy of T. H. Green.
} 
is the impression, and other passages confirm it. Explanatory efficacy for life, not for bare consciousness, seems to be his criterion of truth.

We do not seem to have to get away at all in order to reach the Infinite. The Cairds do not think so, either; far from it. But they sometimes leave us, I think, with the impression that we have made a far journey; and this is what is alleged against them by their objectors. In Green we seem kept with our foot on the terra firma of fact and life, notably our own ethical life, our activity as free subjects trying to do our duty and pressing on towards our ideal, with all our fellows round us. It is true that this is only the order for us: that in the order of real existence the Divine principle comes first, and self perhaps last of all. But we are most affected by the order for us: so the impression made by one who so strenously works from spirit, in our self and in nature, as the object of our knowledge and the source of much that interests us, is that the regressive movement is more potent for belief than the progressive. Our thought keeps running back to God: not from God to ourselves, but from ourselves to God. Green said himself that John Caird's procedure is a sort of 'Sunday of speculation, not a weekday of ordinary thought.'

We may suggest that this is due to the difference between the Scotchmen and the Englishman. The Scotchmen were setting out their philosophy with the traditions of Scottish Intuitionalism in their minds: the Englishman, with those of English Empiricism. The Scottish treatment is akin to Calvinist Theology, from God to man: Green's to Anglican Theology, God manifest in the Church of the Incarnate Word as a source of practice and life. And so Green became quite naturally not the parent of Transcendentalists of the Hegelian kindred but the foster-father of such Idealism as is found in the writers of the Lux Mundi Essays.

\section{$\S 4$}

Strong, T. B. : Manual of Theology, 1892

In this general view of Christian Theology we have a vigorous and realistic assertion of the Transcendentalist position at about the same level as Green's. The character of Theological inference is indicated in the statement of the transcendental method: he is not going to ascend out of experience to 
an object: but to show that the idea of God is involved in experience, which cannot be understood or explained intelligently without it. The idea stands at the beginning of knowledge, it is present all through the process which it guides, and it emerges enriched at the end. It is at once premise and conclusion: we do not first set before ourselves a godless world and fit the idea of God upon it: we try the conception of a godless world, set it by the side of a world dominated and penetrated by the idea of the Supreme Spirit, and see which of these is the most coherent and intelligible. In this we proceed on a line parallel with the way in which we decide whether human life is personal or not.

His first step is to establish this by metaphysics. In philosophy we are in search of a principle of unity, which we obtain by the transcendental method. From this position Mr. Strong is able to retain the traditional 'proofs,' but he gives them a fresh shape. In the Cosmological and Teleological we seek to show this principle as Causal, and we establish the principle as First Cause, in process, and as Final Cause. In the Ontological we posit that " a condition necessary for thought to be true is also necessary for existence." The idea of God, the spiritual principle, cannot in any other way be 'proved.' And as in experience, by the nature of the case, it cannot be shown to be realised in fulness, we have as our alternative an ever-increasing realisation, a progressive approximation.

In Moral Reason the same line conducts us to our goal: our personal life, self-determining towards Goodness, is explicable only in reference to a principle of Goodness, and to man as in communion with it.

Mr. Strong does not dismiss the Asthetic consciousness (Beauty, Art), but places it between the Metaphysical and the Moral. Of itself it is not entitled to speak: "Its result is for the most part pantheistic : the personality of God may easily be left aside; and there is no firm line drawn between the evil and the good."

The Consensus supports Theism so far as it goes.

In relation to Faith and the element of Choice, Mr. Strong's position is shown in his defence of bias in Theology 1_' a readiness to admit the existence of God,' as against our being under compulsion as in Mathematics or pure Logic. That is, the Theistic assumption which explains the world we cannot be 
compelled to make at all: but I take Mr. Strong to think that if we do make it we shall certainly prove it, for the reason that in comparison of a Theocratic world with a godless one coherence and consistency are all on one side, and these are criteria of intellectual truth.

Discipleship of Green appears in Mr. Strong's designating the moral interest of Theism as 'loftier' than the 'purely metaphysical ' ${ }^{1}$ and it is so because it concerns not a 'complex of facts' and of laws (which cannot be broken by us but which might be altered without any result other than that of requiring us to readjust our formula), but a 'society of free persons' (with laws which can be broken by them but cannot conceivably be altered). And farther, it is moral consciousness which brings us into contact, 'into true and friendly communion,' with the personal Power from which it comes. 'Likeness to God' is 'the ideal to which the moral agent tends.'

In his concluding pages Mr. Strong touches upon what he regards as the difficulty of the Transcendental method, that of really finding that the Idea is embedded in the concrete we know. He finds of course the standing difficulty of the happening of things in time, which he considers to be "the hinge of all the questions which we have to regard as finally insoluble": 2 having started with absoluteness, eternity, transcendentally given, he has to show how from them we explain time and temporal process, while the empiricists would all along have told him that his trouble arises from beginning at the wrong end. But also he does not go with the majority of the school, because he finds Matter still on his hands. He has not adopted the spiritualisation of it, but says that we are left in a permanent dualism. Farther consideration of this point, such as Mr. Illingworth, for example, gives, may perhaps satisfy Mr. Strong that the Time difficulty was really the obdurate one.

The volume covers most of the ground of Christian Dogmatics, and but little space is at disposal for Theism. But that little is occupied with successful exposition, and stamps the theology with a broad philosophical character expanded with great freshness and marked ability.

As to method, has Mr. Strong made this quite clear to readers? In a very sympathetic review of this book Professor Banks of Headingley regards him as using only the ordinary scientific hypothesis. This is,

${ }^{1}$ P. 29.

2 P. 423. 
of course, an interpretation against which Mr. Strong has apparently guarded himself by stating that he was employing a method 'distinctly theological': ${ }^{1}$ the theologian requires a 'new method.' ${ }^{2} \mathrm{He}$ distinguishes it from scientific method by regarding this as engaged in placing facts in order, and making no inferences which are not of a verifiable character. The new Theological method deals with the same facts but rests them all on a condition or assumption; verification is not possible in any other mode than by showing that the whole mass is now cohesive in a way that it was not before. This condition or assumption is then held to be justified. But the terms have to be very subtly stated if this assumption is to be differentiated from a hypothesis, and on p. 419 Mr. Strong seems to agree that all sciences have 'to make room for their chief facts at the outset,' in the same way that theology does.

\section{$\S 5$}

Stirling, J. H. : Gifford Lectures, 1889-1890

This veteran Scottish Hegelian has given a set of lectures quite at the opposite pole to the stately and regular treatises of the Cairds. He does not expound a philosophy de novo or show one in historical application; he gives his views a distinctly historical setting of their own by employing them to freshen and restate the old proofs, of which he says uncompromisingly they are Natural Theology. His constructive aim is to draw them out of their old connections and invest them with new force and form by means of his Transcendentalism. And as he does this he ranges far and wide in giving us their old setting and establishes a new hold upon them for the mind which sets great store on drawing the present out of the historic past.

The Ontological argument is reaffirmed as the assertion of the necessary demand of thought for the identity of its object with reality. Causality he holds to be a valid category in its form of dependence, and he finds design in the world and a legitimate inference from this to the Designer. In the theology of nature he says that it is wholly dependent on the design argument: 'the clash of battle is here.' And he combines all three as 'undulations of a single wave.' The arguments are clearly stated, and he incorporates much history, the Greek originals are copiously treated, including a vigorous defence of Aristotle as having an Idealist element and a true Theology.

His plan does not include discussion of other bases.

$$
{ }^{1} \text { P. } 5 .
$$


Critically he examines what he chooses to call a positive phase of scepticism in Hume, a comparative in Kant, and a superlative in Darwin. The scrutiny of Hume's reduction of Theology to teleology and of his rejection of the argument from analogy on the ground that it should show likeness in the cause, after he had told us that anything is able to produce anything, is quite in Hume's own vein. The Proofs are defended from Kant's attack by showing that his polemic was not based on general principles, but on Kantian; and not on true Kantianism either, but on Kant's own personal system with the relics of others still sticking in its mass. As an antidote to Kant's chapters it is effective. The criticism of Darwin is on the same line of ad hominem argument.

No one would recommend these lectures to any one desiring a first introduction to Natural Theology, but to the student they furnish pithy and varied reading. Scholastic phraseology is quite eschewed, and there is indulgence in a grim humour which shows that not a little of Carlyle's characteristics are Caledonian rather than entirely personal. The idealism gives a high tone; and a genial toleration for honest thought, with a determination to look at the bright side of men's thinking, render the lectures suggestive and stimulating.

\section{$\S 6$}

Momerie, A. W. : The Being of God, 1886

This small volume is marked by great clearness of exposition, some of the substantial issues of Transcendental Theism being expressed with admirable lucidity. Its brevity prevents it from being more than a rapid statement of results.

Dr. Momerie begins with Consensus, which he treats very fairly, with Clifford, Lord Amberley, and 'Physicus' (Romanes) as opponents. He turns aside to dislodge Materialism and Agnosticism, and then lays down the argument from Design as his own first position: this he considers indicates 'supernatural purpose,' while the 'unity of design' leads to Theism: but he allows only probability to this argument, as there are things out of harmony, and matter and space have to be presupposed. But the main position is the Transcendental one, that an Infinite Personality is presupposed in experience of any kind and in existence of any kind. We have to suppose an infinite Understanding if the system of things is to be intelligible at all, and that it is 
intelligible even Science supposes. The questions then are, Is the Infinite Thinker God? i.e. is He Good? Experience says so, on the whole our feelings respond and our moral ideals yearn for this as truth. Is this anthropomorphic? Well, it is not the lowest but the highest part of our nature to which we resort, and we can do no more. So that we have as sum a Supernatural Purpose probably disclosed in Nature, an Infinite Thinker certainly disclosed, and Goodness longed for by the highest part of our nature.

For an introduction to the method of this School, Dr. Momerie's little book has the prime qualification of clear-cut thought and terse and well-compacted phraseology.

\section{$\S 7$}

Lindsay, James : Recent Advances in the Philosophy of Religion, 1897

In this book we have a view of the recent literature of our subject with an outlook into the future, in the light of one who is himself a Transcendentalist. As he does not give us an elaboration, a few indications will suffice to show what is the writer's own view.

His chapter on Personality as 'the Archimedean point' from which the Transcendental method operates, is strongly written: Personality is a developing Unity, more and more known as experience proceeds. He will not admit limitation as applicable: this is no question of quantity at all.

He fixes the starting-point for Theology above nature in absolute or definite Personality: not by going backward shall we gain knowledge of the Absolute Spiritual Personality, but by assuming it and going forward: in this way it is progressive, illuminative, interpretative. So, for Causation, any real Cause is above phenomena, not among them, and Teleology should be used when we go forward to apply First Cause. As he also insists that the Ontological argument avails to find a ground for First Cause, he thus vindicates the three-Proof system.

Dr. Lindsay is able from his own transcendental standpoint to review recent thought with great freedom, and to entertain high expectations for the immediate future of religious philosophy.

The volume is by its nature largely composed of criticisms of types of thought and of individual systems. 


\section{$\$ 8$}

Tylen, C. M., Professor of History and Philosophy of Religion, Cornell : The Basis of Religious Belief, 1897

This is a statement of Transcendentalism from the threefold basis of speculation, ethics, and æsthetics. The Ethical basis appears sometimes to be regarded as the most important, but as the Metaphysical is treated first and emphatically asserted, I have placed him in this School. The first half of the volume-itself not lengthy-is occupied with the Science of Religion, which leads Dr. Tyler to claim that recent Anthropology supports decisively the antiquity and practical universality of religious belief in some form or other.

In the philosophy of religious belief the method is Idealist, and is Transcendental in a somewhat imperfect manner. If an Idea is such that reason demands it, validity is claimed for it: 'subjective necessities' of thought are strictly related to objective realities. ${ }^{1}$ The existence of a Personal Ultimate Being is such a demand and the Idea therefore corresponds to Reality.

In our own experience the primary reality is Self, known in Self-consciousness on both objective and subjective sides. It is not known by Intuition; although Professor Tyler uses the term, he does not mean by it what Intuitionalists mean. $\mathrm{He}$ says expressly that we are not conscious of self "by directly gazing at" 2 oneself: but "it knows itself in its acts of knowledge." This "Transcendental self or personality or ideal Ego, a Person we ought to be or become," 3 is always before our phenomenal self, which, indeed, is always striving towards it. This is the "Key to the metaphysical position," 4 and he holds that all attack upon it has failed.

From the idea of our own personality we rise to that of Absolute self. But Dr. Tyler is disappointing here. He says that the reality of Absolute self is 'implicated' in that of the finite self : but all that he makes explicit is that man "feels himself to be dependent upon a Being who cannot be inferior to him in his personality." 5 This is a confused statement, and does not contain what is required to justify our rising to the Absolute. Just where the Cairds have applied so vigorously the transcendental method, Dr. Tyler misses his footing. When he

I P. 121.

${ }^{2}$ P. 123.

${ }^{3} \mathrm{Ib}$.

${ }^{4}$ P. 124.

${ }^{5}$ P. 126. 
turns to the other finite reality--the World-he is elliptical again: he at once 'finds himself face to face' with a new Causality, that of other than self, and knows that it is of the same kind as his own, since "agencies or powers must be homogeneous to limit each other." But where did he get this category of Causality from? From our self, he says; but we had not heard of it before, nor of the maxim about homogeneity.

In a few lines he states as alternatives Transcendence and Immanence, and decides for Immanence, but only in a few assertive phrases. He then briefly contends for Intelligence and for Final Causes.

The Ethical and Æsthetical grounds are stated very well: his Ethics is idealistic, of course; from the categorical imperative and freedom there is inference to belief in a Perfect Being. The Asthetical ground is not so 'sure': "our standards of Beauty are more obscurely discerned than our Moral standards " ${ }^{1}$ though he is confident that Beauty is not wholly a state of subjective pleasure caused by the objects we perceive, but is "something universally valid, something objective in things beautiful, something that reveals the infinite Soul of the World, who appeals to the soul of man." ${ }^{2}$ It is found in Nature,which is no 'dead mechanism,'-in animate life, and in moral character. These beget within us 'infinite longings' only to be realised by 'communion with the universal Soul.' Variation and progress are recognised in both ethics and æsthetics; but "the more refined the spirit of man becomes .. . the nearer we approach a consensus of judgment concerning things Beautiful and Good." 3

He uses Absolute in the sense of implying all relatives, not of excluding them: and he follows Lotze in holding that the self-consciousness of God does not depend upon the existence of a finite world, but that perfect Personality necessarily belongs only to an Infinite Being.

His conclusion is clear-cut- " Reason compels me to hold that there is an Ultimate Reality: the ground of both Mind and Matter; and that this Ultimate Reality is a unitary Being and a personal Being." 4

He then turns to Feeling, and under the term Love treats of the supreme Feeling of the Soul and the impossibility of satisfying
'P. 189.
${ }^{2}$ P. 190.
${ }^{3}$ P. 202.
4 P. 119. 
it without a Perfect Personality. He associates Feeling with Duty, as 'mitigating its rigour.'

And he concludes by reference to history where the Good Will is seen "immanent in the whole process of the world." 1

This is not an original contribution to Theism of this type, nor a clear and explicit exposition of the usual procedure. The Metaphysical treatment is defective and elliptical, and we cannot be quite sure that his mode of inference is really the Transcendental mode. We seem to rise direct from self to the Absolute, and even to have many ways of doing this: so he even uses the term Intuition, "through the reality of our personality we have the intuition of the Divine Being " ; ${ }^{2}$ and again, "through our self-consciousness we have an intuition of the self-consciousness of the Absolute": this is mistiness. Then again, Transcendence is stated as an alternative inconsistent with Immanence, and therefore rejected. Dr. Tyler seems sometimes to feel more confident when on the Ethical ground than when on the Metaphysical, and to be grateful for the 'Ethic-Metaphysic' of recent times. And, again, he says so much for Feeling that he seems carried right away into the Esthetic School. It is, he says, 'the highest God-consciousness of all'; it 'elevates Ethics into Religion.'

This book is, in its philosophical part, brief and rapid: and, as it seems to me, neither decidedly transcendental nor clear in its exposition of that method, but at times leaning strongly towards Ethical and even Esthetic Theism. But it is interesting from being connected with study of the Science of Religion, and as an indication of the kind of philosophical treatment which is congenial to a modern mind well versed in the lore of religious history.

Rotce, Josiah, of Harvard: The Religious Aspect of Philosophy, 1st ed., 1885 ; The Conception of God, a Discussion, 1895, with three other American Professors

Professor Royce is engaged in elaborating a Theism on Transcendental lines. But we are precluded from the necessity of any examination of it by the fact that he himself deprecates any finality for what he has attained so far. His first book was brightly written and has been a good deal read, but in the later

$$
{ }^{1} \text { P. } 26 \% \text {. }
$$

2 P. 120. 
volume cited he dissociates himself from responsibility for it now, and as there is no one else to take it up, little need be said. Martineau gave it some attention, and the reflections I was prepared to make upon it were much in accord with what Martineau said. All that need be done in the case of a writer whose views are still in process of formation, is to indicate the trend in which his thinking has proceeded, so far as it is given to the world. As a living teacher of philosophy who is deeply penetrated with theological interest, and is a remarkably lucid writer, Professor Royce deserves attention, even though unable to ask for a judgment on his work in its present stage.

He opposes the old Demonstrative method as no longer of any service : it was reduced by Kant to the status of 'mediæval artillery.' He takes experience in general and moral experience in particular, and, working transcendentally, infers that a definite Thought or Thinker is necessarily arrived at.

This is the result of positive thinking, Dr. Royce holds, but he enlarges upon the special method of working up to it negatively: by asking ourselves what is meant by 'error' we can get a clear conception of a doctrine of 'truth': this leads us to see that truth must be a system, and that this implies an all-inclusive Thought: "all truth is known to One Thought, and that Infinite." In a parallel way he works up to Infinite Goodness by considerations based on our consciousness of Evil. From conflict we infer harmony: and this is only possible to a Supreme Intelligence which sees the whole conflict, and judges between good and evil. Only by reference to Infinite Thought therefore can we explain truth and error; only by reference to a single Universal Will can we get support for the moral conflict in which we are engaged.

As compared with the Ethical, I think the Speculative argument is exhibited as fundamental: it is in terms of Intelligence, Thought, that he expresses himself most freely. And in the later volume he takes the step of planting his Theism upon a proof of Omniscience as the primary character of the Divine Being. Not exactly that he asserts that it is primary, or that this is the only way of Theism; but it is the way that he himself delights in. In the early volume there was a tendency to lose the Individual in the Divine, and even in the Social community; but in the later, Dr. Royce sets himself 
strenuously to work out Individualism. His final position is yet to be made clear, and in his Gifford Lectures, passing through the press (1900), this is no doubt being done. ${ }^{1}$

\section{\$10. Quasi-Transcendentalism}

Schurman, J. G., Cornell University : Belief in God, 1890

Dr. Schurman's main stress is on the Intellectual side, as the only source of results compelling assent; and I take his method to be that which I have designated Quasi-Transcendentalism.

His datum is the universe in general, which is regarded as alive throughout in a gradation which culminates in the spiritual beings in whom self-consciousness appears. It is necessary to

${ }^{1}$ Dr. Royce's Gifford Lectures, The World and the Individual, 1900, come to hand in time for us to see the position to which he has been working. The change which is most marked is his passage from the speculative conception by which he regarded the Supreme Being as primarily Thought, to a representation of Him as Will and Thought in combination. Making good use of recent psychology, and assisted, as he handsomely acknowledges, by the work of Mr. Bradley, he incorporates will or purpose into the essence of the experience to be explained, and therefore into the essence of the ultimate Being in whom the explanation is found. He elaborates his meaning of an idea: it is not a bare presentation to a knowing mind, but an idea appears in conseiousness as having the significance of an act of Will. It is in this way that the 'internal meaning' of an idea is formed, and this is the primary meaning; then there is the 'external meaning,' the reference to some object supposed to be independent; this is secondary. These two meanings appear at first to be in hopeless contrast, until a third stage is reached in which the external meaning is reabsorbed into an internal meaning, and this is final. In calling himself an Idealist, he means by idea the result of this completed process.

He then proceeds from the imperfection of every idea to the presumption of a complete idea, i.e. to an Absolute Being to whose Will the idea belongs-"An individual type, consisting of the embodiments of the wills represented by all finite ideas" (p. 341). He is keenly alive to the need for making good the character of Individuality: conscious minds are individualities, and the ultimate Being is an Individual in whom all individuals are comprehended: "the Individual of Individuals' (p. 40). In this respect his position is the same as that of those who labour to vindicate Personality in man and in God.

The Conception at which Dr. Royce arrives is a complete one, aecording to the Definition used in this enquiry: the Supreme Being is Absolute; is Necessary; is Transcendent, for $\mathrm{He}$ is the Completion of what in finites is ever uncompleted ; Immanent, for finite conscious beings express His Will and His Thought; Personal or 'Individual'; and Good or Perfect. His position he himself' designates an 'Idealistic theory of the Absolute' (Pref. viii). As the work of one who advances from Hegelian Idealism by means of Mr. Bradley and of recent psychology, guided by a determination to obtain a clear correlation of personality and absoluteness, Dr. Royce's view has a comprehensiveness which gives it a high place in this school, and I regret that the recency of the appearance of this final stage of his development has prevented a fuller account of it in the text. 
observe that in 'spirit' he does not include essentially love of Goodness: the essence is self-consciousness, self-determination, self-existence.

His principle of inference is interpretative hypothesis, not demonstration, nor induction, and not true Transcendentalism: but hypothesis accepted provisionally for subsequent verification, after the manner of the sciences: "there is no higher certainty than that possessed by the working hypotheses of science;"1 by these objective certainty is attainable. Intellect with its demand for unity rightly seeks such a hypothesis in order to explain the world: the idea of God would do this, so the question is, In this idea have we a vera causa? He claims that we have, because the human spirit is such, and indeed is the only vera causa we know: and so a world-spirit is given to us by what he calls 'anthropocosmic Theism.'

His division of the subject is, God as 'Cause or Ground of the World,' as 'Realising Purpose,' and as 'Father of Spirits.'

I. By Causality he means Permanent Cause, not First Cause; one of his strongest points is that there is before us no beginning or end of the world, which is a constant and eternal thing. Nor will he consent to rise out of it: he holds to an 'intra-mundane Cause' of an 'uncreated world': at the heart of the world this Cause is to be sought. He follows Lotze in holding to efficient Causation, now actually in process, and embracing phenomena in a reciprocal activity which is wholly incomprehensible except in reference to an Absolute Being. As the world is active, so in this Being is life, and by reference to ourselves we regard it as spiritual. The world then is the 'eternal self-revelation' of such a Spirit.

II. In Teleology he takes what is practically an $\grave{a}$ priori position. The Divine Spirit in whom we have learned by Causality to believe, when expressing himself will do so in purposes and designs constituting order and relations in the world. The teleology we gather from empirical observation only goes so far as to furnish a means for bringing in the analogy with our own activity: but so far as this is forthcoming there is verification of the great hypothesis. Still, the ends we can clearly see by observation are few and 'not very important': in organisms ${ }^{1}$ P. 43, ed. 1896. 
we catch our best glimpses; and, on the other hand, the dygteleologies are very great.

Yet he expounds clearly the bearing of Natural Selection as not casting 'ends' out of nature, but only altering our knowledge of the 'location and mode' of operation; and he holds that Evolution has revived and strengthened the anthropocentric view of Nature.

It is, however, a great defect that he treats of external nature apart from moral nature, which he takes up in a separate discussion as belonging to heart or soul, not to mind. Hence the extreme meagreness of the 'glimpses' from empirical observation.

III. In his treatment of the Ethical aspect I freely confess myself unable to trace consistency. He depreciates it in comparison with the Causal argument, which proceeds without it; he expressly declares that from Goodness we only get access to the nature not to the existence of the Divine Spirit, that Goodness is an attribute or predicate with which we 'invest' him. And yet he seems to allow that if we knew absolute moral law we could make the inference: "How can we explain man's recognition of moral law apart from an innate endowment which is as distinctively characteristic of the human spirit as intelligence or will, and which, like these, must have its ground in one infinite Spirit?"1 "Such a permanent and essential factor in man's make-up must have its ground in the eternal spirit from which we derive our existence; God, therefore, is a God of righteousness." And against derivative Ethics he affirms a moral ideal in which "we have believed something absolutely worthful "; ${ }^{2}$ and goes on to assert a conviction that no ethical school really denies 'the transcendent ideal.' ${ }^{3}$ How this is reconciled with the statement that only the cosmic argument finds a basis and that there is "no anthropic proof' 4 is beyond my discovery. ${ }^{5}$
1 P. 246.
2 P. 242.
${ }^{3}$ P. 243.
4 P. 238.

5 The whole passage (p. 240) is: "The fact will have to be recognised sooner or later that there is no anthropic proof of the existence of God." (A dictum which sweeps Ethical Theists from the field.) "The moral idea of man may throw some light upon the moral character of God, but is powerless to prove the divine existence. More than this I cannot concede to Dr. Martineau. . . . The true state of the case seems to be that, though conscience does not prove the existence of one infinite spirit, it yet obliges us to invest it, if existent, with the predicate of righteousness. If there be a God, moral laws seem best explained as expressions of his 
Taking his three lines together we have then what he, aptly enough, calls anthropocosmism, the idea of God as universal Spirit, a scientific hypothesis, which is fortified by its interpretative power when teleologically applied, and is invested with farther predicates of Goodness or Love by our moral consciousness.

We do not find strict necessity for religious Belief, although the hypothesis is placed in a position which entitles it to be accepted by 'all conscious minds.' ' True, we have also a statement which carries Dr. Schurman right over into the Transcendental camp, "as eternal ground of all existence, God is not only conceivable but necessary to the thought that goes far enough in its analysis of given reality." 2 What could the pure Transcendentalist say more? But this is not consistent with the general tenor of the lecture on the Logic of Belief.

The Theism is wholly of Immanence: 'intra-mundane,' there is no Transcendence, not even the partial Transcendence of Martineau, which is expressly repudiated. This is the only world, and to think of a First Cause outside it is out of date. ${ }^{3}$ His own expressions are Universal life, World-soul, Eternal spirit, the Father of spirits. Infinity is asserted, but without any discussion; Personality is, of course, of the essence but it is not inclusive of Goodness; inference from Goodness, as we have seen, is not consistently treated.

As compared with master-works, this exposition is somewhat immature, as the inconsistencies above indicated show, and some further reflection is required, which may be expected from the author as time proceeds.

\section{$\S 11$}

\section{Balfour, A. J. : The Foundations of Belief, 1895}

The superficial perspective of Mr. Balfour's book is, perhaps, not quite that into which the contents shape themselves after it has been read. The forefront should rather be occupied by the subject of his Part III., the endeavour to remove the controversy from the close court where Reason sits alone into the open air where men judge and feel in all the plenitude of their natural

nature. It is difficult, if not impossible, to think that the everlasting ground of things should be indifferent to those virtues and graces that constitute for us the chief end of man." [I have italicised some expressions which seem to me to be the Key-words of the paragraph.]
2 P. 37.
${ }^{2}$ P. 148.
3 P. 176. 
faculties. Mr. Balfour protests against the procedure which has placed Reason in a position beyond her power to fill, and beyond her rights as well. Under the somewhat discredited name of 'Authority' he groups many non-rational influences which are to be reckoned with in the formation of the beliefs of mankind, and he sees no justice in the claim made that Reason should dispossess them all and ask men to disbelieve everything save what comes from her mouth. It is this general attitude of mind which, we think, should have been vindicated first; the transition to the next great purpose of the book would then be easy, namely, the criticism of Naturalism as a particular scheme offering itself as sole determinant of human belief, in the name of Reason. And then we should pass to the constructive endeavours of the author; the indication of ampler foundations than mere reasoning can supply for the support of what is credible, and worthy of credit, by mankind.

The first stage of Mr. Balfour's own Theism is the setting out of the Personal life of man as the basis on which beliefs are to be built, and religious belief among them. To do this he takes two steps: first, a vindication of all the elements of life as against the pretensions of the Intellect; and second, a vindication of a wider 'personality' than that of the conscious activity of the individual.

First : his reduction of the pretensions of Reason. Belief of course must in part follow knowledge; what we know we also believe, as for example in the history of England: but it also goes beyond knowledge, and that not only in procuring fresh objects but in investing objects already before us with new character and meaning. Mr. Balfour writes: "If faith be provisionally defined as conviction, apart from or in excess of proof, then it is upon faith that the maxims of daily life not less than the loftiest creeds and the most far-reaching discoveries must ultimately lean." 1 Faith here is that part or kind of belief which is in excess of knowledge; and Mr. Balfour insists on recognising its operation in the maxims of common life as well as in the most elevated region of belief. He protests against the popular philosophy of recent times which has claimed the whole of belief for reason, all else being deemed 'bigoted' and 'absurd.' He indicates ${ }^{2}$ ways in which this 'illusion' has come

1 Part II. c. iii.

${ }^{2}$ Part III. c. ii., and references to Part I. c. iii. and Part II. c. iii. 
about, and caustically examines the capability of empirical and demonstrative Reason for accomplishing such a result as has been claimed; alleging the inadequacy of the senses, the inferiority of Intellect to Instinct and Habit as a guide, and the failure of reason to establish itself in a final philosophy. But men are not really much occupied in seeking reasoned-out systems of thought or codes of rules: "Systems are and must be for the few," he says; "the majority of mankind are content with a mood or temper of the thought." What other sources are indicated? Many might be pointed out even within the compass of the individual's own natural endowments. But in order to gain a full view we had better at once take into account the second step of his procedure, his widening of the import of ' personality.'

Secondly, then: what is our personal life? Mr. Balfour takes a wide sweep: we are not solitaries, we live in 'psychological climates,' which may be those of 'a generation, an epoch, a whole civilisation,' or, narrower, of 'a sect, a family'; "at every moment of our lives as individuals, as members of a family, of a party, of a nation, of a Church, of a universal brotherhood, the silent, continuous, unnoticed influence moulds our feelings, our aspirations, and what we are more immediately concerned with, our beliefs"; " ${ }^{1}$ "Custom, education, public opinion, the contagious convictions of countrymen, family, party, or Church," 2 operate naturally, producing even our interior assents. The error and the absurdity are transferred, in a vehement passage, ${ }^{3}$ to those who suppose that each individual has produced his own codes of belief or of conduct. Reason, then, is reduced to a share, and only a 'slender' share, ${ }^{4}$ in the processes within the individual life, and the individual life itself is placed only as a nucleus round which a complex of forces gather to form the personal life which is the true basis of beliefs, religious belief included.

Mr. Balfour has chosen the term Authority as the designation for the mass of non-rational influences. It is not appropriate to such of them as are processes of the individual life, the 'physiological and psychical processes' which co-operate with reason in 'manufacturing the convictions necessary to the conduct of life.' We usually understand by authority influence from outside ourselves. But there is not much to cavil at in
${ }^{1}$ Part III. c. ii.
${ }^{2} 1 b$.
${ }^{3} 1 b$.
$+\pi$. 
the term, at any rate until a more appropriate one is offered by the critics. Its use enables Mr. Balfour to draw our attention away from the conscious and deliberate reasoning which gives us some of our convictions to the unconscious internal processes and the outside influences acting upon us in our place in the social community, which, in his opinion, count for very much more.

What other processes does he set out? We could have desired a systematic view of them, but as this is not forthcoming we must collect such as are indicated. 'Needs' is his favourite word-" Some wider scheme which though it be founded in the last resort upon our needs, - and they should not be the lowest, - shall at least take account of other needs than those we share with our brute progenitors." With him it is our ethical and æsthetic needs, the demands of our moral nature and of our feelings, particularly the highest feelings, which are to be associated with such satisfaction of Reason as he allows. $\mathrm{He}$ does not cut Reason out: such Reason as that of Leibnitz, Kant, Hegel, and even Spinoza 'interests the world' and is a part of the enjoyment of our life, but an enjoyment limited to a few. Still, a certain interest in Reason belongs to us all. He wants, then, an Object of belief which shall be adequate for the satisfaction of all these 'needs': the human race, for instance, is inadequate for this purpose: if that were our highest object our practical ideal would be 'dwarfed and beggared,' because we have 'aspirations and emotions' which have been in the past 'nourished upon beliefs in the everlasting and the Divine ' ${ }^{1}$ but man as Naturalism shows him is 'an accident, his story a brief and transitory episode' ${ }^{2}$ and this, alleged as in itself a conclusive obstacle to our accepting a naturalistic account of man, shows that Mr. Balfour's view of 'needs' is that they require something everlasting and divine to rest upon. Reverence is indispensable, and the object must be one which will inspire it. Of Ethical needs he says that some would be "effectual for their purpose though nothing corresponding to them should exist " ${ }^{3}$ but there are some which would work more harm than good unless we can sustain the belief that there is somewhere to be found a Reality wherein they can find their satisfaction, and he instances the need of bringing the individual into harmony with the Community. In the summary of propositions which he sets over against Naturalistic dogmata, he aims at

\footnotetext{
1 Part I. c. i.
}

$2 I b$.

${ }^{3}$ Part Iv. c. vi. 
statements which will indicate sources of satisfaction for Reason, and names infinite love, the realisation of true spiritual freedom, the enjoyment of beauty, and the sense of the infinite value of the soul. He therefore claims credence for 'immutable verities of an unseen world,' not because of the requirements of the 'fleeting fancies of the individual,' but because of the demands of "those characteristics of our nature, which we recognise as that in us which, though not necessarily the strongest, is the highest; which, though not always the most universal, is nevertheless the best." 1

Such being the basis, our personal life in this social fulness, what is Mr. Balfour's next stage? what is his method of construction? It is the Method of establishing truth by the justification of presumptions, the kind of proof which Kant called Transcendental. Kant applied it to knowledge and to morality: a Transcendental truth was one which must be supposed in order to explain experience as object of knowledge, or, practically, to give a foundation for morality. It is here applied to the whole range of personal life: that is true, is real, which must be supposed in order to yield satisfaction to the manifold needs of our complex nature, especially at its highest and best, in its permanent and abiding features. Mr. Balfour directly affiliates it with Kant's method, and asks whether "somewhat similar inferences are not fitting portions of the provisional philosophy he is endeavouring to recommend." 2

The Empirical method of reason we know that Mr. Balfour rejects with emphasis; Intuitions engrafted upon sense-perceptions in the eighteenth-century manner are also dismissed; Transcendental Idealism, as establishing a Divine Unity from the unity of self-consciousness, is too abstract. Why not take the whole of experience together? It is a fact, with all its aspirations and needs; and it stands in vacuo, so to speak, unless the presumption of a Divine source and a Divine foundation be accepted. Take it in another form of expression. "Review each of these departments"- - science, ethics, æsthetics - "in turn, and . . . compare its position in a theological setting with that which it necessarily occupies in a naturalistic one." ${ }^{3}$ Does not this mean that as the introduction of certain ideas (theological) gives coherence, significance, interpretation, order to the matter of science, ethics, and æsthetics, incoherent

${ }^{1}$ Part Iv. c. i.

2 Part Iv. c. vi.

${ }^{3} 16$. 
and uninterpretable otherwise, a 'proof' of the validity of those ideas is obtained? And is not this the point of the transcendental method?

Readers of Mr. Balfour's book have been led away from his complete position, I believe, because he has always written against Transcendental Idealism, and he devotes a chapter to adverse criticism of it in this very volume. And they have hastily seized upon his appeal to Authority as his central point, and warned him that all the woes of Naturalism are brought upon him by so naturalistic a procedure. But, as I read it, the appeal to Authority is simply a demand that the basis be broadened in the two directions I have indicated, from reasoning to non-rational processes within the individual, and from the individual in his abstract simplicity to the personality in all its social nature. Certainly the attack on Transcendentalism is not easy to fit in with Mr. Balfour's own method. He objects that the recourse to self-consciousness is abstract; he will not follow into that recess: well, it is not therefore untrue, or even useless, so far as it goes: why should he not accept it for what it is worth? he might very well do so and incorporate it with his own method, and should do so unless he can disprove it. This, it is presumed, he considers that he does, although his reduction of it to Solipsism is hotly resented by its advocates as a misconception of it, strange in so acute a mind. He objects, farther, that if not too narrow, it is too wide; if it issues from out of 'barren' abstractness it cannot be stopped from taking up all experience, the evil and the good. But surely he cannot take both these objections? If he stands by the latter, it is the very objection which he must himself meet, for it applies to his own procedure. 'Needs' must be satisfied: surely this is width itself? And though he does go on to specify ethical, æsthetic, religious needs as those which he has in mind, he does not give that attention to his discrimination of what he would maintain from what he would reject that should have been given: nor does he indicate what he would do with those ' needs' which are ignoble and base and lead to evil, and therefore do not fit into the setting which otherwise he claims as the beneficent effect of the introduction of religious ideas. A canon of discrimination was never more necessary for any one than it is for himself.

Mr. Balfour's attitude to Reason is of special interest. $\mathrm{He}$ feels called upon expressly to denounce the claims of Empirical 
reason: it presumes to shut the door to knowledge of a supersensible world, and his pages gleam and sparkle with epigrams when he has to expose its pretensions; to Demonstrative Reason he can be more respectful, because its aims are worthy though it cannot achieve them: Transcendental Reason he opposes as advocated by Hegelians and especially by Green, and yet he himself resorts to a Method of Proof which is not mere assertion, but a mode of inferential process, and therefore Rational after its kind. For the modes of Reason which do profess to bring us into contact with things 'everlasting and divine' he has, of course, no scorn such as that aroused by the impotence of Empiricism. He regards the philosophical systems of the world as interesting constituents of human life, each of them an effect of its age, and attracting attention and regard in ways not dissimilar to that by which literature generally wins its admirers: something rsthetical is at work in making a man choose between Locke and Spinoza. He would hardly object, we may suppose, to a similar treatment of Methods of Theism. He likes his own, and issues it to the world as a man issues a poem or an oratorio, and leaves it as the expression of his mind, to influence others according to their own inclinations and tastes and 'needs.' But against limitation to the sphere of mundane interests, utilitarian moralities, and empirical conceptions, the whole force of his personality is directed.

We should like to know whether Mr. Balfour has an ideal of what human personality at its best should be, or whether he is content to place the great minds, the choice spirits of the race as a varied host, a galaxy of spirits differing from one another in glory? There are signs that beyond the differences be still believes there is a 'transcendent Truth,' which should be common to all, the varieties coming from the 'half-seen vision' and the 'halting expressions' 1 which limit even the loftiest souls : that there is really "a divine Spirit, Who is the Ground of all being and the Source of all change." 2 This belief is, though not Rational, 'worthy,' and therefore entitled to acceptance with reverence, and to the allegiance of our moral nature. ${ }^{3}$ More

${ }^{1}$ Part Iv. c. iv.

2 Part Iv. c. v.

${ }^{3}$ The affinity of Mr. Balfour's procedure with that of the Value-judgment method now in vogue among Ritschlian theologians is striking enough in itself; and we are not surprised to find that he received a cordial welcome from the great Ritschlian, Kaftan, as soon as his book appeared. See Critical Revieu, vol. vi., 1895. 
than this we cannot look for from one who regards unification of beliefs as only an ideal. If once he ventures to call his work a 'theory,' this is rather a casual expression than his real valuation of it. His book is rather to be taken as a philosophypoem, an expression of personal faith, quasi-æesthetic, to be admired or the opposite as the reader is disposed. If a man, for example, finds the dirge-like poems of doubt and agnosticism more to his taste than Mr. Balfour's bright pages, he may assert his right of choice with Mr. Balfour's full acquiescence. Only, if his satisfaction is limited to what the phenomenal world can yield, he must accept as a correlative fact that his own needs are shallow and his character ill-grown. For $\mathrm{Mr}$. Balfour himself science, ethics, æsthetics all make demands so extensive that satisfaction can come only when man acknowledges himself in the presence of a Divine Being.

\section{$\$ 12$}

Saunders, T. B. : The Quest of Faith, 1899

An interesting variant of this Type is the Theism of $\mathrm{Mr}$. Bailey Saunders in so far as he expresses himself positively in a volume which is in its main purpose critical. Mr. Saunders takes the Object of religious belief to be a Postulate which offers itself as an explanation. "Does the hypothesis of a morally perfect power . . . offer a more satisfying explanation of a greater number of the aspects of life than any other, or rather than universal doubt, the only other possible alternative?" 1 Mr. Saunders accepts the hypothesis, and does not scruple therefore to use the term revelations as descriptive of the contents of religious belief : it is ' a heritage of revelations ... reflected from the great Reality.' ${ }^{2}$ But, on the whole, his other term 'discoveries' is more congenial, for except for this Postulate the whole content of religious belief is regarded as the product of the believers' minds: a subjective character is diffused over the whole field. Like Science and Art and Morality, Religion is the product of men's opinions and desires. He does not take the producing agency to be mankind at large, the vast majority of us are merely recipient in this respect: it is the opinions and aspirations of highly gifted individuals which successively add new content to Religious belief. His position

$$
1 \text { P. } 90 .
$$

${ }^{2}$ Last page. 
is closely akin to that of Sabatier, who, like Mr. Saunders, considers that this is the main outcome of the Kantian position in Theism.

Mr. Saunders' volume is replete with well-expressed criticisms. $\mathrm{He}$ deals with the inconsistencies of Huxley's various utterances; with Mr. Balfour, in whom he finds, as I have done, more of Transcendentalism than Mr. Balfour himself seems aware of, and with whom, indeed, Mr. Saunders is in close affinity; with Dr. Fraser, whom he praises highly; with Drummond; Butler 'once more'; Mr. Lilly and Mr. Wilfrid Ward, as Romanist writers; and with Mr. Crozier, as representative of the witness of History; and he includes also a lucid exposition of Teleology in the light of recent philosophy.

LECKY, W. E. H.: The Majp of Life, 1899

This volume contains the following paragraph (p. 212), which admirably describes this mode of Theism:-

"Young men discuss religious questions simply as questions of truth or falsehood. In later life they more frequently accept their creed as a working hypothesis of life; as a consolation in innumerable calamities; as the one supposition under which life is not a melancholy anti-climax; as the indispensable sanction of moral obligation; as the gratification and reflection of needs, instincts, and longings which are planted in the deepest recesses of human nature; as one of the chief pillars on which human society rests." 


\section{CHAPTER IV}

\section{Type IV.-EThical Theism}

\section{$\S 1$}

THE considerable transfer of influence from Intellectual to Ethical Theism with which we have to deal has perhaps been effected by German Idealism more than by any other assignable agency; that is to say, Idealism has been the agency in the higher region of philosophical and theological thought. But there have been powerful currents working below, all the while, and England has had its own stirrings in this respect. The intellectual schemes of the eighteenth century became less and less competent to satisfy the religious needs of men. The piety which accompanied them was inadequate in the face of the rising evangelical fervour in the Church and in its offshoots in Methodism. The kind of public spirit which accompanied them -not meagre or low in the century which founded our Indian Empire and established our colonial supremacy against the world-was yet giving place to a spirit more humane in temper, powerful enough, though checked by the spirit of wildness in the Gallic Revolution, to cause the nineteenth century to develop quickly the Abolition of Negro Slavery, Reform of the Criminal Code, the widening of the Constitution, the admission of Romanists to political franchise, and Freedom of Trade.

The number was constantly increasing of those whose minds seemed unimpressed by the purely Demonstrative type of Theism; who were turning to ask what is the truth as to the Divine Being from quite other considerations than accounting for the creation of the world. What they desired was, a support for belief in Goodness, a belief which would lie at the heart of trust in the future success of those moral and social reforms which aroused their ardour, and furnish support for attributing religious character to the 'world' 
in some degree of consonance with the ascription of its creation and rule to God as revealed by and in Jesus Christ. Some turned clear away to Revelation: for them there was no intermediate territory; but others found the required terra firma in the moral side of human experience, the declarations of conscience and the broad features of moral order disclosed in the history of mankind: and others still, in the depths of feeling or of mystical intuition. It is those who found their resort in the Moral aspect of life who come into the type of which we are now to take some examples.

Men of this mood said that they found demonstration, though forcible, inadequate for conviction; if left alone to fight with intellectual scepticism the issue was dubious. Others went farther and were not afraid to say that the issue on the purely intellectual basis had been lost. Intellect must therefore cease to press for the supreme place in the formation of belief. At most it led to a hard and unworshipping certitude: it might demonstrate an Almighty power, a wonderful Designer, but this was quite subordinate in interest to the question as to Infinite Goodness and Perfection: so subordinate that it failed to arouse vital interest in seriously religious minds. In England there is evidence, I think, that the bias was setting in all through the century towards this Moral attitude, and it became very pronounced as the nineteenth century advanced. The experience of Robertson of Brighton was widely representative. Intellectual doubt possessed him even to distress of mind; but where he touched bottom was on Morality and Goodness: on that he rested. "I have got so far as this: Moral goodness and moral beauty are realities, lying at the basis, and beneath all forms of the best religious expressions. They are no dream, and they are not mere utilitarian conveniences. That suspicion was an agony once. It is passing away." ${ }^{1}$ And this rest was not secured by induction or demonstration: "the evidence of goodness and wisdom in the external world is very questionable in some moods at least." ${ }^{2}$ It was in his moral consciousness, therefore, that he found rest. ${ }^{3}$

${ }^{1}$ Life, vol. i. 111.

216.341.

${ }^{3}$ As many readers may have a special interest in the way in which religious belief was vindicated by this independent and sensitive mind, a few references to his Life and Letters may be useful. In I. 340, he repudiates Demonstrative Theism; 162, he stands on the Moral basis as above; 227 , he has a 'strong light' about Beauty, as leading through the sensuous to Moral beauty, and so, on 


\section{$\S 2$}

Texple, F., Bishop of London, afterwards Archbishop of Canterbury:

The Relations between Religion and Science, Bampton Lectures, 1884

This is a vigorous statement of 'Religion' as the issue of thought upon Intuitional Ethics. The writer considers himself to be bringing to logical conclusions the doctrine of Butler, and of Kant's Practical Reason. $\mathrm{He}$ does not aim at covering the whole ground of Theism as the title would suggest: Metaphysics is set aside, and among the sciences, Mathematics; the case is taken up as it stands between the Empirical sciences, both external and mental, and religious knowledge or belief. So far as this explicit statement is concerned, Dr. Temple may have a metaphysical argument for Theism; and I shall show that he seems unaware that in these lectures he is really assuming one, as if there were no other before the world. Perhaps he ought not to be classified by means of this piece of work alone; but at any rate, as I have not become acquainted with any expressions of his attitude to Intellectual Theism in other places, so I must guard myself by saying that in this statement I have in view Dr. Temple only as the author of these Bampton Lectures.

Religious knowledge is taken to include belief in a Being who by his personal Will has made the world and now rules it: but this Being is himself in a world beyond sense-knowledge either of physical or of mental phenomena. But besides our sense-knowledge we have a faculty - or rather a general capacity -for receiving from this world beyond us expressions of the Ruler's Will, which to us present themselves as commands. They are addressed to our conscience which is the means of appreciating them and presenting them to us, and also to our Will which is invited to adopt them. In the exposition the order is reversed, from the Moral law exhibited by conscience and presented to Will, we infer that there is a world from which supersensual presentments can issue, and that such commands

to the Infinite; 163 , he has a yearning for the thought of infinity, and prefers Pantheism to Deism; but he illustrates the conflict that comes from the attempt to rise into a supersensuous world ; in Letter 29 such an attempt is made, but his grip on personal life prevents it from carrying him off his feet, and leads him to cling to the lower actualities of life, while still (II. 208) haunted by "the dream of the unfound beauty." $\mathrm{He}$ had been reading Fichte; but the transcendentalism which combines the supersensible and the sensible worlds he had yet to seek. 
are of supreme authority for us, that being addressed to Will, they must be taken as coming from Will, personal and supreme. As basis then, there is first the law of Duty; then its character of supremacy, by right inherent, not 'as accidental fact'; then the personal nature of ourselves, and therefore of its source - "A supreme Being claiming our reverence and asserting Himself to be the Creator, the Ruler, and the Judge of all things that are." 1

The advance made upon Butler's psychology by a doctrine of the Will, and the philosophical employment of it by Kant, is taken advantage of: it explains the duality which had been left unresolved in Butler between the authority of Moral law and its power. Dr. Temple regards Moral law as disclosed by Conscience (Reason), and presented for acceptance to the Will, which is essentially Free.

The way in which Intuitional Moralists provide for Infinity and Necessity of the Divine Being is clearly shown by Dr. Temple: it is because of the absolute character of Moral law. "The moral law in its own nature admits of no exceptions. If a principle of action be derived from this law it has nothing to do with time, or place, or circumstances; it must hold good in the distant future, in planets or stars utterly remote, as fully as it holds good here and now." ${ }^{2}$ As compared with this, the other sciences give us knowledge of a lower order, phenomenal and transient and relative, and they cannot enter into competition with the absolute commands disclosed by Conscience. Against Positivism and Naturalism; therefore, Intuitional Ethics makes Theism secure.

At the same time the Natural course of the world brings us confirmatory evidence: "the creation in its order and its beauty and its marvellous adaptation of means to ends, confirms the assertion of the spiritual faculty that it owes its origin to an intelligent and benevolent purpose. . . Making allowance for the limited range of our knowledge, the general aim of the whole is seen with sufficient clearness," 3 and "the scientific doctrine of Evolution, which at first seemed to take away the force of this argument, is found on examination to confirm and expand it": and he devotes two separate lectures to the maintenance of this. In this teleology the moral order is not explicitly examined. As soon as purpose is vindicated in the
1 P. 231.
${ }^{2}$ P. 48.
${ }^{3}$ P. 234. 
physical creation, Dr. Temple passes to the beneficent effect of Christian Revelation as an historical influence, without a separate reference to the moral order apart from that.

There is no primary appeal to Feeling: the existence of Moral Sentiment is affirmed, but that follows upon Conscience in "a peculiar sentiment, which, except towards its command, is never felt in our souls," 1 and the sentiment is named, after Kant, reverence.

The argument from Beauty is touched upon in a few broad strokes, not independently, but as a part of Teleology.

Three lectures of the eight are upon the Christian Revelation, and the last lecture is a summary of the course.

A criticism of these lectures would show that in several ways they are pronouncedly Ethical of the Intuitionalist type, though including some of the gains of modern Idealism.

In the first place: the attempt is made to keep out metaphysics, but it is not successful. In the following positions certain metaphysical views are assumed: Causation includes Power, as against Hume; ${ }^{2}$ Space is a Reality, against Kant; Personal Identity is a thing in itself, an exception to the relativity of knowledge, against Empiricism, and Kant also ; ${ }^{3}$ Morality is absolute, in no way derived from observation of phenomena, which it entirely overrides, and in opposition to Empiricism the assertion of immediate imperativeness. Duty is opposed to the idealism of Goodness; in Will, Freedom is metaphysically explained $;^{4}$ and his metaphysic of knowledge gives him a supersensuous sphere which is above nature. A partition of the field of belief between empirical knowledge and religious faith is attempted. But it would surely be against all usage to claim Causality, Space, Personal Identity, and Morality for religious faith, and only Empiricists can allow that they are empirical. They belong to the intermediate territory between science and faith: 'Metaphysics' or Philosophy, therefore, has not been dispensed with, as attempted.

By removing these fundamental ideas into the sphere of religious faith, and not giving any place for metaphysics, philosophy is handed over bodily to the empiricists: physical nature and mental are both alike limited to sense-knowledge and the sciences; uniformity is matter of pure observation, and the fact is we are 'surprised' to find it. ${ }^{5}$ Although Dr. Temple
${ }^{1} \mathrm{P} .47$.
${ }^{2}$ Lect. 1.
${ }^{3}$ Lect. II.
${ }^{4}$ Lect. III.
${ }^{5}$ Lect. viII. 
insists on the unity of physical and spiritual nature, this does not lead him, as might have been expected, to full appreciation of Divine action as immanent. This comes out strongly in the lectures on Evolution. The solution there reached is pointedly Deistic, as the following expressions show: if a long process is to be accepted, then "The Creator impressed on certain particles of matter which, either at the beginning or at some point in the history of $\mathrm{His}$ creation, $\mathrm{He}$ endowed with life, such inherent powers that in the ordinary course of time living creatures such as the present were developed": ${ }^{1}$ "it seems in itself . . something more befitting Him ... thus to impress His Will once for all on His creation, and provide for all its countless variety by this one original impress, than by special acts of creation to be perpetually modifying what $\mathrm{He}$ had previously made": "one original creative act"; "the original act of creation." This is a form of Deism; not that form which refers all change to after-interposition, but one which places all Divine activity in origination, and then removes the world from His influence. How different from Butler's protest against the Deism of his day, sagaciously warning us against this very form of it : "Confessing an Author of Nature," "we must not deny Him because His government is uniform," nor " deny that $\mathrm{He}$ does things at all because $\mathrm{He}$ does them constantly." 2 Dr. Temple himself sees the need of a more immanent view; and his references to Teleology are so turned, in his concluding chapter, eloquently enough; but this is not what he had said when at close quarters with Evolution.

A strong point of gain on Butler is the clear acceptance of the fundamental place of the Will in human nature, and in the formation of belief particularly; of such belief as Theism needs at least. Of moral law he says: "its acceptance is bound up in some way with our own wills. How far it is a matter of choice to believe or disbelieve it is not possible to determine. The will lies hidden as it were behind the emotions, the affections, the nobler impulses. But though it be impossible to say precisely how the will is concerned in the spiritual belief, there can be no doubt that it always takes part in such belief. It is the keen conscience, it is the will that can be moved to its depths by the conscience, that grasp most strongly the certainty of the law of duty." 3

${ }^{1}$ Lect. IV.

2 Anal. 1. ii.

${ }^{3}$ Lect. vili. 
And at times Dr. Temple runs very near to the position of the Personal school. 'The perception of things spiritual varies from man to man, and depends on character, and involves action of the will.' 1 And sometimes, frequently indeed, he goes close to what I have called Intuitivism by using the phrase 'spiritual faculty.' His abundant use of the term 'spiritual' is indeed more than he is entitled to. We have seen that his basis is the moral consciousness, and he illegitimately enters upon the enjoyment of the wider term more appropriate to the Personal and Intuitivist schools when he uses 'spiritual' as if it were the equivalent of moral, a proceeding hardly in accordance even with ordinary usage, to say nothing of philosophical.

Another strong point is the uncompromising claim for universality of moral law over and above all that is actual. $\mathrm{He}$ does not use the term Idealism, nor does he join with the modern Idealists in their ethics of Goodness rather than of Duty. He takes his stand clearly with Butler and with what is perhaps the more prominent side of Kant's ethical position.

Clear in expression, strong and impressive in tone, it is a vigorous assertion of Moral Theism. It is marked prominently, first, by the Individualism of its basis, and, second, by leading to what is essentially the Transcendency of the Divine Being, who appears not so much in ruling the world of phenomena as in creating it: governing it, in so far as that is done, only in the moral consciousness of individuals, and this not so much by disclosure of Divine Excellences as by the exhibition of Supreme Authority.

\section{$\$ 3$}

Fraser, A. C. : Philosophy of Theism, Gifford Lectures, 1894-96

Released from the duties of his Professorship as successor of Hamilton in the Logic chair at Edinburgh, and fortified by the prolonged studies embodied in his Editions of Berkeley and Locke, Dr. Fraser brings into order his ponderings on the final problems in these lectures on Theism.

We might place Dr. Fraser with the Traditional School, for he includes both the Cosmological and the Moral lines of argument, but the stress on the moral consciousness is so marked in comparison with that on consciousness in general 
that it would be misleading so to refer him; his goal is the satisfaction of Moral Reason, and he is a Theist because he finds that Goodness is in 'the very heart of things.' Causality pure and simple is operative in producing his own assent, although it does not go so far as to establish personality in his Theism. ${ }^{1}$

His conception is quite the full one: Immanence and Transcendence, with Pantheism and Deism both excluded; Infinity; Personality; and Goodness: and, on the Moral side, Necessity.

Dr. Fraser's doctrine of Cosmology is expressed under the category of Dependence: thus he is not involved in any obligation to determine whether the course of nature ever had a beginning or not; and fortunately so, for he does not consider that our data enable us to answer the question. But whether it had or had not, at least it has characters which show it to be dependent: and we require a self-determined or uncaused cause, independent of change, supernatural. In the chain of 'natural causes' the term cause is employed only as a metaphor: a true cause is always an active agent. What we see in nature are, strictly speaking, only 'signs' of causation, not active agents. Behind the system of natural signs is a meaning which to us is necessarily spiritual. A Spirituality on which the natural system depends is therefore its inevitable suggestion.

In our knowledge of ourselves we have direct cognisance of true causes: and therewith the key to the whole situation. In 'Man Supernatural' we have self-determining cause: here we have consciousness of self-assertion over against the outward system of signs: and from this we find ourselves conscious of the presence of a Final Power, which we take to be Conscious Spirit, like ourselves. "The Spirit of man incarnate in his body is the symbol of Infinite Spirit incarnate in the Universe."

But we go deeper when we take up our Consciousness on its Moral side. Our aims have character, we pursue Goodness. $\mathrm{He}$ also lays stress on our sense of Obligation: we are 'in responsible exercise of deliberate will.' The inference from this is "a perfect Moral personality."

Teleology is vindicated, of course. Mechanical causes being only signs, the true causes are purposive agents. Nor does the change of working by catastrophes rather than by slow processes, or even by a single process, make any difference. This 
teleology it is, Dr. Fraser says, that he has held in his mind during all his twenty-five years of work upon Berkeley and Locke. The teleology he accepts includes order in general, and inherent teleology in organisms: adaptations do not give an independent argument, they are examples of the general order.

Infinity is essential. Well aware as he is of the antinomies which arise when we attempt to realise it, and very deeply impressed by "the appalling sense of the mysteries of infinity," he is careful to state how he regards it. Infinity has two sides, and men differ as to which they are looking at. In an impressive paragraph he writes:

"One finds the Infinite casting its dark shadow in Lucretius and in David Hume, in Schopenhauer and Herbert Spencer. ... Infinity turns its divine side to Plato and Pascal, to Descartes and Bacon and Locke, to Kant and Hegel and Lotze, and to the great religious thinkers, especially of Christendom; it unconsciously inspires martyrs and saints of the Catholic Church; it is latent even in the physical faith of the leaders of modern natural science, and in the common experience of the senses in all human beings." 1 For himself, he says that it is in his mind throughout all his work.

He states it carefully, as 'practically knowable' though not ' infinitely cognisable.' The idea of it 'is included yet not completed in human understanding.' And in this sense he claims to be at one with Origen and Augustine, with Chrysostom and Gregory Nazienzen and 'the great thinkers of the Catholic Church.' But to enter into cognisance of the infinite is beyond us : that would be to 'deify ourselves.' 2

There are expressions where Dr. Fraser comes near what Transcendentalists might claim as utterances in their favour. But he separates himself from them in his first course, and in his second he devotes a lecture to stating his objections. Transcendentalism, he thinks, presumes to place us at the divine centre, but does this by carrying us into 'abstract necessities of reason' beyond the actual mysteries of experience. As refutation he says solvitur ambulando: if there is a scheme in which a perfect

${ }^{1}$ Series Ir. Lect. 1 .

${ }^{2}$ Professor John Watson does actually claim that our knowledge is of the same kind as that of God : though not of same degree. International Journal of Ethics, July, 1892. 
interpretation of experience is forthcoming, let us see it. That Hegelianism achieves this he cannot allow. ${ }^{1}$

The obvious lacuna in this exposition of Theism is the absence of reference to the spiritual community, the kingdom of God: the spiritual datum is the individual soul. $\mathrm{He}$ states the three ultimates as "Ego, Matter, and God," I. 39 ; again, "one's own ego, the collective aggregate of things around one, present in space, and commonly called the external world," and the Divine Being; "the human ego, the outer world in its temporal process or revolution, and the Divine active reason." As he states Locke's view to be 'God, finite intelligences, and bodies,' we cannot suppose that he had not the world of spirits as one of the objects before his mind: he must have set it aside as not an ultimate. And his mode of reference to the Consensus argument in the traditional way, as suggesting and confirming, not as entering into the structure of the argument, indicates the Individualism of his doctrine of spirit.

In the formation of Religious Belief Dr. Fraser admits a combination of interests : intellectual, emotional (from the sense of dependence), and moral. He presses upon us a very strong demand for rationality on the moral side: it is the task of Theism, at any rate, to make our belief intelligent, to show reason for it: and his contention is that this can be done when we bring into the front of our view man as a moral and spiritual being. In this sense Homo mensura is the key to intelligent Faith. Before Europe and America the question now stands, he says, between Pantheism, Theism, and Nescience. And that he casts the weight of his life of careful thought, his great learning, and his gravity of temper on the side of Theism is significant for the history of British thought.

\section{$\S 4$}

Seth, ANDrew : Theism, 1897 ; Lssays, 1897

Dr. Fraser's successor in the chair of Hamilton follows the same general tendency, that of Ethical Theism. Besides the

${ }^{I}$ In the preface to the second edition (1899) Dr. Fraser appears almost desirous to go over into the Intuitivist Type. He uses expressions which imply a factor of belief antecedent to thought, which it is for thought to make explicit. But they do not amount to a recasting of his position, though we should have liked to see them allowed for in the text of the lectures. 
purely philosophical works in which Professor Seth expounds Hegelianism and criticises it, in part disengaging himself from it, in part reshaping it, he has published a small volume on Theism, a volume of essays under the title Man and his Place in the Cosmos, and some articles in the Encyclopcedia Britannica, all abounding in luminous statements of points bearing on philosophy in relation to religion: and especially in acute and judicious criticisms of recent writers.

His own method is transcendental: such a Reality as is a ' necessary assumption' for the explanation of human experience must be believed in. But he declines to stake the issue on speculative transcendentalism apart from practical, and gives emphatic preference to the ethical side of experience. ${ }^{1}$ It is " the absolute value of the ethical life" which is the mainstay of religious belief. He thinks that Kant's resort to this is "the most important contribution of recent philosophy towards a vital Theism."

Yet he separates himself from Kant because Kant remained Deistical after all, having brought in religious belief in a Being outside of experience in order to procure a reconciliation between Happiness and Duty; and also because he was too Individualistic in his Ethics. On these points Professor Seth has learnt from Hegel. But Hegel himself comes in for discriminative treatment, and certain parts of his system and his method are adopted, while others are dropped. The result is, as indicated above, a transcendental Idealism on a basis mainly ethical. It should be noted that in the range of the term 'Ethical,' Beauty is expressly included as well as Goodness. Professor Seth strengthens his position by controversial contrasts, notably with Mr. Bradley's views; and he has searching criticisms of Naturalism as treated by Huxley, and of some recent psychology. And he has a valuable criticism on Mr. Balfour: the most penetrative of the many which have appeared hitherto. If Dr. Fraser's lectures are somewhat of the nature of a farewell message from a veteran philosopher, Professor Seth's essays may be taken as the precursors of more massive and solidly compacted work yet to come.

\section{§. Alsthetic (Beauty)}

The Mediæval Theology which prevailed in Europe had given but slight welcome to the Beautiful, and in the seventeenth

${ }^{1}$ Essays, c. vii.; Theism, p. 22. 
century, even in France, Cousin ${ }^{1}$ can find but one philosophical work on the subject. We could not expect that Empiricism would bring it to the front, and Cousin has to point out that Locke was followed by Condillac in not having a single page upon it. If French genius could so far suppress it, Englishmen would hardly be likely to stand up in isolated guardianship over it. But the resuscitation of this idea for the purposes of philosophy came not from France, but from Scotland, where Hutcheson and Reid made it prominent, and from Germany, where Kant gave it considerable room, though not a place in the front rank. Gradually over the modern spirit admiration for the Beautiful recovered its influence, and in the Romanticism of the early nineteenth century Shelley and Byron, Scott and Wordsworth, Chateaubriand and de Staël, Goethe and Schiller, caused literature to glow with it once more, although in British philosophy recognition still lagged, in spite of Coleridge.

In all this the course of Theism in England was parallel with that of philosophy generally. Every other aspect of things divine could raise up advocates and devotees save this. From many Theisms it was wholly omitted; in some it received a few chill words; in scarce any a genuine welcome. In less than a dozen of the systems treated in this book can it be said to stand in a front place.

The Cambridge Platonists had of course coloured their Intuitivism with a borrowed light: and that not only from Plato, but from Plotinus, who has a treatise on the Beautiful in his Enneads. It casts a glow over their pages, and the presence of it at times empurples their style. The large phrases of Sir Thomas Browne swell with it, as do the fanciful rhapsodies of Henry More, and even in the solemn mood of John Smith there is an ever-present sense of the exceeding Beauty of the Eternal.

In the eighteenth century the third Lord Shaftesbury has gained a special niche for himself by his clear insistance on Beauty in close association with Truth and Goodness, and therefore as an essential attribute of the Divine Being and a ground for believing in Him. A student of Art in Italy, and of Plato, his mind was carried away from his former tutor and lifelong friend, Locke. He begins his Ethics on the old line of inquiring not into Duty but into the Good; and in this he finds that beauty, fairness, admirableness, is a necessary element. He does

\footnotetext{
${ }^{1}$ Le Vrai. le Bcau, et le Bien, p. 134.
} 
not resolve Goodness into Beauty; but his insistance on the latter is marked. In reference to Theism, Shaftesbury found a decisive test in the fact that Atheism reduced the value of Beauty, while Theism gave elevation and grandeur to the aims of life and to the moral affections. The faculty for apprehending Beauty was its own justification, and Shaftesbury entered upon an investigation of the validity of the consequent belief in a Divine source for it. With the result of this he was so much satisfied that, in spite of some vague expressions of respect for Revelation, he was regarded as having abandoned that as superfluous.

Hutcheson contributed much to the philosophy of Beauty, holding the æsthetic sense to be universal and immediate: but he does not appear to have applied this to Theism in any noticeable way. Reid was evidently keenly interested in the subject, and gives a long and detailed account of his views in his Essay on Taste, ${ }^{1}$ vindicating both factors, the 'agreeable emotion or feeling in the mind,' and the 'opinion or belief that the objects have some perfection or excellence belonging to them': and the reference to Beauty formed part of what was the Moral argument, in his view.

Passing from the philosophers, we can see by referring to Shelley how the poets began to put in their protest for the rsthetic side of life. It was precisely during the dominance of a coldly rationalistic Theism in England that Shelley revolted from 'Theism' as it was presented to him. The rationalism of his day gave poetry no place. In Queen Mab, at the age of eighteen, he had said "There is no God": but in his Note he expressly says that he holds to a pervading Spirit co-eternal with the universe. In this Note and in his dialogue, 'Refutation of Deism' (1814), he opposes the 'demonstration' of a 'Creator.' He gives here no original anti-theism: what he says is from Hume and Spinoza and Godwin, and especially from Holbach, the French Materialist, from whom he makes copious quotations: and the Theists he is opposing are Paley and Stewart. And in his Prometheus Unbound he is protesting against a form of Anthropomorphism which represented a King of Heaven who bound the thoughts and aspirations of men in arbitrary bonds, and must be resisted by the spirit which dares to be free.

1 Intellectual Powers, Essay, viii. 
It is plain that he was chafing against distortions: and of these not the least was the deformity which comes when Beauty has disappeared from the object of worship. Current theology was missing that aspect of the sensible world in which Shelley perceived a beauty that to him was not less than sacred. His ardent imagination dwelt on what is admirable in Nature and in Natural man, and the thought of a Spirit behind these was to him infinitely finer and richer than the Theism of Paley based upon anatomical adaptations for utility, or that of Stewart upon intuitional and in some degree arbitrary commands of Duty.

\section{$\S 6$}

Ruskin, John

The writer of whom Englishmen will naturally first think in relation to this type of Theism is John Ruskin. It has indeed been his mission to reawaken among his countrymen a regard for Beauty: to insist upon it, to analyse it, to study its manifestations in Nature and in Art, with a persistence of purpose and a command of literary style which have made him one of the chief influences in the culture of the nineteenth century.

What Ruskin has to say of other sources of religious belief is of small importance compared with what he teaches on this source. He might himself claim to be as much a Moralist as a prophet of Assthetic, and certainly his view of Religion is profoundly ethical. But where he turned up new soil was in the field of Asthetic.

In Modern Painters, vol. ii., under the designation 'Theoretic Faculty, - by which he means $\theta \epsilon \omega \rho i a$, as higher than al $\sigma \theta \eta \sigma \iota s-$ he describes four sources of Beauty: the record of conscience; the symbolising of Divine attributes in Matter; the felicity of living things; and the perfect fulfilment of their duties and functions. I take these to mean Beauty of external nature in which attributes of unity, order, symmetry, vastness, infinity, and the like, are exhibited; the Beauty of Excellence of work done by organs or agents appropriate for its execution; the felicity of sentient beings; and Moral Beauty, as shown by conscience in human life, both personal and national. Ruskin is for objectivity: these qualities are in the objects: perceived by us. His Theistic employment of them is his opinion that in 
all cases Beauty suggests something Divine: External Nature is glorious as a symbol of God's nature; the felicity of animal life is evidence of 'his kind presence'; excellent working is evidence of obedience to His will; and conscience is His approving voice.

This is the general scheme of the thought which underlay Ruskin's belief in God.

In the very trait of enjoyment and worship through External Nature, however, it is a pathetic fact that Ruskin eventually found himself betrayed. He had built too much upon it, and when certain sad miscarriages in the course of life thwarted his personal affections he found External Nature unable to fill their place. "Morning breaks, as I write, along these Coniston Fells, and the level mists, motionless and gray beneath the rose of the moorlands, veil the lower woods and the sleeping village, and the long lawns by the lake shore. Oh that some one had but told me in my youth, when all my heart seemed to be set in these colours and clouds, that appear for a little while and then vanish away, how little my love of them would serve me, when the silence of lawn and wood in the dews of morning should be completed; and all my thoughts should be of those whom, by neither, I was to meet more." And yet men who have received unmeasured access of delight in life, and therefore increased power of seeing the divine, through Ruskin's manifold eloquence and insistance, will not believe that this betrayal was other than a temporary darkening of his spirit on that side, due, no doubt, to the abnormal strain laid upon his æsthetic nature in earlier life. But they will not think that this was such a gloom as to lead to the permanent quenching in him of the light of Eternal Beauty.

\section{$\S 7$}

A striking appreciation of the claims of Esthetic is found in Seeley's Natural Religion, a book of which something will be said in Chapter XI. The artist and the poet are men with that 'enthusiastic appreciation of something' which is the principal element in religious belief, in Seeley's view. It is not only something material and individual or their 'religion would be what has been described as Pagan': there is a profound appreciation of unity. Towards the end of last century a ' remarkable revolution' took place in this department of life; 
"from the time of Rousseau through that of Goethe, Schiller, Chateaubriand, Wordsworth, Coleridge, Shelley, Byron, down to our own age, poets have helped to make opinions, have influenced philosophy, social institutions, and politics." $\mathrm{He}$ dwells at some length on Goethe, indifferent to morality (or worse) and to theology, yet 'setting the whole above the parts and worshipping the unity of things much more than the things themselves,' and so having a 'religion' and a divinity: and on Wordsworth, a mind of simple and unworldly type, reverencing Duty, accepting much of the conventional in Theology, and yet above all 'the saint of the religion of Nature'; to whose heart there came ' a steadfastness, stillness, a sort of reflected or reproduced eternity' from 'the Eternal Being among whose mountains he wandered.' Of him Seeley says finely, "the higher literature was reformed in England by this rnan's fidelity to the object of his worship."

Awe, duty, love, are strong ties which bind men to 'other existences' than their own personal interests: Why, Seeley asks, should admiration be omitted from this enumeration? Has not ' the inspiration of the artist the character of religion, of a binding force such as destroys selfishness and sustains the Higher Life?' "The artist, literary or other, who in Walter Scott's time professed only to furnish amusement to the public and to be richly contented if they applauded him, now assumes the air of a priest and makes it a point of honour to speak of his pursuit as a cult." 1 This is the vein in which Seeley claims admission for the love of Beauty as a constituent of worship, a factor in religious belief. He is not occupied in his book in giving any theory of the Beautiful. His purpose is to point out the loftiness of the claim of those who are devoted to it, and to insist that in the religion of the future the Beauty of the Lord shall have recognition from those who would approach Him.

\section{§. Theologians}

Reference has been made to Mozley's treatment of Beauty in his University Sermons. In a similar volume Dean Church includes a sermon on the Sense of Beauty as a witness to Immortality; for the things that are beautiful there is no explanation if beyond death there is no Easter. And in his 
volume entitled Human Life and its Conditions, he points to Beauty in external nature, in human nature, and in human history, in all of which it is presented to us as beholders, and therefore needs explanation apart from the nature of the beautiful object itself.

Bishop Barry ${ }^{1}$ has a lecture on the Theology of the Imagination, considering it important though subordinate: with a position between Intellect and Conscience, and supplying a link between them: with 'much of the light of the one, and much also of the earnestness and glow of the other.' He too finds 'the passion for Art, the deliberate recognition of the sense of Beauty,' to be 'an integral factor in all high civilisation': and observes that we are now living 'in the midst of a movement of manifold Estheticism.'

$\mathrm{He}$ claims for Beauty a realm of law in spite of the great variety of its manifestations; and passes quickly beyond sensuous forms which do not 'awaken the mind,' to the Beauty of perfection and the Beauty of grandeur, the one with 'exquisite but calm and well-balanced pleasure,' the other with ' a strange delight, a sense of awe, of infinity, of mystery'; and he goes beyond inanimate Nature to the region of personality and character. This yields an intuition of Mind in the Universe : to some it is the old polytheistic divinities, to others an Impersonal Soul of the World, but to those who dwell most on the 'poetry of humanity,' a Personality. The action of Imagination becomes creative of new forms of Beauty, in which those who have achieved most success have always held themselves to be 'inspired'; not truly creators, but discoverers of the Ideas of a Mind which in its Perfection is what we mean by Divine.

$\mathrm{He}$ then shows how this motive to belief knits the others together, and has, besides, two special merits of its own: it is least crossed by the sense of Evil; we learn by training to see in everything "a beauty of its own," and we derive from it a hope of realisation which "we place where alone it can be safe, in God." With all its condensation it is a comprehensive and eloquent presentment of the 'argument' from Beauty.

Mr. J. H. Kennedy's course of Donnellan Lectures at Dublin $^{2}$ includes some polemic against Positivism and Material-

1 Natural Theology. See postea, Chap. xI.

2 Natural Theology and Modern Thought, 1889. 
ism, with a study of Teleology, Free Will, and the Moral Proof: all in a fresh and lucid manner. But the special feature of the book is a lecture upon the Esthetic Proof, containing a careful study of Kant's treatment of the subject, the effect of the argument on the doctrine of Natural Selection, and the lecturer's own opinion.

He considers that Kant's reference of Beauty to a relation between the conception of the object and the perceiving mind cannot be an exhaustive account of it, inasmuch as it ignores the fact that this relation cannot be created by the perceiving mind when and where it likes: and Kant is obliged in fact to distinguish between Beauty and Sublimity, asserting an external cause for the former, but denying one for the latter : a distinction which Mr. Kennedy rejects, claiming objectivity for both.

As a basis for an argument for Theism Mr. Kennedy insists on the analogy with the works of human Art, in which beauty, he says, only appears when intentionally produced. Now it is true that human works in which utility only is in mind may be excruciatingly ugly, as the railway bridges over the Thames: but the gracefulness of the arches of old road-bridges was in no way intentional, it was structural. The grand effect of the piled-up masses of the Old Town of Edinburgh, the delightful form of an old man-of-war under full spread of canvas, or the gracefulness of the sail of an Arab dhow, are not consciously produced. Of course it may be said by Mr. Kennedy that these are not works of $A r t$, and he may desire to limit art to what is produced with a conscious aim at beauty. If this is the meaning, then much of the beauty in human productions is 'natural' only, and the contribution of human effort to the region of the beautiful is narrowed. But the production of beauty by art, with the necessary reference to a designer, certainly offers, when compared with nature external and moral, three terms of an analogy, of which a Divine Artist is suggested as the fourth, as Mr. Kennedy is contending.

In his treatment of Natural Selection as handled by Darwin so as to account for Beauty, Mr. Kennedy insists that Sexual selection is quite out of place within 'Natural Selection' as the survival of the fittest. For into the mechanical operation of generation and modifying forces Sexual selection introduces Choice, preference according to pleasure and delight, consciously operating, and again suggesting an analogy, with a fourth term 
to be filled in. And when we turn to inanimate Nature, "the beauty of mountains and valleys, of forests, of sea and shore, the hues of sunrise and sunset, and the midnight sky;' what has 'survival of the fittest' to do with these?

Taking these points together, the analogy with human art, conscious selection as educing beautiful forms, and the unconsciously produced beauties and sublimities of external nature, Mr. Kennedy concludes that there is a Proof entitled to 'an importance far exceeding that which writers on Natural Theology have hitherto assigned to it.' And his conclusion might have been greatly strengthened by the inclusion of another premise, the appearance of beauty and sublimity in human lives and national histories, not in the least intended by the individuals or the nations themselves, and yet, on Mr. Kennedy's principles, inhering in the objects as presented to the spectator or beholder.

He then examines Kant's hostile criticisms: (1) that Design should not be introduced on pain of unnecessarily multiplying principles; to which Mr. Kennedy replies that Design is not invented for the purpose as a new principle, it is already in operation elsewhere; (2) that beauty in many natural objects, such as crystals and precious stones, seems disconnected with purpose; Mr. Kennedy turns round to show that it cannot at any rate be due to association of ideas, for these objects are not esteemed after they are associated with human uses, but before; (3) that we impose beauty rather than find it; Kant is not consistent, for he acknowledges that in works of art it is the producer, not the spectator, who is the cause of the Beautiful, and his attempt to substitute mechanical cause for conscious operation, in this respect, all over Nature is a paradox; and (4) Kant's separation of the Sublime (with Burke) is invalid in works of Art, literary or other, which are ranked as Sublime: the quality is due to the artist, not to the beholder, as clearly as in the case of the beautiful.

Mr. Kennedy then dwells on the revelations of the microscope and of the telescope, and insists on the 'startling profusion of the splendour with which Nature abounds': and therewith emphasises the cogency of the argument he is defending.

Mr. Kennedy's own Theism contains the Causal argument in its double chain, Mechanical and Purposive, with the Moral Proof: the feature of the book is the strengthening of Teleology 
by fresh insistance on the argument from Beauty. It is of interest to note that Trinity College, Dublin, has given us this lucid defence of Esthetic in the hands of Mr. Kennedy, and also an endorsement of the position from Dr. J. H. Bernard, in his fine translation of Kant's Kritit of Judgment, with Introduction and Notes (1892).

See Appendix B for Professor Howison, The Conception of God. 


\section{CHAPTER V}

Type V.-Intellectual and Ethical Combined

Hooken : Ecclesiastical Polity (Books I.-Iv. 1594)

BeFore turning to those who remained Traditional in their Theism, although they had renounced conscious allegiance to Scholasticism, English Churchmen will desire to note the position occupied by Hooker.

Hooker did not himself raise the question of Theism, how far God is known apart from Revelation, and by what means. His mind was engaged in Church polity and Church doctrine. But he prefaces his treatment of polity by his famous Book I. on the relations of Reason and Revelation. In this he stands by the Scholastic tradition at its best. Where Reason speaks it must be listened to, but its voice has a limited range, and there is another faculty of knowledge beyond it which apprehends what is Revealed. His sphere of Reason is a wide one: men have intellectual conceptions and moral ideas which are universal in character and show not fictions but realities. Consummatory of all these is the idea of God.

Looking out upon what Reason can do, Hooker specifies First Cause "whereupon originally the being of all things dependeth": ${ }^{1}$ and he at once includes Personality; the First Cause is an "Agent which knoweth what and why it worketh." He proceeds to show the Agent as working by Ends which are varieties of Goodness, in which the Infinite Goodness shows His 'beneficence and grace.' And he also leans upon Teleology, which he takes broadly: "the particular drift of every act . . . we are not able to discern." He refers to Consensus, of "the wise and learned among the heathen themselves' 2 : but his references are to a curious medley of authorities, as if he were merely

$$
{ }^{1} \text { I. c. ii. } 3 .
$$

2 Ib. 4. 
filling up a conventional place, not giving his mind to the point in his usual serious way.

That God is Infinite and is Good is the dual starting-point of Hooker's thought, and it follows clearly from this that $\mathrm{He}$ is Personal. His opponents were not questioners of religious belief : they were very vigorous assertors of it. But they were depreciating Reason and disconnecting the ordinary course of the world from relationship with the Divine Being. Hooker's aim is to show that there is goodness in the world, which is to be interpreted as an expression of a Divine Will; and that Reason, in studying the world, discovers general law, which, again, is expressive of the Will of God, that 'Law eternal,' as the famous passage runs. This, of course, depends upon his identification of Will with Practical Reason working for Goodness, as against Will working by arbitrary decrees: he claims that laws of life are disclosed to man by his natural faculties, beyond which there may be a sphere of positive commands which man cannot understand, but may accept upon authority which, on other grounds, he is satisfied is divine.

We have here man endowed with Reason and allowed to read the law of God, and the world as moulded and controlled by that law : it is Rationalism, of course: we can by reason see something of the Divine Being, and the law which we see is explicable only as the expression of His will. Even where we cannot see law we must suppose it: for every particular thing, and also for the 'binding of things together.' But in man the main thing is his striving after perfection: he "covets as much as may be to be like unto God"; ${ }^{1}$ he desires to live on, and to live rationally, therein rising above 'sense and fancy', into things ' not sensible.' As rising into this higher sphere he claims Freedom: the direction of Will according to the Good disclosed by Reason is our perfect life. In his Ethics Beauty is included

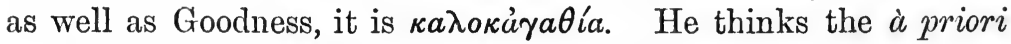
way of discovering Moral law may be too hard: men may have to be conten'i with à posteriori guidance. But he proceeds to indicate general principles $:^{2}$ some axioms of goodness are offered, e.g. a greater quantity to be preferred to a smaller, an axiom which Bentham afterwards made use of: and others more concrete, e.g. God is to be worshipped, parents to be honoured; but what he afterwards gives as the first law of conduct is, 
'the soul ought to conduct the body, and the spirit conduct the soul.'

Reference to Feeling is not omitted: the Desire for happiness is infinite; and the presence of insatiable desire is a ground for belief in an infinite object beyond things of sense and things of intelligence, carrying us into the region of things divine.

Hooker is all along aware that he is not describing man as he is. It is an idealism that he is giving. "We fall short"; and "From salvation and life all flesh is excluded by the natural way." And so we have need for Revelation. What he has been maintaining is that there is a Rational account of Man and of God: it is not all Revelation.

In his application to human nature he draws the line across the ground in a way which gives him his peculiar place in Rational Theology - in the field of human nature he is Individualistic: for the individual there is Law, which Hooker extends even to the Future life. But he does not apply Rational Law to Social life: Reason establishes 'no manner of public regiment'; society depends on consent of individuals, or on laws positive, 'extraordinarily ' revealed. 'Regiment' of some kind is necessary; what kind is 'arbitrary,' so far as Reason can tell. We see that there was every scope for the Political philosophy that was beginning to set itself to work, and when Hooker drew the line of Rationality so as to exclude it, an empirical period was plainly coming on. But when we remember that he is vindicating Reason in the general view of the world, and declaring that the world is Theistic against opponents who regarded it as secular, pagan, profane, we see that Hooker was vindicating the Scholastic tradition, which was also that of early Theology. Bacon, the herald of the new era in science, took sides with the Scripturalists; though he did not despise the world as they did, he thought it lay outside religious interests.

It is not quite easy to assign Hooker to any of the types: like all great men in periods of transition he combines points from different schools. He shares in the Intellectualism of the Tradition, while the prominence of Practical Reason might lead us to regard him as a precursor of the Ethical School. As combining both it has seemed, on the whole, best to place him at the head of those whose Theism is of the Combined type which employs the intellectual and the moral methods on nearly equal 
terms. Some would place him, if preference had to be made, rather with the Intellectualists; for myself, I would rather place him with the Ethical School : I think that the thought of Perfect Goodness is to his heart dearer than that of mere Causation, or Infinity.

\section{$\S 2$}

Berkeley, Bishop : Works, edited by Professor Fraser, 1871

For Theism Berkeley resembles Butler in standing upon the lines of Cosmological and Ethical Rationalism for his general position, while giving chief attention to the construction of particular arguments to meet the particular needs of the time. Butler put his strength into the consolidation of the Moral argument; Berkeley's energy was devoted to an elaboration of the Cosmological according to a method of his own.

Turning at once to Berkeley's special contribution, we find him in search of Substance and Cause. Armed with the theory of Knowledge which Locke had raised to prominence, he is able to make a direct attack upon the growing tendency to attribute the mass of appearances which make up our external world to a substance called 'Matter,' a view which arouses in him the most thoroughgoing hostility; and not least because, while Hobbes had grimly accepted Matter as the Substance par excellence, even Locke had reluctantly allowed himself to be embarrassed by it. Berkeley declared that 'Matter' as Substance and Cause was a mere spectre, a creation of false philosophy; and he set himself to show that all the marks or characters in the external world are to be explained only by reference to Mind or Spirit.

His procedure is, therefore, equivalent to the Cosmological method as applied in Theism, and his philosophy ends in a theological solution. Starting from the mind of the perceiver as a thinking active principle - the existence of which he assumes to be known-in presence of its sensations and ideas, he infers a supreme principle of the same kind, a Being with will and understanding. When we are in face of the external world we are aware of our own experience, but we are aware also of a something which is not due to our perception, but must have some other efficient cause; another Will is, therefore, to be inferred, and inasmuch as with ourselves will and perception go together, so the Supreme Cause is both Will and Understanding. 
Or again (as he puts it in the later Dialogues ${ }^{1}$ ), as we infer the presence of mind in men from the sensible appearances connected with every individual who presents himself to our experience, so from the appearances of the universe we infer Supreme Mind, with a certainty 'at least as clear, full, and immediate.' In doing this, he blends the cosmological and the teleological arguments.

Berkeley then passes on to the exposition of his famous Symbolism: as one man knows of another's mind by this other speaking to him, so it can be shown that in the world God is really speaking to man. ${ }^{2}$ He lays great stress on the arbitrariness of the connections amongst the phenomena of nature, so far as we can judge, taken in conjunction with their utility to us: and this he considers to be strictly parallel with our own spoken and written languages, in which signs are connected with things quite arbitrarily, and yet with the utmost efficiency for our advantage. In the external world this very arbitrariness between signs and things signified necessitates reference to an outside power which has associated them for us with a view to our benefit. "You cannot deny," he says "that the great Mover and Author of nature constantly explaineth Himself to the eyes of men by the sensible intervention of arbitrary signs, which have no similitude or connection with the things signified; so as, by compounding and disposing them, to suggest and exhibit an endless variety of objects, differing in nature, time, and place thereby informing and directing men how to act with respect to things distant and future, as well as near and present. In consequence, I say ... you have as much reason to think the Universal Agent or God speaks to your eyes, as you have for thinking any particular person speaks to your ears." 3 Berkeley's crucial instance is his Theory of Vision applied to the perception of distance, which he holds is an acquired perception, gained from the interpretation of certain arbitrary appearances.

To accuse Berkeley of referring the reality of the external world to the mind of the man who is looking out upon it is quite futile. His problem was just the reverse, to explain so much of the external world as is given to the perceiving mind; and his solution is that there is an Efficient cause other than the perceiver, and that this cause is itself Intelligence or Mind.

1 Alciphron, Iv. $\S \$ 4$ and 5.

$2 I b . \S 7$.

3 Ib. \& 12 . 
And so the whole external universe is a sense-symbolism, which we read as we read a language in order to procure knowledge of the Mind which is speaking from the other side, as it were. We are familiar now with the view of the world as a Symbolism, but in Berkeley's day the method was a new one: he is "persuaded," he says, "that the Theory of Vision ... affords to thinking men a new and unanswerable proof of the Existence and immediate Operation of God." 1 Doubtless Berkeley's sphere of application of his theory is not wide, it is the external world which he interprets, and all the range of human life is unworked as a basis for this theistic inference. But Berkeley's interest was absorbed in the task of opposing Materialism: if he could show that there is behind external phenomena no 'Nature' of a Substantial and Causative character, others might come after and show that there was no such thing as a 'Nature' behind mental and moral phenomena; for himself some being is behind each series, and it is the same being in both cases, and as it is active and intelligent it is not a 'thing' but is Mind, and what men mean by God, philosophically speaking.

Berkeley's procedure is, then, the Rationalism which employs the notion of Causation: this he engrafts upon his psychological analysis of mental phenomena, unlike Hume, who confined himself to the psychological analysis, and by it dissolved even Causation. But Berkeley in his characteristic period did not investigate the notion of Causation; later on, indeed, he made himself more acquainted with the metaphysical position of Plato and Aristotle, and found there a region of Rationalism which was congenial to him by the very fact that he had all along been employing the notions with which their metaphysic was concerned.

In Ethics Berkeley's position is that of Hooker: Goodness and Right are inherent in the nature of the universe because the universe is a product of Eternal Reason. Moral rules are 'laws of nature,' 'eternal rules of reason ' ${ }^{2}$ and this position is only intelligible if they are understood to be the expression of Divine Reason and Will. In his earlier days Berkeley included a reference to the concrete by the introduction of Happiness in accordance with the Hedonism prevalent in English Ethics at that time: the laws are not abstractions, but have a

2 Sermon on Passive Obedience, 1712, § 12. 
purpose of which sensible experience can take account, namely, the general happiness of mankind. In later times, in the Siris, he has moved away from empirical considerations.

I think we must allow that Berkeley is distinguished from the majority of British Theists in seeing that Beauty has a genuine place in the scheme of proof. In Alciphron ${ }^{1}$ he combats Shaftesbury's reduction of Ethics to Fsthetics, but he opposes this not by rejecting Beauty but by showing that it cannot stand by itself, that it needs reference to a Supreme Mind who impresses these characters on the universe, both physical and moral.

As to Consensus, Berkeley always claimed that he was defending common opinion against the fictions of philosophers, and claims that the Theistic interpretation he gives is really an expression of what is in men's minds. His discrimination between the crude employment of Consensus and the legitimate use of it is quite clear. ${ }^{2}$ If we merely collect common opinions, their variety is so striking that 'lazy and superficial minds' will find in them an obstacle to religious belief, and not a support for it: but 'one of more spirit and a juster way of thinking' will proceed differently and gain a different impression. The whole passage is admirable.

In the first Dialogue of the Alciphron Berkeley resorts to what I have called the Quasi-transcendental method in Theism as justified by its power to satisfy our needs, its 'utility and convenience,' to use his own terms. I think that with Berkeley himself this resort to practical efficacy was influential; it certainly influenced him in his attack on 'Matter': but at the same time he was too 'rational' in his habit of mind, too much a seeker after ascertainable 'truth,' to rest here. The various passages in which he vehemently claims for Natural or Rational religion a place alongside Revealed religion show this; but his prolonged labour in the field of philosophy is itself sufficient evidence that he held that it could be truth and truth only which could really be of benefit to mankind. It is doubtless a horror of his own to which he gives expression when he makes Alciphron, so long as he is unable to reconcile notions to his understanding, protest, "My nature abhors the baseness of conniving at a falsehood." 3 Accordingly he allows Alciphron to set this method of utility aside along with Abstract Metaphysics

\footnotetext{
${ }^{1}$ Dialogue III. esp. $\S \S 10$ and 11.

${ }^{2}$ Alciphron, vir. 32.

${ }^{3}$ III. 16.
} 
(Ontology) and the reference to Consensus, and come to close quarters for the main question on grounds of Reason.

For which of the elements in the conception of the Divine Being does the Theism of Berkeley provide? Personality is there, Mind or Spirit he calls it; and Goodness, without question. But as to each of the other elements some scrutiny is necessary.

Taking Necessity (Self-existence) and Infinity together, it is clear that there is no provision for these in Berkeley's characteristic work, before the period of the Siris. He is engaged in accounting for a finite and contingent world of sensible spirits and their experiences, and of the world which is objective to them: he can therefore strictly rise no higher than to a finite and contingent Cause. Declining to embark upon a theory of Causation of a constructive kind, as belonging to 'abstract metaphysics,' he accomplishes no more than others of the da posteriori school in this respect. Quite simply he slides from 'vastly great' to 'infinite' ${ }^{1}$ and though his view of the world was vast enough-the life of man is but a 'span,' his place of sojourn but a 'point'" - there is no assertion of infinity in the universe and no account of how it comes into the Cause. Dr. Fraser thinks that Berkeley's aim was so intensely practical that he purposely 'eliminated the problem of the infinite with its paradoxes and antinomies' 3 altogether: and Berkeley certainly expresses himself uncompromisingly against abstractions and 'barren speculations.' When in Alciphron he says that " the being of a God is capable of clear proof, and a proper object of human reason," 4 and goes on to denounce as vain all attempts to explore 'the mysteries of his nature,' we may suppose that he is here renouncing investigation into Self-existence, Infinity, Omnipresence, and kindred notions.

This at once leads us to doubt whether Berkeley provides for Transcendence, either: whether the Divine Being in his method is more than sufficiently great, so to speak, to yield what is required for the explanation of the Universe, whether God is only God in so far as there is a universe to be accounted for; in short, an Anima Mundi. His Ethics would indeed carry him beyond this, and may be taken for a sign that the higher philosophy of his later life had always had some root in
1 Alciphron, Iv. 5.
2 Ib. Iv. 23.
${ }^{3}$ Vol. ii. p. $170, \mathrm{n}$.
${ }^{4}$ vII. 33. 
his mind even when he was mainly concerned with the interpretation of the finite and contingent.

It is, then, Immanence which seems to stand out as the feature which Berkeley did most to secure, and this was no mean achievement in the days when Deism, with its inferences to an absent Creator, was prominent in the minds even of religiously disposed men. It is an immanent operation that Berkeley himself has constantly in mind. When he has occasion to enumerate the elements in his conception of 'God in the strict and proper sense of the word' 1 they are, spirituality, omnipresence, providence, omniscience, infinite power and goodness; the purport of the definition being plainly to insist on the present operation of spirituality and goodness throughout the universe: and when, twenty years afterwards, he marks the aim of the New Theory of Vision it is the offering of a new proof of 'the Existence and immediate Operation of God and the constant condescending care of His Providence.' ${ }^{2}$ In the Principles he is objecting to the interposition of Second Causes and most especially to Matter as an intervening Cause, inasmuch as it is reference to these which leads men to relegate Divine action to past ages. He will have the Divinity in action at every moment, by 'constant creation':- "This theory of Visual Language proves not a Creator merely, but a provident Governor, actually and intimately present, and attentive to all our interests and emotions, who watches over our conduct, and takes care of our minutest actions and designs throughout the whole course of our lives, informing, admonishing, and directing incessantly, in a most evident and sensible manner. This is truly wonderful," adds Crito. "And is it not so," says Euphranor, "that men should be encompassed by such a wonder, without reflecting on it?"3 To get men to reflect on it was indeed the prime purpose of the persuasive and varied rhetoric of Berkeley's Dialogues, as it was of the lucid exposition of his more formal writings.

The great stress Berkeley laid upon the arbitrariness of the symbolism was due to his desire to exclude causal power from being regarded as resident within phenomena thernselves: the connections are imposed upon things, and it is this which impels us to refer to a Power beyond them. There is, of course, something of a reference to a Deus ex machina in this: it is a polemic

${ }^{1}$ Hylas, 1713, ir. p. 354.

2 Theory of Vision Vindicated, ad init., 1733.

${ }^{3}$ Alciphron, rv. 14. 
against the Mechanical philosophy. Modern advances in the scientific investigation of nature, on the one hand, and of the natural growth of the systems of signs which constitute spoken and written languages, on the other hand, have reduced the arbitrariness on which Berkeley relied, and we are now conscious that a deeper sense of the immanence of the Divine Being is ours the less of arbitrariness we find in the universe. But great as has been the progress since the time of Berkeley we are still obliged to combine gratitude to God for what He shows us in Nature (sight), with a sense of dependence on Him in the much greater range of existence that still looks arbitrary to us (faith).

Besides arbitrariness, however, Berkeley emphasises the fact of regularity and constancy in the connections disclosed to us, and these give the mark of intelligent purpose. For instance, "The Ideas of Sense" 1_i.e. those presented to us, not the ideas of our own representation and imagining- " have a steadiness, order, and coherence: they are not excited at random . . . but in a regular train or series-the admirable connection whereof sufficiently testifies the wisdom and benevolence of its Author": again, " this consistent uniform working . . . displays the goodness and wisdom of that Governing Spirit whose Will constitutes the laws of nature." 2

Taking together his insistance on arbitrariness and the consequent present efficient operation of Deity, and on regularity as proving a constant beneficent purpose, we find that to Berkeley, as to Butler, the point of most vital interest was to counteract the Deistic tendency to revert to an absent Creator who has made the world, but is now, practically, absent from it.

As to Berkeley's later philosophy, we find him, in the chain of Reflexions, 368 in number, which he called Siris, published in 1744, setting himself in line with Platonic and Neo-Platonic speculations : he has become interested in the region of Universal Reason and archetypal Ideas. He no longer looks upon it from afar, as giving him something which he cannot dispense with without falling into the slough of Empiricism, namely, Causality and Ethical Reason, but as itself a region into which he would soar with the great Greeks both of Athens and of Alexandria. But the Berkeley of the Siris is not the Berkeley who rises in

1 Principles, § 30.

2 Ib. $\$ 32$. 
our memory as one of the most distinguished figures in British philosophy. We think of the Berkeley who renders transparent the apparently solid wall of Matter, who spiritualises the external world, and teaches us something of the Language in which the Supreme Spirit speaks to ours. In himself he is at all times rich in Theistic thought: he can draw from Ethics, from Esthetic, from Consensus, and from quasi-transcendental argument, as well as from his own Cosmological procedure. But both in early life, amidst this varied reference, and in later life, as he passes to join the company of the transcendentalists, our personal attraction is to the subtle advocate of the SenseSymbolism which we associate with his name. And we need waste no regrets because of his seeming to pass beyond the position in which he had won his laurels. For, after all, what he then won was indispensable, it was a position that had to be occupied: Matter must be dealt with and Deism must be refuted down in the region where thought is applied to concrete phenomena unless thought is to be absorbed in its own transcendental implications. And perhaps we have yet to see the full fruit of what a philosophy would be which could be transcendental and yet include every element of what was won by Berkeley in the part of his work which gives him his distinct place in literature. Certainly for Theism the English mind especially can profit by patiently following up his thought, expressed as it is in the lucid and pliant English by which he has shown that the reading of philosophy can yield a pleasure of its own.

\section{$\S 3$}

Butler, Bishop : Sermons, 1726 ; Analogy, 1736

Butler might be placed under Ethical Theism, were we only to regard his emphasis on the sense of Duty and the conviction that the world is under a Moral Governor as the foundation of religious belief. But this emphasis must not be taken to mean that Butler himself acquiesced in the abandonment of cosmological Demonstration, as no longer a road to Theistic belief.

Butler will always suffer misconception through having left us no systematic exposition of his own full scheme of Natural Theology. The work he has given consists of splendid fragments so far as a whole scheme is concerned. And what we have is coloured by its forensic aim: his chief work is the statement of 
a 'case' after study of the brief of his opponents. Mr. Gladstone has elaborated this point, and it can never be neglected except by hasty readers. His own declaration is crisp enough: "I desire it may be considered, that in this treatise I have argued upon the principles of others, not my own; and have omitted what I think true and of the utmost importance, because by others thought unintelligible, or not true." 1

On the Intellectual side Butler was certainly cautious in his resort to abstract reasoning: as $\mathrm{Mr}$. Gladstone says, it is quite likely that the lesson learned in early life in his famous controversy with Clarke sank deep, and convinced him that in the high region of Infinity man has not faculties for attaining decisions. $^{2} \quad$ But there was a more concrete sphere, which was still of Intellectual character. "To convince an unprejudiced understanding that there is a God who made and governs the world there is no need," he says, "of abstruse reasonings and distinctions " ${ }^{3}$ he does not say that understanding cannot be convinced, and he implies that something concrete and solid is available. Was this solely in the Moral Sphere? Let us see. The Analogy opens with arguments for the Future Life, which are of an intellectual not of a moral kind: his phraseology includes 'Author of Nature' and 'Creator.' In the Introduction he says that the existence of an "Intelligent Author of Nature and natural Governor of the world has often been proved with accumulated evidence": and in the conclusion of Part I. he says that no other account at all can be given of how this universe came to be, and the course of it to be carried on, as it is. In the sermon on the Love of God he is clear that before the religious affections can have play their Object must be before the mind: we must be in His presence. In the sermon on the Ignorance of Man he says we have "a faculty for discovering speculative truth."

'Proved with accumulated evidence.' Can we piece together his scheme? I should say that our clue should be taken from his own phrase: Proof, not by 'abstruse reasonings and distinctions,' but with 'accumulated evidence': i.e. the reasoning seems to be of the Inductive order. This would suggest that the Teleological argument was for him the most effective; i.e. from Design, or Final Cause as he calls it, ${ }^{4}$ observed to be inwrought in

1 Analogy, II. viii.

3 Analogy, II. Conclusion.

2 But see p. 214.

${ }^{4}$ Introduction. 
nature. And so in this very passage he places it first in order: "this argument of analogy and final causes"; in Chapter III. of Part I. he states it again; in the chapter on Necessity he defends it against the doctrine of Necessity; and in the Conclusion of the Analogy, in a rapid allusion to proof, he states it by itself.

Yet this singling out of Teleology is only a preference: he does not abandon abstract reasonings, but includes them in his enumeration of proofs in the Introduction. We know from the history of Natural Theology that by abstract reasonings Butler means the Cosmological argument. What he is excluding is the extreme abstract form adopted by Clarke. Butler states the Cosmological proof, but very summarily, in the sermon on Ignorance: "It is as certain that God made the world as it is certain that effects must have a cause"; here the certainty is to be observed; and in Analogy, Chapter II., the course of nature " necessarily implies an operating agent." The Causality proof evidently lies in Butler's mind unquestioned.

But farther: the abstract reasoning set aside when speaking of others, is not set aside for himself. We might have supposed it to be so, perhaps, were it not for his very clear statements. In the chapter on Necessity he rises above the usual distrust for the Ontological argument itself, and says: "For we find within ourselves the idea of infinity, i.e. immensity and eternity, impossible, even in imagination, to be removed out of being. We seem to discern intuitively that there must, and cannot but be, somewhat external to ourselves answering this idea or the archetype of it. And from hence (for this abstract, as much as any other, implies a concrete) we conclude that there is, and cannot but be, an infinite and immense eternal Being existing prior to all design contributing to His existence, and exclusive of it." Here it is to be observed that he does not in any way introduce Causality; it is not God as cause of this idea; but he puts down three other principles, from abstract to concrete, from idea to archetype, and from idea to 'somewhat external to ourselves answering to this idea.' He does not enter into discussion of them. And it is to be noted further that it is in connection with infinity and necessity that he brings in this argument. That he held to true infinity-in spite of any impression made upon him by Clarke's failure-comes out clearly in his sermon on the Love of God.

Here another misconception has to be dealt with. Attempt 
has been made to divide Butler: to separate the preacher of the Sermons from the theologian of the Analogy: in the one ranging him as a leader of Intuitional Ethics with moral principles of a categorical order: in the other as content with Morality of the Probable kind. Dr. Fairbairn ${ }^{1}$ writes: "Conscience was Butler's real contribution to the philosophy of human nature; probability was the first principle of his analogy, or special apologetic for the Christian religion. The two positions were full of implicit incompatibilities; the supremacy of conscience made a constitutional authority the guide of life, but according to the doctrine of probability, the guide was a sort of logical calculus. The one doctrine was transcendental, but the other was empirical." It is easy to see how this view comes to be taken. But surely it is a misconception arising from confusing the ground on which Butler closed with his opponents, with the ground on which he would take his own stand if he were defining his own position. The crucial passage above cited proceeds thus: "Thus I have argued upon the principles of the Fatalists, which I do not believe; and have omitted a thing of the utmost importance, which I do believe, the moral fitness and unfitness of actions, prior to all will whatever: which I apprehend as certainly to determine the Divine conduct, as speculative truth and fasehood necessarily determine the Divine judgment." ${ }^{2}$ Again, in the same paragraph, "So likewise that there is, in the nature of things, an original standard of right and wrong in actions, independent upon all will, but which unalterably determines the will of God to exercise that moral government over the world, which religion teaches, . . . this assertion contains an abstract truth, as well as matter of fact." And this is in the Analogy not in the Sermons. The fact is, the opening of the Analogy by referring to Probability has been taken by rapid readers to mean that Butler had quitted both the Moral and Rational bases of Theistic proof. But this is in no way what he does: what he says is that Probability is, to us, the very guide of life; i.e., in the sphere of the varied manifold of our observations on the facts and events of the world; of those actualities which make up the course of Nature. And to us, who have to choose amongst these in directing our actions, probability is our guide. He protests vigorously against reading these by 'hypotheses,' like Descartes, or 'from the attributes of God,' deductively. But most explicitly

\footnotetext{
${ }^{1}$ Christ in Modern Theology, p. 25.
}

2 Analogy, II. viii. 
he is not here thinking of the way of establishing belief in God himself : "for an Author of Nature is here supposed," ${ }^{1}$ supposed because it can be proved, on lines indicated by our citations.

The clear issue is this. Butler himself is to be regarded as building Theism on a very broad basis of Intellectual deliverances, not even excluding the Ontological proof. But he conceived that in his day the special task before him was to vindicate the view of the world as a moral order, as a 'course' to which virtue, and virtue only, has the clue, in spite of all difficulties and objections which men had of late years been accumulating against it.

The defining of Butler's position has engaged what may seem an inordinate degree of attention in view of the scope of this book. But to English minds Butler means so much that his position should be clearly stated. I take it to be that he himself accepted the Traditional Demonstration, with a strong leaning towards what was afterwards to be defined by à priori idealism; that he went farther and made of the Moral argument a separate and strong proof by taking the Moral consciousness as delivering categorical commands and regarding man's truly natural life as involved in his obedience to them; and lastly, that he relied upon the proof from the course of the world as itself a Moral order. The especial need in his day for a vindication of the ethical way to Theism called instant attention to his work, and minds in which ethical considerations are paramount have looked to him as their first great advocate, in Britain at least.

It may be allowed that to the thoroughgoing Intuitionalists in Morals Butler's procedure may be somewhat perplexing: his Analogy may appear a work of the merest supererogation. If conscience speaks with a voice of absolute authority, if there is 'moral fitness and unfitness in actions prior to all will whatever,' why not stand simply on that and defy the 'course of the world'? Is anything to be gained by sallying forth from such a fortress as this, and going down into the open field outside the walls? Is not this what was in the mind of Pitt in his oft-quoted saying that the 'Analogy' affected him by raising doubts rather than anything else? Yes, it so affected him because he had not been in the open field, but was dwelling securely in the fort: but it was not Butler who raised the doubts, but the opponents whom Butler

${ }^{1}$ Introduction. 
came out to combat. But does any Intuitionalist really wish that the Analogy had not been written? Does it not show us in Butler a man with a firm Intuitionalism for himself but with a mind filled with large Inductive sympathies? solid facts and the events of history interested him: but their web was varied to a degree which made it a matter of difficulty to trace out the pattern from first principles, however sure in themselves: the possibility and fact of moral disobedience; the triumph of vice; the obstacles to virtue; the inequalities in the distribution of that happiness which beyond question was a good thing and yet seemed at times disconnected with moral goodness; the brevity and uncertainty of life: all these things seemed to blur the pattern and make difficult and obscure a direct deduction from moral principles and the nature of Him whose universe it is. And inasmuch as some men had concluded that these things must be ignored by a pantheistic necessity, and others more numerous and more clamorous declared that they made impossible all attempts to regard the world as moral at all, that it was merely started with an initiating impulse and some original laws under which it must now run on : he must address himself to this very point, to vindicate the order as moral in spite of objections, showing that these very objections extended beyond moral order, and had analogies which affected the system of nature as well.

To the Moral consciousness as basis Butler applies the Method of $\grave{a}$ posteriori inference.

If we were to construct Butler's argument for him as his successors in Moral Intuitionalism might build it, we should express it as the argument from intuitions of Moral Law, leading to inference to a Supreme Authority. We should take the general moral doctrine from the Sermons and the Dissertation on Virtue, with the addition of elucidatory expressions scattered over the Analogy. Then we could show that this is attached to intellectual conceptions of God as Author, Creator, Governor of the Universe, and as Infinite and Necessary Being. And, finally, that God's Will is regarded as the Goodness which as Law we find reflected in our Conscience. In this he stands with Hooker: moral Goodness is inherent in the Divine nature $;^{1}$ though indeed Butler's expressions: 'the determination of the Divine conduct,' ' unalterable determination of the will of God 
Himself,' are not felicitous: but what they mean is that the laws of goodness are inherently Divine. To us they come in the form of commands, dictates: our possession of them is a proof of the Being from whom they issue and of our affinity with Him : and that we, being placed here by Him, are in spite of all counterappearances placed in a condition in which we can act according to the Divine laws, and take them as our guide. ${ }^{1}$

As to Feeling, Butler does not allow it a primary place: the Object of affection must be before us in order that affection may

1 I am unable to accept Dr. Sidgwick's account of Butler as giving for his last word in Ethics that there is a dualism of the Practical Reason, as between Duty (or Virtue) and Happiness. These Dr. Sidgwick* regards Butler as holding to be theoretically of equal rank, though practically the sense of duty is the better guide by reason of its superior clearness.

I take it that Butler's depreciation of the Happiness principle in the Dissertation on Virtue is wider than Dr. Sidgwick allows when he confines it to the depreciation of Benevolence or the Utilitarian principle. It seems to me to apply to Egoistic Utility also. And as the Dissertation is what comes latest in Butler's thought it should be taken to override whatever else he has said which would assign equality as between reasonable Self-love and Conscience. It was Dr. Silgwick who taught me to regard this brief Dissertation as a declaration of first-rate importance in the history of English Ethics, and I would appeal to his own characterisation of it as preluding the distinction between 'intuitional' and 'utilitarian' ethics which was soon to prevail ; only I would include in the term 'utilitarian,' egoistic self-love as well as benevolence.

In his Fourthly Butler clearly reduces our concern for our own happiness to prudence, and he assigns to imprudence a 'moral' character on the same ground as he does to falsehood, injustice, and cruelty, namely, its condemnation by conscience : prudence is a species of virtue, he says explicitly. And the strong things which he says in his Fifthly against assigning 'moral' character to benevolence apart from the action of conscience are only stronger in degree than what his treatment of prudence implies.

Again, as I read his doctrine of Rewards and Punishments attached first to actions generally and then to moral actions, in the Analogy, the assignment of happiness seems distinctly meant to be an allotment of it to rules or principles on other grounds than their arriving at happiness, namely, their conformity to the deliverances of the Moral faculty.

That Butler's Ethies display growth Dr. Sidgwick points ont, and my appeal is from the stage where he was emerging from contemporary entanglement with Hedonism to the stage when he emerged into clear enunciation of moral approbation apart from Happiness altogether.

It must be borne in mind all the time that Butler was a Theist. That he claims moral approbation as a fact apart from hedonistic considerations or from rationalistic system does not mean that he himself regarded it as a mere fact, without interpretation. In short, it was in this great fact, staring him in the face, so to speak, that he found the ground of religious belief which most required attention at that time.

* History of Ethics, § on Butler. 
arise ${ }^{1}$ the object first, the affections afterwards, and this, it would seem, decides the order of proof. But he goes on to reverse the order when he says that we are endowed with capacities for affections which the things of sense can never satisfy; if so, there would seem to be Feeling before the Object of it is known. But he does not pursue this.

To the Consensus Argument he frequently appeals: he himself adopts the 'conclusion of learned men' that the foundation of Religion was revealed, and has been handed down. But here he means, and should have said, in accordance with his general definition, that the doctrine of a Future life is included. However, when reflecting upon this argument his caution reverts to him, and he closes his fullest statement of it by merely ascribing to it evidential power ' by no means inconsiderable.'

The grave mind of Butler has profoundly impressed Englishmen who are of a seriously thoughtful disposition rather than those who are trained thinkers, so far as concerns the question of Theistic belief. This is because in the line of Speculative inquiry he breaks no new ground, but acquiesces in the old Demonstrative proofs; but the freshness of his treatment of the Moral proof gives his work a force which men of all kinds may feel. There is no need for a man to be speculatively sceptical in order to enjoy the benefit of the Moral proof, of course. But if men have for any reason lost the intellectual side of faith Butler is still open to them by virtue of his applying his strength so earnestly to the moral consciousness, and the practical side of life. His latest editor, Mr. Gladstone, addresses himself to the question whether Butler's influence has waned, because his immediate antagonists, the Deists, have vanished: is it true that "the cause is disposed of" and "the next step is simply to remove it with the winner's as well as the loser's pleadings from the list"? Mr. Gladstone appropriately objects that Butler has compelled the cause to be removed into a higher court, and that the very arguments which compelled this are still of avail, because they contained the grounds on which the higher appeal was justified.

Butler's position in broad effect anticipates that of Kant, namely, in the impetus given to the Ethical factor in religious belief. Kant, indeed, was sceptical on the speculative side, while Butler was not. But Butler contributed no new strength to the

1 Sermon on Love of God. 
Demonstrative or the Ontological arguments: they satisfied him, and he used them, but in the Moral sphere he made a mark of his own. He improved the Moral argument by his theory of conscience, and by his inductive explication of moral order; he gave clearer bases for morality, for a moral Author and Governor of the Universe, and for an Author and Governor simpliciter. He made this basis more full, more real : he exhibited the moral nature of man, and the course of the world in characters which made it less likely that either Deism or Pantheism, much less Atheism, could be a tolerably plausible account of that nature and that world.

That Butler's works contain enduring contributions to the setting forth of that aspect of the world which makes it Theistic cannot be doubted by those best able to judge, namely, those to whom he has actually made it appear to be so; such men find, whenever they are led to turn to him for reference or reperusal, that they are always rewarded by a fresh contact with his patient solidity, his gravity, his hold on the deep things of human life, and the humble reverence of his mind, as a man thinking out towards what is real, and true, and good to know.

\section{$\S 4$}

BoLingbroke, Viscount (Henry St. John): Works, 1754

Bolingbroke's principal writing on theology was prepared for publication by himself, but was not published until 1754 . He had, however, written occasional pieces and in conversation had promulgated his views in circles of high literature and politics. His unsparing attacks on Christianity rank him with the 'Deists,' but in his philosophical position he expressly calls himself 'Theist.' So strong was his conviction that knowledge of the Supreme, all-perfect Being could be demonstrated by connecting our 'clearest and most distinct ideas,' that his opposition to Revelation was nerved by it: this was to him 'surplusage,' and he declared that Archbishop Tillotson really caused himself 'embarrassment' by remaining an advocate of Revelation.

His own scheme is Cosmology with the argument ab eminentid to Intelligence. His form of it was implicitly that of Contingency; he was prepared to accept the infinity of the series of events, but even so they required a Cause: one sole Efficient Cause, with an infinite series of causes acting derivatively. $\mathrm{He}$ 
does not clear his mind as to whether he starts from his own existence, or from that of the world; stating the former, but going on to speak as if he meant the latter. But in his use of mind he was acute enough to seize upon the psychological standpoint at a time when many were reading Mind metaphysically.

$\mathrm{He}$ makes use of the Moral Argument by reference to Happiness, and so to Benevolence: not through Conscience Taking as his basis 'healthy' beings, he finds that they are plainly organised for Happiness: defects and failures are not normal. Hence there is Benevolence in the Creator. This was a view to which Locke might very well have come.

Bolingbroke claims that by his method he follows Locke; as opposed to Descartes who "disarmed the Scholastics but furnished arms to the Mystics" (by his appeal to consciousness); to Cudworth with 'a nonsensical paraphrase of nonsense'; to Leibnitz with the 'ridiculous whimsy of his Monads and his Metaphysical trash.' But though he writes much against Metaphysics he regards some metaphysicians with regretful admiration, that 'fine writer, Malebranche'; Berkeley, 'that sublime genius and good man, the Bishop of Cloyne': but these were men of imagination, poets, whereas mind, the basis, should have been studied as an object of physics (psychology). His own positive result renders him equally violent against sceptics: Hume he thinks 'less than a child compared with Hartley' and 'writing for reputation and entertainment.'

His book contains much history of religion: he used to think Monotheism original, but further inquiry changed his view; he came to think that mankind acquired knowledge as individuals do, by stages: and it is in this light that he sees a necessity for the actual religions of the world, as stages towards Rational Theism.

It was as an attack on Christianity that Dr. Johnson called this posthumous work a 'blunderbuss' left to be 'fired off' after his death. The interest of Bolingbroke's Theism lies in its representing the attitude of many men of the world in Butler's day, especially in literary and political circles, and it is given by a master of invective who is absolutely unreserved in his expression of strong opinion.

\section{$\S 5$}

Edward Steere, afterwards Bishop of Zanzibar, published in 1856 an Essay on the Existence and Attributes of God. It is the 
work of a somewhat solitary mind versed in old modes of thought, especially the Fathers and the Schoolmen, unfamiliar with modern philosophy, and yet aware of there being something in the atmosphere which prevented the old positions from being quite as they were. Himself resorting to Demonstration to the extent to which Aquinas used it, he also falls back on that mode of the Schools which regarded Reason as resting on something beyond itself, 'something like faith'; Reason itself rather 'testing' than 'discovering'; and so he has affinity with the Intuitivists.

He exhibits Cosmology on the lines of Aquinas; and also the Ontological proof, although in this he is not at home, 'it is difficult to be sure of one's footing,' he says; then the argument from Conscience, of which he does not make very much, confusing it a little with the next, namely, that from the Feeling of Dependence, the awe aroused by our sense of loneliness in the presence of Higher Power. He has a touch of Idealism in his references to Infinity and Perfection: and he endorses all by reference to the practical benefits of religious belief both to the individual and to society. Consensus he had used as giving a preliminary ground for careful inquiry, and at the outset he had also inquired into the question of Evil. Steere evidently thought his matter all over for himself and caught glimpses of many of the older views, all of which he tries to incorporate. That a man who proved so admirable a Missionary-Bishop should have had these intellectual interests engages the respect of the student, even though the result is not of any permanently independent value.

R. A. Thompson's Christian Theism (1863) is another work by a recluse student. He makes the mistake of occupying large space with expositions of philosophical positions which were quite well known, arguing de novo everything he puts down, although it is in the main the Natural Realism of the Hamilton School. His method is simple-Causality applied to the data of experience given by 'perception,' including Moral experience, and the sense of the Beautiful and Marvellous, and the Benevolent Affections. It is the width of his basis which gives him his place in the Combined type. He brings out well the parallel with belief in the external world. In this he maintains that Causality has one bridged the gulf between conception and 
belief: its capacity is therefore proved: and it only remains to extend it to Theism. Infinity, as would be expected from his Hamiltonianism, he finds a difficulty, and he endeavours to find a support for it outside Intellect, namely, in the aspirations of Moral Sense, in the sense of Beauty, and in Feeling. He writes gravely and solidly, and his book won high commendation from de Rémusat as a good introduction to the subject for the general reader.

About the same time appeared another exposition of this type, interesting as indicating that the type appealed to men outside the traditional influence of either Romanist or Anglican Colleges. Dr. William Cooke ${ }^{1}$ was for many years the theologian of that branch of English Methodism known as the 'New Connexion,' and a man able to think clearly and to express himself with terse and clear-cut phrase. He takes up the à prior $i$ argument, but sets it aside without repudiating it; $\dot{c}$ posteriori method is preferred as 'more suitable to produce general conviction.' Hence we have an Originator of the Universe, who is Intelligent and (by inference from our own nature) Personal. He then incorporates the Moral argument, from Moral intuitions. Besides looking to the 'assent of nations' for confirmation, Cooke had a glimpse of the quasi-transcendental kind of proof, laying great stress on the 'harmonising' power of the Theistic conception as compared with any others, so far as he knew of them. This method establishes existence, with some definition of nature, and deduction of further attributes follows.

\section{$\S 6$}

WARD, W. G. : Essays on the Philosophy of Theism, ed. Wilfr:d Ward, 1884

This is a volume of Essays by the well-known Oxford man who passed to the Church of Rome from the Tractarian group. He had a keen interest in the philosophical side of Theology, but he did not accomplish a systematic treatise, though he had the plan of one in his mind. His son collected his papers and published them under the above designation. A large part of them is concerned with purely philosophical matter, namely, a vindication of Intuitionalism in Metaphysics ond in Ethics, though not against all opponents, for Pantheism, connected by him with

1 The Deity, by W. Cooke, D.D., 1862. 
Hegel's name, was not in view. The pressing need in England, he thought, was to face Phenomenalism, and especially the writings of Mill; this part of his work is carried out at great length. Of the constructive Theism he had in view we have the results in his polemics, in some essays on certitude and reason, and in an essay on the Ethical side of Theism.

What Ward would have liked to work out, his son tells us, was a Theism resting on intuitions and supported by observations and deductions. We have sufficient material before us, however, to be able to see his position, for he was remarkably clearheaded and had a good level expository style.

Taking him comparatively, there can be little hesitation about placing him in the Demonstrative School. Intuitionalist as he is, he emphatically disclaims Intuitivism. $\mathrm{He}$ endorses Kleutgen's 'consistent and peremptory' refusal to 'credit the human intellect with any direct and immediate knowledge of God.' ${ }^{1}$ The Intuitions which he is concerned to establish are, for Theism, Data or Bases for inference, not categorical assertions of belief. No one is clearer on this than Ward was.

But he differs from such representatives of Roman Theology as Dr. Boedder, in taking Moral Intuitions as 'by far the principal' data; ${ }^{2}$ on these he lays the 'greatest stress.' ${ }^{3}$ He takes very great pains to set out clearly his procedure. Moral judgments as to right and wrong are the primary data: these are particular, not general, in their nature, though he uses the term 'axioms';" and they do not carry within themselves anything more than rightness or wrongness: no Theistic reference. "We must maintain it as most certain, and even most evident, that that attribute which is designated by the term ' wrong 'includes in its motive no reference whatever to God or to any Superior Being." 5 It is by a movement of inference that we pass to the Fact that there is a Supreme Rule of life, 'existing and pervasive' ${ }^{6}$ and it is a further step 'most momentous' 7 by which we pass to the conviction that there is a law imposed by 'rightful personal authority.' 8 He claims Newman and his favourite, Kleutgen, for the same precise position. Hence the first definition reached is, "A Necessary Being, faultlessly Holy, possessing authority rightful, absolutely supreme, exclusive, without appeal, over the whole existent or possible universe of rational or free individuals." 9

1 Vol. ii. 220.

${ }^{6}$ P. 94.

2 ii. 138.

7 P. 95.

${ }^{3}$ P. 140.

4 P. 90.

5 P. 98.
9 P. 104. 
This Ethical factor is the only one which he was able to give us in full.

The second factor is Intellectual, of the $\dot{a}$ priori order: with necessary truth as foundation, the inference to a necessary Being is direct. This inference he did not work out, but his controversy with Mill on behalf of the necessary truths was lengthy. Ward considered the Intellectual factor quite certainly vindicated. It is as a third argument that he resorts to Cosmology : and it is $\grave{a}$ posteriori, not from Intuitions. He reads it as Causative, and considers that it is Personal Cause that gives us the Causation we know best.

He accepts some subsidiary arguments, namely, Design, ${ }^{1}$ which he considers has been strengthened, not weakened, by recent science: and the argument from Beauty: but these only show the character of the Supreme Being. Feeling he does not mention. Consensus he considers only serviceable for the cultured (a curious line to take); and he makes a similar remark on the Ontological argument, which his evident dislike of Descartes leads him to associate only with the name of St. Augustine. This dislike is somewhat surprising; he says, and rightly enough no doubt, that when Descartes resorted to the Veracity of God as the ground for vindication of the objective value of our necessary thoughts, he betrayed the Intuitional cause: but he does not seem to be aware that Descartes had other forms of the argument which are, in effect, identical with what Ward is jealous to maintain, namely, the intrinsic value of the 'avouchments' of our intellectual faculties.

Ward is very clear in his statement of his method of Inference from Intuitions: ${ }^{2}$ whether he really establishes it or not is another matter. There is a passage near the end of Essay xxIII. which indicates some appreciation of where the weakness of the position lies. He says that the existence of Intuitions as 'avouchments' (a favourite expression) of intellect is made known to us not by Metaphysics but by Psychology: they are ultimate facts of mental life, he means. But there is a 'grave danger,' namely, lest prejudice be mistaken for intuition; and he agrees that "Intuitionist philosophers have not as yet given sufficient prominence to the psychological inquiry," and proposed doing so himself, had he been spared. But this, surely, shows that he did not rightly conceive the office of Psychology, which

$$
{ }^{1} \text { Vol. ii. } 140 .
$$$$
2 \text { ii. } 154 .
$$ 
is unable to distinguish between valid avouchments and prejudices. An appeal to common experience would stand him in good stead, and the early Intuitionists, Herbert for example, knew well why they made so much of the appeal to Consensus.

Ward's adhesion to Romanism did not prevent his retaining his broad outlook on belief outside what is produced by systematic processes. He stands with Newman on the distinction between Explicit Reason and Implicit Reason, and evidently enjoys elaborating this. He specially selects it as of firstrate importance in the wider sphere. "The acceptance of Religious Truth, on the part of one who has hitherto repudiated it, will be due far more to active and conscientious exercise of the will, than to subtlety, vigour, perspicacity of intellect." ${ }^{1} \mathrm{He}$ quotes at length from Newman, and his view is practically the same as to the processes by which 'certitude' is actually produced. But he is separated from Newman by his clearly defined attitude in favour of what is accomplished when Reason is called upon to speak and to bring into explicitness what has been implicit before. It can be done, according to Ward; Religious belief can be made so explicit that Theism is a system which is entitled to the adhesion of all reasoning men. "The whole assemblage of 'Religious Doctrine' admits of absolutely conclusive scientific establishment." 2 Its non-acceptance can be caused only through failure of 'intellectual competence,' 3 or unwillingness to sustain attention, or absence of 'patient candour.'

Ward presents himself, I think, as an example of the force of 'implicit reason,' of other influences than pure intellectual perception and inference. He notes, with great justice, the small value of Mill's opinions on Theological topics by pointing out that his lists of writers studied include no great Theologians. Ward's own affinities with certain modern Romanist Theologians, notably Laprune and Kleutgen, lead him to embody in his exposition long extracts from their writings, and, what is more important, to adopt ex animo their methods and conclusions. Still, he might have chosen others, and that he chose these shows us where his preferences lay.

1 Vol. ii. 145-151.

2 ii. 131.

${ }^{3}$ Essay XIII. 


\section{$\S 7$}

There are some Theists of this type who come to their position from a thoroughgoing re-study of Nature in the light of Evolution. The difference from the old view of Nature gives rise to some reconstruction of Theism. But it is to be noticed that in some important respects this is only when compared with quite recent systems, not going farther back than the Mechanical theory of the world in the hands of Cartesians, or the extrinsic teleology of Derham and Paley. The re-shaping comes from setting Nature once more on lines laid down by Greek philosophy, and the theology is akin to that of the Alexandrine Fathers of the Church, with of course much freshness of material. Especially notable are two points: (1) the Causality spoken of is immanent Causality, and (2) the view of Nature which is at the basis is not only inclusive of human nature but is emphatic in regarding human nature as the consummation of all nature known by us, and therefore as the principal basis for Theistic belief. Of these Theists two American Professors, John Fiske and Joseph Le Conte, are good examples.

Fiske, J. : Cosmic Philosophy, 1874 ; Man's Destiny, 1881 ; Idea of God, 1885 ; Through Nature to God, 1899

Professor Fiske is a worker who occupied himself in tracing Evolution through Nature on the lines of Mr. Spencer, and his first issue was similar, a quasi-agnosticism as to a Supreme Being. But as he worked on through External Nature into Man, discovering his spiritual character and his consequent place at the headship of Nature, as we know it, he found in Man the key to all Nature and the true clue to Theistic belief. In explaining Nature he found himself led by Evolution to belief in immanent causality, and, so far, in Pantheism as against Atheism. But spirituality or personality vindicates Personal Theism: 'God is Spirit' is a much more accurate thought than 'God is Force'; for the former phrase alone includes the highest element of what is known. He is not afraid to speak of God as quasihuman, and to declare that as such his existence is 'Religion's First Postulate.'

With this revised 'Nature' as basis, the Cosmological and Teleological arguments are the methods of intellectual construction: Causality shows perpetual Cause always operating in 
Nature; and as our knowledge of Power comes through the sense of our own effort, it is a personal Power that we directly know in Nature, and so our conception of the supreme Power is personal too. Teleology is refreshed by reference to organic life; a flower, not a watch, is the typical simile for Professor Fiske.

Goodness and Righteousness are held to be discerned in spiritual nature; and these being taken in full ideality carry us beyond what is known, towards higher and better, and lead to ascription of Transcendency.

The method being $\grave{a}$ posteriori, we do not find any metaphysical account of Infinity or Absoluteness. It is asserted; but its association with Personality cannot, it is thought, be made clear: we can work here only by 'symbolic conception.'

Consensus shows the vitality of religious belief, and therefore offers a vindication of it. Mr. Fiske came to differ uncompromisingly from Mr. Spencer in the de-anthropomorphisation -Mr. Fiske's own term-which led Mr. Spencer to eliminate from religious belief everything but a final Abstraction. But he takes occasion to revise the conception of God as too commonly set forth, which is Deistic, and super-natural in a false sense. He recalls to notice the Greek conception at its best; especially in the Church of Alexandria he finds congeners, waiting though they were for the confirmation which Evolutional science now gives to their view against the Roman Deism which they opposed and which has in later times usurped so much influence in Theology, with disastrous results. To Clement and Athanasius, not (in this respect) to Augustine, to Spinoza and Schleiermacher and not to Voltaire and Paley, does the philosophy of Nature conduct the thoroughgoing Evolutionist.

The conception of God as immanently operating through Natural Law, and therein through Spiritual Law, renders unnecessary and indeed altogether inept such opposition as the Transcendency view led Leibnitz to offer to universal gravitation, and Agassiz to natural selection in organic life. And similarly, the regarding ordinary phenomena as godless and looking only to extraordinary phenomena for signs of Divine activity is completely contravened.

Professor Le Conte (Evolution, Part III. 2nd ed. 1895) is less philosophical and less erudite than Professor Fiske, but 
he is more at home with the physical sciences. His conclusions are similar. Evolution means the immanency of some power, ' resident operations': which so far, would mean Pantheism. But the reference to Human personality is equally reference to 'Nature,' and it is here that we find the seat of our ideas of Causality and Design; and the Theism to which we advance is, therefore, Personal. Personality must be combined with Theism, although the accomplishment of it is beyond the power of conception, so far as Mr. Le Conte knows. The general tenor of his thought, therefore, is a spiritual Pantheism. 


\section{CHAPTER VI}

Type VI.-Social or Sociological Theism

\section{$\S 1$. Philosophers}

IN the Introduction the varieties of employment of Consensus, or the reference to the collective consciousness of mankind, were stated as (1) confirmatory of the experience of the individual by the Empirical Schools, of the reasonings of the individual by the Rational Schools; (2) as itself contributing a fact of widespread extent, needing interpretation, and yielding material for an inferential argument; these on the one side: and (3) as a substitute for the individual consciousness, or with at least a large share of legitimate authority along with the individual's private judgment.

I am not aware that any English Theists of note have taken up the position of making Collective consciousness the principal source of belief : all that can be done, therefore, in this chapter is to offer some observations on the general attitude to it, and to give a few instances of its treatment by those who have made the social factor prominent, although not giving it the chief place.

The acceptance of Rationalism by the main body of English theologians and philosophers in the seventeenth and eighteenth centuries accounts for the prevalent use of Consensus in the purely Confirmatory sense. Locke, indeed, who had opposed it as being a prop to the theory of Innate Ideas, finds his own Rationalism so completely satisfactory that he has no need of this confirmation; in this he is followed by Mozley (Miracles, Lect. IV.). But the bulk of writers of the Demonstrative type lay considerable stress upon its corroborative assistance. The Deists delighted to appeal to the record of ages; Cudworth, Barrow, and Stillingfleet set forth the testimony with more than ample voluminousness. 
The Intuitionalists found it still more incumbent upon them to resort to it as a way of reaching a Universality which Intuitions did not themselves provide. Herbert of Cherbury regarded ' universality,' in this sense, as one of the six marks of the 'common notions' implanted in man by nature, amongst them being the notion of the Deity; and it was precisely this employment of Consensus which prejudiced Locke against it altogether. In the eighteenth century Theism shared with Philosophy generally the resort to Common Sense which was made by so many of the Scottish School that it provides them with one of their titles. They employed it, as Herbert had done, to support their doctrine of Intuitions. The appeal to Common Sense enabled them to oppose Hume by meeting him on his own ground. $\mathrm{He}$ asserted that custom was the source of belief. "Well," they said, "but the evidence of custom is on our side, not on yours: custom, you say, gives causation without 'power'; we appeal to the common sense of mankind that by a 'cause' men mean that which has a 'power' to do what it does; you say that your own experience does not provide you with a notion of a Deity, but general custom is against you, for the experience of the greater part of mankind does include that notion." It is in a similar vein that a Scottish Intuitionalist of the present day, Professor Knight, gives 'persistence in history' as one of the tests of an Intuition, and claims that it is there to testify to the Intuition of God.

Amongst Empiricists Mill's attenuated Theism was purely a product of his own private reasonings: he disdained the assistance of his fellow-mortals. "To a thinker," he says, "the argument from other people's opinions has little weight; it is but second-hand evidence." 1 Mill's is either the rankest Individualism possible, or else a veiled reliance on thinking, equivalent to the most confident Rationalism.

The few English followers of Comte not only take the position of making Humanity the Subject of religious belief, but they proceed to set it up as also the Object of religion; thereby attempting an entirely new departure in the idea of religion, for self-admiration has been universally regarded as the very antithesis to the religious attitude: and this surely is equally the case whether the worshipper be a single person or a corporate body.

1 Three Essays, p. 156. 
Arnold, Matrhew : Literature and Dogma, 1873 ; God and the Bible, 1875.

Matthew Arnold comes as near as any one to the position of Social Theism. He is looking for a religion for humanity, and he looks to historical beliefs to see what men seem most to have felt the need of, and therefore what they have believed in.

This is the gist of his appeal to 'culture': it is opposed on the one hand to the idiosyncrasies of personal taste, and on the other to the arrogant claims of mere intellect. The man of wide reading in the past and varied intercourse with his fellows in the present will represent the Social mind: as an index to it, his opinions are worth more than those of philosophers, or of metaphysicians rather. So much is he opposed to these that he would rather appeal to the masses than to them: and finds "Messrs. Moody and Sankey masters in the philosophy of history compared with Professor Clifford." It is, indeed, inconsistent in him, as the pleader for wide reading of the best thoughts of humanity, to set himself to belittle the efforts of the greatest thinkers of mankind. But he does so, except for a few favoured ones, for he names as the greatest thinkers Anselm, Descartes, Locke, and Clarke, with Fénelon-a curious list. However, he is quite sincere, for he evidently thought that 'letters' had been a real source of human happiness, but that no one had ever 'enjoyed' the reasonings of 'metaphysicians,' implying that, in his view, the schools of Athens, the lecture-rooms of the Schoolmen, the classrooms of Kant and Hamilton were filled by dull reluctant minds depressed with joyless toil. We must leave him to settle this with such men of culture as Socrates and Cicero, who thought that such arguments as Causality and Design, which Arnold would leave to the lecture-room, were well within the thinking powers of every plain man, and well within the circle of his interests, too.

$\mathrm{He}$ makes the broad appeal to mankind again when he employs his favourite method of interpretation by Philology: and there, by manipulation of historical etymologies, arrives at what he thinks were men's religious ideas: and so he comes to his famous definition: by 'God' men mean Something not themselves which helps or 'makes for' righteousness. Like Spencer, he has pruned without remorse, and with the same result, the personality element has to go: men do not need that. So that, strangely for a man who dislikes Metaphysics, he chooses as the supreme idea a combination of abstractions! That good- 
ness is provided for in the world is surely a very abstract thought: and that the provider is 'something' of which all that can be predicated is that it is not the thinker or anything personal is, if possible, more abstract still. Descartes and Locke were surely more concrete than this. Arnold's writings have tended to discourage the pursuit of truth in Religion, to foster the idea that a number of misguided men have diverted great energies from beneficial purposes into the lost labour of thinking, and thus he has been a hindrance to that culture which he really desired to advance. Counterbalancing this has been his untiring insistance on good conduct, and his word for Theism as at least the belief in a Power over the world which is on the side of virtue. He probably thought that the Zeitgeist, the Social authority to which he appealed, was against thinking as a source of belief in any sphere except the sciences: and this made him all the more eager to fix nobility of conduct and elevation of moral temper on a permanent basis. When he is dealing with Metaphysics or even with plain thought he seems to be wandering. Some think that his religious writings were all waste of energy that ought to have been devoted to poetry and literary criticism. This was not his own opinion: his advocacy of Moral idealism, with Ethical Theism as its consequence, he himself considered to be a worthy service to his age.

As to the problem of Infinity, Matthew Arnold, though no metaphysician, knows the solution: all that can be said in favour of an Absolute Infinite he knows to be wrong: the unlimited is all that is meant, like a myriagon, an indefinite multiplication, that is all. And though no metaphysician he can see through the Ontological, Cosmological, and Teleological proofs, estimate their value and reject them. But though the term Cause has found no favour, he finds himself obliged to admit Power, and later on, though he has dismissed Infinity, he admits Eternity: and these two terms-whatever their significance - are elevated into the definition; the 'Something' becomes an 'Eternal Power.'

So that in his definition we have four points explicit: Eternity, Power, not ourselves, and making for Righteousness. This, though complex, he is not afraid of saying can be known by a single act of mind: men know it so, they have an Intuition of it. 
The main point, however, is the Righteousness, and Arnold's voice is notable because he is heard among those who insist that the moral order of the world and the moral sentiment in man directly suggest an Eternal Righteousness. He commends in the Cambridge Platonists their 'extraordinarily simple, profound, and just conception of religion as a temper, a behaviour,' and as such he is enthusiastic for it, himself. And it is the fact of this protest which gave character to what he had to say. His books were widely read, and in their day had some influence on English culture. The fact, however, remains that while appreciation of his literary criticism and of his poetry has increased since his personality was removed, there seems no sign of an influence beyond his immediate contemporaries issuing from his Natural theology, which is nearly as abstract as Mr. Spencer's, but not quite, for Righteousness is more concrete than Unknowability, after all.

KIDD, B.: Social Evolution, 1894

This book is by an independent student of contemporary science and of history who seems to have been so much surprised by finding religious belief a real influence that he set about seeking to account for it as a factor in evolution. As the function which he is led to ascribe to it is of the Social kind, he may be taken as an example of Social Theism.

In morality and in religion it is the social character which is before Mr. Kidd's mind: not the individual, but the individual in relation to society, to the race, is the subject of moral action: he is in search of beliefs which have a place in the process of history, in the development of men and of societies or nations.

It came to him as a distinct surprise that Intellect as a source of belief had been much less influential than he had supposed. His inference was that religious belief having a manifest superiority over intellect as a controlling and impelling force must have some more vital function to discharge; no merely subjective fancy, much less any invention of interested persons or classes, could have wielded the influence which history discloses; even verified Scientific knowledge seemed less valued by humanity and of less account in determining human life. That function he considers he has found in ethics taken in its wide sense as covering social life, and it is this: There is a 
need, in the interest of general progress, that specially gifted individuals should be brought into harmony with the general body of their fellows. Now natural selection would justify them, prima facie, in taking every advantage of their superiority: it would be simply following nature for them to do so, for especially in the extreme view of Natural Selection expounded by Weismann, they would be assisting nature if they acquiesced in the suppression of the unfit and the full exercise of their own gifts, as the 'fit to survive.' What they did would be reasonable and right. To counteract this no help could be given by Nature or such 'ethics' as Nature could justify. If therefore men could believe that there is a Super-nature which has some regard even for those who are by Nature's judgment 'unfit,' and if in the strong there could arise a sentiment of reverence towards that Super-nature and its wishes, these strong men would have a motive for repressing themselves and applying at least some portion of their powers not to push their own advantage, but to forego it and assist thereby those less endowed than themselves. Such a belief is helpful, and as it could not operate if it were baseless and a delusion, its utility offers a high and noble and necessary foundation for belief in the reality of such a Supernatural Being.

It is obvious at once that this argument is of avail against a particular form of quasi-philosophical belief, positivism or phenomenalism generally and naturalism in Ethics particularly. It has the same theory of Reason which they have, and the same basis of Ethics: Reason is empirical, and Ethics too. And it indicates how Theism may be reached empirically, and justified as a moral force. Against Socialistic Ethics of a more thoroughgoing kind it has little force: its idea of Society is of the atomistic kind, and religion is evoked to change the character of the incessant and inevitable conflict of natural man as so conceived. Hobbist in the character of Society, it is Hobbist also in seeking for an External Power allegiance to which shall give Peace, or rather,-for it goes beyond Hobbes in its hopefulness,-Progress.

To any other kind of Theism it renders no assistance: and it is a sign of the hasty way in which men judge in our days that it was acclaimed as a new ally by theologians whose metaphysical and ethical conceptions must have been dim and inoperative not to have at once made clear the lowly origin and 
scanty range of the contribution which this book had to offer. What it has to give for others than those indicated is simply a support of the Consensus argument: an independent student, not favourably predisposed but quite the opposite, has discovered the prevalence of religious belief, and its great influence, and so has worked out a function for it even within the purely naturalistic sphere. Bright in tone, and written with freshness and confidence, the volume has an attractiveness of its own, within its range.

Another argument from beneficent efficacy in Social life is given by Mr. H. R. Marshall, ${ }^{1}$ much more subtly worked out than Mr. Kidd's. His argument is that the Religious instinct is a device of nature to give us pause in our anti-social impulses, so that the social instincts may come into operation. This is not his account of the whole of religion; but he thinks that this is the side upon which Natural Evolution seizes hold. It is society versus the individual, but in a more refined sense than Mr. Kidd's. The individual may be working for Society, but his Reason gives him only his own interpretation of what Society needs : and the Religious instinct is required to lift him into a higher position than his own Reason can offer him. It therefore places him in a superior position for obtaining knowledge, and gives rise to impulses of more force than would come from what he himself can ascertain. The Religious instinct is treated of quite generally, as it operates in many forms. The book is powerfully written, but is very modest and tentative in its tone.

Mr. Balfour's revindication of Collective Consciousness under the designation 'Authority' has perhaps been dealt with sufficiently under his name. ${ }^{2} \mathrm{He}$ is exceedingly vehement against assigning primacy to the individual as Rational in the 'ordinary and popular,' not in the 'transcendental sense.' 3 He affirms that "a community of which each member should deliberately set himself . . . to examine the grounds whereon rest every positive enactment and every moral precept which he has been accustomed to obey; to dissect all the great loyalties which make social life possible, and all the minor conventions which

1 Instinct and Reason, 1898.

2 See Chap. III. \$ 10.

${ }^{3}$ Foundations of Belief, p. $195 n$. 
help to make it easy .. would stand but a poor chance in the struggle for existence. . . I It could never even begin to be: for if by a miracle it was created, it would without doubt immediately resolve itself into its constituent elements." 1 Again, "It is Authority rather than Reason to which, in the main, we owe, not religion only, but ethics and politics. . . . It is yet no exaggeration to say, that if we would find the quality in which we most notably excel the brute creation, we should look for it, not so much in our faculty of convincing and being convinced by the exercise of reasoning, as in our capacity for influencing and being influenced through the action of Authority." 2 By Authority, as he explicitly states, he means influences contrasted with Reason, "that group of non-rational causes, moral, social, and educational, which produces its results by psychic processes other than reasoning." 3 He carefully explains that he does not mean the argument from authority, but the direct operation upon the mind of other influences than reason. Here then we have the Social factor elevated to the principal place. And if Mr. Balfour is to be taken as unable to accept Transcendental reason, as his polemic against it would suggest, and he has deposed 'ordinary and popular reason' (of the $\dot{a}$ posteriori type), he would find his proper place under this Social or Sociological Type. My reason for not so placing him is given in Chapter III.

In the works (cited in Chapter III.) of John Caird and Dr. Edward Caird we find the Hegelian attitude expressed. Remembering that they mean by Philosophy of Religion its criticism, and justification, by Reason of the Transcendental order, we find that fundamentally it is the Individual, as participant in Universal Reason, who is the primary judge as to Religious belief. But when we descend to the lower stage of the psychological individual and the sociological community, we find Religion allowed by them to be in the main a social phenomenon. In its rites, as in its doctrines and hopes, it is the expression of the collective consciousness of mankind, and the history of Religion is amenable to scientific treatment, which traces the main lines of its development, and even indicates progress towards a far-off and indeed unattainable absoluteness. If the chapter in John Caird on the Necessity of Religion, taken with that on the Speculative Idea of Religion, on one side, is compared
${ }^{2}$ P. 196.
2 P. 229.
${ }^{3}$ P. 219. 
with the chapter on the Relation of the Philosophy to the History of Religion, on the other, this position will be seen in admirable clearness.

Dr. Edward Caird in his Evolution of Religion traces the progress above alluded to. Mankind is regarded as "a unity manifesting itself in an organic process of development " $:^{1}$ history can be looked at as the record of a single life in which all coexistences and successions of individualities are correlated: and the individual mind is a microcosm of this. Again, the Divine Being must be sought in 'the whole powers of nature and history' 2 or nowhere. His main lines are that man works out subjective religions and objective religions separately until he arrives at the stage of uniting both aspects. But all this is on the lower stage: the final vindication resides with the Free Self-conscious Spirit, above all natural society and natural religions.

\section{§2. Theologians}

Turning to theologians, it might have been expected that the difference between Roman and Protestant would have led to the former extending a welcome to Sociological Theism while Protestant theologians would uncompromisingly reject its advances.

That the Roman Theology does not at first appear to adopt this course for Theism is due to its approval of Rationalism as above delineated, which renders unnecessary any use of the Consensus argument except as Confirmatory. The Roman See might have included Theism among the dogmas of the Church as William of Occam had advised, but for a long time there was no necessity to do so. Following Aquinas, official authority regarded it as a truth of Nature not of Grace, yielding praeambula fidei. But in this way they were leaving the whole structure of belief unfortified on that side; for, if a man should be naturally-by natural employment of reason - agnostic, how could he make any beginning at all? The point of this was seen, and the obvious course taken of extending the protection of official authority to the fundamentals of Natural Theology, as seen in Chapter II. $\S 2$. This amounts to a resort to Social Theism: for it says that a man ought by individual reason to be a Theist, and that if, as matter of fact, his own reason fails in this respect, there is defect somewhere, and that it is the Social Authority which must 
be regarded as his deciding tribunal. The Consciousness of the Community expressed and formulated by official bodies seemed therefore to be the foundation of authority, but as this takes the form of insisting upon the sufficiency of Rationalism of the kind described, it would hardly be accurate to place the Roman theologians away from that type. Should, however, any one of them by any defect not see his way rationally, then the resort to Social Theism would be made. ${ }^{1}$ And yet I am not sure whether, taken in the concrete, it would not be more accurate to place the vast body of Romanist theologians simply under the type of Social Theists: Theists because they accept the deliverance of what they hold to be the judgment of the religious community. There is something incongruous in supposing a St. Francis or a Loyola or a Hildebrand to regard all their religous activities as depending in unbroken chain on their securing reasonable assent to the arguments in their manuals of Natural Theology, as necessary praeambula fidei. If pressed, they would have preferred to stand by the Faith of the Church if it had no preambles in nature at all rather than consider that lack of these invalidated the Faith. But inasmuch as the ægis of the Church had been thrown over the decisions of Aquinas the Faith was in that sense extended over them, and a social warrant was communicated to the teaching of that line of Natural Theology; and this warrant is maintained to the present day. A Romanist therefore is in the position of being expected by the Social authority to see cogency in Natural Theology, or at least to acknowledge that he ought to see it; so that if he sees it he comes under our Type II. ; if not, he finds refuge under this.

Is it really different with Protestant theologians? How many of them would advise an inquirer to take good care that he satisfied himself as to Natural Theology, by whatever rational or empirical method appealed to his private judgment, before he ventured to consider his Christian faith securely founded? The necessity for reinsisting on Justification by personal Faith and a

1 This is precisely what Newman had to do. He could not satisfy himself by Reason, and further, he felt the need of Authority in order to make his personal conviction general. Dr. Stanton* says that it was just because Newman thought the Anglican theory of authority was inadequate to provide him with this that he left the Church of England; although, as we shall see, he wrote out a Grammar of Assent afterwards, by no means Roman in tone or method.

* The Place of Authority, p. 4. 
resort to Private Judgment as opposed to counter theological and ecclesiastical exaggerations of other points at the close of the Middle Ages, has much to answer for in the way of setting up Protestant Christians as a mere aggregate of believers taken individually. But would it not be just as incongruous as it was with such older Catholics or such Roman Catholics as those recently mentioned, to suppose a Knox or a Baxter or a Wesley or a Simeon or a Chalmers holding their Christian Faith in temporary suspense whenever considerations for Natural Theology came across their minds? Was there in them any such overpowering necessity of proving a First Cause as there was of proving the doctrines of the Evangelical Faith? And generally, do Anglicans and Presbyterians-to speak of no others-fail, as a rule, to present their doctrine of God as invested with 'social' authority and commended by the acceptance of the Church? Would they not agree in assuring any doubting inquirer that he would do well to rest upon this 'social' approval of Theism, this incorporation of it in the Creed of his Church, pending some solution of his doubts or a retirement into the confines of purely Revelational Faith, should his private judgment finally refuse to yield a positive solution. The recourse to Social authority would hardly be made by Protestants in the peremptory terms of the Vatican Canons. But the essence, the invitation not to run counter to the opinion of the common consciousness of believers, would be the same: it would be an appeal to Social Theism.

In Christian Theology therefore, whether Roman or Protestant, there is either a confidence in some form of Theism, with a treatment of disbelief in it as pathological, or else in the background there lies an appeal to Social Theism for these, as for more recondite doctrines, which any person declares to be uncompassed by his private judgment. As between Roman and Protestant Churches the former has placed itself on a narrow ledge by its official selection of one particular type of Theism as the only one approved of: Protestants can at least make their choice among the various types before the resort to 'authority' need be called upon. The awkward position of Newman in this respect, and the claim for more liberty on the part of some younger Romanists of our day, have been alluded to in their place.

In recent Theology, outside that of the Roman obedience, varie- 
ties of reference to Social or Church consciousness are to be seen. A few examples will suffice to illustrate them :-

Martineau, regarding religion as seated in the consciousness of the individual, goes to the extreme in depreciating Social authority. He was wholly unable to see what collective mind meant in a way that could leave a sphere for individuality at all, and therefore to him influence from Society was 'external,' and, therefore again, not possibly religious: it could give us a must, not an ought. And in his Seat of Authority this individualistic attitude is maintained in reading Christian history. ${ }^{1}$

But Martineau's position is very far from being the attitude of modern of Protestant Theology in Germany, of 'Liberal' Theology even. Schleiermacher had begun with the individual when he rooted religion in the Feeling of Dependence, but he at once proceeded to extend the basis to the common experience of the Christian community, and his disciple Schweizer takes the matter of theology to be given by the devout consciousness of Christians as historically developed: the content of Faith is contributed by Christian experience as a broad history. The marked insistance on the 'Christian Society' or the 'Kingdom of God' is a leading feature in Ritschlianism, amounting, as Pfleiderer says, to 'Social positivism.' 2

In England the recognition of the authority of the Christian community has been a fundamental mark of the Oxford movement, as a change from the extreme individualism into which Evangelicalism had run. Although distinguished from the German contemporary movement by their tendency to run back to the consciousness of the Early Church, it was for the Oxford men essentially the common Christian consciousness which was appealed to. They held in respect the general consensus of

1 The extreme pole of depreciation is not unfrequently occupied by some who resort to Revelation: of which resort it may be either cause or effect. Dryden, for example, in his Anglican days, depreciating private judgment, depreciates only less than that the tradition of the best age of humanity :

\footnotetext{
" Canst thou by reason more of Godhead know

Than Plutarch, Seneca, or Cicero?

Those giant wits, in happier ages born,

When arms and arts did Greece and Rome adorn,

Knew no such system; no such piles could raise

Of natural worship, built on prayer and praise

To one sole God."-Religio Laici.
}

And so he counsels resort to Revelation.

${ }^{2}$ Divelopment of Theology: p. 193. 
religious people for the question of Theism as they held in respect Catholic Tradition for specifically Christian doctrines, although they none of them go so far as to vindicate purely Social Theism. A few illustrations may be given :-

Dean Church, in his book on the Oxford Movement, wrote: "Man cannot enter on his destructive criticism" (of certain doctrines and institutions) "without having to criticise, not one only, but all these beliefs, and without soon having to face the question whether the whole idea of the Church, as a real and divinely ordained Society, with a definite doctrine and belief, is not a delusion, and whether Christianity, whatever it is, is addressed solely to each individnal, one by one, to make what he can of it." Such a doctrine of the virtue of the Social factor in specially Christian belief is easily transferred, mutatis mutandis, to its appraisement for religious belief in general.

Dr. Lock, in his essay on the Church, ${ }^{1}$ opens his exposition with a reference to Consensus in its confirmatory function, but he proceeds: "The idea of a Church, then, as conceived in its most general form, and without especial reference to the Christian Church, is this, that it widens life . . . that it teaches, strengthens, and propagates ideas by enshrining truth in living witnesses, by checking the results of isolated thinkers by contact with other thinkers, and by securing permanency for the ideas; and that it expands and deepens worship by eliminating all that is selfish and narrow, and giving expression to common aims and feelings." In $\$ 2$ Dr. Lock proceeds to elaborate this view of the Community as a witness of truth, a depository, a 'home of ideas.' At the same time, so far as this Essay shows, we are not to put Dr. Lock down as an advocate of Social Theism. Strong as are the expressions used above, and others could be added to them, he has not himself renounced adhesion to reason as the justificatory authority. In order to understand you must first believe, he says; but this is a provisional stage, it is in order that you may understand: the authority is like that of a teacher of science " with assurance that it is rational, and that the pupil will understand it ultimately.' So that Dr. Lock is here quoted not as himself standing outside Rationalism, but only as expressing very clearly an intermediary and provisional function of social authority. By contrast, Mr. Strong resorts only to the Confirmatory use of the religious society. $\mathrm{He}$ has an independent

\section{${ }^{1}$ Lux M undi, Essay Ix.}


rationale of religious belief, as has been indicated in Chapter III., and when he comes to Consensus-which he interprets progressively - it is to find in it corroboration for the Rationalistic conclusion. Wide prevalence shows that the processes marked out are such as men actually follow; they are natural in the sense that human nature does so reason, and so conclude.

In another direction, Bishop Westcott illustrates the reaching out towards a fuller recognition for Social Theism on the part of one who yet will not leave the terra firma of Individualism. In the Gospel of Life there are passages which include clear reference to the corporate mind of humanity as evolving religious belief, notably pages 99 and 107, and his whole attitude to præChristian religions: the chapter on the presuppositions of Christianity is written with man as individual in view, but it could very easily be adapted to mankind as the subject; and the way in which progressiveness in apprehension of the message of the Gospel (p. 274 onwards) is propounded brings in the Race alongside the individual; and we might ask, is not the same parallel applicable to the apprehension of the Divine Being? There are similar tendencies in the Social Aspects of Christianity; Bishop Westcott accepts Comte's reference to the Family, not the Individual, as the unit of mankind, and expatiates on it. $\mathrm{He}$ proceeds to enlarge on the function of Nationality and of Race, and expressly places Religion with Language, Law, and Government as national in character. His words are emphatic here: "Language, law, government, religion, are in fact the fruit and proof of the life of the nation. They cannot be referred finally to the will or to the power of any individual." 1 And on p. 39 he enlarges in eloquent terms upon our debt to an incalculable past: "we cannot if we would start afresh from our simple manhood." And yet the impossible 'isolated man,' the placing of whom at the centre of all things is the "spring of all the anarchy and half the social errors by which we are troubled," 2 remains to Dr. Westcott the final arbiter who looks down upon all the social process only as yielding confirmation to his own personal judgment. ${ }^{3}$

Stanton, V. H. : The Place of Authority in Religious Belief, 1891

Dr. Stanton of Cambridge has devoted a volume expressly to this inquiry, in which the appeal to the Collective Consciousness
1 P. 38.
${ }^{2}$ P. 21.
${ }^{3}$ Gospel of Life, p. 85. 
figures very considerably: so much so that it might almost be called a definite example of this type. A large portion of the volume is occupied with belief in Christian Revelation, and in examining the Church and the Bible as authorities within that sphere; but it includes also a discussion of authority in religious belief in general.

Dr. Stanton himself ${ }^{1}$ endorses the Ethical form of Rational Theism supported by Consensus : to a certain extent only, however: he does not regard it as cogent in the way that Butler or Martineau do: ${ }^{2}$ it is only presumptive. He then extends his range further and brings in what I am calling Sociological Theism: the reference to 'Collective Knowledge.'

$\mathrm{He}$ makes a detailed examination of the reference to 'Collective Knowledge' as authority in things spiritual by comparison with collective knowledge in Mathematics and the Sciences, bringing out three points of resemblance: the necessity (1) for education from childhood's ignorance, which is the universal lot; (2) for progress in knowledge as a whole; and (3) as a substitute for individually acquired knowledge in the great majority. In all these Religious belief is parallel with Mathematics and Science. Then he compares it with Moral belief, and finds two farther points. The first of these is stated in terms not quite clearly marking out the position intended: a 'mysterious correspondence' between our minds and moral truths is given as a ground of our assent to them and to their authority over us; and a similar claim is made for religious beliefs. But Dr. Stanton will not call this Intuitivism: it is not 'intuitive or instinctive, as that doctrine has often been stated.' 3 His Note A shows that he is here repudiating Intuitivism in the sense of a special Faculty, as in Type X. What is it, then? The exact words are "a mysterious correspondence between (moral truth) and the constitution of our being, by virtue of which our trust and obedience may be justly demanded for it, even where we cannot fully verify its decrees " : ${ }^{4}$ and again, "this kind of authority, this spell which truth exerts over the human mind and heart and conscience, by reason of a certain fitness to them and to man's life, which it possesses." 5 If it is fitness to life which is insisted on, we have a strictly empirical ground: if it is fitness to the mind and heart and conscience, judging directly and prior to observation of the
${ }^{1}$ P. 59.
2 P. 63.
${ }^{3}$ P. 25.
${ }^{4}$ P. 28.
${ }^{5}$ P. 52. 
effects in life, we have what is meant by Intuitionalism: the power of the mind and heart and conscience to discern realities directly. But whichever it be, Dr. Stanton regards religious belief as parallel with it. Then there is the last point: these moral deliverances are confirmed by reference to consentient testimony, to correct weaknesses and defects; and similarly for religious distinctions.

So far, then, we have reference to the collective mind only in the sense usual with Intuitionalists and Rationalists, namely, as confirmatory and corroborative.

But Dr. Stanton's treatment includes an employment of it as a separate and principal source of 'authority,' and this in very clear and emphatic terms: "If religious knowledge is to exist objectively at all, and not relatively to the individual consciousness alone, the principle of authority must enter, as it does in every other kind of knowledge." 1 This is unmistakably clear. It is authority which is to carry us outside our individualities and give us 'objective' knowledge: and this is plainly to perform an independent and principal function, not merely to give a confirmation. Again, he considers that "our weak faith may at times be permitted to look through the eye of some strong soul," 2 and that "it may thereby gain a sense of the certainty of spiritual things which before we had not, and which we lose when we return within ourselves": this may be only confirmation, but it reads as if it meant more : and again, "that the volume of the spiritual experience of mankind is a fact vastly greater than the experience of a single individual": a clear statement of what is meant by the collective consciousness I am now considering. Further statements of the same import are made on pp. 58, 59,64,156,189. The last runs thus: "What is the testimony of the Church but the conspiring testimony (of individuals) strengthened and corrected by combination and comparison? ... A true view cannot be formed of the function of the individual if we lose sight of the society, or of the society if we ignore the individual. The individual must think and judge, but he should do so with the consciousness that he is but one member in a vast organism. He must live in a larger life; he must think as one whose own weak and narrow thoughts should be guided and controlled by the worthier, truer thoughts of a vaster mind." Observe, a larger life; and of thoughts,

${ }^{1}$ P. 5.

${ }^{2}$ P. 32. 
not only are weak ones confirmed, but narrow ones are made wider, there is increase of worth and of truth. Additions, that is to say, are made ('a material addition,' p. 62): and that both in extent and in value.

So that on the whole Dr. Stanton's position appears to be the comprehensive one of including Rationalism of the Ethical form strengthened by Consensus, and also direct appeal to Collective Consciousness as another principal source of religious belief.

It is to be noted that the Social Theism is carefully stated so as not to make it necessary to look for a fixed or infallible seat of authority in the collective consciousness. It operates relatively, and the individual may be a better judge than common opinion, and he may be called upon to resist it; at other times the greater authority may be with common opinion. ${ }^{1}$ The old opposition which supposes all the right to be either on one side or on the other is dismissed as 'crude' ${ }^{2}$ the relative functions require careful consideration, and admit of no determination of an absolute and final kind.

See Appendix $\mathrm{C}$ for a note on Anthropology and Social Psychology; and on Professor Baldwin.

${ }^{1}$ P. 7.

2 P. 10. 


\section{CHAPTER VII}

\section{Type VII-Theism of Feeling}

By national character neither Englishmen nor Scotchmen are wont to place a chief reliance upon Feeling as entitled to the control of life. There is no first-rate product of a Theology of Feeling before us, in English Theology. An Irishman might perhaps have ventured, but so far as I can learn, none has. No parallel to Rousseau has appeared among us: our Theologians who have had access to Schleiermacher and Ulrici have not followed them.

And yet there is some ground for surprise that Englishmen have given no great attention to Theology of Feeling when we remember that they certainly have given the world an Ethics of Feeling. For it is Englishmen and Scotchmen who have been the chief advocates, before the modern world, of Hedonism; Hedonism plausible, respectable, serious, yet still Hedonism. The Utilitarianism which takes Happiness as the criterion of right, and desire for it as the only real impulse to action, lives and moves in the realm of Feeling. Reason is yoked as a servitor, a guide to where enjoyable Feeling and happy life are to be found. "Pleasure and freedom from pain are the only things desirable as Ends" 1 was written not by Hobbes but by Mill. And as for desirableness, "the sole evidence it is possible to produce that a thing is desirable is that people do actually desire it." 2 Feeling gives the standard of judgment, it is the ultimate factor in life with the men of this solid and grave school, after all.

Now upon such a basis the construction of a Theism is as easy as could be found anywhere. If I find it pleasant to think of the world as governed by Eternal Beneficence, and very unpleasant to think of an unruled world in which I am a weak 
and perplexed soul, then by natural process I desire the Ruler. It is, in Mill's words, desired, and therefore desirable; the opposite is undesired, undesirable; and so the only valid and effective way in which I could be called upon to relinquish my belief would be to show me some object which I desire more. Can bare assertion of truth do this, and can an undesired and undesirable presentment, because as matter of evidence it seems most likely to be truth, move Feeling more? The actual course of Utilitarianism shows that its advocates suppose that truth is superior after all: that, in short, undesired and undesirable Fact is really the criterion and not Feeling; that in lack of evidence for a God-ruled world, desirable as that might be, belief must follow not desire but fact, even though that fact be a godless and chaotic world, a history without a clue. But the number of men in whom an abstraction called 'truth' can stir more desire than the concrete representation of a God-ruled world is limited. This indeed Hobbes, at the outset of modern Hedonism, plainly saw: to him it appeared that an External Ruler of the world would be a source of greater felicity to that world than no Ruler at all, and therefore the existence of such a Ruler was to be believed in. It would not therefore be forcing matters much to call Hobbism a Theology of Feeling not a Theology of Reason. Nevertheless Hobbes had no following in this. British Utilitarians have been predominantly Atheistic or Agnostic: holding that whether religious belief made men happy or not was irrelevant. They themselves embarked on a most honourable course of public life and wide philanthropy, and with this they satisfied their Feeling: if the world as it is was not an object of desire, then the world as they would make it should be, but there was no need for it to be theistic.

Of those who have set their faces against it as an intruder the Rationalists of course are the severest, and the most exclusive attitude is that of the Rationalists of the Traditional School. Not the Mediævalists, of whom many allowed its inclusion, but the Rationalists of the seventeenth, eighteenth, and nineteenth centuries, whose Notional rationale of belief led them to have the greatest dread of the 'false fires' of enthusiasm in every department, and not least in that of religious belief. This is what is meant by the 'dryness' of Rationalism, and as it ran its course with no lack of outbursts of Feeling all around it, there 
was nothing else for those who participated in these but resort to Mysticism or to retreat within the precincts of Christian Faith.

An instance can be given of an English Theism of Feeling, however, in the person of William James Fox, a well-known Unitarian minister, who afterwards took part in public affairs as member for Oldham. ${ }^{1}$ His position is that, parallel with Sight and Hearing, with belief in the Uniformity of nature, are such faculties as 'veneration, love, fear': these all "carry with them an assurance which leads to belief in external objects." "They have relation to something out of ourselves: which something is a reality." It is obviously true of the lower senses, shall we deny it for the higher? he asks. Religious belief is no accident: it grows as the flowers grow, it belongs to human nature. Fear, gratitude, the sense of beauty, the perceptions of power, lead up: intellect follows and shapes. Peace, hope, joy: these come to us amid the troubles of life and history, and lead us irresistably to belief in a Divine Source. Fox frankly praises Orientalism with its initial intuitions as against the logic of Western proof. The moral factor is there, and it is quite similar: it too is a sense and leads us to belief in a Judge. But it is only one sense among others, and it appears late in his exposition: he uses it chiefly in relation to Immortality. $\mathrm{He}$ prefers to dwell on the expansive Feelings, gratitude, veneration, love.

Fox's Theism is, as R. H. Hutton said, an 'easy-going æsthetic religion,' a 'popular Pantheism.' There is no need of a special Revelation for him, as he holds every good thought to be such. The Power he venerates is all-pervading. And as Providence is asserted in an uncompromisingly universal way there is no making clear what there is for man to do: except to feel. The extremity of idealism is not at all too far for him, and he seems unaware of the caricature he is giving when he asserts ' existence' for Shakespeare's finest characters,-i.e. because they are admired, and raise feeling in us,-and he goes straight on to speak of the 'existence' of the Divine Being as not very different. This is not a philosophical Theism : but it is a view of Religious belief held by an earnest public man, a speaker and a writer of influence in his day. In the dearth of esthetic champions in England it is curious to find that we have one who has

${ }^{1}$ Religious Ideas, Works, 1865, vol. viii. 
marched even beyond the most advanced vanguard of other countries.

In default of any Theism wholly of this type what is of interest is to see what reception has been given to Feeling by those who have allowed it a partial place.

Butler in his two Sermons on The Love of God-our love for God-is engaged in maintaining the naturalness of the affections, and of this one in particular. He dissociates himself from the extravagances of 'enthusiasm' on the one hand, and from neglect of Feeling on the plea of reasonableness in religion on the other; in this latter direction with severe sarcasm- " under the notion of a reasonable religion; so very reasonable as to have nothing to do with the heart and affections."

But he insists that priority must be given to reason, only when objects are presented are 'passions' raised, so "this submission of heart and soul and mind, this religious resignation, would be as naturally produced by our having just conceptions of Almighty God, and a real sense of His presence with us." It is a mark of what was being urged in his day that he actually has to argue that it is legitimate to apply the same justification to the affections which the presence of Him who is Infinite awakens in us, as to those which arise in view of the good and powerful persons who may come to our knowledge in ordinary experience. His chief concern is to impress upon his hearers that our love for God is not the same as enthusiasm or ecstasy, but is a natural affection of the soul.

A century later Julius Hare admits Feeling as an essential part of our complex personality. "We are bound to Christ" (his references are often within the sphere of Christian belief, but I take them generally) "by all our deepest, strongest, most personal feelings, . . . by love on account of love." 1 "Faith in its scriptural sense is not merely the assent of the Mind or Understanding to Divine truth, but that of the Heart, and of the Will." But he treats Feeling as subordinate: sometimes to Reason, upon which we depend for objects- "How can we love, or how can we hope, unless we have already believed in Him whom we love and hope in?"2 sometimes to Will, which in ${ }^{1} V i c t o r y$ of Faith, Sermon III,

2 Șermon I. 
Faith has a chief place, and it is Faith not Love which is made by the Gospel the 'ground of justification.' 1 The Affections are, indeed, placed lowest of the three factors, in order of time at least: "Nor can there be any action of the Will, except where the object it acts upon has been presented to it through the medium of the Intellect, and has at last awakened a ripple on the slumbering surface of the Heart." ${ }^{2}$ Feeling comes in "at last.' Still the general bearing of Hare is to insist that not until Feeling has been awakened is there a real vital hold on the truths of Religion. In his Sermon on The Law of Self-Sacrifice he takes the high ground that in love of God self is overpowered: egoistic love is 'wholly abolished.' It is Love which, so far from being individualist and subjective, is the principle which gives ' the highest glory to the highest life,' and is 'the golden chain whereby the whole creation is bound to the throne of the Creator.'

Newman opposes himself to a full admission of Feeling. $\mathrm{He}$ even asserts that the strength which the emotions contribute to assent is 'adventitious and accidental,' 3 and he gives no separate treatment of this side of our nature. $\mathrm{He}$ admits Feeling of a special kind, the Feeling which attends Conscience, but this is on account of Conscience not of Feeling in itself. And as against superstition he admits Love as a 'safeguard of Faith.'"

Dr. Boedder, ${ }^{5}$ on behalf of Traditional Rationalism, has nothing to say of Feeling: it does not offer one of the possible methods of Theism deserving serious consideration.

Dr. Martineau offers no separate treatment of it. He has said that Religion comes from more sources than one; from our sensitive as well as our intellectual and moral nature. But he dismisses it in less than four lines- "If the first of these were there alone, we should indeed be (God's) creatures, but know it not; the dependent relation would be complete, yet in the dark to us, as to any animal that shares it with us." ${ }^{6}$ So he passes on to the other two sources.

1 Victory of Faith, Sermon I.

${ }^{3}$ Grammar of Assent, II. vi. \$1.

${ }^{5}$ See ante, Chap. II. § 2.
2 Sermon II.

4 Univ. Sermons.

${ }^{6}$ Study of Religion, I. P. 16. 
Dr. Flint says: "Thought, feeling, and will-knowledge, affection, and self-surrender-are admitted to be indissolubly united, inseparably present, in religion, even by those who will not admit them to be all its equally constituent elements." 1 But he writes a special Note (X) on Intuition, Feeling, Belief, and Knowledge in Religion, in which he shuts up belief to knowledge- "In religion, as in every other department of thought and life, man is bound to regulate his belief by the simple but comprehensive principle that evidence is the measure of assent." Simple, indeed, is this principle, but unless a great mass of the Theisms we have before us is to be excluded from our approval, comprehensive it cannot be called.

John Caird in his treatment of Feeling ${ }^{2}$ allows that there is a popular inclination to it, and if religion is to be for all it must largely rely upon Feeling; and he recognises that in Feeling there is a capability for 'elevation of the human spirit into union with the Divine.' But he opposes to it that unless we know what the objects of Feeling are we are at sea; "the rapture of the sensualist and the devout elevation of the saint are precisely on a level; the one has as much justification as the other." We might have supposed that so spiritually minded a man would have readily allowed that the emotional life of a St. Francis had a kind of justification absent from that of an uncontrolled libertine or an unscrupulous but successful tyrant - but he does not. And then he lays stress on the variability: "Feeling is the side of my nature the characteristic of which is to be individual, variable, accidental," and therefore cannot guide me to correspondence with an object 'the very idea of which is so universal, immutable, necessary.' For Intelligence therefore he claims 'in its own nature a right to dominate feeling.'

Bishop Westcott does not treat of Feeling simply, but only as sense of Beauty: and in this he is followed by Mr. Strong.

Mr. Illingworth has an admirable lecture ${ }^{3}$ on 'Moral affinity needful for knowledge of a person,' in which he allows much force to Emotional nature : but he calls it Moral affinity, and does not let us see whether he is prepared to trust Emotion alone.

3 Personality, v. 
A careful and sympathetic account of Feeling is found in Bishop Barry's comprehensive treatise. ${ }^{1} \mathrm{He}$ has dealt with love of Beauty in a separate lecture (VI.), The Theology of the Imagination; then comes The Theology of Conscience, and Lect. viII. is The Theology of the Affections, where Love is entitled to a place in Theism, and an important one, inasmuch as, like Conscience, it leads to Personality and Moral quality.

There is a vigorous statement of its power of carrying us beyond Egoism, and effecting union between man and the Divine Being. In this, Love goes far beyond where Duty goes: its witness to unity between ourselves and God is 'a primary even an absorbing' effect of its influence: "Love is therefore the witness of (for) unity against excessive individuality."

$\mathrm{He}$ is not content to assign Feeling a place after reason has operated: it works itself in all along; in the mundane region "Sympathy gives a certain insight into human nature, denied to passionless intellect, and even to a cold stern sense of duty"; and that this is true for our belief in God also. And he also points out how affection seizes upon the moral excellences and clothes its object with an ideal vesture, and in so doing secures itself at the same time by the strength which comes from the moral basis.

With this high claim for Feeling, Dr. Barry is able to make effective criticism of such substitutes for a Divine Being as Comtism has lately offered the world, and, we may add, as Utilitarian Philanthropists have actually persuaded themselves into accepting as a substitute. And it stands him in good stead when in face of the 'awful mystery of the existence of evil' "the witness of the affections (speaks) with a peculiar beauty and power of its own," it is from Love that there springs ' undying hope.' To Dr. Barry "the Theology of Love completes the harmony of the many voices which testify of God." Coming from ' an independent faculty in the soul' it joins with Conscience and Reason in the great result.

I have no material for forming a judgment as to the Theism of Robert Browning. But a certain view of his position has been brought out with great vividness by Professor Henry Jones in his Browning as a Philosopher and Religious Teacher. To Browning, according to $\mathrm{Mr}$. Jones, Knowledge seemed to have

\footnotetext{
' Natural Theology, Lect. viı.
} 
'failed'; failed to give us compelling and conclusive belief : and he turned to Love. "For him, the principle working in all things is not reason, but love. . . . Love is the highest, richest conception man can form. It is our idea of that which is perfect." 1 Evil itself has an antidote here; "it gives the necessary opportunity for the exercise of love." 2 "All moral endeavour, to him, is the process of Primal Love." ${ }^{3}$ Professor Jones' Chapter x., 'The Heart and the Head-Love and Reason,' sets out at length an appeal on Browning's part from the intellect to the heart, and is well worthy of study from beginning to end; none the less because Professor Jones protests that Knowledge has not failed, and he himself holds a different view of the relative functions of Love and Reason, and strives to show that in Browning "it is not pure emotion, or mere feeling, whose authority is set above that of reason, but rather the Emotion which is the result of Knowledge. The appeal . . . is really an appeal to the character that lies behind the Emotion. . . For Love in man is never ignorant. It knows its object and is a conscious identification of the self with it." 4 And he charges Browning with taking Reason merely "as a faculty which invents arguments, and provides grounds and evidences," 5 whereas "the 'Love' of Browning is really implicit reason . . . : the manifold experiences of life focussed into an intense unity." But readers of Browning must be left to judge whether they regard him as resorting to Love because of failure of Reason, or as magnifying it for its own sake as entitled by its own inherent excellence to be the final arbiter between Agnosticism and Belief.

From an American man of letters who has preferred to remain anonymous we have, in the volume entitled God in His World, ${ }^{6}$ a prose rhapsody which is a Theology of Feeling. It is not an argument, nor an apologetic, but an 'interpretation' of the world as God's world through the presence in it of certain characters.

We might at first be disposed to place it under our Personal type, resting on Life not on Thought; the whole personality, not any part of it, is declared to be the base. Hence we have God not as Cause, but as Father: men not as 'minds,' but as
1 P. 218.
2 P. 271.
3 P. 304.
4 P. 325.
${ }^{5}$ P. 327.

${ }^{6}$ God in His World, Anonymous, London edition, 1890. 
'children of the kingdom.' But this promise of comprehension is not kept. The writer is presently absorbed by the contemplation of the character of Love as felt: " the reality is that of a feeling, divinely moved ': ${ }^{1}$ Love, which 'knows no ethical obligation,' no 'absolute truth.'

The dispensing with 'ethical obligation' leads to a rejection of the claim of Justice as a divine attribute; which 'has no significance save in connection with the conventional adjustments of a perverted life'; it has 'no vital meaning as applied to Nature or to the kingdom of heaven.' " Nay, frankly, "our hope is in the inequities of divine and human love." 3 But this is to cut down the idea of Justice and then disparage the residuum, surely.

Similarly, the dispensing with 'absolute truth' attenuates Thought in respect to objectivity, as distinct from our imaginings.

He sees that Love must be of choice, and that it may be perverted: but he does not meet the objection that in admitting choice he has included other elements than feeling: and he does not see that perversions imply that some standard is referred to, besides Feeling itself.

Hence an atmosphere of dreaminess pervades the whole. As a poetical interpretation it is often exquisite in its delicacy of touch and suggestion. There is an excess of sweetness indeed which, as it is seldom absent, begins to cloy, yet the impression on the reader is hardly likely to be forgotten. It is like a walk on a calm evening of summer, with a sub-consciousness that the impressions enjoyed are likely to be dispelled when the light of day returns and the call to affairs is heard again, when other faculties, other needs of life, will assert themselves and ask for other thoughts of God.

Before leaving this Type note should be taken of the tendency, already strong among philosophers and beginning to be felt among theologians, to incorporate Feeling with Thought in all our working towards beliefs. Under the term 'valuejudgments' it is being asserted that no mere affirmations or negations of bare fact or event or abstract principle are what we mean when we use the noble term, Truth. Every vital judgment is a judgment as to value or worth or it lies idly before us, unless it is only the dictum of some science which

I. xxxvi. xxxi.

2 II. xxvi.

${ }^{3} 16$. 
openly professes to be concerned with some partial aspect of things. And the recognition of this method is necessary when we attempt to cope with life, especially with the life of the soul or spirit, and most of all when we are in face of the relations of the spirit to the possibilities of the Infinite and Absolute, with Perfection and Supreme personal Goodness. Under the influence of Lotze in philosophy and of Ritschl in theology the value-judgment in which feeling has its inalienable place is commending itself more and more widely in Germany and Britain and America.

The appeal to Feeling has been extensively made within the sphere of Revealed Religion. The appeal is made to the 'heart' of man; the feeling of love evoked by the Gospel is regarded as the mainspring of Christian life. Many of those appeals come from those who move entirely within the Christian circle, and hold in light esteem both the successes and the failures of Natural Theism. Some of them issue forth and extend the claim of the heart which has proved itself effective for Christian belief, to the domain of natural religion. And not a few have despaired of Theism because of their dissatisfaction with such presentments of it as they have come into contact with, on the very ground that even if plausible they seemed not to give what was needed, while if manifest failures it was plain that satisfaction must be sought elsewhere. And it is, perhaps, not bold to say that, taking into account the extent of the sway of Feeling in actual life, a vast number of people find no attraction in the study of the philosopy of religion because they derive their religious beliefs from sources instinct with appeal to the life of Feeling and Emotion, if not in simplicity, as a part of the complex Personality, and they are repelled by the absence of Feeling from the systems presented by the great mass of theological and philosophical treatises. 


\section{CHAPTER V III}

\section{TyPe VIII.-TheisM OF THE Will}

THE time has not yet arrived for the appearance of a solid and systematic example of a Theism of this Type. Professor Ward of Cambridge is cited to show how Will is being regarded by a leading Psychologist, and Professor James of Harvard for the same reason, with the addition that Professor James goes some way towards letting us see the effect upon the philosophy of religious belief. There are then given some brief indications of how Theologians are likely to regard this attitude of Psychologists.

\section{§ 1. Psychologists}

Dr. James Ward in his Gifford Lectures, Naturalism and Agnosticism, 1899, makes little positive contribution to Theism. $\mathrm{He}$ is chiefly occupied with a criticism of Naturalism and Agnosticism as entering demurrers against Theism which require removal. Dr. Ward expresses himself in favour of a positive result as against Agnosticism; something can be known about the Supreme, namely, Monism against Dualism, and Spiritual nature as against Materialism. The Spiritualisation of Matter may be taken to be the main outcome of the lengthy discussions. How far Dr. Ward's Spiritual Monism is reached by transcendental method by reference to a Universal Subject of experience we cannot here determine: the book has been differently understood by different readers, and I do not introduce it here in order to place Dr. Ward under this Type, but rather, in order to show how the position of the Will in mental life is regarded by a leader in British psychology.

Dr. Ward's position is that our experience is fundamentally a process, determined by selective interest: a process of self-conservation, of life, a 'sensitive activity' in which 'thought' too is at work, but only as a partner. He says: "it is scarcely 
an exaggeration to say that the objects of experience are not primarily objects of knowledge, but objects of conation, i.e. of appetite and aversion. For though an object must be cognised before it can be liked or disliked, still it is to interesting objects that the subject mainly attends, and it is with these, therefore, that the subject acquires a closer and preciser acquaintance." 1 Again, "it is not that 'content' of objects, which the subject cannot alter, that gives them their place in its experience, but their worth positive or negative, their goodness or badness as ends or means to life": their power, that is, of getting themselves preferred, chosen by Will. In brief, Experience is selfrealisation, and its central feature is Activity.

The use made of this psychology is that the unity of nature is regarded as "the ideal counterpart of the actual unity of each individual experience " $:^{2}$ in this sense Nature is made by Man, the organising, the unifying, is done by the thinker. Causality is a conception arising in connection with our own activity and transferred to Nature; our inner experience is its own 'native domain,' where it is secure from 'attainder' or even 'impeachment' from 'Nature,' as if Nature were primary, independent, and complete in itself. So far therefore from mind being the shadow of Nature as shaped forth, this very shaping is the work of mind.

It is in the sphere of this active 'spirit' that Dr. Ward looks for the basis of Theism. By a treatment of the various finite spirits as acting 'inter-subjectively' we get to a wider world than study of the individual alone would attain. The pathway upward to a Monistic Spirit is merely pointed to: by what method the advance would be made the lectures do not open up. They are here referred to only for the purpose of showing how the Will-psychology can be used in order to make clear the nature of the 'experience' in which the roots of Theism are to be sought.

\section{JAMEs, W.: The Will to Believe, and other Essays, 1897 ; and Principles of Psychology, 1890}

In two of the Essays in this volume Professor James gives in his sparkling way admirable expression of the position which he assigns to Will in the formation of Belief. He holds the purpose of Belief to be in the main practical, and the mode of 
its formation practical also. Whatever may be the ideal condition of things, our beliefs are produced by our ' willing nature,' including not only deliberate volitions but such "factors of belief as fear and hope, prejudice and passion, imitation and partisanship, the circumpressure of our caste and sect." 1 As a rule "we disbelieve all facts and theories for which we have no use": he charges the very Rationalist himself with excluding other factors than reason only because he has ere this decided that these other factors are of no 'use' for himself. For himself the maxim stands, "Perception and thinking are only there for behaviour's sake." 2

He faces clearly enough the question, Is this pathological, or is it the normal way to belief ? ${ }^{3}$ and strongly insists on its normal and legitimate character. His grounds are: (i.) the failure of Rationalistic absolutism: it does not yield compulsory belief: "no concrete test of what is really true has ever been agreed upon" ${ }^{4}$ and he enumerates many which have been offered. The 'objective certitude' of which the schoolmen speak is not in our possession, and yet we are under necessity of acting. $\mathrm{He}$ is himself an empiricist as to knowledge; he knows that errors lie before us as well as truths: but he is less influenced by fear of the error he is certain to include than he is by enthusiasm for the portion of truth he fully expects his choice to secure for him. And (ii.) the inevitableness of these non-rational influences in relation to practical life. In seeking to consolidate scientific knowledge, indifference is required; but for discovery what, he asks, has been done by men who had no interest in the results? In moral questions not only can we often not wait, but our heart, our whole nature indeed, is concerned, and insists on having influence. Personal likings, our attachment to our social organism, are indispensable to us, and they are legitimate influences; so that "in truths dependent on our personal actions, faith based on desire is certainly a lawful and possibly an indispensable thing." 5

In an Essay on Rationality he goes farther, and asserts that "there are cases where Faith creates its own verification" $: 6$ " the truths cannot become true until our faith has made them so." 7 He supports his position by analogy with Reflex action in physiology, in a separate Essay. In our bodily acts a triadic
${ }^{1}$ P. 9.
2 P. 114.
${ }^{3}$ P. 11.
${ }^{4}$ P. 15.
${ }^{5}$ P. 25.
6 P. 97.
7 P. 96. 
course is observed: the impression-reaction in the nerve-centres -outward discharge. Parallel in the mind is the acquisition of objects of knowledge by perception-working-up by intellectand outward discharge (Will working with Feeling) in Conduct. On this analogy reason must not be supposed to work for itself in its middle stage: what it does is for the sake of guiding our conduct.

Applying this to religious Faith, he expresses the first affirmation in a phrase from Secrétan, 'Perfection is eternal,' and the second in the averment that it is good for us to believe this. To turn these affirmations into belief is one of the living, forced, and momentous options which he has distinguished from dead, avoidable, and trivial ones. Scepticism is out of account, for to doubt the good is to miss it as much as if we wholly reject it. $\mathrm{He}$ is convinced that religious belief gives rise to conduct which is other than would be entered upon apart from it: and the agnostic is in the same position as the man who holds positively to atheism inasmuch as he has to dispense with the benefit of religious belief. If the intellect of the individual cannot resolve the great question as to fact, there is before him a legitimate 'freedom to believe' by letting the consequences upon life come into account: Will and Feeling may come in. As an empiricist who is not acquainted with any absolute certainties, Professor James is content 'to take his life in his hand' and decide. And his decision is that in the idea of God he has "the most adequate possible object for minds formed like ours"1_ (i.e. without possession of criteria of absolute truths) - "to conceive as lying at the root of the Universe": it gives us "the most practically rational solution it is possible to conceive." 2

From his Triadic-reflex point of view he is constrained to blame many theologians for not being comprehensive in department One, the objects presented to us; but he is severe against attempts made by Rationalists (and Sceptics) to stop at department Two, where Intellect is at work: this he calls gnostical, ${ }^{3}$ and ascribes to them an 'unassuageable gnostic thirst.' For Theism "Not a sensible 'fact' of department One must be left in the cold, not a faculty of department Three be paralysed; and department Two must form an indestructible bridge." 4

$\mathrm{He}$ acknowledges that on this basis he stands only as an Individualist. But he finds that as an idea "God may be called
1 P. 115.
${ }^{2}$ P. 127 .
${ }^{3}$ P. 138.
${ }^{4}$ P. 130. 
the normal object of man's belief," ${ }^{1}$ as the history of religion shows. The mystical assertions of communion with God, apart from department Two, whether of simple men or of the highest mystics, he thinks a 'position of rational equilibrium' to 'most human minds.' This is as much as an empiricist could be expected to hold. Still, the conversion into belief lacks true universality, he confesses. And he requires that we respect one another's freedom, and live in a 'republic,' where each soul may "indulge its own faith at its own risks." ${ }^{2}$ A very appropriate doctrine for an American citizen, no doubt.

It should be noted that the Idea of God which Professor James has before him is very far from the full idea. Goodness is primary, and Personality ('mental personality' ${ }^{3}$ ) such as can be in connection with man, is clear: "the dead blank it of the world is changed into a living Thou, with which the whole man may have dealings." Infinity may be there if he stands by his term 'Perfection' in relation to Goodness, but when he speaks of Power he only says 'the deepest power in the universe': this empiricism does not really qualify him for dealing with Infinity, nor for Necessity, as we have seen. In these essays he does not enter upon them at all: so no more can be said: and we have another touch of a citizen of the country of many sects in his relegating all except Goodness and Personality to 'sectarian opinion' within Theism. He might have been classed with the Quasi-Theists of Type XII., but his positive contribution is really that of a psychologist contributing from his own science to the support of those who insist on raising to higher rank the function of the Will in religious Belief.

\section{$\S 2$. Theologians}

Turning to look for approval of Theism of Will among theologians, and failing the discovery of any who could fairly be brought wholly under this Type, we should still find a large mass of approval for it where theologians treat of 'Faith.' It will be found that, generally, when Faith is insisted on over against Reason it is either the right of following Feeling or the right of actively exerting Will that is meant, and in Britain by far most frequently the latter.

Dr. Swete, ${ }^{4}$ for example, though Intuitivist in broad effect,
${ }^{1}$ P. 116.
${ }^{2}$ P. 110.
${ }^{8}$ P. 127.
${ }^{4}$ Faith, Part II., see postea, Chap. $x$. 
comes near being content to regard Faith as a natural faculty differenced from Reason by the presence of Will. "Faith is in the last analysis the act of the will and not of the intellect-the surrender of the man at the very centre of his personal life to the love and care of God. . . ." "Faith is in its essence a moral act," which "enters the sphere of the reason and the understanding." Even though regarded as 'supernatural' (p. 26), it is itself an activity, therefore: while receiving revelation we are active.

Similarly, Mr. Scott Holland in his unwearied elaboration ${ }^{1}$ places Faith behind all natural faculties, behind reason, and affections, and even moral acts, as something underlying all those: but he expressly expatiates on its active side, on its calling into active play our innermost self.

Dr. Moule, ${ }^{2}$ whenever he refers to Faith, invariably does so in its sense of our actively exercising confidence or trust. It is not mere credence, but 'personal reliance,' an 'act of accepting reliance in immediate trust.' 3

True, there are theologians who treat of Faith as a kind of intellectual faculty of wider range: issuing in or receiving revelations as passively as when we are exercising intellect in the ordinary way, although, as Dr. Ward has shown, that is not so passive as is commonly expounded. But wherever theology insists that in Faith the element of personal activity, exercise of choice, determination to trust, is the prominent mark, there we have theology which will find itself in a position to welcome as an aid the most recent Psychology. The effect in relation to the future of Theism of the Rationalist types remains to be seen in the generation now before us.

Although, therefore, there is no list of names to be enrolled under this Type as distinctively belonging to it rather than to any other, there are grounds for deeming it likely that there will be an incursion into its territory. First from Theology, on account of its congeniality with the doctrine of Faith as an activity of the Soul. But, even more, from Philosophy: for in Britain Philosophy has ever been sensitive to Psychology: Hobbes, Locke, Berkeley, Hume, reflect national character; and the marked advance of Will-psychology of late years cannot but have influence in calling men's interests somewhat away from the Intellectualistic systems of the past.

1 Lux Mundi, Essay 1., Faith.

2 Outines of Christian Doctrine.

3 Ib. p. 185. 


\section{CHAPTER IX}

Type IX.-Personal Theism

\section{$\S 1$}

Newman, J. H. : Grammar of Assent, 1870 ; University Sermons, 1826-1843; Apologia, 1864

The British protagonist of the Personal School is John Henry Newman. He says himself that Keble started him, and he early addressed himself to the philosophy of belief. The fifteen University Sermons preached between 1826 and 1843 are mainly occupied with it; but these should not be used except for elucidation or to catch a glimpse into the growth of his opinions, for, as he himself says, they were written before he had studied what either Anglican or Romanist theology had to say, and he made acquaintance with Coleridge's writings only as they proceeded. After much further experience and study he 'pursued the subject' and brought out his Essay in Aid of a Grammar of Assent in 1870.

Newman's central position is that the whole personality acts in 'judging' and is concerned in assent; while 'reasoning' proceeds by abstractions and partialities, and no man really depends upon it for the beliefs by which he guides his life. To get a piece of knowledge into being a 'belief ' it must be brought into contact with experience: experience all round, not only of the external world but of the hopes, griefs, passions of our inner life. In his own terms, all 'real assents' are personal in their character.

To Newman 'reasoning' is the Lockian process of putting ideas together, and only going beyond sense to ideas which are copies and modifications of sense-data. It is the discursive process, and is methodised by the logic of Aristotle. It attains to 'general' ideas only by the process of abstraction, and so carries us into a region remote from the concrete living realities 
of life. Now in religion Newman considered that we had to deal with concrete living realities, namely, the soul of man, and God; and therefore, prima facie, abstract reasoning was out of court as the source of Assent: "In the concrete matter in which I am engaged demonstration is impossible." Effective for Mathematics, of a certain use in Logic, it was a mere trespasser if it appeared in the sphere of the concrete. The Assent given to abstractions he called Notional, that to concretes, Real. As this point is quite vital to any attempt to put Newman in his place, quotations must be given with some profusion. In his reply to Dr. Fairbairn he refers to Johnson's Dictionary to justify this limitation of reasoning to its discursive use. ${ }^{1} \mathrm{He}$ says: "The mind has the gift, by an act of creation, of bringing before it abstractions and generalisations, which have no existence, no counterpart out of it." 2 "The terms of a proposition do or do not stand for things. If they do, then they are singular terms, for all things that are, are units. But if they do not stand for things they must stand for notions, and are common terms. Singular nouns come from experience, common from abstraction. The apprehension of the former I call real, and of the latter notional." 3 Again: "We are ever grouping and discriminating, measuring and sounding, framing cross classes and cross divisions, and thereby rising from particulars to generals, that is, from images to notions. So that the terms in general propositions designate notions, abstractions, without counterpart in reality." 4 Again : "First principles are really conclusions or abstractions from particular experiences ... abstractions from facts, not elementary truths prior to reasoning." 5 So that our knowledge begins entirely with things or images, units, not with principles; even 'right and wrong,' 'true and false,' are given as so arrived at. Here we have explicitly the Lockian or Sensationalist theory of how knowledge is gained. It is the Nominalist theory of the Schools: universals are notions, aspects of things drawn out and kept separate by the action of the mind, 'non-existing,' unreal: not belonging to things and realities. And these are various, for one man may abstract one set of general notions, and another man another set from the same objects. There is therefore, so far, no place for general knowledge of the kind meant by those

1 Contemporary Review, 1885.

4 Ib. I. c. iii.
${ }^{2}$ Grammar, Part I. c. i. § 2.

5 Ib. I. c. iv. $\$ 1$.

${ }^{3}$ Ib. I. c. iii. 
who hold to the reality of Universals and the view that Reason is the faculty for discerning them in particulars or applying them thereto.

In a logic which starts from facts without first principles, and without true universals no move to Rational Theism can be made. We have seen that Locke found himself unable to apply it to Theism, and proceeded to borrow universals and principles from the older schools. But Newman is more consistent: he stands by his theory; with the consequence that in face of Theism he asserts that knowledge of the Divine Being is not to be sought at the end of chains of reasoning at all, but is knowledge of Fact. Of all concrete facts the Eternal Being is the supreme; and the assent to His being is not Notional at all, but Real.

How then is Real Assent to the supreme Fact obtained? In the same way as other real Assents, namely, by immediate apprehension in which our whole personality operates, and not by intellect alone. It is parallel with assent to existence of the external World, of other personalities, and of self: there is a rudimentary apprehension, and upon this follows what the process of experience contributes. Among these interpretative processes abstract reasoning is certainly to be reckoned: doctrine may be superimposed upon apprehensions, but the order cannot be reversed. Newman does not fly off, when reason is reduced to this secondary position, to some special faculty for religious belief, as is commonly supposed. The knowledge of God is Real and comes under Apprehension; his chapter on the Being of God is in Part I. of the Grammar, which deals with Apprehension. True, he invents a special term, the "Illative Sense," and this has proved misleading; but it is not for religion specially; and what he means by it is that 'sense' or apprehension is carried into the sphere usually claimed for Intellect: variations derived from our whole nature are carried forward into the field hitherto restricted to reasoning alone: it is 'a natural and spontaneous ratiocination,' and 'proceeds from concrete to concrete' ${ }^{1}$ 'no analysis is subtle and delicate enough' 2 for it; it varies between man and man: "one man may deduce from his moral sense the presence of a moral Governor, another not." Our personal characters are with us all along: in our memory, in our virtues- "there may be a hundred memories,

${ }^{1}$ G. A. Pt. II. c. viii. $\$ 3$.

${ }^{2}$ Sermon xiII. 
as there are a hundred virtues"1-and so in our inferences, which are personal also. And the Illative Sense in religion is of this kind: not a special faculty at all, but an activity in which the whole character is concerned. It "passes from point to point, gaining one by some indication; another on a probability; then availing itself of an association; then falling back on some received law; next seizing on testimony; then committing ourselves to some popular impression, or some inward instinct, or some obscure memory; and thus it makes progress not unlike a clamberer on a steep cliff, who, by quick eye, prompt hand, and firm foot, ascends how he knows not himself, by personal endowments and by practice, rather than by rule." 2 "Nay," he goes on to say, "leaving the track behind him and unable to teach another." 3

As individual, therefore, as the landscape viewed from the mountain-top, is the Divine Being of whom a glimpse is attained by the man who has ascended from the narrow valley of everyday experiences. That the mountaineer could so win access to a different and a boundless world is not to be supposed, and so it is too with the climber of the mind: no universal Being such as necessary and universal thought has before it could be so known; but this Newman does not say.

What place then is to be assigned to reasoning as one of the factors of the illative sense, as applied to Theism? It contributes some notions and notional inferences; by the vast majority quite unreflected upon, by the theologian examined and set in order: these are the 'Proofs' of Natural Theology. Of these, however, Newman has no high opinion. Of the Cosmological he says, "it is to me a perplexity that grave authors seem to enunciate as an intuitive truth, that every thing must have a cause": 4 it is "no intuitive truth, but only an analogy, from our own Will, by which we insist on reading all the world : its efficacy is only that of a formula under which things are conveniently represented." 5 Now if Newman had gone on to remember that the convenience was so great that every thinking person resorted to it, he might have reposed great confidence

1 G. A. Pt. II. c. viii. § 3.

${ }^{2}$ Sermon XIII.

3 It may interest readers to observe that the most distinguished Oxford layman of our day, Mr. Gladstone, followed Newman closely in this account of how knowledge is gained.

G. A. I. c. iv. $\$ 1$.

5 16. 
in Causality on his own principle; he disparages it because it could only lead to a notional assent, not direct to reality. But he need not have disparaged it at all, from his position that reasoning is supposed to do only a part of the work.

Teleology he accepts also as a maxim, in the form that order proves intelligence: of adaptation he is suspicious. And as to the fact of order, he does not find himself in a world in which it is manifest to the degree necessary to make this a conclusive argument. ${ }^{1}$ In the famous passage in the Apologia the perturbed aspect of the world is depicted with distressing gloom. In questioning the fact of order he sinks down to lower depression than Mill.

How, on this view of what intellect can do for Theism, he missed being the object of the Anathema Sit of the Vatican ${ }^{2}$ is a question of his personal history. It is in vain that Mr. Lilly $^{3}$ seeks to defend him by referring to a few scattered expressions of deference towards the formal proofs and to his attitude to the Moral proof: the Roman See requires consent to the validity of the intellectual testimony. In vain that Dr. Barry, the Romanist theologian, appeals for a sympathetic reading of Newman's phraseology, for he has to confess that "the language is remarkably unlike that of our schools." 4 In vain that Newman himself protested in Note II. and in his reply to Dr. Fairbairn ${ }^{5}$ that he did not understand himself to be opposing the official Tradition. I cannot read him as its ally myself, nor do I find that Romanists in general do so. In the Tablet ${ }^{6}$ a writer says: "Cardinal Newman's Grammar of Assent in no way represents the current and immemorial teaching of Catholic philosophical schools. The Natural Theology of our schools, whether English or Continental, is based frankly and wholly on the appeal to reason"; and he refers to the Decrees. And again, a recent article in that paper, written in an attitude of discipleship towards Newman, expressly rejoices that there are signs of departure from the official tradition towards Newman's position: a notable circumstance, but one implying that there is a wide difference between them. I shall have a further reflection to make later on.

As to the Moral argument, Newman's resort to Personality in

${ }^{1}$ G. A. II. c. vii. \& 2.

${ }^{3}$ Note II. in $G r$. of $A$., ed. 1895.

${ }^{5} \mathrm{Ib}$.

6 28th March 1899.
2 See ante, Chap. Ir. § 2.

${ }^{4}$ Contemporary Review, 1885.

${ }^{7} 24$ th June 1899. 
no way precludes resort to it, of course; and it may very well be that we shall find that it counts for more than the Intellectual did in the complex process. And this is the general impression he produces. Like Locke, ${ }^{1}$ he quits the sphere of abstract generals, and considers that he has found a 'first principle': Locke's was Causality, Newman finds his in Morality, Conscience. It is 'a moral sense, and a sense of duty'; "a judgment of the reason and a magisterial dictate." ${ }^{2}$ That is, he recognises both aspects: the sense of goodness and the sense of authority. ${ }^{3}$ Sometimes he speaks of one, and we get the impression that the Theistic inference will be to an 'External Master,' 4 especially prominent in the Sermons, but also very emphatic at times in the Grammar: it is a voice 'imperative and constraining'; it is 'a solemn dogma' 5 (that conscience is the voice of God): ' the inward voice of a solemn Monitor, personal, peremptory, unargumentative, irresponsible, minatory, definitive' $;{ }^{6}$ i.e., not a joyous voice, awakening gladness and praise in the heart of the hearer. Sometimes, but rarely, he speaks of the other aspect: conscience perceives the goodness of the law, and therefore of the Lawgiver." He has both in his view: 'the tribunal over which conscience has no power,' and 'the excellence which it does not possess ' ${ }^{8}$ but the sternness of command is uppermost, as I read him. The importance of Conscience for Theism is emphasised: "Conscience is nearer to us than any other means of knowledge" ; 9 "I use it, because I must use myself" : ${ }^{10}$ so, "it is the essential principle and sanction of Religion in the mind ": ${ }^{11}$ when aiming at a succinct statement as to why we believe in God, ${ }^{12}$ he says: "I feel it impossible to believe in my own existence (and of that fact I am quite sure) without believing also in Him who lives as a Personal, All-seeing, All-judging Being in my Conscience." A survey of the system and course of the world confirms the inward disclosure, though there are many difficulties; and he appeals also to Consensus, ${ }^{13}$ to the existence of the positive religions, their doctrines and their rites, in further confirmation.

So far as is indicated above, Newman recognises Morals with its essential ideality: he takes into account what ought to be;
${ }^{1}$ G. A. I. c. v. $\S 1$.
$2 I b$.
${ }^{3} \mathrm{Ib}$.
${ }^{4} \mathrm{Ib}$.
${ }^{5} I b$.
${ }^{6}$ I. c. $\nabla . \S 2$.
7 I. c. v. $\$ 1$.
${ }^{8}$ Sermon II.
${ }^{9}$ G. A. II. c. x. $\S 1$.
${ }^{10} \mathrm{Ib}$.
${ }^{11}$ Sermon II.
${ }^{13}$ Apol. c. iv. § 2.
13 G. $A$. I. c. v. § 2. 
and so far too he is emphatically for an Ethical basis of Theism, as part-the very core-of the Personal basis.

But Newman could not for long quit the region of the concrete; and it is because he turns from the ideal to the actual, from conscience de jure to conscience de facto, that there come from him those sombre utterances which are a mark of his attitude to the world of life; and thus it is that he talks of reason murmuring against conscience, i.e. fact against ideality, for he is here assigning the actual to the report of reason, and remitting the ideal to Conscience alone: thus he thinks that the view which Conscience should give is often obscured. In the Pagan world, before Christ, for instance, he thinks the voice was nearly suppressed; and at times he almost abandons idealism in his depressed view of what the majority of men actually are.

Besides the oft-quoted passage from the Apologia on the miserable moral condition which is disclosed to the man who faces the history of mankind, I would add the depressing passage in the Grammar ${ }^{1}$ where, in his insistance on the varieties in national and personal character, morality itself seems to be submerged: "nor will ever so many sermons about the inward satisfaction of strict conscientiousness create in my mind the image of a virtuous action and its attendant sentiments, if $I$ have been brought up to lie, thieve, and indulge my appetites": what more could Buckle or Mr. Leslie Stephen say? But Newman would urge, I think, that this is not our nature: it is deficiency and loss, even apart from the special doctrine of the Fall. This is what Butler would have urged, and as our English Intuitionalists generally have not been slack to deplore human failure to conform to the Moral law, these grim acknowledgments cannot be used to dissociate Newman from that school.

With Reason reduced in importance, and Conscience presented predominantly as authoritative, and with all the range of personality expressly claimed, we might have expected Newman to give room for the love of Beauty as a motive to religious belief: but he does not; when he comes within sight of such a claim he opposes it. Conscience "reaches forward to something beyond self, but the sense of the beautiful is simply for its own sake" :2 Conscience is a 'voice,' a term "we should never think of applying to the sense of the Beautiful"-(alas for Plato and Cousin and Ruskin !). At other times words escape him which show that

` Part I. c. iii.

${ }^{2}$ G. A. I. c. v. $\$ 1$. 
he had not thought it out, but could perceive that beauty might be a quality of objects. ${ }^{1}$ But the passage, "here, however, Faith and Conscience part company . . . in our experience," 2 is crucial against his resort to this argument. It is passing strange that so fine a spiritual genius should have had in his view Beauty as appertaining to external objects chiefly, and not have brought before himself the Beauty of personal life, the pathos of suffering, the emotions evoked by the drama of history.

On Feeling in general he would not rely: this too he would regard, taken alone, as not necessarily telling us about objects. But he does not treat of it separately: it works in and out with reason and conscience: indispensable for the attainment of real assents. But he cannot conceive it as the prius. "From the age of fifteen, dogma has been the fundamental principle of my religion; I know no other religion; I cannot enter into the idea of any other sort of religion; religion as a mere sentiment is to me a dream and a mockery. As well can there be filial love without the fact of a father, as devotion without the fact of a Supreme Being." ${ }^{3}$ This deep-seated distrust of sentiment as a basis for religion he communicated to his contemporaries at Oxford in a way that affected the Tractarian movement, in its early stages at least.

On the sufficiency of Natural Religion Newman stands where Pascal stood. His mind is grave : religion and morality are serious things: the joyousness of Faith is not its character for him. And he is deeply impressed with the prevalence of wrong and evil, of the fact that the life of piety and virtue is a conflict, with many defeats to be endured even by those who are to be eventually victorious: he is unable to disguise from himself the severity of the scene, and the solemnity of the inner voice, which he feels too deeply for him to be one of those who could trust the finding of God to that natural man to whom religion is so often not a joy, but a weariness.

In Newman, then, we have found as his idée-mère the appeal to the whole personality as the source of our natural Theism. Within that personality, instead of constructive Reason, such as Hare, for example, incorporated with Will and Feeling in the fulness of personality, we have a bare Nominalism, and the confinement of reality to individual things and persons: we do not come into sight of universal truths. Such notions as are

${ }^{1}$ G. A. I. c. $\nabla . \S 1$.

${ }^{2} \mathrm{Ib}$.

${ }^{3}$ Apol. c. ii. 
admitted are not 'common' by any necessity; every man selects his own. For himself he accepts religious 'notions'- - he can go so far as to enumerate twenty-two of them as predicates of the Divine Being, ${ }^{1}$ - and he hopes, no doubt, that others have the same or similar ones. But when we follow some of his subtle analyses, such as that in Chap. III. $\S 1$, where we are assured that the apprehensions which fill our minds are so varied as to be incommunicable, and that no Englishman can possibly appreciate a French salon or comprehend the passionate natives of Italy, our common nature seems to slip away from us, to be dissipated in millions of idiosyncrasies. What avenue to common belief, then, is possible? As to Notional knowledge, that is always inferior in strength and influence, and must always yield to the individual qualities which enter into the construction of the assents which are real. And so variety marks mankind; and, in fine, it is 'by minds carefully formed,' 'these favoured minds,' 2 that the high object of religion is apprehended. And in the general mind Newman's influence has, in this respect, fostered that very 'Liberalism' in matters of belief which he regarded as so pernicious. Young men who believe in nothing are known to say that they understand that Newman has shown that religious belief is variable: one man has it, another not; and they happen to find themselves in the latter category.

The place where he touches upon a bottom which could be a universal foundation is his Intuitional Idealism in Ethics; hence it would not be wrong, if a universal basis is to be taken as the only one we can seriously consider, to place him simply in the Ethical school. But he himself could not be satisfied with that: he has marked out so explicitly and with such wealth of refined analyses the whole personality as his basis that it would be trifling with history to refuse to take him at his word. Taken so, then, we have to say that his position is individual and personal to the last degree. For Newman, when the individual takes in ideas from society, he transmutes them into his own before he can use them; the veracity and authority of the mother is the ground of the child's real assent: but the turning it into a 'ground' is the act of the child's mind. ${ }^{3}$ It is open to him from this either to become ultra-protestant, Methodistic, or to look outside himself for an External authority as the guardian and teacher of common religious belief. As we

${ }^{1}$ G. A. I. c. v. $\$ 1$.

${ }^{2} \mathrm{Ib}$.

${ }^{3}$ G. A. c. ii. 
know, his resort is to Authority, by a procedure which he can justify on his own principles. For though the creeds, articles, and dogmata of the Church of Rome are notional, this is quite understood by her, and she does not require of her members an inner or real assent to what by the vast majority of men and women in the case of most doctrines, and by everyone in the case of some, cannot be comprehended; but the Church herself is a concrete fact, and claims adhesion by a real assent: on the basis of this, the notional assents are accepted, "for to believe in her word is virtually to believe" in all her doctrines. And amongst these Theism may be included in the case of those who, by their personal deficiencies or idiosyncrasies, have not been able to attain to a real assent for themselves.

It is known that Newman strongly resented the charge made against him that he was an intellectual sceptic who took refuge in External Authority for the foundations of belief. ${ }^{1}$ Dr. Fairbairn was somewhat severely handled by him for alleging this; and yet, what can we say? By no stretching of the term Rationalism can it be made to cover Newman's view : so far as reasoning is concerned he recognised no necessary principles which could enter into construction of universal belief: he believed that the principles which were set up by Rationalists were deluding them into accepting a narrow range of belief quite inadequate to the variety and complexity of experience, and he denounced the claim set up for Reason, and marked out a very limited range for its operation, namely, as an instrument to be used by other faculties of the soul. In comparison, therefore, with those who are looking only at Reason when they ask, Can man know God? Newman was a sceptic.

But if we exchange the term Rational for Natural, and ask is there a Natural knowledge of God, the whole volume of his work expressly declares his belief that there is, for the individual. For (1) he stands to the clearness of the Moral way of knowledge, and (2) he surrounds it with the multifarious processes of imagination, feeling, and reasoning as above adduced; and this is his Grammar of Assent. It is because he thought he was being charged with having no natural access to God at all that he called the language of Dr. Fairbairn 'monstrous.' That Newman has a Natural Theology, then, is just what he took so much pains to tell us: that it is Rational in the sense that Reason is

1 Contemporary Review, 1885. 
its source we cannot say, nor would he wish to claim it. How far it is of service as a truly theological exposition yielding universally binding truth, or how far it is so individualistic as to leave every man's faith to depend on the issues of his own individual meditations, what has been said in the text may suffice to show. Newman did well in avoiding the term Logic and naming his method after a positive science, Grammar; for it is really a psychology of how assents are reached, not how they should be.

Of course, for Newman himself, his study of the way of Theistic belief is a tribute to his interest in philosophy. He was himself in possession of Religion, and its issue in a life of piety. He needed no logic of belief any more than a St. Francis or a Wesley or a Lord Shaftesbury. But he was alive to the fact that the question was raised by the keener intellects of mankind, and the problem appealed to his own subtle and searching mind.

And so by long and patient steps he elaborated the Theism indicated above. But had he wholly failed, and the natural scepticism with which he has been charged been his, his religious beliefs and hopes would have been unaffected. He worked to satisfy his own intellect, with an ardour and a patience which are his own tribute to the claims of philosophy. For others there can be little doubt that in exposing the working of his own mind he had an implicit conviction-itself a matter of faith - that all men were capable of making the same assent that he made. If this is equivalent to saying that Newman was fundamentally a Mystic, so be it. In a history of the philosophy of religion, nevertheless, he is to be placed according to the method he laboured to vindicate.

\section{$\S 2$}

Hont, F. J. A. : The Way, the Truth, and the Life (1874-1893)

What we have from the late Dr. Hort is rather a gleaning of characters of Theological belief than a Scheme : and his writings are too desultory to enable us to make one out for ourselves. Nevertheless, in him the combination of learning with power of independent thinking was so remarkable that a brief attempt to make the gleaning into a sheaf must be made.

The difficulty arises from the comprehensive sweep of his interests: his mind was a battle-ground of the very highest 
forces at work in the nineteenth century: and no decisive result had been attained, immersed as he was in textual and other labours which, valuable as the results were, might well have been spared to a mind gifted with so much original thinking power.

I take him to have begun in the school of Hare, ${ }^{1}$ through the intermediary of Maurice, and to have been disposed to make the whole nature of man the tribunal of belief. But in this he did not remain. Notably he was unable to allow a leading place to Feeling: he regards it with distrust, of itself it is 'fleeting' $;^{2}$ reliance on emotions proved fatal to the heathen religions, involving them in the sickness and death which seized upon the emotional life of the Greco-Roman world. Again, in strong language he dissociates himself from felicity as a criterion: 'phantom truth' and 'salutary illusion' he will not have: truth is above efficaciousness: " economic truth concerning God would make every advance in knowledge an advance towards godlessness " $;{ }^{3}$ our 'felt wants' without 'apprehension' of something in Him beyond what we want "is not really converse with the true and perfect God, but with a self-made idol." 4 Feeling was a consequent of belief, and, at most, a source of confirmation. ${ }^{5}$

But it is on the intellectual side that his hesitation is most apparent. Coleridge and Hare included Reason: Hort was, at times at least, disposed to disparage it. He wrote to Dr. Westcott" in 1881: "I cannot feel or understand any necessity of . . . thinking God; belief in Him seems to me a secondary process, a result capable of being either received or rejected." 7 Against this we have to set his vehement assertions of the supreme value of 'Truth': " unfaltering faith in truth is, next to the faith in Christ crucified and risen, perhaps the power in man on which the future of human welfare most depends." Again, he really takes up a position in the field of Transcendentalism. He speaks of truth of which " the evidence is to be found in the light which it brings, far more than in any light which it receives ": 8 just as he said of Christianity, "if it is assumed as true, the universe can be beheld as subject to a comparatively worthy order, which falls to pieces when

${ }^{1}$ Life, ii. 155.

4 P. 212.

${ }^{5}$ P. 95.

It is a sign of the weakening of the Hare tradition in Trinity College that Hort says that he imagined that most of the members of the Erasmus Club took this view.

8 P. 12. 
Christianity is assumed to be a delusion." 1 And, generally, "all the great speculative questions are insoluble except on some view which gives unity to the universe." 2 And, explicitly for Theism, "Belief in God is not a supplement to other beliefs, but the only bond of their coherence and trustworthiness": ${ }^{3}$ "the impossibility of building (truth) without the keystone which the knowledge of God supplies." And, earlier, he had said that divine knowledge is indispensable: "the way of man is known only so far as the way of God is known." 4 He agrees with Hegelians in insisting that truth is progressive, but it is the Hegelians of the Left, for he substitutes this approximate truth for comprehensive and complete truth, which is not to be looked for as the result of a dialectical process from abstract to concrete.

I can only reconcile these attitudes by supposing that when Dr. Hort is depreciating 'thinking,' Reason, it is in the sense of abstract thought, purely intellectual activity; while he regards Truth as a concern of our whole personality, our life. When he is speaking of intellect he means 'logic and method,' 5 whereas by 'truth' 6 he means something that comes through vision which makes call upon our personal activity, such as no oracle or law or example could give.us, any more than any logic. That, in short, the percipient in truth is personal and the true object of it is personal also.

So that he comes back again to the resort to our whole nature: as he had said, "it may be that no element of our compound nature is entirely shut out from taking part in knowledge." 7 And, in spite of his disparagement of Feeling, and of the logical use of intellect, this would appear to be the representation of his prevailing attitude.

Intuitivism he will not have: "the truth of God ... calls not for the separate exercise of a unique faculty." 8 It is our natural faculties on which we are to rely. And if we take as our basis our whole personal life, in full activity, then coherence, order, explanation, are before us if we accept Divine truth, not otherwise.

It is to be noticed, further, that the sphere of experience which is to yield Theistic belief is the common experience of mankind. Any individual's experience is 'the merest atom of
1 P. 180.
${ }^{2} I b$.
3 P. 181.
${ }^{4}$ P. 17.
5 P. 172.
${ }^{6}$ Pp. 69, 172, 173.
7 P. 92.
${ }^{8}$ P. 76. 
the vital experience of mankind ${ }^{\prime}{ }^{1}$ the social form of personalism is what he builds upon. But here also there is no clear-cut decision: even for the 'mere atom' a strong and independent place at the centre is indicated, in which each man is to control the influences which affect him.

The interest of Dr. Hort's characterisation of belief is therefore to be sought in its exhibiting the play of diverse forces upon a grave mind, deeply pondering, conscientiously scrupulous. $\mathrm{He}$ sees the full width of the basis of belief, personal life, though he has not learnt to trust its æsthetic side; he sees the nature of Transcendental method, though he has not acquired confident trust in it; and his faith remains, on the whole, an expression of his personality. It is independent; there is no reference to names: other men's thoughts are there only if adopted and made personal. For reasons above indicated we have only these aphoristic notes instead of the 'system' which would have demanded more concentration of attention than Hort had opportunity of giving. They suffice to show that, had his mind been free, English Theology might have been enriched by such a 'system' of Theology as the Germans reproach Englishmen for failing to produce.

\section{$\S 3$}

Аввотт, E. A. : The Kernel and the Husk, 1888

This series of letters on spiritual Christianity gives an account of religious belief in the Personalist way. It is of special interest because of its evident independence; it appears not to be issuing from any great school of philosophy, but rather as a movement towards philosophy, in a mind trained by a liberal education, both classical and mathematical, and a spiritual conception and feeling formed by Evangelical Christianity. Full of autobiographical detail, especially as to the changes in Christian belief, much of the wider range of Theism is implicitly traversed also.

For belief the admixture of Imagination is insisted upon even in scientific knowledge and in daily conduct, much more therefore in our relation to the supernatural-the Being over nature who originated and supports it. The whole compass of personality is operative whenever we are concerned with knowledge of a person: "no human being can be understood in the 
daylight of Reason alone: affection and Imagination are needed to transport us, as it were, into the heart of a fellow-creature "; 1 "imaginative love, or sympathy, gives us the key to the knowledge of all human nature." 2 And so it is with worship of a Divine Being; reason is inadequate to lead us to that. Even ' higher Reason,' which he admits, and partly incorporates with Imagination, cannot do it. ${ }^{3}$ But he does not expect Proof, ${ }^{4}$ although he allows a saving possibility for proof by the Moral argument. He admits an act of Faith in religious belief, by which a desire is chosen and its object made a principle. And he asserts fully a practical nature for belief. The exposition is invested with autobiographical interest, and with the emphasis of original thinking.

\section{Mason, A. J., D.D. : Faith of the Gospel, 1887}

Dr. Mason opens his Manual of Christian doctrine with a chapter on the Being and Nature of God. He takes the position that absolute intellectual proof is not to be expected, but that practical certainty is at our disposal.

The influences of authority and education are noted, and the argument from Consensus is commended for its impressiveness rather than for logical force. The Cosmological argument is considered to be obvious, but not to be so cogent as some writers maintain. The Teleological proof is explained and commended. The peculiarity of treatment is in the stress laid on idealism; on ideals of perfection in the region not only of Right but also of Beauty: for these ideals seem not to be creations of the imagination but to point to Reality. The Moral basis is given by the appeal to history as well as to Conscience.

There is here more cogency in the separate factors than Newman could find, but the final result is not achieved until all are fused in 'moral purification' and 'spiritual effort'; these bring 'experience' to the soul. The Method is Personalism.
1 P. 43.
2 P. 53.
${ }^{3}$ P. 47 , note.
4. 69. 


\section{CHAPTER X}

\section{Type X.-Intuitivism, oR Mysticism}

This type of Theism arises in Britain in several quarters and works itself out in various ways. In most of its adherents it is engrained in their faith as Christians and in their mode of conceiving the life of the Gospel. In the 'Inner Light' of the 'Society of Friends,' with its claim that divine knowledge comes immediately by the operation of the Spirit, who is to men an 'inward guide and monitor'; in the 'experience' of the Evangelical Churchman and of the Methodist, quite personal and yet containing an assurance of entrance into transcendent truth, Britain has found its native parallels to the mystical doctrine of the Fénelons and Madame Guyons of the French Church. But with such Christian believers as gave any attention to Natural Theology the resort to Exclusive Mysticism has been exceedingly rare. ${ }^{1}$ With Mysticism of the Comprehensive type the case is very different, as the following pages will show.

1 For English Mystics of all kinds Vaughan, in his Hours with the Mystics, found twenty pages out of his seven hundred suffice him, and most of this is given to Fox and Barclay, the exponents of Quakerism. He thought our English nature so little adapted to the reception of mysticism that he wrote: "the torches of the Bacchantes, flung into the Tiber, were said still to burn: but what whirling enthusiast's fire could survive a plunge into the Thames?" (Bk. xI. c. i.). This gives an opportunity for a word on Vaughan's book. He was a Congregationalist minister who died in the prime of life. His study of Mystical writers has many excellent points and shows some sympathy, sufficient at least to have caused him to sojourn among them as matter of choice. But on the whole his judgment goes against them to a degree that amounts to harshness and severity, and could only have proceeded from a mind unable to set itself at all in accord with their temper, and as he proceeds this repugnance seems to grow upon him. The study is tentative and has the fault of missing a becoming balance between tediousness and levity in the style of the dialogue in which it is expressed. Had Vaughan lived longer he would have done better, though hardly in this direction. It is therefore a curious fact that the first Englishman in this country to take up Mysticism as a chief study was himself at heart opposed to it. Nearly all of what Vaughan says, however, is applicable only to the Exclusive Mystics : those who use Intuitivism as a startingpoint he cannot be said to include within his treatment at all. For a very different estimate see Mr. Inge's Bampton Lectures of 1899. 
In the seventeenth century, when the revived Classical learning had become a settled influence, and when Anglican theologians had followed it up by a renewal of attention to the Greek 'Fathers' of the Church's theology, there arose a band of friends who were moved by both these influences, and formed what may be called a School of English Mystics, the so-called 'Cambridge Platonists.' Heralded by two Oxford men, Sir Thomas Browne, the physician, ${ }^{1}$ and Dr. Thomas Jackson, the theologian, ${ }^{2}$ this was a group of fine-tempered men resident at Cambridge who found in the schools of Alexandria, both Pagan and Christian, an opening into the religious realm which the growing force of Baconian Empiricism on the one hand, and Cartesian Rationalism on the other, appeared to be closing to the natural vision.

\section{The Cambridge Platonists}

The Intuitivism which seemed to men like Whichcote and More indispensable for religious belief caused this group not

'Sir Thomas Browne's Religio Medici, 1634, was written when he was about thirty years old. He had studied at Padua as well as at Oxford, and took his M.D. at Leyden, so that it was not English influences to which we are to confine ourselves if inquiring for the sources of his Mysticism. Browne was one of the most genuine of British Mystics. It is not only that in literature he selects Mystical reasons, but his own temper was beyond question Mystical. In Philosophy as in Theology 'sturdy doubts and boisterous objections' had been conquered, 'not in a martial posture, but on my knees.' * The Faith to which he resorts is not only a higher Reason but over and above, and if need be against, Reason; Eternity, for example, is a solecism which 'confounds the Understanding,' yet puts the mind into 'an extasie.' A few tributes are payable to Wisdom, $a$ priori and $a$ posteriori both, as leading us to things divine: and he is a thorough devotee of Beauty, deformity being unreal to his eye. The world has a soul, man is a microcosm of it, Heaven and Hell are internal conditions, our neighbour is to be loved for God's sake, and God for His own.

2 Thomas Jackson, President of Corpus Christi, Oxford, in his Being and Attributes of God, anticipates the attitude of Cudworth, in combining 'Internal Experience ' with 'Speculative Argument': or rather in leaving them as alternatives ; some minds may prefer to lean on the one, some on the other. In his reading of Greek philosophy he approves of Plato (Timaeus) and Seneca on Plato against Aristotelianism, and he has already commenced giving the attention to Plotinus which was to be prevalent elsewhere. Among the Schoolmen it is Anselm whom he brings forward. There is no need to elaborate on his work : it was already regarded as 'sufficiently obscure' in 1651 even by Tuckney, a friend of the Cambridge men. But it is of interest as showing that the Platonic vein was already being worked shortly before the Cambridge men came forward. His Commentaries on the Creed, in which the above is embodied, were commenced in 1613: he died in 1640. 
to be satisfied with replacing Aristotle by Plato. For Plato had a dialectical ladder which they could not use, as they required immediate access; for this the methods of the philosopher Plotinus and the Christian teacher Origen offered themselves. And so they drank of those waters and gave us the most mystical form of Theism we possess.

They varied a good deal among themselves. Cudworth was much occupied with intellectual theology, and More began with inclusion of Cartesianism, gradually, however, growing more and more rhapsodical; but there was sufficient agreement in their reliance on Mysticism in the final resort, for theology, if not all over the field, to constitute them into a definite 'School.'

Not an originative school, and now removed for the most part out of the current of operative influences, I have to acknowledge that I have contented myself with a study of John Smith, and a glance over the voluminous pages of Cudworth. A fresh study of them seemed hardly called for when we have accessible the careful and detailed account of the group given by the late Principal Tulloch in his Rational Theology in England in the Seventeenth Century, 1872, in which they occupy the chief part of his second volume: to which may be added the criticism of Cudworth in Dr. Martineau's Ethical Theory, vol. ii.

Cudworth was the most learned of the group and the most powerful intellect. But unfortunately he had so little discretion in the employment of his talents that his chief work, 'The Intellectual system of the Universe,' is but a torso; it contains only Part I., 'The Reality of Divine Intelligence versus Atheism,' and the Conclusion; he wrote separately what would have been Part II., and it was published as 'Immutable Morality' nearly fifty years after his death, but he uses also the gist of what he would have said in Part III., 'Freedom and Responsibility.' And the pervading polemical form of most of his work leaves to us the necessity of collecting his own definite positions from out of the vast mass. Bolingbroke said that Cudworth ' read too much to think enough, and admired too much to think freely": this is from a hostile pen, but even Tulloch acknowledges that he was 'buried amidst a mass of philosophical antiquarianism'; that his work is an 'obscure labyrinth', as compared with that of his contemporaries Descartes and Hobbes, 
who also excelled him by 'turning up new thought,' not giving the results of exploration derived from learning already before the world; and from Martineau we have the endorsement that he was 'buried in massive erudition.'

In his Part I., against Intellectual Atheism, besides giving a voluminous treatment of the Consensus argument, Cudworth sets out the Ontological arguments of Anselm and Descartes, with a modification; he displays the Cosmological argument in the form of contingency, and insists, further, on perfection. But he proceeds to add the Platonic argument which gives character to the School, from the nature of knowledge through ideas,

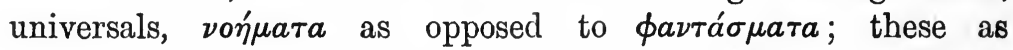
' modes' imply the existence of an External Mind. In Ethics he emphasises absoluteness - 'immutable and eternal' are his words: and from this infers the Moral character of the Divine Being in whom this character figures so conspicuously that he decides for Goodness as above Wisdom (and for both above Will): both of which are included by him when he speaks of Intellectual Apprehension. The 'Plastic Medium' which he interposes in order to explain creation is, of course, akin to Plato's 'soul of the world': on its materialistic side it has its modern analogies in some of the biological systems of our time. He was the most Intellectual, the least Intuitivist of the school.

In Henry More the gratitude owed to Platonism for drawing him out of his early doubts did not prevent his passing from Plato to Plotinus, and as he grew older he became more fanciful and theosophical. But he wrote with a charm of style and spirituality of tone which gave him the widest circle of readers obtained by any of the school; yet so mingled with rhapsody that they 'never became literature,' Tulloch considers: and no part of them has really survived into this century.

With John Smith it is very different. He died young, and what he had time to write is all contained in a single volume: we are spared all controversy; and he attains a largeness of style and impressiveness of tone which brings his work distinctly into literature. Matthew Arnold is emphatic in his praise of the fine piece, The Excellency and Nobleness of True Religion, and claims for it a place in English literary history as well as in every theological student's library. With this piece we take 
The Way or Method of attaining Divine Knowledge and On the Existence and Nature of God (in the volume published by the Cambridge Press in 1859, Select Discourses of John Smith).

With Smith it is not in knowledge but in life that the way to a Divine Being lies. Knowledge is only real when 'digested into life and speech'; without virtue and goodness it is dry and empty: divine truth upholds itself in hearts and lives. He sets out the fourfold way of Simplicius, the Neo-Platonist-the life of body, of body and soul, of the lower soul, and of the beginning of the purified soul. At the end of the discourse on Existence he gives the threefold knowledge of ' the Platonists '- $\kappa a \tau$ ' $\epsilon \pi \iota \sigma \tau \eta \mu \eta \nu$,

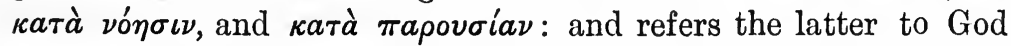
alone, and even the second is only partially attainable by us in this life of vision 'through a glass, darkly.' Through this glass, however, we can see signs of the Deity, but Smith looks chiefly into the soul for them, not into external nature; in the latter we may trace only footsteps, in the soul we may see a reflection of His face. In these reflections he sees Goodness and Beauty: it is no bare intellectual conception.

But in other places he is more under the influence of Plotinus and makes claims for Intuitivism; we can 'converse'

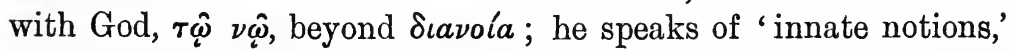
of 'intellectual touch.' The discourse on Excellency is permeated with the notion of a separate religious faculty by which we appropriate the light flowing direct from the Divinity; ' the word that God speaks, having found a way into the soul, imprints itself there, as with the point of a diamond,' directly, immediately. Taking this latter discourse as showing the attitude in which he died, in the bloom of his powers, it seems that while he allows something to the mediacy of 'reflections' in the life of the soul, he is becoming more and more Intuitivist in his way of Divine knowledge.

That Goodness and Beauty rather than any intellectual characters are the conspicuous features of the Divine Nature is plain throughout. A few words are desirable to indicate how ingrained was his appreciation of the æsthetic aspect. In divine truth he says 'there is an inward sweetness and deliciousness ' ${ }^{1}$ he appreciates Plotinus' expression 'divine knowledge makes us amorous of divine beauty, beautiful and lovely"; "wheresoever we find true beauty, love, and goodness, we may say, here

1 P. 9.

2 P. 20. 
or there is God"; " ${ }^{1}$ "those scattered rays of beauty and loveliness which we behold spread up and down over all the world, are only the emanations of that inexhausted light which is above." 2 He speaks of the "infinite beauty and loveliness of the Divinity'; of 'the delights and sweetnesses of the religious life'; of 'the sweet relishes of Divine goodness'; 'the anticipations of blessedness.' These citations are made because it is undoubtedly rare in English theology to find the enthusiasm for beauty; and yet, so far as is known, John Smith was of pure English descent: he was the son of a small farmer in Northamptonshire: and the hardening of English theology in the eighteenth century, and of its ethics too, is ordinarily explained by a sweeping reference to the English character as essentially prosaic. True, much of this in Smith came through Plotinus and the Alexandria mystics, but why did he go to them? and how is it that the beauty of religion so evidently possesses his inmost nature?

We may broaden the range of this last paragraph, and notice how profound is the essence of Theism as conceived by John Smith and his fellows, at their best. Philosophy could not give it, if by philosophy we mean only intellectually gained knowledge: for them religion is a mood, a temper, a habit of soul ; and God is Wisdom, Beauty, Blessedness.

Tulloch marks three defects in the foundations of this Cambridge group: (1) Confusion of Platonism with Neo-Platonism, (2) Fancifulness, (3) Misappreciation of evidence.

Of these defects John Smith at least is scarcely chargeable with the second; but as to the third, a mere glance over the sources of his quotations and the authorities to which he refers shows that Tulloch's objection is just; if he wished to prove anything he had little conception of what authoritative evidence meant. But 'proof' was but little in their mindsexcept Cudworth's. They were Intuitivist, they possessed their own intuitions, and if they found writings where similar intuitions were set forth, or where a happy phrase gave a fine expression for what was in their own thought, they cited and quoted. On the first head they all stand open to the objection : they were not Platonists but Plotinists, as Coleridge said. At the same time, I think that Tulloch was hardly able to give 
them full justice, nor Coleridge either; both were opposed to the Intuitivism of which Plotinus is an extreme example, and of which Cousin said that it was "le mysticisme le plus savant et le plus profond qui soit connu." ${ }^{1}$ It was not quite that, but it was near it. As Professor Seth writes, while marking its transitional character, and severely reprehending its departure from the actualities of life, Neo-Platonism has "refined and strengthened our emotions and susceptibilities," and produced "the consciousness that the only blessedness which can satisfy the heart must be sought higher even than the sphere of reason." ${ }^{2}$ I think we may assign to the Cambridge Platonists a similar influence in their day.

They have not won a permanent influence, for they suffered in not being sufficiently independent. They went back along the tracks of culture and brought up buried treasure; which proved too rich for themselves and superseded injuriously the necessity for their own efforts of independent toil. But their influence was sufficient to let English Theology feel that the height of Mysticism was not wholly in foreign occupation; and many a touch of high thought which brightens the seventeenth and eighteenth centuries is due to the men of the Cambridge School. ${ }^{3}$

\section{§ 2. Eighteenth Century, especially William Law}

The eighteenth century is commonly thought of as the age which protested against Enthusiasm. It certainly did so, and in a sense which immediately concerns our present inquiry, for the protest was made, as Mr. Abbey points out, ${ }^{4}$ not so much against practical enthusiasm as against 'certain modes of thought and feeling,' theology included. A succession of dignitaries, theologians, and philosophers joined in protest, but from this very fact an inference is suggested, namely, that the current of 'Enthusiasm ' must have been fairly strong to need so continuous and so keen a line of disclaimers and warnings. The fact is that a current of Mysticism was running fairly strong just underneath

${ }^{1}$ Le Vrai, le Beau, et le Bien, Leçon v.

${ }^{2}$ Ency. Brit., art. 'Neo-Platonism.'

${ }^{3}$ The documents which Matthew Arnold would save are Hales of Eton's Remains ; Whicheote's Sermons and Aphorisms; Cudworth's Sermon before the House of Commons and Sermon II.; More, Simple Sayings ; and Smith's Discourses.

+ English Church in the Eighteenth Century, c. vir., Enthusiasm. 
the surface: and Mr. Abbey notes its appearance above it in the following facts: the discussions on Spiritual Illumination as compared with Reason, Scripture, and Church Authority; on the properties of evidence and the nature of Reasonable religion; on the essentials and non-essentials of Christianity; on toleration and comprehension; the attention given to Fénelon, Guyon, and 'other foreign Quietists'; the influence of the Moravians; and the position occupied by the Quakers, who 'at the beginning of the century had attained the zenith of their numerical power.' To these we may add occasional utterances in favour of Mysticism on the part of men usually thought of as eminent for eighteenth century attachment to a sober temper in all things, such as Johnson and Cowper; and also that it is to be looked for, not so much in writings on Natural Religion, where philosophic calm prevailed, but in expositions in which the Gospel was connected with Natural Religion by a mystical treatment of both. It remains true, however-and in saying this I find that I can claim, implicitly, the great authority of Mr. Abbey-that the protest against Enthusiasm in the high quarters of literature, philosophy, and theology availed to prevent the appearance of a Mystical Theism of the Moderate or Comprehensive kind: what did appear was of the Extreme type.

Of this, however, we have an example of a high order of interest in William Law, a man whose powers as a writer everywhere win encomium, while a tribute of deeper admiration is accorded when Mr. Leslie Stephen is impressed by him as 'the most religious mind of the time.' 1 Much of Law's writing is occupied with controversy, and much with practical exhortation; moreover, in his later life he passed under the influence of the seventeenth century German Mystic, Jacob Behmen, and to some extent obscured his own individuality, strong as it was, and alienated most of those Englishmen who had hitherto regarded his influence as beneficent, notably Wesley. Still, in whatever proportion the ideas were original or borrowed, Law's writings form an integral part of our literature, and the traces of Teutonic haze or dreaminess vanish in the eminently luminous English of which Law was a master; while the absolute sincerity of tone throughout declares that the ideas he is expressing were vital forces in his own earnest mind.

The book most germane to our purpose is The Way to Divine

${ }^{1}$ English Thought in the Eighteenth Century, vol. ii. p. 405. 
Knowledge, published in 1752 : three dialogues intended expressly as an introduction to a new edition of Behmen, and written with the Christian Gospel as part of the subject-matter of 'Knowledge,' but including a philosophy of religion in general. That the way is by direct intuitive apprehension, apart from the ordinary channels of knowledge, is the thesis maintained. Religious knowledge is self-evident, a man must find it in himself. "Observe the word self-evident, for there lies the truth of the matter; for you have no more of the truth of religion than what is self-evident in you. . . . You can know nothing of God, of Nature, of Heaven, of Hell, or yourself, but so far as all these things are self-evident in you." 1 What he is here protesting against is demonstrative reason compared with immediate apprehension in any department of 'knowledge,' and afterwards he separates knowledge of God from all other kinds of immediate apprehension. He proceeds indeed to discard the term 'knowledge ' in favour of 'life,' 'spirit,' which can in no way come to a man, but must be 'born' within him, when indeed it constitutes his true 'nature.' It is the awakening of a 'particle of Divine Life' ; ${ }^{2}$ even the Light and Goodness of God cannot 'enter into' a creature 'as an external thing that may be given to it,' they 'must be brought forth as a birth in it.' ${ }^{3}$ But that the knowledge of God may be so born in every man is the ground-idea of the whole of Law's religion.

Other sources of knowledge are quite out of the question: and Reason especially is repudiated every time there is opportunity. "Reason has only its one work or power, which it cannot alter, or exceed; and that one work is, to be a bare observer and comparer of things that manifest themselves to it by the senses: . . . when, therefore, reason takes upon it to determine on things not manifested to it by the senses, as to judge about a Divine New Birth, a Divine Faith, or how the soul wants, or does not want God; it is then as much out of its place or office as the eye that takes upon it to smell." 4 And as Reason can do nothing for Religion, neither can it do anything against it- " only where religion is become a dead form, has lost its true state, and is dwindled into opinion." 5 By Reason he means the Reason of Empirical philosophy, of course, and his position on the intellectual side comes to this: Reason cannot give knowledge at

1 P. 185.

2 P. 126.

3 P. 61.

${ }^{4}$ P. 51.

${ }^{5}$ P. 184. 
all; the springs of ordinary knowledge are the senses, and no one of these can in the least be testimony against any other: while beyond the senses is the Spirit which is 'born' in a man, and against this no single sense, nor all the senses together, can testify; it is an original and independent source of knowledge itself, and of a different order from them all.

Although Law's conception of the Divine Being is ethical, belief is not arrived at by a moral argument; we cannot begin at that end, for the moral life has no real worth in itself, all its value comes when looked at from the other side, as dependent on spiritual apprehension of Divine Goodness. It is important to note, however, how thoroughly ethical Law's conception is; the intellectual conception is wholly valueless to him: "For what a God is this, that is only proved to be, because something now is, and therefore something must always have been, an infinite, eternal something. . . . What a God, I say, is this, which is as serviceable to the cause of Arianism, Deism, Idolatry, and Atheism, as it is to Christianity? For the Atheist has his omnipotent, eternal, first cause, as well as all the disputees for a God ": ${ }^{1}$ the terminology here shows that to Law belief in a First Cause did not remove a man from the category of Atheism at all. On the other hand, his own favourite definition of the Divine Being is 'the Eternal Will to all Goodness,' and his consequent account of man is that he is a 'creaturely' Will which wills and works with God, who is the immutable Will to Goodness; and the enjoyment of the goodness of God is the crown of blessing.

As Law remits altogether the intellectual problems as to Infinity, Personality, Transcendence, and Immanence, there is no scope for doing more than note their absence; the questions do not concern him, or if raised they are answered by him with a simple reassertion of his intuitive way to knowledge. His method is individualistic, of course; social character does not enter into the essence of religion for him : every man is in direct union with the Eternal Goodness. Still, religion is impressively stated as being of universal scope: what is true for one man is true for all. "Wherever the heart looks up to God ... there all are of the one true religion, and worshippers of the true God, however distant they may be from one another as to time and place." 2 Besides the Gospel side of Christianity he affirms an "original universal Christianity which began with Adam, was

${ }^{1} \mathrm{P} .187$.

${ }^{2}$ P. 76. 
the religion of the patriarchs, of Moses and the prophets, and of every penitent man in every part of the world that had faith and hope towards God." 1 This universality is one of the impressive features in Law. Another is the intensity of his appeal to personal individuality in religion: "Nothing can make any change in you, but the change of your will. For everything, be it what it will, is a birth of that will which worketh in you. You have nothing, therefore, to inquire after, nor anything that you can judge of yourself by, but the state of your will and desire ... where these are, there are you; and what these are, that are you : there you live and to that you belong; and there you must have all the good and evil that can be called yours. . . . If your will is with God, you work with God; God is then the life of your soul, and you will have your life with God to all eternity." 2

This is the language of a strong man under emotion, and the student is grateful to Mr. Leslie Stephen for the words of respect which fall from him before he begins his critical account of William Law. Tempted, however, as we may feel to leave him in silence, there is a word or two required, especially to account for the fact that Law's position as an English divine seems to fall far short of what the unanimous accord of historical students would seem ready to allow him.

There is much disencumbering to be done in Law's case: in early life he was immersed in controversy first as a Nonjuror, and afterwards against the Deists, and those controversies seem now dead. And then in later life he yielded to the guidance of Behmen into certain realms of fanciful theosophy, such as cut great admirers adrift from him in his lifetime; farther, he dissociated himself very considerably from the historical side of Christianity, and lost repute among Evangelicals generally; while on the philosophical side he had so poor a philosophy before him that his hostility to philosophy altogether was not to be wondered at, and his resort to Mysticism, however necessary for himself, might be no necessity where a better philosophy was available. As for Natural Theology, therefore, we cannot give Law a place in the greater school of English Mystics: he is not a true connecting link between the Cambridge Platonists and Coleridge: these strove to bring all Nature into the Divine light, and gladly called themselves Rationalists in the high sense in which they used the term Reason, while Law denounces all but

$$
{ }^{1} \text { P. } 77 .
$$

2 P. 137. 
the Inner Sense, and cuts out immense tracts of human life from influence by the will of God. Nevertheless, Englishmen are likely to be glad to see in the eighteenth century this torch of Mysticism, even though of the extreme type, shining in what is clearly on its surface a utilitarian and common-sense age, and to see in Law the union of a most admirable gift of emphatic expression with a temper of unfailing charity and a piety which ruled his own life. If Locke's sincere reasonableness gave him predominance in the University classrooms during the century, the equally sincere Mysticism of Law sent his writings, through many editions, into the homes of thoughtful people at large, as an under-current in the days when the scepticism of Hume and Gibbon was on the surface on the one side, the rising force of Evangelicalism in Christianity on the other, and intellectual, evidential, and moral theology in mid-stream.

The Comprehensive Intuitivism which has gradually grown increasingly influential upon English theology in the nineteenth century has two principal stages: the first is the outcome of at least three powerful determinants: a reversion to a direct study of Platonism; German Idealism of the Fichte and Schelling order; and the Evangelical revival: the second stage takes up these and partly modifies them, partly exchanges Plotinism for Platonism plus the doctrines of Alexandria as found not in Plotinus but in Origen and the Christian Platonists; Fichte and Schelling are replaced by Hegel; and Evangelicalism receives an embodiment in Sacramentalism in the Oxford Movement. In each of these two stages a number of writers appeared; there were others who are not definitely to be placed with either the one or the other, as they seem to a considerable extent to have worked to their positions without personal association, at any rate, with either school. It will make the prospect clear if I at once state that by the two stages I mean, first, Coleridge, Hare, and Maurice; in the second, the writers of the Lux Mundi group.

In the first stage the greatest influence of an individual was that of Coleridge, the irresponsible layman, philosopher, and poet; but the immediately operative weight on the mind of the English Church was that of a group of men holding responsible offices, who, having learnt much from Coleridge, proceeded by strenuous studies of their own. Some of these were Oxford men, notably 
Arnold, and later, Frederick Robertson: but the main influence upon theology was from a group of Fellows of Trinity College, Cambridge, who in the second quarter of the century taught with the emphasis of deep personal conviction and the authority of responsible educational and ecclesiastical positions. These were Adam Sedgwick, Julius Hare, Whewell, Thirlwall, and a younger man who did not hold office at Cambridge until after he had gained his fame outside it, Frederick Maurice.

\section{$\S 3$}

Coleridge: The Friend, 1818 ; Aids to Reflection, 1825; Confessions of an Inquiring Spirit, 1840

Coleridge, as is well known, was attracted by German Idealism, and he is generally hailed as the harbinger of its influence in England. His place in a high literary circle and his untiring insistance on the views he adopted soon brought the mode into vogue. His writings were informal, not to say haphazard, but not the less for that, perhaps, they were rapidly influential in educated circles.

A first impression of Coleridge is that he belongs to a Rationalist school. A main point which interested him was the distinction revived by the Idealists between Understanding and Reason. It seemed to him that the depressed state of recent thinking could be explained as due to the confinement of attention for some time past to the former only; and that the weakened position of religious belief as against scepticism, among the educated classes, was due to the inefficiency and partiality of the Intelligence to which appeal was made, with the consequence that scepticism had the advantage. The abstract-forming Understanding could easily get into perplexities if it carried its abstractions too far towards Universality, but if there was a faculty for direct knowledge of Universals, then à priori knowledge was possible, and the issue for religion would be different. For twenty years, Coleridge said, ${ }^{1}$ he laboured to get this distinction accepted by his countrymen : and the fact of his having to 'labour' is evidence of the extent to which a debased Rationalism had prevailed.

Yet Coleridge did not attribute constructive power to pure Reason: he followed Kant in the distinction between Pure Rea- 
son and Practical, and did not allot knowledge of Reality to the former taken alone. For Theism,-a ground and principle of the Universe is to be supposed, but it is only as a hypothesis, "necessary as a hypothesis, but having only a logical and conditional necessity": he did not penetrate to the position that this necessity might be found to mean or imply a reality of a higher order than logical or conditional: he did not attain to transcendentalism of the constructive kind. He therefore follows Kant in requiring that Practical Reason be brought in. Like Kant, he by no means regards this as a confession of failure; for Practical Reason has as true and as noble a function in life as Speculative Reason, and the man who offers Theism its support is not thereby proffering a secondary or a weaker source of strength. Practical or Ethical Reason is Reason, too: it is indeed fuller Reason, brought into relation with Moral responsibility and Will. It is true that "where evidence of sense fails us and beyond the precincts of sense-experience there is no reality attributable to any notion," 1 but this is not to say that there is no reality from some other source than 'notions,' and he means 'Revelation, or Law of Conscience, or the necessary interests of Morality.' The reality which the Notion could not give to the hypotheses of Pure Reason is conferred by Morality and Religion, and so we attain to the 'Idea of a living God.'

Coleridge applies this view to the whole field of Theology. An objection to 'Creation' arising from the notions of eternity and immutability of the Deity supplied by Pure Reason must fall through, for the less real is attempting to overset the more real: it is Morality and Religion which require belief in a created world, and their claim is superior, and must prevail. "Let the believer never be alarmed by objections wholly speculative . . . if he can but satisfy himself that the result is repugnant to the dictates of conscience and irreconcilable with the interests of morality." 2 To set up a notion against these, can only be done by 'Fancy,' he says - what Kant called the illegitimate 'envisaging' of ourselves in the supersensible world postulated, and only postulated by speculative reason. To the Moral basis he adds that of Feeling, the life of the Affections.

But Coleridge at times goes out beyond the field of ordinary experience altogether and acknowledges an instinct for the supersensible which is of an Intuitive kind. He reaches out 
beyond Will and Reason towards a region higher than natural faculties could attain. He draws not only from Kant but from Jacobi and Schelling, or rather he is in sympathy with them, for he had taken in this source of belief before Schelling had given out some of his best work; and Schelling himself acknowledged that Coleridge was no plagiarist from him.

When he looks at the 'so-called Demonstrations' from his superior standpoint they appear to prove either too much or too little, he says. They would show that the world is God: or else they draw out a conclusion already put into the premises, and therefore their process is no 'proof' at all; the idea or concept of Deity was there already in the Ontological argument, that of First Cause in the Cosmological. If he were left to demonstration alone, he would not be satisfied, ${ }^{1}$ he says, and yet it is impossible not to believe, and he breaks out into his famous utterance "a grain of sand sufficing, and a whole universe at hand to echo the decision "- but this is because other resources of interpretation are at our disposal. But he marks out a particular function for Speculative Reason, of a higher kind than Demonstrative. "Do I exclude Speculative Reason from Theology and Philosophy?" he asks. "No, it gives a regulating criterion, non-contradiction: it shows that the conception of a Divine Being is 'cogitable' in Philosophy, and indeed is the only 'cogitable': but with that declaration its office ends."

The insistance on Will and Morality is so emphatic that it might seem better to class Coleridge under Ethical Theism. But his inclination to pass beyond both Will and Reason is sufficiently strong to require him to be placed as the progenitor of our British Intuitivist School of the nineteenth century. His affinities with Jacobi and Schelling, and the general impression as a Mystic among philosophers which he made on his own generation, confirm the impression of the importance of this aspect of his general view of religion.

Coleridge won his position after severe struggle. It is he, Mill said, who 'alone of all writers' had given a true expression to that state of dejection which was so impressive a feature in Mill's own history: a dejection which therefore Coleridge must have experienced in intensity. But when he had come through, and had found the bases and methods above indicated, he was almost exuberant in his elevation of spirit, and his influence

${ }^{1}$ Aids to Reflection. 
became very great. After him, says Mark Pattison, in Essays and Reviews, "the evidence-makers ceased from their futile labours, as beneath the spell of some magician "; and Mr. Goldwin Smith regarded him as the successor of Butler; as "the anchor by which the religious intelligence of England has ridden out, so far as it has ridden out, the storms of this temptestuous age." These opinions seem high-flown now ; they were written in 1860 and 1861, and are cited to show how Coleridge appeared to the men of the generation after him. To us it will appear that on his own line Coleridge gave a first impulse which set others in motion, but also that there were other influences than his, beyond the ken, it would seem, of Pattison and Mr. Goldwin Smith.

\section{Wordsworth}

A few words on Wordsworth seem called for after this indication of Coleridge's position. Wordsworth was not disposed to elaborate a Theism: "system," says Mr. Morley, "is the heavy lead of poetry." $1 \mathrm{He}$ comes nearest to addressing himself to Theism as an answer to questionings when he takes up the question of Divine Providence. In Book III. of the Excursion he has expressed the despondency of the Solitary, who had lost faith in God and confidence in man. Book IV. is 'Despondency Corrected,' and the Wanderer now urges the necessity of Theistic Faith :

\footnotetext{
For the calamities of mortal life

"One adequate support

Exists-one only; an assured belief

That the procession of our fate, howe'er

Sad or disturbed, is ordered by a Being

Of infinite benevolence and power,

Whose everlasting purposes embrace

All accidents, converting them to good."
}

To secure this we can draw from two resources: first, Nature-

"How beautiful this dome of sky,

And the vast hills, in fluctuation fixed

At Thy command, how awful!"

"How bountiful is Nature! he shall find

Who seeks not; and to him who hath not asked

Large measure shall be dealt."

"Take courage, and withdraw yourself from ways

That run not parallel to Nature's course."

1 Preface to Wordsworth, lxii. 
Then, Conscience-

"The victory is most sure

For him who, seeking faith by virtue, strives

To yield entire submission to the law

Of conscience,-conscience reverenced and obeyed,

As God's most intimate presence in the soul,

And His most perfect image in the world."

"O blest seclusion! when the mind admits

The law of duty; and can thereby live

Through each vicissitude of loss and gain,

Linked in entire complacence with her choice."

And for the manifestation of the influence of both these he turns to the people who live amidst scenes of nature and have their inner life simple and decided. Mr. Ruskin has set the reference to the beauty and virtue in lowly lives as Wordsworth's chief characteristic: but this is so, I think, because Wordsworth thought that he found there the continued operation of the two influences he esteemed so highly, love of nature and loyalty to duty.

He passes on to expressions indicating the height beyond-

"Pious beyond the intention of your thought, Devout above the meaning of your will."

In comparison with these how stands it with Reason? She is to Wordsworth

"The inferior Faculty that moulds,

With her minute and speculative pains,

Opinion, ever changing."

Even were she able to convince us thoroughly, this would not be enough-

"Though immovably convinced, we want

Zeal, and the virtue to exist by faith

As soldiers live by courage; as, by strength

of heart, the sailor fights with roaring seas."

On the broad basis of a deeper faith he can say-

"Here then we rest; not fearing for our creed

The worst that human reasoning can achieve

To unsettle or perplex it."

Wordsworth does not himself deny to reasoning all power to clear the pathway, even $\dot{a}$ posterior $i$ reasoning; he recommends some study of human history as corrective of despondency, denying that vice has the victory, though it is in the region of 
humble lives rather than in that of public affairs that he finds best evidence for virtue.

It is well known how beneficent an influence Wordsworth's interpretation became to Mill in his hour of deep despondency. This was very much because of the appeal to Nature as a source of consolation, and of gratification, in the stage of despondency which the philanthropic philosopher had reached. But to some it is Wordworth's insistance on Duty which is most impressive; and to others, the appeal to the necessity of bringing into play something deeper still, Faith. Wordsworth is not a philosopher, however, but a Poet: and it may be allowed that it is not as Moralist, nor as advocate for Faith, that he has his influence, but as Interpreter of Nature: that it is as such that he is a Teacher and a Master. Yet he himself did not regard Nature as teaching in her own authority, nor man's enjoyment of her presence to be its own final explanation. Behind Nature was God; behind Enjoyment, Faith.

\section{$\S 4$}

The Trinity College, Cambridge, group

The irregularity of Coleridge's genius and the irresponsibility of his position made necessary some intermediary before the general body of Englishmen concerned with religious thought could be attracted and influenced; and the alarm which was felt by ardent Evangelical believers, and was causing them to dig wide the trench between the sphere of Christianity and that of Natural Religion, also necessitated a similar mediation, if the actively religious world was to be brought in. Such intermediaries appeared at Trinity College, Cambridge, in a group of men specially well equipped for this important function. All of them were men of impressive personality, and held in the highest respect in College and University. They had the various gifs required for creating a complex impression. Hare and Thirlwall were men of the widest erudition, with admirable taste and balance of judgment; their own classical learning was enlarged by extensive acquaintance with modern literature, not only French and German, but Italian and Spanish, and English. They had acquaintance also with German philosophy, especially as worked into Theology, most notably with that of Schleiermacher. But all this had to pass into their own thoroughly English 
minds and take an English shape there. If Mysticism or oversubjectivity were in the Germans, these elements were reduced, though not eliminated, in the earnestly sober minds of Hare and Thirlwall. Then there was Whewell, of a less philosophical turn of mind, but a master in the Inductive Sciences, and the great advocate of the necessity of Imagination as a chief factor in their progress as against the renewed resort to Hobbist and Lockian Empiricism in the hands of Mill: and he was the great reorganiser of the University curriculum at Cambridge. Adam Sedgwick had been the first to call public attention to the depressing state into which University studies had fallen: and the genial and cheery geologist was just the man to bring to the group some contributions from physical science, and to ward off such harsh judgments as might be passed by timidly conservative minds. Later came Maurice, to carry their influence more dirctly within the sphere of the theology of the Christian religion itself.

And.it should be added that the group participated in the concurrent revival of æsthetic life, through the influence of Wordsworth, whom they had early appreciated and with whom they were personally friends; his brother, Christopher, indeed, was their official superior as Master of Trinity. A single comparison may show how English was the character of these Idealists, and how untrue it is to attribute everything new in this way to German sources. For instance, take Thirlwall's estimate of Goethe: he wrote of him, "It will not cost me much time to let you know what I think about him. He was never in earnest about anything but art and some scientific explanations which were suggested to him by his poetical view of nature. But as for any practical interests of humanity-morals, politics, or religion-he played about them like a bee, only to take in honey for his art-cell." While of Wordsworth Hare carried the admiration which he had expressed at the Bachelors' table at Trinity, so early as 1814 , into the dedication to him of 'Guesses at Truth' in 1838. Neither for the æsthetic element, then, did these Englishmen depend mainly upon Germans; nor in theology, much as they learnt from Schleiermacher, did they bring all from Königsberg or Berlin: any more than our Reformers of the sixteenth century had nothing of their own to add to what they learnt at Augsberg or Geneva. And another point of difference was their loyalty to Christian theology on the 
moderate lines of the English interpretation: neither in Philosophy nor Morals nor Art did they judge or estimate apart from the Evangelical conceptions and the ideas of Church order which were a part of their faith. In this way, then, it came that this type of Theism has had an introduction into England under auspices as favourable as could well be imagined.

The first public utterances of the school which carry us into the field of Religious belief were two University Sermons of Hare's, Children of Light, 1828, against eighteenth century rationalism; and Self-Sacrifice, 1829, against Utilitarian ethics. The next, a veritable trumpet-blast, was Sedgwick's famous Discourse in the chapel of Trinity on Commemoration day, 1832. In this the 'masters of the schools' at Cambridge, Locke and Paley, were criticised and denounced unsparingly for their philosophy of knowledge, of morals, of politics, and of religious belief-each and all. Then in 1839 came Hare's University Sermons on Faith.

Taking first the more general appeal, that of the senior man, Sedgwick :-

In the Discourse he early expresses his sorrow at finding that Christian believers were estranged from Natural Religion, as he had often heard in sermons in that very College Chapel, he says. But he really vindicates those preachers when he goes on to expose the hollowness of the Natural Theology against which they were preaching. He proceeds to insist upon the use of Imagination as well as Reason in the formation of Belief. In Imagination he includes the sense of poetry, and feeling generally, and claims that the presence of the qualities of Beauty disclosed in the world to the imagination of men is a proof of the same kind as that from the adaptation of material objects to lower parts of our mental fabric. In his own general scheme-if we try to make one out from the Discourse-he does not dispense with the Demonstrative tradition, but he places the Moral argument above it, and insists, as has been said, on the recourse to Imagination and poetical feeling besides. The Causality argument he considers cogent, including the inference to Personality. On Teleology he vindicates the old-standing argument, and maintained a lifelong protest against the rising tide of Darwinism. The $\grave{a}$ priori method is not rejected: an innate idea of God he does not claim, but our innate capacity 
for knowing Him, he does. And even the Ontological argument he accepts for himself. "I pause to express my conviction that there is a proof (sometimes called a priori) of the being of a God, derived from the mind of man and the right exercise of its inner powers, which no one can gainsay without renouncing reason "-but he shrinks from carrying out the rigour of the last clause, as he goes on to consider the case of those who ' do not accept' it, or find it 'little suited to their habits of thought.' There is also a touch of what I have called QuasiTranscendentalism: "There are certain elements of religion within us-we have a religious nature. These elements, when acted on agreeably to God's will, lead us to higher knowledge . . . and when religion is contemplated by us as a law it becomes capable of incomparably better illustrations and higher proofs than it was at its first beginning ": ${ }^{1}$ but he goes on to refuse adhesion to the position that such progressive proof is effective without other foundations, which is what we shall find is the position held by a group of thinkers of our own time. In Ethics he is against $\dot{a}$ priori systems such as Clarke's and Kant's, and stands on Intuitionalism of a simple kind.

At the same time he agrees with Hare, inasmuch as he strongly insists on the right of Will and Imagination (Feeling) to have full co-operation with Reason in the production of belief. The neglect by Locke of the imaginative powers and the 'creative energy' of mind are points for unsparing reprobation -which is all the stronger as he is emphatic in his expression of respect for the work of Locke in some directions. But the time had come to protest, and he writes, "Men decide not on reason only-incline not naturally to the right side, like the scale of a balance, by mere weight of evidence. They act in common cases through habit or affection; and in trying circumstances the determination of will is often more by feeling than by reason." 2 The narrowness of the Utility element he says he first realised through Robert Hall's sermons; the insufficiency of study of External Nature was borne in upon him by the reflection that Rousseau, impure and sensual, as well as Wordsworth could be enthusiastic about her, and the tendency seemed to be Pantheistic; hence he turned to Intuitional Morals, and insisted on the whole of our faculties being taken into account. And, further, he comes under the type we are now dealing with

${ }^{1}$ Preface, p. ccliv.

P. 50. 
by reason of his respectful inclination towards an intuitive belief behind all.

Julius Hare made considerable advance towards an enunciation of this Comprehensive type of Intuitivism. In 1839 he preached six sermons before the University, The Victory of Faith; they are largely occupied with the contents of the Christian Faith, but they bring into view the whole question of Belief, Religious Belief, in general.

He chooses the term 'Faith' for Religious belief : it is " the faculty whereby man can be conscious of a relation with God": he prefers it to any new-made expression such as "Godconsciousness'; again, he chooses it rather than 'belief'; lover of philology as he and his brother Augustus were, he enters at length upon this, explaining that 'belief' is more intellectual in its associations than 'faith': just as credo is in comparison with $\pi \iota \sigma \tau \epsilon v \omega$, and $\pi \iota \sigma \tau \epsilon \dot{v} \omega$ with the corresponding Hebrew word.

Hare starts from the thought that many are surprised that a faculty which seems to be insisted on in the New Testament under the name Faith seems to find no counterpart in men's way of talking in ordinary life: obedience, purity, love, seem to belong to ordinary life, but does faith? Is the thought of this, then, only an idea belonging to the Biblical circle?

He first explains that by Faith he does not mean intellectual assent yielded to certain truths beyond the reach of reason but assented to on the authority of inspired teachers, which again rests on Miracles-the Paleyan evidential system is definitely rejected.

Then, for Intellect itself and what it can teach he has respect for it, but finds that it cannot hold its own as our guide when vice and sin oppose; when passions arise against it and when Will defies it. Observe, it is not weakness of intellect within itself after the manner of the Relativist school, of which he speaks: Understanding has, indeed, its 'phantasies' as the senses have: but it is weakness as against competing powers: our religious opinions may be as decided as that of our belief in the fact of the Norman Conquest, but their strength is not sufficient to ensure victory. 'Notional theology,' ' notional faith,' is 'feeble' and has never 'wrought great works.' ' And 
so he comes to the position of the modern Will-psychology : it is Will that gives the essential quality - "the moral action of the Will is a stronger element in Faith than the judicial exercise of the Understanding." 1 Will comes first, even in priority of time -it is 'the primary germinal act.'

And then Feeling comes in, which Hare treats specially as Love. $\mathrm{He}$ is led, however, by the need of protesting against the resort to Benevolence of a completely unqualified kind which Utilitarianism was fostering, to insist that even Love must not be set up alone. The doing this has led to 'sentimental theophilanthropy' during the previous century, but the "persons in whose character Love has been the prominent feature have not seldom been disposed to rest in heavenly meditations and contemplations": ${ }^{2}$ and the Gospel does not make Love the ground of Justification, but "it showed its wisdom, and its knowledge of man's weakness and of his wants, in this more especially, that it made Faith the ground of Justification." 3 Whether this be so or not is not here discussed: it is Hare's position that Love is not the basis of religious belief, but he ascribes to it another office, that of being its crown. Then he insists on keeping together all three, Will, Feeling, Reason: 'let Reason have way', he says to the undergraduates before him, 'but keep it in with a steady hand: let it substantiate its forms, and give them a body of sound experiential and historical knowledge': but "let not this body be without the vital warmth of the Affections nor without the beautiful ever-varying hues of the Imagination. No one of the powers with which God has endowed us is useless. . . . Only when they are knit together and working in unison and harmony may one hope that the vision of Truth will descend upon them."

But this is not all: the combining of Will, Reason, Feeling, is not all that Hare means. He looks behind them for ' $a$ living, unifying power,' for " a living principle which constitutes each man's individual, continuous, immortal personality." This is not Will, though he has such strong sayings about Will that a rapid reader might be led to take him as regarding it as the ultimate of our being; the vehemence arising from the necessity of vindicating it as against Reason. But early in Sermon III. he distinctly goes behind Will, when he says " rather in that central

1 Sermon I.

2 Sermon Ir.

3 Sermon $\mathbf{~}$. 
principle of our personality, in which the Understanding, the Affections, and the Will co-exist in their original unity." This inner principle he calls Faith, and he regards it, e.g. in Sermon Iv., as capable of "lifting up the Heart and the Will, as well as the Understanding, from things seen to things unseen." ${ }^{1}$ Things unseen? Yes, it is to this primary region that we are to look for things unseen: here is the seat of our consciousness of God. Now, to say this is to be an Intuitivist. And the purpose of Sermon IV., on the power of Faith on man's natural life, is not to reduce religious Faith to a power concerned with things of the natural kind, but to show that in bringing it forward for Religion he is only bringing forward a power which can indubitably be shown to be operative in the lower sphere. But of Faith itself the proper region is not 'the visible world,' but the spiritual: it is "the faculty in man through which the spiritual world exercises its sway over him, and as such is the only Faith by which we can live and stand." 2

The answer, then, to the question as to the Scriptural faculty of Faith is that it has abundant parallels in ordinary life: in our trust in Nature; in the conduct of everyday affairs; our childhood is full of it_- "a child's soul lies in Faith as in a nest "; ${ }^{3}$ in our affections; in our patriotism. From all these it is quite obvious that human life in its ordinary ranges is actuated by something which is neither Will, nor Reason, nor pure Feeling. When, therefore, appeal is made to an inner faculty for religion no surprise is felt: we have an inner nature, and it is but one step further into its recess to claim a power of direct apprehension of things in a world higher than that of ordinary, 'natural,' life.

Having secured this Intuitive consciousness, Hare then applies it as the power behind all other faculties in the mode of Comprehensive Intuitivism. Among these, as was seen above, he fixes upon Will first, and then he admits the Feeling and Reason in much the same way as Coleridge had done. As against the eighteenth century, he claims that he is reverting not only to

1 Sermon IV.

2 Sermons III. and IV.

8 Sermon IV.

${ }^{4}$ I am not free from suspicion that I have read into Hare more Intuitivism than he meant. His language is not sufficiently clear to enable us quite to see whether he referred religion to a specific faculty in any shape or form, or not. It is because of this doubtfulness that I regard him as advancing towards Intuitivism rather than as clearly professing it: and the uncertainty has perhaps been a cause of his having had only a temporary influence. 
the true Biblical conception of Faith, but to that of the Schoolmen too, who themselves treated Faith in this way, although not emphatically enough, because they were not 'alive to the necessity of regenerating the Church by it,' and therefore Luther was required, and even Calvin, to reassert it. And this is true, as against the 'Reason' of the eighteenth century, so against its Utilitarian Morals. $\mathrm{He}$ regards himself as continuing in an English University the reform which began in the sixteenth century in the Universities of Saxony: on a wider field.

Hare does not attempt to claim completeness for the result of Faith in Natural Theology. He even claims less for it than might be expected from some of his emphatic expressions; especially in his regarding Natural Religion as shrinking into somewhat narrow limits from the dimness of Personality in its Object. $\mathrm{He}$ is oppressed with the sense that natural truths are 'partial and imperfect, barren and confined'; wanting in practical effectiveness; not acting in the generality of men, strange to the learned and unknown to the lowly, to a degree which, as in Dr. Flint's case, undoes no small amount of the work he has gone through. And then the fact of incessant struggle and the frequent falls, even within the souls of those who have in some degree attained a life of vigorous Faith, demand the outlook for a Revelation.

Taken on the whole, Hare's work is strong, of admirable texture, and written in a noble English style. It is open to attack from outside itself, of course: but this is only saying that it sets up a definite position. He rests on Intuitionalism in Morals, and on a dogmatic use of Reason, although there are traces of affinity for Reason of the transcendental kind, e.g. the sentence "indeed the business of Reason is not so much to divine what is not shown as to discern and exhibit the consistency of what is shown." 1 But on the whole his position is dogmatic as to Reason. In his reference to Will he is not in close contact with Ethics: it is not Der Wille zum Guten of the Idealist school on which he is insisting: it might be a hard Will, blind in its aim so far as good is concerned, forceful in pursuit of the worthless as of the worthy: as effective in working for the satisfaction of the corrupt affections as of the pure. He sees this sometimes: "it is true the strength of Will in a character is far from a test of its own purity

1 University Scrmon, 1828. 
or worth." But by ascribing perception of Goodness to Reason and including Conscience under Rationality, as he does in some places though not in all, he does not articulate Reason and Will. And if Will has been laid down as primary, and it may be blind, then the Morality which Practical Reason discloses, and upon which Affections attend, being secondary, and attached to the primary only by an external bond, we are by our very constitution in a perilous position, and normally so, not through defect or fall. The acute analysis by which Schopenhauer, with all his faults, did service in making clear what comes from the immoral aspect of Will were not yet in possession, of course. Still, the essential connection of Good and Will had been laid down by Kant, and might have been expected to make clear that if once Will can be set over against Goodness a fatal schism is made, which will leave no one in philosophical peace who is affected by it.

Thirlwall has left little or nothing explicit on Natural Theology, but his tone of mind was that of Hare. Whewell gave his strength to the Logic of the Sciences and to University life: his Moral Philosophy aimed at a resetting of Intuitionalism, but it was not successful even at the time, and it has left no mark: as the founder of the new Triposes at Cambridge for both the Moral and the Natural Sciences, he initiated the reform in the studies of the place which Sedgwick and Hare had so earnestly appealed for.

\section{§5. Maurice, Frederick Denison}

Maurice was somewhat younger than the others: a pupil of Hare and afterwards in closest ties of intimacy with him. The general impression which the history of theology in England gives is that the group has had more influence through Maurice than directly: it is to him that a great number of modern English theologians express grateful and ardent and affectionate regard as their guide to intelligent and broad-based convictions. By a common Intuitivism some other influences were allied with his own, notably that of Thomas Erskine of Linlathen and its affinity with the Inner light doctrine of the Society of Friends. But for our present inquiry there is little to be said about this great teacher. Maurice, like St. Augustine, had passed through 
severe struggle, and like him he found the sense of Sin so strong as to affect his whole attitude in religious thought. Hence, although Natural Religion was akin to the Christian Gospel in being a Revelation, all was so inadequate without the Incarnation of the Divine Being in Jesus Christ that Maurice's best energies were absorbed in the interpretation of thought from the standpoint of the Incarnation. In the preface to his Essays ${ }^{1}$ he is most explicit that without Christian Revelation "the facts of Sin and Misery which I witness around me, which I feel within me, would be far too mighty for any dreams of a restoration which may sometimes visit me." Observe how little he thinks here of Natural bases: 'dreams'; and they come irregularly, 'sometimes'; and are external, they 'visit me,' not arise inherently and of necessity within me. He saw that others had such confidences in natural faith, but their "easy interpretations of the universe were not for him." In the moral sphere he thinks that a 'Theology of consciousness' which excludes the sense of sin will work out consequences that the Creator is a tyrant and oppressor-a system of horror 'opposing and antagonising conscience,'-i.e. that the facts disclosed will oppose the just demands of our Moral thought. There is, indeed, inconsistency even here. For in other references he is filled with the conviction of the predominance of Love to a degree which leads a warm admirer, Richard Hutton, to say that Maurice carries Universal redemption so far as to obliterate the sense of the positive character of sin.

Inasmuch as Maurice, even more than Sedgwick and Hare, finds human nature the seat of struggles in which victory for the rightful principle cannot be depended upon, and there is a sense of the inherent insufficiency of our nature for the perfect life, we are not surprised to find him concerning himself chiefly with theology within the circle of Christian doctrine. It was ever to such topics as Revelation, and especially to Progress in it, with the Personality of Christ as central ; Inspiration; Justification; Sacrifice; and the conception of the Church, that his most strenuous attention was directed. As to Rationalism, against Mansel's reintroduction of speculative difficulties in the sphere of Religion, Maurice protested with all the vehemency of 'an outraged faith,' as Hutton says; but inasmuch as Maurice had himself laid so little stress on Rationality, there is evidently

1 Third Edition. 
truth in Hutton's further opinion that there was some waste of energy in the attack, for Mansel was expressly coming forward to maintain the content of Christian doctrine.

To the rigorously logical mind of Mozley, Maurice appeared to hold views of which he had never systematised the principles; but in this Mozley associated him with some heroic companions: St. Augustine and Luther. To many others, however, Maurice has appeared as strong in separate convictions, rather than cousistent in his presentation of Religion as a whole. And all this has to be held as compatible with the fact that the men who have admired him, and revered him, have been some of the strongest and also some of the finest minds of recent English theology: Plumptre dedicates his sermons on the life after Death ' to the loved and honoured memory' of Maurice; Baldwin Brown said "probably Mr. Maurice is leaving a deeper mark on his age than any other of our public teachers," 1 and dwells on his harmonising scriptural with recent secular truth; Hutton says he owed more to him than to any living man the belief that Theology is a true science; Hort says of his work "I owe to him chiefly a firm and full hold of the Christian faith." 2 Dr. Stanton is of opinion that "The chief religious movements of the past sixty years are connected with the names of Newman and Maurice. They are the two men during this period whom we may speak of-if the term be permissible at all-as men of religious genius." 3 But just as Dr. Stanton found "little direct help' from him on the question of Authority, so too for Theism, or Natural Religion, I have not been able to find positive contributions on the various topics, or any complete scheme, although it is my impression that through Maurice there was carried into the ranks of thoughtful Englishmen, both clergy and laity, the general influence of the work so nobly accomplished by the Trinity College group in effecting the transition from eighteenth century empiricism to the generous and expanded bases of belief which have become so extensively resorted to at the close of the nineteenth. In Maurice, however, the factors were not distinctly discriminated and appreciated, as they were by Hare. All were fused in personal faith; and the impression which he produces is finely expressed by Mr. Shorthouse-“"Within consciousness, and as a man sees his friend, Frederick Maurice knew God." "

1 The Divine Life in Man, p. 95.

3 Place of Authority, 1891, p. 210.
${ }^{2}$ Life, ii. 55.

1 Nineteenth Century, May 1884. 


\section{§. Carlyle and Emerson}

With the school of Intuitivism or Mysticism we may include the two men who next to Coleridge have been the vehicles of impressing it upon the minds of English-speaking people in the nineteenth century, Carlyle and Emerson. They were caught up by the influence of German Idealism as they were turning away from what they had learned from their own immediate teachers -for the one, Scottish Calvinism, and later, through Gibbon's incentive, Scepticism; for the other, New England Unitarianism with its 'pale negations.' Through Coleridge they passed to Goethe and Richter and Novalis, Fichte and Schelling; and elevated by the spirit of these men to new ranges, they became, in Carlyle's own phrase, 'heralds and prophets' of a new order of faith for the youth of England, Scotland, and America. No metaphysicians, but eager for results and careless of processes, they owed their influence to the literary Art which they brought into the service of their mission.

No man of English blood ever walked more serenely in the path illuminated by Theistic belief than Emerson; but Carlyle's soul-history was far less sunny in its course; and their attainments were different. The fitful inequalities of Carlyle's spiritual judgments, his perversions of standards of worth, can only be accounted for by supposing that he could not succeed in bringing his Intuitions over into ordinary life. 'Plato he does not read,' says Emerson; ${ }^{1}$ and thus a gulf lay between them. Glimpses Carlyle had. From his early failure to follow Wordsworth in devotion to Nature, and his failure to find intellectual satisfaction anywhere, he passed to some share of intuitive faith in the existence of Infinity, and some share of Ethical conviction, though hard and grim, and not embodying the infinite ideality of Goodness. The end of man set itself before him as action, not thought; conduct, work, became his means of realising his ideals. He penetrated towards the shrine in his Selbst-tödtung, but this was only to get half-way, and it will always remain a question whether he ever got farther, into true Idealism with its supreme joy of self-finding again, in the service of God and humanity. Looking back, what was the Negation which depressed him to the valley of Tophet? It was not the sense of evil, but of weakness: 'a feeble mind in the midst of threatening

\footnotetext{
1 First Visit to England.
} 
Infinitude'; it was strength that he yearned for, the strength which might justify him in daring to be Free. When this sense of Freedom-of release from constraint and fear-was secured, he was 'baptized,' he 'began to be a Man.' Then what was the centre of Indifference which followed? That he was Nobody, of no use to the Family of Man. He is nearing the threshold of the shrine-he looks within and sees that the Infinite is Love; but he does not enter, he falls back. He had his highest mood, to which he never returned: he recedes into the outer court. Thenceforth it is Duty, to be done: Happiness must be foregone; the man of God can dispense with that. The Stoic-Puritan separation of Happiness and Duty reduces Moral life to obedience to external injunctions laid upon the soul; men might be driven into the road along which they should march: and the religious life was wonder at might and sublimity, not love; little more than the Fate of pagan thought. In his chapter on NaturalSupernaturalism, Time and Space are changed into Eternity and Infinity, but human goodness is not carried up in the transmutation. A gulf is fixed between things human and things divine, a gulf which only unconscious genius can bridge; and so he turned in later years to show to the world a new lkind of 'Hero' in Frederick of Prussia, and emitted copious cynical and depreciating diatribes, as one to whom stupidities and vulgarities overlay without remedy both the plain virtues and the noble devotions of ordinary life with which we happen to know for certain his generation abounded, all unappreciated by him. How should such a vision see ethical character in God? even though retaining the Time and Space Infinity to which his intellect had climbed. The awe and reverence towards God with which his father's religion and example had impressed him never left him, but the communion of sonship with the Eternal Father was not vouchsafed to him, so far as man may read.

Over the soul of Emerson the sunshine of an Intuitive faith was spread. $\mathrm{He}$ was an admirer of Nature, yet any claim of hers to independence is soon disposed of by him: 'substance' must be of higher order than she can show: 'accidents' and ' effects' sufficiently explain her. Spirit only has necessary existence. He read Nature as Wordsworth did, and brought his reading of her into even closer touch with humanity. In him we find Spirit as 'over-soul,' self-confident that what it does is good, so that it can even venture to think that it participates in 
the Supreme Good: it can pass over into hyperbole, and clain divinity.

The idea of right the soul carries within itself, and imposes it, with other intuitions, upon the world. And this Goodness is not stern; with it is Beauty: the æsthetic is very prominent in him. Though mainly and predominantly individualistic, he has more than glimpses of social ethics. His mood is pervadingly ethical; the true Transcendentalist is reformer and citizen, not philosopher, with him; although he has some high words to say about Intellect in its place.

All that he writes is Theistic. It is because the Divine lives in the soul, and goodness is in our ideals ever manifesting itself, that we are vested with a vice-regency over the world, and impose upon it what we call our laws. We are deputies of the rank of those who are permitted to know directly the Sovereign's mind. Our soul has a free right to believe in what is worthy : and the spirit of Nature is perceived to be in accord, bearing witness to the omnipresence of Infinite Love. Evil itself is really only privative; the hurt done to self is the only evil, and that is because it is depriving ourselves of the good which should be ours, for which we are designed. A refined Mysticism expressed in literature is the Theism of Emerson, but it runs out towards the Oriental form of indefiniteness in the Absolute, and disappearance of independence in the personality of man.

\section{$\S 7$}

Newman, Francis : The Soul, 1849 ; Phases of Faith, 1850; Theism, 1858

The name Newman links two men whom there is some incongruity in thinking of together-the one an isolated mystic, the other a great leader; the one a recluse, the other at the centre of a great movement; the one chiefly known to vegetarian propagandists, the knowledge of the other a part of English culture itself. And yet there was quality in Francis Newman that might have won him a name, a depth of sympathy and a fineness of mental fibre that made him in himself a man of attraction and charm. But to esteem him as 'far superior (to John Henry) in depth and clearness of thought and in moral courage,' ${ }^{1}$ as Pfleiderer does, is only to recall to our mind that extreme difficulty, perhaps impossibility, of a man of one.

${ }^{1}$ Development of Theology, p. 317. 
nation passing judgment on the deeper matters of another to which Cardinal Newman himself pointed as an instance of the variations in human nature.

Francis Newman's Phases of Faith is a narrative of his passage from Christian Faith-the so-called 'Evangelical'to simple Theism. His impulse was not from philosophy, but from examination of evidences and application of criticism to the authority of the Bible and the Church: criticism resting upon reason and conscience of the purely individualistic order.

Theism is a series of didactic utterances in a curious arrangement of lines, but without metre, and of unequal length; he enunciates his views in a form and a tone so oracular as to make criticism irrelevant. It is to his book of 1849, The Soul, that we turn for his contribution to Theism.

The general impression is that he is even more Individualistic than his brother: more personal in his method of attaining belief. His attitude is developed by giving a history of the appreciation of God by the soul of Man.

$\mathrm{He}$ confines his assent to what he personally can include, and does not go forward to any external evidence for another region of truth beyond that: he can admit only what his own soul approves. Against Intellectualism his protest is continuous and vehement. Yet he might seem to be a Realist, as he says that man knows the Infinite; we 'have a sense of the Infinite without us': but his Infinite is only a relative one: the absence of bounds. What is really known is his own personality, and this yields him knowledge of God as Personal. It is all quite individual, there is no chapter on the spiritual community.

Personal Theism lodged securely in the soul is offered as the antidote to "the desolating Pantheism" which is abroad. He traces the appearance in the soul, as it works towards God, of awe, wonder, enthusiasm, sense of order, of design, of Mind; and then of a soaring to the Boundless Eternal. The Teleological argument he thinks adequate, expounding it in a broad combination with Causality, but he allots only two or three pages to it, and protests against a separate way to belief being made out of these arguments. Then he establishes Personality, then Goodness-which is at first known $\dot{a}$ posteriori, then $\dot{a}$ priori-and Wisdom.

But then, when all this is present to the soul, there arises 
'a totally new affection,' Reverence; by this the edifice of religious belief is crowned; the soul is won for God.

Is this anthropomorphic? he asks; and he replies that every Theism is so, necessarily: only, his own is not the result of abstractions, but expresses the real experience of the soul in its depths.

Is it all subjective? No, he says; it implies its object just as our feeling for the world of Matter does: the parallelism is close, and the right to trust the Theistic feeling the stronger because it is much the deeper of the two.

So that what he means by Soul is, as he says, "Now the soul is the special sense by which we come into contact with God " $;^{1}$ its testimony must be treated with no less respect than is accorded to the senses of Touch and Taste, but with more. For this is a tendency 'great and glorious,' the 'most powerful' in man. It may be absent: men may miss attaining to it; he believes in a new birth: "God has two families of children, the once-born and the twice-born."

In Part III. he treats of Progress, after birth of religious sentiment, and of the means of Grace; in Part IV., of the hope of immortality; in Part v., of Christianity. Pfleiderer classes it with Schleiermacher's Reden, and allows it some superiority on account of its being more ethical than emotional. But this is an overestimate; its influence, compared with that of Schleiermacher's work, has been trivial: though it may be allowed to be a tender, eloquent, and attractive utterance of Mystic Faith.

\section{$\oint 8$}

In this section I am placing together some Theologians of different denominations of English Christianity. They are brought together because, so far as appears, they have drawn their theology from some common sources which they do not specify, but which may be taken to be generally accessible; and their treatment is not sufficiently extensive to require more than an indication of their position. To find teachers and men of science or letters from different ecclesiastical divisions occupying what is practically common ground in Natural Theology, in this type as in some others, evokes satisfaction rather than surprise.

1 P. 92. 


\section{LidDon, H. P.: Some Elements of Religion, 1872}

The Theism which Liddon presents in his six lectures entitled Some Elements of Religion is of the Comprehensive Intuitivist type. His view is that "Religion consists fundamentally in the practical recognition of a constraining bond between the inward life of man and an unseen Person "1 - the depth intended to be reached by this definition lying below the level where the separate faculties of the soul are at work.

He commences by opposing the claim of each of these, taken separately, to be sufficient to constitute religious belief. He rejects Feeling as the one essential element, against Schleiermacher : Feeling may be for physical objects, or it may be misdirected, or it may be selfish. He rejects Knowledge, as against the Gnostics in the second century, and Schelling and Hegel in the nineteenth: Knowledge may fail to govern the moral nature. He rejects Morality: as contained within itself it is too narrow, and it cannot be complete.

He lays down as the foundation 'a preparatory idea or intuition,' ${ }^{2}$ a belief which comes to us in answer to " the voice, the exceeding great cry, of that unquenchable passion, of that irrepressible aspiration, whereby the soul of man shows forth its truest dignity and highest virtue in seeking the better to know and love and serve its Highest and Invisible Object." ${ }^{3}$ It comes in response to "restlessness of the mind, to "wasting fever of the heart' of man, to unwillingness to be satisfied with any earthly good." 4 "The spontaneous activity of (man's) consciousness brings with it, contains in itself, the thought of One who is greater, if not also stronger and better, than all else," 5 it is "an instinctive perception and affirmation.'

He appeals to Consensus: this basal consciousness is " that upward attraction of the soul upon which Plato dilates; it is the universal hypothesis which Aristotle registers; it is the worldwide prejudice, of Epicurus; it is the 'anticipation' naturally embedded in the human mind, of Cicero." It is "a fact in psychological science.'

From the profundity of this psychological factor of belief we are to expect the Object of religion to be 'mysterious': in the answer to our questionings much will "shade off into the unknown and the incomprehensible." 6 And yet 'within limits'

${ }^{1}$ Lect. I. \$ 1 .

${ }^{2}$ Lect. Ir. § 2.

* Lect. II. Introduction.

s Lect. Ir. $\$ 2$.

Lect. 11. $\$ 1$.

${ }^{6}$ Lect. I. \$2. 
it must be definite; positive, not negative; true absolutely, and not relatively to certain persons or under certain circumstances.

It is when this fundamental idea is secured that we look to the separate faculties of the soul for its elucidation and embodiment in terms of life. It precedes demonstration; it is out of the reach of criticism; "it resists hostile argument" ${ }^{1}$ but with it the mind 'looks out' upon experience and then it brings in what it finds. In experience Liddon includes Intellect, Feeling, and Morality (Will).

In Intellect he does not reject the Ontological argument, but rates it as the 'weakest'; ${ }^{2}$ the Cosmological and the Teleological are maintained. But with these alone he thinks we should only be left oscillating between Deism and Pantheism, and he proceeds to incorporate the appeal to our Moral nature, which is the strongest practically.

The Intuitivist position is further shown in the Lecture on Prayer, the Devotional life. ${ }^{3}$ This is 'Religion in action': "it is the soul of man engaging in that particular form of activity which presupposes the existence of a great bond between itself and God." And Prayer proceeds to put into motion understanding and affection and will. We have here, therefore, a clear-cut exposition of the Comprehensive form of Intuitivism, given with the vehement and impassioned utterance of an orator in many respects akin to the great French preachers.

\section{Maituand, Brownlow : Theism or Agnosticism, 1878}

This 'Essay on the Grounds of Belief in God,' by a clergyman of the Church of England, follows the lines of Comprehensive Intuitivism. The fundamentals of the belief are given by the Method of Consciousness: consciousness gives us the belief directly, and it has a right to be trusted. No logically constructed bridge satisfies us, but instinctive consciousness does. $\mathrm{He}$ rejects induction from the physical sciences as unable to prove 'spirit,' and that from our own conscious life as unable to carry us outside that sphere: and deduction from axioms because the axioms themselves must be first established. $\mathrm{He}$ is a bold antagonist of Rationalism : "he is prepared to go to complete scepticism, and to give up belief in self and in others and in the physical world, if logical proof is to be expected and required.

${ }^{1}$ Lect. Ir. $\S 2$.

$21 b$.

${ }^{3}$ Lect. v. 
His 'Method of Consciousness' lays down some beliefs as instinctive, 'intuitive,' 'felt to be true': they are primary, the foundation of knowledge and the bases for practical life. Together with belief in the external world and the reign of law therein, and in our own personal identity, this method yields us belief in God.

Mr. Maitland accepts 'development' for some of our intuitive beliefs. Some of them may be universal, never absent: but others 'grow' to be what they are, deriving nourishment from experience and reflection: such is our knowledge of gravitation, such is our growth in the knowledge of God. (The parallel is hardly a good one: as no part of knowledge of law of gravitation is instinctive, except the general notion of law itself.)

As we study the life of will, of intellect, of morality, and of spirit (including thoughts of eternity and infinity), these appear as possible inlets for the revelation of the Divine Being, suggesting Him and illustrating Him: and by mankind at large they have been so regarded. Then, and not till then, they take formulated shape in the Cosomological, Teleological, and Moral arguments: and then also come into operation the spiritual acts of worship, prayer, trust, reverence. It is from such an Instinctive nucleus, with nourishment from experience, that our domestic, social, and public beliefs are formed. Materialism and Pantheism and Positivism are opposed by this 'filling up,' not by the Instinctive basis.

The whole scheme is consistently expounded, very orderly in arrangement, and in excellent temper.

EllicotT, C. J., Bishop of Gloucester: The Being of God, 1880

Bishop Ellicott in 1879 made Theism the subject of his Visitation Charge. His great reputation has been gained as a Classical Scholar, which placed him in the chair of the New Testament Revision Company. But he is strongly impressed with the presence of atheism, and desires to see the clergy devote attention to Natural Theology. Far outside the range of textual criticism the great scholar sees an urgent need for acquaintance with the fundamental problems of Theology.

His scheme is fourfold, and he lays the parts out in a connected order, which he calls Ascensive. The Consensus furnishes a presumption; then Cosmology is applied to matter, life, and motion; Teleology informs us of the nature of the 
Divine Being; and the Moral argument completes the scheme.

There is no elaborate discussion from any philosophical standpoint: it is all assertive exposition. And even so, it is seriously limited, in several ways. The Cosmological Proof is applied only to the physical world, except for a very disproportionate reference to mind at its close: probably the writer thought that in the moral argument the main feature of mental life was appealed to. But an impression is made that we are not being led beyond Deism, especially as First Cause is represented as necessary to account for the beginning of the world: 'Sustaining' is mentioned twice, but it is rather dragged in, and the pervading tone is that of accounting for a finite world which has begun to be. The Esthetic bases are not resorted to: the sense of Beauty is incidentally touched upon in connection with Teleology, that is all. The Moral basis is dogmatic Intuitionalism, consciousness of Duty, with a touch of aspiration after Goodness. The range of literature before the writer's mind is narrow: Mill, and Romanes in his antitheistic book, are the chief opponents in view, and Ulrici and Janet have supplied a great part of the defence. Although the main bearing of the book is in support of the Demonstrative Method applied to the bases indicated, there is express recognition of an Intuitive region, and Reason is regarded as 'insufficient for conviction,' though with substantial uses; indeed probably 'ultimately imperative,' apart from 'the higher degree of cogency' conferred upon the inferences by direct influences working in the soul. ${ }^{1}$

\section{Swete, H. B. : Faith, 1895}

The Intuitivist position is asserted in a succinct form in these short addresses by Professor Swete. He asserts our possession of truths antecedent to the operation of our natural faculties: the main truths of the Christian Gospel are of this kind, and so are the main truths of Theism. "A believer cannot permit himself to regard the Being and the Personality of God as open questions ": ${ }^{2}$ questions, that is, which ordinary faculties have a right to ask to be submitted to their judicial scrutiny. To these natural faculties the foundations of Theism present themselves as 'presuppositions,' 'axiomatic' principles, 'positive truths.' 3 How do they come? Through a 'super-

1 P. 28,

1. 21.

2 P. 23. 
natural faculty,' a 'higher gift': and they are of a 'spiritual' order. $^{1}$ There are two realms of truth and two organs of acquiring it. The office of Reason is to work out the truths which are apprehended by Faith. Reason is enriched by this new order; it has something else added for its operations, beyond the data supplied by 'natural' faculties: "a whole region is added to its empire." ${ }^{2}$ Life is enriched when it is the expression of the spiritual beliefs as well as those of natural faculties. The moral life is invigorated and enlarged, and advance is made into the life of saintliness.

The addresses are brief, but they put the cardinal position very clearly.

\section{Pope, W. B. : A Higher Catechism of Theology, 1883}

Dr. Pope was, in his day, the theologian of the Wesleyan Methodist Connexion. His doctrine of God was on the lines of this type of Theism, and through his teaching it has been widely influential among the ministers and lay-preachers of that body. Only the heads of his position need be given: the space allotted by him to Natural Theology is small, and his estimate of what it can effect is a low one.

The foundation of religious belief is intuitive. "Rightly understood, the idea of God is innate. As man surely comes to consciousness of self and the outer world, not self, so he comes to the consciousness of a Being above both: all this being innate or connate, though at first undeveloped. It is born in or with man as a faculty to seek and a capacity to receive the knowledge and enjoyment of the God who made him." This knowledge is not only sufficient but real; "there is no knowledge more real," 3 i.e. apart from Revelation.

The resort to arguments is for the purpose of encouraging or confirming this belief, not for generating it. He accepts the Three Proofs, with the addition of the Moral and Consensus. The Ontological gives us belief in the Infinite, the Cosmological an absolute First Cause; the Teleological, Design in the Creator; the Moral includes the sense of dependence, and aspiration, as well as responsibility; and the Consensus yields evidence of at least 'some sense of the supernatural.' Dr. Pope holds that the lines of scriptural argument are identical with these, only their purpose in Scripture is not that of Natural Theology,
${ }^{1}$ P. 26.
${ }^{2}$ P. 30.
${ }^{3}$ Book II. c. iii. $\$ 1$. 
to convince unbelief, but 'to rebuke man's trifling with his convictions.'

Fisher, G. P. : Grounds of Theistic and Christian Belief, 1889

The portion of this volume, by a Congregationalist Professor at Yale, U.S.A.—about one-fifth-devoted to Theism shows an Intuitivist character: it is a Theology of Consciousness. The plummet is let down not into external Nature, but into the depths of consciousness, and there is found not only a self which is self-conscious and self-determining, but a consciousness of God. These are not transcendentally deduced, but are 'presented immediately,' and carry with them their own 'conviction of reality.' In analogy with immediate perception of the world through external sense is the immediate perception of self and of God in consciousness, in the inner experience of the soul.

Upon this fundamental consciousness supervene the thoughts, the yearnings and aspirations, the feelings of dependence and of obligation, wherefrom the idea of the Absolute and Infinite is filled in. In this Dr. Fisher includes the contribution by the three Proofs, which he, so far, accepts.

$\mathrm{He}$ himself expresses special obligation to Johannes Muller, to Ulrici, and to Lotze, siding with them rather than with Schleiermacher, as giving more intellectual form to the consciousness which is regarded as fundamental. This is claimed so far that it would be easy to place Dr. Fisher with the Intuitionalists, but the general impression given is rather that Theism comes from a special endowment of Consciousness rather than from an intellectual act of the kind which gives us knowledge of the finite.

\section{De Vere, Aubrey; and LiLly, W. S.}

I think we must place under this type these two distinguished Roman Catholic men of letters. In an article in the Nineteenth Century (1883) Mr. de Vere claims that "it is the total being of man, intellectual, moral, and spiritual, not a fragment of his mind, that receives the sacred challenge of Divine Truth." And again, "the whole vast and manifold being of man." In what he says of Reason, it is Reason as understood by Coleridge : not ' the faculty for judging according to sense,' but like Mathematical thought, like Conscience, like apprehension of Beauty. As for Will, he refers explicitly to Coleridge for the 
necessity of Will, Good Will, as co-operating. He insists that this reference of belief to the joint operation of all our powers -which may be called Faith - is less open to the charge that belief so fashioned would be effected by compulsion than attributing belief to exercise of intellect would be. Faith is more active, it is essentially active, the whole spirit is in action. A venture is made, power is put forth, a 'virile gift' is exercised.

If this opens out a region beyond the range of ordinary faculties, he finds no objection, and denies that Mysticism in this sense is reactionary: "If religion included no mystery it would inspire no reverence," whereas in so far as mystery is indicated it is an exchange of minor mysteries for one "sun-like mystery: power and healing, of life and love.' And so it has beneficent of effect on all the mysteries of the region below.

Mr. Lilly's views are given at length in The Great Enigma (1892). The volume is chiefly occupied with criticism; its positive chapters being-V. Rational Theism, and VI. Mysticism; and VII. on Christian Theology.

The peculiarity of the position is the combination of Rationalism and Mysticism, both being effective for belief, the latter the 'complement' of the other.

His Rationalism is Traditional: Causality, which he regards as "the sine qua non of all ratiocination," 1 and as building upon Will; Design; and the Moral Argument, which infers from Duty, Goodness, and Beauty. These are all built together, Mr. Lilly holds, by 'an architectonic law' by which "our intellect is compelled to refer the complete realisation of these ideas to the Ultimate Reality." The Reality is Personal, for we are so; it includes Substance, Consciousness, Beauty, and Goodness. Personality is conceived as properly belonging to the Absolute, and not to limited beings. "In the proper sense of the word, Personality_Für sich sein-can be predicated only of the Infinite . . . what we call personality, selfhood in man, is but the dimmest shadow, the faintest effluence from the source and fount of Being, in whom alone is perfect Reason, perfect Will." $2 \mathrm{He}$ agrees with the orthodox school of Romanist Theism that so much concerning the Ultimate Reality we know: ' the only alternative is to deny the validity of intellect alto-

$$
{ }^{1} \text { P. } 203 .
$$

2 P. 241. 
gether.' ${ }^{1}$ He explains, briefly, the kind of knowledge we can have, also on the lines of Aquinas. Yet there are perplexities and difficulties; e.g. as to the possibility of creation, and especially as to the securing of belief in Perfection in the face of 'such a world as this.' Hence his movement onward to Mysticism.

Mysticism is knowledge by the 'Inner Light.' He regards it as fundamentally required for full Christian belief, and in its essence as common to Theism generally. "It is based upon what I take leave to call the indubitable fact, that the spirit of man comes into contact with a Higher Spirit, whose manifestations carry with them their own proof, and are moral in their nature, are out of time and place, are enlightening and purifying." ${ }^{2}$ The way of knowledge is immediate. "The mystic is one who knows divine things otherwise than by hearsay, who sees them by an inner light: one to whom the Infinite and Eternal is no mere article of belief, but an experience." 3 It is present wherever religion is profound: "Every great faith of the world has originated in mysticism, and by mysticism it lives." 4 It is found in (1) the Upanishads of Brahmanism, associating Buddhism with it; (2) Socrates and Plato, and Plotinus; (3) the Sufite school of Islam; and (4) Christianity; "from mysticism has come the illumination of those who, age after age, have entered most fully into the secret of Jesus: thence are the bright beams which stream from the pages of St. John's Gospel, St. Augustine's Confessions, the Imitation of Christ, the Divine Comedy, the Pilgrim's Progress." 5 And he cites the examples of the Great Christian mystics of the Middle Ages.

Mr. Lilly considers that he finds it in Kant, with whom the Critique of Pure Reason is like the Via Purgatoria, the 'dark night of the soul' of the Mystics, while the Practical Reason, 'the revealing agency of supersensual realties,' is 'the opening into the transcendent region,' the Via Illuminativa of Catholic theology. But he would go much farther than Kant: Duty is not the only revealing Intuition: there is Personality; Will; 'the region of prescient instinct ... of artistic intuition, philosophical insight, religious apprehension.' ${ }^{6}$

There is not much more than an assertion of this view : but two objections are dealt with-(1) that the inner light can at most

- 1 P. 243.

4 P. 283.

2 P. 255.

S. 266 .

${ }^{3}$ P. 256.

${ }^{B}$ P. 281 . 
be subjective, and (2) that there are varieties and discrepancies in the contents of Mystic faith. As to the first, he claims that this kind of experience has as good a right to be reckoned as testimony for reality as any other, and indeed, when examined and seen to belong to the choicest of mankind, and at their best moments, its claims are the highest of all. As to the second, 'refraction' is inevitable when supersensible ideas are passing into the sensuous sphere of human experience.

Mr. Lilly's Theism is comprehensive of the two great types of Romanist Theology, and his combining them reminds us that the assent of Protestant believers has endorsed the Roman canonisation not only of St. Thomas Aquinas but of St. Francis of Assisi, not only of St. Anselm but of St. Bernard and St. John of the Cross. And though, no doubt, these all saw God through the Revelation of Jesus Christ, there can be found in them, more or less explicit, and in various degrees, those elements of Faith which constitute Theistic belief of the kind here indicated.

\section{$\S 9$}

Westcott, B. F., Bishop of Durham: The Gospel of Life, 1892 ;

Reigious Thought in the West, 1891

In this volume Bishop Westcott sets forth the philosophy of Religion as it worked itself out in his mind during his twenty years' occupancy of the Regius Professorship of Divinity at Cambridge. Two-thirds of the space is occupied with Christian Theology, the religions of China and India, and Zoroastrianism. For the Natural Religion which he himself expounds, less than a hundred short pages are at command: but the attack is so direct, and the conclusions are expressed, not exactly with terseness, but with such condensed solidity, that there is more of real Theism here than in many an exposition which appropriates a large volume to itself. The Essay on Origen in the other volume mentioned assists in defining Dr. Westcott's position.

The position is plainly Comprehensive Intuitivism: he holds to the intuitive nature of the idea of God: but with this as the essence, he articulates the whole range of human experiences. But 'experience' itself is made different by the connection: the Divine idea illuminates it all; significance, value, harmony, are given to it: knowledge, duty, life and its aims, all are transformed when interpreted theologically. And the experience 
of which he is thinking is experience of every order, not only our thoughts and our feelings, but our whole life, and that of the natural world which is connected with it; it is therefore the personal method of apprehension qua experience, while it is to a special ulterior faculty that the primary idea is due.

Dr. Westcott himself avoids the terms 'intuition' or 'intuitive'; but what he says contains what these terms usually mean. The Divine Being is known ultimately by direct outlook, yielding immediate conviction : in a way parallel with that by which we know self and the external world : not identical, but parallel. True, it is in experience that we become conscious of Him, but the consciousness is not a complex one, although the idea emerges into sight only on the occasion of ordinary experience Take some of his phrases - "we are so constituted," " "as men we necessarily recognise" ; "I feel . . . that there is that which is absolutely One and Eternal "; 3 the consciousness of God "belongs to the nature of man"; "we are made so as to live under the influence of the belief." 4 He speaks, therefore, of a unique faculty, "a consciousness underlying all thought," 5 a natural capability of knowing something over and above phenomena, an 'ultimate faculty,' ${ }^{6}$ ' an appropriate organ,'7 the 'spiritual faculty,' 8 by which man receives communications from God. Even when he dwells on the necessity for including intellect and moral sense and feeling, there is a spiritual faculty which 'blends' them. ${ }^{9}$ The object so perceived or apprehended is Real, and it is beyond Experience (of the ordinary kind), a Something outside ourselves which can influence us from above ourselves. We go beyond the presentments of our senses, and are aware of a single External world: beyond those of our mental life, and are aware of Self: beyond both these, and we attain to apprehension of God.

Having this idea or belief, we look again into experience and re-read it all. In a quasi-trascendental way this operates as a verification, for order and harmony, purpose and meaning, now appear: and this is true both of our personal life and of the history of mankind. This is especially applied as a mode of proof of the Gospel, but it is expressed in terms which cover Theism generally. A Theistic world-view is an intelligent one
1 Gospel of Life, p. 2.
2 P. 4.
${ }^{3}$ Pp. 6, 7.
4 P. 7.
5. 7.
- Pp. 7, 8 .
7 P. 205.
${ }^{8}$ Religious Thought, p. 242.
${ }^{9}$ Gospel of Life, p. 94. 
and one that can be personally welcomed, and this is a verification of our original belief. The employment of this spiritual faculty in our interpretation of the world marks out the proper sphere of Theology.

Dr. Westcott devotes a chapter to what may be called the logic of belief. Mathematical science has its own logic and its own validity, and calls into play a certain faculty of our nature: physical science has its own method and faculty: history, its own; and these form a scale in which the higher takes up the lower. Theology imposes another meaning and proceeds to form a fresh world-view : namely, a symbolism, whereby all things are $\sigma \eta \mu \epsilon \hat{i} a$, manifesting to us the way of God, and intelligible in a new way when so regarded. Historically verified as all the ' facts' must be, and physically and mathematically verified on those sides of their nature (if they have such sides at all), neither the physical nor the historical account of them ends what can be said-the spiritual significance remains, it is another type of Truth, and the study of this belongs to Theology. It may be observed that Dr. Westcott does not give any separate place to Psychology, but includes the experiences of mental life, as such, under History; but a more serious omission is that of Ethics and Metaphysics, with an effect which we shall presently notice in his attitude to Philosophy. For the Theological aspect we must not, then, confine ourselves to what the sciences can tell us: we must bring to bear that spiritual faculty which sees God and brings direct from Him what He is pleased in His own way ${ }^{1}$-i.e. immediately, apart from the phenomena as already known, I suppose-to disclose. Dr. Westcott speaks sometimes as if totally new 'facts' were given by Revelation, interposed in a mass of facts which are not a revelation;-but this is not his principal meaning, as I take it, which is that all facts have, in addition to their significance for the sciences, aspects which are spiritual, and are to be read as signs of the Divine activity. As he says, "the outward facts become facts in a higher sense, truths without ceasing to be facts"; ${ }^{2}$ " ordinary and exceptional phenomena equally reveal the action of God "; ${ }^{3}$ and the passages on pages 85-89 seem to have the comprehension of at least all human life in view. Still there are passages where it would seem that it is specific facts only which he has in view as the facts on which Theology builds that higher meaning. So that
1 Gospel of Life, p. 78.
2. 82.
${ }^{3} \mathrm{P}, 3 \pi$, 
perhaps we may presume that at least a possibility of being symbols of divinity belongs to all phenomena, although in actual life man is granted specific facts with spirituality writ larger upon them. In either case these facts are such as appeal to our whole personal experience ; they are facts of life; not intellectual conceptions presented only to the Reason.

This brings us to Dr. Westcott's attitude to Reason-or rather to Reasoning, for he is inclined to allow the term 'Reason' to cover spiritual apprehension or Faith. By reasoning he means criticism, and 'formation '1 in the sense of setting in order, not in the creation of ground-ideas. But between spiritual or intuitive apprehension and the lower range of ratiocination there might come the field claimed by the higher Rationalism, both Demonstrative and Transcendental. This is not occupied; and the omission accounts for his depreciatory attitude to reason, which is very marked. For example, it is his opinion ${ }^{2}$ that, so far as reasoning is concerned, neither the Hindu denial of the reality of self and of the external world, nor the assertion of only one of them in Materialism can be overset. 'Mysteries' and 'speculative difficulties and contradictions' 3 beset us; "difficulties begin as soon as we attempt to set our thoughts upon the idea of God in order"; ${ }^{4}$ and "riddles remain to the last unsolved." 5 Again, the 'proofs' of Theism are no proofs; ${ }^{6}$ he can find place for these as forms of filling in experience, but if they are set up as of independent force they 'break down'; the Cosmological argument issues in Pantheism, the Teleological is inadequate. In fact, these are all, in his view, attempts to substitute Sight for Faith. Nor has he any sphere of constructive Ethics, such as could yield a true Moral argument. $\mathrm{He}$ has no rationale of moral life between reference to religious ideas and Egoistic Hedonism : even Utilitarianism has no footing: the so-called religion of Humanity will 'vanish' if "the light of the Incarnation be quenched." " $\mathrm{He}$ has expressions which imply a counter-view in the reference to "an infinitely larger order in which we are a part," 8 though this may involve religion perhaps: but the acknowledgment of absolute obligation when a moral principle is presented as something 'answering to our ultimate constitution ' 9 is a breath from another atmosphere than that in which his Ethics, as explicitly given, is found.
1 P. 290.
${ }^{2}$ P. $x x$.
3 P. 9.
${ }^{4}$ P. 34.
${ }^{5}$ P. xix.
${ }^{6}$ P. 35.
7 P. 49.
8 P. 63.
${ }^{9}$ P. 82. 
Failing dependence upon Rationalism of any high kind, Dr. Westcott, like Newman, insists on the appeal to personality, to life, as giving the kind of facts which can be spiritualised. Religion is of deep moment for the whole nature of man. That by this personal activity Theistic belief should be strenuously sought, Dr. Westcott insists as strongly as any Rationalist. It might not matter to Mr. Leslie Stephen what our 'beliefs' are, according to his view of the relation of belief and conduct. But Dr. Wescott maintains that "all experience goes to show that conduct in the long run corresponds with belief "; ${ }^{1}$ and "if we acquiesce in" (the insolubility of the enigmas) "our whole life will be modified by the confession of blank negation "; ${ }^{2}$ and again, "the final spring of power is conviction." 3 But with him the appeal is from reason alone to the whole capacity of the living soul. Nothing worthy is left out; truth, happiness, goodness, and the 'joy of service' (a favourite expression with Dr. Westcott) are all involved.

We are therefore not surprised to find that Infinity is regarded as a speculative notion with which Religion need not concern itself; nor is the idea of the Absolute in any other position. The purpose of religion is not the satisfaction of speculative difficulties, although (I suppose) that is part of it: the main purpose is to guide and stimulate and elevate life. Essential, therefore, in the central idea of God is Perfection-i.e. internal completeness-Goodness and Righteousness, and with this, Beauty, and all in Personal form. It is not any Ethical satisfaction that is offered, but the whole life of the soul which is to be harmonised; "life through the power of Good ... in every region of human thought and conduct." 4 And in reference to Feeling-which also has its place-it is not of "personal, arbitrary, or chance desires, but of those which answer to our constitution and which have found the widest and most spontaneous expression" that he speaks when he says, "I cannot but hold thai human desire includes potentially the promise of satisfaction." 5 The central ideal of Perfect Goodness is to be filled up from experience, in part 'naturally,' in part consciously. In this respect the world is symbolical for us, interpreted by reference to our Ideal.

There is some indeterminateness as to whether the individual has capacity for working this out alone, or whether
${ }^{1}$ P. 48.
${ }^{2}$ P. 58.
${ }^{8} \mathrm{P} .60$.
$4 P$. xxi.
${ }^{5}$ xix. 
the co-operation of society is not absolutely required. When Dr. Westcott says "The conviction rests ultimately on my personal consciousness; but, as far as I can see, my fellowmen " 1 act under its influence also; and again, "all around me act, as far as I can judge, on the same convictions (namely, of reality of self, of world, and of God)" $;^{2}$ and again, "the conviction which is primarily personal is brought to a social trial," 3 the primariness of the individual is plainly asserted. And, in fact, the 'world' which is one of the three primary realities is the external world, not the world of men. But there is a more thorough incorporation of social experience when he traces the history of the idea of religion; in which, indeed, he has to acquiesce in national or racial activity rather than in individual. But the social character of human life is not so strongly insisted upon in the primary region as we might have expected from Dr. Westcott's other writings, especially his Social Aspects of Christianity.

Dr. Westcott is among those who have a very definite recognition of the function of Beauty in religious belief. From his Essay viI. on the relationship of Christianity to Art, much might be gathered to show how strongly he estimates its place in personal life, and therefore in religion.

His view combines Transcendence and Immanence if we can take him as including all Nature and Life as symbolical; but if we must decide by the expressions which seem to limit spiritual meaning to certain groups of facts, Immanence would be missing.

It must be noted that Dr. Westcott's conception of Personality is not that of the high speculative school; his is only the minor form, which regards it as essentially limited. "For us personality is expressed by and is the expression of limitation." 4 Hence comes the old difficulty of in any way carrying it up into our conception of the Perfect Being. How can a limited personality be carried up? and if the limitations are removed, by the above definition personality disappears also. Hence the relation between man and God is an impenetrable mystery. It is not necessary for Dr. Westcott so to regard personality; and, in fact, he has previously joined other Intuitivists in including in the intuitive idea Unity, for example, and Eternity. ${ }^{5}$ That Personality really is included by Dr. Westcott, though not ex-
${ }^{1}$ P. 4.
${ }^{2}$ P. 5.
${ }^{3}$ P. 85.
4P. 36.
s. . 
plicitly, there is no real question, for his whole attitude is one which is only tenable towards a Person: "One who may be loved and who Himself loves." 1

This leads us to another uncertainty in his scheme. If religious belief is a product of intuition in combination with experience, 'if we are by nature so made' that we 'necessarily recognise Him,' we should look to see the belief in universal possession; intuitions like this would surely be inevitable. But when we collect what Dr. Westcott says of the history of religion we have to recognise the ideal character of all that has been said; the actuality is far different. $A s$ is well known from other sources, Dr. Westcott connects Revelation of the Gospel with Natural Religion in both ways, the Thomist and the Scotist; it is needful because of the failure of Natural Religion in actuality, and it is also a development and continuation of Natural Religion as ideal. The extent to which failure is acknowledged gives us some surprise if we come straight to it from the comprehensive and clear-cut claims made for the intuitive faculty at the outset, and for the patent character of the $\sigma \eta \mu \epsilon \hat{\imath} a$ afterwards, to those who have the spiritual faculty: and there is no hint given that this is not a universal endowment: 'we are so constituted' and similar phrases which have been cited are quite in the opposite sense. How shall we reconcile this with Dr. Westcott's view that in the last days of Greco-Roman civilisation religious life ran so low that human frailty ceases to explain it, and there would seem to have been ' a gradual withdrawal of God from the world ' ? ${ }^{2}$ and with a similar view as to the cause of the decline of Israel ? ${ }^{3}$ As experience becomes 'agelong' it seems to remove God farther from us! He even thinks that such 'must' be the tragic course of religion both in human history and in the individual life; that increase of knowledge widens the gulf between the creature and the Creator; "reason fails, and then feeling." 4 This pessimistic utterance is no doubt connected with Dr. Westcott's indecisiveness as to the extent to which natural phenomena are capable of spiritualisation. But the gap between the actual and the ideal seems fearfully wide, and we had had no warning that the 'nature' so often referred to when the Intuitivist foundation of his Theism was being laid was so 'ideal.' And if it is not presumptuous, one would like to claim more for Natural Religion
${ }^{1}$ P. 6.
2 P. 37.
${ }^{3}$ P. 40.
${ }^{4}$ P. 39. 
out of the pages of Dr. Westcott's own book. If the efforts of the various races after religion have shown phases of 'disastrous delusion' and 'sad defeat' as well as of 'noble endeavour' and 'advancing conquest,' 1 yet we find that Dr. Westcott claims equality as between 'ordinary' and 'exceptional' phenomena, and thinks that "the natural voice of humanity proclaims with no uncertain sound that God has, in fact, made Himself known in various ways and at various times "-and therefore that there has been, so far, a wide extension of the spiritual faculty in man.

In Dr. Westcott we find, then, the leading positions of Intuitivism: his affinities reach back to Alexandria-not to the philosophers, but to the Christian Platonists, especially Origen. There is no need to elaborate a comparison. Quite explicitly in his Essay on Origen he says, after summing up Origen's philosophy, "such is the true position of the Christian philosopher " ${ }^{2}$ and again, "Origen may have erred, and I think he did err, on many points, but he never lost sight of the true ground and method and end of the Christian revelation, and so of Christian thought. His view of life was imperfect, but not his view of the relation of religion to life. He strove, with however many failures, to recognise all the facts of reflection and experience, and to present in an intelligible union, man, the world, and God." 3 By means of the Cambridge Platonists Dr. Westcott ${ }^{4}$ may be linked with the Alexandrians. He participates in the advances which they made over Platonism and over Neo-Platonism in holding to the conviction that a Revelation is not only possible but is given naturally, and that the new Gospel was to be expected; that the Supreme Good is Personal; and that we are entitled to carry up our conceptions of Goodness and Love-though not our speculative conceptions of Infinity and Absoluteness-into our belief of what the Divine Being is. The widening of human experience since the days of Alexandria, the gains of physical science and of historical knowledge have been used by Dr. Westcott for the enrichment and elevation of what we mean by the natural revelation of God.

The adoption by Dr. Westcott of the revelational view of knowledge which Transcendentalism and Intuitivism both make prevalent in our day, brings Theism into closer contact with the positive Religions of the world. The high confidence of believers in historical religions comes from their interpreting life in the
1 P. 101.
${ }^{2}$ R. W., p. 241.
${ }^{3}$ P. 252.
" See the Essay on Whichcote. 
light of the Divinity who is presumed to be therein disclosing His purposes and His laws; each religion, however, only covering such portion of experience as has been accessible to its followers. But here we find the same confidence carried over the whole field of human life, when Natural Religion generally is regarded as itself also a Revelation, and God is seen in Nature, in the Soul, and in History, and nothing is common or unclean, nothing alien or profane. If this attitude as expressed on pages 86 to 89 is Dr. Westcott's, we can see how he is led on to his systematically sympathetic treatment of the Positive Religions. Each interprets the $\sigma \eta \mu \epsilon i a$ to which it has access, by interpretations defective and transitory, yet having their value. And therefore we easily attain to the view of them all as preparatory for the consummatory interpretation which Christian Theology claims that it can provide when it reviews all in the light of the Gospel of the Incarnation. And moreover, since all this, being Revelational as shown by God, is Interpretative as grasped by man, we have the conception of a single Theology, which is not abstract, but fully and essentially an Historical Theology.

\section{$\S 10$}

Moore, A. L. : Lux Mundi, Essay Ir., 1889 ; Science and the Faith, 1889 ; Essays, 1890

Aubrey Moore was a theologian of great promise, well versed in history, science, and philosophy, and not least so in historical theology. He was especially engaged in surveying his ample stores of knowledge through his belief in the Incarnation and the consequent doctrine of the Divine Trinity. To him, therefore, it was not of personal consequence to work out a Natural Theism; the world was before him as it appears to the Christian believer in the light of the Incarnation. But he was interested in showing what men had been enabled to see by other lights, and in bringing together the results in relation to the Christian view. As he did not live to set out the form of Theism which he may have considered to be most congenial with the modern knowledge which was at his disposal, we can only collect the hints he gives as to where he would seem to have ranged himself.

I take it that Moore stands with the Intuitivists of the Comprehensive school, appealing to the whole of our personal 
life as the agency by which the original idea would be filled up : in the main parallel with Dr. Westcott's position, but with important differences.

The idea of God is in its origin 'instinctive,' ${ }^{1}$ he says ; he can speak of the idea of God as in our possession apart from our moral and rational nature; it arises in 'an unreasoned consciousness of dependence,' ${ }^{2}$ which may be afterwards ' interpreted ' from experience or left as it stands : its 'birthplace' is 'secret,' 3 'behind all the distinctions of modern psychology'; it is 'a primitive undefined belief' upon which "light is turned back as our moral and intellectual nature develops." 4 In our experience of life this primitive belief finds 'confirmation,' 'corroboration,' 'attestation'; and his Essay is largely occupied with tracing the varied process of confirmation in the history of religion.

$\mathrm{He}$ does not found his Idea upon the processes of our natural faculties: he believed that without it they could not give the results they do. "Conscience, as we know it, has won, not indeed its existence, but the delicacy of its moral touch, and the strength of its ' categorical imperative' from the assured belief in a real relationship between man and a holy and loving God." 5 It is under the influence of this master-idea that the moral sense has been 'trained and perfected.' And there is a parallel relation between the speculative faculty and the religious idea.

The rich results of moral experience and of speculative inquiry are then accumulated around the central idea to constitute a full and living religious conviction.

The idea, therefore; is intuitively gained, but.its content is the result of the joint action of our ordinary faculties interpreting the whole of our experience. Historically, the elements of our nature have been employed in separation: men have tried to form purely speculative religions, and have left the moral life apart; or purely moral religions, and have left the intellect to its own devices; or religions of feeling. But all must be combined, and it is in having a larger confidence in what both the speculative and the moral faculties can give that Moore differs from Dr. Westcott.

His speculative factor does not yield very extensive results, however: he has little to speak of beyond Unity and Immanence : perhaps there was a predominance of interest in Physical Science in his mind at the time, and the Metaphysical problems seemed
${ }^{1}$ Lux Mundi Essay, \$ vir..
$2 \S I V$.
$3 \S I l$.
4 VIII.
$5 \mathrm{Ib}$. 
less pressing. His speculative method is at least akin to Transcendentalism. Unity is a conception which justifies itself as the means of explaining experience, of gathering phenomena into a cosmos. And he says in one place ${ }^{1}$ that in experience it is selfconsciousness which is 'the highest category within our reach.' He has a distinct affinity with the Transcendentalists within the limit he assigns to intellectual activity. From Demonstrative Rationalism he dissociates himself explicitly, and denounces allegiance to the 'proofs' as such : verification, corroboration, and so on, are the proper functions of intellectual processes.

Nor is it different with the Moral argument; within the range assigned it is effective, for Duty is not a result of associative processes, but gives a standpoint of its own.

The life of Feeling is not set out as a distinct source of corroboration. He spealss of 'awe,' of an impression of 'fear,' when laying down the primitive deliverance: but he does not dwell upon this, and when an opening is before him for treating of Feeling (between $\S \S$ vi. and viI.), he does not avail himself of it.

In reference to the contribution of both speculation and the moral sense, however, we must bear in mind that Moore does not rate highly their efficacy apart from their being themselves influenced by religious belief, as pointed out above. "The lumen naturale in its lowest development "-i.e. apart from religious belief-"gives but a faint and flickering gleam." 2 But as co-operating with the Intuitive idea our philosophical and moral and æsthetic faculties give us a Theistic faith. It is, I think, the fact that Moore was so penetrated with the desire to show what Christian Theism could do, that he had not worked out what his own principles could contribute to Natural Theism. This would have been much more than Dr. Westcott, for example, could have attained on the intellectual and moral principles which he accepts. For Moore, too, his belief, as a matter of fact, came from authority and tradition, which when inquired into by reason, he set out as 'instinct.' Hence it is not unsympathetic to say that perhaps he was not equipped for other work than that which is before us, and the Head of his College, Dr. Talbot, in his sympathetic Memoir prefixed to the Essays, ${ }^{3}$ says this without much hesitation. And in one place ${ }^{4}$ Moore himself speaks of Theism apart from

\footnotetext{
'Essay, § III. ${ }^{2} \S$ vir. $\quad{ }^{3}$ Essays, Preface. ${ }^{4}$ Science and Futh, Introduction.
} 
Christianity as 'tremblingly conscious' that it cannot withstand the ' rising Hood of Pantheism,' and he does not dissociate himself from the feeling: if the 'intellectual safeguard' of eighteen centuries is set aside, a 'rational defence of theism' is 'no easy matter,' he says. In this mood, although only at the age of forty-two when he died, he could hardly have done more than he did, which was, to set forth Christian Theism in historical connection with much, though far from all, of the course of philosophical and religious history.

Illingworth, J. R. : Lux Mundi, Essay v., 1889 ; Personality (Bampton

Lectures), 1894 ; Divine Immanence, 1898

Mr. Illingworth's work, like Dr. Westcott's and Moore's, is directed mainly to the Religion of the Incarnation: but his larger scale enables him to include a more definite presentment of general Theism.

It might easily be supposed that with him the basis is our whole personality, that Theism starts from that, and that the ' logic' also is personal apprehension by our whole nature. This impression is derived perhaps from his lectures on Personality apart from his later work. But it is inaccurate. When he expressly sets himself to state what is the precise starting-point of our religious belief his words are as follows: "We start from the fact that our belief in a Personal God is founded on an instinctive tendency, morally and philosophically developed. It cannot be called simply either an intuition or an instinct, for it has neither the clearness of the one, nor the unerring action of the other, and it is best, therefore, described as an instinctive tendency. Man has an instinctive tendency to believe in a God or gods." 1 Now here is the emphatic repetition of certain words: they are evidently carefully selected, and may be taken to express, better than any others at least, what is in Mr. Illingworth's thought. To what do they amount? He will not call it Intuition, for it is not seen clearly: not as Reid saw it, or Morell, or as Professor Knight sees it now. But its generic character is asserted to be 'instinctive.' This term has usually been applied to a lower region of mental activity than knowledge, a region 'already existing' before, by reason and experience, we come to ' unfold its significance.' This is its essence then: but inasmuch as it may lie dormant, or be obstructed, or not unfolded at all, the word 
'tendency' is added: defectiveness, exceptions, want of universality, absence of ' unerring' character, are so provided for; although Mr. Illingworth ventures to speak of it soon after as persistent, irresistible, practically universal. ${ }^{1}$ I may be wrong, but I take 'instinctive tendency' to be the phrase of his choice, and others, such as instinctive judgment, intuition, instinct, to be merely rhetorical synonyms. If so, then this is the position I have called Intuitivism. ${ }^{2}$

It is stated to be complex, though immediate; ' highly complex,' in fact. ${ }^{3}$ We should have liked to know the maximum of its content according to Mr. Illingworth's view of it. For example, unity is not included, for he inserts the plural 'gods' as well as the monotheistic term. Is Infinity there? and what else?

Mr. Illingworth's Intuitivism is of the Comprehensive order, like Moore's; and he passes on to show how experience is to be brought in, namely, by the activity of the whole of our personality. Not reason alone, nor affections, nor practical considerations: "all these feel about for contact with some supreme reality": satisfied only when the "mind speaking for its companion faculties names that reality a Person." 4 So that the 'instinctive tendency' is met not by intellect only with its stores, but by feeling and will also, which, as well as intellect, ever reach out beyond what they already contain: the filling up is carried on from the resources of "our whole self with its complex interaction of emotion, intellect, and will." The Intellect therefore must not arrogate the whole field; the protest against this presumption is vigorous. Reason has its claim, but it is not essentially a better claim than that of other parts of our nature: "if I trust my reason, I am trusting one function of my complex personality; that is to say, I am trusting my personality in one of its activities "; ${ }^{5}$ "but there is no possible ground for elevating one element of our personality above another, or above the action, which is what here occurs, of our personality as a whole." ' In the analysis of Divine Personality the 'proofs' are stated with a judgment of their inadequacy as they stand: and he then proceeds to show the

1 Personality, p. $7 \%$.

${ }^{2}$ A reference to Mr. Illingworth's volume of University Sermons confirms this view.

$\div$ P. 80.

${ }^{5}$ Divine Immanence, $\mathbf{1} 60$.

3 Personality, p. 81.

' 16. I. 63. 
need of 'moral affinity' 1 for filling in knowledge, analogously with our knowledge of a person of our own kind. By 'moral' he means more than ethical; our whole emotional nature is included: 'spiritual' would have been a better term.

Taking the several factors separately, Mr. Illingworth has a great deal to say for each, always provided it does not claim a suzerainty. As to intellectual activity the important point of his position is given in his intuition of human personality, with its 'fundamental characteristic, self-consciousness,' ${ }^{2}$ and the proximate characteristic, self-determination, including satisfaction of 'desire' : in this, personality is a living thing, 'better described as an energy than as a substance.' It is Personality which is the inevitable and necessary starting-point of all human thought: we cannot "get behind it or beyond it or imagine the method of its derivation from anything else." It is our means of seeing that there is "an order of experience which transcends the order of sensible experience," and that we are of this order: "man has always believed himself to be a spiritual being." He is aware of the objection that this is to 'intuite' something beyond the region of understanding, to hypostatise what Kant had claimed to be only a synthetic unity : but he does not draw back: if it is not 'substance,' then call it an 'energy'; what gives us the canon of reality must surely be a 'real' itself. This is Intuitivism. And in Theism there is a parallel procedure, namely, an 'instinctive tendency' which seizes the idea of God and places it as a reality at the front of our knowledge and in constant recurrence, as instinctive all the while that experience is building upon it. ${ }^{3}$ The traditional Proofs ${ }^{4}$ have great historical interest and some permanent value as accounts of the modes in which intellect does its work of building; and he gives a careful statement of them as conceived by one who has gone past Kant's criticism of them because he does not exaggerate their office, as he agrees that Kant's predecessors had done. In the statement of the Cosmological argument, he prefers the inferences from effect, from dependence, and from finiteness. The Ontological argument is the assertion of correspondence between thought and reality, i.e. the underlying assumption of all our thinking. On the Teleological proof he dwells at length, in view of modern objections, especially in the Lux Mundi Essay and in Personality, Chapter Iv. But he hesitates as to whether Teleology is to be
' Personality, Lect. $v$.
2 Personality, 11.
${ }^{3}$ Ib. p. 80.
4lb. c. IV, 
vindicated against Mechanism by showing limits to the scope of mechanical process, and the need of something supplementary; or, by installing Teleology side by side with Mechanism after Lotze's manner. His inclination is towards the latter course, I think; especially as he vindicates intrinsic teleology as well as general order, and in Divine Immanence, Chapter I., he works to a conclusion of which the formula is that "matter exists for the sake of spirit" and so is teleological as well as mechanical all the while.

The ethical factor of Theism is similarly treated, but is ranked higher than the speculative factor. It is morality which is 'the nerve of personality,' 1 and supplies to Theism 'the crowning argument.' In his analysis of personality he has insisted on Freedom, but he has not brought out the aspect of Goodness in that analysis. Accordingly, for the corresponding determination of the Divine Personality, it is human freedom and obligation which he takes as our starting-points: it is morality as 'sense of duty or obligation,' 2 as an 'authoritative voice,' which he employs. It must in fact be obeyed 'blindly,' ${ }^{3}$ he says: though the obedience will issue in 'personal development and social progress' 4 that could not and need not be foreseen by us. How from this starting-point he is to find Goodness in the Divine idea is not made clear.

$\mathrm{He}$ makes no separate use of Feeling ${ }^{5}$ it is there, but it is not used as giving a separate factor of belief or indication of the Divine Nature: it works in its place as a part of the whole personality.

The perception of Beauty he uses in Lux Mundi and Personality ${ }^{6}$ as a part of Teleology, of which it is one 'aspect ' $:{ }^{7}$ but he brings it to the front in his latest work, where he evinces great esteem for it; although only as Beauty of external nature: I do not find any explicit reference to moral Beauty. But it is curious that he endorses it not by analysis, but by reference to its appearance in the history of religious belief. Egyptian, Vedic, Hebrew, Greek, and Roman literature testify to it: so do the early Christian Fathers: and though the Schoolmen neglected it, modern literature and modern theology have revived it. Yet he will not set it out as yielding an independent
1 Personality, pp. 65, 103.
4 Personality, p. 111.
${ }^{2}$ Ib. p. 108.
${ }^{3}$ Divine Immanence, r. 75.
Personality, Note 17.
5 Divine Immanence, c. IIr.
${ }^{7}$ Divine Immanense, c. III. 
' argumentative inference' ${ }^{1}$ it only operates in its place in the whole personality.

To neither aspect of Esthetic, therefore, Feeling or the sense of Beauty, will he allow the degree of independent force which he allows to Intellect and the Moral sense. For example, in giving a summary of Theistic argument ${ }^{2}$ he is capable of letting resthetic slip out of his memory altogether.

The Consensus argument he allows, as would be expected of one who is Intuitivist in his fundamental position. And the personal filling up obviously enriches the content of the idea as the generations of mankind increase. The men of early days could not have known as much of God as those of later times: he signalises Augustine, Luther, and Kant as eminent contributors to the enrichment. And he claims that 'the inductive basis of the argument has been strengthened by modern investigation,' ${ }^{3}$ and that this strengthening is found also when we "remember the minds that it has satisfied; not merely their number, but their philosophic ability and their moral worth." 4

A few observations may be added. As to the speculative element: Does Mr. Illingworth take a Transcendental position ? At first I thought he did when he establishes self-consciousness as the root of personality, as our spring for getting beyond the ring of sense-phenomena. But what use does he make of this, for philosophy or for Theism? Not the transcendental use : but such a use as Kant warned all who would learn from him to avoid, the turning into a substance, or a quasi-substance, or at least into an object, what Kant himself calls only a synthetic unity, only 'an active principle,' 5 not in any way a possible object to itself. And in his recourse to personal identity Mr. Illingworth comes near dragging the synthetic unity down amongst phenomena as an Ego with 'sides' and 'aspects.' When he claims the support of Kant he does indeed say that he means Kant as he would have been, without that peculiar doctrine of noumena which led the actual Kant to protest against this use of the synthetic unity, as the paralogism of Rational Psychology. But true Transcendentalists agree that Kant was right in refusing to allow the Transcendental self to be regarded as a possible object of experience such as reference to the sense of personal identity could confirm. However this may be, what concerns

1 Divine Immanence, p. 62.

Ib. p. 206.
2 Personality, p. 9.

5 Ib. p. 29.

3 16 . Note 15. 
us here is to point out that we do not find $\mathrm{Mr}$. Illingworth making the transcendental interpretation of self-consciousness his method for theology after the manner of the Cairds; he replaces it by his Intuitivism: his reference to it is only in the after-process, the filling-up of our conception of God; when the belief in existence has already been secured. When we come down to experience we find self-consciousness and self-determination, and these give us means for investing the original idea with concreteness. ${ }^{1}$

Mr. Illingworth does not seem decided between self-consciousness pure and simple (speculative) and consciousness of goodness and freedom (moral) as the point on which to fix his thought when about to move beyond phenomena: nor yet does he place them side by side. He alternates as to which he prefers. In Personality ${ }^{2}$ the fundamental characteristic of personality is self-consciousness, but in another place ${ }^{3}$ it is morality which is the nerve of personality: and again, ${ }^{4}$ Will is the faculty which must predominate; what differences lurk under the varieties of metaphor I should not like to have to determine.

As to the moral basis: we have not got beyond Kant here; it is command, obligation, duty: when associated with freedom, there is human personality. But how can we go up from this to Divine Personality, in any other sense than that of the supreme Lawgiver? The bringing of Goodness rather than obligation into alliance with Freedom is not explicit, at any rate: we obey the moral law 'blindly, as regards any distinct foresight of its results ' $;^{5}$ although it is also said to suggest 'paternal care,' and to be 'loved' by the saints, heroes, and philosophers. ${ }^{6}$

We have to ask of Mr. Illingworth, as of all Intuitivists, where precisely does Infinity come in? From an instinctive tendency worked out by personal development we achieve the conception of a Divine Being; but we miss clear indication of the place where Infinity is brought in. In a few words it is asserted that " personality suggests infinitude of life " : ${ }^{7}$ and that it does so by virtue of being itself not ' a fixed and finite thing' but 'a seed, a germ, a potency'; and we have a presage that it may be 'almost infinitely magnified in capacity and character, in intensity and scope.' This is only a meagre clue to the vindica-

${ }^{1}$ See the University Sermons for some more explicit statements to the same effect.

2 Personality, p. 28.

${ }^{3}$ Ib. p. 65.

4 Ib. p. 125.

5l. p. 111.

${ }^{6} \mathrm{Ib}$.

${ }^{7}$ P. 211. 
tion of belief in a real Infinite; but it seems that it is all that Mr Illingworth is able to allow.

Closely allied with this is the question whether Mr. Illingworth has any provision for Transcendence at all. His last work, it is true, is on the Divine Immanence, and it is possible that a farther book, on the Transcendence, is to come at a future time. At present all that we have is an obscure analogy. As the human spirit transcends Matter, so the Divine Spirit transcends-what? Matter? or human spirit? The latter no doubt is what is meant: but the mode of the establishment of the transcendence of human spirit over matter cannot be applied to the relation between the human spirit and a true Divine Spirit. The terms do not form similar ratios. In the one case one order of finitude transcends a lower order, in the other we expect to see finitude transcended by the Infinite: if so, the word transcendence is not used in the same sense in both cases. Where then is Transcendence provided for?

Mr. Illingworth's method, then, I take to be Comprehensive Intuitivism: Instinctive tendency gives the alpha of Theism, and Personality in all its activities and susceptibilities carries on the development. As he himself sums it up-"Religious instinct points to a Person ... reason and conscience justify this instinct" $:^{1}$ with the Asthetic element (Beauty) approved and rescued from neglect, yet not ranked on equal terms with reason and conscience: and with Consensus supporting the broad result. The grave differences from the bulk of modern Theistic thought are the absence of clear provision for Transcendence, for Infinity, for Goodness. It is to be remembered, however, that to Mr. Illingworth, and to the writers associated with him, it is only in the Christian doctrine of God that full satisfaction is to be looked for.

Of this school of Theism Mr. Illingworth is the one who stands on the farthest border away from exclusive Mysticism. His very designation for the special faculty, 'instinctive tendency,' is redolent of other associations altogether; he is more inclined

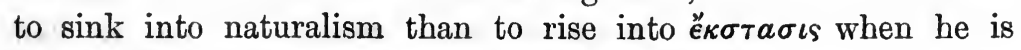
in search of the Extra-personal which he needs.

His contribution to Theism is rich in material, and persuasive in tone. A wide culture is drawn upon. And it is of special attraction for English Churchmen as it is in contact

1 Personality, p. 205. 
with so much of standard Theology, Patristic, Scholastic, and Anglican, as well as with Kantian philosophy and with modern science, both physical and psychological.

In that group of Oxford men whose unity of conviction enabled them to give the world the admirably balanced set of essays published in 1889 under the title Lux Mundi, the division of labour, no doubt spontaneously determined, left the philosophical work chiefly with Aubrey Moore and Mr. Illingworth. It is not only on their own individual account, therefore, but as spokesmen for this influential group that careful study of these writers is of interest and importance. The congruity of what is held by the other writers with the main positions of .Moore and Mr. Illingworth is manifest whenever these other writers treat of questions of Rational Theology. It is commonly understood that Dean Church was the teacher of the older generation whom this group most delighted to honour. His general position seems to have been the one here indicated- "a true and trustworthy faculty for knowing God, separate from the faculties by which we judge of the things of sense and the abstractions of the pure intellect" (Lectures on Sacred Poetry, $a d f i n$.$) ; and this is filled in from all the variety of human$ experience. Mr. Holland's opening paper on Faith in Lux Mundi, his Essays entitled On Behalf of Belief and Logic and Life, are all expressions of this Intuitive foundation-as an act of Faith behind the operations of our ordinary faculties, filled in by those operations afterwards, though perhaps he allows less for Reason, both speculative and moral, than his philosophical fellow-workers do. His essay on Faith takes him more amongst the Mystics, and in other places he is inclined to revert to Revelation entirely. Dr. Paget's Faculties and Difficulties of Belief, and Dr. Gore's outline of Theism in the second of his Bampton Lectures, with the notes appended, contain the same fundamentals: and Mr. Vernon Staley's small volume, Natural Religion, is an admirable presentation for popular use.

Tulloch called the work of the Cambridge Platonists 'the first attempt to wed Christianity and philosophy made by any Protestant school.' He did not live to see the issue of the Lux Mundi Essays, or it can hardly be doubted that he would have given cordial recognition to this as the second combined attempt of a group of sympathetic friends to articulate philosophy and 
history with theology. The temper of this later group is not a whit less attractive than that of the older: while their work is in form so superior, in style so much more literary, as a whole, that their prospect of permanent influence is much greater. Among the honourable rivalries of Cambridge and Oxford not the least worthy of honour are these two instances of men making participation in University life the means of admirably articulating their common work in the presentment of Theology.

\section{Romanes, G. J.: Candid Examination of Theism, 1878 ; Thoughts on Religion,} ed. Canon Gore, 1895

A prominent writer on Evolution who gave much thought to its theological significance was George John Romanes. In his writings we see as in an open book the passing of a mind from the Traditional Theism through scepticism to a form of Personal Theism in which Evolution can find explanation and satisfaction. Commencing his published work with a Cambridge Prize Essay on 'Prayer,' Romanes became immersed in the eager work of the Darwinians, and was closely associated with both Darwin himself and Huxley. He felt called upon to examine Theism, and for that purpose took up Dr. Flint's book: his results he published in his Candid Examination of Theism, and acknowledged that he was led to Agnosticism of an extreme type. But as time went on other influences operated upon him, among which he himself enumerates the following: a diminution of confidence in abstract reasoning; a rejection of Mr. Spencer's Persistence of Force; adoption of Will as the source of our idea of Causation; the formulation of the source of Causality as self-conscious and intelligent. All these influences brought him in the first place into the field where Dr. Martineau and Professor Fiske stand, and they sufficed to cause his return to Theistic belief.

In external Nature he considered that the Paleyan teleology is untenable, but he stands by teleology from the survey of ' the broad area of Nature as a whole.'

In the use of the Moral argument he had not attained a clear ground for satisfaction. The absence of any high morality in so much of human nature seemed a great difficulty to what he calls the Anthropopsychic mode of argument to a Perfect Cause. Waste and purposelessness in Physical Nature do not trouble him: the difficulty about these may be due to our 
ignorance. But the Utilitarian view of Morals gives no help to Theism, as it is concerned with the progressive attainment of Happiness alone, and that is unattributable to the Divine Being. The Social character of Morality is again a source of difficulty, but here Mr. Gore, the editor of the 'Thoughts,' interposes a note on the Social nature of the Divine Being according to the Christian Doctrine of the Holy Trinity. Distrusting the Moral argument it would appear that Romanes secured his inference to a Causal Mind, but when secured there seemed a blankness, except for purely intellectual attributes. ${ }^{1}$

Romanes died in middle life, but his editor has fortunately secured some Notes which show that he was preparing to pass into the Intuitivist School in which he found his Oxford friends were working. He was investigating further what is represented as the realm of spiritual experience, and he arranges the sources of belief as follows: sensation; the higher intelligence; moral experience; and spiritual experience : and in this last he intended to look for the special source of religious ideas. His detachment from the Intellectual school was proceeding very fast: $\S 4$ of the Notes is on Faith as incorporating Feeling and Will, and Will is elevated to great prominence as bringing in the moral element. But beyond this he also came to see a distinction between moral and spiritual, by 'spirituality' meaning 'the religious temperament.' 2 He had experiences in his own inner life which he felt were distinguished from forms even of moral life: and, further, he claimed, as against Mill, that even if a man had no such inner experiences himself he was not precluded from accepting as facts what others had to report as experienced by them. ${ }^{3}$

It is evident therefore that Romanes was much influenced in his advance towards the Intuitivist position by recognising that there are in religious minds assertions of experience not found in those whose interests are wholly intellectual and moral, and that in his own experience there gradually arose, or revived, a corrorobative voice which echoed these utterances and won his assent. From the known fact of his personal association in middle life with the Oxford School here dealt with, it is scarcely hazarding what would have been uncongenial to himself if we attach the name of this man of science to theirs.

I think I can hardly be wrong in placing in close connection I P. $8 \%$.

${ }^{2}$ P. 143.

${ }^{3}$ P. 147. 
with the Lux Mundi group Mr. Inge's Bampton Lectures on Christian Mysticism. ${ }^{1}$ Transferred from Whichcote's College at Cambridge to residence in Oxford, Mr. Inge's treatment reflects the tradition of Cambridge Platonism, enlarged by the modern treatment of his Oxford contemporaries.

His lectures are historical, and it is Mysticism within the Christian Church which is his principal subject; within these limits they offer a rich and eloquent vindication of Comprehensive Intuitivism as the true Mysticism. So great does Mr. Inge consider the progress in this direction to have been that he regards Morality and Art as now successfully brought into that religious region which rests ultimately upon Intuitive belief: for the future he regards a similar spiritualisation of Science as the constructive work requiring attention. As a Christian theologian he points to the security from fanciful aberrations which is enjoyed by those who regard the soul in its character of member of a Kingdom or Church.

\section{$\S 11$}

\section{Upton, C. B. : Hibbert Lectures, 1893}

These lectures are an exposition of what the author decides eventually to call 'Ethical Theism': but his basis is very much

${ }^{1}$ Christian Mysticism, 1899.

It is fair to myself to say that I carefully avoided having recourse to Mr. Inge's lectures until after I had written all that appears in the text of this book. Long dissatisfied with the usual treatment of Mysticism by English theologians and philosophers, I had worked to the position that it was justified in claiming a position as a sane and attractive method of Theism, providing discrimination be made between the forms which I have designated Exclusive and Comprehensive. By the failure to mark this difference prejudice has been created, and confusion has prevailed. Hence I am free to enjoy all the satisfaction which arises from finding that Mr. Inge's extensive historical study in this field has led him to a similar treatment. Perhaps the fact that the position of a specialist in this field coincides with that which has resulted from study of the wider range of Natural Theology covered by the scheme attempted by the present writer may be taken as giving some cumulative evidence that in the future this method of Theism is likely to engage more sympathetic attention in Great Britain.

Some principal points in which I have found corroboration in Mr. Inge's lectures are:-The distinction between Exclusive and Conprehensive Mysticism; the necessity of protesting that most of Mediæval Mysticism was plainly a distortion, as also was most of the earlier German Mysticism; the vindication of Comprehensive Mysticism to a legitimate place in Theology; the insufficiency of mucl criticism of Mysticism through confinement of attention to its via negativa; the value of the nature-symbolism in which it takes shape; and the light it throws on the religious teaching of men like Carlyle, Emerson, and Wordsworth. 
wider than pure Ethics, it is only because he includes Ethics in opposition to the pure Intellectualists that he selects this term. $\mathrm{He}$ follows Martineau to some extent, and modestly announces that these lectures are an introduction to his master's work. But there are differences of great importance. Within the 'Ethical' range he places in a prominent position the contribution of the Emotional factor. Following Lotze he claims for the Affections, especially for Love, 'a universal and eternal element': our consciousness includes 'a deep and comforting sense of relationship with the Eternal.' ' In some minds it is by the contact with external nature that this is awakened, by the 'beauty, goodness, and beneficence' there shown; in others, it is by the survey of human life, its 'moral beauty and sublimity'; and in eloquent passages the power of spiritual love to lead to belief in the Supersensual is asserted. Further, in the sphere of strictly moral consciousness Mr. Upton's method is different from Martineau's (1) in his taking ideal goodness rather than categorical obligation as the essence of morality, and (2) in that he does not proceed by inference to a Moral Lawgiver, but finds that our consciousness of moral quality is an immediate apprehension of the presence of the Source of our ideals, who is in them manifesting Himself.

On the Intellectual side he rejects the Absolute Idealism of Hegel and the Neo-Hegelians with considerable freshness and animation; the Ontological argument he does not state, but he accepts the Cosmological and Teleological as leading to valid belief. In his treatment of the Cosmological proof the old way of inference to First Cause is rejected, as open to the criticisms made by the Empiricists and by Kant; but the kind of Cause used in it he regards as belonging only to Science: Philosophy, he holds, requires an ultimate Cause, self-causing, as much required to explain present phenomenal existence as the beginning of such existence. He does not follow Martineau in laying chief stress on the human mind as the starting-point for the conception of Causation, but adopts the Monism of Lotze. In Teleology he follows him in relying upon the existence of Order in the Universe as a whole and not upon special adaptations.

But a more important divergence from Martineau is in Mr. Upton's attitude to Intuitivism. We have seen that 
Martineau really relies upon this, yet does not give it formal acknowledgment in his scheme; Mr. Upton brings it to the frout in reality, though still endeavouring to withhold a full acknowledgment that he is doing so. In his opening lecture he claims that the essential 'nature of religious belief' is a 'felt relationship,' an 'immediate feeling,' a 'direct apprehension,' a 'consciousness of personal union and communion,' a 'Godconsciousness'; with a variety of phrase and an emphasis which seem unmistakeable. He repudiates Mysticism when it is an attempt to confine this ultimate consciousness to Feeling. But he endeavours also to dissociate himself from those who hold that religious belief depends upon a 'special faculty;' by claiming that it is in our Feeling, in our Reason, in our Conscience that this sense of union with God arises. But it certainly seems that he is endeavouring to hold at once that our fundamental religious apprehension is direct and immediate and at the same time is through manifestations. His intention clearly is to sever himself from advocates of a special faculty, but his phraseology is precisely the same as theirs; and still more, the way in which he works downward from the Infinite to the finite in every department of our conscious life, Reason, Feeling, and Morality, places him with Theists of the Intuitivist type.

On a general view, therefore, there is a closer affinity between Mr. Upton and the writers cited in this chapter than there is between him and Martineau, and so I have classed him with them. For final confirmation I would refer to some words of his own in his impressive closing lecture-" In addition to man's intellectual and moral nature, there is our specially spiritual or religious nature, which lies at the deepest heart and core of our being." 1

1 P. 354. 


\section{CHAPTER XI}

\section{Composite Types}

As indicated in Part I., under this type are ranged a few methods of Theism in which factors of belief from various quarters are set side by side or more or less woven together. There are men in whom the distinction between Rational and Empirical excites no alarm, for they are ready to draw upon both. Of course they cannot take such incompatible positions as holding the primacy of Will and the primacy of Reason together, but they decline to embarrass themselves with questions of rank. They take one or other of the Rationalist methods and one or more of the Empirical and construct a Cumulative system. This differs from the Personalism of Newman, because he treats of several factors acting in fusion, actually and concretely, in our life; under this type I would place men who delight to point out the separate cogency of several factors, and then to expatiate on their converging or cumulative force. I am not aware of any prominent instances in the seventeenth and eighteenth centuries; the examples to be cited are all from the last quarter of the nineteenth.

BARry, Bishop : Natural Theology, the Boyle Lectures, 1876

Bishop Barry's treatment is not remarkably searching, but it is distinguished for comprehensiveness of scope. No scheme combines so many factors, and it is certain that the dimensions of his volume, by producing over-compression, have militated against its taking a more prominent place as a statement of Theism.

Dr. Barry makes a great point of the cumulative force of the several lines which are delineated. His insistance on this is emphatic: at the beginning and at the end of the lectures it is insisted that Man is complex, and that his consummating belief must sum up his whole nature. 
Prefacing with some observations on the method of Theology, and including an appeal to the Consensus argument, Dr. Barry then gives his cumulative scheme, Causation and Design, the Theology of the Intellect; Beauty, the Theology of the Imagination; Morality, the Theology of the Conscience; and Feeling, the Theology of the Affections.

On the Cosmological argument he takes the modern ground of making Will, not external nature, the starting-point: first, our own Will, and then that of other persons: and only afterwards does he turn to the nature of external things. This procedure of course supplies him with Personality at the outset, and stands him in good stead when he engages in controversy with the Materialist and the Pantheist. He does not enter into argument about a theory of Causation either by analysis or by inquiring why we can trust it to carry us beyond experience. And the absence of any other fundamental line of Reason leaves him somewhat remote from Infinity and Immanence. $\mathrm{He}$ of course protests against Deism, and speaks of the Divine Being as 'still impressing' His laws: but there is an inclination to dwell more on creation and origination of changes, than is advisable for any but the Deist.

In Teleology he includes both the general plan, and the perception of special intrinsic ends, and special adaptations. $\mathrm{He}$ values it especially as against Pantheism : by it he is enabled to include intelligent Will in the cosmos, and so he thinks Teleology " the delight of the Theist, and the abomination of the Pantheist." This may be true, but the remark might just as well have been made on the Cosmological argument by one who had included Personal Will in Causation.

The devotion of a special chapter to the argument from Beauty gives a special character to Dr. Barry's scheme. He acknowledges his indebtedness to Mozley for this, and to the writings of Ruskin, of which he speaks as having early influenced him in this direction. He takes 'Beauty' in all its forms.

The argument from Duty is on the usual lines. The Affections are then treated as vindicating the reality of their Object.

Only the Ontological argument has been omitted, though it is not 'denied' ${ }^{1}$ and as no substitute for it has been included, we have in Dr. Barry's scheme no secure foothold for Infinity.

${ }^{1}$ P. 45. 
He himself seems satisfied with a relative Infinity: "what we may call relative Infinity, that is, transcending our power perfectly to conceive. . . . Righteousness and Love like our own but indefinitely transcending our own": " beyond these conceptions of Infinity the mind in itself cannot go." 1 But he proceeds to insist that we have the notion of the Absolute given in Causation and in Morals, and when we invest it with the attributes established by the other arguments we pass to 'an Absolute Infinity.' And lastly, he says that "the meeting-point of the Absolute Conception, and the various lines of Induction converging to it, lies behind the veil: nevertheless its existence is invariably assumed." 2 But the treatment of Infinity and Absoluteness occupies only two or three pages.

But Dr. Barry does not omit an Instinctive factor. Indeed, his first lecture is devoted to a treatment of religious belief as instinctive, and his account of the 'method of the knowledge of God ' in Lecture II. finds the root of it in 'instinctive conception.' It would therefore be expected that he would be ranged under Type X. My reason for not placing him there brings into light the true character of the Intuitivist position as I understand it. Intuitivism makes a claim for a direct access to the supersensible and supernatural, in our immediate consciousness. Now such consciousness must be unique in its character: the Infinite, if known immediately, must be known by a unique capacity of our nature. Those whom I have placed under that Type speak with more or less clearness in this way, while Bishop Barry does not. He even says of 'immediate intuition' that it is 'impossible ' ${ }^{3}$ the instinctive element which he places at the beginning of religious belief is so placed only historically, in the order of development of religious knowledge; and, further, it is not peculiar to religious knowledge at all so to develop; all knowledge has the same stages, first it is rudimentary and dim, then it is clear in abstractions, then it comes into full reality. To say that religious knowledge begins dimly just as all knowledge does is not to claim a special faculty for transcending the finite, it is not really laying an Intuitivist foundation. In fact the instinctive stage is in the past for the man who has his eyes opened and can see; which is very different from referring to a power which is never dispensed with but gives a kind of knowledge which is always the foundation, the forming principle.
${ }^{1} \mathrm{P} .321$.
2 P. 322.
${ }^{3}$ Preface, p. viii. 
Dr. Barry will probably acknowledge descent from Hare and Coleridge to a degree which might entitle him to be grouped with them: but the affinities with Jacobi and Schelling displayed by Coleridge are absent from Dr. Barry's Theism, as the disclaimer above cited confirms. And finally, in the cumulative forces and converging lines which Dr. Barry so comprehensively displays there is a note of a confidence that could only be placed there when a truly Intuitive or Mystical foundation is not recognised. Hence I take his Theism to be of a 'composite' order, Reason both speculative and practical, Feeling, Will, construct a 'manifold chord,' whereby Natural Theology carries us out of a region of dim and rudimentary conceptions into a region of clear-sighted conviction.

\section{Lias, J. J : Is it Possible to Know God? 1883 ; The Nicene Creed, 1897}

This paper, read before the Victoria Institute, was written to supply an antidote to the agnosticism caused by Mansel and Mr. Spencer. Against these writers Mr. Lias protests that the objections urged by them lie against belief in space, time, motion, self, and other realities in which we believe as well as against belief in a Divine Being; and Mansel and Mr. Spencer should not single out the latter for rejection while obliged to acquiesce in the reality of the others. Mr. Lias himself acquiesces in the charge of failure made against metaphysics as applied to Theology; indeed 'abstract principles are fatal to the progress of thought' generally : he accepts the Conceptualism of Mansel, that abstract principles are only subjective in their character, useful for our guidance but not implying realities. The Divine Being is neither Infinite, Absolute, nor Unconditioned, as Mr. Lias understands those terms.

But he holds that we have sufficient sources for valid belief in the Divine Being as 'a living Power which governs the world': the sources indicated being the Arguments from Design, from Conscience, and from Consensus. Mr. Lias also recognises Intuitivism as a parallel source of belief, but only in a note towards the end of the paper.

In the later work cited, however, we have from Mr. Lias a clear statement of the Intuitivist position. He lays down the primacy of 'Faith' in religious belief, and Faith he defines as " the faculty, or instinct, which realises the truths of the unseen world, and produces in the mind a definite conviction of their existence." 1 
It is parallel with sight in giving objects upon which Reason works, i.e. it is a separate and independent source of knowledge of objects or facts, which is what Intuitivism means. Again, the conception of God is 'an innate idea,' 1 which is afterwards 'strengthened' by its correspondence with the results of observation. Among these results are, that there is a Power manifested in the universe, a Will-power; that Goodness is manifested to Conscience and by the course of history; that our emotional life corresponds; and, besides these, there is the argument from our needs. So that Mr. Lias lets down a very wide net for the 'strengthening' and-we may suppose-the filling-in of the conception intuitively given at the outset.

\section{Suith, R. Travers : Man's Knowledge of Man and of God, 1884-1885}

In this course of Donnellan lectures we have a reference to manifold sources of belief, which recalls the scheme of Dr. Barry. Causality, Conscience, Feeling, are all organs for the discovery of truth, and especially of the kind of truth we are in search of in religion, namely, truth of personality, of character. The prominent feature of Dr. Travers Smith's treatment is that he studies knowledge of God in close comparison with knowledge of Man. Mathematical, Physical, Metaphysical methods are set aside in favour of the method by which we learn to know personal mind and character. In obtaining knowledge of men the inference by intellectual analogy is enforced by our affections and moral sympathy, and the knowledge of God is not different in kind: the difficulties and inexplicabilities in the latter are found in the former, and yet we do not reject the former as impossible: why then stumble with regard to the latter? Dr. Smith recognises in both kinds an element which he can only refer to instinct, to faith: ${ }^{2}$ if men have not this they may regard other men as only things.

So that in this respect we might place Dr. Smith in the type of Comprehensive Intuitivism. But the chief impression given by his treatment is that his procedure is of this Composite type, for the 'mystery' in the Divine Being to account for which he resorts to instinct he finds also in every human ' person,' and therefore it is not specially of a super-phenomenal character. 
Martineau, James: Types of Ethical Theory, 1885; A Study of Religion, 1887

There is no question that Martineau came to the task of Theism with a magnificent equipment. In an autobiographical passage of great interest, because to many others typical of what has happened to themselves, he tells us how he began his thinking life "steeped in the 'Empirical' and 'Necessarian' modes of thought," from Locke and Hartley, Edwards and Priestley, to Bentham and James Mill : he was thoroughly acquainted therefore with this native school of ours, and we can see that when he left it he 'spoiled the Egyptians' to good purpose. His change was provoked externally by the necessities of his position as a teacher, which to him meant being a life-long student; internally by the growth of his moral consciousness and his sense of a spirituality for which the formula of Empiricism had found no room; and so he " educated himself out of a school into which he supposed he was educating others." He then worked through Plato and Aristotle under Trendelenburg, and made a close study of Spinoza. And behind all this study worked the profound and yet delicate spiritual experience which rendered him a teacher of religion to many who were not concerned with philosophical questions at all.

A first impression of Martineau's method of Theism is, that the belief in a Divine Being is a result of demonstration, by two ways, namely, by the proof from Causality and the proof from Conscience. These are both asserted and elaborated, and seem to give his whole account of Theism: God as Cause and God as Perfection is his own Summary. If this were so, he would go under our Type V. as combining both forms of Rationalism, the Speculative and the Ethical.

I confess to having for some time taken him at his word and regarded the presence of any other factors as due to some failure on his part to see that they were different from these. ${ }^{1}$

1 This impression was produced on some at least of his own attached students. The Rev. R. A. Armstrong, a student and a successor in one of Martineau's pastorates, says: "The two great contentions in which Martineau has held my mind captive ever since I have been able to understand him are these:-The argument to God as Power from our inalienable sense of Cause; the argument to God as Righteousness from the experience of conscience. Since I have understood Martineau on these two great themes, I have been able to think no other ... Martineau's own Theism had always been built on . . . [these] . . . two bases only." -Inquirer, Memorial number, 20th January 1900. 
But from two sources the impression grew that this was by no means a complete account of Martineau's true position, firstly, in his other religious writings there seemed to be flowing a stream of ampler volume than could run within the banks of Rationalism, and, secondly, the two treatises themselves contained so much of the extra-rational factor that it seemed incumbent on a seeker after truth to ignore Martineau's own apparent Rationalism, to unravel this factor and set it out in full light along with the others.

Let us begin by taking up his two Rationalistic arguments. First, God as Cause; the principle of Causality is the valid speculative principle of Theism. By Causality he means the inference from dependence to the 'eternal ground and essence,' the 'eternal ground of time events'; the 'abiding ground of transient phenomena'; 'something enduring, central, regulative, reposing in the midst of the momentary whirl of appearances'; the "essence which, occupying this and that particular being, gives it what reality it has "; the 'nucleus of the real,' without which 'phenomena alone would be but as drapery, hanging upon no solid form.' ${ }^{2}$ Causality is applied to Nature, and throughout he has both mind and external nature in view; 'all that happens'; 'things in so far as they enter and quit our field of perception': External nature is much in view certainly, and from his early studies he brings a wide acquaintance with the conceptions of physical science; but it is the domain of consciousness which has the place of honour, and his exposition is enriched from still fuller stores of psychological and moral observation. His inclination is to call attention away from Nature as a spectacle, and in the observed workings of the human will to find his chief material: "it is the Will which supplies whatever meaning there is in the word Causality." 2 It is not as Spectators that we acquire the conception but as Agents. "Not till we put forth and direct our own Causality, whether simply precipient or motory, have we revelation of the Causality of the World; so that it is not in mere exposure to changes, but in concomitant production of them, that this intellectual intuition is gained." 3 From our experience of Will we are led by a priori necessity to look upon the physical universe no less than upon the life of men as pervaded by purposive Will which chooses and orders things to be what they are.

\footnotetext{
${ }^{1}$ Ethical Theory, Introduction. $\quad$ 'study of Religion, Bk. II. c. i. $\quad{ }^{3} I b$.
} 
About the Ontological Argument, it may be noted in passing, he has no hesitation: he rejects it, discharging it as 'scholastic and artificial." 1

The Teleological argument he treats with vigour, on modern lines. The old Teleology he calls appeal to 'partial samples,' and regards it only as giving some material to be gathered up for a wider argument. He boldly plants teleology in the nature of the 'First Cause,' and looks upon the world as a manifestation of intelligent causative purpose; and he proceeds to investigate the world for confirmation or otherwise. He seeks the verification in human life first; beyond that it may not always be secured, though he holds that it is so in the main. His treatment of this topic gives legitimate scope for the picturesqueness of style for which he is eminent. It is pleasant to note his kindly opinion that if Paley had lived in our day he would have taken full advantage of recent science, and rejoiced to enlarge his notions of teleology accordingly.

This intellectual proof secured, Martineau proceeds to deduce the Attributes which are implied in such a Being. This is done very succinctly for Power (Omnipotence), Unity, Intellect, Infinity and Eternity. He reaches Infinity and Eternity by reference to Time and Space. The world, the cosmical system as we know it, he allows to be finite, and therefore not to give a basis for inference to an Infinite Cause: so he takes the method followed by Clarke by referring to Time and Space: Space we can affirm to be infinite, and there can be no 'disparity of scope between the Cause and the Condition of all things'; 'the scene of existence' is unlimited: and so is Time; whether or not the cosmos be eternal, the self-existent Cause cannot have begun, cannot be bounded in a limited time.

When we come to the Moral proof we cannot fail to be impressed with the emphasis of its presentation as the argument from the Moral Consciousness disclosing Obligation. In the opening of his own Ethical Theory ${ }^{2}$ it is the sense of Obligation which is marked down as the 'fundamental ethical fact'; he is profusely fertile in expressing its imperative character: ' $\mathrm{I}$ am not at liberty to go with the wrong impulse,' 'we have no right to dispose of ourselves,' 'a law over me not my own making,' 'commands not to be canvassed but obeyed,' the 'will bends in homage'; it is authority which in moral consciousness

${ }^{1}$ Study of Religion, Bk. II. c. i.

¿E. T'. vol. II. 
is the analogue to externality in perception; with a culminating statement that the Moral Law is 'imposed by an authority foreign to our personality,' ${ }^{1}$ an expression so forbidding that were it not for the fact that it is italicised one would have ignored it as a lapsus. It would be impossible to find in our literature a more emphatic enunciation that it is the sense of obligation which leads us to religious belief on the Moral side; in his own terms, "just in this feature of the conscience do we find the point of vital connection between morals and religion." 2

Yet we hardly like to pass from the moral proof without asking whether Martineau really confines himself to the strict imperative of Duty, or whether he does at all admit influence from that aspect of Morality in which Goodness is regarded as attracting us by its inherent quality. For the view that he really does restrict the scope of Morality to Duty, we find evidence in his attitude to the Hellenic conception of the Summum Bonum, in which, as he puts it, Beauty and Wisdom are combined with Duty: this procedure he repudiates as missing the element of 'peculiar and paramount authority,' and his opinion is that if it were accepted ethical life would cease to be 'a matter of universal obligation' and become 'the monopoly of philosophers.' ${ }^{3}$ He goes so far as to say, when dealing with Shaftesbury, that to take as our starting-point the conception of Good instead of that of Duty would be to begin from the heathen side rather than the Christian.4 Again, in describing conscience he says, Right, oughtness, obligation, responsibility, guilt, sin, form a ' circle of

${ }^{1}$ S. R. Bk. II. c. ii.

${ }^{2}$ It is a point of some interest but of minor comparative importance to ask whether Martineau qua Rationalist works by simple Intuitionalism or by inference. He says himself ( $S$. $R$. Bk. II. c. ii.) : "I care not whether this be called an immediate vision of God in the experiences of conscience; or whether it be taken as an inference drawn from the data which they supply." And his phraseology fluctuates from 'immediate introduction' to God in our moral consciousness, to 'pathways froin moral consciousness to religious apprehension,' 'a rational passage from the phenomena of human thought to superhuman being.' But on the whole he is clearly on the side of those who stand on Reason as a constructive power reflecting on the order of the physical and moral worlds. If he is to be taken as an Intuitionalist in the sense of finding that the conception of the Divine Being is one of our Intuitions he is exposed to the objection that he does not give us any system of the ultimate intuitions of the mind. Indeed, he himself expressly declines to construct a regular table of Intuitions or First Principles, claiming liberty to use such as he requires; a procedure all very good for himself as a free-lance, but where is the seat of authority, if others think they find some other principles with consequences irreconcilable with his? (E. T. Pt. II. Bk. I. c. ii.).

${ }^{3}$ E. T. Pt. 1. Bk. I.

${ }^{4}$ E. T. Pt. II. Bk. II. Brauch III. 
ideas ' ${ }^{1}$ the circle seemingly is closed up without Goodness at all. Once more, "the superior terms in the" (moral) "scale do not court us by their charms and graces, but claim us by their authority." $2 \mathrm{He}$ seems over and over again to look Goodness and Attractiveness in the face, so to speak, and to refuse to allow them place. On the other side we can collect a few indications, however: his designation of the result of the moral proof, "God as Perfection," leads us to expect some recognition of Goodness; he speaks of "the inspiring aspect of Infinite perfection,' and of our having in God 'all that is great and good ' ${ }^{3}$ and he expatiates in these pages on Holiness and Perfection. Again, he speaks of 'a homage of the heart,' a 'joyful humility,' a 'humbling of the soul with cries not only of dependence but of aspiration.' ${ }^{4}$ If we turn to his account of Reverence ${ }^{5}$ we feel that the phrases which had given tone to the argument from sense of Duty are here replaced by others of a tenderer and more alluring import, such as would arise if the object of regard were not only the source of authority but the essentially and supremely Good, whom the Soul might desire as the hart desireth the water-brooks.

What are we to say? Two courses seem open: first, to say that Martineau has in his progress enlarged his conception of the content of the moral consciousness, and then corrected his earlier phraseology accordingly; but this I think would be found to go clearly against the grain of his general treatment of Ethics, and would alter its predominant character. The other course would be to say that Martineau is incorrect in describing his method of Theism as only twofold, Causality and Morality (Duty), and to bring out that his scheme includes a quite different feature, namely, an Intuitive apprehension of the Divine Being. This course we adopt.

Before entering upon it we note that after his exposition of the Moral argument he draws out a set of Moral Attributes parallel with the Intellectual: Benevolence, Justice, Amity, and (very abruptly) Kingship of a theocratic Society. Then follows the identification of the deliverance of Intellect with that of Moral judgment; the Causal Being is the same with the Perfect Being; the eternal ground of the things that appear is the same with the Perfect Will which commands our obedience. The

${ }^{I}$ S. R. Bk. II. c. ii.

${ }^{2} \mathrm{Ib}$.

${ }^{3} \mathrm{Ib}$.

IE. T. Pt. 1. Bk. 1. c. v.

s. T'. Pt. II. Bk. I. 
historical religions have often failed to combine these, and have run out to Nature-worship or to Moral systems, in separation. His first ground for identification is the unity of the natural and the moral in ourselves; his second, its confirmation in human history and in that discipline of life where the natural and the moral systems play into one another, and only when they are unified is our mind capable of being satisfied.

We have now to adduce the evidence for the view that Martineau is really Intuitivist or Mystic as well as Rationalist. The clearest evidence is in his setting up of a faculty of Reverence, which he also calls explicitly ' the religious sense.' 1 It is treated as a 'Primary Sentiment' in Part II. Bk. I. c. v. section 4, and there is a farther treatment on 'the Supreme Place of Reverence' in c. vi. section 9. It is different from the Moral sense and from all others. It carries us into a higher sphere: by it we look upward; the goodness of which we are aware is transcendent; by this sentiment we 'step across the line of the real' and find the ideal; our attitude to the dictates of the perfect Mind is different from obedience, it becomes 'deep consent and secure love '; the term 'sacred' comes in, there is 'devotion' to God. When speaking of the supreme place of Reverence among the springs of action, he describes it as lifting us above the scenes of conflict where moral judgments lie, to 'free sanctity,' a 'saint's rest,' to 'perfected aims' and 'final beatification' and 'assimilation with God.' The difference between Morality and Religion is declared to turn expressly upon Religion being ' a conviction of an Eternal Holiness in correspondence with the individual conscience,' it is a 'communion of God's life and love.' 2 Then, again, he has a clear exposition of Religion and Morality as two different concerns; Religion makes use of the moral life and finds in it resources for its own development. In point of priority in time the two are not wholly concurrent, for in some men morality attains a certain maturity before religion comes, while in others - 'the great mass of the human race'-it is religion which receives the earlier development. ${ }^{3}$

If, then, there is a sense of Religion which is different from the Moral consciousness, as it is also different from Intellect, and from Feeling, what is it? It is plainly unique, i.e. intuitive or mystical in the sense in which $I$ am using these terms. There is no mistake about its high character: it is supreme: it is in
${ }^{1} E$. T. Pt. II. Bk. I. v. c.
'S. I. Bk. 11. c. ii.
${ }^{3}$ E. T. Pt. II. Bk. I. c. iii. 
authority, not like the other sources of belief which are but 'children' of the house. ${ }^{1}$ It is by means of the religious sense and not by the moral sense or the æsthetic, or by intellectual proof from Causality, that Martineau represents man as finally passing to belief in a transcendent Being: these other modes point up to Him, but they do not give us entrance into His presence. It is this which is the 'crowning recognition,' ${ }^{2}$ and Martineau is so deeply impressed by it in contrast with the 'inchoate' and 'misty' indications of lower faculties that he speaks of it as 'opening the heavens,' as 'a great redemption,' as ' converting the life of Duty into the life of Love,' ${ }^{3}$ and bringing us from Law to Gospel. What makes it quite certain that this is neither rhetorical fervour nor temporary exaltation is that we find him in his last work ${ }^{4}$ giving us a view of Natural and Revealed or Supernatural Religion in which he rejects the claim that Natural Religion must first be secured as a preambula fidei, declaring emphatically that there has been a Revelation in our minds all along, ' an imrnediate divine knowledge, strictly personal and individual . . . born anew in every mind.'

This being so, we can only put it down to his own imperfect orientation of himself that Martineau disclaimed association with professed Intuitivists and set out his method of Theism as dual, by Causality and by 'Perfection.' Prejudiced against Mysticism because of its tendency to absorb the human in the Divine, he is for calling his method 'Ethical Theism' $:^{5}$ but this is doubly misleading (1) because his Rational method is not only from an Ethical basis but also from Causation, and (2) still more, because of the Intuitive or Mystical element. On the other hand, Martineau differs from many of those standing under Type $\mathrm{X}$. in their being so emphatically Intuitive that they underestimate what Reason can do either speculatively or ethically, whereas with him Reason is both cogent and conclusive. For him while it is Reverence, the religious sense, which gives direct access to Divine knowledge, there are also concurrently well-laid roadways made by our 'intellectual judgment' 6 when directed to the cosmos and to the authoritative character of moral consciousness.

Our comparative method makes us conscious of omissions in Martineau's Theism. There are, indeed, passages where he
${ }^{1} S$. R. Introduction.
${ }^{2} I b$.
${ }^{3} \mathrm{Ib}$.
${ }^{4}$ Seat of Authority, Bk. III.
${ }^{5} S . R$. Preface.
${ }^{6} S . R$. Introduction. 
himself seems to be ready to admit other methods than his own : ${ }^{1}$ but he cannot make up his mind fully to acknowledge them, for he proceeds to hint that they are probably only his own, in disguise, in so far as they are worth anything at all. Some of the methods which are approved by other minds and for which he might have found some place along with his own he explicitly rejects, notably any argument from Feeling, from Beauty, or from Social authority. Feeling is dismissed as not giving knowledge: 'if Feeling were there alone, we should indeed be God's creatures, but know it not.' 2 His position as to Feeling is that it follows upon knowledge, upon the presentation of objects, and therefore that it is only knowledge which can conduct us to belief. It is a cardinal point with him to keep Feeling out of the foundation of Ethics; to build upon it is to be Hetero-psychological; and similarly it is no true foundation for Religion; although this disallowance is obviously inconsistent with the claim that in a sentiment, 'Reverence,' we have a power which can 'open the heavens.'

The argument from Beauty we miss with some surprise from a work in which style is richly marked with æsthetic quality. When we saw the term Perfection chosen to designate the nature of the Divine Being disclosed by the second argument we had expectations that love of Beauty would be included along with the more strictly moral element; and when we found that he admitted that Beauty has objective quality, we quite expected to find some place allowed to it. But Martineau will not recognise the Esthetic argument: he comes in sight of it over and over again, but he always views it with distrust and seems almost to shiver if it is ranked alongside the Moral. It is not confined to personal character, he says, and it lacks the mark of imperativeness : these defects are fatal to its claim for admission to the front rank; it leads to a form of hetero-psychological ethics which is among the false theories. When Hutcheson's doctrine comes near being moral cesthetics only, Martineau is 'afraid'; when he finds that the same philosopher has not succeeded in ' dissolving moral essence in the flood of beauty' he takes his leave of him 'not without gratitude.'3 And in Religion this attitude is maintained in terms, though not in practice, for Martineau could not fail again and again to express something

${ }^{1} S$. R. Introduction and Bk. IIr. ad init.

$2 S$. R. Introduction.

${ }^{3}$ E. T. Pt. II. Bk, II. 
of the mood of adoration when, free from his theory, he is thinking upon the Divine Being. We are often like Tantalus in the stream, when we find so much acknowledged from time to time yet not incorporated: and we are disappointed to find that a source of religious belief which Martineau had noble gifts for treating very attractively had no attraction for himself. ${ }^{1}$

As to Social authority, Martineau's well-known Individualism prepares us for his hostility. His treatment of both Ethics and Religion is thoroughly individualistic, and we find but scanty resort to the history of mankind even for illustrative references. $\mathrm{He}$ builds his intellectual argument on individual experiences; in them, too, he finds the seat of moral judgment; and there also is the abode of the Intuitive faculty which we have disengaged. Martineau allows that there is some corroboration to be obtained where there is wide acceptance, but it was perhaps due to his lifelong association with a small body of religious believers that he draws small sustenance from the common opinion of his fellows, and certainly he can place no seat of authority in the consensus gentium. Religion may seem to pass from mind to mind by 'lateral transmission,' but this is pseudo-religion: unless the echo which is awakened is a personal conviction it is not truly religious. For influencing personal conviction he will not hear of any 'legislative function vested in the general assembly of dead and unborn men, together with the miscellany of living populations.' $^{2}$ In spite of the eloquent passage on the way in which lofty souls supply 'a lever lifting the elementary masses of society' ${ }^{3}$ he also writes, "Second-hand belief assented to at the

1 As a matter of biographical interest, what Mr. Armstrong records in the obituary article above referred to is noteworthy. After referring to the two great arguments, "With some inward tremor I asked Martineau whether he thought I was justified in building, and in my mode of building, on a third foundation . . . the sense of beauty through which man recognises God as Love. His reply was a wonderfully cordial and unqualified assent. In answer to a further inquiry, he added that he considered that the argument was quite qualified to rank in importance, and to be co-ordinated with, his own two great arguments from the concept of causality and from conscience." This refers to a conversation in 1897, and it bears out what I have put forward in the text as to what might have been expected from Martineau. But to have admitted it would have necessitated a more considerable reconstruction of Martineau's work in both Ethics and Natural theology than at his age was at all likely to be attempted. It may be added that Mr. Armstrong's terminology does not make it quite clear whether there is not here some reference to the argument from Feeling as well as to that from Beauty, and I take it that it is only the latter to which Martinean was ready to offer welcome.
${ }^{2} E$. T. Preface to 2 nd Ed.
'S. R. Bk. Ir. c. ii. 
dictation of an initiated expert without personal response of thought and reverence in myself ... has no more tincture of religion than any other lesson learned by rote "; $;^{1}$ and his diatribe against 'Right by Social Vote' 2 is charged with caustic scorn of public opinion as an influence over moral judgments. Yet Martineau's view of the Individual is not that man is a 'lonely' being who wakes all his own echoes: society is the means of 'discovering us to ourselves'; but the inherent essence after all is a self-judgment made by every man as a type of human nature; we are all members of a kind, 'my fellow is myself over again'; and he thinks that by taking this view our experiences enable us to 'sweep into the widest generality' yet 'without asking a question of our fellow-men,' the 'revelation of authority to one mind (being) valid for all.'

The provision for Infinity is not a strong point of Martineau's work. In expounding the Causality argument he lays hold of infinity by assuming that it is given to us in Space and Time, the 'scene of our existence,' a course which opens the door to metaphysical criticism from many quarters. And the difficulties attaching to the conception of a Personal Infinite he does not face.

It cannot but be considered a serious defect in Martineau's Natural Theology that he has incorrectly marked the lines of his procedure: he has misled sympathetic students into taking him simply for an advocate of the dual Rationalism which proceeds by Causality and Conscience,- - the two sources of Religion unfolded in these volumes,' ${ }^{3}$ is his own phrase: in short, as moving on the Traditional lines, with correction and enrichment from modern science, physical and psychological; whereas his work is impregnated also with an Intuitivist temper, recognition of which is given only from time to time and not when setting out the scheme. We feel that the opinion that his gifts for analysis and criticism were greater than his talent for construction is a correct one; and it is because of the absence of articulation of the Intuitive factor with the others that I think his right place is under this Composite type.

But when these deficiencies are noted and allowed for, the student of the philosophy of religion will still feel that in Martineau we have one of the great masters of the subject, one of the men who have made contributions of permanent value to

\footnotetext{
${ }^{1}$ Seat of Authority, Preface.

2S. R. Bk. II. c. ii.

SS. R. Preface.
} 
its literature in Great Britain. His treatment of Causality made the intelligent interpretation of the cosmos sauter aux yeux once more in an age when mechanical theory was enveloping men with mist. His emphasis on the authority of conscience marks him as the truest successor of Butler in the history of English Ethics, making us, children of Utilitarianism as so many of us are, once more feel the 'law over us which is not of our making,' the obligation which is ' underived from our will, independent of our idiosyncrasies,' and impressing once more that sense of moral objectivity which has to so many been the fulcrum of religious conviction. In his dealing with the objections and difficulties in the way of belief in a Perfect Ruler, Martineau draws on a rich store of moral and spiritual experience and gives us a result of enduring value. Lastly, his insistance on the personal nature of religious conviction, with the self-evidence and self-disclosure which are involved in it, and the necessity of substituting a Religion of Consciousness for the Religion of Custom-to use an early phrase of his own-though pressed to exaggeration and consequent defect in other directions, brings into relief one aspect of religious faith which can never for a moment be obscured without pernicious consequences to religion itself.

If to these excellences we add the extraordinary profusion of delicate analyses of experience, of expressions of original thought and profound personal feeling, given to us in nervous, lucid, and most richly varied English, we can see that Martineau has secured one of the places of highest honour in the literature of our English Theism, and has given us many thoughts of the kind which raise the whole level of man's religious meditations.

\section{$\S 3$}

Conder, E. R. : Bases of Faith, 1877

We have here a Theism evolved by an apparently solitary thinker. At first reading there seems in this work to be a setting at naught of the classification which I have adopted, so various are the bases resorted to. For instance, Conder goes against all other schemes-and surely against common logic? -in treating of Revelation between the Intellectual and Moral arguments. Again, he seems to retain a grasp on Intellectualism, but with a wavering hold, while he also endeavours to set forth Belief as a product of our whole nature, after the Personal manner. 
A mark of the solitary student is that there is incorporated in the book a long exposition of Theory of Knowledge, in which he hoped that he was furnishing a new departure in Metaphysics; but most of what he says had been said before, and of the effort as a whole no more has been heard. Again, his judgment as to authorities is quite uncritical, both in philosophy and theology; and positions which are quite well known, are regarded as commended when some minor or obsolete authorities are quoted in their support.

On the Intellectual side Conder accepted the First Cause argument, which he expounds only by refuting objections; and also the Teleological. But $\dot{a}$ priori metaphysical argumentations he repudiates: the Absolute and Unconditional are abstractions, although he presently puts down the Infinite as a known fact; at the end of the book he retracts, and again calls it an abstraction. On the two Intellectual bases chosen he cannot, however, place much confidence; and besides, they are not indispensable: elsewhere, indeed, he turns round and abuses them: "these demonstrative arguments are ambitious but unsuccessful," 1 indeed "they wholly fail," 2 for religion. Why he had lingered so long with them is, therefore, not clear. But he now turns away to Inductive Teleology or History, and prints in large type what he has found to be the Basis of Faith. But his confidence again oozes away, the Inductive teleology proves to be too intellectual, so it is upon History of the belief that we must fall back. After all this, then, we find ourselves at the beginning of things, on the old familiar ground of the Consensus argument. This is stated very well by referring to the moral and practical as well as intellectual convictions which are habitual with mankind.

And then at last-after Revelation-he comes also to the Moral argument: wherein he includes, not only conscience, as part of the voice within us, but also love, aspiration, prayer.

There is something in his Theory of knowledge which would have given a special character to his work had it been constantly adhered to: namely, his basing belief on the common ways of obtaining knowledge in actual life, in which the individual acts in combination with the collective mind of mankind. Here we ask whether Conder had read Ritschl and was going to place all on the appeal to common Consciousness: in which I $\mathrm{P}, 97$.

2 P 100. 
case we should have placed him under Social Theism. But he makes no reference to German assistance, he refers instead to Henry Rogers, William Jackson, and Mr. Murphy. And as he does not adhere to this method, but states others as well, though in his own way and in a peculiar order, I regard him as holding that belief must be justified to the Individual mind apart from Common-consciousness; and as, again, he does retain Intellect, but considers Feeling at least as coeval and reacting constantly upon it, and the Practical element (or Will) as also essentially co-operating, we have a variety of the Composite Type.

\section{$\S 4$}

Voysey, C. : Theism, 1895, and various Addresses

In Mr. Voysey we have a man who has a confidence in this type of Theism so strong that he regards it as capable of furnishing a dogmatic creed not merely for individuals but for a 'Church.' Going beyond those pure Theists who stop short of practical organisation on the basis of their opinions, Mr. Voysey has succeeded in keeping together a congregation in the heart of London for thirty years under the title of 'The Theistic Church'; a testimony to the vigour of his faith and the largeness of his conception of what religions should do.

His views have been given in innumerable sermons and addresses, of which one of the best is that printed among a series of addresses, entitled Religious Systems of the World, ${ }^{1}$ delivered at the South Place Institute, London. $\mathrm{He}$ is very individualistic in tone; every man is for himself the sole seat of authority: even if reason is appealed to, it is reason as exercised by the man who makes the appeal. The basis is threefold: reason; conscience; and the affections. A religious instinct is added as a fourth; but it is not defined, or worked in, and indeed there is no mysticism in his general tone. Indeed in the volume published in 1895 he opposes reliance upon Instinct as being too 'imaginative,' and as possibly leading to superstitions; men believe in devils as well as in deities. In the region of reason it is the Teleological argument on which he relies; in conscience, on Intuitional morality. His reliance on Feeling is very marked: he finds that belief in God is the highest spring of love, that to obey Him is a delight. Indeed he urges the

${ }^{1}$ Published in 1890. 
practical effect of the belief on conduct and on feeling so vehemently as almost to carry himself into either the Ethical or the Emotional school: as also is suggested by his marked regard for Francis Newman. Contemplating the thought of a Divine Being and a world which is His, he finds the survey stimulating and ennobling, and the carrying out of life in accordance with it a service of peace and hope. It is all, as was said, sharp-cut Individualism: he enunciates a credo: but with an implicit conviction that men are all identical and that this creed may be, and should be, their common possession.

\section{$\S 5$}

SeELex, Sir J. R. : Natural Religion, 1882

Seeley comes under this type because his view of the sources of religion is that there are three, and he treats them as if operating separately and not in fusion. He finds in different men a passion for one or the other separately, and does not refuse to any of them the epithet 'religious' on that account, although he would have them combine the factors.

Natural Religion, for him, is threefold, "consisting of that worship of visible things which leads to art, that worship of humanity which leads to moral disciplines, and that worship of God which is the soul of philosophy and science." 1 Beauty, Goodness, and Truth, are all here. He does not give a constructive Theism himself : there is no exposition of processes. What he gives is the result of his reflection on the history of culture and religion. He asks himself, What forces have operated on the minds of men of the first rank to a degree which has stirred them to enthusiasm? His method is inductive: his field of observation is the minds of men; his criterion, the power to quicken and to fill the souls of the mighty. Whether he is entitled to apply the term 'religion' to the possession of an influence which rouses to enthusiasm, even if it is roused by finitudes only, is a matter of usage: he is, at any rate, quite consistent with himself all along, and allowance can be made for the reduced sphere in which he uses it.

Looking upon the history of culture since the French Revolution, he finds that Science, Art, and Conduct have each exercised commanding influence on choice human minds. And 
he therefore claims recognition for each as a factor of religious belief.

He shows them at work in separation: First, the pursuit of knowledge has become an absorbing passion-it gives rise to the feelings 'love, awe, admiration, which together make up worship.' I It is 'capable of inspiring a fanatical zeal' and 'bears in its hand a budget of practical reforms' ${ }^{2}$ it gives men as strong convictions as can be found, so that they are filled with a desire to 'remodel all education and all preaching in order that the knowledge they have obtained may become a common possession of mankind.' ${ }^{3} \mathrm{He}$ notes, however, that the students of science rail off philosophy and erudition from their sacred enclosure: and he confesses that he finds them 'sometimes narrow and fanatical,' but in their 'energy' they have the true religious stamp.

Next, the lover of the Beautiful, the artist and the poet, who find Nature 'infinitely interesting, infinitely beautiful,' and "have continually the exquisite pleasure of discerning or half discerning divine laws; regularities, ... analogies,... and the sense of a vast unity not yet discoverable or nameable." 4 This goes beyond 'mere appreciation of material and individual beauty,' to the 'appreciation of the unity in things.' ${ }^{5}$ He notes the revolution which came in the age of Goethe and Wordsworth: artists and poets "assumed a high and commanding tone" ; "the function of the prophet was revived, and poets for the first time aspired to teach the art of life."

And thirdly, in conduct, morality. Here Seeley, as might be expected from him, takes the large social view of conduct and dwells on the ardour of reformers of national life since the Revolution as the ardour of men with a 'creed,' a religion.

$\mathrm{He}$ does not fail to notice that these several enthusiasms are by no means necessarily united. "The artist has long cherished a secret grudge against morality"; and he cites Goethe as an example of this: "the idea of duty and selfsacrifice appears not to be very sacred in his mind-rather, perhaps, to be irritating, embarrassing, odious to him " : 7 and the contempt of some scientific men for Art is another instance.

But he reprobates this: it is 'terrible': "the direct shock
${ }^{1}$ P. 73.
2 P. 42.
${ }^{5}$ P. 95.
${ }^{6}$ P. 96.
${ }^{3}$ P. 20.
iP. 98.
${ }^{4}$ P. 21. 
of contrary enthusiasms has something appalling about it." 1 He delights to show how Wordsworth rose serene above such conflict, though he had his own supreme enthusiasm. And he endeavours to show scientific men how beauty is unveiled by their labours, and the artists and poets that the advance of knowledge has given and is giving far more than sufficient to compensate for the imaginative illusions which it has destroyed. And he claims that in the older view of religion the separateness we have in recent times seen strained to point of conflict was not in men's minds: religion was not divorced from nature, or from beauty, or from right conduct.

In all this we are in the region of inner experience only, the subjective side of belief. Seeley is only showing that certain pursuits can be absorbing, overmastering, passionate, enthusiastic, to a degree which has been thought characteristic of religion: to these 'beliefs'-even taking them separately-he would allow the title 'religious,' but would himself prefer to see them all combined. The irreligious man is the man who has no such zeal, no ardour, no 'love, admiration, or awe' for anything; 'feeble' in character, struck with a 'demoralising palsy', the increase of such men would be fearful to contemplate. But this, Seeley thinks, is only to be feared by those who have other views of religion than his: for him the progress in 'the redemption of the poor and the pacification of mankind' which is going hand in hand with the deeper views of the universe and the beauties revealed by science and appreciated by the increase of culture, show that real atheism is rarer than ever.

This testimony to religion is really the main feature of Seeley's work, that which gives it special character and value. Coming from a penetrative and highly cultivated mind accustomed to range freely and to think independently, its value is great as testimony for the fact of man's capacity for beliefs of high and elevating order, whether we are to call them 'religious' or not.

The question now is, Are they religious in the accepted meaning of the term? If so, what is the Theology with which they correspond? In so far as Seeley welcomes them, and acclaims their religious character, what is the Theism which is in his mind? We must avoid limiting him to such conceptions as he attributes to others. His book is defective in form 
because it is difficult to disentangle what he describes as satisfying others from what he demands for himself, and therefore, it may be presumed, would recommend to others and would desire to see become universal.

To many he appears at once as a diluter of Theology: he does not consider that either Personal Will or Perfect Benevolence, or occasional intervention by Miracles, is indispensable to the conception of the Divine Being. ${ }^{1}$ If these are gone, what does he retain? Unity, at least, and Power, and therefore a regularity in the universe which renders it fit for man's confidence. ${ }^{2}$ To these we must add-as appears laterInfinity and Eternity. ${ }^{3} \mathrm{He}$ acknowledges that this amounts to what is often called Pantheism, but it is Theism at least, not Atheism, he maintains. However, he does not rest here, for we find Personality quietly slipping back: e.g. p. 46, where he uses the term Being as a parallel with the term human being which is so close as to lose its meaning if they are not similar; and again (p. 71), "the God of Nature has so much of personality that $\mathrm{He}$ takes account of the distinction of virtue and vice, that $\mathrm{He}$ punishes crime, and that He relieves distress." Now this is just the belief which makes Theists, not Pantheists, and so the ejection of Personality in the former place is remedied by its reintroduction just where it is required if Seeley wishes to come out of Pantheism. In fact it is to be remarked that when he was rejecting it he was rejecting the old view of Personality as necessarily limited: when he reintroduces it, it is apart from that speculative defining.

As to Intellect, he shuns the sphere of abstract intellectuality : "there is an atheism which is a mere speculative crotchet": 4 he regards Intellect as showing the real universe with which we come into personal contact in life and conduct. If a man disbelieves that God exists in the universe, and thinks that it is irregular and lawless, such a man is a real atheist. But such a disbelief is, in his opinion, 'speculatively monstrous,' ' is a kind of mental deficiency or perversion.' A man may even have a wrong belief about God, and yet be no atheist: if he believes that $\mathrm{He}$ exists in the above sense he is a Theist. How Seeley would lead him to acknowledge Infinity and Eternity does not appear.

For what the Moral Faculty and the sense of Beauty contribute we may take his endorsement of the enthusiasm of
${ }^{1}$ P. 13.
${ }^{2}$ P. 15.
${ }^{3}$ P. 46.
${ }^{4}$ P. 27. 
the moral and social reformers, and of the poets and artists, as involving his acceptance of the infinite Beauty and the perfect Goodness which led them on.

Is Transcendence admitted? or does Seeley rest content with the Immanence which he himself indicates as satisfying the demands of the natural mind, as exemplified in many of the reformers, men of science, and poets of whom he speaks? If we may take his term 'Supernatural' to refer to Transcendence of nature and the natural, then his position is-(1) It is indispensable; purely natural Theism is insufficient: if you ask on what rests 'so happy and inspiring a belief' 1 as comes from the answers of Christianity to our questions as to the reward for virtue, the compensation for undeserved misery, the sureness of retribution for crime, the hope that the vicious man may become virtuous, the means by which the pressure upon the conscience produced by wrong-doing may be removed, the means of defence against temptation, the worth of life, the habitableness of the Universe for one in whom a sense of duty has been awakenedall these he enumerates-the evidence, he says, is in part Supernatural: and he closes the book with a powerful expression of the insufficiency of natural thought. But (2) resort to God as Transcendent must not be exclusive and it must not be introduced too soon : ${ }^{2}$ natural thought must do its work first. And he claims that this was how the older Theology proceeded. ${ }^{3}$ For "the true object of theology at the beginning was to throw light upon natural laws": the separation began when theologians stood rigidly firm to old conclusions and regarded fresh knowledge as opposed to them, until what theology included seemed 'miraculous' over against the new laws exhibited by advancing knowledge. Similarly in the moral sphere: "Christianity in its original character had an evident analogy with that modern liberal movement ... it breathed something of the spirit of equality and still more of the spirit of fraternity .... (of) brotherhood between classes and nations." 4

Of course this is not exactly what is meant by Transcendency, which is itself held by Theists to be included in the domain of Natural Theology, and not to be 'supernatural.' Seeley is thinking of resort to Revelation: but his admission of the possibility of that resort is the clearest evidence I can find that he held transcendency and not the identification of Nature with the
${ }^{1}$ Pp. 25, 64, 261.
${ }^{2}$ Pr. 41, 42.
${ }^{3}$ P. 28.
4 P. 38. 
Divine Being: for if he had asserted such identity he would have had to follow Spinoza and deny the possibility of such an appeal beyond Nature as he himself obviously allows and makes.

Any attempt to determine Seeley's own position meets with great difficulty in the peculiarly involved form of his book. I offer with diffidence what is above sketched. But I repeat the opinion that the value of his book is to be found in its testimony to the power of the religious spirit in men of this present age; in the post-Revolution period, as he would put it.

The men of science, the poets and artists, the moral and social and political reformers of whom he is thinking may not have been on good terms with each other, each being filled with zeal for his own pursuit: and they quarrelled, most of them, with the current Theism. But it is a misnomer to call them Atheists, he contends; they were neither sceptics nor triflers, but earnest men, passionate men : they had something to believe in which lifted them high, and they seemed prophets, even priests, with a right to impress upon the world what they saw and believed. He thinks that "an age which is called atheistic, and in which atheism is loudly professed, shows in all its imaginative literature a religiousness - a sense of the Divine-which was wanting in the more orthodox ages." $1 \mathrm{He}$ disentangles real atheism from what is only reformed and readjusted Theistic belief, or what is at least on the way towards that: and distinguishes transitory forms of Theism from fundamental forms which persist through changes. That his discernment is absolutely sure or his decision infallible is not pretended. But the lavish brilliance of his epigrams and his command of the resources of modern culture make his book one of the most striking in our theological literature: not likely to be read without leaving a strong mark on the reader's mind.

\section{$\S 6$}

DAvidson, W. L., Theism, 1892-93

Professor Davidson in his Burnett Lectures casts his net in several directions. As I read him, he works by the Quasitranscendentalist argument from our nature as a whole, and also by other forms of Rationalism, and he incorporates also the assurances of Feeling.

2. 109. 
A considerable portion of his space is occupied with elaborating certain positions outside our present scope, which is confined to the use made of the positions themselves: there is a good deal of Psychology, and still more of Ethics: his own position for Theism can be obtained from Lectures V. and vI.

The conception which he has before him is the full one, as he uses the term 'All-perfection' to include Infinity and Necessity as well as Goodness. His method is to commence with the argument from the needs of our nature, which I have called Quasi-transcendentalism: our nature at its 'highest and best' makes a demand which can be legitimate only if there is an object corresponding to it-such an object as Religion puts before us. Dr. Davidson gives special attention to the inquiry as to what kind of demand is entitled to be used for this kind of inference. He gives a clear account of Wants of our Nature as compared with 'mere desires or wishes': a Want is organic in us, and natural science itself leads us to see that such wants could not arise unless there were sources of satisfaction for them: they could not arise wholly apart from objects. Now the demand which comes up in religion is one that arises in our nature at its 'highest and purest': moreover, the acquiescence in the corresponding belief has been ' $a$ condition and a means of human progress,' it has led to health and development, it has "stimulated men to the practice of righteousness." We have therefore two broad conclusions before us, The being of God is a 'want' of man's nature at its best; and, The acceptance of the validity of the demand has proved beneficial. Dr. Davidson's treatment gives a character of solidity to the presentment of this argument; if Religious belief is proved to be a constant and a beneficent feature of mental life, satisfying a persistent and elevated demand of our nature, it stands justified at the bar of reason. Before quitting his exposition Dr. Davidson distinguishes his method from that other mode of Quasi-transcendental inference which proceeds by verification of hypotheses: but his treatment of the distinction is not so full as might have been expected from a writer who has given special attention to Logic.

The above argument takes in view our nature as a whole: he then proceeds to incorporate arguments from its parts. In the sphere of Emotion he finds certain powerful Feelings, namely, Awe (distinguished from Fear), the sense of Beauty 
and Sublimity (placed under Feeling, not under Ethics), and the sense of Dependence, going forward into Gratitude: these cannot arise causelessly, so to speak, and therefore in their appearance we have a ground for belief. In his Ethics he takes up a special position, making the consequences to society the criterion of Goodness. This gives a spring to religion because of the need to bring the individual into connection with social good without reducing him to submission to something external to himself. In the thought of a Divine Being with whom the individual and society are all related this externality is transcended : if the welfare of society expresses the Will of God, the individual can devote himself to social Good by reason of loyalty to God, an inner and necessary loyalty takes the place of external obligation. The failure to attain any accomplishment of social good gives a further reason for looking beyond actuality to some Being in whom the ideal is true.

On the Intellectual side Dr. Davidson finds concurrent support. He places Teleology first in order of treatment, with some deference to the genius loci, as it seems that Aberdeen men have always been attached to it. He does not regard it as furnishing us with a syllogistic proof : it is the working out of an assumption by inductive verification. Then follows the Cosmological proof. Of the Ontological-'the least popular'-he says that it is no argument, but the defining of a conception. He proceeds, therefore, to give his own Ontology, which is that the supreme reality is Conscious Mind.

Consensus is referred to as confirmatory: but he had already made another use of it in developing his first line of proof, his argument from the wants of human nature.

If we look at his treatment of Ontology we should feel disposed to regard Dr. Davidson as a Transcendentalist, establishing a conscious Mind, Spirit, by Metaphysics, with deduction of attributes, and teleology and causality as modes of application to the cosmos. But he does not himself articulate a scheme in this way, nor does he put Speculative proof in the front position at all: in fact he rates it lower than Ethical proof for the purpose of religious belief, regarding Intellectual proof as only a luxury, while Ethical satisfaction is the more pressing concern, as it arises in connection with conduct, which is threefourths of our 'life.' The broad position, therefore, is that Dr. Davidson regards belief as arising in reference to the whole 
sphere of human life, which, both as a whole and in its æsthetic, moral, and intellectual functions, unites to justify belief in God. The freshest part of the exposition is where he is making good his first line, the validity of belief based upon the Wants of our nature at its highest and purest.

See Appendix C for Professor Baldwin, Ethical and Social Interpretations. 


\section{CHAPTER XII}

Some QUaSI-TheIsms

\section{$\S 1$}

HoвBES : especially Leviathan, 1651

To find Hobbes placed under Quasi-Theism may surprise the general reader who has been accustomed to hear of Hobbes as a leader of Atheism. The difficulty is easily settled. Hobbism was at once taken as leading to Atheism, and as such it was the grindstone on which the wits of Apologists were sharpened. But Hobbes himself did not take that path, nor is it reasonable to accuse him of mental reservation or dishonesty in avoiding it. In Natural Theology his procedure was strictly on a par with his procedure in Political Philosophy. In Politics he vindicated Tyranny as a reasonable form of Government, odious as it might seem to most minds: in Theology he vindicated a Deity, although of a character which to others seemed worse than worthless, and impossible as an object of worship. In both cases what Hobbes wanted was an Object entitled to Obedience: the recommendation to acceptance rested upon the misery or pain which disobedience entailed, not upon any joy which issued either from king or from Deity.

The fact is, Hobbes was not a true Inductive Empiricist of the school of Bacon. His philosophy is synthetic, governed by a procedure of a mathematical kind, more akin to that of Descartes than to that of Bacon. He appealed to experience for his elementary data, and found them in sensations and feeling, taking as his whole stock the most meagre selection of experiences with which any modern philosopher ever started; and his constructive principles were equally scanty. The value of his work is that it shows what could be accomplished from those data, as worked up by those principles. They led him to uphold 
what we should call a Tyrant Monarch in the State, and to recommend obedience to what we should equally call a Tyrant Deity in religious life.

Hobbes, in spite of his opposition to Scholasticism, did not himself depart from the Traditional Method in Theism. His opposition amounted to abhorrence, and perhaps there is no case of a thinker, usually reckoned as in the first rank, so grossly vituperating another as Hobbes vituperated Aristotle. ${ }^{1}$ The clearing of Aristotle's philosophy out of Religion he considered one of the most salutary points of the Reformation. But Aristotle was not cleared out qud Theism: and Hobbes himself does not abandon the argument to a First Mover, a First and Eternal Cause, or such non-empirical conceptions as Unity, Eternity, Infinity, and Omnipresence as attributes of the Deity. The first basis he lays down is Feeling; and in Feeling taken very simply, merely the desire of pleasure or aversion from pain. There is the plain and obvious feeling, Fear; men find themselves in presence of an irresistible Power, the fear of which is 'worship.' The Moral basis is there, but by the Hobbist analysis it is reduced to Feeling, desire for pleasure. He sometimes speaks of goodness as if it were something with a character of its own, but in his definite statements the Good is what we like: God is Good to us if $\mathrm{He}$ gives us what we like, not otherwise. Fear of the Power which can give or withhold what we like is his basis in Feeling.

But Hobbes has also an Intellectual construction on the basis of things in general. He has not abandoned the distinction between First cause and secondary cause, and holds that reflection upon the latter leads up to the former. He does not indeed consider that we attain to knowledge of an Infinite: the simple I AM is all we can speak of; then by Negatives (Infinite) or Superlatives (Most High) or indefinites (Holy) we can do something towards setting Him before our minds. In history we find recourse to the First Cause constantly brought into natural explanations to fill up ignorance of second causes, and to explain 'things causal,' and against this Hobbes protests. But he does not desire to regard the world as now out of relation with the First Cause; the term 'God' includes Father, King, Lord; and Providence is one of the necessary attributes. Hobbes is no Deist, according to his own claims: indeed his

1 Leviathan, c. 46. 
Fear of an irresistible Power seems a ground for Immanence as definite as could be imagined, for if there were only an original Creator, not a Power now governing, Fear would be at an end.

In apportioning weight of influence as between his basis in Feeling and his Intellectual Theism, Hobbes ranks the latter as the higher; in early stages of culture Fear operates most, and we have Polytheism, with a minimum of assistance from Intellect; but later, 'curiosity about Causes operates,' and does so quite intellectually, 'without thought of their fortune': and then Monotheism comes.

In passing any judgment on Hobbes' idea of the Deity we must remember what he needed and was in search of: an All-powerful First Cause would be to him a perfect ruler, and entitled to man's absolute obedience: an Atheist would be an idiot or a madman in that presence; or, what was worse in Hobbes' eyes, a rebel, an enemy of God, of man, and of himself. As to goodness, Hobbes' Deity was just as much and just as little good as was his monarch. Hobbes, as we know, keenly and seriously desired to see a peaceful civil Commonwealth; for this, power in the Ruler and submission in the subject were the indispensable requisites: and it was similar for affairs ecclesiastical. For the Universe at large, therefore, we may, I think, take him to have been in calm, sober earnest in setting forth belief in an irresistible Powerful Being ruling over absolutely obedient men as the perfection of order and government. For such a Being, Fear, and search for First Cause, were adequate grounds of proof.

Such a conception of God appears the most outrageously antiChristian that a distorted imagination could conceive: hence the fierce attribution of Atheism to Hobbes, and the genuine horror inspired by his name in pious lovers of God. Yet he himself claimed that he was a Christian, and he occupies a large part of the Leviathan with an exposition of his views. It is a mistake, therefore, to class him with Bacon as holding Religion in a separate compartment from Natural Knowledge, as is commonly done. Hobbes has a Natural Theology: there is a God (of a sort); and the connection with Revelation is that God has spoken: there is evidence for it: besides Creation there is His Word: when this has been established by evidence, Reason has the further task of interpreting and understanding it.

Hobbes on Religion and Hobbes on Human Nature are 
identical: he is unique in our philosophical literature; we think we are reading some sardonic irony in a satire by Swift : but in Hobbes it is genuine; he meant what he wrote.

If, therefore, we find Hobbes called ' the first Great Christian sceptic in England,' the epithet can be allowed from the point of view of a full Theism, but not on Hobbes' own view of 'Reason' and of 'God': he was a rational Theist. At the same time it is not to be denied that when history judges Hobbism it finds in it the seeds of the materialism and the scepticism of the eighteenth century.

\section{§2. Transcendence only: the Deists}

The limitation to Transcendence has always been the danger threatening those who rely too closely on the Causation Argument, especially when it is taken in the form of First Cause; when the element of Time is taken as entering into the phenomena, and all that we are in search of is the Prius in a time-series. The tendency to regard the Divine Being as a Creator only becomes almost unavoidable. It is thought that when $\mathrm{He}$ created $\mathrm{He}$ did so in a very full sense; He endowed creatures with their full natures, and imposed on them the laws of their being. This done, nothing more remained; or at least nothing more than the bare conception of a continued support of what had been inaugurated. No fresh action was probable, as that would be a re-creation, an interference. In early stages of civilisation such interventions might be thought of as necessary to account for the appearance of everything that was new; there might be hundreds of such interventions, thousands, millions: but the growth of Science, and the consequent increasing perception of the persistence of uniformities in the operation of a few forces, effected the dismissal of these interventions and fresh creations, one after the other, until their total disappearance was conceived. Then the Divine Creator sat on His throne and His world went on without His intervention, as a spectacle before Him. If, therefore, the habit has been to regard 'occasional' events as the chief incentives to religious belief, and the successes of science or new methods of philosophy have reduced these events both in number and volume by showing uniformities unsuspected and connections previously concealed, those who appreciate the new knowledge will tend strongly to reduce the 
Theistic conception to transcendence only, and to see no continued immanence of the Divine in the World.

These conditions came into effect in England in the seventeenth century. The Baconian induction and the Cartesian Mechanical philosophy co-operated to commend a view of the world as a machine working by laws-both worlds, i.e. the physical and the mental. The achievements of Galileo and Newton for the physical world ran side by side with the psychological mechanisms of Hobbes and Locke: and the metaphysical theories of Descartes and Leibnitz were easily adaptable as a support from philosophy.

In Theological speculation there arose the view that there was no need to be continually going outside the world for explanations: let its creation be ascribed to the Almighty and Infinite and Intelligent Cause which reason insisted in placing at the origin, and its support or annihilation as a whole be referred to Him, and man's theological belief was exhausted.

In support of this view there appeared in England a procession of writers known as the Deists, in the sense of (1) philosophical Deists as against Theists, and (2) others who were called Deists in the sense of rejectors of Revelation and restrictors of belief to Natural Religion. In some the position remained philosophical. Deism was their Natural Theology: the Christian Gospel they regarded as a fresh intervention rendered necessary by the ignorance and sin of mankind, or rather granted as a merciful dispensation because of this ignorance and sin. This was the position of such a Christian believer as Locke. But others carried their principle over into their view of the Gospel : they set aside its claim for separateness from the general religion of nature, and covered the whole with the conception of a single universe governed by a single system of laws. 'Christianity as old as the Creation' is the keynote of Tindal, perhaps the ablest of this division of the Deists.

As there is confusion prevalent, due to the ambiguous use of the term Deist, the classification of Samuel Clarke may be noticed:

(i.) Those who believe that there is a Supreme Being, but that "He does not at all concern Himself with the government of the world." This is the class against which Bentley directed his Sermon I., and whom Clarke characterises in strong terms in his letter to Leibnitz. 
(ii.) Those who acknowledge Providential government, but do not find that it is moral: it works only by Necessity : there is a Creator and a course of Nature, but not a Moral Governor. Clarke regards Swift-not by name-as holding this, though at times indicating something higher.

(iii.) Those who think of Him wholly as Transcendent: and deny a future Life because they do not accept the fact of government by Rewards and Punishments.

(iv.) Those who believe in Moral Government, but deny independent character to Revelation, from which they remove everything that is inconsistent with what Natural Religion has ascertained, yet without renouncing for themselves the title of Christians.

It is class iv. who are 'the only true Deists,' says Clarke. This is merely a decision as to the use of the word in his own time: men who opposed Christianity in so far as inconsistent with Natural Religion, or accepted it by reducing it to Natural. As a matter of fact the term Deist was known in France and Italy before 1600 , Leland says: and it meant there a man who believed in God but not in the Gospel; what might now be called a pure Theist. The distinction between Deism and Theism now current was not in mind originally.

Herbert of Cherbury was the pioneer of the English Deists: he did not speak quite decisively and would not quite make up his mind; but Leland regards him as their progenitor. Butler begins by arguing against class iii.: ${ }^{1}$ he will justify Natural Religion including the hope of a Future Life, against those who confine man within the present visible system of Nature; but in the chapter on Necessity he goes deeper down, to class ii., those who in the name of Fate or Necessity deny any other world than the Mechanical order. His Part II. is directed against Deists of class iv. It is through this varying use of the term that we find Clarke, the vehement opponent of Deism, actually placed by Mr. Leslie Stephen among the Deists. ${ }^{2}$ Clarke is opposing the rationalisers of Christianity: Mr. Stephen is thinking of those who expound a Transcendent conception of the Divine Being. But even philosophically it is by no means to be agreed easily that Clarke was Deistic: I take his view to be more akin to Pantheism. Locke, on the other hand, was Deistic in both senses: his philosophical concep-

${ }^{1}$ Analogy, Part r. c. i. $\quad{ }^{2}$ English Thought in the Eightecenth Century. 
tion is Transcendent, and in his treatment of Christianity he is Rationalistic. In this latter sense he was greeted by Toland as his Master, and the claim was allowed to be just by Stillingfleet: Voltaire "never tired of prostrating himself" before Locke, in both senses. Locke disliked the discipleship of Toland, it should be said, and expressed himself with asperity when associated with the Deists of his day. Archbishop Tillotson, too, had to see himself acclaimed by Collins as the man whom "all English free-thinkers own as their head,"-Deism being held to be the equivalent of freedom in Thought. Shaftesbury spoke with hesitation, and his contemporaries were unable to make up their minds about him. Bolingbroke preferred to call himself a Theist.

We have no need here to enter into the voluminous controversy between Christian advocates and the rationalising Deists, though the controversy was more interesting than has sometimes been supposed by unsympathetic historians such as Mr. Stephen. A German philosopher, Professor Külpe of Würzburg, considers that it was important in the history of religion: "the earliest independent treatment of the philosophy of religion is, perhaps, to be found in the writings of the English 'freethinkers' of the seventeenth and eighteenth centuries. Toland, Tindal, etc. These men set out to lay a new foundation for the contents of religion in a criticism of Christianity and the doctrines of the Church." 1 "The result of this effort," he goes on to say, "was a deism, a purely mechanical conception of the universe, accepted under stress of the discoveries of modern natural science, and leaving no room for a God who should interfere with the destiny of the world"-i.e. they became philosophical deists also. As to which came first, the philosophical or the anti-Revelational motive, it would be hard to say. In the former field the new philosophy was urging men into this direction, and in Christian theology the heated strife of the century succeeding the Reformation had left so much unrest that there seemed a real relief to some minds in reducing that theology to purely natural religion. As Professor Gwatkin says, "Christians were tired of controversy, and inclined to look to natural religion for the substance of their duty; while Deists readily fell in with principles which seemed to make the gospel needless" ; ${ }^{2}$ and again, "Both Christians and Deists were at

1 Introduction to Philosophy, translated 1897, p. 92.

2 Expositor, 1891. 
one in an ideal view of Nature which enabled them to agree fairly well upon the outlines of Faith and Duty." Yes: Christianity carried into Nature could not but idealise it, and when this course was opposed, and Nature looked at nakedly, as by Hume, the day of optimistic Deism was gone by. The permanent work of the world was not to be accomplished by men under stress of a sense of weariness, on the one hand, or hastening to adopt an immature philosophy on the other. The flavour of philosophical deism has, however, lingered long within the lines of orthodox Theology, guarded from danger as it seemed to be by the acceptance of the Old Testament Dispensation and the Gospel, as interventions for which adequate evidence was in men's possession.

\section{$\S 3$}

There are Quasi-Theisms which recognise no Infinity: which acquiesce in finite character even for the Supreme Being.

All men agree that the world and ourselves are finite, limited, conditioned. And some add, And the world is all that man can know, and therefore it is mere dreaming to talk of anything not limited, not conditioned. If a man adopts completely an empirical theory of what human knowledge is, he must take this limited view of the objects of that knowledge, and we shall find our examples of this type among those philosophers who hold to Empiricism. To them Infinity or Absoluteness is either the same thing as mere ignorance of limits or conditions, or else mere words without significance.

Empiricists looking out on the world of phenomena and desiring to obtain such explanation as is aimed at by inquiry into the question of Divine Being, may find that the phenomena explain themselves, that no theological explanation is needed: or they may find that the known phenomena present characters which seem to be imposed upon them by some unknown hand, some mind not itself included among them, yet not recognised or known by any other means than these very characters. On this limited basis a man is not likely to be impressed by the Causality argument. The aggregate of phenomena being finite, his inference would be only to a finite Cause; and that would be superfluous: it would give no satisfaction different from that derived from supposing the world to be its own cause. For a finite cause, or a first cause of a finite series, would itself raise the question of a cause 
over again: and this would be only the same question as the existence of the world raised before: any answer to it would be mere surplusage. Further, if Empirical theory issues, as it usually does, in reducing Causation to antecedence in a timeseries of events, there is no gain whatever in speaking of a separate cause at the beginning of the series other than whatever event or phenomenon history discloses as the first actual event. Therefore for an Empiricist who adopts a purely mechanical theory of the universe, philosophy reduces itself to being a description, a history of what is observed and recorded: no foothold for a theology is presented at all. So far, for Cosmology.

But if the Empiricist is not prepared to dispense with Teleology in interpreting the universe, the case is different. By discerning marks of purpose and signs of a general order beyond what mechanical processes would produce, he is in face of data which impel him to refer to some source other than the phenomena themselves: this source may indeed be a phenomenon, but it is one which is known only by virtue of these marks: it is the unseen made known by qualities which supervene upon the things we see.

Again, observation may disclose in the world of sentient beings the special mark of being organised for happiness: there may appear signs that happiness is attached to conduct in ways which cannot reasonably be regarded as due to the conscious aims of the creatures themselves. A world of beings which always attained precisely the happiness due to their own conscious endeavour would need no further explanation: it would be described as being what it is, and there explanation would end. But a world in which happiness is the consequence of the following out of instincts, and is attached to conduct of which the felicific effect is not known to the agent beforehand, would lead to the suggestion that some other beneficent agency was at work. And a similar inference would be suggested by the recognition of beauty and sublimity over and above what conscious choice produced. Now Empiricists agree in regarding happiness as the only determinant of goodness; and it is on the ground just indicated that we find them employing a Moral argument in a Theistic sense, when they employ it at all. Only, inasmuch as happiness, including enjoyment of beauty, is finite, and the beings affected are finite, no inference lies beyond that to a finite beneficent agency. 
We have two prominent examples of this type, in Hume and John Stuart Mill.

Hume : Dialogues concerning Natural Religion, 1750 (published 1779); The Natural History of Religion (published 1757)

The scepticism of Hume is both philosophical and theological: he dissented from all the conclusions of philosophy which contained any claim for knowledge beyond that which was composed of sensations and their copies as put together by association. Substance and cause, self and matter in any supraphenomenal sense could not be known. There was no causation except observed successions, no intuition of Infinity, no principle of Reality except perceptibility, none of Personality except as a series of experiences: no criterion of Goodness except its subservience to pleasure, social and elevated, but still pleasure. If a Theism had appeared on such foundations as these, great indeed would have been the astonishment of posterity.

In relation to Christianity his position was ambiguous; it was contended by some of his friends that his writings were not, and were not intended to be, expositions of his own religious Faith, which might possibly be determined in other ways than by reason, e.g. by acceptance of Revelation after the manner of men in Type XIII. But to Natural Theology he devoted much attention, and amongst the MSS. which he specially excepted from destruction at his death were the Dialogues on Natural Religion, which he had kept by him for twenty-six years, and there is also a Natural History of Religion which he published himself.

In these, especially in the Dialogues, we find prolonged discussions, in which it is far from easy to ascertain the writer's own opinion. A defender of Natural Theology on the Traditional (Demonstrative) lines is set against one who is a Christian believer, but a sceptic as to rational Theology, and another who is a complete sceptic in both fields. Can we glean that Hume himself accepted any rational Theism at all? If he did, it was only that modicum yielded by the Teleological argument in the limited use of it indicated above: but even this is dubious.

In the Dialogues he touches upon two or three of the chief arguments, e.g. the Feeling of Dependence; the misery and evil of life are so great that they seem to suggest to man in his 
weakness a sense of the wisdom that would come from depending on some power mightier than himself. Such a power man figures to himself, but Hume thinks that he cannot make sure of it, that it is but a fiction. The Cosmological argument he describes so forcibly, for the moment, that the opponent, Philo, shrinks from attempting to overthrow it altogether, and is prepared to allow it, with the expression that the existence of the Deity is not in question at all, but only His Nature, the former being ' unquestionable and self-evident.' But this is only rhetorical. As he will not allow power in Causation, so he cannot allow it in the Deity as Cause; in Part IX., indeed, he expressly withholds it: so that this seeming acknowledgment of cogency in the Causation argument reduces itself to acknowledgment of the existence of a powerless Cause; surely as idle as 'a painted ship on a painted ocean.'

When he comes to Teleology he evidently does not wish to admit it: he says in several places that the order observable may, after all, be 'self-caused'; he opposes to it not only the usual objection, as to fact, from misery and evil; but advances an objection often associated specially with his name, that the argument from design depends upon an unsound analogy, because the world is unique and we have no right to compare it with watches and other articles which exist by thousands. We may argue from the existence of one watch to a maker, because this watch is similar to those known to come from a factory: but the world is hors concours, so to speak; no comparison and therefore no analogical argument is possible. Whatever analogy can possibly be allowed is very remote, he says: its force is so slight as to be incompetent to furnish "any inference that affects human life," any 'source of action.' Over against this, however, he puts some words to a different effect in the mouth of Cleanthes, who is set before us as the speaker who seems most to represent what ought to be said, if not to represent the writer of the Dialogue himself. "Take care, Philo," replied Cleanthes, "take care: push not matters too far: allow not your zeal against the false religion to undermine your veneration for the true. Forfeit not this principle, the chief, the only great comfort in life, and our principal support amidst all the attacks of adverse fortune. The most agreeable reflection which it is possible for human imagination to suggest is that of genuine Theism, which represents us as the workmanship of a Being 
perfectly good, wise, and powerful; who created us for happiness." 1 We may say that a man of high principle would not have written this if he thought that Teleology had failed: and therefore that it was Hume's opinion that it had not. But it may be meant only dramatically. And he closes the Dialogues with a paragraph in which the strength of the Teleological argument is extenuated to a feebleness which removes it from any sense in which it can be practically useful, concluding with a counsel of resort to Revelation, which, however, is not an assertion that there is one, but rather a wish that there were.

The impression left on Huxley, as given in his account of Hume, ${ }^{2}$ is that Hume despaired of light altogether: that he thought Nature and Man are shrouded in 'impenetrable darkness and eternal silence.' Of course, we have to consider that this would only be logical for Hume the philosopher, and, since it is really as such that his work permanently affects us, we might approve of his sagacity in not building in the sandy soil of Empiricism. Hume has aroused very different feelings and estimates, and rightly so. As a philosopher he ranks high among the original thinkers of the world, contributing the most negative philosophy of modern times. But outside philosophy he had not the perception of realities: without adopting Macaulay's scathing charge that his history of England is full of 'insidious sophistry,' it is certain that he failed to discern the true importance of events and to mark the real course of national life. He was no historian : it was his task to perfect the sense-philosophy, even to the loss of all constructive principles. He was stimulating: his negation supplied the goad to Kant: and, in our century, to Green: he found a sympathiser in the clear scientific mind of Huxley. And while one Edinburgh professor (Blackie) doubted whether he really 'believed in his own bepuzzlements,' an Edinburgh philosopher (Stirling), in acutely but kindly dissecting Hume's Natural Theology, suggests that it was not religion but superstition that Hume was opposing. I doubt this: but at least it is to be recorded that his own character resisted the corrosion of his opinions: as Hobbes was able to win the high regard of Lord Clarendon, so Hume died enjoying the esteem and affection of the author of the Wealth of Nations. With such a meagre allowance of Theism, however, I ought hardly to have included him even under this type. A

1 Part x., near close.

${ }^{2}$ Hume: Men of Letters series. 
feeling of debt owed to him made me reluctant to omit him altogether from these pages.

\section{Mind, J. S. : Three Essays on Religion, 1873}

The nineteenth century gave us Mill: another Empiricist of Scottish blood. Like Hume, he was a man of wide literary culture, of cosmopolitan interest in affairs, keenly interested in political philosophy, and a master of style. A still further resemblance would no doubt have been found in his negative attitude to Theology, had we not had from Mill his three Essays. Like Hume's Dialogues, they were published after the author's death, although they had, in part at least, been in: manuscript for years: but the effect was of a contrary kind. Hume's seems to have been reserved lest his many orthodox friends should be shocked, Mill's lest he should be charged by his philosophical associates with abandoning them for at least the rearguard of orthodoxy in Natural Theology. In his case the unexpected was the positive element which had grown into his views on the great question.

The interest of these Essays is due to their context, so to speak : to the eminent position in the history of culture in the nineteenth century won by their author. It was really a remarkable position. Heavily engaged in an important official capacity, home-educated, and living in a small but influential circle of literary and public men, he was so much a Master that in subject after subject as he issued his results they at once became text-books for study at the Universities of which he was not a member. In Political Economy, Logic, Politics, Ethics, the holders of the academic chairs had no chance against him in point of influence as teachers. Many Englishmen and Scotchmen of the generation now in authority in public affairs were brought up when Mill's influence was at its height, and the mark is still visible, but it has almost disappeared from the generation now rising. In Mill we see a fine British tradition taking its highest form: Empiricism and Individualism coming to bloom in Free Trade, and Liberalism, and Inductive Logic; but now being submerged in the Darwinian and Hegelian broadening out of human thought.

Of these Essays, two on the Nature and Utility of Religion were written in the fifties: the last, Theism, about 1870, three years before his death. Taking them together, we find some 
things that his previous work leads up to, and others which cause surprise. The dissatisfaction with physical nature expressed in the first, and yet the retained trust in human nature, made an unstable position for one whose philosophy could only find a permanent substance behind physical nature, not in the soul of man. In the second Essay the dominance of logic and the precedence of truth as the final object of human search were retained, along with a growing recognition that it was not solely on this line that men sought for guidance in life or often found it. But there are protests against 'subornation of evidence' in favour of what men may desire to believe, and the admission of imagination to a place of legitimate influence in forming belief is hesitating and grudging.

The chief change that came was in the intellectual region: the force of what intellect could do and the scope for influence which it could rightly claim was regarded differently. Was Mill led to this by any glimpses of the insufficiency of the Empirical philosophy? It does not appear so. In this last Essay he reiterates his old maxims without any tendency to allow a foot us ground for Traditional Intellectualism or German Idealism. in Theism the Cosmological argument is still disallowed: on his theory of Causation we can get only antecedent events in a series, in which also a lower thing could quite well 'cause' a higher that came after it: all we.can say is that the series seems to have commenced, but we can say no more. But here what is perhaps his strongest inconsistency asserts itself. He repeats his belief in one 'Substance,' which is permanent,- -he even says 'eternal ';-namely, Matter and Force, as he calls it. This, he thinks, the physical sciences do really disclose, in spite of his reaffirmation of the sensational theory of knowledge. But this is all: no second Substance embarrasses him, none such appears behind the world of Consciousness. The Materialistic influence of his writings is, of course, due to this; for the general reader is sure to rise from them with an increased respect for that part of the universe which is based on a Substance, and a diminished respect for that in which all is only transitory and insubstantial. He might therefore fairly be pressed to mean that the Cosmological argument is effective; and that which it proves is that Matter is the basis, the source, the first antecedent, the cause; the substitute for what most men have called the Divine Being. But he does not press it to this point, and as he has no con- 
ception of a similarly substantial permanent Mind, he dismisses Cosmological proof altogether. Concerning the Ontological argument he naturally can have little to say: it is still one of the most egregious cases of the 'Fallacy of simple inspection': on his theory of what ideas are and what facts are, no one is concerned to dispute what he says. Of Transcendental proof he has nothing further to say-Hegel had been placed with Plato, and even with the Vedas, in the chapter on Fallacies in Mill's work on Logic, and Mill never saw reason for bringing him from out of that company of 'Mystics,' as he names them.

Neither the Moral argument nor that from Feeling receives admission as a primary factor. Feeling of dependence he thinks powerful, but it comes only after Intellectual action, not before it, and the Moral argument can only tell us about attributes, not about existence. The appeal to Consensus is disallowed: he will have no second-hand evidence.

But where the Essay raised some surprise was in his finding more cogency in the Design argument than he had ever found before. His survey of external Nature and of human history yields considerable evidence for design : not complete, and with some grave exceptions, but still, a preponderating probability: and this evidence is of 'a really scientific character,' 1 and deserves to have influence in the region of belief. And so he follows it up to the position of belief in a Creative mind. $\mathrm{He}$ foresees that the new doctrine of Natural selection may weaken the argument again by 'attenuating the evidence,' but he does not do more than simply state this.

Following our Type II. in thus establishing existence by an Intellectual argument, he then proceeds to consider what is to be learnt about the attributes. Infinity is quite disallowed, it is far beyond what can be proved. The Moral argument is then taken up: does it enable us to believe that the Creative mind is perfectly Good? He thinks not, if we try to think that it is also all-powerful. The imperfections of the world are set out in a passage as strong as that in Hume's Dialogues, and the inductive inference is taken to be conclusive against the combination of Might and Goodness. Inasmuch as the very nature of design implies 'contrivance,' as against opposing or resisting power, almightiness is given up: and on the other hand the abandon-

${ }^{1}$ P. 167. 
ment of complete goodness is refused: of the alternatives therefore, it is Power which is acknowledged to be incomplete, limited, set over against another power which thwarts it. So we are back on the most ancient track of human thought: a power completely beneficent is behind the world, but it is neither sole creator nor sole governor of it. The duty of man is to take his place on the side of the beneficent Power in the perennial conflict between Good and Evil.

Such being the result of the inference from evidence, he so far repudiates Agnosticism. In a final chapter he steps out from Intellect into the field of Imagination: into the region of our moral and rsthetic life. $\mathrm{He}$ now is prepared to give candid recognition to the beneficent effect of allowing such considerations to influence our belief. As compared with the 'moral bribery' and 'subornation of the understanding' of Essay II., we have in III., "Literal truth is not the only thing to be considered." To retain beliefs because they elevate morals and inspire ideals has become to him even a mark of 'wisdom.'

$\mathrm{He}$ is very fair in disallowing many of the stock charges brought against the influence of Religion, but as he himself goes on to withdraw from its sphere much of what has been done in its name as really due to social opinion and ordinary morality, he feels no need for himself to go beyond a Religion of Humanity, even in the region of imagination and sentiment.

All that Theism can claim for this final deliverance is that Mill has consented to a partial removal of the case from the closed court of logical estimation of evidence, and that within even that court he has parted from Atheism and Agnosticism to the extent of seeing enough evidence for a Creative Mind. Against this must be set the ultimate limitation of Creative power: his reiteration that 'Matter and Force' is eternally in the background, and not Mind; and his own contentment, in the realm of Imagination and Feeling, with a world-view in which humanity is the highest object of regard, its welfare the highest goal of effort.

There are in these Essays some indications that the grave and sincere conscientiousness of Mill had its reward. In a sense he died young: there was within him a germ which his span of life did not suffice to mature. True, no other intellectual vision was clearly attained by him than his old logic gave. But the 
old Individualism was struggling with ampler views: in the eloquent passage on Authority in Essay II., as in those on Socialism in his later Economic writings, and the passages on social influence in Morals which glisten in his Utilitarianism, we see a growing recognition of the moral and imaginative sides of life : and prospects open out of more spacious fields into which his earnest and solid mind might have carried him had another period of mental activity been permitted him.

If between Mill and Hume there were strong likenesses, not least in their singular ability to rest intellectually on the narrowest ridge of philosophy which has ever satisfied British minds, there was also a difference. The gravity and pellucid sincerity of Mill was the mark of a nobler character than Hume's. The expression of his views in a Dialogue in which the most careful reader is mystified as to what belief the writer is recommending, if any at all, on so grave a subject as Religion was below Mill altogether : no man can speak of sophistries in connection with his name.

\section{$\S$ 4. The 'Religion of Humanity'}

This is perhaps the most convenient place for a few words upon this claimant for admission as a Religion. The claim to be considered a Religion is itself a significant tribute to the change of front on the part of non-theists as compared with their tone in the eighteenth century : there is now a disposition, on the part even of objectors, to claim instead of repudiating the association; that which was for a time regarded as the product of imposture on the part of a section of mankind, and either of puerility or sheer imbecility in the rest, is now asked to permit its terminology, and not a few of its rites, to be borrowed even by those who stand aloof. But the claim is resisted from nearly all quarters, and from the point of view of historical inquiry the resistance is justified. If $\Theta$ còs is to be made identical in

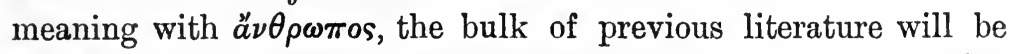
misread, language will be trifled with, and the means by which common intercourse is maintained and the thoughts of men rendered intelligible to one another will be endangered. 'Mankind' is plainly in antithesis to 'Deity' and not a species or form of it. There is an ample supply of terms and phrases without this perversion of traditional usage: if a man considers 
that all theology fails, he may still be a 'patriot,' a 'lover of men,' and surely these noble designations may suffice the man to whom the phenomenal world is all in all.

Those who have endeavoured to retain the phraseology of religion while really standing on philanthropy have not been numerous in Britain. The little band of Comtists, especially Bridges and Congreve, have just been sufficient to show that England has a place for every form of opinion: Cotter Morison's mind was a torso; Mr. Frederic Harrison has long been listened to with the respect due to his broad philanthropy and his literary eminence, but he is too honest not to have been obliged sooner or later to throw off the mask. This he was driven to do in the heat of a controversy with Mr. Spencer: "I have no wish," he burst out at length, " to "worship' Humanity in any other sense than as a man worships his own father and mother." 1 Precisely so; then why go on using such words as 'worship' and 'religion' when 'honour and love' and 'filial affection' are at hand to express what is meant? To claim the term 'religion' for filial duty while refusing Mr. Spencer's request to be allowed to apply it to the Unknowable Infinite, can only be called a new test of orthodoxy invented and applied by Mr. Harrison himself.

\section{George Eliot}

It was not really different with 'George Eliot': her position is quite simple : as an Artist she was interested in character, and her philosophy is a simple Humanism. There is interest to English men and women in seeing how the questions of Theism looked to this great writer, and we can ascertain this without having to enter upon a laborious gleaning from the field of her fiction. She has herself given a succinct expression to it in a Dialogue, or rather a Symposium, written, in blank verse, in 1874, under the title $A$ College Breakfast Party. ${ }^{2}$

George Eliot sets forth in this some alternative philosophies of life. The Epicurean is there, who holds that a butterfly which speculated on its existence would be living in worse sort than if it followed its deepest wisdom, which is simply that of being

"A sipping, marrying, blue-winged butterfly."

This position is set aside by an interlocutor, who declines to measure man by what is wise for a butterfly. Then speaks a

${ }^{1}$ Nineteenth C'entury, 1884.

¿ Macmillan's Magazine, July, 1878. 
Priest, who suggests what is equivalent to a Theism of Will-

\footnotetext{
"The strong bias which we name the Soul, Though fed and clad by dissoluble waves, Has antecedent quality, and rules By veto or consent the strife of thought, Making arbitrament what we call faith."
}

On being pressed farther, the Priest advances from this to a counsel of obedience to the Church because of a 'Presence which it carries,' and of the claims for obedience which it categorically puts forth: after which he takes his leave.

His counsel is then criticised as not including a criterion for discriminating between superstition and tyranny on the one hand, and legitimate faith and submission on the other. Another speaker then stands up for Individualism in belief, of the Moral Intuitive kind: while another goes with him as to the Individualism, but would replace Moral intuitions by Taste. The next speaker is permitted to denounce Philanthropism with a relentlessness which shows that George Eliot herself had not adopted her own final creed without close scrutiny and clear-eyed perception of at least some of the objections to it. Social Opinion, as giving the final standard of Good, is but Custom, she makes this speaker say-

$$
\text { "Your social Good, }
$$

Like other deities by turns supreme,

Is transient reflex of a prejudice,

Anthology of causes and effects

To suit the mood of fanatics who lead

The mood of tribes or nations."

An Optimist follows, who takes the ground that the denouncer of philanthropy had underestimated the actual good attainable and attained: the man who enjoys the large benefits of social life

$$
\text { "And yet denies }
$$

A human good worth toiling for, is cursed With worse negation than the poet feigned In Mephistopheles."

A further defence of Social Good is made by reference to the powerful and beneficent elements in the moral and spiritual nature of man, in the life of 'duty, love, submission, fellowship.' If the transitory character of human good is urged, if

"the small arc of Being we call man

Is near its mergence"; 
then the very sorrows and woes involved by the approaching death of all the human race might give rise to

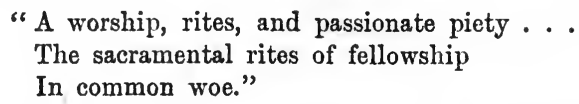

This might well have been the end of the dialogue, as it is its climax as an exposition: but the advocate of Taste, as Art and Poetry, is allowed another speech, to be subjected to another criticism, before it ends. The broad meaning of the whole is that Rational argument cannot establish Theism, that no Empirical assertion avails, and therefore that a substitute must be sought, which, after criticism, is found in the copious variety of the social life of man, especially as enriched and elevated by Art and Literature. Without the Hegelianism of her early teachers, Strauss and Feuerbach, George Eliot could hardly have attained her position so clearly, no doubt; but in this dialogue there is the enrichment due to her own prolonged meditations and to her own power of literary expression.

\section{$\S 5$}

Schrller, F. C. S. : Riddles of the Sphinx, 2nd ed., 1894

The main point of this brightly written book is the explicit acquiescence in a conception of a Divine Being who is limited, finite, even imperfect.

The basis is the finite and limited world; not all things, but what we know of them; a world which began and will come to an end; this is what science tells us of, and metaphysics, Dr. Schiller thinks, knows no more. The ontological position is that of Spiritual Pluralism: the ultimate realities are selves, souls, spiritual beings, in immense numbers, acting and reacting upon one another. Matter he spiritualises: and the world is a process in Time.

The inference to a Cause is by the Quasi-transcendental process: a hypothesis is required to account for the worldprocesses, as Neptune was discovered through the need for accounting for certain astronomical facts: only in the case of Theism it is not residual phenomena but the character of the whole process for which the hypothetical cause is sought. A supra-phenomenal cause is the only possible hypothesis, he holds: and yet he will not regard this as a completely cogent 
proof, for it is an alternative as to the choice of which there is some discretion; Intellect will not speak out with irresistible demand, and Will has its place in the final decision.

Mr. Schiller's view of this (hypothetical) Cause is that it is self-existent, but in holding that a self-existing Cause can be imperfect and finite he occupies a peculiar position. This is all that he claims, however; a Cause sufficient for a finite and imperfect world may itself be finite and imperfect.

The order of the world is teleological, a view which he holds to be commended by the theory of Evolution : the world-process is a fact, exhibiting movement towards an end as well as from a beginning. When the Moral order is taken into account, as it must be, then we see that there is Moral character in the Cause : the teleological inference to Divinity is plain.

$\mathrm{He}$ asserts immanence: the cause works within phenomena; and personality, a volitional causal activity; or super-personality, if that be regarded as a better term; and Goodness, it works for Good. We have therefore Immanence, Personality, Goodness, plainly, and a claim is made on peculiar grounds for Self-existence and Transcendence; only Infinity is expressly excluded.

The rejection of Infinity needs attention. The world $\mathrm{Mr}$ Schiller holds to be defined and limited: with a beginning and a probable termination. It is also imperfect, its realities are only becomings, and it is in Time, which itself is imperfect, a limitation of the Eternity of which at least we have an ideal. $\mathrm{He}$ thinks that it is these very imperfections which set us thinking, it is 'the discordant aspect of facts' which gives ' the impetus to thought.' But, surely, this is a perversion of the ground of philosophising: it is in so far as things tend to perfection that we want to know about them, not because of their deficiencies or of the difficulty of harmonising them. In politics we have learned that if all men were wise and rich and industrious the task of Government would not be gone, organisation for higher ends than individuals could accomplish would be required still; Mathematics works on the supposition of perfect triangles; if all water were pure there would still be a chemistry, if all thoughts correct, a logic: if all the facts of the world were in their nature completed facts, Metaphysics would still have its place. And so for a finite world in which spiritual realities appear, if these were working to the utmost of their capacities, there would still be 
need for inference to a super-phenomenal Cause. But with his resort to imperfections as the data on which he reasons, it is not surprising that in the super-phenomenal which Mr. Schiller reaches, the character of imperfection is retained. He certainly has the courage of his opinions : the super-phenomenal is involved in all the weaknesses and the suffering of creation, and, together with the souls of the men and the world at large, is the subject of Redemption !

Mr. Schiller does not stand firmly on Reason, for Theism : he says, indeed, that the world does not appear to be self-caused, self-supporting, or self-sufficing: and that the inference to a self-existing being is 'necessitated,' 'as certain as any of our inferences can be.' 1 And yet he concludes the book by saying that it is a hypothesis, and that a man can reject it in spite of its explanatory power. Either the Pessimism which follows upon the failure of explanation or the Theism which is built upon its success can be 'intellectually warranted.' 2

In his treatment of the Infinite and Absolute-with which he advises us to dispense, as not inferrible, and only a source of embarrassment-Mr. Schiller does not touch the true Infinite which coexists with finitudes, nor the true Absolute. When he deals with Perfection he seems to come nearer to them, but he goes on to hold that this is only an Ideal to which the Real tends, and he will not accept Perfection as a character of reality even for the super-phenomenal being. In short, to him it is finitude and imperfection which are marks of reality, and this he holds to be true both for phenomena and superphenomenon.

The writer is strong in his appeal to agnostics and positivists to adopt this much of Theism, but, after all, is it anything more than an invitation to them to improve their phenomenalism, not to abandon it? As a Rational Theism it falls far below what the problem requires; while Ethical Theism will regard it as equally unable to account for the conviction that the Ideal is the Real. Mr. Schiller will say that these Theisms seek the unattainable: but there is sufficient of the idealist in him to prevent him from blaming those who are more venturesome than himself, even they have to share with him the epithet, 'romantic,' which he does not wholly disclnim.

' Pp. 370, 372.

2 P. $45 \pi$. 


\section{$\S 6$}

\section{Spencer, Herbert : The Synthetic Philosophy, especially First Principles; and Articles in Nineteenth Century, 1884}

It might not have been thought likely by readers of this book that any English thinker would have been found to proclaim a Theism of which the only constituent was the belief in Infinity. We have so many writers who reject it, so many who ignore it, and so many who fail to establish it in any obvious way, that it might almost seem as if it were merely to fill a vacant place in a series of possibilities that a Theist should appear to whom Infinity is at once the beginning and the end of the doctrine of God. This is, however, the position of Mr. Herbert Spencer.

Mr. Spencer's theory of knowledge is purely empirical: he attempts to give it a universal character by reference to the conception of Evolution; but this is really quite irrelevant: the history of an aggregate of particulars is quite another thing from the exposition of a true universal. It was from an empirical point of view that Religion won his regard: and we need not be surprised at the consequence of this in the range which he is led to assign to it. He may be said to have come to it from the Consensus direction. As an observer he was aware of the extent of religious belief and of the intensity with which it has, as a matter of fact, played its part in human history: as an Evolutionist he was not prepared to acquiesce in regarding either as trivial or fictional a belief so prevalent and so persistent. To set up either priestcraft or statecraft as capable of producing a force of such a character might be possible to superficial or angry men, but not to an unprejudiced observer. "A candid examination of the evidence quite negatives the doctrine maintained by some, that creeds are priestly inventions." 1

His condensed statement in opening his system indicates the following positions: ${ }^{2}$

Any human belief which has been accepted 'originally contained, and perhaps still contains, some small amount of verity';

Length of duration and width of diffusion increase the presumption ;

Perennial and 'nearly or not quite universal' beliefs must be ranked very highly: "life is impossible unless through a certain

\footnotetext{
${ }^{1}$ First Principles, Part I. Chap. I.

${ }^{3} 16$.
} 
agreement between internal convictions and external circumstances";

Reference to 'authority' is no counter-explanation of a belief, for 'a general congruity with the various other beliefs of those who receive it' is proved even by acceptance without critical examination. Even if majorities are usually wrong, they "have usually not been entirely wrong."

The assertion that religious ideas are products of religious sentiment is no explanation: for whence come the sentiments? It is in this vein of 'catholic thinking' that he then sets out upon an inquiry into religious belief.

He proceeds by his Abstraction Method of Knowledge. The various religious beliefs are to be brought together and compared: the multiform elements to be laid aside one after the other, as accidental, until at length we get down to the common and therefore essential element found in all. "The soul of truth" exceeds "in abstractness the most abstract religious doctrines"; and this part of the inquiry ends with the enunciation of the ' ultimate religious truth' that there is a 'mystery' which is ' utterly inscrutable.' Science agrees: it too has its mysteries, its 'imbecilities,' 'Force, Space, and Time pass all understanding': here then is the reconciliation between Religion and Science,Mystery.

So far we have been led by examination of the actual contents of the ideas exhibited in the religions of mankind.

The next step is to go to work 'rationally,' 3 by which Mr. Spencer means ' by deduction from the nature of our intelligence.' There has been a good deal of hard brain-work given to this kind of 'rational' process; with varied results. Mr. Spencer, however, has not time to write a history of philosophy, and his mind is evidently already made up, for he proceeds to put forth, as the only view worth listening to, the then recent doctrine of Sir William Hamilton, especially as 'more popularly presented' by Mansel : ${ }^{4}$ and some quotations are given. It is given as 'demonstrating the necessarily relative character' of human knowledge. He had before given considerations derived from analysis of the 'product' of thought-but very briefly, and he now adds to Hamilton and Mansel a confirmation from the fact that in

$1 \$ 21$.

$2 \S 27$.

${ }^{3}$ Chapter $1 v$.

4 Mansel's Bampton Lectures, delivered in 1858; First Principles, first issued to subscriber's 1860 . 
knowledge we 'class' things, and to class them there must be 'likenesses': the Infinite and the Absolute cannot be like anything else, therefore they cannot be classed and cannot be known. And there is still another consideration, that thinking as a process of life is purely relative, being an adjustment of internal relations to external relations.

This metaphysic seems to land us wholly within relativity. What then becomes of the Mystery? Mr. Spencer departs from Hamilton and Mansel as not putting quite enough into their premises : besides definite consciousness there is indefinite, besides complete thoughts there are "thoughts which it is impossible to complete," and yet which are real, in the sense that they are "normal affections of the intellect": and this he thinks Hamilton and Mansel do in some places allow for. In short, the Relative implies the Non-Relative, or else the Relative itself becomes 'Absolute.' And so we have the doctrine of a knowledge which is only of the relative, but for that very reason gives us knowledge of an Absolute; and this is identical with the Mystery found as the common element in all religious ideas.

Its existence, then, is known: everything else about it unknown and incapable of being known by us, and the favourite designation is now 'the Unknowable.'

Is there any need to criticise this doctrine? Hardly, unless we are to embark in metaphysical inquiry. The reader has really only to mark (1) what function is assigned to knowing as a factor of belief, (2) of what kind of knowing Mr. Spencer is speaking: if he accepts these, then his conclusion seems a very carefully 'demonstrated' one. So that we may put it: If a man regards knowing as the sole mental activity concerned in producing belief, and if he considers that knowing is exhaustively described in the empirical, abstraction-forming process which Mr. Spencer follows, then he may be disposed to accept the Unknowable, the Mystery, as the supreme content of religious belief. He will perhaps stumble a little at that point where Mr. Spencer gets out on to a sort of marshland of indefinite consciousness; he may desire to learn a little more of that, as containing possibilities of something better than 'knowing'; and this may trouble him when he remembers that he is invited to step on to that dubious surface in order to come into contact with the Mystery which had seemed to be unreachable on the solid ground of relativity. 
Unknowable, however, as is the Absolute, the need of bringing it into some relation with 'Science' urged Mr. Spencer to some ventures of penetration into its recesses. We find Omnipresence asserted, and Power; and he even slips into the old term Cause : it becomes the Ultimate Cause. Later on, we have Eternity, and Power expressed more concretely as Energy, so that it is 'the Infinite and Eternal Energy.' But this is all. We might have expected some addition from his Ethics, for there we are led to a doctrine of absoluteness or Perfection as necessary to complete a true Ethical system, and this might have been carried up into the Absolute as well as Energy, one would think. But Mr. Spencer avoids doing that.

Two criticisms suggest themselves. First, Can Mr. Spencer really hold the Relativity of knowledge and the conception of an Infinite together? Of a knower who knows only relativities, including himself, and cannot possibly know more, there is nothing else to be said: but if he professes to know that he is relative, and therefore, by mere correlation, that there is something over against all relatives which is not relative, then the doctrine of Relativity is abandoned: in this case it would be better frankly to admit that the conception of this correlative infinite constitutes knowledge, and then set to work to see what that may imply. But Mr. Spencer tries to combine his thoroughgoing Relativity with the doctrine that we know something which is not relative, and therefore is not capable of being known. Secondly, Mr. Spencer has been led by his naturalist method to respect the voice of mankind in its deference to Religion, and this has led him to seek for the ground of the deference. But does he at all satisfy himself, or make good to other minds, that this bare Infinity, or rather Unknowability, is the ground of this prevalent belief? that it is the one single and sole factor which is present in all ideas of a Divine Being? It may be so: but the history of Religions must be very thoroughly searched and bring a very definite testimony if we are to accept it. For it is in itself astonishing to learn that the thought of an impersonality wholly inscrutable, with neither moral nor spiritual nature or character, has been the prime and universal factor in the religious beliefs of mankind. To most men it would appear that this is rather the last result of abstraction : as far removed from operative influence as any other purely metaphysical conception would be acknowledged to be. A vindication of Religious belief which proceeds by 
emptying the object of worship of all known character, and assigning to it only a position of inscrutability, is as far removed from referring to experience as the method of any dogmatist could be.

Mr. Spencer suggests Spinoza. There is One Divine Being and two series of phenomena, Consciousness and, according to Mr. Spencer, 'Force' - the dualism between these being resolved by the 'two-aspect' theory. And like Spinoza, with his Substance either infinitely full or infinitely empty, according to the point of view, Mr. Spencer regards the Infinite source of phenomena as emptiness itself, an abyss in which phenomena grow paler and paler on our approach, until knowledge fades away.

In some places Mr. Spencer evidently fails to observe his own boundary-line between Religion and Science, given by the distinction between the Unknowable Reality and the Known phenomena. He claims that religious sentiments are expanded by the growth of science. But he is too logical to stand by this, and when pressed he acknowledges that he must not admit into the sphere of religion either ' worship,' ' devotion,' ' prayer,' ' hope,' or' 'consolation ' ${ }^{1}$ these cannot attach to the Unknowable, but must belong to the scientific and historical observer in so far as they are retained at all. In his reply to Mr. Frederic Harrison he rejects Humanity as a possible object of religious devotion: it is not a conscious unity, and therefore is no true object at all; and neither as an aggregate nor in its individual members does it excite veneration. Of religious sentiments there remain only two, 'awe' and 'wonder': a reduction in the Esthetic sphere consistently parallel with the reduction of content in the idea of the Object of Religion: a belief on its intellectual side is contracted to acknowledgment of Mystery, so on the side of Feeling it is contracted to Awe. Has it any Practical or Ethical side at all? Mr. Spencer maintains that he differs from Mansel in being positive, not negative, in his doctrine of the Infinite of which man may, nay must, think: he claims that his answer is an Everlasting Yes : ${ }^{2}$ but to what question is it an answer? To what demand of life? of practical aim? of Feeling? Simply that we must feel awe as we think of a Reality which our knowledge cannot grasp, which in no way affects us in our lives, and is, on its part, utterly beyond reach of aught that we can think, or feel, or do.

${ }^{1}$ Nineteenth Century, November, 1884.

2 Ib. July, 1884. 


\section{$\S 7$}

Braplex, F. H.: Appearance and Reality, 1893

It is not easy to give an account of this Essay for the purpose of Theism; the aim is philosophical, and the method is not simple. It does not profess to be a complete treatise, but to be a criticism of principles rather than a construction : but the criticism involves so much construction that the net result is a contribution to positive thought. Again, the whole inquiry is what might be regarded as Theistic, although the nomenclature is different: it is an inquiry into the ultimate meaning of the world and its relation to the Absolute, or, as Mr. Bradley calls it, of Appearance and its relation to Reality. If we substituted the term 'Divine Being' for 'Reality' we should see how much the book contains of what would occupy us in a Theological inquiry.

Mr. Bradley aims at explaining what the true conception of Reality must be. That there is Reality is not doubted: it is the grasping it by thought which is to be inquired into: he says "The end of metaphysics is to understand the universe, to find a way of thinking about facts in general which is free from contradiction." 1 Thought is regarded as having a standard: intelligence possesses a criterion of what Reality must be: the criterion is a double one. (i.) The demand for self-consistency, inherent harmony, absence of 'internal jar,' is an inexorable demand. Now this demand cannot be satisfied by any of the facts of experience as they stand: attempts to claim reality for Primary qualities of matter, for example, for matter itself, for space and time, even for self, all fail: "the self is, no doubt, the highest form of experience which we have, but, for all that, it is not a true form: it does not give the facts as they are in reality; and, as it gives them, they are appearance, appearance and error." These, then, are all stamped with self-inconsistency and therefore are only Appearances. (ii.) The second criterion is Comprehensiveness: nothing in the world of Appearances can possibly be left out of Reality.

Of the method which takes the sum of appearances for Reality-Phenomenalism-he is highly contemptuous: "But when Phenomenalism loses its head and, becoming blatant, steps forward as a theory of first principles, then it is really not

${ }^{1}$ P. 120. 
respectable. The best that can be said of its pretensions is that they are ridiculous."

Are we then to go outside experience in order to satisfy Thought? This is impossible, and therefore there seems an affinity with Mr. Spencer, who speaks of a Reality which yet is unknowable. But Mr. Bradley is equally opposed to this. A Reality which could not be known would be one which could not appear, and so appearances-i.e. experience-would be out of connection with it, and in fact the supposed Reality would be a phantasy: or, as Mr. Bradley puts it, "Mr. Spencer's attitude towards his Unknowable strikes me as a pleasantry, the point of which lies in its unconsciousness." 1

Reality is, and it must be considered to be able to appear, and to it all appearances belong. But if it is not the sum of these appearances, what else is it? It is all these and more; they, in all their content, are not it: they are not complete, but only partial; they constantly advance in scope and fulness of character, and yet they can never reach Reality; but always remain only appearances of it.

But are there no assignable characters of Reality? Yes: three. (1) It is a single system, owning all appearances, every element of the universe, far more than are known to us; (2) it holds all appearances, and the 'more,' harmoniously and consistently; and (3) it includes sentiency : in the sense that Thought and Feeling and Will are all in it: and therefore he is not afraid to call it an Individual. In these characters Reality is a demand, a necessity, of Thought: that is all, but for Metaphysic it is sufficient. Mr. Bradley says he does not know whether this is Realism or Idealism: but perhaps he will not object to his readers deciding from its appearance to them, and a comparison with the Cairds makes it clear that in its broad features it is Transcendental, or, as John Caird calls it, Speculative Idealism.

The Moral basis is clearly laid out. In his earlier Ethical Studies the last chapter closed with a lucid and vigorous indication of the passage from Moral consciousness to the necessity of Religion. Ethics ends in "a point of view which cannot be final," "the claim remains in the end a mere claim," therefore "reflection on morality leads us beyond it": "morality issues in religion," i.e. in a sphere where the ideal must be real. This Idealistic inference is here reinforced with luminous

1 P. 128. 
phrases. The good we know is defective: it is relative, subordinate, self-contradictory, it cannot be made perfect as it stands, it requires transmutation: it is therefore only appearance. But that the Reality is absolutely Good, Perfect, is a demand of our moral Reason.

The basis of Feeling is insisted upon. Our desire for completeness or perfection in our sensible experience in the way of pleasure or happiness is never satisfied, and yet we hold to the reality of Perfection in this aspect of life also. This boldness in vindicating an independent place for sensibility is perhaps a chief distinguishing mark of Mr. Bradley from others in this school. But Mr. Bradley is emphatic in separating the three factors of experience: he insists that moral ideals do not involve the necessity of corresponding existence, of giving theoretical truth, of compelling speculative assent. Act so or be dissatisfied, says Morality: well, you may be dissatisficd, replies Intellect, but this decides nothing about existence: but when Intellect says Think so, it is Think so, or be false, i.e. take the non-existent to exist. ${ }^{1}$ Morality must not dictate to the Intellect: and, on the other hand, it could not itself accept dictation, and profess to be satisfied when it was not so: it would still assert its ought to be in spite of all that Intellect tells of what $i$. And with Sensibility similarly: our desires for pleasure, our dissatisfaction with pain or with a balance of pain, impel us to look out for perfect happiness. But Mr. Bradley can see no direct road from any one of these to any other: there is no way of showing that perfect Goodness (believed in through Morality) and perfect Happiness (hoped for through Sensibility) exist for Intellect.

But because the lines are separate it does not follow that they do not combine: and so he builds the three into the positive Idea of Reality. He makes no claim that the demand of Intellect should stand alone: he strongly repudiates any claim for superiority as a 'deplorable error.' ${ }^{2}$ It may be preferred, but there is no compulsion that it should be. In fact, our main wants-for truth and life and for beauty and goodness-must all seek satisfaction, but each on its own line. And we have seen that this consummation must somehow be experience, and be individual. Every element of the universe, sensation, feeling, thought, and will, must be included within one comprehensive Sentience. Again, we have "the general idea of a total experi${ }^{1}$ P. 153.

2 Preface and p. 159. 
ence, where will and thought and feeling may all once more be one." 1 And so the Absolute is before us ideally, in its main features, and "our conclusion, so far as it goes, is real knowledge" of it, "positive knowledge built on experience,' 2 " unity which transcends and yet contains every manifold experience." And the result is 'certain'; 'inevitable when we try to think consistently.'

He then proceeds to confront objections and difficulties, and at the close reaffirms his confidence in the conclusion- "to doubt it is logically impossible."

We have, then, in Mr. Bradley's conception of the Reality both Transcendence and Immanence: Immanence, because a wholly Transcendent Thing is itself 'ridiculous'; Transcendence, for the sum total of appearances is only just what it is, and Reality is something more. As to Infinity, it is obvious that this idea is present all along, only Mr. Bradley prefers the designation, the Absolute. Necessity is of the very essence of the object of his search, and, as we have seen, he considers that it is found. As to Personality, his decision is, in terms, against it: "Of course the Absolute has personality, but it fortunately possesses so much more, that to call it personal would be as absurd as to call it moral." 3 It is somewhat a question of terms. If $\mathrm{Mr}$. Bradley will not allow the term 'moral,' though he has included Goodness, he is unreasonable in his rejection: and it would be quite easy to show that 'personality,' in the sense in which Theism requires it, is not repudiated by him. He includes Thought, Feeling, Will-Sentience as he calls it: and every instructed Theist understands that if these are expressed in human forms they are not in those forms predicable of the Infinite Being, but they are there eminently in an infinite instead of a finite manner : only, they are there. Spiritual Theism will therefore claim Mr. Bradley as being on its side when he ends his book as follows: "We may fairly close this work by insisting that Reality is spiritual. . . Outside of spirit there is not, and there cannot be, any reality, and the more that anything is spiritual, so much the more is it veritably real."

But it is not easy to reconcile this reading of him with the ruthlessness of his cutting 'appearances' away from Reality in some places. At times he says, and must say, on his principles,
${ }^{1}$ P. 160.
${ }^{2}$ P. 160.
3 P. 173. 
that Reality includes them all : at others they seem to be refused admission. But if every known quality is refused admission as a predicate, as being self-contradictory when affirmed absolutely,in other words, if every attribute of humanity is excluded from Reality, if personality as we know it is repudiated, if goodness as we know it is to be left out, together with beauty and happiness, and if the excision of these has been preceded by the excision of time and space and matter and self,- - he is in plain peril of standing on an edge and looking out either upon an abysmal void, or else an indefinable and impenetrable 'solid,' as he may prefer, for it would be all the same. And thus doubt is thrown over his whole result, as not distinguishable, so far as the interest of Theism is concerned, from Nescience itself. Professor Seth ${ }^{1}$ considers that Mr. Bradley runs past Spinoza to Erigena, to Neo-Platonism, to Brahmanism. My own impression is that the admission of 'Sentience' does in itself mark a difference, upon which Mr. Bradley might take a firmer stand. When he speaks of the qualities of human sentience as transcended and transmuted in the Absolute, although by the nature of the case we cannot follow up any process, we feel that the position is tenable. And as Mr. Bradley sums up by declaring the Reality to be 'spiritual,' we will take it that he does testify for spiritual Theism in spite of the counter-assertions. Is it an impertinence to suggest to an original thinker that a consideration of the canon of 'application of terms of human thought to the Deity,' formulated by Aquinas, and never surpassed in penetrative and judicious subtlety, might relieve the vacillation and inconsistency which is the great defect of Mr. Bradley's work as it stands?

Mr. Bradley works as a philosopher and uses philosophical terminology for the most part. But as Aristotle called Theology what was afterwards known as Metaphysics, we are making no strain in calling this a Theological treatise; and in regarding it as a most important contribution to nineteenth century Theism. Religion he regards as related to Theology, much as the Cairds do. Imagination comes into Religion, and Fear and Admiration carried to a high degree, and our Asthetic nature generally. To Will he does not allow the primacy claimed for it in other quarters: but characterises resort to it as 'a would-be refuge for the troubled in philosophy '; ${ }^{2}$ this is in philosophy; but in 
Religion it may have a better claim, and although he does not say so himself, it is consonant with what he says of Religion to say it for him.

The book is irregular as a philosophical treatise: the author allows himself all sorts of liberties with style, which is cramped and rugged as Browning's in places, with epithets on adverse opinions after the freest manner of Carlyle. But it is at least English : it provides its leading phrases for itself, and has not the Anglo-German character of the other chief writings of the Transcendentalist school.

Regarded as our most considerable recent statement of what Metaphysics can offer us for Theology, it is notable. It has much that can be taken as a declaration on the side of Theism, and though there is wavering and consequent ambiguity, the declaration can easily be rendered more emphatic than the author explicitly allows. He seems at times to be forced, in spite of himself, to acknowledge that man can know something of the Real, and that what he can know is much of what the Theologian has required. To the Christian Theist who looks for assurance such as that offered by certain other schools where men give themselves whole-heartedly to their conclusions, there is some sense of loss in the restraint and holding-back of himself shown by this able thinker: but his testimony, coming as it does from a critical mind engaged above all in suggesting doubts and delighting in raising the most subtle difficulties, is more weighty than that of many very assertive but also very uncritical Theists who appear to have achieved more positive and peremptory conclusions.

\section{$\$ 8$}

JowteT, B. : Essay on Natural Religion

Objection will be felt to some of the Types that they are too subjective in their character: at least to those who stand on other lines they seem so, though this is not ex confesso on the part of their advocates. But we shall find some who really have no other purpose than that of vindicating a belief as a belief, as a psychological or historical fact in the history of mankind. The philosophy of religion to them is a history of human belief ; critical it may be, judicial, selective, issuing in commendation of one only : but all within the sphere of belief. There is no ontological investigation going beyond a vague assertion. The test of a 
belief is its worthiness, its value as a constituent of character, an influence in mental life: whether it is true or not, there is no possible means of our knowing.

A graceful and delicate handling of Theism as a belief, with small inquiry as to objectivity, is that of the late Dr. Jowett, in an essay printed as an appendix to his commentary on the Epistles of St. Paul. His standpoint is that he finds in men beliefs, as he finds desires and tastes; he is not careful to inquire into objects corresponding to them, in the one case any more than in the others. His own standing comparison is with a Language. " Religions, like languages, are inherent in all men everywhere-in their fantastic creations the play or sport of the same faculty of speech : they seem also to be based on a spiritual affection which is characteristic of man equally with the social ones."

Illustrating from history, he indicates with some fine touches that what we find in the Old Testament are 'impressions of God in nature'; but these are described not as drawn out by thought upon objects presented, but as expressions of Feeling: and he dwells on the various moods found in Job and Ecclesiastes, and claims that in no other sacred books do we find such a range of Feeling as in the 18 th or 29 th Psalms.

He does sometimes seem to allow objectivity in the very simple sense of a Power or Powers above us. But he does not think that Reason can show us what such a Power or Powers must be, and what qualities or characters must be attributed. His view of what Reason can do is only that belonging to a theory of its character as relative: what it has to say is limited: it progresses, indeed, growing, like language, with the process of human needs, i.e. the feelings which reason is intencled to provide for. Of the three arguments from ' final causes,' from ' first causes,' and from 'ideas' he says, "We must place ourselves above them, not below": we must not bind ourselves by them in perpetuity: "Logical categories may give as false a notion of the Divine nature in our age, as graven images in the days of the patriarchs." He criticises all three in a deft and graceful way: but he lays stress on the defects with greater zest than on the strong points. E.g., his eriticism of the Design argument: (1) it is too 'poor' to carry us to nature; (2) works of art are isolated phenomena; (3) only part of the world is brought under the argument; (4) the moral field is not covered, for there is much 
waste; (5) the Deity is represented as an Artist, not as a Spirit; (6) there is a transference from the field of mind to that of matter which may be illegitimate. Of Causation he says that the argument is 'necessary and natural,' but only if we keep the action of cause and effect before us in simplicity; if we begin to analyse it at all it dissolves. Of all the three arguments he says, 'They belong to the Understanding'; and he goes on to ask questions which show that he does not regard Understanding as capable of giving categorical answers. We seem to be in an atmosphere not of Platonism but of the New Academy: Dr. Jowett has a perfect right to choose it, of course, only we must not allow that his influence is that of a Platonist.

Taken on the whole, the Essay is a comparison of the beliefs men have actually held, without any confidence in the power of speculative thought to constitute a Rational Theism. Such he evidently does not need for himself; but more, he does not like it. Hence he finds pleasure in pricking holes here and there in all schemes as they pass before him. $\mathrm{He}$ is himself in possession of religious belief; and if pressed to account for it he is content with the reference to its history: he has inherited it, as he inherited the use of the English language, and he is not careful to give a profound account of either the one or the other inheritance. But we can see that his philosophy of the matter must really be that in face of Powers above-the only objective element allowed-varied Feelings arise in the human soul. For the gratification of these, Imagination and a very relative Understanding construct for us ideas or notions which are a kind of Language. Further, there is no Universal Language of the Soul of this kind, but nations and races vary in their symbols, and individuals come by inheritance and education into the use of one form or another. Comparison does, he believes, show the Christian 'Language' to be the highest, the consummation, so far as mankind has at present gone. And even his subjective Theism is rather the Theism involved in Christianity, than the product of feelings, tempers, and moods of Soul otherwise produced or called out. 


\section{CHAPTER XIII}

\section{RESORT TO REvELATION ONLY}

\section{$\S 1$}

By Revelation is understood a sphere of truth, of knowledge, or matter of belief, not given through natural faculties-either moral or intellectual or other : but through extraordinary channels attested either by external credentials or by internal evidence. It may give an extension of the territory of knowledge, new facts, new conceptions, new laws: or it may be only a 'republication' of the facts, conceptions, and laws already before us, but insufficiently comprehended or lacking in force or impressiveness.

Our post-Reformation theology started from the standpoint of the Schools in regarding Revelation in both these ways. Aquinas had written: "Quaedam vera sunt de Deo, quae omnem facultatem humanae rationis excedunt, ut: Deum esse trinum et unum. Quaedam vero sunt, ad quae etiam ratio naturalis pertingere potest: sicut est Deum esse, Deum esse unum, et alia hujusmodi quae etiam philosophi demonstrative de Deo probaverunt, ducti naturalis lumine rationis." 1 But for these latter he proceeds to claim a necessity for confirmation from above natural reason: on the specified grounds that the exercise of reason is a privilege which few possess to a sufficient extent, and that many who had the capacity for it have not resorted to it, from one cause or another, until they are too far advanced in years to be able to use it; and that even with the best, error is found mixing itself up with truth. These are the lines marked out by Hooker also: "Capable we are of God both by understanding and will : by understanding, as $\mathrm{He}$ is that sovereign Truth which comprehendeth the rich treasures of all wisdom; by will, as $\mathrm{He}$ is that sea of Goodness whereof whoso tasteth shall thirst no more." 2 This is

\footnotetext{
${ }^{1}$ Contra Gentiles, I. 3.
}

2 Ecclesiastical Polity, I. xi. 3. 
strong; and yet we read: "From salvation therefore and life all Hesh being excluded this way, behold how the wisdom of God hath revealed a way mystical and supernatural ": ${ }^{1}$ because of failure, of misery, and of sin. "Man having utterly disabled his nature unto those means"-the appointed natural means - " hath had other revealed from God, and hath received from heaven a law to teach how that which is desired naturally must now supernaturally be attained." 2 But this is not all : " together with such Supernatural duties as could not possibly have been otherwise known to the world, the same law that teacheth them, teacheth also with them such natural duties as could not by light of Nature easily have been known." So that here we have both the disclosure of new and the republication and confirmation of old truths.

It is the same with Butler: Christianity is considered: "First, as a republication and external institution of natural or essential Religion, . . . and Secondly, as containing an account of a dispensation of things not discoverable by reason, in consequence of which several distinct precepts are enjoined us. For though natural Religion is the foundation and principal part of Christianity, it is not in any sense the whole of it." 3 Butler is speaking of Christianity, and with reference to Theism his view was that Revelation only confirms it: for he shared a good deal of the confidence in Reason prevalent in his day, although he did not carry the idea of republication so far into Christian Theology as Tillotson did. On the other hand, a modern advocate of Demonstrative Theism, Dr. Flint, ${ }^{4}$ after his nine lectures on the positive side surprises us by the very limited range of cogency which he allows to Natural reason when he is establishing the contention of his concluding lecture 'Mere Theism Insufficient.' He holds also that Revelation contains new truths. John Caird, too, takes both grounds, but with him the prominent character is the efficacy of the new in gathering together and consummating the old.

Some examples of those who reject Theism altogether and resort to Revelation alone must be taken more at length.

1 Ecclesiastical Polity, 1. xi. 6.

${ }^{2}$ Analogy, II. c. i.

2 Ib. r. xii. 3.

${ }^{4}$ T'heism, Lect. $\mathrm{x}$. 


\section{$\S 2$}

Bacos, Francis : especially Advancement of Learning, 1605; and Essays, $1597,1612,1625$

The mind of Bacon as a philosopher of nature is filled with rejoicing at the promise of the Inductive method in the pursuit of knowledge, and he is at the same time a loyal Christian, an adherent of the 'Holy Faith,' ${ }^{1}$ i.e. he adopts, or makes for himself, the division of territory which regards Religion as pertaining to Revelation, and Nature alone as coming under the scope of the new method. Everything is either divine knowledge or human: 'Oracle' or 'Sense.' '

To him Religious belief has a sphere of its own, with divisions parallel with those of Natural Knowledge, namely, History, Poetry, Reason. The office of Reason in the religious sphere is (a) to receive the mysteries, the placita or fiats of the Almighty, and $(b)$ to apply them. ${ }^{3}$ His objection to the Schoolmen is that they attempted to combine philosophy and theology in one scheme, which they wished to be both systematic and perfect: as to system they failed, as to perfection they ought never to have looked for it. ${ }^{4}$

In Ethics Bacon distinguishes what we should call idealism, perfection or absoluteness, from the ethics of ordinary life: the former he sets over the dividing-line on the side of religion: ${ }^{5}$ in this sense Conscience is the voice of God. Of ordinary conduct he has a good deal to say, and it is with him a cardinal point that human good is of a social character. ${ }^{6}$

In Causation the dividing-line appears again : there is First Cause and Final on the religious side, Material and Efficient on the other side. ${ }^{7} \mathrm{He}$ considers that Plato confused these, and was theological when he should have been scientific: and that Aristotle, too, uses Formal and Final causes across the line, in both spheres: but that Democritus knew better.

Again, in Religion the Heathens, i.e. the Græco-Romans, carried Reason over into the sphere of Religion, while Mahomet put Religion where Reason should be supreme.

It follows that what we call Natural Theology was to Bacon a monstrosity. Nature yielded no Theology: sensible and

${ }^{1}$ Advancement of Learning, Clarendon Press edition, p. 139.
${ }^{2}$ P. 85.
${ }^{3}$ P. 255.
${ }^{6}$ Pp. 181-217.
${ }^{4}$ P. 259.
S P. 254.
7 P. 44.

P. 181-217. 
material things could not yield knowledge of the nature and will of God. ${ }^{1}$ Not that he was always quite easy in this rejection of Natural Theology. Everyone will recall to mind the Essay on Atheism (1612, seven years after the Advancement of Learning), in which he says "depth in philosophy leadeth a man to religion," and he actually proceeds to touch commendingly on the Cosmological and Teleological arguments themselves: and further, he goes on to descant on the elevation and the strength given by study to the belief in something above us, i.e. natural effects are regarded as grounds of belief. But I take it that the demarcation into spheres is his normal position. In making it he is not depreciating Religion, but exalting it, he thinks. ${ }^{2}$ Faith is more 'worthy' than Knowledge; 'Natural Reason' was resorted to by Sarah to her confusion, Abraham looked higher by 'Faith': and he thinks that from the sphere of Religion have proceeded additions to Ethics, e.g. Love your Enemies. His own exposition of the Nature of God in the sphere of Theology is to state not the doctrine of the First Cause, ${ }^{3}$ but that of the Holy Trinity, but only in a few lines."

Bacon's position is very readily explained. There is no need for the suggestion that in his expression of religious faith he was in any way insincere. His dualism is quite intelligible. For what does he mean by Reason? He means, as he says himself, 'reason, sense, induction, argument ' $;^{5}$ the exercise of thought by the new method of Induction; and he was quite aware that this was competent to deal with the sphere of second causes only. From his chronological position it is easy to see how he stood. The world was waiting for a reinvestigation of Higher Reason: Descartes was at school and Spinoza was not yet born when the Advancement of Learning was being written. Failing, therefore, our modern vindication of Higher Reason and out of heart with the later developments of Scholasticism as issuing in a false Abstract Reason, he had no means of combining the knowledge of First Cause and that of secondary causes, of Infinity and of the finite, of God and of the world: and therefore he naturally and logically marked out his separate spheres.

Bacon's disallowance of Natural Theology was due to Intellectual considerations. We have no great Englishman in the seventeenth century to quote, so far as I can learn, who makes
1. P. 8.
2 P. 253.
${ }^{3}$ P. 253.
4 P. 265.
${ }^{5}$ P. 254 . 
the resort to Revelation on Moral grounds after examination of what Moral Theism can do; no one like Pascal, an Idealist in face of a moral discord within man and over all human history, to whom the suggestions of Natural Reason seemed mocked and thwarted to a degree which-in spite of some Theistic argument and thoughtful rational Apology for Christianity-rendered it almost trifling to speak of Religion apart from Revelation.

In England even Hobbes bound them together, and the tide of 'free-thinking' was with the Deists, whose fundamental aim it was to draw Revelation within the region of Natural Theology. As the eighteenth century proceeded, the revival of Evangelical religion caused many religious minds to draw away from all Natural Theology: so many orthodox believers who were also Natural Theologians were following Tillotson and Locke and Clarke in allowing the specific features of Revelation to be effaced by rationalising processes, that the whole subject became distasteful to men who rested their hopes on a Gospel which presented itself as far exceeding Nature, even if not in some important respects opposing the natural man and all his thoughts. The Religious system offered by the Rationalisers seemed cold and meagre and without spiritual salt. And they could not but be aware that there were many who followed Reason and yet disagreed with the Rationalising Christians and invited men to surrender religious faith: if there were Butler and Berkeley on one side, there were the Deists on the other, and, behind them, the destructive scepticism of Hume and the French 'infidels.'

And so men came to maintain that the knowledge of Godnot only the Christian Gospel, but Theism itself-came by Revelation and not through Nature; they took up definitely the position that Revelation is the sole foundation; they condemned the Apologists who allowed the Deists so much ground. Religion, they said, was surely an affair of every human being, yet how few had either the leisure or the wit or the inducements to enter upon a course of study of Nature. Innate ideas had been effectively exploded, and no other pathway to the Unseen had been opened out adequate for the use of all men. Again, natural knowledge was the result of great toil, and had been built up gradually, whereas religious belief was general and possessed by many who had never laboured for it. As for the Design argument-I am giving the pith of what was said at the 
close of the eighteenth century on the part of earnest ministers of religion-Hume's argument, that there is only one world to argue from, and therefore that there is no analogy with a watch, which resembles other watcbes which have been seen in process of manufacture, had not been answered; the argument to First Cause was fraught with danger, as Evil would have to be taken up as well as Good: a mixed Cause seemed the result of its logic. And yet religious belief is a great fact all over the world: ergo, it must come from Revelation: in Christendom it is from the Scriptures that men have learnt that there is a God. Hume closes his Dialogue with Philo's assertion, "To be a philosophical sceptic is, in a man of letters, the first and most essential step towards being a sound believing Christian." Whether Hume meant this or not-and Christian belief he certainly did not profess to hold-he had in his mind the position occupied by many believers, some of them his own intimate friends, for it has been noticed that he consorted much with the orthodox doctors of divinity who held high offices in the Kirk and in the Universities of Scotland.

\section{$\S 3$}

MANser, H. L. : Limits of Religious Thought, Bampton Lectures, 1858 ; Metaphysics, Encycl. Brit., 8th ed., pub. 1860

The most interesting recent instance of this Type appeared in 1858, when Mansel stood before the University of Oxford and proclaimed that the time had come to have done with philosophy of religion and to have recourse to Faith in Revelation.

Mansel's reputation as a scholar, a teacher, a leader in the University, and a wit, ensured a first hearing, and the vehemence with which he uttered his clear-cut and confident appeals secured crowded congregations of University men throughout the course, and his book became the topic of the day in this field. It is important to note this, because not a few religious men have carried away for life the impressions then produced, that the Christian believer had nothing solid to expect from Natural Theology.

Mansel's motive was clear. He found elements in the Christian gospel which were being refined away by German Idealism: the philosophical results of Fichte, Schelling, and 
Hegel had been applied to Christian theology by Vatke, Baur, and Strauss. He was alarmed at the effect produced; his own studies had led him to different views in philosophy, and he was convinced that the immediate call upon him was to apply himself to the criticism of the Idealism, which, as matter of fact, he considered untenable and delusive; in his own terms, 'a web of contradictions.' Further, from Mansel's own standpoint opposition to others than the Idealists was called for: the Demonstrative School was wrong too: in fact, every school which affirmed the possession by man of knowledge of God by natural faculty.

He had himself been attracted by the position of Sir William Hamilton, and it is part of the source of interest in Mansel that he is often taken to be expressing articulately in Theism the philosophical principles of Hamilton. ${ }^{1}$ Mansel expounds 'a philosophy of consciousness ': all knowledge must be expressible in terms of consciousness; now consciousness is always of relatives, and therefore all our knowledge is of relatives: the door is closed against all talk of the Absolute or Infinite, it is impassable for us, being what we are. Demonstrationists, Intuitivists, Idealists are all in the same cloudland. Against Idealists it was necessary to object that their distinction between Reason and Understanding was fictitious: "the function of thought is in all cases the same, to represent reflectively what is presented intuitively" $;^{2}$ to reflect upon our perceptions, not to provide any new materials for knowledge. The mind, indeed, could and did frame a vague conception of an Unconditioned in relation with the Conditioned objects of experience: but this conception had no positive content, it was purely the idea of a logical correlative constructed by the 'reflective understanding': in a list of pairs of notions: relative-absolute; conditioned-unconditioned ; real-unreal : the absolute is classed with the unreal. "The infinite, like the inconceivable, is a term which expresses only the negative of

${ }^{1}$ It is difficult to pass over the name of this great philosophical scholar, but it cannot be said that Hamilton spoke with clearness upon Theism. He has been interpreted (1) as remitting Religion wholly to Revelation, (2) as holding a Moral Theism, and (3) as resorting to Intuitive 'Faith.' From his varied writings quota. tions can be made in support of each of these interpretations. His daughter in her account of him in the Encyclopoedia Britannica seems to give a preference to the last-mentioned view when sho associates him with Jacobi rather than with Kant, but in another place in the article her opinion would seem to be that his method was Ethical Theism.

${ }^{2}$ Mclaphysics, p. 280. 
human thought"; " ${ }^{1}$ the infinite cannot be an object of human consciousness at all; and it appears to be so only by mistaking the negation of consciousness for consciousness itself." $\mathrm{He}$ refers to Hamilton's 'admirable remarks' in the Discussions, and goes on to claim that Kant came, in effect, to the same conclusion: so that the German Idealists had no true claim to call him their master.

In support of his position, that it was vain to claim knowledge of God as the Infinite, Mansel raked the fields of scepticism ancient and modern and gleaned a sheaf of Agnostic utterances from the Christian Fathers and from modern divines. And he insisted that those who made the claim were Gnostics or Pantheists. Knowledge of the Infinite must therefore be renounced.

Had Mansel any other methods of Natural Theism? It would appear in some places that he is inclined to except Morals from the corrosion of the doctrine of Relativity: ${ }^{2}$ to allow absolute character to Right and Duty; and to infer from this that "consciousness of Moral obligation compels us to postulate a Moral Deity": though not an Infinite one. The Feeling of Dependence, too, he dwells upon as operative in the mind $;^{3}$ but its force is not more than suggestive, it cannot itself lead to the Infinite. Causation and Design, similarly, are only ancillary and illustrative. The limits he imposes on natural thought seem to confine us to the suggestions of the. Feeling of Dependence, the stronger suggestions of Moral consciousness; with some support from Causation and Design, and a logical idea of a negative Infinity. And the whole issue is a Personal Being of whom we must not pretend to assert that we know Him to be Infinite.

As to the Moral factor, Mansel does not really accept absolute Moral law. No such law is really known; men differ in their moral consciousness; neither Kant's universal nor any other is really known. The cardinal notion with Mansel is that of justice. Beauty he holds to be purely relative: so that his use of the moral factor is much too meagre to entitle him to be regarded as an Ethical Theist. He seems, indeed, to have a wish to secure Personality: 'it is our duty to think of God as personal' is his phrase: but even so it is only a relative and empirical personality: he can be so concrete as to

${ }^{2}$ Lect. vIr. and Iv. p. 85 ; Metrphysics, p. 158.

${ }^{3}$ Mctaphysics, p. 375 . 
allow such "attributes of personality as showing favour or severity, and being regarded with feelings of hope and fear, and addressed in terms of prayer and praise." 1

But in all this there is nothing that can be carried up to the Infinite: that is, knowledge is unattainable except by direct Revelation, especially to chosen souls. And Mansel invites us to rejoice in the failure of Reason, not to regret it: for the appearance of a demonstration would show that we were being deluded, ${ }^{2}$ taking a human construction beyond the limits where human faculties can work. But a Revelation can only be made; what it will contain we have no means of foretelling, nor have we any faculty for judging it when it is presented.

Mansel's position was that of a controversialist, and his lectures evoked a chorus of hostile voices both from philosophy and from Christian theologians. It was a reassertion of Bacon's separation of Reason and Religion, in spite of all that had been done for Reason since Bacon's day, and the Demonstrative and Idealist schools alike were in arms. The Demonstrationists complained that they were ignored, and declined to consider Wolff-with whom Mansel specifically deals-as their sole exponent: the constructive Idealists were of course absolutely opposed, and mocked at Mansel's Negative Infinite. The growing school of Ethical Theism was perhaps specially aggrieved: they thought the Ethical basis had been secured from the wreckage on the 'Critical' rock, and Mansel himself seemed at times to be with them. Indeed both the Ethical and the Personal schools thought they had secured a territory between Pantheism and pure Faith in the supernatural. Only the Empiricists rejoiced: they thought that the surrender of philosophy meant victory for them, and that they could soon dispose of Mansel's claim to make resort to Revelation, which would have to be fought on the old ground of External Evidences. It was in defence of Theism that Maurice came forward with a most vehement attack on Mansel: in defence also of Revelation, but not as a refuge to be reached by a ladder of historical evidence, and containing ideas wholly beyond appreciation by our natural faculties, or possibly running counter to them altogether. In the name of an outraged Faith, as Richard Hutton said, Maurice embarked on a controversy, which, however, only left Mansel reasserting his position. 
Criticisms of Mansel followed fast from all the other Schools. The defenders of knowledge of the Infinite or Absolute agreed in pointing out that Mansel does not come in sight of a true Infinity. He looks not only at a merely negative infinite, the unlimited, but also only at a quantitative one, such as that of time and space, in which finitudes enter as parts of a whole. The 'web of contradictions' in which Mansel enmeshed himself in connection with that kind of infinity had been known all along; the complaint was that Mansel did not seem to know that a doctrine of the Infinite had been developed in face of those contradictions and in order to transcend them. Such Absolutes as Absolute First Cause, which is uncaused cause and never effect; Absolute Spirit, in which the distinction between subject and object is transcended; Absolute Goodness, which has no parts, but is valid simpliciter-these he does not touch. The negative Infinite, the purely unconditioned of Hamilton, was not what was defended by Theists of the Traditional School: nor could it be accepted by Idealists as a true reading of Kant: imperfect as had been his conclusion, he meant more than that. Kant's contrast between Man as a being of minute physical dimensions in a space-world, and Man as a being who is also a a member of an intelligible world, in which he acts as a free personality, Mansel never saw. And farther, his method of rising to a sphere of Revelation by means of Miracles, breaking the observed order, was far removed from Kant's seeing God in the order, and therefrom rationalising revelation: so that it is impossible to admit Mansel's claim to be a representative of Kant. Believers in Revelation, on their part, soon came to see that if man's nature is such that he can have no ideas of God, he cannot be a recipient of them by Revelation; the conception of human nature as 'image of God' has gone completely.

When it was seen that Mansel's philosophical weapons were drawn from a peculiar philosophical armoury, the excitement calmed down, and the once famous Bampton Lectures are now serviceable chiefly to Rationalists and Idealists, who find in them a convenient contrast and foil to their own doctrine of the Infinite or Absolute. The most permanent effect of Mansel's thinking has been its having supplied Mr. Spencer with the negative aspect of his Quasi-Theism. Mansel personally was a hard reader, and of a true metaphysical turn of mind, and he was a man of deep religious character, and had hosts of friends 
who believed that he was opening out a true way to religious peace in perplexed times. It was not the incompetence of Reason which gave him pleasure, vigorously and racily as he expressed himself on that head, but the possibility of holding fast by Religious belief whatever Reason, apart from Evidence, might or might not have to contribute to its formation and justification.

\section{§. Various}

Dr. Dale of Birmingham would probably be supposed by his friends to stand with Butler on a Moral Theism. If we turn to the place where he faces the problem explicitly, however, in the first two of his Discourses on Christian Doctrine," 'The Existence of God,' we find that he takes his stand on the affirmations of intuitive faculty: the belief in God is parallel with that in the external world and in self. It is a simple belief, not resting on constructions of the Intellect: that would be to make it stand in 'the wisdom of men,' not in 'the power of God.' 2 The fact is, we are 'so made' as to have all these three beliefs: we have 'a natural faculty' for them: we 'see' or 'perceive' God by the mind, as by the organs of sense we see the material world.

To fill in the perception he turns to experience: and it is only to such fuller content that he applies the term 'knowledge': before that he calls it a 'belief.' In these experiences Moral experience is very prominent, the Moral Law-also known immediately, intuitionally - with the sense of Judgment (praise or censure); and it suggests inference to a Power, or rather a Judge. The Teleological argument also is used: but only in its general form from Order to Intelligence; 'Design' he will not commit himself to. ${ }^{3}$

So far, then, we have the position of the Intuitivist: and I might well place Dr. Dale under that Type. But to do so would be to misrepresent the character of his mental attitude. If we pursue our study of his exposition we become aware that there is no high demand for Natural Theism at all. As a Christian believer he does not accept any need for Theism as a presupposition, whatever need there may be logically. He even has suspicion of it; it may be set up as a barrier, or raised as a substitute. And under the influence of this suspicion he withdraws some of the support he had already given to it. It

$$
{ }^{1} 1894 . \quad \text { ' P. } 4 . \quad{ }^{3} \text { P. } 16 .
$$


is all very well, he thinks, so long as you are left to yourself to assert your natural intuitions: but if questioning begins, what then? In the presence of doubt you must face the possibility of finding no logical solution at all: and Dr. Dale evidently has no confidence that you would find one; a sceptical attitude which he finds strengthened when he reminds himself of the negative results of the history of speculation. ${ }^{1}$

When he asks how belief in God actually arises, he refers to tradition, education, social institutions, and so on, and then to the experiences which turn it from traditional 'belief' into ' knowledge.' 'But he confines himself to men of to-day: declining to speak as to primitive man, and regarding much of the recent endeavour to get at his mind as invalid from lack of proper material. ${ }^{2}$ Consequently upon the varieties of experience, 'knowledge' is much mixed, and only appears in purity in the minds of a few members of the human race.

In addition to his Intuitivism we also find that Dr. Dale speaks as if he accepted what the Demonstrative School mean, for he speaks of God 'perceived through the things that are made,' and 'through conscience,' ${ }^{3}$ but he thinks this method only partial; that is to say, it is one of the varieties of human religious experience; and we infer that the Intuitivism he has asserted for himself is another. And so we conclude that he found his own real satisfaction in the Christian Revelation of God: that he experienced no practical need for Natural Theology, either personally or as a teacher and guide of others. To a man of his masculine mind the uncritical dogmatism of his first two chapters would not really have passed muster had he required Theistic proof for himself as a vital need. When that need rose in his own mind, or in face of the requirements of his pastoral duty, he settled it by considerations on a different plane of certitude, by the convictions he had attained that the Divine Being was manifested in the Christian dispensation.

In the late Dr. Bruce's Apologetics, 1892, the small portion allotted to Theism is chiefly occupied with a polemic against Pantheism, Deism, Materialism, and Agnosticism. As a matter of fact, Dr. Bruce occupied the Christian standpoint, and had not cleared his mind as to methods of Theism. But he says sufficient to show that it was Intuitivism which might have attracted him
Note $A$.
${ }^{2}$ Note B.
${ }^{3}$ Pp. 26, 39, 42. 
had he pursued an inquiry. "He notes that it is in methods that Theists differ, while in belief they agree : and he considers that this harmony is significant: "it suggests the thought that the belief in God is antecedent to evidence, and that in our theistic reasonings we formulate proof of a foregone conclusion innate and inevitable." 1 In reference to Dr. Royce's line of proof, for example, "How weak the proof here," said Dr. Bruce, "but how strong the conviction! So it is, more or less, with us all. In our formal argumentation we feebly and blunderingly try to assign reasons for a belief that is rooted in our being." He will not pronounce against all the methods, he says, but he adopts Intuitivism as a 'policy': and this we may take to indicate sufficiently the bent of his preference. But inasmuch as we find the Proofs treated of only in a chapter on Agnosticism, and only in order to show that their advocates, by their mutual contradictions, justify the sceptical attitude of agnostics, we should have to enrol Dr. Bruce among the Exclusive Mystics, which would be incongruous; so it is no doubt truer to his actual mind to rank him with those who have no real confidence in any other source than historical Revelation.

Dr. Wace, in his The Foundations. of Faith, 1879, conveys the impression of being unprepared to allow much force to Natural Theology. As would be expected from his other works, it is to the Ethical side alone that he looks for any assistance: and in these Bampton Lectures he expresses himself unreservedly on the insufficiency of speculative argument. What it points to is at most ' a conception vast, vague, intangible,' 2 but it does not point clearly even to that, "the understanding soon loses itself in the labyrinths of its own infinite analysis "; ${ }^{3}$ the German speculations of the present century are classed with Gnostic and Jewish speculations of earlier centuries. ${ }^{4}$

The Moral argument is stated from Intuitions of right and wrong, and of responsibility, leading us to belief in a Righteous Judge. But the argument which Conscience offers seems to stand unsupported; the course of the world has not been in accord with moral expectation; Theism was failing to maintain itself when Christianity appeared. The statements are so strong that the impression produced is that Dr. Wace is not prepared to advocate Theism apart from Revelation.

'. 157.

? P. 57.

'Il.

$+1 b$. 
In sermons preached in St. Paul's Cathedral by Canon Scott Holland we have the following quite unambiguous utterances: "Is the pressure (of the enigmas of life) less to-day than it was then (when Christianity first appeared)? The intellectual enigma, for instance: Man is made to know God, and yet fails to know Him. . . . Now, to-day, at the end of all our seeking to find God, we find, on every side, that men are so despairing of success in the search that they are seriously doubting whether the search ought ever to have been made-whether it be not true that man was never made to know God. All around us reason is in retreat. . . . It capitulates; it resigns itself to accept its own ignorance; it deems it useless to prolong the struggle. . . Surely the intellect of the day is in full retreat from out of all the country it once claimed to occupy. ... Man was not made to know the reality of things; man cannot know God. This is the melancholy lesson which reason is enforcing." 1 This is, apparently, spoken of others: but the preacher proceeds: "If man is ever to know God there is at this moment but one road left open, there is but one offer for him to consider. For all other claimants are retiring. . . . Only one claimant remains, challenging us to follow Him." 2 And in similar vein he proceeds to acquiesce in the total defeat of Natural Theology in face of 'the moral enigma,' and the moral issue is left depending wholly on the Gospel. "Without this, who dares hope? With this, who dares fail ?" The resort to Revelation is thus proclaimed to be the only way to knowledge of God by one of the most cultivated preachers in the Church of England at the close of the nineteenth century, himself in the van of progressiveness in ecclesiastical and social interests.

An expression in this sense from a student of Church History is given in a paper by Professor Gwatkin, The Fourfold Revelation of God: ${ }^{3}$ in Nature, History, Life, the Scriptures. Nature has been resorted to for Religion, Mr. Gwatkin thinks, when people have become weary of controversy within Christian lines, as was the case in the seventeenth and eighteenth centuries. But for his part he regards the Natural Religion which became prominent as largely dependent on ideas imported from Christianity: thinking that from a study of Nature belief in neither

\footnotetext{
${ }^{1}$ On Behalf of Belief, 2 nd ed., 1892, p. 89.
}

2 P. 92.

${ }^{3}$ Expositor, 1891. 
infinite benevolence nor future life can be derived: and, similarly, that in the sphere of life Providence cannot be proved, nor can a plan be discerned in human history. But if only we will admit Scriptural verities, unity at once appears in Nature, in Life, in History.

\section{$\S 5$}

There must arise in every serious mind a sentiment of sadness when contemplating the variations in man's confidence in his natural faculties in relation to the knowledge of God. After every rising to a crest of confident assurance there seems to follow a decline more or less deep, touching sometimes the bottom, when resort is made to Revelation alone, as in the cases dealt with under this Type. We know that from the great constructive systems of Scholasticism the intelligence of the time sank slowly down into the speculative scepticism-combined, of course, with Christian faith-of the last great Schoolman, our English William of Ockham; and we know that Dante, after duly venerating the great Doctors, retreated into the Faith based on Revelation alone, or chiefly :

"I in one God believe;

One sole eternal Godhead, of whose love

All heaven is moved, himself unmoved the while.

Nor demonstration physical alone,

Or more intelligential and abstruse,

Persuades me to this faith: but from that truth

It cometh to me rather, which is shed

Through Moses; the rapt Prophets; and the Psalms;

The Gospel ; and what ye yourselves ${ }^{1}$ did write,

When ye were gifted of the Holy Ghost."2

And yet it is always possible to take a more cheerful view by holding that this is a deceptive and delusive representation of human progress on the whole. It may be that a treasure secured by the mighty effort of one generation is not appreciated by the children of those who discover it, and yet that it remains a treasure still, waiting for a later generation to recognise it and rejoice in it.

The history of belief as a natural thought and natural faith is discontinuous, in appearance, by reason of these undulations. But the true history may be sought by neglecting the depressions and tracing the onward course from crest to crest.

1 The Apostles.

a Paradiso, Canto xxiv. (Carey's Tr.). 
From Plato and Aristotle the Theistic faith passes on to Alexandria, from Augustine onward to Anselm and Abelard and Aquinas, from them to Descartes and Leibnitz, and so to Kant and Hegel, with other collateral lines; and a continuous development and increase of assurance can be traced.

Still, we are uneasy at the thought of these depressions, and we feel that the tracing of a splendid line from summit to summit is not all that we need when we remember the remoteness of those heights from the level of ordinary human life and thought. And not least is the difficulty a pressing one for those who are aware how various are the methods by which assurance is obtained, as this outline of English Theism shows them to be. The need of making a choice becomes a burden on the conscience of those who do not feel in themselves any competence for making it.

For those who fall back on the position indicated in this Type the burden is removed by their renouncing the need for making resort to Natural Theology at all. Their feeling is not dissimilar to that of a man who is aware of the inadequacy of Arithmetic for dealing with a complex problem, but is indifferent to it, because he has Algebra at hand ; or of the man who is undisturbed by the meagre result of observational Astronomy because he knows that the telescope and spectrum analysis are at his service. They feel that Evolution itself bids us live now in the higher stages of belief, and remit the lower to the framers of histories of the past. The believer in Christian Revelation regards Natural Religion as only germinal, and will not be distressed beyond measure if he has to abandon expectation of its yielding a conclusive result. Such sentiments as these must, so long as Natural Theology either speaks with uncertain voice or offers alternative assurances inconsistent with each other, render the attitude described in this last Type very attractive for Christian believers, whose respect for Natural Theology will then be due to such reflected and derivative light as it receives from Christian Revelation. 


\section{RETROSPECTIVE}

THE Theisms which have passed before us suffice to show that in Great Britain and Ireland nearly every one of the Types delineated in Part I. has secured its advocates. Into the border territory where Philosophy meets Theology men have entered, some from the side of Philosophy, some from the side of Theology, and have taken up positions in such variety that nearly every one of the areas we marked out is occupied by a respectable company. Some of them, indeed, are tenanted but sparsely, while other's are crowded with dense phalanxes, from which we have been obliged to select representatives only. As to the occupants, some seem to be ill at ease in their chosen plot, as men conscious of being in a precarious situation, and we detect something of wistfulness in their looks towards other areas, as if they surmised that these contained something which they themselves miss; others stand with confident assurance, like men who have won for themselves ground among marshes, and the only firm ground that there is.

This variety has prevailed from the first, as a glance backward will show. Looking beyond the time when our examples begin, the time of the Reformation and the Renaissance, to the 'Schools' of the Middle Ages, we find that in that magnificent international university it was neither an obscure nor a monotonous part that was played by natives of Britain. Two Britons at least would be named in any selection of the six greatest Scholastics: John Scotus Erigena (Ireland) and Duns Scotus (either Ireland or Northumbria) would be ranked with Anselm, Albert, Abelard, and Aquinas: while Alexander of Hales (Gloucestershire), Richard of St. Victor (Scotland), William of Ockham (Surrey), and Roger Bacon (Somerset) would stand in the front rank of those next after the Masters. Making full allowance for the fact that the Schoolmen had a common standpoint as Theologians with religious belief in possession looking to Natural Theology to see what corroboration 
could be obtained there, we cannot but be struck with the fact that the main varieties of Theism were well established by them, and we now notice that British representatives are to be found under each type. Scotus Erigena, the earliest of the Schoolmen, found Platonism, or rather Neo-Platonism, attractive to his mind, and would come under our Intuitivist or Mystic type; Alexander of Hales was the first great Aristotelian, with a Rationalist turn of mind; Richard of St. Victor followed Hugo in retreating upon Feeling; Duns Scotus was practical in his mood, setting Will above Intellect; Roger Bacon was inclined to withdraw religion from philosophy; and William of Ockham had no hesitation in asserting the incompetence of philosophy and retreating within the confines of Revelation. Another glance over these names, however, shows us that the weight of the British Schoolmen was not thrown into the scale of Intellectual method: even Alexander of Hales can hardly be grouped with Aquinas; he was a Franciscan, and Bonaventura, the Mystic, was one of his pupils.

The general expectation raised by a glance over this period is that the British mind will tend to run towards the side either of Ethical or of Empirical theology. When the revival of mental activity came, therefore, we are not surprised to find that our first English theologian, Richard Hooker, insisted on the double reference to the Divine Being as the source of Goodness as well as the Cause of existence, giving forth His Law of Reason not only as universal and necessary but as the Summum Bonum. And we take it as very natural that Berkeley and Butler, two of our greatest names, should follow on that line.

It is to be observed, however, that when the Reformation and the Renaissance affected Britain, the mass of Theologians remained content with the Natural Theology of the Intellectual type, after Aquinas. The See of Rome had set its approval upon it-no doubt in endorsement of Christian opinion rather than in attempt to guide it-and our Reformers had no special interest in disputing it; controversy in other parts of the field was too keen and absorbing. Luther, indeed, had cried Des Teufels Braut, Ratio! but Melanchthon was an Aristotelian and Thomist, and Luther's utterance awoke few echoes among English Churchmen. Adherents of Intellectualism have, therefore, continued in great numbers to our own day, by a sort of 
persistence along what may be called the line of best established action. The number of treatises, and especially of textbooks for instruction, in which this method is expounded is very large: the bulk of the official teachers of theology in our Universities and Colleges, Anglican, Presbyterian, Independent, Methodist, and Romanist, in Britain and in America, have inculcated the Proofs from Causality supported by the Moral Argument and Consensus, as the staple of Natural Theology: so that with us, as in countries where the Roman See retains authority, this may still be regarded as the type in official favour. In its main features a tradition, it has also secured from time to time fresh advocacy from men of high intelligence, who have thought it all out again and come forth from their labours not only satisfied with it, but confident in its validity and its power. Refreshed and refined under the pressure of controversy and enriched with the gains of the sciences, it still stands vigorous before the world. In the eighteenth century the wide-ranging intellect of Leibnitz gave it accession of force, while in England the Teleological part of it, with its appeal to our instinctive affinity for inductive method, was elaborated with untiring assiduity from Derham to Paley and Chalmers. In the nineteenth century the Causalists, after some hesitation, have appropriated two of the most important reforms in science, the making prominent of the Will in psychology and the conception of Evolution; and as the century closes it may be said that the double proof from Causality stands intrinsically more attractive than ever, whatever is to be said comparatively, in view of the increased potency of competing methods.

The assertive Ontology of Anselm and Descartes never found favour in Britain: and as Anselm himself was only a sojourner among us, and Clarke's famous ' $\dot{\alpha}$ priori demonstration ' is no true example of it, we cannot find a name of mark among those who claim for it the front place, while, as we have seen, those who have admitted it as a partner in a scheme of argument have done so with unmistakable frigidity and uneasiness. In Intuitionalism we find what may be regarded as a substitute for it.

As we advance along the nineteenth century we find Intellectualism taking new form as Transcendental idealism, and entering upon a career of official dignity in Oxford and in Scotland under the Cairds and Green, and in America. 
There has been but slight resort to Ethical Theism taken by itself. At least this is so when we take into view the whole compass of the work of several writers whose names occur at once to our mind as eminent for their contributions to the moral side of theology, Butler, for example. But of these men it must be said that their adhesion to proofs of the intellectual order was somewhat conventional in kind: these proofs were rather 'taken as read,' while ardour and strenuousness marked their exposition of the Moral argument. And it is scarcely venturesome to put in a word for the eighteenth century (and the early nineteenth with it) and suggest that the inner mind of the great bulk of the official teaching and preaching was of this moral temper. It is common to charge the period with being dry and rationalistic, devoted to intellectual argumentation, either abstract or evidential. But a good case may be made out for the opposite view, that the period was mainly ethical in its real interests, and was only by convention or force of habit employed in intellectual argumentations: the period of Johnson and Cowper, of the Pitts and Burke, of Wesley and Wilberforce, can only be called 'dry' on its moral side when viewed through some distorting medium. However we decide this, what is certain is that in Theism little or nothing was done in Britain during this period for the improvement of the Cosmological proof, while the Teleological was developed with some ardour, very largely because of the facility for adapting its result to moral persuasion, and the direct appeal to the argument from Conscience was gathering strength all the time. In the later nineteenth century some writers who stand in this Type have come to their position under the influence of the Kantian attack on intellectual proof, though they do not all follow his method on the ethical side, but content themselves with claiming his vindication of it in a broad way, and then walk on lines of their own.

The claim that Will and the practical aims of life, taken quite empirically, give the true clue to belief is too recent in Britain to have had time to give birth to any system: at present it is in the stage of vigorous and promising youth. The direct resort to Feeling has won but meagre support among us, and that chiefly among poets: while the complex 'personal' method of Newman finds few supporters as presented by him, and no one else of front rank has put it forth. 
It is very different with the Intuitivist or Mystic Schools. The extremists, indeed, the Mystics pure and simple who soar above ordinary experience altogether in the development as well as in the rise of religious faith, have been little known among us at any time. But the increase of inclination to take an Intuitive starting-point, and then to articulate with it the range of ordinary experience, is unmistakable. In the seventeenth century the affinity for Mysticism gave us our Cambridge Platonists, some being Extremists, but the best of them precursors of the Comprehensive type; and with somewhat of a leap over the eighteenth century we find Coleridge and Hare and Maurice in the early and middle nineteenth, followed by men who included even something of Transcendentalism in the important Oxford school which has risen to prominence at its close.

Partial Theisms have abounded: invitations to reduce the high demand of Christian theology and to dispense with this or that factor or constituent of the conception of the Divine Being have never been lacking from the time of Hobbes to that of Mr. Spencer.

Quite at the outset, too, we find examples of our last type. Almost simultaneously with Hooker we find Bacon, in his animosity to the intellectual Scholasticism with which he had acquaintance, going back to where William of Ockham and Roger Bacon had left off, separating theology from philosophy altogether and remitting religion to revelation and faith. This lead has been followed by a considerable number of men of science and members of learned professions, while the deep under-current of perplexity manifested in literature and in society at the close of the nineteenth century, implying distrust in what Natural Theology has done or can do, causes many Christian believers to agree that there is divergence between what nature and thought can give us and the content of Revelation enjoins upon us to require.

In this survey our concern has been with the literature of the Natural Theology evolved by British minds. We have not for a moment supposed that it has been developed in isolation from the literature of neighbouring nations. Many of our writers openly tell us from what foreign sources they have drawn guiding principles, the indebtedness of others lies on the surface of their work, and in others, although it lies below, we discover it without much toil; but of these not a few have 
really made what they have acquired quite their own, and have invested it with an outward form in which it moves so easily and effectively that its exotic character is forgotten save by the curious. And here and there we can say of a writer that he is distinctly British and has given us a genuinely native method. In thus combining native and derived elements, Natural Theology is like all other fruits of the higher life; but there is in it too much of the personal factor to allow it to be so cosmopolitan as either the physical or the mathematical sciences, for example; and one may venture to suppose that if a German or a Frenchman were to cast his eye over these pages he would find that the lineaments of the presentation as a whole differ from those which he would observe in a similar conspectus of German or French philosophy of religion since the Reformation. Is it patriotic bias which leads to the suggestion that such an observer would find in this literature of ours, taken as a whole, that tenacity for old and well-tried lines is well balanced by open-mindedness for new influences? that this is matched with a fair combination of capacity to appreciate both the speculative and ethical aspects presented by Religion? and further, thatstill taking the literature as an aggregate-while appeals to ordinary experience and to reason predominate, there is not wanting an appreciation for that mystical transcendence without which no literature could be regarded as comprehensive?

In some minds the feeling at the close of the survey will be one of surprise that Natural Theology has been so varied all through the period, and remains varied at its close: the human mind has been appealed to for the purpose of ascertaining on what grounds religious belief is justified, and a collection of the answers given by English-speaking thinkers alone gives us not a single Theism but a complex literature. Many who have learned to acquiesce in the diversity which prevails within the area of Christian Theology are astonished to learn that diversity does not disappear when resort is made to the natural faculties of man unfettered by authority and applied freely to every aspect of human experience. The surprise is not an agreeable one to minds simply and seriously in search of truth on this fundamental article of human faith, and there arises a temptation to doubt whether man is really responsible for his beliefs after all. Now, when a fact is before us we know that it is no real explanation of it merely to point to other facts like it: nevertheless, 
the edge of disappointment is somewhat turned by such a reference, and the mind is placed slightly more at ease. I will therefore conclude with pointing to two most important features of the higher life which stand in the same position. First, Philosophy: in spite of the arduous and unwearied efforts of men of the highest intellectual power it cannot be affirmed that the last three centuries have provided us with a philosophy of acknowledged supremacy, in relation to which all others can be set in place as historical stages superseded by a consummating system. Neither in Germany nor in France, nor in the British world, taking them separately, has this been achieved: much less has it been accomplished over Europe as a whole. And, secondly, in Christian Theology as the dogmatic exposition of the contents of the Gospel, the Reformation has caused a bisection, and has not brought uniformity even on the Protestant side of the line; while in the application to Church government and to modes of worship the situation is still more varied and diversified. If this is so for Philosophy on the one hand and for Christian Theology on the other, ought we to be surprised that variety has prevailed, and still prevails, in the region of Natural Theology, where these have a certain extent of common interest? No doubt Christian men had thought that the period in which Truth was revealed

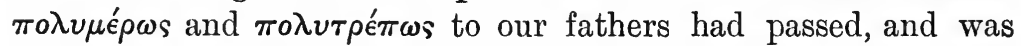
superseded in these latter days by the revelation of the Son. But it would seem as if men's hopes for uniformity had gone beyond what was promised, and beyond what Divine Wisdom judged best for the religious education of mankind. Our notions of times and days may be too small when it is God and the human race of which we are thinking, and the progress made both in the natural knowledge of God and in the apprehension of the Gospel may be all that was in the Divine Counsel, where 'days' are thousands of years. And therefore we may say that even in the natural ways of establishing religious belief a variety of method is beneficently adapted to the variety which marks our human nature: and that this is in no way an obstacle to each man's striving after God with all his heart and mind and soul and strength. 


\section{A P P ENDICES}

\section{APPENDIX A}

This recent example of Ontological Rationalism belongs to Chap. II. of Part II., and should come on p. 145

LADD, G. T.: $A$ Theory of Reality, 1897 ; 2nd edition, 1899

THE equipment which was lacking to Clarke is fully at the disposal of Professor Ladd. $\mathrm{He}$ is an Ontologist who enjoys the benefit of the Kantian Criticism and remains Ontologist still. He has not given us a Theological work, and the name of the Divine Being occurs but rarely in the volume, but it is Theology on its metaphysical side. The position maintained is, that man knows the Absolute. That there is a One and Ultimate Ground of the world, and that it is a self-conscious Spirit, 'our cognitive experience' avails to assure us.

The method is assertive Rationalism; Mr. Ladd holds that the highest categories of thought disclose attributes of Reality; the attributes are 'recognised' as being there, and as belonging to Reality. It is not that we have these categories as 'ideas' and then by a movement of inference pass to a corresponding objectivity; they inherently assert objectivity: there is no dualism, it is Realism. Man has an 'ontological consciousness' ${ }^{1}$ 'ontological speculation is an essential function of the human race' $;{ }^{2}$ 'the necessary forms of thought are ... insights into the nature of Reality.' 3

This is Dogmatism, as Kant used the term; only Mr. Ladd is working with a thoroughly revised list of categories as compared with those which Kant set himself to criticise. The older ones, e.g. Substance and Causation, are retained, with modifications suggested by recent metaphysics, fresh ones are added, and the whole scheme is reconstructed. With reference to the three Proofs, for instance, Mr. Ladd holds that it was wrong to deck them with a logical dress; there is no inference in them, it is insight: we see causation and teleology immanently in the world, it is not a regressus but a getting deeper down. Again, Mr. Ladd's view of Kant's agnostic position is, that it

P. 9.

2 P. 16 423
3 P. 27. 
was really effective against all who turn natural science into ontological speculation, but not against those who keep ontology for the realities, God, Freedom, and Immortality; and that this was what Kant was feeling after. The human mind seeks after 'the unity of an explanatory Ground,' and finds it: it recognises as the inner and ultimate truth of the world that it is 'the expression, the manifestation, the realisation of Absolute Mind.' 1

The Absolute so recognised is positive, and full: the very opposite of the Unrelated, it is the fruitful source of all relations. It is Spiriti.e. ' a Will self-active in the realisation of ideal ends' ${ }^{2}$ this is 'the innermost essence of all Reality.' It is the knowing Subject, from which issues 'the most fundamental and comprehensive's of all relations, that between the knower and what is known. It is immanent in the world, and yet it is transcendent, being Absolute; and (but less emphatically) it is the source of ethical and æsthetical relations. It may be taken, as I understand it, to include all the six attributes included in the Definition I use, with others as corollaries.

Two points where opposition will be made may be specially noted.

Mr. Ladd carefully guards against Pantheism, and is able to do so by making Transcendency fundamental : the sum total of reality which is known by man-or knowable by man-is not the Absolute, as is clearly set forth in the chapter on The Actuality of the Ideal. But it is here that the Idealist will make his objection against Mr. Ladd's endeavour to set up Realism: what can Mr. Ladd say of that part of the Absolute which is not actualised, except that it is an Idea? We may all come to terms as to the reality corresponding to those ideas which are actualised in the concrete of the universe we know; but what is that surplus which is unactualised, so far as our cognitive experience goes, except an Idea? And as we are finite, and the Absolute is infinite, is not the major part of the sphere, all of it except a mere fragment, only Idea after all ?

The other point is, that Mr. Ladd stands almost within Intellectualism, if not quite. It is true that he is sympathetic towards the ethical and æsthetical requirements of man when seeking after God, but he seems on the whole to relegate these to the sphere of what he calls 'philosophy of religion,' on a level with philosophy of art and of ethics, and to regard the fundamental problem to be one of 'knowledge.' It is true, again, that in his Theory of Knowledge he insists upon the play of Will and Feeling; cognition itself, he says, is 'quasi-ethical.'" ${ }^{4}$ But if we look at his definitions of Spirit and Mind, ${ }^{5}$ the references to Goodness and to Feeling are not explicit and prominent. He seems
${ }^{1}$ P. 521.
2 P. 409.
3501.
${ }^{4}$ P. 544.
${ }^{5}$ Pp. 409, 538. 
to regard the work of 'general metaphysic' to be to give the framework, the foundation, upon which religion (with ethics and art) are to build. But this is to take a definite side for the Intellect as the arbiter to which the fundamental problem of all is to be submitted: it is to make the relation of knower and known the fundamental relation, and to impoverish the foundation-conception of Spirit and Mind. This Mr. Ladd need not have done, and should not have done, if he meant to stand by the account he gives in some places, $^{1}$ of the Absolute as the source of all relations. In this respect his affinity is with John Caird, and an Intellectualist mark is on his solution of the problem.

Professor Ladd is one of those who have shed lustre on American Psychology: in this Metaphysical treatise he seems not quite settled as to how far he will keep close to the fulness of experience and how far he will carry the problem of Reality into a region which to many must appear 'abstract.' The underlying intention is to be comprehensive, I think; and the treatise as a whole is likely to be congenial to men of scientific habit of mind. In force of expression, and in range of knowledge, it is no unworthy vindication of Ontologism in the full light of post-Kantian philosophy and of nineteenth-century science.

${ }^{1}$ Cf. pp. 499, 501. 


\section{APPENDIX B}

\section{Howison G. H.: Ethical Theism}

A REFERENCE might have been made to the suggestion of an Ethical Theism which is sketched by Professor Howison, of the University of California.

A philosophical discussion on Theism took place before some members of the University of California in 1898, which has been printed under the title, The Conception of God (New York, 1898), the participants being Professors Royce (see chap. iii. $\S 9$ of Pt. II. of this book), Le Conte (see chap. v. § 7), Mezes, and Howison. The last named opposes the other disputants, in part, from the standpoint of Ethical Theism, and indicates with a few broad strokes what his own position is. It is not easy to disentangle the positive matter from the controversial, but there is sufficient material for seeing that $\mathrm{Mr}$. Howison holds a powerful brief for the Ethical type of Theism.

$\mathrm{He}$ is an Idealist in the sense that 'the absolute reality is mind' (p. 34), and that the necessity given by thought is not a necessity due to. ' limitation and impenetrable ignorance,' but is ' the sign of real power and genuine knowledge' (p. 102). Against his brother Idealists, especially Professor Royce, his position is that we must recognise Pluralism in the sense of there being a reality of created beings as well as a real Creator (p. 90): even an Infinite Self as 'a unity inclusive of an indefinite multitude of quasi-selves' ( $p .113$ ) will not suffice him. He is for the reality of a 'City of God,' of which finite beings are citizens; of a moral order composed of personalities; in a sense which he considers to be unprovided for by the Absolute Idealism of Hegel or of Dr. Royce.

And he holds that in the conception of the Absolute we must include Goodness at the very centre; Conscience as well as Omniscience. For man in search of the Divine Being it is moral reason which is the true guide. He maintains that Kant pointed out this path but did not himself walk in it; where he paused Mr. Howison starts, and so, instead of taking refuge in 'faith' he relies upon moral insight, and attains a belief in God which is thoroughly philosophical when 'reason' is comprehensively conceived.

Many valuable hints and happy expressions are to be found; and we look forward with confidence to a complete exposition of the doctrine here indicated rather than set forth. 


\section{APPENDIX C}

\section{ANTHROPOLOGY AND PSYCHOLOGY}

I HAVE not brought forward any Anthropologists in this section, for I have not searched that literature for the purpose of ascertaining the philosophical views of the leading workers. Anthropologists, as such, are men of science, the science of religion; they give us the result of their study of the tribes, nationalities, and races of mankind, on the religious side. But they are not called upon to philosophise upon their results; when they have presented their historical work they may stop, and decline to formulate any Theism at all. There is a probability, perhaps, that they may have been so deeply immersed in their historical researches as to be inclined at the close to say that what they have found is itself the philosophy of the matter: that is, they may be 'Social, or Sociological, Theists,' as I use the term. But there is no proper pressure upon them to take up this attitude; they may quite well be Rationalists of any type, or Empiricists of some other type than that of Social Theism. As the literature of Anthropology is so varied, and at present the science is so obviously immature, I have not examined it for the purpose of inquiring what are the philosophical views which its masters either imply in their work or express when they definitely face the philosophical problem.

A parallel remark may be made here as to Psychology. The religious side of the life of the 'Soul' may be studied by psychological method. This may be done either analytically, by investigating the mature soullife of the highest type of human being; or genetically, by tracing the growth of the soul on its religious side. But there is here, also, no reason for expecting that the man of science will take either this or that line in the philosophy of religion. At least there is no other reason than the expectation of some bias due to absorption in any pursuit, leading to exaggeration of the import of the results obtained. But the Psychologist may have had due instruction in Philosophy, and be well aware that if he does make a claim that his psychological analysis gives final answer to the problem of religious belief, he is choosing a particular form of philosophy, namely, Empiricism. I have therefore foregone the scrutiny of Psychologists who have not come forward in some definite way 
to make some claim of the Empirical kind: although I have referred to some psychologists because their results have been used by certain schools of Theism, whether the psychologists themselves made that use of them, or not.

Reference might have been made in the text to what is being done by Psychologists to reduce the opposition between Individualistic Theisms and Social Theism. There is much work being done now upon the assumption that the life of the soul is the life of an individual in society; giving and taking from what amounts to being a social-soul, so to speak.

A notable example of this is Professor J. M. Baldwin's work, Social and Ethical Interpretations in Mental Development: a Study in Social Psychology (New York, 1897 ; 2nd ed. 1899). His method is genetic ; he traces the growth of the soul, in its ealier stages, but up to the point when all the leading features have made their apppearance, including the genesis of the religious sentiment. It might be expected that these studies would furnish material for a philosophy of religion of the Social type. But its general issue both for Ethics and Religion is, I take it, on the Personal side, after all : in both, the onus of conviction is thrown on the personal self as contrasted with the social. Although the investigation has led to the denial of 'opposition between society and the individual in the matter of the essential demands of the moral and religious consciousness,' the sanction, however, in ethics "is administered exclusively by the individual Conscience: it is a personal sanction," and "the same may be said in the main of the religious life." 1

Of course Professor Baldwin is here working as a man of science; what his position as to philosophy of religion is I have not the material at hand for ascertaining. It is of interest, however, to note that this able psychologist finds actually operative in the soul-life, as he observes it, some of the thoughts on which Rationalists depend and some of the 'Feelings' on which Empiricists rely. The religious sentiment he traces to the operation of $(a)$ Feeling of Dependence, in which is involved the thought of Causation, and of Teleology (ethically employed); and (b) Feeling of Mystery, sense of the Unknown, which seems to be just the element which Mystics would expect him to find, only that Professor Baldwin expresses his in rather too negative a form for the true Mystic to be satisfied with. Taking these together, and remembering also the constant reference to the social-life of the soul, we should expect the philosophy of religion which would commend itself to Professor Baldwin to be of a richly composite type.

${ }^{1}$ Chap. x. $\$ 4$. 


\section{N D E X}

The black figures indicate the places where writers or subjects receive their principal treatment.

A bвEY, C. J., Mysticism in Eighteenth Century, 279, 280.

Abbott, E. A., 27 r.

Absolute, speculative use, see Infinite; Ethical, see Ethical Theism.

Absolute Idealism, see Transcendentalism. Essthetic, p. xvi; (the sphere of the Beautiful), included under Ethical Theism, 52; historical, 187 ; see also Knight, Bentley, Mozley, Paley, E. Caird, Tyler, Seth, Seeley, Hooker, Berkeley, John Smith, the Trinity College group, Westcott, Illingworth, Barry, Bradley.

Agnosticism, as to Theism, 94 ; historical, 400.

Alexandrian Theology, 109 ; view of Nature, 222 ; see Cambridge Platonists, Westcott, Fiske.

Anselm, his Ontological argument, 27.

Anthropology, see Appendix C.

A posteriori, meaning of, 20.

$\dot{A}$ priori, the Ontological argument, 27 ; Transcendentalism, 29 ; Clarke's Theism, 141.

Aquinas, scheme of Theism, 108 ; officially sanctioned, 105 ; his form of Cosmological argument, 21 ; canon of application of attributes to Deity, 59, 119 ; on Revelation, 400.

Argyll, I38.

Aristotle, on Consensus, 14 ; Cosmological argument, 20, 21, 27 ; Teleology and Mechanism, 26 ; application of conceptions to Supreme Being, 58 ; claimed for Theism by Stirling, 158; Hobbes on, 366 ; on Theology, 397.

Armstrong, R. A., on Martineau, 343 n., $351 \mathrm{n}$.

Arnold (M.), 227 ; on John Smith, 276 ; Cambridge Platonists, $279 \mathrm{n}$.

Arnold (T.), 285.

Attributes of Deity, the six taken as indispensable for Christian Theism, 1 ; canon of application, 58-60; see Conception, Definition.
Authority, as source of Belief, see Social Theism, 225 ; see also Balfour, Stanton, Jowett.

BACON (Francis), 402; his reform in philosophy, 106; compared with Hooker, 199 ; with Hobbes, 365.

Bacon (Roger), 417.

Baden Powell, $\mathbf{1 3 2 .}$

Baldwin, J. M., see Appendix C.

Balfour, A. J., I68; his Quasi-Transcendentalism, 46 ; use of Authority, 85 ; Saunders on, 176 ; Social Theism, 231.

Banks, J. S., on|Mr. Strong's method, 157.

Barrow, 128 ; Consensus, 225.

Barry, Bishop, 338 ; compared with Flint, 123 ; Esthetic, 193 ; Theism of Feeling, 248.

Bayle, causes of Consensus, 11 .

Beattie, 98.

Beauty, the Beautiful, see Esthetic.

Behmen, or Boehme, see Law, 280.

Belief, compared with conception, 1.

Bentley, II5.

Berkeley, 200.

Bernard, J. H., 196.

Bereridge, Ir6.

Boedder, B., example of Roman official Theism, I08; on Theism of Feeling, 246.

Bolingbroke, 2I5 ; on Cudworth, 275.

Bradley, F. H., 392 ; see general criticism of Transcendentalism, $36 s q . ;$ Royce indebted to, $165 \mathrm{n}$.

Brougham, I3I.

Brown (T.), I3I ; on Will, 75 ; on Clarke, 144.

Browne (Sir T.), 274 ; 死sthetic, 188.

Browning, 248 ; Feeling and Knowledge, 66.

Bruce, 411.

Butler, 207; statement of Ethical argument, 7 ; not Mystical, 72 ; differs from Clarke, 142; progenitor of Chalmers, 134 ; Green on Butler's Ethics, 154 ; Temple and Butler, 179, 
182 ; compared with Berkcley, 200, 206; on Feeling in Theism, 245; Newman, 264; Martineau and, 353 ; on Revelation, 401.

Burnet, I I6.

CAIRD (John), I46; and see Transcendentalism, 36 sq.; fundamental position, 7 ; his definition, 10 ; his form of Cosmological argument, 21 ; on Clarke, 143-4; Green on, 154 ; on Social factor, 232 ; on Theism of Feeling, 247 ; Revelation, 401.

Caird, Edward, 150; and see Transcendentalism, 36 sq.; his definition, 10 ; compared with Green, 155 ; on Social factor, 233.

Cambridge Platonists, 274 ; on Asthetic, 188 ; Arnold on, 229 ; Westcott, 321 ; and Lux Mundi writers, 332.

Cambridge, Trinity College, a group of writers at, 285 .

Carlyle, 301 ; Symbolism, 36.

Causality, Cansation, the argument from, see Cosmological.

Cazenove, on the Ontological argument, 139.

Chalmers, I33.

Christian Theology, in relation to Natural Religion, 2, 17, 105, 202, 299,400 ; interpretation of Nature, 49 ; neglect of Esthetic, 57, 88; relation to Theism of Will, 73,76 , $256 \mathrm{sq.;}$ relation to Intuitionalism, 97 ; to Transcendentalism, 36, 41 ; choice of Aquinas from the Schoolmen, 105; reversion from Deism, 119; relation to Mysticism, 87, 92, 273, $306,309,321,322,335$; to Theism of Feeling, 251 ; to Social Theism, 233 $s q . ;$ relation to the Deists, 369 sq.; independent of Natural Religion, see Part I. Type XIII., and Part II. Chap. XIII., and Retrospect.

Church (Dean), 332; on Æsthetic, 57, 192 ; Social factor, 237.

Clarke, R. F., I09 ; the Moral argument, $47,110$.

Clarke (Samuel), I4I ; various opinions on, 135, 141, 144; and Ontology, 28 ; and Butler, 143 ; his classification of Deists, 369 .

Clarke, W. N., I27.

Classification, principles adopted, 4; Scheme, 8.

Coleridge, 284 ; on Cambridge Platonists, 278 ; and Carlyle and Emerson, 301; De Vere and, 311.

Combined Speculative and Ethical Theism, 58 ; historical, 197 .

Composite Method, i.e. both Rational and Empirical factors, 92 ; historical, 338 ; distinguished from Personalism, 80, 92 .
Comte, on Consensus, 16 ; Social Theism, 226 ; Comtists, 226, 382.

Conception of Divine Being, see Definition ; legitimacy of predicating attributes, 58-60.

Conder, 353.

Consensus, ro ; see also Social Theism, 225 ; and see Wilkins, Berkeley, W. G. Ward, Kidd, Marshall, Liddon, Illingworth, Conder, Spencer, Jowett.

Cooke, 216.

Cosmological Argument, meaning of, $p$. xvi. 20 ; varieties of, 21 ; historical, 105; relation to Transcendentalism, 36 ; see also the Three Proofs.

Cousin, 89.

Cudworth, 275 .

Cuthbert, on Newman, 111.

DALE, 4IO; Æsthetic, $57 \mathrm{n}$.

Dante, Revelation only, 414 .

Davidson, W. L., 36I.

Definition of Supreme Being, I, Io ; various Definitions, 10, 11.

Deism, applications of the term, 369 ; relation to First Cause argument, 21, $119,182,209,222$.

Deists, the English, 368; and Consensus, 225 ; and see Herbert, Clarke, Butler, Bolingbroke, Tucker.

Deity, see Divine Being.

Delitzsch, meaning of 'Heart' in Theology, $88 \mathrm{n}$.

Demonstrative Proof, in Theism, the term, p. xvi ; a posteriori form, 20 ; historical, I05; and Retrospect.

Derham, I29; used by Paley, 130.

Descartes, his definition, 10 ; Ontological argument, 27 ; his reform in philosophy, 107 ; Stillingfleet against, 116 ; Bolingbroke against, 216 ; W. G. Ward against, 220.

Design, the argument from, see Teleology.

Desire, the argument from, 44 : see Balfour, Davidson, and Value-judgments. De Vere, A., $3 \mathbf{I}$.

Divine Being, validity of belief in, the problem of Theism, 1 ; conception of, six points in, I and Io ; various conceptions, 10.

Dorner, on the Three Proofs, 140.

Dryden, resort to Revelation, (quotation) $94,236$.

Dwight, II8.

EDwards (Jon.), 117.

Eighteenth Century, influence of Locke, 113 ; of Clarke, 144; adhesion to $a$ posteriori method, 114 ; rise of Ethical Theism, 177 ; Asthetic in, 188; against Feeling, 244; Deism in, 369; Mysticism, 279, 284; Common Sense School, 226 ; Coleridge, Sedgwick, Hare, 
against, 292 sq.; and sce Retrospect.

'Eliot, George,' 382.

Ellicott, Bishop, 308 ; his definition, 11.

Emerson, 30r.

Empiricism, p. $x v$; in Theism, 5 ; Part I. Types VI. $-X$. ; Part II. Chapters vi. -X.; welcomes Consensus, 11.

English Philosophy of Religion : British Schoolmen, 416; intellectual character prominent after Reformation, 17 ; $\dot{a}$ posteriori method, 39, 114, 119 ; preference for Teleology, 24, 26, 27 ; little affinity for Ontological argument, 27,28 ; rise of Ethical Theism, 177; neglect of Esthetic, 57, 188 ; Theism of Feeling, 65, 242 ; Theism of Will, 77, 791; Social Theism, 63, 85, 225; Mysticism, 88, 279 ; Composite Theism, 93 ; Transcendentalism, 37, 150 ; recourse to Revelation, 400 ; and see Retrospect.

Erskine, and Maurice, 298.

Ethical Theism, meaning of, p. xvi, 6, 46 ; historical, I77; distinguished from Intuitionalism, 97 ; relation to Theism of Will, 75.

Evolution; and Teleology, 25 ; and Consensus, 15; and Theism of Feeling, 66 ; and Theism, see especially Mozley, Paley, Schurman, Temple, Fiske, Le Conte, Romanes.

Fairbairn, A. M., on Butler, 210; on Newman, 267.

Fairbrother, W. H., on Green, 152.

Faith, three meanings, p. xvi; used in text in broad sense as equivalent to religious belief; see the various writers for their way of using the term.

Feeling, Theism of, 64 ; historical, 242 ; confused with Mysticism, 71, 89 ; see Value-judgments.

Final Causes, see Teleology.

Fisher, G. P., 3 II.

Fiske, J., 222.

Flint, R., I22; his definition, 11 ; on Teleology, 24 ; on Transcendentalisn, 39 ; on the Moral argument, 47 ; on Feeling, 247 ; Romanes on, 126 ; followed by Hodge, 126.

Fox (W. J.), 244.

Fraser, A. C., I83; on Transcendentalism, 40 ; on Clarke, I4I ; Saunders on, 176 ; on Berkeley, 204.

\section{Gillespie, I44.}

Gladstone, on Butler, 208, 214 ; affinity with Newman, 261.

God, see Divine Being.

'God in His World' (anonymous American volume), 249.
Goethe, stress on Esthetic, 57 ; Seeley on, 192, 357; Thirlwall on, 291; Carlyle and Emerson, 301.

Gore, C., 332, 334.

Green, I 53, $36 \mathrm{sq}$. ; form of Cosmology, 21; Mr. Strong, 157 ; Lux Mundi writers, 155 ; and see Transcendentalism.

Gwatkin, H. M., 4I3; on Deists, 371.

Hamilton, 406 n.; influence on Spencer, 388 ; on Mansel, 405.

Hare, J. C., 290 ; on Feeling, 245.

Harris, S. T., Ior.

Harrison, F., 382.

Heart, signification in religion, $82,88 \mathrm{n}$.

Hegel, his definition, 10 ; on Consensus, 16 ; Transcendental Theism, 30, 34; on the Ontological argument, 140 ; Social factor, 58, 64, 77, 78, 232; Seth on, 187 ; Mansel on, 405 ; see Transcendentalism.

Hegelians, division among, 35, 37 .

Herbert of Cherbury, 98 ; Consensus, 226 ; pioneer of Deists, 370.

Hobbes, 365 ; Clarke on, 142-3 ; Kidd's affinity with, 230 ; Theism of Feeling, 243 ; Revelation, 404.

Hodge, A., r26.

Höffiding, on Religions Feeling, 67 ; on Will, 75.

Holland, H. S., 332 ; Will in Faith, 257. Hooker, I97 ; compared with Berkeley, 202 ; with Butler, 212 ; on Revelation, 400.

Hort, 268 ; on Maurice, 300.

Howison, G. H., see Appendix B.

Hume, 374 ; his definition, 10 ; on Teleology, 405; Stirling on, 189 ; Bolingbroke on, 216 ; on Consensus, 226 ; and Mill, 377 sq.; on Revelation, 405 .

Hutcheson, I89, 54 .

Hutton, on W.J. Fox, 244 ; on Maurice, 299 ; on Mansel and Maurice, 408.

Huxley, on Hume, 376.

Hypothetical Theism, see Quasi-Transcendentalism.

IDEA OF GoD, see Conception and Definition.

Illingworth, J. R., 325 ; Cosmological argument, 21; spiritualisation of Nature, 49 ; on Feeling, 247.

Immanence, affected by form of Cosmological argument, 21 ; strongly impressed by Transcendentalism, 35 and passim; see especially Berkeley, Fiske, Le Conte, Illingworth, Seeley, Bradley.

Infinite, Infinity, (cf. Absolute): two meanings, positive and negative, p. xvi ; for positive use, see Intuitionalists, and Transcendentalists, also Clarke, Temple (ethical), Fraser, 
Hooker, Butler, W. G. Ward (ethical), Newman (ethical), Liddon, Martineau, Bradley; for negative use, see Locke, Paley, Stewart, Priestley, M. Arnold, F. Newman, Hobbes, Spencer, Mansel; hesitation about, Mozley, M'Cosh, Barry, Conder ; not provided for, W. N. Clarke, Chalmers, Argyll, Berkeley, James, Law, Westcott, Lias; rejected, Hume, Mill, Schiller.

Inge, W. R., 335, $273 \mathrm{n}$.

Intuitionalism, in Theism, meaning of, $\mathrm{p}$. xvi, I7; historical, 97 ; distinguished from Intuitivism, 89, 91, 101, 103, 104 ; Chalmers against, 134 ; $\mathrm{M}^{\prime} \mathrm{Cosh}$, 136 ; Hort, 270 ; Martineau, 346 n.

Intuitivism, or Mysticism, meaning of, p. xvi, 86 ; historical, 273 ; distinguished from Intuitionalism, 89, 91, 101, 103, 104 ; from Theism of Feeling, 72 ; confused with latter, 71, 90 n. ; E. Caird on, 153 ; see Barry, Lias, R. T. Smith, Martineau, Conder, Davidson.

JACKSON (T.), 274.

Jacobi, Coleridge and, 287 ; Hamilton, $406 \mathrm{n}$.

James, W., 253; on Hypothetical Theism, 43 ; on Will, 75.

Jevons, F. B., on Consensus, 14.

Joly, H., on Christian Mystics, 88.

Jones, H., on Browning, 248.

Jowett, 397.

KANT, his definition, 10 ; on the Ontological argument, 140 ; Cosmological, 21,22 ; Teleological, 26, 27; on the Three Proof system, 29, 155 ; Stirling on this, 159; his Transcendental method, 29, 34, 39, 178; application of attributes to the Deity, 38 ; his Categories, 43 ; his Ethical Theism, 48 , 187 ; Individualism, 63 ; on the argument from Beauty, 57, 188, 194 ; the same criticised by Kennedy, 194 ; Temple's use of, 179; Butler and Kant, 214 ; Coleridge and Kant, 285 ; Mystical element in, 313 ; E. Caird on Kant, 151; Illingworth on, 329 ; Mansel's use of, 407.

Keble, influence on Newman, 258.

Kennedy, J. H., 193.

Kidd, B., 229.

Kleutgen, authority for Patristic Theism, 108 ; used by W. G. Ward, 219.

Knight, W., ro3.

Kuilpe, O., on English Deists, 371.

LADD, G. T., see Appendix A.

Latham, H., 55.

Law (W.), 280.

Lecky, W. E. H., 176.

\section{Le Conte, 223.}

Leibnitz, his form of Cosmological argument, 21 ; Teleology and Mechanism, 26 ; Ontological argument, 27, 140 ; strengthened Rationalism, 418.

Lias, J. J., 34 I.

Liddon, 306.

Lilly, W. S., 312 ; on Extreme Mystics, 87 ; on Newman, 262.

Lindsay, J., r60; on the Three Proofs, 140.

Lock, W., Social Theism, 237.

Locke, III ; his fundamental position, 7 ; his definition, 10 ; form of Cosmological argument, 21; and Herbert, 98; his reform in philosophy, 107; no Esthetic, 188 ; and Berkeley, 200 ; Newman and, 259, 260, 263; Sedgwick against, 292 ; Deism of, 370.

Lotze, Teleology and Mechanism, 26, 328 ; Monadism, 77 ; on Personality, 162 ; on Feeling, 251, 311, 336; Monism, 336.

Luther, against Reason in Theology, 417.

Lux Mundi, volume of Essays, 322-335; influence of Green, 153.

M'Cosh, I36.

Maitland, B., 307.

Manning, on Vatican endorsement of Aquinas, 107.

Mansel, 405; on application of Attributes to Deity, 59; Maurice on, 299 ; Spencer, 388.

Marshall, H. R., 231 ; on Consensus, 14.

Martineau, 343; his definition, 11 ; form of Cosmological argument, 21 : Individualism, 62, 236; on Feeling, 246 ; on Clarke, 143; on Royce, 164 ; Upton and, 335 .

Mason, A. J., 272.

Maurice, 290, 298; on Mansel, 408.

Mechanical theory, Mechanism, and Teleology, 26, 328.

Methodism and Intuitivism, 273.

Mill (J. S.), 377 ; on Social Theism, 62 ; and Brown, 131; W. G. Ward on, 219 ; against Consensus, 226 ; resort to Feeling, 243; and Newman, 262 ; and Coleridge, 287 ; and Wordsworth, 290 ; Romanes, 334 ; and Hume, 377, 379.

Milton, 128.

Momerie, A. W., 159.

Monadism, 77, 91.

Moore (Aubrey), 322 ; his definition, 11.

Moore, H. H., 145.

Moral Theism, see Ethical Theism.

More (Henry), 275, 276.

Morell, roo.

Moule, H. C. G., Will in Faith, 257.

Mozley, 120; on Consensus, 16; on Maurice, 300 ; Barry and, 339. 
Münsterberg, H., on Will, 75.

Murphy, J. J., I02 : Conder and, 355. Mysticism, see Intuitivism; the term, 87 n. ; Christian Mystics, 87; and Theism of Feeling, $90 \mathrm{n}$.

Natural Theology, use of term, p. xv, 3 ; see Philosophy of Religion.

Neo-Platonism, see Cambridge Platonists. Newman (F. W.), 303.

Newman (J. H.), 258; fundamental position, 7 ; twenty-two predicates, 10 ; individualism, 12, 62; Personalism, 81 ; relation to official Roman Theism, 110 ; W. G. Ward on, 221 ; on Social Theism, 234; on Feeling, 246; and Francis Newman, 303, 304.

Nineteenth Century, Demonstrative Theism in, 119 ; social factor and individualism, 85 : Teleological Theism, 132 ; and see Retrospect.

Ooкнам, William of, 414, 416.

Ontological, The, argument, 27 ; historical, I39; see Clarke, Locke, Shillingfleet, Flint, J. Caird, the Schoolmen, Cudworth, Butler, W. G. Ward, Sedgwick, Liddon, Martineau, Davidson.

Origen, 314, 321.

Oswald, 98.

Oxford, Lux Mundi writers, 322-335; the 'Oxford Movement' and Social Theism, 236-8.

Paget, F., 332.

Paley, 29; praises Tucker, 117 ; Brougham on, 132 ; Sedgwick on, 292 ; Romanes on, 333.

Pantheism and Transcendentalism, 41.

Parker (Theodore), 99.

Parkinson, $134 \mathrm{n}$.

Pascal and Mysticism, 90 ; combination of 'esprit' and 'intelligence,' 93 ; and Infinity, 120 ; and Newman, 265.

Pattison, on Coleridge, 288.

Paulsen, return to dual division in Psychology, 70.

Pearson, II4; his definition, 10.

Personalism, in Theism, p. xvi, 80 ; historical, $25^{8}$; how different from Composite Type, $80,92,338$.

Pfleiderer, on Schleiermacher 70 n., 72 ; on Ritschl, 236; on the Newmans, 303 : on F. Newman, 305.

Philosophy, aim of, p. xv ; Empiricism not excluded, 6.

Philosophy of Religion, aim of, p. $\mathrm{xv}$; the term, 3 ; scope of, 1 ; and Science of Religion, 3.

Plato, Teleology, 26; see Cambridge Patonists, 274.

Plotinus, and Mysticism, 26, 87 ; see Cambridge Platonists, 274.
Pope (W. B.), 310

Practical Reason, see Ethical Theism.

Priestley, I3I.

Proofs, the Three Proofs scheme, 29, 34, 140 ; see Strong, Stirling, Butler, M. Arnold, Newman, Coleridge, W. B. Pope, Fisher, Moore, Illingworth, Davidson, Jowett.

Protestant Theology and Social Theism, 233.

QUAKERS, and Intuitivisn, 273 ; and Maurice, 298.

Quasi-Theisms, 94; examples of, Part II. Chap. XII.

Quasi-Transcendentalism, 42; historical, I65; see Berkeley, Cooke, Sedgwick, Davidson, Schiller.

RANDLES, M., I26.

Randolph, II7.

Rationalism in Theism, defined, 4 ; explained, Part I. Types I.-V.; historical, Part II. Chaps. I.-v.; retained after Reformation, 17 ; opposition to Theism of Feeling, 244.

Ray, Teleology, 128.

Reid, II8; on Æsthetic, 189 ; not Intuitionalist in Theism, 98 .

Religion of Humanity, $38 \mathrm{r}$; and Social Theism, 61; Mill, 380 .

Revelation, resort to, 94 ; historical, 400 ; Deists and, 368 ; relation to Transcendentalism, 41; see also Flint, Randles, Chalmers, M'Cosh, Tulloch, Newman, Maurice, Hare, Westcott, A. Moore, Illingworth, Hobbes; see also Christian Theology.

Robertson, 178, 285.

Roman See, official Theism, 105, 107 ; repudiates Ontology, 29 ; Newman's position, 90, 262; other Romanists, 110,129 ; W. G. Ward, 221; and Social Theism, 233 ; see Boedder, R. F. Clarke, W .G. Ward, Newman, De Vere, Lilly.

Romanes, 333.

Royce, J., I63; Bruce on, 412.

Ritschlianism, Value-judgments, $174 \mathrm{n}$., 251; Social Theism, 236; Conder, 354.

Ruskin, I90, 57 ; on Wordsworth, 289 ; Barry and, 339.

SAUNders, T. B., I75.

Schelling, and Coleridge, 287 ; Carlyle and Emerson, 301 ; Mansel, 405.

Schiller, F. C. S., 384 .

Schleiermacher, on Social factor, 70, 236 ; Mysticism, 72, 89 ; Theodore Parker, 99; Morell, 110 ; Flint against, 123 ; F. Newman and, 305.

Scholasticism, see Schoolmen. 
Schoolmen, ou Aisthetic, 54; on Ontologism, 139 ; Aquinas officially chosen, 105 ; Hooker and, 197 ; Hare on, 297 ; Bacon and, 402 ; and Revelation, 400 ; Retrospect.

Schopenhauer, on Will, 75, 298.

Schurman, J. G., I65; on Paley, 130.

Science of Religion, 3, 61 ; testimony for Intuitivism, 86; see Tyler, Bolingbroke, Westcott, the Deists.

Scottish Intuitionalists, 98, 134, 226.

Sedgwick, 290.

Seeley, 356; on Fsthetic, I9r.

Seth, A., I86 ; on Neo-Platonism, 279 ; on Bradley, 396.

Seventeenth Century, Course of Theism, 114 ; of Astheticism, 187 ; the Deists of, 369 ; and see Retrospect.

Shaftesbury, I88; on Locke, 113; and Deists, 371.

Shelley, I89.

Sidgwick, on Clarke's Ethics, 143 ; on Butler's, $213 \mathrm{n}$.

Smith, Goldwin, on Coleridge, 288.

Smith (John), 276 ; Esthetic, 187.

Smith, R. T., 342.

Social Theism, 60 ; historical, 225 ; see also Consensus, Romanes, George Eliot, Jowett.

Speculative, equivalent to Intellectual, p. XV.

Spencer, H., 387 ; use of Consensus, 13 ; application of attributes, 59 ; Fiske and, 222 ; Romanes and, 333 ; F. Harrison on, 382 ; Bradley on, 393; relation to Hamilton and Mansel, 409; compared with M. Arnold, 227, 229.

Spinoza, Ontological argument, 27 ; Clarke and, 142-3 ; Spencer and, 391.

Spiritual, meaning of, p. xvi, 82 .

Staley, V., 332.

Stanton, V. H., 238; on Newman, 234; on Maurice, 300 .

Steere, 216.

Stephen, L., on Clarke, 370 ; on Law, $280,283$.

Stewart, II8 ; on Clarke, 144.

Stillingfleet, II6; against Locke, 114; on Consensus, 225.

Stirling, J. H., I58; on the Three Proofs, 140 ; on Hume, 376.

Stout, G. F., on Will, 75.

Strong, T. B., I55; the Three Proofs, 140 ; the Social factor, 237.

Sully, J., on Will, 75.

Swete, H. B., 309 ; Will in Faith, 82, 256.

Symbolism, Berkeley's, 200 ; Carlyle's, 301 ; Westcott's, 316 ; Jowett's, 399.
TELEOLOGY, the argument, 22 ; historical, I28; Mechanism and teleology, 26, 328 ; see Murphy, Mozley, Flint, Barrow, Stirling, Schurman, Fraser, Kennedy, Fiske, Sedgwick, Romanes, Martineau, Barry, Hume, and Mill.

Temple, Archbishop, I79.

Tennyson, on Asthetic, 57.

Theism, the term, p. xv, 3 ; see Philo. sophy of Religion.

Thirlwall, 290.

Thompson (R. A.), 2 I7.

Tillotson, Bolingbroke on, 215 ; alleged Deism, 371 ; on Revelation, 401.

Transcendentalism, p. xvi; in Theism, 29 ; criticism of, 36 ; historical, I46; Balfour on, 173 ; Fraser on, 185 ; in Moore, 324; in Illingworth, 329.

Trinity College, Cambridge, group, 290.

Tucker (A.), II7; commended by Paley, 129.

Tulloch, I37 ; on Cambridge Platonists, 275, 278, 332 .

Turton, on Paley, 139 ; on Clarke, 143. Tyler, C. M., I6r.

ULRICI, 309, 311.

Upton, C. B., 335.

Utilitarianism, 78, 113, 242 ; Sedgwick and Hare against, $292 s q . ;$ Martineau leaves, 343.

VALUE-JUDGMENTS, theory of, 50, 78, 250 ; Balfour, 174 n. ; Davidson, 362. Vaughan, (R.), on Mysticism, 89, 273 n. Voysey, C., 355.

WACE, H., 412.

Ward, J., 252; spiritualisation of Nature, 49 ; Will, 75 ; Monadism, 77.

Ward (W. G.), 2 I8.

Waterland, I I6.

Watson, J., on Knowledge, $185 \mathrm{n}$.

Wesley, and W. Law, 280.

Westcott, Bishop, 3I4; fundamental position, 7 ; his definition, 11 ; on Social factor, 238; on Feeling, 247 ; compared with A. Moore, 323.

Whewell, 290.

Wilkins, II4; on Consensus, 14.

Will, Theism of, 72 ; historical, 252.

Will, in Psychology, modern insistance upon, $74 s q . ;$ applied to Theism, $252 s q$.

Wolff, on Ontology, 27, 140.

Wordsworth, 288; on Esthetic, 57 ; influence at Cambridge, 291; Carlyle and, 301 ; Emerson and, 302 ; Seeley on, 357.

Wundt, on Will, 75. 


\section{A CATALOGUE OF BOOKS} AND ANNOUNCEMENTS OF METHUEN AND COMPANY PUBLISHERS : LONDON 36 ESSEX STREET

$$
\text { W.C. }
$$

\section{CONTENTS}

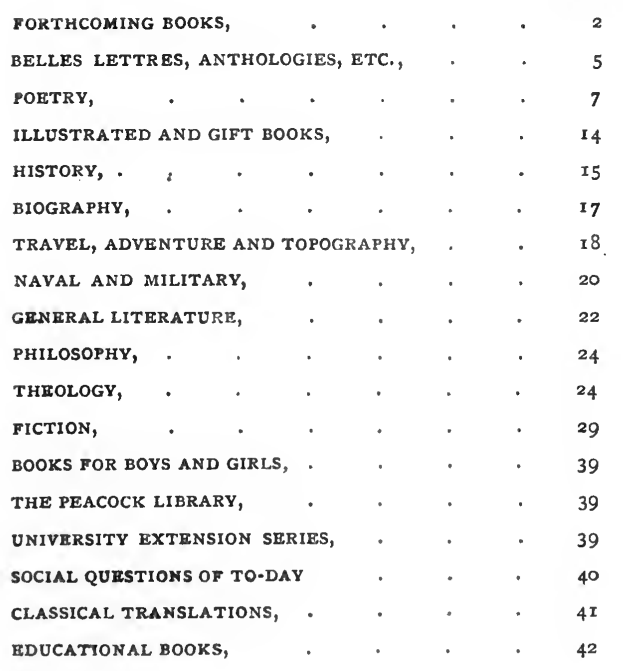

NOVEMBER I 900 


\section{MESSRS. METHUEN'S A N N O U N C M E N T S}

\section{Travel, Adventure and Topography}

THE INDIAN BORDERLAND : Being a Personal Record of Twenty Years. By Sir T. H. Holdich, K.C.I.E. Illustrated. Demy 8vo. 15s. net.

This book is a personal record of the author's connection with those military and political expeditions which, during the last twenty years, have led to the consolidation of our present position in the North-West frontier of India. It is a personal history of trans-frontier surveys and boundary demarcations, commencing with Penjdeh and ending with the Pamirs, Chitral, and Tirah.

MODERN ABYSSYNIA. By A. B. WyldE. With a Map and a Portrait. Demy 8vo. I 5 s. net.

An important and comprehensive account of Abyssinia by a traveller who knows the country intimately, and has had the privilege of the friendship of King Menelik.

\section{Revised by Commanding Officers.}

THE HISTORY OF THE BOER WAR. By F. H. E. CUNLIFFE, Fellow of All Souls' College, Oxford. With many Illustrations, Plans, and Portraits. Vol. I. Quarto. 15s. Also in Fortnightly Parts. Is. each.

The first volume of this important work is nearly ready. When complete, this book will give an elaborate and connected account of the military operations in South Africa from the declaration to the end of the present war. It must remain for some years the standard History of the War. Messrs. Methuen have been fortunate enough to secure the co-operation of many commanding officers in the revision of the various chapters.

The History is finely illustrated.

A PRisoner of WAR. By Colonel A. Schiel. Crown 8vo. 6s.

This remarkable book contains the experiences of a well-known foreign officer of the Boer Army-from 1896 to 1900 - both as a Boer officer and as a prisoner in British hands. Colonel Schiel, who was captured at Elandslaagte, was a confidential military adviser of the Transvaal Government, and his story will cause a sensation.

DARTMOOR: A Descriptive and Historical Sketch. By S. Baring Gould. With Plans and Numerous Illustrations. Crown 8vo. $6 s$.

This book attempts to give to the visitor a descriptive history of the antiquities and natural features of this district. It is profusely illustrated from paintings and from photographs. Plans are also given of the chief antiquities. The book is uniform. with the author's well-known Book of the West.

THE SIEGE OF MAFEKING. By ANGUS Hamilton. With many Illustrations. Crowen 8vo. 6s.

This is a vivid, accurate, and humorous narrative of the great siege by the wellknown Correspondent of the Times. Mr. Hamilton is not only an admirable writer, but an excellent fighter, and he took an active part in the defence of the town. His narrative of the siege is acknowledged to be far superior to any other account. 
THE PEOPLE OF CHINA. By J. W. RobertSon-SCOTT. With a Map. Crown 8vo. 3s. $6 d$.

This book of 200 pages contains a complete account of the history, races, government, religion, social life, army, commerce, and attitude to foreigners of the Chinese.

THE RELIEF OF MAFEKING. By FiLson Young. With Maps and Illustrations. Crown 8vo. $6 s$.

This book gives a spirited and vigorous account of the work accomplished by Mahon's flying column and its relief of Mafeking. It also relates the defeat of Colonel Villebois and his death. The book deals in the main with episodes in the war which have not yet been described in any work.

WITH THE BOER FORCES. By Howard C. Hillegas. With I6 Illustrations. Crown 8vo. 6 s.

This highly interesting book is a narrative of the episodes of the Boer war by a correspondent with the Boer army. Mr. Hillegas was present at many of the most exciting and most dramatic episodes of the war. He was with the force which attempted to relieve Cronje at Paardeberg, was present during a considerable part of the siege of Ladysmith, at the battle of Colenso, at the surprise of Sanna's Post. His book, written with dramatic vigour, is a spirited description of the Boer methods, of their military strength, and contains vivid character sketches of most of the Boer leaders with whom Mr. Hillegas was on terms of fairly intimate friendship. This book, though written by one who sympathises with the Boers, is permeated by a spirit of chivalry, and it contains little that can offend the most sensitive of Englishmen. It throws a flood of light on many of the episodes which have been mysterious, and explains the secrets of the many successes which the Boers have won.

\section{History and Biography}

THE LETTERS OF ROBERT LOUIS STEVENSON TO HIS FAMILY AND FRIENDS. Edited with an Introduction and Notes by Sinney Colvin. Fourth Edition. Tzoo volumes. Crown 8vo. I $2 s$.

This is a completely new edition of the famous Letters of Robert Louis Stevenson, published in 1899 .

THE LIFE AND LETTERS OF SIR JOHN EVERETT MILLAIS, President of the Royal Academy. By his son J. G. MiLlaIS. With over 300 Illustrations, of which 9 are in Photogravure. Cheaper Edition, Revised. Two volumes. Royal 8vo. 20s. net.

THE WALKERS OF SOUTHGATE : Being the Chronicles of a Cricketing Family. By W. A. Betresworth. Illustrated. Demy 8vo. 15 s.

A History OF EgYPT, From the EARLIEst Times to the Present Day. Edited by W. M. Flinders Petrie, D.C.L., LL.D., Professor of Egyptology at University College. Fully Illustrated. In Six Volumes. Crown 8vo. 6s. each.

Vol. VI. Egypt Under the Saracens. By Stanley LanePOOLE.

Illustrated and Gift Books

THE LIVELY CITY OF LIGG. By Gelett BuRGESS. With 53 Illustrations, 8 of which are coloured. Small $4 t o$. $6 s$. 
GOOP BABIES. By GELETT BuRgess. With numerous Illustrations. Small 4to. $6 s$.

THE EARLY POEMS OF ALFRED LORD TENNYSON. Edited, with Notes and an Introduction by J. CHURTON Collins, M.A. With Io Illustrations in Photogravure by W. E. F. BRITTEN. Demy 8vo. Ios. $6 d$.

This beautiful edition contains ten charming sketches by Mr. Britten, reproduced in the highest style of Photogravure.

NURSERY RHYMES. With many Coloured Pictures by F. D. BEDFORD. Super Royal 8vo. 2s. $6 d$.

'An excellent selection of the best known rhymes, with beautifully coloured pictures exquisitely printed.'-Pall Mall Gazette.

\section{Theology}

THE PHILOSOPHY OF RELIGION IN ENGLAND. By Alfred Caldecott, D.D. Demy 8vo. Ios. $6 d$.

[Handbooks of Theology.

A complete history and description of the various philosophies of religion which have been formulated during the last few centuries in England and America.

ST. PAUL'S SECOND AND THIRD EPISTLES TO THE CORINTHIANS. With Introduction, Dissertations, and Notes by James Houghton Kennedy, D.D., Assistant Lecturer in Divinity in the University of Dublin. Crown 8vo. $6 s$.

THE SOUL OF A CHRISTIAN. By F. S. GRANGer, M.A., Litt.D. Crown 8vo. $6 s$.

Professor Granger abandons the conventional method of psychology by which the individual is taken alone, and instead, he regards him as sharing in and contributing to the catholic tradition. Hence the book deals not only with the average religious life, but also with the less familiar experiences of the mystic, the visionary, and the symbolist. These experiences furnish a clue to poetic creation in its various kinds, and further, to the miracles which occur during times of religious enthusiasm.

\section{Oxford Commentaries.}

THE ACTS OF THE APOSTLES. Edited, with an Introduction and Notes, by R. B. Rackham, M.A. Demy $8 v o$.

\section{Tbe Tibrary of Devotion}

Pott 8vo. Cloth 2s.; leather 2s. 6d. net. NEW VOLUMES.

A GUIDE TO ETERNity. By Cardinal Bona. Edited with an Introduction and Notes by J. W. STANBRIDGE, B.D., late Fellow of St. John's College, Oxford.

THE PSALMS OF DAVID. With an Introduction and Notes by B. W. Randolph, D.D., Principal of the Theological College, Ely.

A devotional and practical edition of the Prayer Book version of the Psalms.

LYRA APOSTOLICA. With an Introduction by Canon SCOTT Holland, and Notes by H. C. BeEching, M.A. 


\section{Belles Lettres}

\section{The Iittle Gutoes}

Pott 8vo. Cloth, 3s.; leather, 3s. 6d. net.

NEWV VOLUMES.

WESTMINSTER ABBEY. By G. E. Troutbeck. Illustrated by F. D. BEDFORD.

SUSSEX. By F. G. BRabant, M.A. Illustrated by E. H. New.

\section{Uittle JBiograpbies}

Fcap. 8vo. Each Volume, cloth 3s. 6d.; leather, 4s. net.

Messrs. Methuen will publish shortly the first two volumes of a new series bearing the above title. Each book will contain the biography of a character famous in war, art, literature or science, and will be written by an acknowledged expert. The books will be charmingly produced and will be well illustrated. They will make delightful gift books.

THE LIFE OF DANTE ALIGHiERI. By Paget Toynbe. With 12 Illustrations.

THE LIFE OF SAVONAROLA. By E. L. Horsburgh, M.A., With Portraits and Illustrations.

\section{The Wuorks of জbakespeare}

New volumes uniform with Professor Dowden's Hamlet.

ROMEO AND JULIET. Edited by EDWARD DOWDEN, Litt.D. Demy 8vo. 3s. 6d.

KING LEAR. Edited by W. J. Craig. Demy 8vo. 3s. $6 d$.

\section{Metbuen's জtandard Tibrary}

MEMOIRS OF MY LIFE AND WRITINGS. By EDWARD GIBBON. Edited, with an Introduction and Notes by G. BIRKBECK Hill, LL. D. Crown 8vo. Gilt top. $6 s$.

THE LETTERS OF LORD CHESTERFIELD TO HIS SON. Edited, with an Introduction and Notes by C. STRACHEY and A. Calthrop. Two volumes. Crown 8vo. Gilt top. 6s. each. 


\section{Messrs. Methuen's Announcements}

\section{The Mrovels of Cbarles $\$$ ickens}

With Introductions by George Gissing, Notes by F. G. Kitton, and Illustrations.

Crown 8vo. Each Volume, cloth 3s. net, leather 4s. 6d. net.

The first volumes are :

THE PICKWICK PAPERS. With Illustrations by E. H. NEw.

Tro Volumes.

NICHOLAS NICKLEBY. With Illustrations by R. J. WILliams.

Trwo Volumes.

[Ready.

BLEAK HOUSE. With Illustrations by BeATrice Alcock. Two

Volumes.

OLIVER TWIST. With Illustrations by E. H. New. One Volume.

\section{Tbe $\mathfrak{L i t t l e} \mathfrak{L i b r a r y}$}

With Introductions, Notes, and Photogravure Frontispieces.

Pott 8vo. Each Volume, cloth is. 6d. net.; leather 2s. 6d. net.

NEW VOLUMES.

THE EARLY POEMS OF ALFRED, LORD TENNYSON. Edited by J. C. Collins, M.A.

MAUd. By Alfred, Lord Tennyson. Edited by Elizabeth WORDSWORTH.

A LITTLE BOOK OF ENGLISH LYRICS. With Notes.

PRIDE AND PREJUDICE. By JANE AUsten. Edited by

E. V. Lucas. Two Volumes.

PENDENNIS. By W. M. Thackeray. Edited by S. Gwynn. Three volumes.

EOTHEN. By A. W. KINGLAKE. With an Introduction and Notes.

LAVENGRO. By GEORGE Borrow. Edited by F. Hindes GROOME. 2 Volumes.

CRANFORD. By Mrs. Gaskell. Edited by E. V. LuCAS.

THE INFERNO OF DANTE. Translated by H. F. CARY. Edited by PAGET TOYNBEe.

JOHN HALIFAX, GENTLEMAN. By Mrs. Craik. Edited by AnNie Matheson. Troo volumes.

A LITTLE BOOK OF SCOTTISH VERSE. Arranged and Edited by T. F. HENDERSON.

A LITTLE BOOK OF ENGLISH PROSE. Arranged and Edited by Mrs. P. A. BARNeTt. 


\section{Poetry}

WRIT IN BARRACKS. By EDGaR WALlaCe. Cr. 8vo. 3s. $6 d$.

Mr. Edgar Wallace, a member of the Royal Army Medical Corps, is a follower of Mr. Kipling, and his ballads of soldier life and sufferings are well-known in South Africa. They are spirited, pathetic, and true, and at the present time they should enjoy a considerable popularity.

THE RUBAIYAT OF OMAR KHAYYAM. Translated by Edward FitzGerald, with a Commentary by H. M. Batson, and a Biography of Omar by E. D. Ross. $6 s$.

This edition of the famous book, the text of which is printed by permission of Messrs. Macmillan, is the most complete in existence. It contains FitzGerald's last text, and a very full commentary on each stanza. Professor Ross, who is an admirable Persian scholar, contributes a biography, containing many new, valuable, and interesting facts.

\section{Scientific and Educational}

THE CAPTIVI OF PLAUTUS. Edited, with an Introduction, Textual Notes, and a Commentary, by W. M. Lindsay, Fellow of Jesus College, Oxford. Demy 8vo. IOs. 6 d. net.

For this edition all the important Mss. have been re-collated. An appendix deals with the accentual element in early Latin verse. The Commentary is very full.

THE CONSTRUCTION OF LARGE INDUCTION COILS. By A. T. HARe, M.A. With numerous Diagrams. Demy 8vo. 6 s.

THE SCIENCE OF HYGIENE. By W. C. C. PAKes, Guy's Hospital. With many illustrations. Demy 8vo. I5s.

THE PRINCIPLES OF MAGNETISM AND ELECTRICITY: An Elementary Text-Book. By P. L. Gray, B. Sc., formerly Lecturer on Physics in Mason University College, Birmingham. With numerous diagrams, Crown 8vo. 3s. 6d.

LACE-MAKING IN THE MIDLANDS, PAST AND PRESENT. By C. C. Channer and M. E. RoberTs. With 16 full-page Illustrations. Crown 8vo. 2s. $6 d$.

AGRICULTURAL ZOOLOGY. By Dr. J. Ritzema Bos. Translated by J. R. Ainsworth Davis, M.A. With an Introduction by Eleanor A. ORMEROD, F.E.S. With 155 Illustrations. Crown 8vo. 3s. $6 d$.

A SOUTH AFRICAN ARITHMETIC. By Henry Hill, B.A., Assistant Master at Worcester School, Cape Colony. Crown 8vo. 3s. $6 d$.

This book has been specially written for use in South African schools.

A GERMAN COMMERCIAL READER. By S. BALLY, M.A. Crown 8vo. 2s.

[Methuen's Commercial Series. 


\section{Fiction}

THE MASTer CHRistian. By Marie Corelli. Crown 8vo. 6 s.

QUISANTE. By Anthony Hope. Crown 8vo. 6s.

A MASTER OF CRAFT. By W. W. JACOBS, Author of 'Many Cargoes.' With 12 Illustrations by W. OWEN. Crown 8vo. 6s.

THE GATEless BARRIER. By Lucas Malet, Author 'The Wages of Sin.' Crown 8vo. 6s.

CUNNING MURRELL. By ARThur Morrison, Author of 'A Child of the Jago,' etc. Crown 8vo. $6 s$.

FOR BRITAIN'S SOLDIERS : Stories for the War Fund. By Rudyard Kipling and Others. Edited by C. J. Cutcliffe Hyne. Crown 8vo. 6s.

A volume of stories, the proceeds of which will be given to the War Fund. Among the contributors are:-Rudyard Kipling, Sir W. Besant, S. R. Crockett, A. E. W. Mason, Max Pemberton, H. G. Wells, C. J. C. Hyne, Mrs. Croker.

THE FoOTSTEPS OF A THRONE. By Max Pemberton. Crown 8vo. 6s.

SONS OF THE MORNING. By Eden Phillpots, Author of 'The Children of the Mist.' With a frontispiece. Crown 8vo. 6s.

THE SOFT SIDE. By HeNry James, Author of 'What Maisie Knew.' Crown 8vo. 6s.

TONGUES OF CONSCIENCE. By RoBert Hichens, Author of 'Flames.' Crown 8vo. 6s.

THE CONQUEST OF LONDON. By DOROThEa GERARD, Author of 'Lady Baby.' Crown 8vo. 6s.

WOUNDS IN THE RAIN : A Collection of Stories relating to the Spanish-American War of 1898 . By STEPHen Crane, Author of 'The Red Badge of Courage.' Crown 8vo. 6s.

WINEFRED. By S. BARING GoUld, Author of 'Mehalah.' With 8 Illustrations by EDGaR Bundy. Crown 8vo. 6s.

THE STRONG ARM. By ROBErt BARR, Author of 'The Countess Tekla.' Illustrated. Crown 8vo. 6s.

THE SEEN AND THE UNSEEN. By Richard Marsh. Author of 'The Beetle,' 'Marvels and Mysteries,' etc. Crown 8vo. 6s. 


\section{Messrs. Methuen's Announcements}

SERVANTS OF Sin. By J. Bloundelle Burton, Author

'The Clash of Arms.' Crown 8vo. 6s.

PATH AND GOAL. By AdA Cambridge. Crown 8vo. 6s. ELMSLIE'S DRAG-NET. By E. H. Strain. Crown 8vo. $6 s$. A FOREST OFFICER. By Mrs. Penny. Crozen 8vo. $6 s$.

A story of jungle life in India.

FitZjames. By Lilian Street. Crozen 8vo. 3s.6d.

\section{The Movelist}

A monthly series of novels by popular authors at Sixpence. Each Number is as long as the average Six Shilling Novel. Numbers I. to XII. are now ready :-

XiII. THE POMP OF THE LAVIlettes. Gilbert Parker.

XIV. A MAN OF MARK.

Anthony Hope.

XV. THE CARISSIMA.

LuCas MaLeT.

XVI. THE LADY'S WALK.

Mrs. Oliphant.

XVII. DERRICK VAUGHAN.

EDNa Lyall.

[November.

\section{SDetbuen's জixpenny Library}

A New Series of Copyright Books.

I. THE MATABELE CAMPAigN. Maj.-General BAden-Powell.

II. THE DOWNFALL OF PREMPEH.

Do.

III. MY DaNish SWEetheart. W. Clark Russell.

IV. IN THE ROAR OF THE SEA. S. BARING GOULD.

V. PEGGY OF THE BARTONS. B. M. CROKER.

VI. BADEN-POWELL OF MAFEKING : a Biography. J. S. FletCHER.

[November.

VII. ROBERTS OF PRETORIA. J. S. Fletcher. [December. 
A CATAlOGUE OF

\section{MessRs. MethuEN'S}

\section{P U B L I C A T I O N S}

\section{Poetry}

Rudyard Kipling. BARRACK-ROOM BALLADS. By RUdYARD Kipling. 68th Thousand. Crown 8vo. 6s. Leather, 6s. net.

' Mr. Kipling's verse is strong, vivid, full of character. ... Unnistakeable genius rings in every line.'-Times.

'The ballads teem with imaginalion, they palpitate with emotion. We read them with laughter and tears; the metres throb in our pulses, the cunningly ordered words tingle with life; and if this be not poetry, what is?'-Pall Mall Gazette.

Rudyard kipling. THE SEVEN SEAS. By RUDYARD KIPLING. 57th Thousand. Cr. 8vo. Buckram, gilt top. 6s. Leather, 6s. net.

'The Empire has found a singer; it is no depreciation of the songs to say that statesmen may have, one way or other, to take account of them.'-Manchester Guardian.

'Animated through and through with indubitable genius.'-Daily Telegraph.

" Q." POEMS AND BALLADS. By "Q." Crown 8vo. 3s. 6d.
"Q." GREEN BAYS : Verses and Parodies. By "Q." Second Edition. Crown 8vo. 3s. 6 d.

E. Mackay. A SONG OF THE SEA. By ERIC MACKAY. Second Edition. Fcap. 8vo. $5^{\text {s. }}$

H. Ibsen. BRAND. A Drama by HENRIK IBSEN. Translated by William Wilson. Third Edition. Crown 8vo. 3s. $6 d$.

A. D. Godley. LYRA FRIVOLA. By A. D. Godley, M.A., Fellow of Magdalen College, Oxford. Third Edition. Pott 8vo. 2s. 6 d.

'Combines a pretty wit with remarkably neat versification. ... Every one will wish there was more of it.'-Times.

A. D. Godley. VERSES TO ORDER. By A. D. Godley. Crown 8vo. 2s. 6d. net.

'A capital specimen of light academic poetry.'-St. James's Gazette.

J. G. Cordery. THE ODYSSEY OF HOMER. A Translation by J. G. CoRDERy. Crown 8vo. 7s. $6 d$. 


\section{Belles Lettres, Anthologies, etc.}

R. L. Stevenson. VAILIMA LETTERS. By RoBERT LOUIS STEVENSON. With an Etched Portrait by William Strang. Second Edition. Crown 8vo. Buckram. 6s.

'A fascinating book.'-Standard.

'Unique in Literature.'-Daily Chronicle.

G. Wyndham. THE POEMS OF WIL. LIAM SHAKESPEARE. Edited with an Introduction and Notes by George Wyndham, M.P. Demy 8vo. Buckram, gilt top. Ios. $6 d$.

This edition contains the 'Venus,' 'Lucrece,' and Sonnets, and is prefaced with an elaborate introduction of over $140 \mathrm{pp}$.

'We have no hesitation in describing $\mathrm{Mr}$. George Wyndham's introduction as a masterly piece of criticism, and all who love our Elizabethan literature will find a very garden of delight in it.'-Spectator.

w. E. Henley. ENGLISH LYRICS. Selected and Edited by W. E. Henley. Crown 8vo. Gilt top. 3s. $6 d$.

'It is a body of choice and lovely poetry.'Birmingham Gazette.

Henley and Whibley. A BOOK OF ENGLISH PROSE. Collected by W. E. HENLEY and CHARLES WhiBley. Crown 8vo. Buckram, gilt top. $6 s$.

H. C. Beeching. LYRA SACRA : An Anthology of Sacred Verse. Edited by H. C. BeEching, M.A. Crown 8vo. Buckram. 6s.

- A charming selection, which maintains a lofty standard of excellence.'-Times.

“Q." THE GOLDEN POMP. A Procession of English Lyrics. Arranged by A. T. QUIller Couch. Crown 8vo. Buckram. 6s.

W. B. Yeats. AN ANTHOLOGY OF IRISH VERSE. Edited by W. B. YEATS. Revised and Enlarged Edition. Crown 8vo. $3^{\text {s. } 6 d .}$

'An attractive and catholic selection.'Times.

G. W. Steerens. MONOLOGUES OF THE DEAD. By G. W. STEEVENS. Foolscap 8vo. $3 s .6 d$.
W. II. Dixon. A PRIMER OF TENNYSON. By W. M. DrXoN, M.A. Cr. 8vo. 2s. 6 d.

'Much sound and well-expressed criticism. The bibliography is a boon.'-Speaker.

W. A. Craigie. A PRIMER OF BURNS. By W. A. CRAIGIE. Crown 8vo. 2s. 6d.

'A valuable addition to the literature of the poet.'--Times.

L. Magnus. A PRIMER OF WORDSWORTH. By LAURIE MAGNUS. Crown 8vo. 2s. 6d.

'A valuable contribution to Wordsworthian literature.'-Literature.

sterne. THE LIFE AND OPINIONS OF TRISTRAM SHANDY. By LAWRENCE STERne. With an Introduction by CHARLES WHIBLEY, and a Portrait. 2 vols. 7 s.

Congreve. THE COMEDIES OF WILLIAM CONGREVE. With an Introduction by G. S. STREeT, and a Portrait. 2 vols. $7 s$.

Morier. THE ADVENTURES OF HAJJI BABA OF ISPAHAN. By JAMES MORIER. With an Introduction by E. G. BROWNE, M.A. and a Portrait. 2 vols. $7 s$.

Walton. THE LIVES OF DONNE, WO'TTON, HOOKER, HERBERT AND SANDERSON. By IZAAK WALTON. With an Introduction by VERNON BLACKBURN, and a Portrait. $3 s .6 d$.

Johnson. THE LIVES OF THE ENGLISH POETS. By SAMUEL JoHNSON, LL.D. With an Introauction by J. H. MILLAR, and a Portrait. 3 vols, ros. $6 d$.

Burns. THE POEMS OF ROBER'T BURNS. Edited by ANDREW LANG and W. A. Craigie. With Portrait. Second Edition. Demy 8vo, gilt top. $6 s$.

'Among editions in one volume, this will take the place of authority.'-Times. 
F. Langbridge. BALLADS OF THE BRAVE; Poems of Chivalry, Enterprise, Courage, and Constancy. Edited by Rev. F. LANGBRIDGE.
Second Edition. Cr. 8vo. 3s. $6 d$. School Edition. 2s. 6 d.

'The book is full of splendid things.'World.

\section{Metbuen's $\mathfrak{F t a n d}$ ard $\mathfrak{L}$ ibrary}

Dante. LA COMMEDIA DI DANTE ALIGHIERI. The Italian Text edited by PAGET TOYNBEE, M.A. Crown 8vo. 6s.

'A carefully-revised text, printed with beautiful clearness.'-Glasgow Herald.

Gibbon. THE DECLINE AND FALL OF THE ROMAN EMPIRE. By Edward Gibbon. A New Edition, Edited with Notes, Appendices, and Maps, by J. B. BURY, LL.D., Fellow of Trinity College, Dublin. In Seven Volumes. Demy 8vo. Gilt top. 8s. 6d. each. Also Cr. 8vo. 6s. each.

'The time has certainly arrived for a new edition of Gibbon's great work. . . . Professor Bury is the right man to undertake this task. His learning is amazing, both in extent and accuracy. The book is issued in a handy form, and at a moderate price, and it is admirably printed.'-Times.

'At last there is an adequate modern edition of Gibbon. ... The best edition the nineteenth century could produce.Manchester Guardian.

'A great piece of editing.'-Academy.

'The greatest of English, perhaps of all, historians has never been presented to the public in a more convenient and attractive form. No higher praise can be bestowed upon Professor Bury than to say, as may be said with trutb, that he is worthy of being ranked with Guizot and Milman.'-Daily Nezus.

c. G. Crump. THE HISTORY OF THE LIFE OF THOMAS ELL.
WOOD. Edited by C. G. CRUMP, M.A. Crown 8vo. 6s.

This edition is the only one which contains the complete book as originally published. It contains a long Introduction and many Footnotes.

“ "The History of Thomas Ellwood " holds a high place among the masterpieces of autobiography, and we know few books that better deserve reprinting. Moreover, Mr. C. G. Crump's new edition is accurate and convenient, and we com. mend it ungrudgingly to all those who love sound and vigorous English.'

-Daily Mail.

Tennyson. THE EARLY POEMS OF ALFRED, LORD TENNYSON, Edited, with Notes and an Introduction by J. CHuRTON Collins, M.A. Crown 8vo. $6 \mathrm{~s}$.

An elaborate edition of the celebrated volume which was published in its final and definitive form in 1853 . This edition contains a long Introduction and copious Notes, textual and explanatory. It also contains in an Appendix all the Poems which Tennyson afterwards omitted.

' $\mathrm{Mr}$. Collins is almost an ideal editor of Tennyson. His qualities as a critic are an exact and accurate scholarship, and a literary judgment, which has been trained and polished by the closest study of classics both ancient and modern. Mr. Collins' introduction is a thoroughly sound and sane appreciation of the merits and demerits of 'Tennyson.'Literature.

\section{The ruorks of Ibakespeare}

\section{General Editor, EDWARD Dowden, Litt. D.}

MESSRS. METHUEN have in preparation an Edition of Shakespeare in single Plays. Each play will be edited with a full Introduction, Textual Notes, and a Commentary at the foot of the page.

The first volume is :

HAMLET. Edited by EDWARD

Dowden. Demy 8vo. 3s. 6 d.

'An admirable edition.... A comely volume, admirably printed and produced, and containing all that a student of "Hamlet" need require."-Speaker.

'Fully up to the level of recent scholarship, both English and German.-Academy. 


\section{Messrs. Methuen's Catalogue}

\section{The Thovels of Charles Dickens}

Crown 8vo. Each Volume, cloth 3s. net; leather 4s. 6d. net.

Messrs. METHUEN have in preparation an edition of those novels of Charles Dickens which have now passed out of copyright. Mr. George Gissing, whose critical study of Dickens is both sympathetic and acute, has written an Introduction to each of the books, and a very attractive feature of this edition will be the illustrations of the old houses, inns, and buildings, which Dickens described, and which have now in many instances disappeared under the touch of modern civilisation. Another valuable feature will be a series of topographical and general notes to each book by Mr. F. G. Kitton. The books will be produced with the greatest care as to printing, paper and binding.

The first volumes are:

THE PICKWICK PAPERS. With Illustrations by E. H. NEw. Two Volumes.

'As pleasant a copy as any one could desire. The notes add much to the value of the edition, and Mr. New's illustrations are also historical. The volumes promise well for the success of the edition.'-Scotsman.

\section{Tbe $\mathfrak{I}$ ittle $\mathfrak{L}$ tbrary}

'The volumes are compact in size, printed on thin but good paper in clear type, prettily and at the same time strongly bound, and altogether good to look upon and handle.'-Outlook.

Pott 8vo. Each Volume, cloth Is. 6d. net, leather 2s. 6d. net.

Messrs. Methuen intend to produce a series of small books under the above title, containing some of the famous books in English and other literatures, in the domains of fiction, poetry, and belles lettres. The series will also contain several volumes of selections in prose and verse.

The books will be edited with the most sympathetic and scholarly care. Each one will contain an Introduction which will give (I) a short biography of the author, (2) a critical estimate of the book. Where they are necessary, short notes will be added at the foot of the page.

Each book will have a portrait or frontispiece in photogravure, and the volumes will be produced with great care in a style uniform with that of 'The Library of Devotion.'

The first volumes are :

VANITY FAIR. By W. M. THACKERAY. With an Introduction by $\mathrm{S}$. GwYNN. Illustrated by G. P. JACOMB HoOD. Three Volumes.

'Delightful little volumes.'-Publishers' Circular.

THE PRINCESS. By ALFRED, LORD TENNYSON. Edited by ElizABETH WORDSWORTH. Illustrated by W. E. F. BRITTEN.

' Just what a pocket edition should be. Miss Wordsworth contributes an accept. able introduction, as well as notes which one is equally glad to get.'-Guardian.
IN MEMORIAM. By ALFRED, LORD TENNYSON. Edited, with an Introduction and Notes, by H. C. BEECHING, M.A.

'An exquisite little volume, which will be gladly welcomed.'-Glasgow Herald.

'The introduction, analysis, and notes by the Rev. H. C. Beeching are all of the sound literary quality that was to be expected.'-Guardian.

'The footnotes are scholarly, interesting, and not super-abundant.'-Standard.

'It is difficult to conceive a more attractive edition.'-St. James's Gazette. 


\section{The Iittle Guides}

\section{Pott 8vo, cloth 3 s. ; leather, $3 s .6 d$. net.}

OXFORD AND ITS COLLEGES.

By J. Wells, M.A., Fellow and Tutor of Wadham College. Illustrated by E. H. NEw. Third Edition.

'An admirable and accurate little treatise, attractively illustrated.'-World.

'A luminous and tasteful little volume.'Daily Chronicle.

CAMBRIDGE AND ITS COLLEGES. By A. HAMILTON THOMPSON. Illustrated by E. H. NEW.

'It is brightly written and learned, and is just such a book as a cultured visitor needs.'-Scotsman.
SHAKESPEARE'S COUNTRY. By B. C. WindLE, F.R.S., M.A. Illustrated by E. H. NEw. Second Edition.

' Mr. Windle is thoroughly conversant with his subject, and the work is exceedingly well done. The drawings, by Mr. Edmund $\mathrm{H}$. New, add much to the attractiveness of the volume.'-Scotsman.

' One of the most charming guide books. Both for the library and as a travelling companion the book is equally choice and serviceable.'-Academy.

'A guide book of the best kind, which takes rank as literature.'-Guardian.

\section{Illustrated and Gift Books}

Phil May. THE PHIL MAY ALBUM. 4to. 6 s.

'There is a laugh in each drawing.'Standard.

A. H. Milne. ULYSSES; OR, DE ROUGEMONT OH TROY. Described and depicted by A.H. MILNE. Small quarto. 3s. 6d.

'Clever, droll, smart.'-Guardian.

Edmund Selous. TOMMY SMITH'S ANIMALS. By Edmund Selous. Illustrated by G. W. ORD. Fcap. 8vo. 2s. $6 d$.

A little book designed to teach children respect and reverence for animals.

'A quaint, fascinating little book: a nursery classic.'-A thenaum.

s. Baring Gould. THE CROCK OF GOLD. Fairy Stories told by $\mathrm{S}$. BARING Gould. Crown 8vo. $6 s$.

'Twelve delightful fairy tales.'-Punch.

M. L. Gwynn. A BIRTHDAY BOOK. Arranged and Edited by M. L. GWynn. Deiny 8vo. 12s. 6d.

This is a birthday-book of exceptional dignity, and the extracts have been chosen with particular care.

John Bunyan. THE PILGRIM'S PROGRESS. By JOHN BUNYAN. Edited, with an Introduction, by C. H.
FirTh, M.A. With 39 Illustrations by R. ANNing Bell. Crozen 8vo. 6s. "The best "Pilgrim's Progress."'-

Educational Times.

F. D. Bedford. NURSERY RHYMES. With many Coloured Pictures by $\mathrm{F}$. D. BEDFORD. Super Royal 8vo. 5 s.

s. Baring Gould. A BOOK OF FAIRY TALES retold by S. BARING GouLD. With numerous Illustrations and Initial Letters by ARTHUR J. Gaskin. Second Edition. Cr. 8vo. Buckram. 6s.

s. Baring Gould. OLD ENGLISH FAIRY TALES. Collected and edited by S. BARING Gould. With Numerous Illustrations by F. D. BEDFORD. Second Edition. Cr. 8vo. Buckram. $6 s$.

'A charming volume.'-Guardian.

s. Baring Gould. A BOOK OF NURSERY SONGS AND RHYMES. Edited by S. BARING Gould, and Illustrated by the Birmingham Art School. Buckram, gilt top. Crown 8vo. 6s.

H. C. Beeching. A BOOK OF CHRISTMAS VERSE. Edited by H. C. BEECHING, M.A., and Illustrated by Walter Crane. Cr. 8vo, gilt top. 3 s. $6 d$. 


\section{History}

Flinders Petrie. A HISTORY OF EGYPT, FROM THE EARLIEST TIMES TO THE PRESENT DAY. Edited by W. M. Flinders Petrie, D.C.L., LL.D., Professor of Egyptology at University College. Fully Illustrated. In Six Volumes. Cr. 8vo. 6s. each.

VOL. I. PREHISTORIC TIMES to XVIth Dynasty. W. M. F. Petrie. Fourth Edition.

VOL. II. THE XVIITH AND XVIIITH Dynasties. W. M. F. Petrie. Third Edition.

Vol. IV. THE EgYPT OF THE Ptolemies. J. P. Mahaffy.

Vol. V. ROMAN EgYPT. J. G. Milne.

'A history written in the spirit of scientific precision so worthily represented by Dr. Petrie and his school cannot but promote sound and accurate study, and supply a vacant place in the English literature of Egyptology.'-Times.

Flinders Petrie. RELIGION AND CONSCIENCE IN ANCIENT EGYPT. By W. M. Flinders PETRIE, D.C.L., LL.D. Fully Illustrated. Crown 8vo. 2s. $6 d$.

- The lectures will afford a fund of valuable information for students of ancient ethics.'-Manchester Guardian.

Flinders Petrie. SYRIA AND EGYPT, FROM THE TELL EL AMARNA TABLETS. By W. M. Flinders Petrie, D.C.L., LL.D. Crown 8vo. 2s. 6d.

'A marvellous record. The addition made to our knowledge is nothing short of amazing.'-Times.

Flinders Petrie. EGYPTIAN TALES. Edited by W. M. Flinders PETRIE. Illustrated by TRISTRAM ELLIS. In Two Volumes. Cr. 8vo. 3s. 6d. each.

'Invaluable as a picture of life in Palestine and Egypt.'-Daily News.
Flinders Petrie. EGYPTIAN DECORATIVE ART. By W. M. FLINDERS PETRIE. With I20 Illustrations. Cr. 8vo. 3s. $6 d$.

'In these lectures he displays rare skill in elucidating the development of decorative art in Egypt.'-Times.

c. W. Oman. A HISTORY OF THE ART OF WAR. Vol. II. : The Middle Ages, from the Fourth to the Fourteenth Century. By C. W. OMAN, M.A., Fellow of All Souls', Oxford. Illustrated. Demy 8vo. 2xs.

' The whole art of war in its historic evolution has never been treated on such an ample and comprehensive scale, and we question if any recent contribution to the exact history of the world has possessed more enduring value.'-Daily Chronicle.

S. Baring Gould. THE TRAGEDY OF THE CAESARS. With numerous Illustrations from Busts, Gems, Cameos, etc. By S. BARING Gould. Fourth Edition. Royal 8vo. I5s.

'A most splendid and fascinating book on a subject of undying interest. The great feature of the book is the use the author has made of the existing portraits of the Caesars and the admirable critical subtlety he has exhibited in dealing with this line of research. It is brilliantly written, and the illustrations are supplied on a scale of profuse magnificence.' -Dailv Chronicle.

F. W. Maitland. CANON LAW IN ENGLAND. By F. W. MAITLAND, LL.D., Downing Professor of the Laws of England in the University of Cambridge. Royal 8vo. 7s. 6d.

'Professor Maitland has put students of English law under a fresh debt. I'hese essays are landmarks in the study of the history of Canon Law.'-Times. 
H. de B. Gibbins. INDUSTRY IN ENGLAND : HISTORICAL OUT. LINES. By H. DE B. GIBBINS, Litt.D., M.A. With 5 Maps. Second Edition. Demy 8vo. ros. $6 d$.

H. E. Egerton. A HISTORY OF BRITISH COLONIAL POLICY. By H. E. Egerton, M.A. Demy 8vo. I2s. $6 d$.

' It is a good book, distinguished by accuracy in detail, clear arrangement of facts, and a broad grasp of principles.'Manchester Guardian.

Albert Sorel. THE EASTERN QUESTION IN THE EIGHTEENTH CENTURY. By ALBERT SOREL. Translated by F. C. BRAMWELL, M.A. Cr. $8 v o$. 3s. $6 d$.

c. H. Grinling. A HISTORY OF THE GREAT NORTHERN RAILWAY, I845-95. By C. H. GRINLING. With Illustrations. Demy 8vo. ros. $6 d$.

' Mr. Grinling has done for a Railway what Macaulay did for English History.'The Engineer.

W. Sterry. ANNALS OF ETON COLLEGE. By W. Sterry, M.A. With numerous Illustrations. Demy 8vo. 7s. 6d.

'A treasury of quaint and interesting reading. Mr. Sterry has by his skill and vivacity given these records new life.'Academy.

G. W.Fisher. ANNALS OF SHREWSBURY SCHOOL. By G. W.

MFisher, M.A. With numerous Illustrations. Demy 8vo. ros. $6 d$.

'This careful, erudite book.'-Daily Chronicle.

'A book of which Old Salopians are sure to be proud.'-Globe.

J. Sargeaunt. ANNALS OF WESTMINSTER SCHOOL. By J. SARGEAUNT, M.A. With numerous Illustrations. Demy 8vo. 7s. $6 d$.
A. Clark. THE COLLEGES OF OXFORD: Their History and their Traditions. Edited by A. CLARK, M.A., Fellow of Lincoln College. 8vo. r2s. $6 d$.

'A work which will be appealed to for many years as the standard book.'Athenaum.

T. M. Taylor. A CONSTITUTIONAL AND POLITICAL HISTORY OF ROME. By T. M. TAYLOR, M.A., Fellow of Gonville and Caius College, Cambridge. Crown 8vo. 7s. 6 d.

'We fully recognise the value of this carefully written work, and admire especially the fairness and sobriety of his judgment and the human interest with which he has inspired a subject which in some hands becomes a mere series of cold abstractions. It is a work that will be stimulating to the student of Roman history.'-A thenaum.

J. Wells. A SHORT HISTORY OF ROME. By J. WELls, M.A., Fellow and Tutor of Wadham Coll., Oxford. Third Edition. With 3 Maps. Crown 8vo. 3 s. $6 d$.

This book is intended for the Middle and Upper Forms of Public Schools and for Pass Students at the Universities. It contains copious Tables, etc.

'An original work written on an original plan, and with uncommon freshness and vigour.'-Speaker.

o. Browning. A SHORT HISTORY OF MEDIAEAL ITALY, A.D. I250-1530. By OSCAR BROWNING, Fellow and Tutor of King's College, Cambridge. In Two Volumes. Cr. 8vo. 5s. each.

VOL. I. I250-I409.-Guelphs and Ghibellines.

VoL. II. I409-I530.-The Age of the Condottieri.

O'Grady. THE STORY OF IRELAND. By STANDish O'Grady, Author of 'Finn and his Companions. Crown 8vo. 2s. $6 d$. 


\title{
Messrs. Methuen's Catalogue
}

\section{JBgzantíle Terts}

\author{
Edited by J. B. Bury, M.A.
}

ZACHARIAH OF MITYLENE. Translated into English by F. J. HAMILTON, D.D., and E. W. BROOKS. Demy 8vo. 12s. 6d. net.

EVAGRIUS. Edited by Professor
Léon Parmentier and M. Bidez. Demy 8vo. ros. 6d. net.

THE HISTORY OF PSELLUS By C. Sathas. Demy 8vo. r. $5^{s}$. net.

\section{Biography}

R. L. Stevenson. THE LETTERS OF ROBERT LOUIS STEVENSON TO HIS FAMILY AND FRIENDS. Selected and Edited, with Notes and Introductions, by Sidney Colvin. Third Edition. Demy 8vo, 2 vols., 25s. net.

'Irresistible in their raciness, their variety, their animation .... of extraordinary fascination. A delightful inheritance, the truest record of a "richly compounded spirit" that the literature of our time has preserved.'-Times.

'There are few books so interesting, so moving, and so valuable as this collection of letters. One can only commend people to read and re-read the book. The volumes are beautiful, and Mr. Colvin's part of the work could not have been better done, his introduction is a masterpiece.'-Spectator.

J. G. Millais. THE LIFE AND LETTERS OF SIR JOHN EVERETT MILLAIS, President of the Royal Academy. By his Son, J. G. Millais. With 3 I9 Illustrations, of which 9 are in Photogravure. Second Edition. 2 vols, Royal 8vo, 32s. net.

'The illustrations make the book delightful to handle or to read. The eye lingers lovingly upon the beautiful pictures.'Standard.

This charming book is a gold mine of good things.'-Daily Nerus.
'This splendid work.'-World.

' Of such absorbing interest is it, of such completeness in scope and beauty. Special tribute must be paid to the extraordinary completeness of the illus. trations.'-Graphic.

s. Baring Gould. THE LIFE OF NAPOLEON BONAPARTE. By S. BARING Gould. With over $45^{\circ}$ Illustrations in the Text and 12 Photogravure Plates. Large quarto. Gilt top. $3^{6 s .}$

'The main feature of this gorgeous volume is its great wealth of beautiful photo. gravures and finely-executed wood engravings, constituting a complete pictorial chronicle of Napoleon I.'s personal history from the days of his early childhood at Ajaccio to the date of his second interment.'-Daily Telegraph.

P. H. Colomb. MEMOIRS OF ADMIRAL SIR A. COOPER KEY. By Admiral P. H. Colomb. With a Portrait. Demy 8vo. I6s.

Morris Fuller. THE LIFE AND WRITINGS OF JOHN DAVENANT, D.D. (r57r-r64r), Bishop of Salisbury. By MORRIS FULLER, B.D. Demy 8vo. Ios. 6d.

J. M. Rigg. ST. ANSELM OF CANTERBURY: A CHAPTER IN THE History OF RELigion. By J. M. Rigg. Demy 8vo. 7s. 6d. 
F. W. Joyce. THE LIFE OF SIR FREDERICK GORE OUSELEY. By F. W. JOYCE, M.A. 7s. $6 d$.

W. G. Collingwood. THE LIFE OF JOHN RUSKIN. By W. G. Collingwood, M.A. With Portraits, and $\mathrm{I}_{3}$ Drawings by $\mathrm{Mr}$. Ruskin. Second Edition. 2 vols. 8vo. 32s. Cheap Edition. Crown 8vo. $6 s$.

c. Waldstein. JOHN RUSKIN, By Charles Waldstein, M.A. With a Photogravure Portrait, Post 8vo. $5 \mathrm{~s}$.

A. M. F. Darmesteter, THE LIFE OF ERNEST RENAN. By
Madame Darmesteter. With Portrait. Second Edition. Cr. 8vo. 6s.

W. H. Hutton. THE LIFE OF SIR THOMAS MORE. By W. H. Hutton, M.A. With Portraits. Second Edition. Cr. 8vo. $5^{5}$.

'The book lays good claim to high rank among our biographies. It is excellently, even lovingly, written.'-Scotsman.

s. Baring Gould. THE VICAR OF MORWENSTOW: A Biography. By S. BARING Gould, M.A. A new and Revised Edition. With Portrait. Crozon 8vo. 3s. $6 d$.

A completely new edition of the well known biography of R. S. Hawker.

\section{Travel, Adventure and Topography}

Sven Hedin. THROUGH ASIA. By Sven Hedin, Gold Medallist of the Royal Geographical Society. With 300 Illustrations from Sketches and Photographs by the Author, and Maps. 2 vols. Royal 8vo. 20s. net.

'One of the greatest books of the kind issued during the century. It is im. possible to give an adequate idea of the richness of the contents of this book, nor of its abounding attractions as a story of travel unsurpassed in geographical and human interest. Much of it is a revelation. Altogether the work is one which in solidity, novelty, and interest must take a first rank among publications of its class.' - Times.

F. H. Skrine and E. D. Ross. THE HEART OF ASIA. By F. $\mathrm{H}$. SkRINE and E. D. Ross. With Maps and many Illustrations by Verestchagin. Large Crozon $8 v 0$. Ios. $6 d$. net.

'This volume will form a landmark in our knowledge of Central Asia. ... Illuminating and convincing. - Times.

R. E. Peary. NORTHWARD OVER THE GREAT ICE. By R. E. PEARY, Gold Medallist of the Royal Geographical Society. With over 800 Illustrations. 2 vols. Royal 8vo. 32s. net.

' $\mathrm{His}$ book will take its place among the permanent literature of Arctic exploration.' -Times.

E. A. FitzGerald. THE HIGHEST ANDES. By E. A. FitzGerald. With 2 Maps, 5I Illustrations, I3 of which are in Photogravure, and a Panorama. Royal 8vo, 3os. net. Also a Small Edition on Hand-made Paper, limited to 50 Copies, 4 to, $£ 5,5^{\text {s. }}$

'The record of the first ascent of the highest mountain yet conquered by mortal man. A volume which will continue to be the classic book of travel on this region of the Andes.'-Daily Chronicle. 


\section{Messrs. Methuen's Catalogue}

F. W. Christian. THE CAROLINE ISLANDS. By F. W. CHRISTIAN. With many Illustrations and Maps. Demy 8vo. I2s. 6d. net.

'A real contribution to our knowledge of the peoples and islands of Micronesia, as well as fascinating as a narrative of travels and adventure.'-Scotsman.

H. H. Johnston. BRITISH CENTRAL AFRICA. By Sir H. H. Johnston, K.C.B. With nearly Two Hundred Illustrations, and Six Maps. Second Edition. Crown 4 to. I8s, net.

'A fascinating book, written with equal skill and charm-the work at once of a literary artist and of a man of action who is singularly wise, brave, and experienced. It abounds in admirable sketches.'-Westminster Gazette.

L. Decle. THREE YEARS IN SAVAGE AFRICA. By LIONEL DECLE. With roo Illustrations and 5 Maps. Second Edition. Demy 8vo. Ios. 6d. net.

'Its bright pages give a better general survey of Africa from the Cape to the Equator than any single volume that has yet been published.'-Times.

A. Hulme Beaman TWENTY YEARS IN THE NEAR EAST. By A. Hulme Beaman. Demy 8vo. With Portrait. ros. $6 d$.

Henri of Orleans. FROM TONKIN TO INDIA. By PRINCE HENRI OF ORLEANS. Translated by HAMLEY BENT, M.A. With roo Illustrations and a Map. Cr. 4 to, gilt top. $25 \mathrm{~s}$.

s. I. Hinde. THE FALL OF THE CONGO ARABS. By S. L. HINDE. With Plans, etc. Demy 8vo. 12s. 6d.

A. St. H. Gibbons. EXPLORATION AND HUNTING IN CENTRAL AFRICA. By Major A. ST. H. GiBBONS. With full-page Illustrations by C. WHYMPER, and Mans. Demy 8vo. $\mathrm{I}_{5}$.
Fraser. ROUND THE WORLD ON A WHEEL. By JOHN FOSTER Fraser. With IOO Illustrations. Crown 8vo. 6s.

'A classic of cycling, graphic and witty.'Yorkshire Post.

R. L. Jefferson. A NEW RIDE TO KHIVA. By R. L. JEFFERSON. Illustrated. Crown 8vo, $6 s$.

The account of an adventurous ride on a bicycle through Russia and the deserts of Asia to Khiva.

'An exceptionally fascinating book of travel.'-Pall Mall Gazette.

J. K. Trotter. THE NIGER SOURCES. By Colonel J. K. TrotTER, R.A. With a Map and Illustrations. Crown $8 v 0$. 5 s.

Michael Davitt. LIFE AND PROGRESS IN AUSTRALASIA. By Michael DAVITT, M.P. 500 pp. With 2 Maps. Crown 8vo. 6s.

W. J. Galloway. ADVANCED AUSTRALIA. By William J. GALLOWAY, M.P. Crown 8vo. 3s. $6 d$.

' $T$ his is an unusally thorough and informative little work.'-Morning Post.

w. Crooke. THE NORTH. WESTERN PROVINCES OF INDIA: THEIR ETHNOLOGY AND Administration. By W. Crooke. With Maps and Illustrations. Demy 8vo. Ios. $6 d$.

A. Boisragon. THE BENIN MASSACRE. By CAPTAIN BOISRAGON. Second Edition. Cr. 8vo. 3s. 6d.

'If the story had been written four hundred years ago it would be read to-day as an English classic.'-Scotsman.

H. S. Cowper. THE HILL OF THE GRACES : or, THE GREAT STONE TEMPLES OF TRIPOLI. By $\mathrm{H}$. S. Cowper, F.S.A. With Maps, Plans, and 75 Illustrations. Demy $8 v 0$. Ios.6d. 
W. B. Worsfold. SOUTH AFRICA. By W. B. WORSFOLD, M.A. With a Map. Second Edition. Cr. 8vo. 6s.

'A monumental work compressed into a very moderate compass.'-World.

Katherine and Gilbert Macquoid. IN PARIS. By KATHERINE and GILBER'T MACQUOID. Illustrated by Thomas R. MACquoId, R.I. With 2 maps. Crozon 8vo. Is.

'A useful little guide, judiciously supplied with information.'-A thenaum.
A. H. Keane. THE BOER STATES : A History and Description of the Transvaal and the Orange Free State. By A. H. Keane, M.A. With Map. Crown 8vo. 6s.

'A work of clear aims and thorough execution.'-Academy.

'A compact and very trustworthy account of the Boers and their surroundings.' - Morning Post.

\section{Naval and Military}

G. S. Robertson. CHITRAL: The Story of a Minor Siege. By Sir G. S. Robertson, K.C.S.I. With numerous Illustrations, Mapand Plans. Second Edition. Demy 8vo. ros.6d.

'It is difficult to imagine the kind of person who could read this brilliant book without emotion. The story remains immortala testimony imperishable. We are face to face with a great book.'-Illustrated London News.

'A book which the Elizabethans would have thought wonderful. More thrilling, more piquant, and more human than any novel.'- Nerucastle Chronicle.

'As fascinating as Sir Walter Scott's best fiction.'-Daily Telegraph.

R. S. S. Baden-Powell. THE DOWNFALL OF PREMPEH. A Diary of Life in Ashanti, I895. By Maj.-Gen. BADEN-POWELL. With 2 I Illustrations and a Map. Cheaper Edition. Large Crown 8vo. $6 s$.

R. S. S. Baden-Powell. THE MATABELE CAMPAIGN, r896. By Maj.Gen. BADEN-POWELL. With nearly roo Illustrations. Cheaper Edition. Large Crown 8vo. $6 s$.

J. B. Atkins. THE RELIEF OF LADYSMITH. By JOHN BLACK Atkins. With I6 Plans and Illustrations. Second Edition. Crown 8vo. $6 s$.

This book contains a full narrative by an eye-witness of General Buller's at tempts, and of his final success. The story is of absorbing interest, and is the only com. plete account which has appeared.

'The mantle of Archibald Forbes and G. W. Steevens has assuredly fallen upon Mr. Atkins, who unites a singularly graphic style to an equa ly rare faculty of vision. In his pages -we realise the meaning of a modern campaign with the greatest sense of actuality. His pages are written with a sustained charm of diction and ease of manner that are no less remarkable than the sincerity and vigour of the matter which they set before us.'-World.

'Mr. Atkins has a genius for the painting of war which entitles him already to be ranked with Forbes and Steevens, and encourages us to hope that he may one day rise to the level of Napier and Kinglake.'-Pall Mall Gazette.

- It is the record told with insight and sympathy of a great conflict. It is as readable as a novel, and it bears the imprint of truth.'-Morning Leader.

H. W. Nevinson. LADYSMITH : The Diary of a Siege. By H. W. NEvinsoN. With 16 Illustrations and a Plan. Second Edition. Crown 8vo. 6s.

This book contains a complete diary of the Siege of Ladysmith, and is a most vivid and picturesque narrative:

' There is no exaggeration here, no straining after effect. But there is the truest realism, the impression of things as they are seen, set forth in well-chosen words and well-balanced phrases, with a mea- 


\section{Messrs. Methuen's Catalogue}

sured self-restraint that marks the true artist. Mr. Nevinson is to be congratulated on the excellent work that he has done.'-Daily Chronicle.

'Of the many able and fascinating chroniclers of the sad and splendid story, Mr. Nevinson is among the ablest and most fascinating.'-Pall Mall Gazette.

E. H. Alderson. WITH THE MOUNTED INFANTRY AND THE MASHONALAND FIELD FORCE, I896. By Lieut.-Colonel ALdERSON. With numerous Illustrations and Plans. Demy 8vo. Ios. $6 d$.

Seymour Vandeleur. CAMPAIGN. ING ON THE UPPER NILE AND NIGER. By Lieut. SEymour VANDELEUR. With an Introduction by Sir G. Goldie, K.C.M.G. With 4 Maps, Illustrations, and Plans. Large Crown 8vo. Ios. 6 .

Iord Fincastle. A FRONTIER CAMPAIGN. By Viscount FINCASTle, V.C., and Lieut. P. C. ELLIOTT-LOCKHART. With a Map and 16 Illustrations. Second Edition. Crozun 8vo. 6s.

E. N. Bennett. THE DOWNFALL OF THE DERVISHES: A Sketch of the Sudan Campaign of 1898. By E. N. BENNETT, Fellow of Hertford College. With a Photogravure Portrait of Lord Kitchener. Third Edition. Crown 8vo. 3s. 6d.

W. Kinnaird Rose. WITH THE GREEKS IN THESSALY. By W. KINNAIRD ROSE. With Illustrations. Crown 8vo. $6 s$.

G. W. Steevens. NAVAL POLICY : By G. W. Steevens. Demy 8vo. $6 s$.

This book is a description of the British and other more important navies of the world, with a sketch of the lines on which our naval policy might possibly be developed.

D. Hannay. A SHORT HISTORY OF THE ROYAL NAVY, FROM
EARly Times to the Present Day. By David HANNAY. Illustrated. 2 Vols. Demy 8vo. 7s. 6d. each. Vol. I., I200-I688.

'We read it from cover to cover at a sitting, and those who go to it for a lively and brisk picture of the past, with all its faults and its grandeur, will not be disappointed. The historian is endowed with literary skill and style.'-Standard.

c. Cooper King. THE STORY OF THEBRITISH ARMY. By Colonel CoOper King. Illustrated. Demy 8vo. 7s. 6d.

'An authoritative and accurate story of England's military progress.'-Daily Mail.

R. Southey. ENGLISH SEAMEN (Howard, Clifford, Hawkins, Drake, Cavendish). By Robert Southey. Edited, with an Introduction, by Davil, Hannay. Second Edition. Crozon 8vo. 6s.

'A brave, inspiriting book.'-Black and White.

W. Clark Russell. THE LIFE OF ADMIRAL LORD COLLINGWOOD. By W. Clark Russell. With Illustrations by F. BRANGWYN. Third Edition. Crown 8vo. 6s.

'A book which we should like to see in the hands of every boy in the country. St. James's Gazette.

E. I. S. Horsburgh. WATERLOO: A Narrative and Criticism. By E. L. S. Horsburgh, B. A. With Plans. Second Edition. Crown 8vo. 5s.

'A brilliant essay-simple, sound, and thorough.'-Daily Chronicle.

H. B. George. BATTLES OF ENGLISH HISTORY. By H. B. George, M.A., Fellow of New College, Oxford. With numerous Plans. Third Edition. Cr. 8vo. 6s.

- Mr. George has undertaken a very useful task - that of making military affairs intelligible and instructive to non-military readers - and has executed it with a large measure of success.'-Times. 


\section{General Literature}

s. Baring Gould. THE BOOK OF THE WEST. By S. BARING GOULD. With numerous Illustrations. Two volumes. Vol. 1. Devon. Vol. II. Cornwall. Crown 8vo. 6s. each.

'They are very attractive little volumes, they have numerous very pretty and interesting pictures, the story is fresh and bracing as the air of Dartmoor, and the legend weird as twilight over Dozmare Pool, and they give us a very good idea of this enchanting and beautiful district.'-Guardian.

'A narrative full of picturesque incident, personal interest, and literary charm.'Leeds Mercury.

s. Baring Gould. OLD COUNTRY LIFE. By S. BARING Gould. With Sixty-seven Illustrations. Large $\mathrm{Cr}$. 8vo. Fifth Edition. $6 s$.

" Old Country Life," as healthy wholesome reading, full of breezy life and movement, full of quaint stories vigorously told, will not be excelled by any book to be published throughout the year. Sound, hearty, and English to the core.' -World.

s. Baring Gould. AN OLD ENGLISH HOME. By S. BARING Gould. With numerous Plans and Illustrations. Crown 8vo. $6 s$.

'The chapters are delightfully fresh, very informing, and lightened by many a good story. A delightful fireside companion." -St. James's Gazette.

s. Baring Gould. HISTORIC ODDITIES AND STRANGE EVENTS. By S. BARING Gould. Fourth Edition. Crown 8vo. 6s.

s. Baring Gould. FREAKS OF FANATICISM. By S. BARING Gould. Third Edition. Cr. 8vo. 6s.

s. Baring Gould. A GARLAND OF COUNTRY SONG: English Folk Songs with their Traditional Melodies. Collected and arranged by S. BARING Gould and H. F. SHEPPARD. Demy 4 to. $6 s$.
S. Baring Gould. SONGS OF THE WEST: Traditional Ballads and Songs of the West of England, with their Melodies. Collected by $\mathrm{S}$. BARING Gould, M.A., and H. F. Sheppard, M.A. In 4 Parts. Parts I., II., III., 3s. each. PartIV., $5^{5}$. In one Vol., French morocco, $\mathbf{x}_{5}$.

'A rich collection of humour, pathos, grace, and poetic fancy.'-Saturday Review.

s. Baring Gould. YORKSHIRE ODDITIES AND STRANGE EVENTS. By S. BARING GOULD. Fourth Edition. Crown 8vo. 6s.

s. Baring Gould. STRANGE SURVIVALS AND SUPERSTITIONS. By S. BARING Gould. Cr. 8vo. Second Edition. 6s.

s. Baring Gould. THE DESERTS OF SOUTHERN FRANCE. By S. BARING Gould, 2 vols. Demy 8vo. 32s.

Cotton Minchin. OLD HARROW DAYS. By J. G. COTTON Minchin. C.r. 8vo. Second Edition. 5s.

W. E. Gladstone. THE SPEECHES OF THE RT. HON. W. E. GLADSTONE, M.P. Edited by A. W. HutTon, M.A., and H. J. Cohen, M.A. With Portraits, Demy 8vo. Vols. $I X$. and $X$, , 12s. $6 d$. each.

J. E. Marr. THE SCIENTIFIC STUDY OF SCENERY. By J. E. MARR, F.R.S., Fellow of St. John's College, Cambridge. Illustrated. Crown 8vo. $6 s$.

An elementary treatise on geomorphology -the study of the earth's outward forms. It is for the use of students of physical geography and geology, and will also be highly interesting to the general reader.

'A fascinating book, a real fairy tale.'Pall Mall Gazette.

'Mr. Marr is distinctly to be congratulated on the general result of his work. He has produced a volume, moderate in size 


\section{Messrs. Methuen's Catalogue}

and readable in style, which will be acceptable alike to the student of geology and geography, and to the tourist.' -Athenaum.

' Can be read with pleasure alike by the expert and the general reader.' -Manchester Guardian.

M. N. Oxford. A HANDBOOK OF NURSING. By M. N. OXFORD, of Guy's Hospital. Crown 8vo. 3s. 6d.

This is a complete guide to the science and art of nursing, containing copious instruction both general and particular.

'The most useful work of the kind that we have seen. A most valuable and practical manual.'-Manchester Guardian.

E. V. Zenker. ANARCHISM. By E. V. Zenker. Demy 8vo. 7s. 6d.

'Herr Zenker has succeeded in producing a careful and critical history of the growth of Anarchist theory.

A. Silva White. THE EXPANSION OF EGYPT: A Political and Historical Survey. By A. Silva WhiTE. With four Special Maps. Demy 8vo. I5s. net.

'This is emphatically the best account of Egypt as it is under English control that has been published for many years.'Spectator.

Peter Beckford. THOUGHTS ON HUNTING. By PETER BECKFORD. Edited by J. OTHO PAGET, and Illustrated by G. H. JALLAND. Demy 8vo. IOs. 6d.

"Beckford's "Thoughts on Hunting" has long been a classic with sportsmen, and the present edition will go far to make it a favourite with lovers of literature.'Speaker.

E. B. Michell. THE ART AND PRACTICE OF HAWKING. By E. B. MICHELl. With 3 Photogravures by G. E. LODGE, and other Illustrations. Demy 8vo. Ios. $6 d$.

A complete description of the Hawks, Falcons, and Eagles used in ancient and modern times, with directions for their training and treatment. It is not only a historical account, but a complete practical guide.

'A book that will help and delight the expert.'-Scotsman.
'Just after the hearts of all enthusiasts.'Daily Telegraph.

'No book is more full and authorative than this handsome treatise.

$$
\text { -Morning Leader. }
$$

H. G. Hutchinson. THE GOLFING PILGRIM. By HORACE G. Hutchinson. Crown 8vo. $6 s$.

'Without this book the golfer's library will be incomplete.'-Pall Mall Gazette.

J. Wells. OXFORD AND OXFORD LIFE. By Members of the University. Edited by J. Wells, M.A., Fellow and Tutor of Wadham College. Third Edition. $\mathrm{Cr} .8 v 0$. 3s. $6 \mathrm{~d}$.

'We congratulate Mr. Wells on the production of a readable and intelligent account of Oxford as it is at the present time, written by persons who are possessed of a close acquaintance with the system and life of the University.'Athenaum.

C. G. Robertson. VOCES ACADEMICA. By C. GRANT Robertson, M.A., Fellow of All Souls', Oxford. With a Frontispiece. Pott 8vo. $3^{s} .6 d$. 'Decidedly clever and amusing.'Athenaum.

Rosemary Cotes. DANTE'S GARDEN. By Rosemary Cotes. With a Frontispiece. Second Edition. Fcp. 8vo. 2s. 6d. Leather, 3s. 6d. net.

'A charming collection of legends of the 1 flowers mentioned by Dante. - Academy.

lifford Harrison. READING AND READERS. By CLIFFORD HARRISON. Fcp. 8vo. 2s. 6 d.

'An extremely sensible little book.'-Manchester Guardian.

L. Whibley. GREEK OLIGARCH. IES: THEIR ORGANISATION AND CHARACTER. BY L. Whibley, M.A., Fellow of Pembroke College, Cambridge. Crown $8 v 0.6 s$.

L. L. Price. ECONOMIC SCIENCE AND PRACTICE. By L. L. PRICE, M.A., Fellow of Oriel College, Oxford. Crown 8vo. 6s. 
J. S. Shedlock. THE PIANOFORTE SONATA : Its Origin and Development. By J. S. SHEdLOCK. Crown 8vo. $5^{s}$.

' This work should be in the possession of every musician and amateur. A concise and lucid history and a very valuable work for reference.'-A thencum.

A. Hulme Beaman. PONS ASINORUM; OR, A GUIDE TO BRIDGE. By A. Hulme BeAMAN. Fcap 8vo. 2s.

A practical guide, with many specimen games, to the new game of Bridge.

E. M. Bowden. THE EXAMPLE OF BUDDHA: Being Quotations from
Buddhist Literature for each Day in the Year. Compiled by E. M. BowDEN. Third Edition. r6mo. 2s. $6 d$.

F. Ware. EDUCATIONAL REFORM. By FABIAN WARE, M.A, Crown 8vo. 2s. $6 d$.

An attempt by an expert to forecast the action and influence of the New Second. ary Education Act, with suggestions for useful developments.

'Mr. Ware's book may be warmly commended to all who have at heart the desire for the intellectual prosperity of the British race.'-Morning Post.

'Any one who really wants to know how education stands to-day should read it.' - Literature.

\section{Philosophy}

L. T. Hobhouse. THE THEORY OF KNOWLEDGE. By L. T. HOBHouse, Fellow of C.C.C., Oxford. Demy 8vo. 2Is.

- The most important contribution to English philosophy since the publication of Mr. Bradley's "Appearance and Reality." '-Glasgonu Herald.

W. H. Fairbrother. THE PHILOSOPHY OF T. H. GREEN. By W. H. Fairbrother, M.A. Second Edition. Cr. 8vo. 3s. 6d.
'In every way an admirable book.'Glasgon Herald.

F. W. Bussell. THE SCHOOL OF PLATO. By F. W. Busseli, D.D., Fellow of Brasenose College, Oxford. Demy 8vo. ros. 6d.

F. S. Granger. THE WORSHIP OF 'THE ROMANS. By F. S. Granger, M.A., Litt.D. Crown 8vo. 6s.

\section{Theology}

W. R. Inge. CHRISTIAN MYSTICISM. The Bampton Lectures for r899. By W. R. INGE, M.A., Fellow and Tutor of Hertford College, Oxford. Demy 8vo. r2s. 6d. net.

A complete survey of the subject from St. John and St. Paul to modern times, covering the Christian Platonists, Augus. tine, the Devotional Mystics, the Mediæval Mystics, and the Nature Mystics and Symbolists, including Böhme and Vordsworth.

'It is fully worthy of the best traditions connected with the Bampton Lectureship.'-Record.

S. R. Driver. SERMONS ON SUBJECTS CONNECTED WITH THE OLD TESTAMENT. By $\mathrm{S}$. R. DRIVER, D.D., Canon of Christ Church, Regius Professor of Hebrew in the University of Oxford. Cr. 8vo. $6 s$.

'A welcome companion to the author's famous "Introduction."-Guardian.

T. K. Cheyne. FOUNDERS OF OLD TESTAMENT CRITICISM. By T. K. Cheyne, D.D., Oriel Professor at Oxford. Large Crown 8vo. 7s. $6 d$.

A historical sketch of O. T. Criticism.

Walter Lock. ST. PAUL, THE MASTER-BUILDER. By WALTER Lock, D.D., Warden of Keble College. Crown 8vo. 3s. $6 d$.

'The essence of the Pauline teaching is condensed into little more than a hun. dred pages, yet no point of importance 


\section{Messrs. Methuen's Catalogue}

is overlooked. We gladly recommend the lectures to all who wish to read with understanding.'-Guardian.

H. Rashdall. DOCTRINE AND DEVELOPMENT. By HASTINGS RASHDALL, M.A., Fellow and Tutor of New College, Oxford. Cr. 8vo. 6s.

'A very interesting attempt to restate some of the principaldoctrines of Christianity. in which Mr. Rashdall appears to us to have achieved a high measure of success. $\mathrm{He}$ is often learned, almost always sym. pathetic, and always singularly lucid.' Manchester Guardian.

H. H. Henson. APOSTOLIC CHRISTIANITY: As Illustrated by the Epistles of St. Paul to the Corinthians. By H. H. Henson, M.A., Fellow of All Souls', Oxford. Cr. 8vo. 6s.

H. H. Henson. DISCIPLINE AND LAW. By H. Hensley Henson, B.D., Fellow of All Souls', Cxford. Fcap. 8vo. 2s, 6d.

H. H. Henson. LIGHT AND LEAVEN : HISTORICAL AND Social Sermons. By H. H. Henson, M.A. Crown 8vo. 6s.

Bennett and Adeney. A BIBLICAL INTRODUCTION. By W. H. BENNETT, M.A., and W. F. ADENEY, M.A. Crown 8vo. $7 s .6 d$.

'It makes available to the ordinary reader the best scholarship of the day in the field of Biblical introduction. We know of no book which comes into competition with it.'-Manchester Guardian.

W. H. Bennett. A PRIMER OF THE BIBLE. By W. H. BENNETT. Second Edition. Cr. 8vo. 2s. 6d.

' The work of an honest, fearless, and sound critic, and an excellent guide in a small compass to the books of the Bible.'Manchester Guardian.

C. F. G. Masterman. TENNYSON AS A RELIGIOUS TEACHER. By C. F. G. Masterman. Crown 8vo. $6 s$.

'A thoughtful and penetrating appreciation, full of interest and suggestion. - World.

William Harrison. CLOVELLY SERMONS. By WILLIAM HARRI-
SON, M.A., late Rector of Clovelly; With a Preface by 'LUCAS MALET.' Cr. 8vo. 3s. 6d.

Cecilia Robinson. THE MINISTRY OF DEACONESSES. By Deaconness Cecilia Robinson., With an Introduction by the Lord Bishop of Winchester. Cr. 8vo. 3s. $6 \mathrm{~d}$.

'A learned and interesting book.'-Scots. man.

E. B. Layard. RELIGION IN BOYHOOD. Notes on the Religious Training of Boys. By E. B. LAYARD, M.A. I8mo. Is.

T. Herbert Bindley. THE OECU. MENICAL DOCUMENTS OF THE FAITH. Edited with Introductions and Notes by T. HERBERT Bindley, B.D., Merton College, Oxford. Crown 8vo. 6s.

A historical account of the Creeds.

'Mr. Bindley has done his work in a fashion which calls for our warmest gratitude. The introductions, though brief, are always direct and to the point; the notes are learned and full, and serve admirably to elucidate the many difficulties of the text.'-Guardian.

H. I. Barron. TEXTS FOR SERMONS ON VARIOUS OCCASIONS AND SUBJECTS. Compiled and Arranged by H. M. BARRON, B.A., of Wadham College, Oxford, with a Preface by Canon SCOTT Holland. Crown 8vo. $3 s$. $6 d$.

W. Yorke Fausset. THE $D E$ CATECHIZANDIS RUDIBUS OF ST. AUGUSTINE. Edited, with Introduction, Notes, etc., by W. Yorke Fausset, M.A. Cr. 8vo. 3s. $6 d$.

F. Weston. THE HOLY SACRIFICE. By F. Weston, M.A., Curate of St. Matthew's, Westminster. Pott 8vo. 6d. net.

A Kempis. THE IMITATION OF CHRIST. By Thomas À Kempis. With an Introduction by DEAN FARRAR, Illustrated by C. M. GERE. Second Edition. Fcap. 8vo. 3s. 6d. Padded morocco, 5 s.

'Amongst all the innumerable English 
editions of the "Imitation," there can have been few which were prettier than this one, printed in strong and handsome type, with all the glory of red initials. Glasgow Herald.

J. Keble. THE CHRISTIAN YEAR. By JOHN KEBLE. With an Intro- duction and Notes by W. Lock, D.D., Warden of Keble College. Illustrated by R. ANNING BELL. Second Edition. Fcap. 8vo. $3^{s .6 d}$. Padded morocco. 5 s.

' The present edition is annotated with all the care and insight to be expected from Mr. Lock.'-Guardian.

\section{Orforo Commentaries}

General Editor, Walter Lock, D.D., Warden of Keble College, Dean Ireland's Professor of Exegesis in the University of Oxford.

THE BOOK OF JOB. Edited, with Introduction and Notes, by E. C. S. Gibson, D.D., Vicar of Leeds. Demy 8vo. 6s.

'The publishers are to be congratulated on the start the series has made.'-Times.

'It is in his patient, lucid, interest-sustaining explanations that Dr. Gibson is at his best.'-Literature.

' We can hardly imagine a more useful book to place in the hands of an intelligent layman, or cleric, who desires to eluci- date some of the difficulties presented in the Book of Job.'-Church Times.

' The work is marked by clearness, light. ness of touch, strong common sense, and thorough critical fairness.

'Dr. Gibson's work is worthy of a high degree of appreciation. To the busy worker and the intelligent student the commentary will be a real boon; and it will, if we are not mistaken, be much in demand. The Introduction is almost a model of concise, straightforward, prefatory remarks on the subject treated.'Athenaum.

\section{Thandbooks of Tbeology}

General Editor, A. Robertson, D.D., Principal of King's College, London.

THE XXXIX. ARTICLES OF THE CHURCH OF ENGLAND. Edited with an Introduction by $\mathrm{E}$. C. S. Gibson, D.D., Vicar of Leeds, late Principal of Wells Theological College. Second and Cheaper Edition in One Volume. Demy 8vo. 12s. 6d.

'We welcome with the utmost satisfaction a new, cheaper, and more convenient edition of Dr. Gibson's book. It was greatly wanted. Dr. Gibson has given theological students just what they want, and we should like to think that it was in the hands of every candidate for orders.'-Guardian.

AN INTRODUCTION TO THE HISTORY OF RELIGION. By F. B. Jevons, M.A., Litt.D., Principal of Bishop Hatfield's Hall. Demy 8vo. Ios. $6 d$.

'The merit of this book lies in the penetration, the singular acuteness and force of the author's judgment. $\mathrm{He}$ is at once critical and luminous, at once just and suggestive. A comprehensive and thorough book.'-Birmingham Post.

THE DOCTRINE OF THE INCARNATION. By R. L. OTTLEY, M.A., late fellow of Magdalen College, Oxon., and Principal of Pusey House. In Two Volumes. Demy 8vo. I5s.

'A clear and remarkably full account of the main currents of speculation. Scholarly precision ... genuine tolerance . . intense interest in his subject-are $\dot{\mathrm{Mr}}$. Ottley's merits. - Guardian.

AN INTRODUCTION TO THE HISTORY OF THE CREEDS. By A. E. BURN, B.D., Examining Chaplain to the Bishop of Lichfield. Demy 8vo. IOs. 6d.

' This book may be expected to hold its place as an authority on its subject. Spectator. 


\section{Messrs. Methuen's Catalogue}

\section{Tbe Cburchmall's Iibrary}

General Editor, J. H. BURN, B.D., Examining Chaplain to the Bishop of Aberdeen.

THE BEGINNINGS OF ENGLISH CHRISTIANITY. By W. E. CoLLINS, M.A. With Map. Cr. 8vo. 3s. $6 d$.

'An excellent example of thorough and fresh historical work.'-Guardian.

SOME NEW TESTAMENT PROBLEMS. By ARTHUR WRIGHT, M.A., Fellow of Queen's College, Cambridge. Crown 8vo. 6s.

THE KINGDOM OF HEAVEN HERE AND HEREAFTER. By CANON WinTERBotham, M.A., B.Sc., LL.B. Cr. $8 v 0.3 s .6 d$.

'A most able book, at once exceedingly thoughtful and richly suggestive.'-Glas. gow Herald.

\section{The Cburchman's JBible}

General Editor, J. H. BURN, B.D.

Messrs. METHUEN are issuing a series of expositions upon most of the books of the Bible. The volumes will be practical and devotional, and the text of the authorised version is explained in sections, which will correspond as far as possible with the Church Lectionary.

THE EPISTLE OF ST. 'AUL TO THE GALATIANS. Explained by A. W. RoBINSON, Vicar of All Hallows, Barking. Fcap. 8vo. is. $6 d$. net.

'The most attractive, sensible, and instructive manual for people at large, which we have ever seen.'- Church Gazette.

ECCLESIASTES. Explained by A. W. Streane, D.D. Fcap. 8vo. Is. 6 d. net.

\section{Tbe Iibrary of Devotion}

'Scholarly, suggestive, and particularly interesting.'-Bookman.

THE EPISTLE OF PAUL THE APOSTLE TO THE PHILIP. PIANS. Explained by C. R. D. Biggs, B.D. Fcap. 8vo. Is. 6d. net.

'Mr. Biggs' work is very thorough, and he has managed to compress a good deal of information in to a limited space.'

-Guardian.

Pott 8vo, cloth, 2s.; leather, 2s. 6d. net.

'This series is excellent.'-THE BISHOP or LondoN.

'Very delightful.'-The Bishop OF BATH AND Wells.

'Well worth the attention of the Clergy.'-THE Bishop of Lichisield,

'The new "Library of Devotion" is excellent.'-The Bishop of Peterborough.

'Charming.'-Record.

THE CONFESSIONS OF ST. AU- 'The translation is an excellent piece of GUSTINE. Newly Translanted, with an Introduction and Notes, by C. BigG, D.D., late Student of Christ Church. Third Edition. English, and the introduction is a mas. terly exposition. We augur well of a series which begins so satisfactorily.'Times. 
THE CHRISTIAN YEAR. By JOHN

KEBLE. With Introduction and Notes by WALTER LOCK, D.D., Warden of Keble College, Ireland Professor at Oxford.

'The volume is very prettily bound and printed, and may fairly claim to be an advance on any previous editions.'Guardian.

THE IMITATION OF CHRIST. A Revised Translation, with an Introduction, by C. BIGG, D.D., late Student of Christ Church. Second Edition.

A practically new translation of this book, which the reader has, almost for the first time, exactly in the shape in which it left the hands of the author.

'A nearer approach to the original than has yet existed in English.'-Academy.

A BOOK OF DEVOTIONS. By J. W. STANBRIDGE, B.D., Rector of Bainton, Canon of York, and sometime Fellow of St. John's College, Oxford.

' It is probably the best book of its kind. It deserves high commendation.'-Church Gazette.
LYRA INNOCENTIUM. By JOHN KEBLE. Edited, with Introduction and Notes, by WALTER LOCK, D.D., Warden of Keble College, Oxford. Pott 8vo. 2s. ; leather, 2s. 6d. net.

' This sweet and fragrant book has never been published more attractively.'Academy.

'The work is given in as dainty a form as any it has yet taken.'-Scotsman.

'The analysis and notes are discriminating, scholarly, and helpful.'-ChurchReview.

A SERIOUS CALL TO A DEVOUT AND HOLY LIFE. By WILLIAM LAw. Edited, with an Introduction, by C. BIGG, D.D., late Student of Christ Church.

This is a reprint, word for word and line for line, of the Editio Princeps.

THE TEMPLE. By GEORGE HERBERT. Edited, with an Introduction and Notes, by E. C. S. Gibson, D.D. , Vicar of Leeds.

This edition contains Walton's Life of Herbert, and the text is that of the first edition.

'As neat and desirable an edition of the work as can be found.'-Scotsman.

\section{ILeaders of TReligion}

Edited by H. C. BEECHING, M.A. With Portraits, Crown 8vo. 3s.6d.

A series of short biographies of the most prominent leaders of religious life and thought of all ages and countries.

The following are ready-

CARDINAL NEWMAN. By R. H. AUGUSTINE OF CANTERBURY. HUTTON.

JOHN WESLEY. By J. H. OverTON, M.A.

BISHOP WILBERFORCE. By G. W. DANIELL, M.A.

CARDINAL MANNING. By A. W. HUTTON, M.A.

CHARLES SIMEON. By H. C. G. MOULE, D.D.

JOHN KEBLE. By WALTER Lock, D. D.

THOMAS CHALMERS. By Mrs. OLIPHANT.

LANCELOT ANDREWES. By R. L. OTTLEY, M.A. By E. L. Cu'TTS, D.D.

WILliAM LAUD. By W. $\mathrm{H}$. HUTTON, B.D.

JOHN KNOX. By F. MACCUNN.

JOHN HOWE. By R. F. HORTON, D.D.

BISHOP KEN. By F. A. Clarke, M.A.

GEORGE FOX, THE QUAKER. By T. HODGKIN, D.C.L.

JOHN DONNE. By Augustus JESSOPP, D.D.

THOMAS CRANMER. By. A. J. MASON.

BISHOP LATIMER. By R. M. CARLYLE and A. J. CARLYLE, M.A.

Other volumes will be announced in due course. 


\section{Fiction}

\section{SIX SHILLING NOVELS}

\section{Marie Corelli's Novels}

Crown 8vo. 6s. each.

A ROMANCE OF TWO WORLDS. Twenty-first Edition.

VENDETTA. Sixteenth Edition. THELMA. Twenty-third Edition.

ARDATH : THE STORY OF A DEAD SELF. Twelfth Edition.

THE SOUL OF LILITH. Ninth Edition.

WORMWOOD. Tenth Edition.

BARABBAS: A DREAM OF THE WORLD'S TRAGEDY. Thirtyfifth Edition.

'The tender reverence of the treatment and the imaginative beauty of the writing have reconciled us to the daring of the conception, and the conviction is forced on us that even so exalted a sub. ject cannot be made too familiar to us, provided it be presented in the true spirit of Christian faith. The amplifications of the Scripture narrative are often con. ceived with high poetic insight, and this "Dream of the World's Tragedy" is a lofty and not inadequate paraphrase of the supreme climax of the inspired narrative.'-Dublin Review.

THE SORROWS OF SATAN. Forty-second Edition.

'A very powerful piece of work. ... The conception is magnificent, and is likely to win an abiding place within the memory of man. . The author has immense command of language, and a limitless audacity.... This interesting and remarkable romance will live long after much of the ephemeral literature of the day is forgotten. . . A literary phenomenon ... novel, and even sub. lime.'-W. T. STEAD in the Review of Reviews.

\section{Anthony Hope's Novels}

\section{Crown 8vo. 6s. each.}

THE GOD IN THE CAR. Ninth Edition.

- A very remarkable book, deserving of critical analysis impossible within our limit; brilliant, but not superficial; well considered, but not elaborated; constructed with the proverbial art that conceals, but yet allows itself to be enjoyed by readers to whom fine literary method is a keen pleasure.'-The World.

A CHANGE OF AIR. Fifth Edition.

'A graceful, vivacious comedy, true to human nature. The characters are traced with a masterly hand.'-Times.

A MAN OF MARK. Fifth Edition.

'Of all Mr. Hope's books, "A Man of Mark" is the one which best compares with "The Prisoner of Zenda." National Observer.

\section{THE CHRONICLES OF COUN'T ANTONIO. Fourth Edition.}

'It is a perfectly enchanting story of love and chivalry, and pure romance. The Count is the most constant, desperate, and modest and tender of lovers, a peerless gentleman, an intrepid fighter, a faithful friend, and a magnanimous foe.' -Guardian.

PHROSO. Illustrated by $H . R$. MILlar. Fourth Edition.

'The tale is thoroughly fresh, quick with vitality, stirring the blood.'-St. James's Gazette.

"From cover to cover "Phroso" not only engages the attention, but carries the reader in little whirls of delight from adventure to adventure.'-A cademy. 
SIMON DALE. Illustrated. Fifth Edition.

'There is searching analysis of human nature, with a most ingeniously constructed plot. Mr. Hope has drawn the contrasts of his women with marvellous subtlety and delicacy.'-Times.

THE KING'S MIRROR. Edition.
'In elegance, delicacy, and tact it ranks with the best of his novels, while in the wide range of its portraiture and the subtilty of its analysis it surpasses all his earlier ventures. '-Spectator.

" "The King's Mirror" is a strong book, charged with close analysis and exquisite irony; a book full of pathos and moral fibre-in short, a book to be read.'Daily Chronicle.

\section{Gilbert Parker's Novels}

Crown 8vo. 6s. each.

PIERRE AND HIS PEOPLE. Fifth Edition.

'Stories happily conceived and finely executed. There is strength and genius in Mr. Parker's style.'-Daily Telegraph.

MRS. FALCHION. Fourth Edition.

'A splendid study of character.'-

$$
\text { Athenaum. }
$$

\section{THE TRANSLATION OF A} SAVAGE.

'The plot is original and one difficult to work out; but Mr. Parker has done it with great skill and delicacy.'

$$
\text { -Daily Chronicle. }
$$

THE TRAIL OF THE SWORD.

Illustrated. Sevenh Edition.

'A rousing and dramatic tale. A book like this, in which swords flash, great surprises are undertaken, and daring deeds done, in which men and women live and love in the old passionate way, is a joy inexpressible.'-Daily Chronicle.

WHEN VALMOND CAME TO PONTIAC: The Story of a Lost Napoleon. Fourth Edition.

'Here we find romance-real, breathing, living romance. The character of Valmond is drawn unerringly.'-Pall Mall Gazette.
AN ADVENTURER OF THE NORTH : The Last Adventures of 'Pretty Pierre.' Second Edition.

' The present book is full of fine and moving stories of the great North, and will add to Mr. Parker's already high reputation.'-Glasgow Herald.

THE SEATS OF THE MIGHTY. Illustrated. Tenth Edition.

'Mr. Parker has produced a really fine historical novel.'-A thenaum.

'A great book.'-Black and White.

THE POMP OF THE LAVILETTES. Second Edition. 3s. $6 d$.

'Living, breathing romance, unforced pathos, and a deeper knowledge of human nature than Mr. Parker has ever displayed before.'-Pall Mall Gazette.

THE BATTLE OF THE STRONG : a Romance of Two Kingdoms. Illustrated. Fourth Edition.

'Nothing more vigorous or more human has come from Mr. Gilbert Parker than this novel. It has all the graphic power of his last book, with truer feeling for the romance, both of human life and wild nature.'-Literature. 


\section{Messrs. Methuen's Catalogue}

\section{S. Baring Gould's Novels}

\section{Crown 8vo. 6s. each.}

"To say that a book is by the author of "Mehalah" is to imply that it contains a story cast on strong lines, containing dramatic possibilities, vivid and sympathetic descriptions of Nature, and a wealth of ingenious imagery.'-Speaker.

'That whatever Mr. Baring Gould writes is well worth reading, is a conclusion that may be very generally accepted. His views of life are fresh and vigorous, his language pointed and characteristic, the incidents of which he makes use are striking and original, his characters are life-like, and though somewhat exceptional people, are drawn and coloured with artistic force. Add to this that his descriptions of scenes and scenery are painted with the loving eyes and skilled hands of a master of his art, that he is always fresh and never dull, and it is no wonder that readers have gained confidence in his power of amusing and satisfying them, and that year by year his popularity widens.'Court Circular.

ARMINELL. Fifth Edition.

URITH. Fifth Edition.

IN THE ROAR OF THE SEA. Seventh Edition.

MRS. CURGENVEN OF CURGEN-

VEN. Fourth Edition.

CHEAP JACK ZITA. Fourth Edition.

THE QUEEN OF LOVE. Fifth Edition.

MARGERY OF QUETHER. Third Edition.

JACQUETTA. Third Edition.

KITTY ALONE. Fifth Edition.
NOÉMI. Illustrated. Fourth Edition. THE BROOM-SQUIRE. Illustrated. Fourth Edition.

THE PENNYCOMEQUICKS. Third Edition.

DARTMOOR IDYLLS.

GUAVAS THE TINNER. Illus. trated. Second Edition.

BLADYS. Illustrated. Second Edition.

DOMITIA. Illustrated. Second Edi. tion.

PABO THE PRIEST.

Wages of Sin,' etc. Third Edition. Crown 8vo. 6s.

George Gissing. THE TOWN TRAVELLER. By GEORgE Gissing, Author of 'Demos,' 'In the Year of Jubilee,' etc. Second Edition. Cr. $8 v o .6 s$.

' It is a bright and witty book above all things. Polly Sparkes is a splendid bit of work.'-Pall Mall Gazette.

'The spirit of Dickens is in it.'-Bookman.

George Gissing. THE CROWN OF LIFE. By GEORGE Gissing, Author of 'Demos,' 'The Town Traveller,' etc. Crown 8vo. 6s.

' $M r$. Gissing is at his best.'-Academy.

'A fine novel.'-Outlook.

s. R. Crockett. LOCHINVAR. By S. R. CROCKETT, Author of 'The Raiders,' etc. Illustrated. Second Edition. Crozon 8vo. 6s.

'Full of gallantry and pathos, of the clash 
of arms, and brightened by episodes of humour and love....'-Westminster Gazette.

s. R. Crockett. THE STANDARD BEARER. By S. R. CROCKETT. Crown 8vo. 6s.

'A delightful tale.'-Speaker.

'Mr. Crockett at his best.'-Literature.

Arthur Morrison. TALES OF MEAN STREETS. By ARTHUR MORRISON. Fifth Edition. Cr. 8vo. 6s.

'Told with consummate art and extra. ordinary detail. In the true humanity of the book lies its justification, the permanence of its interest, and its indubitable triumph.'-Athenoum.

'A great book. The author's method is amazingly effective, and produces a thrilling sense of reality. The writer lays upon us a master hand. The book is simply appalling and irresistible in its interest. It is humorous also; without humour it would not make the mark it is certain to make.'-World.

Arthur Morrison. A CHILD OF THE JAGO. By ARTHUR MORRIson. Third Edition. Cr. 8vo. 6s.

'The book is a masterpiece.'-Pall Mall Gazette.

'Told with great vigour and powerful simplicity.'-Athenaum.

Arthur Morrison. TO LONDON TOWN. By ARTHUR MORRISON, Author of 'Tales of Mean Streets,' etc. Second Edition. Crown 8vo. 6s.

'We have idyllic pictures, woodland scenes full of tenderness and grace. . . This is the new Mr. Arthur Morrison gracious and tender, sympathetic and human.'Daily Telegraph.

'The easy swing of detail proclaims the master of his subject and the artist in rendering.'-Pall Mall Gazette.

M. Sutherland. ONE HOUR AND THE NEX'T. By THE DUCHESS of Sutherland. Third Edition. Crown 8vo. 6s.

'Passionate, vivid, dramatic.'-Literatune.

'It possesses marked qualities, descriptive, and imaginative.'-Morning Post.
Mrs. clifford. A FLASH OF SUMMER. By Mrs. W. K. ClifFORD, Author of 'Aunt Anne,' etc. Second Edition. Crown 8vo. 6s.

'The story is a very beautiful one, exquisitely told.'-Speaker.

Emily Lawless. HURRISH. By the Honble. Emily LAwLEss, Author of 'Maelcho,' etc. Fifth Edition. Cr. 8vo. 6s.

Emily Lawless. MAELCHO : a Sixteenth Century Romance. By the Honble. Emily Lawless. Second Edition. Crown 8vo. 6s.

'A really great book.'-Spectator.

'One of the most remarkable literary achievements of this generation.'-Manchester Guardian.

Emily Lawless. TRAITS AND CONFIDENCES. By the Honble. EMILy Lawless. Crown 8vo. 6s.

Eden Phillpotts. THE HUMAN BOY. By EDEN PHILlPotTs, Author of 'Children of the Mist.' With a Frontispiece. Fourth Edition. Crown $8 v 0.6 s$.

'Mr. Phillpotts knows exactly what schoolboys do, and can lay bare their inmost thoughts; likewise he shows an all-pervading sense of humour.'-Academy.

E. W. Hornung. THE AMATEUR CRACKSMAN. By E. W. HORNUNG. Crown 8vo. $6 s$.

'An audaciously entertaining volume.'Spectator.

Jane Barlow. A CREEL OF IRISH STORIES. By JANE BARLOW, Author of 'Irish Idylls.' Second Edition. Crown 8vo. $6 s$.

'Vivid and singularly real.'-Scotsman.

Jane Barlow. FROM THE EAST UNTO THE WEST. By JANE BARLOw. Crown 8vo. 6s.

Mrs. Caffyn. ANNE MAULEVERER. By Mrs. CAFFYN (Iota), Author of 'The Yellow Aster.' Second Edition. Crown 8vo. 6 s. 


\section{Messrs. Methuen's Catalogue}

Benjamin swift. SIREN CITY. By Benjamin Swift, Author of ' Nancy Noon.' Crozen 8vo. 6s.

" "Siren City" is certainly his best book, and it is the work of a strong man. It has sobriety, not only of manner, but of spirit.'-Academy.

J. H. Findlater, THE GREEN GRAVES OF BALGOWRIE. By JANE H. FINDLATER. Fourth Edition. Crown 8vo. $6 s$.

'A powerful and vivid story.'-Standard.

'A beautiful story, sad and strange as truth itself.'-Vanity Fair.

'A very charming and pathetic tale.'-Pall Mall Gazette.

'A singularly original, clever, and beautiful story.'-Guardian.

'Reveals to us a new writer of undoubted faculty and reserve force.'-Spectator.

'An exquisite idyll, delicate, affecting, and beautiful.'-Black and White.

J. H. Findlater. A DAUGHTER OF STRIFE. By JANE HELEN Findlater. Crown 8vo. $6 s$.

J. H. Findlater. RACHEL. By JANE H. Findlater. Second Edition. Crown 8vo. $6 s$.

"A not unworthy successor to "The Green Graves of Balgowrie." -Critic.

Mary Findlater. OVER THE HILlS, By MARY Findlater. Second Edition. Cr. 8vo. 6s.

'A strong and wise book of deep insight and unflinching truth.'-Birmingham Post.

Mary Findlater. BETTY MUSGRAVE. By MARY FINDLATER. Second Edition. Crown 8vo. 6s.

'Handled with dignity and delicacy. ... A most touching story.'-Spectator.

Alfred ollivant. OWD BOB, THE GREY DOG OF KENMUIR. By Alfred Ollivant. Third Edition. Cr. 8vo. 6s.

'Weird, thrilling, strikingly graphic.'Punch.

'We admire this book. . . . I I is one to read with admiration and to praise with enthusiasm.'-Bookman.

'It is a fine, open-air, blood-stirring book, to be enjoyed by every man and woman to whom a dog is dear.'-Literature.

B. I. Croker. PEGGY OF THE BARTONS. By B. M. CROKER,
Author of 'Diana Barrington.' Fourth Edition. Crown 8vo. 6s.

Mrs. Croker excels in the admirably simple, easy, and direct flow of her narrative, the briskness of her dialogue, and the geniality of her portraiture.'-Spectator.

Mary L. Pendered. AN ENGLISH. MAN. By MARY L. PENDERED. Crown 8vo. 6s.

'Her book is most healthy in tone, and leaves a pleasant taste in the mouth.'Pall Mall Gazette.

'A very noble book. It is filled with wisdom and sympathy.'-Literary World.

'At once sound and diverting.'-Academy.

Morley Roberts. THE PLUNDERERS. By MORLEY ROBERTS, Author of 'The Colossus,' etc. Crown 8vo. 6s.

'The author secures and maintains the reader's lively interest in his clever absurdities.'-Pall Mall Gazette.

'The whole atmosphere is one of high spirits and high comedy.'-Globe.

'Mr. Roberts writes of real people who do things and know things.'-Black and White.

Norma Lorimer. MIRRY-ANN. By NORMA LORIMER, Author of 'Josiah's Wife.' Crown 8vo. 6s.

'The heroine is rare and striking, but thorough woman and altogether lovable, and the plot is brisk and well sustained. -Pall Mall Gazette.

' It is a Manx story, and a right able story. The atmosphere is excellent, the descriptive passages fine, and the story is one which will repay perusal.'-Glasgow Herald.

'A Manx novel which is at once sincere, poetical, and in the best sense true.'Academy.

Helen shipton. THE STRONG GOD CIRCUMSTANCE. By HELEN ShIPTON. Crown 8vo. 6s.

'A story of high merit and many attractions.'-Scotsman.

'An up-to-date story-and a very beautiful one-of self-sacrifice.' - Daily Telegraph.

'A most effective story, written with both insight and imagination.'-Leeds Mer. cury. 
Violet Hunt. THE HUMAN INTEREST. By VIOLET HUNT, Author of 'A Hard Woman,' etc. Crown 8vo. 6s.

'Clever observation and unfailing wit.'Academy.

'The insight is keen, the irony is delicate.'-World.

H. G. Wells. THE STOLEN BACILLUS, and other Stories. By H. G. Wells. Second Edition. Crown 8vo. $6 s$.

'The impressions of a very striking imagination.'-Saturday Reviez.

H. G. Wells. THE PLATTNER STORY AND OTHERS. By H. G. Wells. Second Edition. Cr. 8vo. $6 s$.

'Weird and mysterious, they seem to hold the reader as by a magic spell.'-Scots. man.

Richard Marsh. MARVELS AND MYSTERIES. By RICHARD MARSH, Author of 'The Beetle.' Crown 8vo. 6s.

'While under their immediate influence the reader is conscious of nothing but thrilling excitement and curiosity.'-Glasgow Herald.

'Ingeniously constructed and well told.'Morning Leader.

'Admirably selected and of the very best.' - Christian World.

Esmé stuart. CHRISTALLA. By EsMé STUART, Crozun 8vo. $6 s$.

'The story is happily conceived, and entertaining throughout.'-Scotsman.

'An excellent story, pathetic, and full of humour.'-A thenaum.

'We wish that we came across more books like this clever and charming story.Leeds Mercury.

Sara Jeannette Duncan. A VOYAGE OF CONSOLATION. By SARA Jeannette Duncan, Author of 'An American Girl in London.' Illustrated. Third Edition. Cr. 8vo. 6s.

'A most delightfully bright book.'-Daily Telegraph.

'The dialogue is full of wit. -Globe.

Sara Jeannette Duncan. THE PATH OF A STAR. By SARA JEANNETTE
Duncan, Author of 'A Voyage of Consolation.' Illustrated. Second Edition. Crown 8vo. 6s.

' Richness and fullness of local colouring, brilliancy of style, smiting phrases, and the display of very pretty humour are graces which are here in profusion. The interest never flags.'-Pall Mall Gazette.

C. F. Keary. THE JOURNALIST. By C. F. KeARY. Cr. 8vo. 6s.

'It is rare indeed to find such poetical sympathy with Nature joined to close study of character and singularly truthful dialogue: but then "The Journalist" is altogether a rare book.'-A thenaum.

W. E. Norris. MATTHEW AUSTIN. By W. E. NorRIS, Author of 'Mademoiselle de Mersac,' etc. Fourth Edition. Crown 8vo. $6 s$.

'An intellectually satisfactory and morally bracing novel.'-Daily Telegraph.

W. E. Norris. HIS GRACE. By W. E. NoRRIS. Third Edition. Cr. 8vo. $6 s$.

W. E. Norris. THE DESPOTIC LADY AND OTHERS. By W. E. NORRIS. Crown 8vo. $6 s$.

W. E. Norris. CLARISSA FURIOSA. By W. E. NORRIS. Cr. 8vo. 6s.

'As a story it is admirable, as a jeu d'esprit it is capital, as a lay sermon studded with gems of wit and wisdom it is a model.' - The World.

W. E. Norris. GILES INGILBY. By W. E. NorRIS. Illustrated. Second Edition. Crown 8vo. $6 s$.

'Interesting, wholesome, and charmingly written.'-Glasgow Herald.

w. E. Norris. AN OCTAVE. By W. E. NORRIS. Second Edition. Crown 8vo. 6 s.

'A very perfect exposition of the selfrestraint, the perfect knowledge of society and its ways, the delicate sense of humour, which are the main characteristics of this very accomplished author.'-Country Life.

Ernest Glanville. THE DESPATCH RIDER. By ERNEST GLANVILle, Author of 'The Kloof Bride.' Crown 8vo. $6 s$.

A highly interesting story of the present Boer War by an author who knows the country well, and has had experience of Boer campaigning. 


\section{MessRs. Methuen's Catalogue}

W. Clark Russell. MY DANISH SWEETHEART. By W. CLARK Russell. Illustrated. Fourth Edition. Crown 8vo. $6 s$.

Robert Barr. IN THE MIDST OF ALAKMS. By ROBERT BARR. Third Edition. Cr. 8vo. 6s.

'A book which has abundantly satisfied us byitscapital bumour,'-Daily Chronicle.

'Mr. Barr has achieved a triumph.'-Pall Mall Gazette.

Robert Barr. THE MUTABLE MANY. By ROBERT BARR. Second Edition. Crown 8vo. 6s.

- Very much the best novel that Mr. Barr has yet given us. There is much insight in it, and much excellent humour.'Daily Chronicle.

Robert Barr. THE COUNTESS TEKLA. By ROBERT BARR. Third Edition. Crown 8vo. 6s.

'Of these mediæval romances, which are now gaining ground, "The Countess Tekla" is the very best we have seen. The story is written in clear English, and a picturesque, moving style.'-Pall Mall Gazette.

Andrew Balfour. BY S'TROKE OF SWORD. By A. BALFOUR. Illustrated. Fourth Edition. Cr. 8vo. 6s. A banquet of good things.'-Academy.

-A recital of thrilling interest, told with unflagging vigour.'-Globe.

'An unusually excellent example of a semibistoric romance. - World.

Andrew Balfour. TO ARMS! By ANDREW BALFOUR. Illustrated. Second Edition. Crown 8vo. $6 s$.

'The marvellous perils through which Allan passes are told in powerful and lively fashion.'-Pall Mall Gazette.

Andrew Balfour. VENGEANCE IS MINE. By ANDREW BALFOUR, Author of 'By Stroke of Sword.' Illustrated. Crown 8vo. 6s.

A vigorous piece of work, well written, and abounding in stirring incidents, - Glas. gow Herald.

J. Maclaren Cobban. THE KING OF ANDAMAN: A Saviour of Society. By J. MAClaren CobBan. Crown 8vo. 6s.

- An unquestionably interesting book. It contains one character, at least, who has in him the root of immortality.'-Pall Mall Gazette.
J. Maclaren Cobban. THE ANGEL OF THE COVENANT. By J. MACLAREN COBBAN. Cr. 8vo. 6s.

R. N. Stephens. AN ENEMY TO THE KING. By R. N. Stephens. Second Edition. Cr. 8vo. 6s.

'It is full of movement, and the movement is always buoyant.'-Scotsman.

'A stirring story with plenty of movement.' - Black and White.

R. N. stephens. A GENTLEMAN PLAYER. By R. N. STEPheNS, Author of 'An Enemy to the King.' Crown 8vo. $6 s$.

'A bright and spirited romance of adventure, full of movement and changing action.'-Scotsman.

R. Hichens. BYEWAYS. By ROBERT Hichens. Author of 'Flames, etc.' Second Edition. Cr. 8vo. 6s.

'The work is undeniably that of a man of striking imagination.'-Daily Nezws.

J. s. Fletcher. THE PATHS OF THE PRUDEN'T. By J. S. FLETCHER. Crown 8vo. $6 s$.

J. B. Burton. IN THE DAY OF ADVERSITY. By T. BLOUNDELLEBurton. Second Edition. Cr. 8vo. 6s. 'Unusually interesting and full of highly dramatic situations.'-Guardian.

J. B. Burton. DENOUNCED. By J. Bloundelle-Burton. Second Edition. Crown 8vo. 6s.

'A fine, manly, spirited piece of work.'World.

J. B. Burton. THE CLASH OF ARMS. By J. Bloundelle-BuRTON. Second Edition. Cr. 8vo. 6s.

'A brave story-brave in deed, brave in word, brave in thought.'-St. James's Gazette.

J. B. Burton. ACROSS THE SALT SEAS. By J. BloundELlE-Burton. Second Edition. Crown 8vo. 6s.

'The very essence of the true romantic spirit.'-Truth. 
w. c. Scully. THE WHITE HECATOMB. By W. C. Scully, Author of 'Kafir Stories.' Cr. 8vo. $6 s$.

'Reveals a marvellously intimate understanding of the Kaffir mind.'-A frican Critic.

w. c. scully. BETWEEN SUN
AND SAND. By W. C. Scully, Author of 'The White Hecatomb.' Cr. 8vo. 6s.

'The reader passes at once into the very atmosphere of the African desert: the inexpressible space and stillness swallow him up, and there is no world for him but that immeasurable waste.'-A thenaum.

\section{OTHER SIX-SHILLING NOVELS}

Crown 8vo.

DANIEL Whyte. By A. J. Daw- GALlia. By Ménie Muriel SON.

THE CAPSINA. By E. F. BENSON. DODO: A DETAIL OF THE DAY. By E. F. BENSON.

THE VINTAGE. By E. F. BENSON. Illustrated by G. P. JACOMB-HOOD.

ROSE À CHARLITTE. By MARSHALL SAUNDERS.

WILLOWBRAKE. By R. MURRAY GILCHRIST.

THINGS THAT HAVE HAP. PENED. By DOROTHEA GERARD.

SIR ROBERT'S FORTUNE. By Mrs. Oliphant.

THE TWO MARYS. By Mrs. OLIPHANT.

THE LADY'S WALK. By Mrs. OLIPHANT.

LONE PINE: A ROMANCE OF MEXICAN LIFE. BY R. B. TOWNSHEND.

WILT THOU HAVE THIS WOMAN? By J. MACLAREN COBBAN.

A PASSIONATE PILGRIM. By PERCY WHITE.

SECRETARY TO BAYNE, M.P. By W. PETT RIDGE.

ADRIAN ROME. By E. DAWSON and A. MOORE. DOWIE.

THE CROOK OF THE BOUGH. By MÉNIE MURIEL DOWIE.

A BUSINESS IN GREAT WATERS. By JULIAN CORBETT.

MISS ERIN. By M. E. Francis.

ANANIAS. By the Hon. Mrs. Alan BRODRICK.

CORRAGEEN IN '98. By Mrs. ORPEN.

THE PLUNDER PIT. By J. KEIGHLEY SNOWDEN.

CROSS TRAILS. By Victor WAITE. SUCCESSORS TO THE TITLE. BY Mrs. WALFORD.

KIRKHAM'S FIND. By MARY GAUNT.

DEADMAN'S. By MARY GaUnT.

CAPTAIN JACOBUS : A ROMANCE OF THE ROAD. BY L. COPE CORNFORD.

SONS OF ADVERSITY. By L. COPE CORNFORD.

THE KING OF ALBERIA. By LAURA DAINTREY.

THE DAUGHTER OF ALOUETTE. BY MARY A. OWEN.

CHILDREN OF THIS WORLD. By Ellen F. Pinsent.

THE BUIIDERS. By J. S. AN ELECTRIC SPARK. By G. FLETCHER. MANVILLE FENN. 


\section{Messrs. Methuen's Catalogue}

UNDER SHADOW OF THE THE STONE DRAGON. By MISSION. By L. S. MCChESNEY. MURRAY GILCHRIST.

THE SPECULATORS. By J. F. BREWER.

THE SPIRIT OF STORM. By RONALD ROSS.

THE QUEENSBERRY CUP. By Clive P. WOLLEY.

A HOME IN INVERESK. By T. L. PATON.

MISS ARMSTRONG'S AND OTHER CIRCUMSTANCES. By JOHN DAVIDSON.

DR. CONGALTON'S LEGACY. By HENRY JOHNSTON.

TIME AND THE WOMAN. By RICHARD PRYCE.

THIS MAN'S DOMINION. By the Author of 'A High Little World.'

DIOGENES OF LONDON. By $\mathrm{H}$. B. MARRIOTT WATSON.

A VICAR'S WIFE. By Evelyn DICKINSON.

ELSA. By E. M'Queen Gray.

THE SINGER OF MARLY. By I. HOOPER.

THE FALL OF THE SPARROW. By M. C. BALFOUR.

A SERIOUS COMEDY. By Herbert MORRAH.

THE FAITHFUL CITY. By HERBERT MORRAH.

IN THE GREAT DEEP. By J. A. BARRY.

BIJLI, THE DANCER. By JAMES Blythe Patton.

JOSIAH'S WIFE. By NоRMA LORIMER.

THE PHILANTHROPIST. By LUCY MAYNARD.

VAUSSORE. BY FRANCIS BRUNE.

\section{THREE-AND-SIXPENNY NOVELS}

\section{Crown 8vo.}

DERRICK VAUGHAN, NOVEL- THESIGN OF THE SPIDER. Fifth IST. 42nd thousand. By EDNA LYALL.

A SON OF THE STATE. By W. PETT RIDGE.

CEASE FIRE! By J. MAClaReN Cobban. Crown 8vo. 3s. 6d.

A stirring Story of the Boer War of 1881 , including the Siege of Potchefstrom and the Defeat of Majuba.

'Brightly told and drawn with a strong and sure hand.'-St. James's Gazette.

'A capital novel.'-Scotsman.

'Fact and fiction are so deeply woven together that the book reads like a fascinating chapter of history.'-Pall Mall Gazette.

THE KLOOF BRIDE. By ERNEST GLANVILLE.

A VENDETTA OF THE DESERT. By W. C. SCULly.

SUBJECT TO VANITY. By MARGARET BENSON.

Edition. By BERTRAM MITFORD.

THE MOVING FINGER. By MARY GAUNT.

JACO TRELOAR. By J. H. PEARCE. THE DANCE OF THE HOURS. By 'VERA.'

A WOMAN OF FORTY. By EsMÉ STUART.

A CUMBERER OF THE GROUND. By Constance Smith.

THE SIN OF ANGELS. By EvelyN DICKINSON.

AUT DIABOLUS AUT NIHIL. By X. L.

THE COMING OF CUCULAIN. By Standish O'Grady.

THE GODS GIVE MY DONKEY WINGS. By ANGUS EvAN ABbOTt. 
THE STAR GAZERS. By G. MAN- A CAVALIER'S LADYE. By Mrs. VILLE FENN. DICKER.

THE POISON OF ASPS. By R. THE PRODIGALS. By Mrs. ORTON PROWSE.

THE QUIET MRS. FLEMING. By THE SUPPLANTER. By P. NeUR. PRYCE.

DISENCHANTMENT. ByF.MABEL A MAN WITH BLACK EYEROBINSON.

THE SQUIRE OF WANDALES. A HANDFUL OF EXOTICS. By By A. SHIELD.

A REVEREND GENTLEMAN. By AN ODD EXPERIMENT. By J. M. COBBAN.

A DEPLORABLE AFFAIR. By TALES OF NORTHUMBRIA. By W. E. NORRIS.

\section{HALF-CROWN NOVELS}

Crown 8 vo.

HOVENDEN, V.C. By F. MABEL IN TENT AND BUNGALOW. By ROBINSON.

THE PLAN OF CAMPAIGN. By MY STEWARDSHIP. By E. F. MABEL ROBINSON. MR. BUTLER'S WARD. By F. JACK'S FATHER. By W. E. MABEL ROBINSON.

ELI'S CHILDREN. By G. MANVILLE FENN.

A DOUBLE KNOT. By G. MANVILLE FENN.

DISARMED. By M. BETHAM EDWARDS.

A LOST illusion. By Leslie KEITH.

THE TRUE HISTORY OF JOSHUA DAVIDSON, Christian and Communist. By E. LYNN LYNTON. Eleventh Edition. Post 8vo. Is.

\section{Tbe Hovelist}

Messrs. Methuen are making an interesting experiment which constitutes a fresh departure in publishing. They are issuing under the above general title a Monthly Series of Novels by popular authors at the price of Sixpence. Many of these Novels have never been published before. Each Number is as long as the average Six Shilling Novel. 'The first numbers of 'THE Novelist' are as follows :-

I. DEAD MEN TELL NO TALES. E. W. HORNUNG.

II. JENNIE BAXTER, JOURNA. LIST. ROBERT BARR.

III. THE INCA'S TREASURE. ERNEST Glanville.

1V. A SON OF THE STATE. W. PetT Ridge.

V. FURZE BLOOM. S. BARING GOULD.

VI. BUNTER'S CRUISE. C. GLeIG.

VII. THE GAY DECEIVERS. VIII. PRISONERS OF WAR. A. BOYSON WEEKES.

IX. THEADVENTUREOF PRINCESS SYLVIA. Mrs. C. F. WiLliaMSON.

X. VELDT AND LAAGER: Tales of the Transvaal. E.S. VALENTINE.

XI. THE NIGGER KNIGHTS. F. NORREYS CONNELL.

XII. A MARRIAGE AT SEA. W. Clark Russell. 


\section{Books for Boys and Girls}

$A$ Series of Books by well-known Authors, well illustrated.

THREE-AND-SIXPENCE EACH

THE ICELANDER'S SWORD. BY MASTER ROCKAFELLAR'S VOYS. BARING GOULD.

TWO LITTLE CHILDREN AND CHING. By Edith E. Cuthell. TODDLEBEN'S HERO. By M. M. BLAKE.

ONLY A GUARD-ROOM DOG. By EDith E. CUTHEll.

THE DOCTOR OF THE JULIET. By HaRry Collingwood. agE. By W. Clark Russell.

SYD BELTON: Or, The Boy who would not go to Sea. By G. MANVILLE FENN.

THE WALLYPUG IN LONDON. By G. E. FARRow.

ADVENTURES IN WALLYPUG LAND. By G. E. FARROW. $5 s$.

\section{The Peacock Library}

A Series of Books for Girls by well-known Authors, handsomely bound, and well illustrated.

\section{THREE-AND-SIXPENCE EACH}

THE RED GRANGE. By Mrs. DUMPS. By Mrs. PARr.

\section{MOLESWORTH.}

THE SECRET OF MADAME DE

MONLUC. By the Author of HEPSY
'Mdle. Mori.'

A GIRL OF THE PEOPLE. By L. T. MEADE.

OUT OF THE FASHION. By L. THE HONOURABLE MISS. By T. MEADE. L. T. MEADE.

\section{University Extension Series}

A series of books on historical, literary, and scientific subjects, suitable for extension students and home-reading circles. Each volume is complete in itself, and the subjects are treated by competent writers in a broad and philosophic spirit.

Edited by J. E. SYMES, M.A.,

Principal of University College, Nottingham.

Crown 8vo. Price (with some exceptions) 2s. $6 d$.

The following volumes are ready :-

THE INDUSTRIAL HISTORY OF ENGLAND. By H. DE B. GibBINS, Litt. D., M.A., late Scholar of Wadham College, Oxon., Cobden Prizeman. Seventh Edition, Revised. With Maps and Plans. $3^{s}$.

A HISTORY OF ENGLISH POLITICAL ECONOMY. By L. L. PRICE,
M.A., Fellow of Oriel College, Oxon. Third Edition.

PROBLEMS OF POVERTY : An Inquiry into the Industrial Conditions of the Poor. By J. A. HOBSON, M.A. Fourth Edition.

VICTORIAN POETS. By A. SHARP. 
THE FRENCH REVOLUTION. By J. E. SYMES, M.A.

PSYCHOLOGY. By F. S. GRANGER, M.A. Second Edition.

THE EVOLUTION OF PLANT LIFE : Lower Forms. By G. MASSEE. With Illustrations.

AIR AND WATER. By V. B. LEWES, M.A. Illustrated.

THE CHEMISTRY OF LIFE AND HEALTH. By C. W. Kimmins, M.A. Illustrated.

THE MECHANICS OF DAILY LIFE. By V. P. SELls, M.A. Illustrated.

ENGLISH SOCIAL REFORMERS. By H. DE B. GibBINS, Litt.D., M.A.

ENGLISH TRADE AND FINANCE IN THE SEVENTEENTH CENTURY. By W. A. S. HEwINS, B.A. THE CHEMISTRY OF FIRE. The Elementary Principles of Chemistry. By M. M. PATtison Muir, M.A. Illustrated.

A TEXT-BOOK OF AGRICULTURAL BOTANY. By M. C. POTTER, M.A., F.L.S. Illustrated. 3s. $6 d$.
THE VAULT OF HEAVEN. $\dot{A}$ Popular Introduction to Astronomy. By R. A. GREGORY. With numerous Illustrations.

METEOROLOGY. The Elements of Weather and Climate. By $\mathrm{H}$. N. Dickson, F.R.S.E., F.R. Met. Soc. Illustrated.

A MANUAL OF ELECTRICAL SCIENCE. By GEORGE J. BURCH, M.A., F.R.S. With numerous Illustrations. 3 s.

THE EARTH. An Introduction to Physiography. By EvaN SMALL, M.A. Illustrated.

INSECT LIFE. By F. W. TheoBALD, M.A. Illustrated.

ENGLISH POETRY FROM BLAKE TO BROWNING. By W. $M$. Dixon, M.A.

ENGLISH LOCAL GOVERNMENT. By E. JENks, M.A., Professor of Law at University College, Liverpool.

THE GREEK VIEW OF LIFE. By G. L. Dickinson, Fellow of King's College, Cambridge. Second Edition

\section{Social Questions of To-day}

Edited by H. DE B. GIBBINS, Litt.D., M.A.

Crown 8vo. 2s. $6 d$.

A series of volumes upon those topics of social, economic, and industrial interest that are at the present moment foremost in the public mind. Each volume of the series is written by an author who is an acknowledged authority upon the subject with which he deals.

The following Volumes of the Series are ready :-

TRADE UNIONISM-NEW AND|THE CO-OPERATIVE MOVE OLD. By G. Howell. Second MENT TO-DAY. By G. J. HolyEdition. OAKE. Second Edition. 
MUTUAL THRIFT, By Rev. J. Frome Wilkinson, M.A.

PROBLEMS OF POVERTY. By J. A. HoBson, M.A. Fourth Edition.

THE COMMERCE OF NATIONS. By C. F. BASTABle, M.A., Professor of Economics at Trinity College, Dublin. Second Edition.

THE ALIEN INVASION. By W. H. Wilkins, B.A.

THE RURAL EXODUS. By P. ANDERSON GRAHAM.

LAND NATIONALIZATION. By HAROLD Cox, B.A.

A SHORTER WORKING DAY. By H. DE B. Gibbins, D. Litt., M.A., and R. A. HADFIELD, of the Hecla Works, Sheffield.

BACK TO THE LAND : An Inquiry into the Cure for Rural Depopulation. BY H. E. MOORE.

TRUSTS, POOLS AND CORNERS. By J. STEPHEN JEANS.

THE FACTORY SYSTEM. By R. W. COOKE-TAYLOR.

THE STATE AND ITS CHILDREN. By GERTRUdE TUCKWELl. WOMEN'S WORK. By LADY DILKE, Miss Bulley, and Miss Whitley.

SOCIALISM AND MODERN THOUGHT. By M. KAUFMANN.

THE HOUSING OF THE WORKING CLASSES. BY E. BOWMAKER.

MODERN CIVILIZATION IN SOME OF ITS ECONOMIC ASPECTS. By W. CUNNINGHAM, D.D., Fellow of Trinity College, Cambridge.

THE PROBLEM OF THE UNEMPLOYED. By J. A. HoBSON, B.A.

JIFE IN WEST LONDON. By Arthur Sherwell, M.A. Second Edition.

RAILWAY NATIONALIZATION. By Clement EDWARDS.

WORKHOUSES AND PAUPERISM. By LouISA TWINING.

UNIVERSITY AND SOCIAL SETTLEMENTS. ByW. REASON, M.A.

\section{Classical Translations}

Edited by H. F. FOX, M.A., Fellow and Tutor of Brasenose College, Oxford.

ESCHYLUS - Agamemnon, Chöephoroe, Eumenides. Translated by LEWIS CaMpBell, LL.D., late Professor of Greek at St. Andrews. $5^{s}$.

CICERO-De Oratore I. Translated by E. N. P. MOoR, M.A. 3s. 6d.

CICERO-Select Orations(Pro Milone, Pro Murena, Philippic II., In Catilinam). Translated by $H$. E. D. BLAkiston, M.A., Fellow and Tutor of Trinity College, Oxford. $5^{s}$.

CICERO-De Natura Deorum. Translated by $\mathrm{F}$. BROoks, M.A., late Scholar of Balliol College, Oxford. 3s. $6 d$.

CICERO DE OFFICIIS. Translated by G. B. GaRDiner, M.A. Crown 8vo. 2s. $6 d$.
HORACE: THE ODES AND EPODES. Translated by A. GODLEY, M.A., Fellow of Magdalen College, Oxford. $2 s$.

LUCIAN-Six Dialogues (Nigrinus, Icaro-Menippus, The Cock, The Ship, The Parasite, The Lover of Falsehood). Translated by S. T. IRWIN, M.A., Assistant Master at Clifton; late Scholar of Exeter College, Oxford. 3 s. $6 d$.

SOPHOCLES - Electra and Ajax. Translated by E. D. A. MORSHEAD, M.A., Assistant Master at Winchester. $2 s .6 d$.

TACITUS-Agricola and Germania. Translated by R. B. TownSHEND, late Scholar of Trinity College, Cambridge. $2 s .6 d$. 


\section{Messrs. Methuen's Catalogue}

\section{Orford Classical Texts.}

Messrs. Methuen are about to publish in conjunction with the Clarendon Press a series of classical texts edited by competent scholars from the best MSs.

THUCYDIDIS HISTORIAE, LIBRI I.-IV. By H. STUART JONES. Paper Covers, 3s. Limp Cloth, $3^{\text {s. }} 6 d$.

PLATONIS OPERA, TOM. I. (TETRALOGIAE I.-II.) By J. BURNET. Paper Covers, 5s. Limp Cloth, 6s.

LVCRETI CARI DE RERVM NATVRA. By C. RAIley. Paper Covers, 2s. 6d. Limp Cloth, 3 s.

CORNELII TACITI OPERA MINORA. By H. FURNEAUX. Paper Covers, Is. 6d. Limp Cloth, 2s.
AESCHYLI TRAGOEDIAE CUM FRAGMENTIS. By A. Sidgwick. Paper Covers, $3^{\text {s. }}$ Limp Cloth, 3 s. 6 d.

APOLLONII RHODII ARGONAUTICA. By R. C. SEATON. Paper Covers, 2s. 6d. Limp Cloth, 3 s.

ARISTOPHANIS COMOEDIAE. TOM. I. By F. W. HALL and W. M. Geldart. Paper Covers, $3^{s}$. Limp Cloth, 3s. 6d.

XENOPHONTIS OPERA. TOM. $\mathrm{x}$. (Historia Graeca). By E. C. MARCHANT. Paper Covers, 2s, 6d. Limp Cloth, $3^{s .}$

\section{Educational Books}

\section{CLASSICAL}

THE NICOMACHEAN ETHICS OF ARISTOTLE. Edited with an Introduction and Notes by JOHN BURnet, M.A., Professor of Greek at St. Andrews. Demy 8vo. 15 s. net.

This edition contains parallel passages from the Eudemian Ethics, printed under the text, and there is a full commentary, the main object of which is to interpret difficulties in the light of Aristotle's own rules.

'An edition which reflects every credit upon its author's learning and critical acumen, and which cannot but prove heartily welcome to all classes of Greek scholars.' -Scotsman.

'It forms a valuable addition to the existing literature on the subject.'

-Glasgow Herald.

'We must content ourselves with saying, in conclusion, that we have seldom, if ever, seen an edition of any classical author in which what is held in common with other commentators is so clearly and shortly put, and what is original is (with equal brevity) of such value and interest.
PLAUTI BACCHIDES. Edited with Introduction, Commentary, and Critical Notes by J. M'Cosh, M.A. Fcap. 4to. r2s. 6 d.

A GREEK ANTHOLOGY. Selected by E. C. MARCHANT, M.A., Fellow of Peterhouse, Cambridge, and Assistant Master at St. Paul's School. Crown 8vo. 3s. $6 d$.

PASSAGES FOR UNSEEN TRANS. LATION. By E. C. MARCHANT, M.A., Fellow of Peterhouse, Cambridge; and A. M. CooK, M.A., late Scholar of Wadham College, Oxford; Assistant Masters at St. Paul's School. Crown 8vo. 3s. $6 d$.

'We know no book of this class better fitted for use in the higher forms of schools.'Guardian.

TACITI AGRICOLA. With Introduction, Notes, Map, etc. By R. F. DAvis, M.A., Assistant Master at Weymouth College. Crown 8vo. $2 s$. 


\section{Messrs. Methuen's Catalogue}

TACITI GERMANIA. By the same Editor. Crown 8vo, 2s.

HERODOTUS : EASY SELEC. TIONS. With Vocabulary. ByA.C. Liddell, M.A. Fcap. 8vo. Is. 6d.

SELECTIONS FROM THE ODYSSEY. By E. D. STone, M.A., late Assistant Master at Eton. Fcap. 8vo. Is. $6 d$.

PLAUTUS: THE CAPTIVI. Adapted for Lower Forms by J. H. Freese, M.A., late Fellow of St. John's, Cambridge. Is. $6 d$.

DEMOSTHENES AGAINST CONON AND CALLICLES. Edited with Notes and Vocabulary, by F. DARWIN SwIFT, M.A. Fcap. 8vo. 2s.

EXERCISES IN LATIN ACCI. DENCE. By S. E. WINBOLT,
Assistant Master in Christ's Hospital. Crown 8vo. Is. $6 d$.

An elementary book adapted for Lower Forms to accompany the shorter Latin primer.

NOTES ON GREEK AND LATIN SYNTAX. By G. BuCKLANDGREEN, M.A., Assistant Master at Edinburgh Academy, late Fellow of St. John's College, Oxon. Crown 8vo. 3.s. $6 d$.

Notes and explanations on the chief difficulties of Greek and Latin Syntax, with numerous passages for exercise.

NEW TESTAMENT GREEK. A Course for Beginners. By G. RoDWELL, B.A. With a Preface by WALTER LOCK, D.D., Warden of Keble College. Fcap. 8vo. 3s. $6 d$.

THE FROGS OF ARISTOPHANES. Translated by E. W. HUNTINGFORD, M.A., Professor of Classics in Trinity College, Toronto. Cr. 8vo. 2s. 6d.

\section{GERMAN}

A COMPANION GERMAN GRAM- GERMAN PASSAGES FOR UN. MAR. By H. DE B. GibBins, D. Litt., M.A., Headmaster at Kidderminster Grammar School. Crown 8vo. Is. 6d. SEEN TRANSLATION. By E. M'Queen Gray. Crown 8vo. 2s. $6 d$.

\section{SCIENCE}

DAIRY BACTERIOLOGY. A Short Manual for the Use of Students. By Dr. ED. VON FREUDENREICH, Translated by J. R. Ainsworth DAvis, M.A. Second Edition, Revised. Crown 8vo. 2s. $6 d$.

OUTLINES OF BIOLOGY. By P. Chalmers Mitchell, M.A. Illustrated. Cr. 8vo. 6s.

A text-book designed to cover the new
Schedule issued by the Royal College of Physicians and Surgeons.

A MONOGRAPH OF THE MYXOGASTRES. By GEORge MASSEE. With 12 Coloured Plates. Royal $8 v 0$. I8s. net.

'A work much in advance of any book in the language treating of this group of organisms. Indispensable to every student of the Myxogastres.'-Nature. 
ORNAMENTAL DESIGN FOR WOVEN FABRICS. By C. STEPHenson, of The Technical College, Bradford, and F. SudDARDS, of The Yorkshire College, Leeds. With 65 full-page plates. Demy $8 v o$. Second Edition. 7s. 6d.

'The book is very ably done, displaying an intimate knowledge of principles, good taste, and the faculty of clear exposition. -Yorkshire Post.

GENERAL ELEMENTARY SCIENCE. By J. T. DUNN, D.Sc., and V. A. MUNDELla. With many Illustrations. Crown 8vo. 3s. $6 d$.

[Methuen's Science Primers.

THE WORLD OF SCIENCE. In- cluding Chemistry, Heat, Light, Sound, Magnetism, Electricity, Botany, Zoology, Physiology, Astronomy, and Geology. By R. Elliott Steel, M.A., F.C.S. 147 Illustrations. Second Edition. Cr. 8vo. 2s. $6 d$.

ELEMENTARY LIGHT. By R. E. STEEL. With numerous Illustrations. Crown 8vo. 4s. $6 d$.

VOLUMETRIC ANALYSIS. By J.

B. Russell, B.Sc., Science Master at Burnley Grammar School. $\mathrm{Cr}$. 8vo. Is.

'A collection of useful, well-arranged notes.' -School Guardian.

\section{Tertbooks of Tecbnology}

Edited by PROFESSORS GARNETT and WERTHEIMER.

HOW TO MAKE A DRESS. By J. A. E. Wood. Illustrated. Cr. $8 v o$. Second Edition. Is. 6 d.

'Though primarily intended for students, Miss Wood's dainty little manual may be consulted with advantage by any girls who want to make their own frocks. The directions are simple and clear, and the diagrams very helpful.'-Literature.

CARPENTRY AND JOINERY. By F. C. WEBBER. With many Illustrations. $C r .8 v o$. 3s. $6 d$.

'An admirable elementary text-book on the subject.'-Builder.

PRACTICAL MECHANICS. By Sidney H. Wells. With 75 Illustrations and Diagrams. Cr. 8vo. 3 s.6d.

PRACTICAL PHYSICS. By $\mathrm{H}$.
Stroud, D.Sc., M.A., Professor of Physics in the Durham College of Science, Newcastle-on-Tyne. Fully illustrated. Crown 8vo. 3s. $6 d$.

MILLINERY, THEORETICAL, AND PRACTICAL. By Miss Hill, Registered Teacher to the City and Guilds of London Institute. With numerous Diagrams. Crown 8vo. $2 s$.

PRACTICAL CHEMISTRY. By W. French, M.A. Part I. With numerous diagrams. Crown 8vo. Is. $6 d$.

'An excellent and eminently practical little book.'-Schoolmaster.

\section{ENGLISH}

ENGLISH RECORDS. A Companion THE ENGLISH CITIZEN : HIS to the History of England. By H. E. RIGHTS AND DUTIES. By H. E. MALden, M.A. Crown 8vo. 3s. 6d. MALdEN, M.A. Is. $6 d$. 
A DIGEST OF DEDUCTIVE LOGIC. By JOHNSON BARKER, B.A. Crown 8vo. 2s. 6 d.

A CLASS-BOOK OF DICTATION PASSAGES. By W. WILliamSON, M.A. Third Edition, Cr. 8vo. Is. 6d.

A SHORT STORY OF ENGLISH LITERATURE. By EMMA S. Mellows. Crown 8vo. 3s. $6 d$.

The history of English literature told in a simple style for young students. It is particularly rich in biographical detail, and contains a considerable number of illustrative extracts.
'A lucid and well-arranged account of the growth of English literature.' - Pall Mall Gazette.

TEST CARDS IN EUCLID AND ALGEBRA. By D. S. CALDERwOOD, Headmaster of the Normal School, Edinburgh. In three packets of 40, with Answers. Is. Or in three Books, price $2 d ., 2 d$., and $3 d$.

THE METRIC SYSTEM. By LEON Delbos. Crown 8vo. 2s.

A theoretical and practical guide, for use in elementary schools and by the general reader.

\section{METHUEN'S COMMERCIAL SERIES}

Edited by H. DE B. GIBBINS, Litt.D., M.A.

BRITISH COMMERCE AND COLONIES FROM ELIZABETH TO VICTORIA. By $\mathrm{H}$. DE $B$. GibBINS, Litt.D., M.A. Third Edition. 2s.

COMMERCIAL EXAMINATION PAPERS. By H. DE B. GIBBINS, Litt. D., M.A. Is. $6 d$.

THE ECONOMICS OF COMMERCE. By H. DE B. GibBINS, Litt. D., M.A. Is. $6 d$.

FRENCH COMMERCIAL CORRESPONDENCE. ByS. E. BALLY, Master at the Manchester Grammar School. Second Edition. 25 .

GERMAN COMMERCIAL CORRESPONDENCE. By S. E. BALLY. $2 s .6 d$.

A FRENCH COMMERCIAL READER. By S. E. BALLY. Second Edition. 2s.
COMMERCIAL GEOGRAPHY, with special reference to the British Empire. By L. W. Lyde, M.A. Second Edition. 2s.

A PRIMER OF BUSINESS. By S. JACKSON, M.A. Third Ed. 1s. $6 d$.

COMMERCIAL ARITHMETIC. By F. G. TAYLOR, M.A. Third Edition. Is. $6 d$.

PRÉCIS WRITING AND OFFICE CORRESPONDENCE. By E. E. WhitField, M.A. $2 s$.

A GUIDE TO PROFESSIONS AND BUSINESS. By H. JONES. Is. $6 d$.

THE PRINCIPLES OF BOOKKEEPING BY DOUBLE ENTRY. By J. E. B. M'Allen, M.A. Cr.8vo. $2 s$.

COMMERCIAL LAW. By W. DOUGLAS EDWARDS. $2 s$.

WORKS BY A. M. M. STEDMAN, M.A.

INITIA LATINA: Easy Lessons on FIRST LATIN LESSONS. Sixth Elementary Accidence. Fourth Edition. Crown 8vo. $2 s$. Edition. Fcap. 8vo. Is. 
FIRST LATIN READER. With Notes adapted to the Shorter Latin Primer and Vocabulary. Fifth Edition revised. $18 m o$. Is. $6 d$.

EASY SELECTIONS FROM CASAR. Part I. The Helvetian War. Second Edition. I8mo. Is.

EASY SELECTIONS FROM LIVY. Part 1 . The Kings of Rome. r 8 mo. Second Edition. Is. $6 d$.

EASY LATIN PASSAGES FOR UNSEEN TRANSLATION. Seventh Edition. Fcap. 8vo. rs. 6d.

EXEMPLA LATINA. First Lessons in Latin Accidence. With Vocabulary. Crown 8vo. Is.

EASY LATIN EXERCISES ON THE SYNTAX OF THE SHORTER AND REVISED LATIN PRIMER. With Vocabulary. Eighth and cheaper Edition, re-written. Crown $8 v o$. Is. $6 d$. Issued with the consent of Dr. Kennedy. KEY 3 . net.

THE LATIN COMPOUND SEN. TENCE: Rules and Exercises. Second Edition. Cr.8vo. Is. 6d. With Vocabulary. 2s.

NOTANDA QUAEDAM : Miscellaneous Latin Exercises on Common Rules and Idioms. Fourth Edition. Fcap. 8vo. Is. 6d. With Vocabulary. $2 s$.

LATIN VOCABULARIES FOR RE. PETITION : Arranged according to Subjects. Ninth Edition. Fcap. 8vo. Is. 6d.
A VOCABULARY OF LATIN IDIOMS. I8mo. Second Edition. Is.

STEPS TO GREEK. Second Edition, Revised. I8mo. Is.

A SHORTER GREEK PRIMER. Crown 8vo. Is. $6 d$.

EASY GREEK PASSAGES FOR UNSEEN TRANSLATION. Third Edition Revised. Fcap. 8vo. Is. 6d.

GREEK VOCABULARIES FOR REPETITION. Arranged according to Subjects. Second Edition. Fcap. 8vo. Is. 6d.

GREEK TESTAMENT SELECTIONS. For the use of Schools. Third Edition. With Introduction, Notes, and Vocabulary. Fcap. 8vo. 2s. $6 d$.

STEPS TO FRENCH. Fifth Edi. tion. r8mo. $8 d$.

FIRST FRENCH LESSONS. Fourth Edition Revised. Crown 8vo. Is.

EASY FRENCH PASSAGES FOR UNSEEN TRANSLATION. Fourth Edition revised. Fcap. 8vo. Is. 6d.

EASY FRENCH EXERCISES ON ELEMENTARY SYNTAX. With Vocabulary. Second Edition. Crown 8vo. 2s. 6d. KEY 3s. net.

FRENCH VOCABULARIES FOR REPETITION : Arranged according to Subjects. Ninth Edition. Fcap. 8vo. Is.

\section{SCHOOL EXAMINATION SERIES}

Edited by A. M. M. STEDMAN, M.A. Crown 8vo. 2s. $6 d$.

FRENCH EXAMINATION PAPERS IN MISCELLANEOUS GRAMMAR AND IDIOMS. By A.M.M.STEDMAN, M.A. Eleven th Edition.
A KEY, issued to Tutors and Private Students only, to be had on application to the Publishers. Fourth Edition. Crown 8 vo. 6s. net. 


\section{Messrs. Methuen's Catalogue}

LATIN EXAMINATION PAPERS IN MISCELLANEOUS GRAMMAR AND IDIOMS. By A. M. M. Stedman, M.A. Tenth Edition. KEY (Fourth Edition) issued as above. 6s. net.

GREEK EXAMINATION PAPERS IN MISCELLANEUUS GRAMMAR AND IDIOMS. By A. M. M. StedmAN, M.A. Sixth Edition.

$\mathrm{KEY}$ (Second Edition) issued as above. 6s. net.

GERMAN EXAMINATION. PAPERS IN MISCELLANEOUS GRAMMAR AND IDIOMS. By R. J. MORICH, Clifton College. Fifth Edition.

$\mathrm{KEY}$ (Second Edition) issued as above. 6s, net.
HISTORY AND GEOGRAPHY EXAMINATION PAPERS. By C. H. SPENCE, M.A., Clifton College. Second Edition.

SCIENCE EXAMINATION PAPERS. By R. E. Steel, M.A., F.C.S. In two vols.

Part I. Chemistry ; Part II. Physics.

GENERAL KNOWLEDGE EXAMINATION PAPERS. By $A$. M. M. Stedman, M.A. Third Edition.

$\mathrm{KEY}$ (Second Edition) issued as above. 7s, net.

EXAMINATION PAPERS IN ENGLISH HISTORY. By J. TAIT WARDLAW, B.A., King's College, Cambridge. Crown $8 v 0$. 2s. 6 d. 




THIS BOOK IS DUE ON THE LAST DATE - STAMPED BELOW

\section{AN INITIAL FINE OF 25 CENTS} WILL BE ASSESSED FOR FAILURE TO RETURN THIS BOOK ON THE DATE DUE. THE PENALTY WILL INCREASE TO 50 CENTS ON THE FOURTH DAY AND TO \$1.00 ON THE SEVENTH DAY OVERDUE.

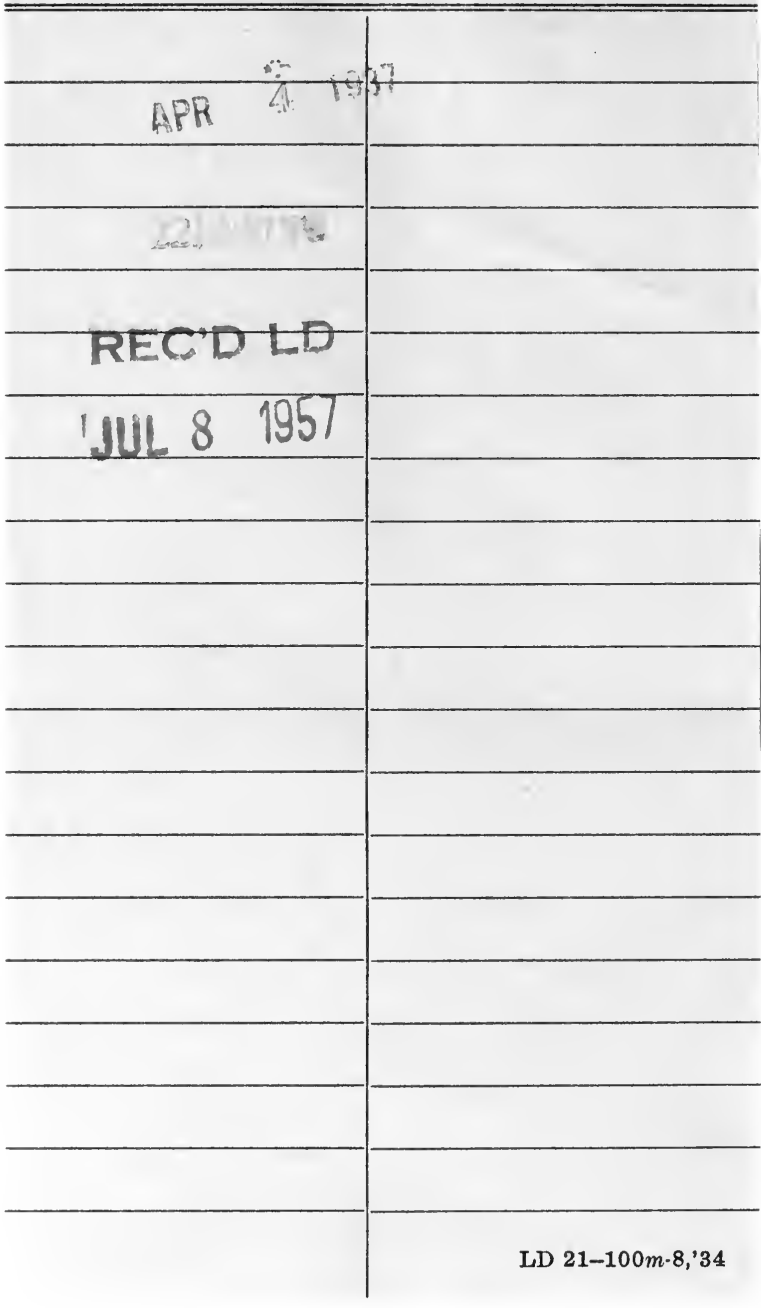




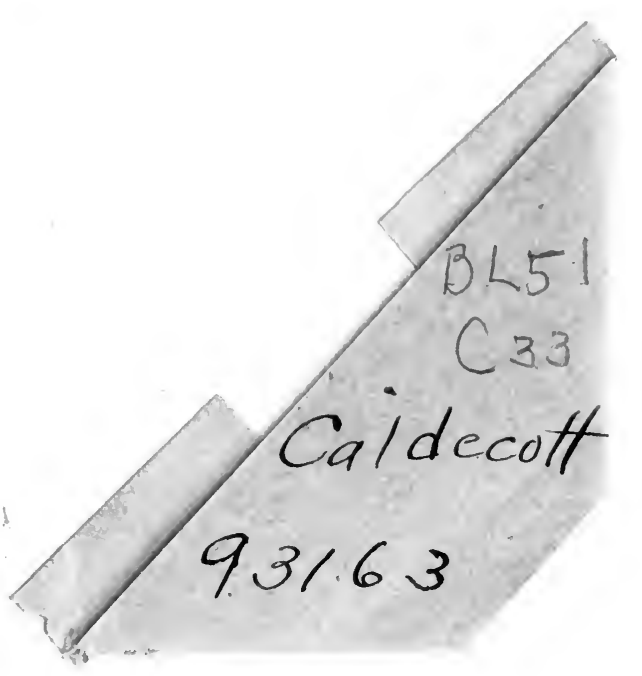


